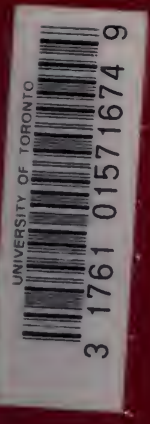







\section{OEUVRES}

$$
\text { DE }
$$

PASTEUR 



\section{OEUVRES}

DE
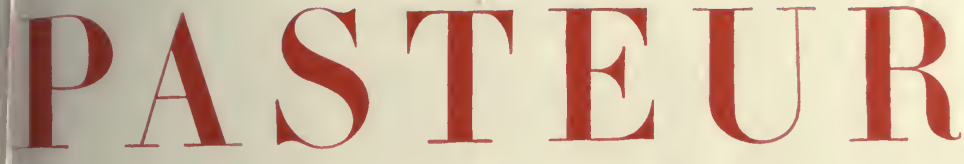

\section{RÉUNIES}

PAR

\section{PASTEUR VALLERY-RADOT}

MÉDECIN DES HÔPITAUX DE PARIS

TOME III

ÉTUDES SUR LE VINAIGRE

ET SUR LE VIN

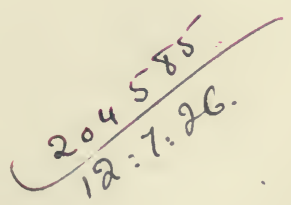

\section{PARIS}

MASSON ET C $\mathrm{C}^{\mathrm{i}}$, ÉDITEURS

L I B R A I RES DE L'ACADEMIE DE MEDECINE

120, BOULEVARD SAINT-GERMAIN 


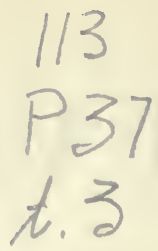

Nous avons reproduit intégralement le texte de Pasteur. Cependant des ponctuations et des fautes typographiques ont été rectifiées. Quand une faute de cel ordre a déterminé une correction importante du texte, nous avons mentionné en note la correction que nous avons dû faire subir au texte.

Les [ ] qui entourent certains mots indiquent que ces mots ne figurent pas dans le texte original.

Les indications bibliographiques ont été vérifiées; un grand nombre ont été rectifiées ou complétées.

Les notes suivies de ces mots : Note de l'Édition sont celles que nous avons ajoutées au texte. Les notes qui ne sont accompagnées d'aucune mention sont celles du texte original.

Parfois un même mémoire fut publié par Pasteur dans divers bulletins avec des variantes. Nous avons, soit reproduit les différents textes, soit mentionné en notes les variantes.

Tous droits de reproduction, de traduction et d'adaptation réservés pour tous pays. y compris la Russie.

Copyright 1924 by Pasteur Vallery-Radot. 


\section{INTRODUCTION}

DU TOME III

Après les fermentations lactique et alcoolique, Pasteur est amené 1 l'étude de la fermentation acétique. Il découvre en 1861 le rôle des nycodermes et bientôt il établit les principes scientifiques de la fabrication du vinaigre.

Le grand mémoire de 1864 sur la fermentation acétique et la leçon sur le vinaigre faite à Orléans en 1867 - mémoire et leçon que Pasteur réunit sous forme d'opuscule intitulé « Études sur le vinaigre, sa fabrication, ses maladies, moyens de les prévenir » - sont le développement des communications sur le inême sujet faites en 1861 et 1862 à la Société chimique et à l'Académie des sciences.

Nous avons groupé ces recherches sur le vinaigre en suivant l'ordre chronologique de leur publication.

Pendant que Pasteur étudiait la fermentation acétique, sa pensée était déjà hantée par les études à entreprendre sur les maladies des vins. Au mois de septembre 1858, en regardant au microscope des vins altérés du Jura, il voit un ferment offrant la plus grande ressemblance avec le ferment lactique qu'il a découvert l'année précédente. Dès lors, il a l'idée de rechercher si les maladies des vins, au lieu d'être, ainsi qu'on le croyait, des altérations spontanées, ne sont pas dues à la présence de germes microscopiques semblables à ceux qu'il étudie si ardemment et auxquels il attribue les phénomènes des fermentations. 
Ainsi, dès le premier moment où il examine un vin malade, par c don d'observation et cette faculté d'intuition qui sont propres à so génie, tout s'éclaire : voici enfin que va être découverte la caus des altérations des vins, une voie nouvelle s'ouvre devant lui. Mai étant en pleines recherches sur les fermentations, il a la volonté de le poursuivre et de les terminer avant de s'attaquer aux maladies de: vins.

Trois ans plus tard, en novembre 1861, il étudie sur la demand de Balard un vin altéré provenant des vignobles de Montpellier. Il J reconnaît le ferment dont il a constaté la présence dans les vin malades du Jura : la voie entrevue en 1858 était la vraie, il n'a plu qu'à s'y engager. Mais, maintenant comme en 1858, il ne se laissera pas entrainer vers ces recherches, il veut auparavant mener jusqu'au bout les études entreprises sur la fermentation acétique.

C'est seulement quand il eut presque achevé les travaux sur le vinaigre, à l'automne de 1863, qu'il aborda les maladies des vins.

Dès janvier 1864, après avoir donné quelques semaines auparavant une étude sur l'influence de l'oxygène de l'air dans la vinification, il démontre que les altérations des vins sont dues à des productions microscopiques de la nature des ferments.

Ses expériences antérieures sur la résistance des micro-organismes à l'influence de la chaleur l'amènent en 1865 à découvrir un moyen simple de prévenir les maladies des vins en tuant les germes, causes de ces maladies.

En 1866, il réunit et complète ses recherches dans un ouvrage intitulé : «Études sur le vin. Ses maladies; causes qui les provoquent. Procédés nouveaux pour le conserver et pour le vieillir ». La première partie de cet ouvrage renferme la description des maladies des vins et des ferments qui les déterminent. La seconde traite de l'influence de l'oxygène de l'air dans la pratique de la vinification. La troisième relate un procédé industriel de conservation des vins par l'action de la chaleur.

Après une longue controverse au sujet de la priorité du chauffage des vins et la publication de quelques Notes nouvelles, Pasteur donne en 1873 une deuxième édition des " Études sur le vin ».

Nous avons réuni ces travaux. On trouvera d'abord intégralement reproduit l'ouvrage "Études sur le vin » - avec des annotations et les indications des variantes entre la première et la deuxième édition -, œuvre capitale où ont été rassemblées et ordonnées par Pasteur toutes ses recherches sur ce sujet. A ces "Études sur le vin " font 
suite les communications, les articles, les discussions qui forment la trame des divers chapitres de l'ouvrage.

Dans ce volume se montre, allié à la recherche scientifique, le souci de l'application pratique : double aspect du génie de Pasteur. On voit en pleine puissance la logique inflexible de ces travaux qui tous s'enchainent : les études sur le vinaigre font suite aux études sur les fermentations, émanées des découvertes sur la dissymétrie moléculaire; les études sur la cause et le traitement des maladies des vins sont la conséquence des études sur les fermentations et sur les générations dites spontanées; elles sont elles-mêmes le prélude aux recherches sur les maladies contagieuses. 



\section{ÉTUDES SUR LE VINAIGRE}





\section{SUR LA FERMENTATION ACÉTIQUE (1)}

M. Pasteur expose les premiers résultats de ses recherches sur la fermentation appelée acétique. M. Pasteur a découvert dans les plantes cryptogamiques du genre mycoderma, dont il figure trois des espèces les plus intéressantes, une propriété remarquable qui donne l'explication complète de l'acétification des liquides alcooliques.

Voici quelques-unes de ses expériences :

$\Lambda$ la surface d'un liquide organique quelconque, renfermant essentiellement des phosphates et des matières albuminoïdes, on fait développer une espèce quelconque du genre mycoderma, jusqu'à ce que toute la surface du liquide en soit couverte. Alors, avec un siphon, on enlève le liquide générateur de la plante, en s'arrangeant de manière que le voile de la mucorée ne soit pas déchiré et ne tombe pas en lambeaux au fond du vase, condition très facile à remplir. Ensuite on remplace le liquide par de l'alcool pur étendu d'eau, marquant, par exemple, $10^{\circ}$ à l'alcoomètre centésimal. Le mycoderme, difficilement mouillé par les liquides à cause de ses principes gras, se soulève et recouvre la surface du nouveau liquide. La petite plante est alors placée dans des conditions exceptionnelles. Sa vie est très gênée, si elle n'est pas rendue tout à fait impossible, parce qu'elle n'a plus pour aliments que les principes qu'elle peut trouver dans sa propre substance, surtout si on a la précaution de la laver en dessous avec de l'eau pure avant de la mettre à la surface du liquide alcoolique. Or, l'expérience démontre que la plante, dans ces circonstances anormales de maladie ou de mort, met immédiatement en réaction l'oxygène de l'air et l'alcool du liquide. L'acétification commence sur-le-champ et se poursuit avec une grande activité. A près quelques jours, l'action de la plante se ralentit, mais elle est loin d'être épuisée. Elle est gênée par l'acidité de plus en plus grande de la liqueur. Enlève-t-on celle-ci pour la remplacer par une nouvelle portion d'alcool pur étendu d'eau, l'acétification continue pour le deuxième liquide, et cette suite d'opérations peut se prolonger pendant des mois entiers. D'autre part, lorsque l'acétification s'arrête pour une liqueur déjà très acétique, elle peut continuer si cette liqueur vient à être introduite sous une mucorée qui n'a pas encore agi.

Pendant tout ce travail, la plante éprouve des modifications assez profondes, sans toutefois augmenter de poids. Tout au contraire elle subit une sorte de combustion qui dissont ses matériaux, de telle sorte que le

1. Bulletin de la Société chimique de Paris, séance du 26 juillet 1861, p. 94-96. (Résumé.) 
liquide devient peu à peu apte à nourrir la plante ou l'une des espèces qui l'avoisinent dans le même genre mycoderma. A ce moment des phénomènes entièrement différents, au moins en apparence, s'accomplissent. L'acide acétique et l'alcool disparaissent complétement avec la plus grande rapidité. Quelques jours suffisent pour enlever au liquide toute son acidité. Il arrive à une neutralité parfaite et propre, en conséquence, à donner naissance à des infusoires divers, et par suite à une altération putride.

Toute cette seconde partie des phénomènes annoncés par M. Pasteur peut se produire lorsque l'on fait développer les mycodermes sur des liquides alcooliques qui renferment les aliments propres à la nourriture de la plante, tels que le vin, la bière, les liquides fermentés en général, à moins que, par des circonstances fortuites ou déterminées par l'opérateur, la plante ne soit placée dans des conditions analogues à celles où elle se trouve dans la première partie de l'expérience.

En résumé, l'acétification est produite par les espèces du genre mycoderma. Lorsque la plante est en pleine vie et santé, elle ne donne pas lieu à une formation effective d'acide acétique. Bien plus, si cet acide existe dans la liqueur, elle le détruit ainsi que l'alcool. Au contraire, si la plante est malade, si on lui refuse ses aliments, ou si, tout en les possédant, elle est gênée par une autre cause quelconque, elle transforme l'alcool en aldéhyde et en acide acétique.

Tout ce qui a été dit sur l'influence des corps poreux organisés ordinaires dans l'acétification est entièrement erroné. Voici les expériences qui le mettent en évidence :

M. Pasteur fait écouler le long d'une corde de l'alcool étendu d'eau. Les gouttes qui tombent à l'extrémité de la corde ne renferment pas la plus petite quantité d'acide acétique. L'expérience a duré plus d'un mois avec une vitesse d'écoulement extrêmement faible, une goutte par deux à trois minutes. Mais si l'on répète cet essai en ayant la précaution de tremper la corde, au début de l'expérience, dans un liquide à la surface duquel se trouve une pellicule de mycoderme qui reste en partie sur la corde lorsqu'on retire celle-ci, l'alcool qui s'écoule lentement le long de cette corde au contact de l'air se charge d'acide acétique. L'acétification peut se prolonger pendant plusieurs semaines.

Il est évident, par cette double expérience, que dans le procédé d'acétification dit allemand les copeaux de hêtre sont sans action, et qu'ils n'ont d'autre role que de servir de support à la plante.

Dans la fabrication telle qu'elle se pratique à Orlèans, l'acétification, d'après M. Pasteur, est duc uniquement à une pellicule presque insensible, d'une minceur excessive, qui recouvre le liquide des tonneaux, et qui est formée par la plus petite espèce des mycoderma. La mère du vinaigre, c'est-à-dire le dépót qui est au fond des tonneaux et sur lequel on verse tous les huit jours dix litres de vin après avoir retiré dix litres de vinaigre, n'a aucune influence sur le phénomène. Tout le travail se fait à là surface, dans la pellicule d'une ténuité excessive qui recouvre le liquide. Mais si, pour un motif quelconque, cette pellicule vient à épaissir, à se développer, l'opération passe aussitôt à la phase de disparition de l'alcool et de l'acide acétique. Le vinaigre, laissé dans le tonneau, a précisément pour effet de 
modérer le développement de la plante, de la rendre maladive, mais il n'intervient pas autrement dans l'acétification.

Les rapports des mycodermes avec l'oxygène ne se bornent pas aux phénomènes dont il vient d'être question. M. Pasteur a reconnu que, mis en présence du sucre, hors de tout contact avec le gaz oxygène, ils avaient la propriété de se développer. Leur respiration s'effectue alors, sans nul doute, à l'aide de l'oxygène enlevé au sucre. Or, il est fort remarquable que dans ces conditions le sucre fermente. Ces faits, comme on le verra lorsque l'ensemble des obscrvations sera publié, ajoutent un nouvel appui à la théorie de la fermentation proposée récemment par M. Pasteur. En même temps, ils rendent compte de tous les prétendus changements de forme de la levùre de bière ou des spores des mucédinées qui ont souvent appelé l'attention des micrographes. En effet, dans ces nouvelles conditions de vie et de développement, les mycodermes éprouvent des modifications dans la grosseur de leurs articles, dans leur mode de propagation, qui au premier abord peuvent faire croire à des transformations en des espèces nouvelles. C'est quelque chose d'analogue aux métamorphoses des insectes et des vers intestinaux.

M. Pasteur publiera bientot l'ensemble de ses observations sur ce sujet. Il annonce également des résultats sur l'acidification, par le moyen des mycodermes, des alcools autres que l'alcool ordinaire. 


\section{[OBSERVATIONS ( ${ }^{1}$ ) \\ AU SUJET D'UNE NOTE DE M. TERREIL :

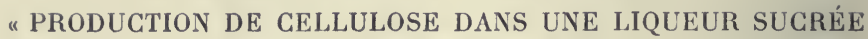 \\ AYANT FERMENTÉ (2) "]}

M. Pasteur fait observer que la matière cellulosique signalée par M. Terreil n'est évidemment autre chose que la mère du vinaigre, qui, comme toutes les plantes inférieures, renferme un poids considérable de cellulose. La transformation de matières hydrocarburées ou autres en cellulose par la végétation n'a rien qui doive surprendre. Tous les caractères que vient d'indiquer M. Terreil appartiennent au mycoderma aceti.

1. Bulletin de la Société chimique de Paris, séance du 8 novembre 1861, p. 111.

2. Ibid., p. 109-111. Une boisson, oubliée dans un tonneau pendant plusieurs mois, et qui avait été préparée avec les substances suivantes :

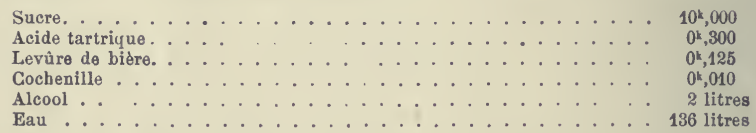

se trouva, lorsqu'on voulut s'en servir, recouverte d'une couche épaisse d'une matière solidepesant de 10 à 12 kilogrammes, ressemblant ả la chair de certains poissons, ou plutôt à du gras de lard, et présentant, suivant l'auteur, tous les caractères de la cellulose pure. (Note de l'Édition.) 


\section{ÉTUDES SUR LES MYCODERMES. \\ ROLE DE CES PLANTES DANS LA FERMENTATION ACÉTIQUE (1)}

Les naturalistes désignent sous le nom de mycodermes ces pellicules lisses ou ridées, vulgairement appelées fleurs $d u$ vin, fleur's de la bière, fleurs du vinaigre, etc., que l'on voit apparaître à la surface de tous les liquides fermentés.

Tout ce que l'on sait sur ces petites plantes se borne à de courtes descriptions de leurs formes.

L'une d'elles mérite une mention spéciale. On trouve quelquefois dans les vases qui renferment du vinaigre, sous l'aspect de membranes plus ou moins difficiles à déchirer, une matière gélatineuse que l'on a désignée depuis longtemps, dans le langage des fabriques, du nom caractéristique de mère de vinaigre.

Voici comment Berzelius s'exprime à ce sujet :

" Le vinaigre, dit-il, conservé dans des vases où il est en contact avec de l'air [qui peut se renouveler], perd sa transparence; peu à peu il s'y rassemble une masse gélatineuse, cohérente, qui paraît glissante et gonflée quand on la touche, et d'où l'on ne peut point retirer par la pression le liquide qu'elle contient.

"Cette masse a reçu le nom de mère de vinaigre, parce que l'on a cru à tort qu'elle était susceptible de déterminer la fermentation acide....; à l'état de pureté, elle est dépourvue de cette propriété, qu'elle doit uniquement à l'acide acétique qui se trouve renfermé dans ses pores... (2) $)$

Diverses pratiques des vinaigreries s'accordent complétement avec l'opinion de Berzelius.

Un fait remarquable, découvert en 1823 [1820] par Edmund Davy $\left({ }^{3}\right)$, a exercé une grande influence sur la théorie autant que sur les procédés

1. Comptes rendus de l'Académie des sciences, séance du 10 février 1862 , LIV, p. 265-270

2. Berzeltus (J.-J.). Traité de chimie. Paris, $1829-1833,8$ vol. in-80. Tome VI, 1832, p. 552 et p. 555 .

3. Davy (Edmund). On some combinations of platinum. Philosophical Transactions of the Royal Society of London, 1820 (Part I), p. 108-125. (Notes de l'Édition.) 
de fabrication industrielle de l'acide acétique. - Le noir de platine, arrosé avec de l'alcool étendu d'eau, s'échauffe et donne naissance à de l'acide acétique.

Ce fait est devenu l'occasion d'un nouveau procédé d'acétification. On fait écouler des liquides alcooliques sur des copeaux de hêtre entassés dans des tonneaux où. l'air peut circuler librement. Les copeaux, dit-on, font l'office du noir de platine. C'est un corps poreux qui condense l'oxygène de l'air.

En résumé, rien de plus obscur, rien de plus mystérieux, que cette ancienne fabrication du vinaigre, entièrement livrée à l'empirisme et à la routine...

Dans les recherches que je poursuis depuis plusieurs années sur les fermentations, divers indices m'avaient porté à penser que les mycodermes pourraient bien n'être pas étrangers à la formation de l'acide acétique. Ces indices se multipliant et s'accusant de plus en plus, j'appliquai tous mes efforts à les suivre par des expériences directes.

Des diverses espèces mycodermiques, l'une des plus faciles à cultiver, si l'on me permet cette expression, est sans contredit la fleur du vin, le mycoderma vini ou cervisix. C'est par elle que je commençai mes études. Leurs premiers résultats furent directement contraires à ce que j'attendais. En faisant développer la fleur du vin sur divers liquides alcooliques au contact de l'air, je n'obtenais pas du tout d'acide acétique. Bien plus, si j'introduisais directement dans le liquide une certaine proportion de cet acide, il disparaissait peu à peu. Il en était de même de l'alcool.

Néanmoins ces résultats n'étaient pas constants.

Mais ce qu'il est essentiel de remarquer, tous ces faits étaient subordonnés à la présence et à la vie du mycoderme.

Je vais revenir à ces complications apparentes. Considérons auparavant, non plus la fleur du vin, mais la fleur du vinaigre, le mycoderma aceti.

En cultivant cette nouvelle espèce, pure et sans mélange, à la surface de liquides alcooliques divers, je reconnus, cette fois, que le sens général des phénomènes était constant. L'alcool s'acétifiait toujours, avec formation intermédiaire de petites quantités d'aldéhyde. Quant à la corrélation entre la manifestation des phénomènes chimiques et la présence de la plante, elle était aussi rigoureuse que dans le premier cas.

Cela posé, répétons les essais précédents relatifs à nos deux mycodermes, dans des vases clos, où nous pourrons enfermer, outre le 
liquide et la semence de la plante en expérience, un volume d'air déterminé, et de telle sorte que l'on puisse à chaque instant joindre à l'analyse du liquide l'analyse de l'atmosphère du vase. Alors l'intelligence des phénomènes se montre dans toute sa simplicité. On reconnaît, en effet, que le mycoderme du vinaigre prend l'oxygène de l'air et le fixe sur l'alcool pour en faire de l'acide acétique; que le mycoderme du vin prend également l'oxygène de l'air et le fixe également sur l'alcool, mais pour en faire de la vapeur d'eau et de l'acide carbonique. On reconnaît de plus que, si l'on supprime l'alcool et que l'on fasse développer le mycoderme du vinaigre sur un liquide acétique, l'acide est transformé en eau et en acide carbonique. Avec le mycoderme du vin l'effet est le même, encore bien qu'il puisse y avoir de l'alcool en dissolution dans le liquide.

Conséquemment, si nous remarquons que l'aldéhyde n'est autre chose que de l'alcool moins de l'hydrogène, que l'acide acétique est de l'alcool qui a subi une combustion plus avancée, et qu'enfin l'alcool et l'acide acétique lorsqu'ils éprouvent une combustion complète se transforment en eau et en acide carbonique, nous déduirons logiquement de ce qui précède que la fleur du vin se comporte exactement comme la fleur du vinaigre, et qu'il y a seulement pour elle des circonstances où sa propriété s'exalte, c'est-à-dire que la plante, au lieu de prendre à l'air deux ou quatre molécules d'oxygène pour les fixer sur une molécule d'alcool et en faire de l'aldéhyde ou de l'acide acétique, s'empare de huit ou de douze molécules de ce gaz, et transforme complétement à leur aide l'alcool et l'acide acétique en eau et en acide carbonique.

Et tous ces faits s'accomplissent avec une grande puissance, avec un grand dégagement de chaleur et une rapidité qui étonnerait l'imagination la plus hardie.

Voilà comment la même plante qui provoque l'acétification de l'alcool peut détruire l'acide acétique qu'elle a formé. Voilà comment le fabricant, qui le premier a appelé mère de vinaigre la fleur du vinaigre, a été guidé par un instinct sûr. Voilà comment Berzelius, d'autre part, en refusant à la mère de vinaigre le pouvoir d'acétifier parce qu'elle détruisait cet acide, avançait un fait vrai, dont l'interprétation seule était erronée.

J'ai reconnu que la fleur du vinaigre ne détermine plus l'acétification dès qu'elle est submergée. Il faut, pour qu'elle agisse, qu'elle recouvre la surface du liquide. Dans les vinaigreries les dépóts des 'tonneaux que les fabricants appellent mères n'ont aucune espèce d'action acétifiante. Tout se passe à la surface du liquide. 
Voici la démonstration expérimentale de ces faits. Je détermine l'acétification d'un liquide alcoolique à l'aide du mycoderme du vinaigre, et de façon que le voile de la plante devienne assez résistant pour que toutes les parties en soient liées ensemble et difficiles à disjoindre. En même temps je mesure jour par jour le progrès de l'acidité de la liqueur. Puis, à un instant donné, je submerge le voile au moyen de lourdes baguettes de verre qui l'obligent à tomber au fond du liquide. Aussitôt l'acétification s'arrête, et cela dure ainsi deux, trois, quatre, cinq, six jours et plus. Et, dès 'qu'un voile nouveau reparaît, l'analyse continuée du liquide accuse immédiatement la reprise de la formation de l'acide acétique.

Ce résultat prouve que la plante n'agit pas par un principe qu'elle sécréterait pour le répandre dans le liquide. Il montre en outre que la cause du phénomène chimique qui accompagne la vie de la plante réside dans un état physique propre, analogue à celui du noir de platine. Mais il est essentiel de remarquer que cet état physique de la plante est étroitement lié avec la vie de cette plante.

Voici l'une des preuves de cette assertion.

A la surface d'un liquide alcoolique renfermant essentiellement des phosphates et des matières albuminoïdes, je fais développer la fleur du vin jusqu'à ce que toute la surface du liquide en soit couverte. Je constate jour par jour qu'il y a disparition de l'alcool et de l'acide acétique si l'on en a ajouté dans le liquide. Alors, avec un siphon, j'enlève le liquide générateur de la plante, sans déchirer le voile de la mucorée, condition facile à remplir. Ensuite je substitue au premier liquide de l'alcool pur étendu d'eau. Le mycoderme, difficilement mouillé à cause de ses principes gras, se soulève et recouvre la surface du nouveau liquide. La petite plante n'a plus alors pour aliments que les principes qu'elle peut trouver en elle-même. Or, l'expérience démontre que, dans ces circonstances anormales de maladie ou de mort relative, la plante, qui un instant auparavant, en pleine santé, opérait la combustion de l'alcool et de l'acide acétique, transforme maintenant pour une part l'alcool en acide acétique.

Cette expérience prouve que la plante malade fait les mêmes choses que la plante bien portante, mais avec moins d'énergie.

J'arrive maintenant au procédé d'acétification par les copeaux de. hêtre. Tous les auteurs sont d'accord sur l'explication théorique de ce mode de fabrication. Les copeaux, dit-on, agissent comme corps poreux, à la façon du noir de platine. Cette opinion est tout à fait. erronée. Je vais démontrer que les copeaux n'ont aucune action par eux-mêmes, et qu'ils ne font que servir de support au développement. 
de l'un des mycodermes, particulièrement du mycoderma aceti. En effet, faisons écouler sur des copeaux ou le long d'une corde de l'alcool étendu d'eau. Les gouttes qui tombent à l'extrémité de la corde ne renferment pas la plus petite quantité d'acide acétique. Mais répétons cet essai en trempant la corde, au début de l'expérience, dans un liquide à la surface duquel se trouve une pellicule mycodermique qui reste en partie sur la corde lorsqu'on la retire du liquide : l'alcool, que l'on fait ensuite écouler lentement le long de cette corde au contact de l'air, se charge d'acide acétique.

Si les mycodermes avaient seulement la propriété d'être des agents de combustion pour l'alcool et l'acide acétique, leur rỏle serait déja bien digne de fixer l'attention. Mais j'ai reconnu que cette propriété avait une généralité d'action qui ouvre un champ nouveau d'études à la physiologie et à la chimie organique. En effet, les mycodermes peuvent porter l'action comburante de l'oxygène de l'air sur une foule de matières organiques, les sucres, les acides organiques, divers alcools, les matières albuminoïdes, en donnant lieu dans certains cas à des intermédiaires dont j’ai déja aperçu quelques-uns $\left(^{(1)}\right.$.

J'ajouterai encore que la propriété dont il s'agit se retrouve à des degrés variables dans les mucédinées, et, tout me porte à le croire, dans les plus petits des infusoires. J'ai reconnu que l'on pouvait par le développement d'une mucédinée transformer en eau et en acide carbonique des quantités relativement considérables de sucre, sans qu'il restât dans la liqueur la plus faible proportion de cette substance.

Si les êtres microscopiques disparaissaient de notre globe, la surface de la terre serait encombrée de matière organique morte et de cadarres de tout genre (animaux et végétaux). Ce sont eux principalement qui donnent à l'oxygène ses propriétés comburantes. Sans eux, la vie deviendrait impossible, parce que l'œuvre de la mort serait incomplète.

Après la mort, la vie reparaît sous une autre forme et avec des propriétés nouvelles. Les germes, partout répandus, des êtres microscopiques commencent leur évolution, et, à leur aide et par l'étrange faculté qui fait l'objet de ce Mémoire, l'oxygène se fixe en masses énormes sur les substances organiques que ces êtres ont envahies et en opère peu à peu la combustion complète.

Qu'il me soit permis, en terminant cette trop rapide exposition, de caractériser brièvement à un autre point de vue les résultats de ce

1. Il me parait nécessaire de reprendre, au point de vue de ces nouvelles idées, tout ce qui concerne la nitrification. 
travail. Nous venons d'apprendre qu'il existe des cellules organisées qui ont la propriété de transporter l'oxygène de l'air sur toutes les matières organiques, les brûlant complétement avec un grand dégagement de chaleur ou les arrêtant à des termes de compositions variables. C'est l'image fidèle de la respiration et de la combustion qui en est la suite, sous l'action de ces globules organisés que le sang apporte sans cesse dans les cellules pulmonaires, où ils viennent chercher l'oxygène de l'air pour le répandre ensuite dans toutes les parties du corps, afin d'y brûler à des degrés divers les principes de l'économie. 


\section{SUITE A UNE PRÉCÉDENTE COMMUNICATION SUR LES MYCODERMES.}

NOUVEAU PROCÉDÉ INDUSTRIEL DE FABRIGATION DU VINAIGRE (1)

J'ai eu l'honneur de faire connaître à l'Académie, dans une de ses séances du mois de février de cette année (2), la faculté que possèdent les mycodermes, notamment la fleur du vin et la fleur du vinaigre, de servir de moyens de transport de l'oxygène de l'air sur une foule de substances organiques et de déterminer leur combustion avec une rapidité parfois surprenante.

L'étude de cette propriété des mycodermes m'a conduit à un procédé nouveau de fabrication du vinaigre, qui me paraît destiné à prendre place dans cette industrie ${ }^{(3)}$.

1. Comptes rendus de l'Académie des sciences, séance du 7 juillet 1862, LV, p. 28-32.

Cette Note a été publiẻe en brochure sous le titre : Nouveau procédé industriel de fabrication du vinaigre. Paris, 1862, Mallet-Bachelier, 7 p. in-4. Nous avons signalé les variantes.

2. 11 s'agit de la Communication qui précède. (Notes de l'Édition.)

3. Comme il arrive fréquemment que des principes scientifiques, livrés à la publicité par leurs auteurs, deviennent, entre les mains d'autrui, l'objet de brevets d'invention par l'addition de dispositifs d'appareil ou de modifications insignifiantes, j'ai pris antérieurement à ma Communication du mois de février, d'aprẻs l'avis de personnes autorisées, un brevet qui primerait tous ceux auxquels mon travail aurait pu donner lieu; et j'ajoute que je suis résolu dès aujourd'hni à laisser tomber ce brevet dans le domaine public. (Note de Pasteur qui ne figure pas dans les Comptes rendus de l'Académie des sciences.)

Voici le texte du brevet :

“ Brevet n 50359 , en date du 9 juillet 1861. (Extrait des Brevets d'invention, année 1861, LXXXI, classe XIV, fascicule 7, p. 3.)

A M. PASTEUR, pour la fabrication du vinaigre ou acide acétique au moyen des mucors et en particulier des mycoderma vini et mycoderma aceti.

J'ai reconnu que ces plantes étaient la cause de la fermentation acétique.

Le procélé consiste à faire développer ces plantes sur une grande surface, au moyen de liquides organiques propres à les nourrir, renfermant essentiellement des phosphates et des matières azotées, puis à les mettre au contact du liquide alcoolique que l'on veut acidifier, en présence de l'air atmosphérique.

Simplicité et rapidité d'exécution, qualité des produits, et application possible, très facile même, à l'alcool étendu d'eau, sont des avantages qui paraissent acquis à l'emploi de ce mode de fabrication.

Centificat en date du 12 décembre 1861.

Ainsi que je l'ai annoncé dans le brevet que j'ai pris à la date du 9 juillet 1861, l'acétification des liquides alcooliques est produite par les espéces végétales du genre mycoderma, 
Voici ce procédé, amené à un assez grand degré de simplicité et d'économie, à la suite de nombreuses expériences ( $\left.{ }^{1}\right)$ :

Je sème le mycoderma aceti, ou fleur du vinaigre, à la surface d'un liquide formé d'eau ordinaire contenant 2 pour 100 de son volume d'alcool et 1 pour 100 d'acide acétique provenant d'une opération précédente, et en outre quelques dix millièmes de phosphates alcalins et terreux, comme je le dirai tout à l'heure. La petite plante se développe et recouvre bientôt la surface du liquide sans qu'il y ait la moindre place vide. En même temps l'alcool s'acétifie. Dès que l'opération est bien en train, que la moitié, par exemple, de la quantité totale d'alcool employée à l'origine est transformée en acide acétique, on ajoute chaque jour de l'alcool par petites portions, ou du vin ou de la bière alcoolisés, jusqu'à ce que le liquide ait reçu assez d'alcool pour que le vinaigre marque le titre commercial désiré. Tant que la plante peut provoquer l'acétification, on ajoute de l'alcool.

Lorsque son action commence à s'user, on laisse s'achever l'acétification de l'alcool qui reste encore dans le liquide. On soutire alors

notamment par le mycoderma aceti. Ces plantes ont la propriété de déterminer la combinaison de l'oxygène de l'air arec l'alcool.

Elles ont également la propriété de déterminer la combinaison de l'oxygène de l'air avec l'acide acétique et de transformer complétement cet acide en eau et en acide carbonique.

Il résulte de lá que tout le secret d'une bonne fabrication consiste :

1. A fournir à la plante des aliments;

$2^{\circ}$ A la placer dans les conditions où elle opère l'acétification de l'alcool, sans aller jusqu'à la combustion des éléments de l'acide acétique.

Les procédés d'acétification par l'emploi des copeaux de hêtre reposent sur des idées théoriques entièrement erronées.

Il n'y a qu'une sorte de corps poreux qui acétifie dans les divers procédés qu'utilise l'industrie : ce sont les plantes dont je parle.

Les copeaux ne font que servir de support à leur développement.

Ces faits, rigoureusement établis par des expériences très précises, m'ont conduit au procédé suivant d'acétification de l'alcuol.

Le liquide alcoolique que l'on veut acétifier, formé, par exemple, de 1 partie d'un liquide fermenté quelconque, biére, cidre, jus de betterave, vin, etc., de 1 partie dé vinaigre d'une opération précédente et de 3 parties d'alcool (flegmes quelconques), au titre voulu pour obtenir le titre désiré de l'acide acétique, le liquide alcoolique, dis-je, est placé dans des cuves de grandes dimensions très peu profondes, de 10 centimètres, plus ou moins.

A la surface du liquide on sème la plante et l'on recouvre la cuve avec un couvercle ordinaire ou avec une cuve pareille à la précédente.

La plante se multiplie avec une rapidité extrême et provoque l'acétification complète du liquide.

Ce procédé permettra de livrer au prix de revient de 10 centimes le litre des acides acétiques à 7 ou 8 pour 100 d'acide; son application n'a pas de limites.

On pourrait dans l'espace de quelques jours, presque sans frais de main-d'ceuvre ni d'installation, fabriquer des milliers d'hectolitres d'acide acétique de force quelconque et presque sans perte d'alcool.

La fabrication peut, sans aucun inconvénient, être arrêtée ou mise en train quand on veut. Il est également facile de la rendre continue. " (Note de l'Édition.)

1. Cette phrase ne figure pas dans les Comptes rendus de l'Académie des sciences. (Note de l'Édition.) 
ce dernier, puis on met à part la plante, qui par lavage peut donner un liquide un peu acide et azoté capable de servir ultérieurement.

La cuve est alors mise de nouveau en travail. Je viens d'indiquer l'une des formes de la mise en travail d'une cuve. On peut la modifier de diverses manières (1).

Il est indispensable de ne pas laisser la plante manquer d'alcool, parce que sa faculté de transport de l'oxygène s'appliquerait alors, d'une part à l'acide acétique qui se transformerait en eau et en acide carbonique, de l'autre à des principes volatils, mal déterminés, dont la soustraction rend le vinaigre fade et privé d'arome. En outre, la plante détournée de son habitude d'acétification n'y revient qu'avec une énergie beaucoup dininuée. Une autre précaution, non moins nécessaire, consiste à ne pas provoquer un trop grand développement de la plante; car son activité s'exalterait outre mesure, et l'acide acétique serait transformé partiellement en eau et en acide carbonique, lors même qu'il y aurait encore de l'alcool en dissolution dans le liquide.

Une cuve de 1 mètre carré de surface, renfermant 50 à 100 litres de liquide, fournit par jour l'équivalent de 5 à 6 litres de vinaigre. Un thermomètre donnant les dixièmes de degré, dont le réservoir plonge dans le liquide et dont la tige sort de la cuve par un trou pratiqué au couvercle, permet de suivre avec facilité la marche de l'opération.

Je pense que $\left.{ }^{2}\right)$ les meilleurs vases à employer sont des cures de bois rondes ou carrées, peu profondes, analogues à celles qui servent dans les brasseries à refroidir la bière et munies de couvercles. Aux extrémités sont deux ouvertures de petites dimensions pour l'arrivée de l'air. Deux tubes de gutta-percha, fixés sur le fond de la cuve et percés latéralement de petits trous, servent à l'addition des liquides alcooliques sans qu'il soit nécessaire de soulever les planches du couvercle ou de déranger le voile de la surface.

Les plus grandes cuves que la place dont je disposais m'ait permis d'utiliser avaient 1 mètre carré de surface et 20 centimètres de profondeur. J'ajoute que les avantages du procédé ont été d'autant plus sensibles que j'ai employé des vases de plus grandes dimensions et que j’ai opéré à une plus basse température.

J'ai dit que le liquide à la surface duquel je sème le mycoderme devait tenir des phosphates en dissolution. Ils sont indispensables. Ce sont les aliments minéraux de la plante. Bien plus, si au nombre de

1. Ces deux dernières phrases ne figurent pas dans les Comptes rendus de l'Académie des sciences.

2. Cies trois mots ne figurent pas dans les Comptes rendus de l'Académie des sciences. (Notes de l'Édition.) 
ces phosphates se trouve celui d'ammoniaque, la plante emprunte à la base de ce sel tout l'azote dont elle a besoin; de telle sorte que l'on peut provoquer l'acétification complète d'un liquide alcoolique renfermant environ un dix millième de chacun des sels suivants : phosphates d'ammoniaque, de potasse, de magnésie, ces derniers étant dissous a la faveur d'une petite quantité d'acide acétique, lequel fournit en mème temps que l'alcool tout le carbone nécessaire à la plante.

Cependant, afin d'avoir un développement un peu plus rapide et un état physique plus actif du mycoderme, il est bon d'ajouter au liquide à phosphates une petite quantité de matières albuminoïdes qui offrent l'azote et le carbone, et sans doute aussi une partie des phosphates, sous une forme plus assimilable. J'emploie à cet effet soit de l'eau d'orge, soit de la bière, soit de l'eau de levûre, ou encore de l'eau de macération des radicelles d'orge germée... Le vin, le cidre, tous les liquides fermentés et même la plupart des jus naturels pourraient être utilisés. Mais afin que l'on comprenne bien le rôle de ces liquides organiques albumineux, et combien sont erronées les idées qui avaient cours dans la science sur la prétendue transformation en ferments des matières albuminö̈des par l'altération de ces dernières au contact de l'air, je répète que l'on peut facilement faire développer le mycoderma aceti, et dans des conditions où il est capable d'acétifier de grandes quantités d'alcool, en lui fournissant uniquement, pour aliment azoté, de l'ammoniaque; pour aliment carboné, de l'acide acétique et de l'alcool; pour aliments minéraux, de l'acide phosphorique, uni aux principales bases alcalines et terreuses.

A la température de $15^{\circ}$, si la semence est bonne, il faut deux à trois jours au maximum pour que le mycoderme recouvre le liquide à la surface duquel il a été semé, quelles que soient les dimensions de la cuve. Par bonne semence, j'entends une plante jeune, en voie de multiplication, qui se présente au microscope sous la forme de longs chapelets d'articles et non d'amas de granulations, comme cela a lieu quand elle est un peu ancienne et qu'elle a déjà servi pendant plusieurs jours d'agent de combustion. Pour ce qui est de la quantité de la semence, un petit vase de 1 décimètre de diamètre, renfermant 100 centimètres cubes de liquide et recouvert de la plante, suffit pour ensemencer une cuve de 1 mètre carré de surface. On trempe dans ce vase l'extrémité d'une baguette de verre. Le voile du mycoderme s'y attache en partie, et lorsqu'on porte ensuite la baguette dans le liquide de la cuve, il s'en détache et reste à la surface du liquide à ensemencer. On répète cette manipulation tant qu'il y a une portion de voile à la surface du petit vase. 
Dans une fabrique en travail, il y aurait toujours de la semence toute prète. Si l'on n'en a pas, il suffit d'abandonner au contact de l'air un liquide alcoolique et acétique de la nature de ceux dont j'ai parlé, pour y voir apparaître le mycoderme dont il s'agit. Seulement, dans ce cas, il peut se faire que l'on soit obligé d'attendre plusieurs jours, et même plusieurs semaines, avant que l'air de l'atmosphère dépose le germe de la plante (1).

Quels sont les avantages de ce nouveau procédé d'acétification? Arant de les indiquer, je rappellerai qu'il existe aujourd'hui deux procédés industriels de fabrication du vinaigre. L'un, connu sous le nom de procédé d'Orléans, est surtout en usage dans le Loiret et dans la Meurthe. On ne peut l'appliquer qu'au vin. Dans des tonneaux de 200 litres environ de capacité, disposés par rangées horizontales, on place du vinaigre de bonne qualité, environ 100 litres par tonneau, et un dixième du volume en vin ordinaire de qualité inférieure. Après six semaines ou deux mois d'attente, plus ou moins, on retire tous les huit ou dix jours 10 litres de vinaigre et on ajoute 10 litres de vin. Une fois en travail, chaque tonneau fournit donc environ 10 litres de vinaigre tous les huit jours. On ne touche d'ailleurs aux tonneaux que lorsqu'ils ont besoin de réparation.

Un autre procédé est connu sous le nom de procédé des copeaux de hêtre, ou procédé allemand. Le liquide que l'on veut acétifier tombe goutte a goutte par les extrémités de tuyaux de paille ou de ficelle sur des copeaux de bois de hêtre entassés dans de grands tonneaux. Les copeaux reposent sur un double fond placé vers la partie inférieure, où se rassemble le liquide, que l'on repasse à plusieurs reprises sur les copeaux. Des trous pratiqués dans les douves du tonneau permettent l'arrivée de l'air qui s'échappe par le haut après avoir passé dans les interstices des copeaux où il est en contact avec le liquide alcoolique descendant. Ce procédé est très expéditif, mais il ne peut s'appliquer au vin, ni à la bière en nature, et ses produits sont de qualité inférieure, surtout quand on les retire d'alcools mauvais goût. Le prix des vinaigres de vin est environ deux fois plus élevé que celui des vinaigres d'alcool, dénomination par laquelle on désigne ordinairement les vinaigres fabriqués par le procédé des copeaux. Ce procédé donne lieu en outre à des pertes considérables de matière première, parce que le liquide alcoolique très divisé est toujours soumis à un courant d'air échauffé par suite de l'acétification elle-même.

1. Ces trois derniers alinéas ne figurent pas dans les Comptes rendus de l'Académie des sciences. (Note de l'Édition.) 
Je ferai remarquer d'ailleurs que la supériorité des vinaigres d'Orléans ne tient pas uniquement, comme on serait porté à le croire, à ce qu'ils sont fabriqués avec du vin, mais surtout à leur mode même de fabrication qui conserve au vinaigre ses principes volatils indéterminés, d'odeur agréable, principes qu'enlèvent à peu près entièrement le courant d'air et l'élévation de la température dans la fabrication des vinaigres d'alcool. Grâce à ces principes, le vinaigre d'Orléans paraît plus fort à l'odorat et au goût que les vinaigres d'alcool, lors même que la proportion d'acide n'y est pas supérieure et quelquefois moindre.

On reproche donc surtout au procédé d'Orléans d'être lent et seulement applicable au vin. En outre, comme il est entièrement livré à la routine par l'insuffisance des progrès de la science en ce qui le concerne, tous les accidents de fabrication sont préjudiciables, et l'on n'a pas de moyens sûrs d'y porter remède ou de les éviter. Enfin, quel que soit le prix du vin ou de l'alcool, il faut fabriquer. Un chômage total ou partiel d'une vinaigrerie dans le système d'Orléans est impossible. Mais la qualité des produits et l'application possible du procédé, exclusive même au vin, lui permet de lutter avec avantage avec le procédé des copeaux, qui ne peut être utilisé pour le vin et en général pour les liquides chargés de principes albuminoïdes, parce qu'il se formerait sans nul doute des quantités si abondantes de mère de vinaigre qu'il y aurait obstruction des interstices des copeaux, et, l'air ne pouvant plus circuler, l'acétification s'arrêterait (1).

Mais il est utile que j'entre encore dans quelques détails sur un inconvénient très singulier du procédé d'Orléans, qui a été tout à fait inaperçu jusqu'à présent. Cet inconvénient est dû, comme je vais l'expliquer, à la présence bien connue, dans les tonneaux de fabrication, des anguillules du vinaigre.

Tous les tonneaux, sans exception, dans le système de fabrication d'Orléans en sont remplis, et, comme on ne les enlève jamais que partiellement, puisque de 100 litres de vinaigre on ne retire que 10 litres tous les huit jours, en rajoutant 10 litres de vin, leur nombre est quelquefois prodigieux. Or, ces animaux ont besoin d'air pour vivre; d'autre part, mes expériences établissent que l'acétification ne se produit qu'à la surface du liquide, dans un voile mince de mycoderma aceti qui se renouvelle sans cesse. Supposons ce voile bien formé et en travail d'acétification active, tout l'oxygène qui arrive à la surface du liquide est mis en œuvre par la plante qui n'en laisse pas

1. Cet alinéa ne figure pas dans les Comptes rendus de l'Académie des sciences. (Note de l'Édition.) 
du tout aux anguillules. Celles-ci alors, se sentant privées de la possibilité de respirer, et guidées par un de ces instincts merveilleux dont tous les animaux nous offrent à des degrés divers de si curieux exemples, se réfugient sur les parois du tonneau où elles viennent former une couche humide, blanche, épaisse de plus d'un millimètre, haute de plusieurs centimètres, tout animée et grouillante. Là seulement ces petits êtres peuvent respirer. Mais on comprend bien que ces anguillules ne cèdent pas facilement la place au mycoderme. J'ai maintes fois assisté à la lutte qui s'établit entre elles et la plante. A mesure que celle-ci, suivant les lois de son développement, s'étale peu à peu à la surface, les anguillules réunies au-dessous d'elle, et sourent par paquets, s'efforcent de la faire tomber dans le liquide sous la forme de lambeaux chiffonnés. Dans cet état elle ne peut plus leur nuire, car j'ai montré qu'une fois que la plante est submergée, son action est nulle ou insensible. Je ne doute pas que presque toutes les maladies des tonneaux dans le procédé d'Orléans ne soient causées par les anguillules et que ce ne soient elles qui ralentissent et souvent arrêtent l'acétification.

Tout ceci posé; les avantages du procédé que j'ai l'honneur de communiquer à l'Académie peuvent être pressentis. J'opère dans des cures munies de couvercles, à une basse température. Ce sont les conditions générales du procédé d'Orléans, mais je dirige à mon gré la fabrication. Il n'y a qu'une chose qui acétifie dans le procédé d'Orléans, c'est le voile de la surface. Or, je le fais développer dans des conditions que je détermine et dont je suis maître. Je n'ai pas d'anguillules, parce que, si elles prenaient naissance, elles n'auraient pas le temps de se multiplier, puisque chaque cuve est renouvelée après que la plante a agi autant qu'elle peut le faire. Aussi l'acétification est-elle au moins trois à quatre fois plus rapide qu'à Orléans, toutes choses égales d'ailleurs.

Relativement au procédé des copeaux, les avantages sont, d'une part dans la conservation des principes qui donnent $d u$ montant au vinaigre, parce que l'acétification a lieu à une température basse, et d'autre part dans une grande diminution de la perte en alcool, parce que l'évaporation est très faible pour un liquide placé dans une cuve couverte. Enfin le nouveau procédé peut être appliqué à tous les liquides alcooliques et probablement avec autant de facilité dans une cure de 10 mètres carrés de surface que dans une cuve de 1 mètre carré (1).

Je n'ignore pas cependant que l'auteur d'un nouveau procédé

1. La fin de cette phrase, à partir de " et probablement... ", ne figure pas dans les Comptes rendus de l'Académie des sciences. (Note de l'Édition.) 
industriel est toujours prompt à s'en exagérer l'importance, et je n'ai pas la prétention d'être à l'abri de ce préjugé. Je livre donc le résultat de mes études à la discussion et à l'expérience des personnes compétentes ou intéressées, sans y rechercher autre chose que le progrès de la science et de ses applications. 


\section{[QUELQUES RÉSULTATS NOUVEAUX RELATIFS AUX FERMENTATIONS ACÉTIQUE ET BUTYRIQUE(1)]}

$1^{\circ}$ L'acide succinique paraît accompagner constamment l'acide acétique dans la transformation de l'alcool en acide acétique par l'oxygène de l'air sous l'influence du mycoderma aceti.

La meilleure méthode à suivre pour constater l'existence de l'acide succinique consiste à faire développer le mycoderme à la surface de liquides alcooliques renfermant du phosphate d'ammoniaque et des phosphates alcalins et terreux dissous à la faveur de petites quantités d'acide acétique. M. Pasteur a reconnu que, dans ces conditions, la plante se développe très bien, empruntant son carbone à l'alcool ou à l'acide acétique, son azote à l'ammoniaque, ses matières minérales aux phosphates. L'alcool s'acétific. On obtient de cette manière tous les produits de la fermentation acétique sans autre mélange que des phosphates faciles à éliminer après l'évaporation ménagée du liquide acétique, lequel renferme constamment dans les expériences de M. Pasteur des proportions sensibles d'acide succinique, ainsi que d'autres substances encore indéterminées.

$2^{\circ}$ M. Płsteur annonce en outre à la Société qu'ayant repris l'étude de la fermentation butyrique du lactate de chaux, il a constaté que l'équation de cette fermentation n'est pas aussi simple qu'on l'admet. Le rapport des volumes de l'acide carbonique et de l'hydrogène ne correspond pas i beaucoup près à l'équation

$$
\mathrm{C}^{12} \mathrm{H}^{12} \mathrm{O}^{12}=\mathrm{C}^{8} \mathrm{H}^{8} \mathrm{O}^{4}+\mathrm{C}^{4} \mathrm{O}^{8}+\mathrm{H}^{4} .
$$

L'hydrogène est en défaut. Du reste, il y a variation des proportions de ces deux gaz, dans une meême fermentation à dẹs époques différentes, ou dans des fermentations distinctes.

Ce fait annonçait la formation de produits hydrogénés non encore aperçus. M. Pasteur a reconnu que ces produits, quelques-uns du moins, sont de la nature des alcools, et il croit pouvoir affirmer que l'alcool butylique est un produit ordinaire de la fermentation butyrique.

Dans certains cas même, il se dégage de l'acide carbonique pur sans traces d'hydrogène ni d'un autre gaz quelconque.

Enfin, M. Pasteur ajoute que, dans ces derniers temps, il a confirmé par des preuves nouvelles la découverte qu'il a fait connaître l'an dernier 
d'animalcules infusoires vivant sans gaz oxygène libre et déterminant la fermentation butyrique (1). Ces animalcules jouissent en outre de la faculté de se développer sans avoir à leur disposition d'autres aliments que des substances hydrocarbonées (au nombre desquelles il faut placer l'acide lactique), de l'ammoniaque et des phosphates.

1. Voir p. 136-138 du tome II des. Euvres DE PAsteur : Animalcules infusoires vivant sans gaz oxygène libre et déterminant des fermentations. (Note de l'Édition.) 


\title{
MÉMOIRE SUR LA FERMENTATION ACÉTIQUE (1)
}

\author{
PREMIÉRE PARTIE
}

Historique.

\section{I. - L'acide acétique provient de l'oxydation de l'alcool par l'oxygène de l'air.}

Le vin, la bière, le cidre, en général tous les liquides alcooliques fermentés s'aigrissent au contact de l'air, surtout pendant l'été; c'est un fait bien connu et depuis les temps les plus reculés.

Quelle est la nature du phénomène considéré sous un point de vue purement chimique? La science a été longtemps à s'en rendre compte avec précision. Que ce soit l'alcool qui devienne acide acétique, on ne l'ignorait pas. Que l'air puisse favoriser cette transformation, on ne l'ignorait pas davantage; mais on était loin de savoir comment l'air intervient. Dans le Dictionnaire de chimie de Macquer, dont la seconde édition a paru en 1778, ouvrage remarquable, mais malheureusement encore enveloppé dans les obscurités du phlogistique, on trouve cette phrase : "Becher, dans sa Physique souterraine [Physica subterranea, lib. I, sect. 5, cap. 2] a fait digérer du vin, pour le convertir en vinaigre, dans une bouteille scellée hermétiquement. A la vérité, ce vin a été plus longtemps qu'à l'ordinaire, c'est-à-dire, qu'avec le concours de l'air, à se convertir en vinaigre, mais ce vinaigre était aussi beaucoup plus fort (2). " Ainsi, en 1778, l'un des plus habiles chimistes admet

1. Ce Mémoire a été publié dans les Annales scientifiques de l'École Normale supérieure, I (avril) 1864, p. 113-158 (avec 5 fig.) et sous forme de brochure à la librairie Gauthier-Villars, Paris, 1864,46 p. in $-4^{\circ}$ (avec 5 fig.).

Pasteur l'a reproduit dans un opuscule intitulé : “ Etudes sur le vinaigre, sa fabrication, ses maladies, moyens de les prévenir; nouvelles observations sur la conservation des vins par la chaleur. „Paris, 1868, Gauthier-Villars et Victor Masson et fils, vir-119 p., in-80 (avec 7 fig.). Foir la note de la p. 78.

Le texte donné ici est celui de 1868. Les variantes ayant quelque importance ont été signalées.

2. Macquer. Dictionnaire de chimie. Paris (seconde édition), 1778, 4 vol. in-8॰. Tome IV, p. 236-237. (Notes de l'Édition.) 
encore que le vin peut se convertir en vinaigre très fort sans le concours de l'air.

L'abbé Rozier fit une expérience qui démontrait l'absorption de l'air pendant la fermentation acéteuse. Elle consistait à faire un trou à la douve d'un tonneau dont le vin s'aigrissait et à y sceller une vessie munie d'un tube et d'un bouchon, et préalablement gonflée d'air. La vessie, dit-il, devient flasque; et il ajoute que, chaque fois que cette vessie a été vidée d'air, le vin paraît plus aigre qu'auparavant $\left({ }^{1}\right)$. Cependant la lecture de l'article où cette expérience est relatée montre que les idées de l'abbé Rozier étaient encore mal assurées.

Lavoisier est plus net. Il ne s'agit plus seulement de l'air, mais nommément de l'oxygène. « La fermentation acéteuse n'est autre chose que l'acidification du vin qui se fait à l'air libre par l'absorption de l'oxygène $\left({ }^{2}\right)$. „ Cependant, comme il ignore la composition de l'alcool et celle du vinaigre, qu'il ne fait que les pressentir, on le voit, un peu plus loin, interpréter une expérience de Chaptal, en faisant concourir à l'accomplissement du phénomène, outre l'alcool et l'oxygène, une certaine proportion d'acide carbonique.

Pour Lavoisier lui-même et pour les chimistes qui adoptaient ses idées, tous les doutes n'étaient donc pas encore levés au sujet de cette réaction chimique. Dans un passage de l'Appendice à la Statique chimique, Berthollet s'exprime ainsi : “ L'oxygène qui s'absorbe pendant la fermentation acétique, selon l'observation de Rozier, peut servir à décomposer la combinaison vineuse, en se combinant avec l'hydrogène, ou bien il entre immédiatement dans la composition de l'acide acétique; mais, à en juger par l'altération du vin qu'on laisse en contact avec l'air, il produit beaucoup plus le premier effet que le second $(3)$. " Ainsi le sujet fut un peu compliqué par Berthollet. Mais il le fut bien davantage à la même époque par Th. de Saussure, dans un chapitre de ses Recherches chimiques sur la végétation, intitulé : Emploi du gaz oxygène dans l'acétification. De Saussure prétendit avoir observé que, pendant la fermentation acétique, il se dégage un volume d'acide carbonique égal à celui de l'oxygène absorbé, et que l'acidité du vin provenait, non de la fixation de l'oxygène, mais de la

1. Rozien. Cours complet d'agriculture, ou Dictionnaire universel d'agriculture. Paris, 17811800,10 vol. in-4.4. Tome IV, p. 525.

2. Lavorsier. Traité élémentaire de chimie. Paris, 1793 (seconde édition), 2 vol. in- $8^{\circ}$. Tome Ier, p. 159.

3. Benthollet. Essai de statique chimique. Paris, 1803, 2 vol. in-8. Tome II (Appendice), p. 525. (Notes de l'Édition.) 
soustraction du carbone et de son élimination partielle sous forme d'acide carbonique ( $\left.{ }^{1}\right)$.

Une circonstance qu'il ne faut pas omettre et qui a contribué à obscurcir ce sujet à cette époque et dans les années suivantes, c'est la production de l'acide acétique dans des phénomènes de fermentation, mais sans emploi d'alcool et sans communication avec l'air. On lit par exemple, à la suite du passage de la Statique chimique de Berthollet que je viens de citer : "Cependant la production de l'acide acétique n'est pas toujours rlue à ces' causes. Il s'en forme pendant la fermentation vineuse du sucre et de la levûre (Lavoisier), même sans communication avec l'air. Il est vrai qu'alors il peut être dû à la portion d'amidon que contient toujours la levûre : c'est un objet qui reste à éclaircir ( 2 . "

Puis, après avoir rappelé que Parmentier, Deyeux et Vauquelin $\left(^{3}\right)$ ont reconnu que l'eau sure des amidonniers renferme une assez grande quantité d'acide acétique, il émet l'opinion que cet acide acétique ne doit pas être un produit d'oxydation de l'alcool, et il essaye de vérifier cette opinion par l'étude de la fermentation d'un mélange de gluten et d'amidon. Il s'est formé promptement, dit-il, de l'acide acétique sans indice de liqueur spiritueuse. Enfin, il termine en faisant remarquer que " les observations précédentes paraissent prouver que l'acétification est principalement due à l'action du gluten, ou d'une substance qui en approche, sur l'amidon ou sur une substance analogue, quoiqu'il puisse s'en former aussi un peu par la fermentation vineuse ou par l'action de l'oxygène sur le vin $\left({ }^{4}\right)$ ».

La production de l'acide lactique, acide inconnu à cette époque et volontiers confondu avec l'acide acétique, ajoutait encore, ainsi que l'a remarqué M. Dumas, aux difficultés de se bien rendre compte dans tous les cas de la véritable origine de l'acide acétique (5).

Il faut arriver jusqu'en 1821 [1820] et 1827 pour que tous les doutes soient levés touchant la réaction qui nous occupe. En 1821 [1820], Edmund Davy découvrit le noir de platine et ses propriétés remarquables (6). En chauffant du sulfate de platine avec de l'alcool, il

1. Saussure (Th. de). Recherches chimiques sur la végétation. Paris, an XII, in-80, p. 143-147.

2. Berthollet. Loc. cit., p. 525 et 526.

3. Annales de chimie, XXXVIII, an IX, p. 248-270.

4. Berthollet. Loc. cit., p. 525 et 526 .

5. Dumss. Traité de chimie appliquée aux arts. Paris, 1826-1848, 8 vol. in- 8 . Tome VI, p. 339.

6. Davy (Edmund). On some combinations of platinum. Philosophical Transactions of the Royal Society of London, 1820 (Part I), p. 108-125. - Ce Mémoire fut traduit en 1821, dans le Journal für Chemie u. Physik, XXXI, p. 340. (Notes de l'Édition.) 
obtint un précipité noir, qui, desséché, jouissait de la singulière faculté de devenir incandescent lorsqu'on l'humectait avec de l'esprit-de-vin, et de continuer à rougir tant qu'il restait de l'alcool. Pendant cette combustion, l'alcool était transformé en acide acétique.

"C'est ce fait, dit Liebig à qui l'on doit une Note précieuse sur la préparation du noir de platine et son mode d'action (1), qui fournit a Dœbereiner la clef du développement théorique de la transformation de l'alcool en acide acétique. Ce dernier chimiste démontra, en effet, que l'alcool, en absorbant de l'oxygène, donne de l'eau et de l'acide acétique sans dégager de l'acide carbonique $\left(^{2}\right)$. En mesurant le volume d'oxygène absorbé par une quantité déterminée d'alcool, il parvint à prouver que les éléments de 1 atome d'alcool se combinént avec 4 atomes d'oxygène, de sorte que, la composition de l'acide acétique étant d'ailleurs connue, il était facile d'en conclure qu'il devait se former 1 atome d'acide acétique et 3 atomes d'eau :

$$
\mathrm{C}^{4} \mathrm{H}^{12} \mathrm{O}^{2}+4 \mathrm{O}=\mathrm{C}^{4} \mathrm{H}^{6} \mathrm{O}^{3}+3 \mathrm{H}^{2} \mathrm{O}\left({ }^{3}\right) \text {. " }
$$

\section{\$II. - Nécessité d'un ferment pour l'oxydation de l'alcool} dans la fermentation acétique. Idées sur la nature de ce ferment.

Il ne sera pas moins intéressant de suivre historiquement le progrès des idées en ce qui concerne la cause probable à laquelle on doit attribuer le phénomène de l'acétification.

Il y a bien longtemps que l'on sait que l'alcool pur ne peut s'acétifier au contact de l'air, que l'eau-de-vie, par exemple, ne se transforme pas en vinaigre, quel que soit son titre alcoolique.

"L'acétification, dit Berzelius, ne s'établit que par le concours d'un ferment. G'est par cette raison que les vins de bonne qualité ne deviennent pas acides, parce qu'ils ont laissé déposer tout le ferment, tandis que les vins mauvais s'acétifient, même dans des flacons bouchés (4). 》 Et plus loin : “ Dès que la formation de l'acide acétique

1. Liebig (J.). [Sur le précipité noir de platine de M. Edmund Davy, et sur la propriété de l'éponge de platine d'enflammer l'hydorogène.] Annales de chimie et de physique, 2。 sér., XLII, 1829, p. 316-330.

2. Doebereiner. Neu entdeckte merkwûrdige Eigenschaften des Platinsuboxyds, des oxydierten Schwefel-Platins und des metallischen Platinstaubes. Journal für Chemie $u$. Physik, XXXVIII, 1823, p. 321-326. - Propriétés nouvelles et remarquables reconnues au sous-oxyde de platine, au sulfure oxydé et à la poussière du même métal. Annales de chimie et de physique, 2 e sér., XXIV, 1823, p. 91-96.

3. Liebig (J.). Traité de chimie organique. Paris, 1840-1844, 3 vol. in-80. Tome Ior, p. 387. (Notes de l'Édition.)

4. Chaptal avait dit, en effet : "Un vin parfaitement dépouillé de tout principe extractif, ou par le dépôt qui se fait naturellement avec le temps, ou par la clarification, n'est plus 
a commencé, cet acide contribue singulièrement à accélérer la fermentation. C'est pour cela que les brasseurs et les fabricants d'eau-de-vie doivent nettoyer avec le plus grand soin les vases dans lesquels on a fait fermenter des liquides, pour enlever tout l'acide acétique avant de s'en servir de nouveau. Sans cette précaution; la masse s'acidifierait pendant la fermentation vineuse, à mesure qu'il se formerait de l'alcool. L'acide acétique est donc lui-même un ferment propre à déterminer la fermentation acide; et la levûre, le levain qui est devenu acide, le pain aigri, en un mot les corps qui déterminent la fermentation vineuse, possèdent la mème propriété dès que la fermentation acide y a commencé. On cite aussi comme un corps propre á déterminer la fermentation acétique la substance mucilagineuse connue sous le nom de mère de vinaigre; mais, à l'état de pureté, elle est dépourvue de cette propriété, qu'elle doit uniquement à l'acide acétique qui se trouve renfermé dans ses pores ${ }^{(1)}$. "

Remarquons bien cette dernière phrase. Elle implique : $1^{\circ}$ que, par l'emploi de cette matière visqueuse, l'acétification est possible; $2^{\circ}$ qu'elle ne doit alors sa vertu qu'à l'acide acétique renfermé dans ses pores.

Ces deux assertions sont-elles fondées? Est-il vrai qu'on puisse acétifier un liquide alcoolique à l'aide de la matière visqueuse? Sans aucun doute, le fait était connu depuis très longtemps. Voici un passage de la Chimie de Fourcroy : "On voit ici que le vinaigre déjà formé sert de ferment au vin que l'on ajoute. Quand on est obligé de recommencer cette opération par une circonstance quelconque et que l'on veut refaire un baril de vinaigre pour la première fois, on jette dans le vin qu'on y met une peau ou espèce de membrane qu'on retire des barils contenant du vinaigre depuis longtemps, et qu'on nomme mère de vinaigre. C'est un dépòt muqueux, concret, dù à la décomposition lente du vinaigre, et qui sert de ferment pour faire naitre la fermentation acide dans le vin $\left({ }^{2}\right)$. ”

susceptible de tourner à l'aigre. J'ai exposé des vins vieux, dans des bouteilles débouchées, à l'ardeur du soleil des mois d'aoùt et juillet, pendant plus de quarante jours, sans que le vin ait perdu de sa qualité; seulement le principe colorant s'est constamment précipité sous la forme d'une membrane qui tapissait le fond de la bouteille. Ce même vin, dans lequel j'ai fait infuser des feuilles de vigne, a aigri en quelques jours. On sait que les vins vieux, bien dépouillés, ne tournent plus à l'aigre. "Chaptal. Traité sur les vins (4* partie). Annales de chimie, an IX, XXXVI, p. 2/5-246. - Nous verrons ce qu'il faut ajouter et retrancher à ces assertions. En ce moment je ne juge pas, je me borne á exposer historiquement la suite et le progrès des idées au sujet de la cause de la fermentation acétique.

1. Berzelius (J.-J.). Traité de chimie. Paris, 1829-1833, 8 vol. in-80. Tome VI, p. 552.

2. Fourcroy (A.-F.). Systéme des connaissances chimiques et de leurs applications aux phénomènes de la nature et de l'art. Paris, an IX, 5 vol. in-4\%. Tome IV, p. 46\%. (Notes de l'Edition.) 
Est-il vrai, d'autre part, qu'on puisse acétifier un liquide alcoolique en y ajoutant seulement du vinaigre? Nous verrons plus loin que c'est la pratique constante d'Orléans pour la mise en train des tonneaux, et que, dans cette ville même, on éloigne avec soin toute espèce de dépòt muqueux ou autre pour ne se servir que de vinaigre limpide. Enfin, est-il vrai qu'en lavant la mère de vinaigre et la privant de son acide interposé, elle ne pourrait plus servir à l'acétification? Nous verrons également, par les détails du Mémoire actuel, que cette assertion est fondée sur l'expérience.

Arrêtons encore notre attention sur cette matière mucilagineuse. Voici comment Berzelius parle de sa formation :

« Le vinaigre, conservé danś des vases où il est en contact avec de l'air qui peut se renouveler, perd sa transparence; peu à peu il s'y rassemble une masse gélatineuse, cohérente, qui paraît glissante et gonflée quand on la touche, et d'où l'on ne peut point retirer par la pression le liquide qu'elle contient. Cette masse a reçu le nom de mère de vinaigre, parce qu'on a cru, à tort, qu'elle était susceptible de déterminer la fermentation acide. La plus grande partie se trouve dans les tonneaux dans lesquels le vinaigre est produit par fermentation, et dans les vases que les marchands placent sous le robinet des tonneaux à vinaigre. Le vinaigre répandu tombe dans ces vases, qui sont quelquefois entièrement remplis de mère de vinaigre. A l'état humide, la mère de vinaigre est entièrement transparente et mucilagineuse. Elle contient beaucoup de vinaigre qu'il est très difficile d'en exprimer. Elle se dessèche peu à peu en une peau transparente, jaunâtre, qui ressemble tout à fait à une membrane animale. Cependant elle ne donne point d'ammoniaque à la distillation sèche. Dans l'eau et surtout dans le vinaigre, elle se gonfle au point de revenir presque à son volume primitif. Débarrassée du vinaigre adhérent, elle est insipide. Elle est produite aux dépens des éléments du vinaigre, et celui-ci s'affaiblit d'autant plus qu'il se forme une quantité de mère de vinaigre plus grande. Celle-ci est en quelque sorte le produit de la putréfaction du vinaigre (1); elle ne prend pas naissance dans le vinaigre très concentré, mais dans le vinaigre étendu; elle se forme d'autant plus facilement que celui-ci est plus faible (2). »

1. Scheele avait déjà dit: "C'est une chose généralement connue que le vinaigre ne peut se conserver longtemps, qu'il s'altère au bout de quelques semaines, particulièrement dans les chaleurs de l'été, qu'il devient trouble et se couvre á la surface d'une viscosité épaisse, d'où il arrive que son acidité s'affaiblit de plus en plus et disparaì à la fin entièrement, au point qu'on est obligé de le jeter là. " Scheele. Mémoires de chimie. Dijon et Paris, 1785, in-12. [Seconde partie. XIX. Remarques sur la manière de conserver le vinaigre (tirées des Mémoires de l'Académie royale des sciences de Stockholm, année 1782), p. 137-140.]

2. Berzelius. Loc. cit., p. 555-556. (Note de l'Édition.) 
On voit que Berzelius refusait complétement le caractère de ferment à cette matière mucilagineuse, et que, d'après lui, il y avait des ferments acétiques divers : les matières extractives du vin, la levûre, le pain aigri, mais surtout l'acide acétique.

Il est assez remarquable que les pratiques des vinaigriers paraissent confirmer, comme nous allons le voir, l'opinion de Berzelius.

Bien avant que la science pùt éclairer la théorie de la fermentation de la bière, on savait pertinemment que, dans la fabrication de cette boisson, le liquide se trouble et laisse peu à peu déposer une matière jouissant au plus haut degré du caractère ferment, et que l'on utilisait depuis longtemps pour cette propriété dans la fabrication même. Se passe-t-il quelque chose d'analogue dans les fabriques de vinaigre? On pourrait le penser d'après le passage de la Chimie de Fourcroy, que j'ai rappelé tout à l'heure, mais les pratiques des fabriques elles-mêmes conduisent à une tout autre manière de voir.

"Le vinaigre, dit Macquer (Dictionnaire de chimie, t. IV, p. 239), ne dépose point de tartre comme le vin, quand même il aurait été fait arec du vin qui n'aurait pas encore laissé déposer le sien; mais son sédiment est une matière visqueuse [et huileuse] très disposée à la putréfaction. Le sarment et les rafles dont on se sert, comme nous l'avons dit, dans la fabrique du vinaigre pour le faire fermenter plus promptement $\left({ }^{1}\right)$ et pour en augmenter la force, se trouvent, après avoir servi à cette opération, enduits de ce dépôt visqueux : on les lave pour le leur enlever; mais quand ils en sont débarrassés, on les conserve

1. Macquer fait ici allusion à un ancien procédé pour faire du vinaigre, décrit déjá dans les Éléments de chimie de Boerhaave [Paris, 1754, 6 vol. in-12]. "Cette méthode [dit Iacquer] consiste à mettre le vin, déjà plus ou moins altéré et aigri spontanément, dans deux cuves placées verticalement sur un de leurs fonds, et ouvertes supérieurement. A 1 pied an-dessus du fond de ces cuves est établie une espèce de claie sur laquelle on met un lit de branches de vignes vertes, et par-dessus des rafles de raisin jusqu'au haut de la cuve; on distribue le vin dans ces deux cuves, de manière que l'une en est totalement remplie et que l'autre ne l'est qu'à moitié. Vers le second ou troisième jour, la fermentation commence dans la cuve demi-pleine : on la laisse aller pendant vingt-quatre heures..., jusqu'à ce que la fermentation soit achevée, ce que l'on reconnait à la cessation de mouvement dans la cuve demipleine; car c'est dans cette dernière que se fait principalement la fermentation. Comme le défaut d'air la fait cesser presque totalement dans la cuve pleine, on interrompt par cette manœuvre la fermentation qui ne se fait, à proprement parler, que de deux jours l'un, et on l'empêche de s'emporter trop loin, quoiqu'on la mène d'ailleurs avec l'activité qui lui est favorable. La fermentation du vinaigre conduite de cette manière dure environ quinze jours en France pendant l'été; mais lorsque la chaleur est trés grande, comme au $25^{\circ}$ degré du thermomètre de M. de Réaumur, et au delá, on fait de douze en douze heures le changement d'une cuve à l'autre, dont nous avons parlé. MacQuer. Dictionnaire de chimie. Paris (seconde édition), 1778,4 vol. in-8. Tome $1 \mathrm{~V}$, p. 237-238.

Cette méthode n'est plus pratiquée en France. Elle a, comme on le voit, assez de rapport avec le procédé allemand, si répandu de nos jours, le procédé des copeaux, qui est le seul utilisé aujourd'hui, conjointement avec le procédé d'Orléans, lequel est très ancien et était déjà suivi au dernier siècle, à Orléans, et même à Paris. Voir Macouer, même page. 
soigneusement pour les faire servir à la fermentation de nouveau vinaigre, parce que celui dont ils sont déjà tout pénétrés devient une espèce de levain qui détermine la fermentation acéteuse avec efficacité. Il en est de même des tonneaux dans lesquels s'est faite cette fermentation : il faut les nettoyer de la matière visqueuse dont ils sont pareillement enduits; mais, après cela, ils valent beaucoup mieux que les tonneaux neufs pour y faire de nouveau vinaigre. "

L'opinion de Berzelius paraît donc avoir gain de cause. Le dépôt de matière visqueuse était enlevé par le lavage, soit dans les tonneaux, soit sur les rafles. Et, on le voit, Macquer partageait aussi cette autre opinion de Berzelius, que c'était le vinaigre, dont ces tonneaux et ces rafles étaient imprégnés, qui servait de levain, de ferment à des opérations subséquentes.

Consultons les pratiques plus récentes des vinaigriers, notamment celles qui ont le plus de réputation, celles d'Orléans, par exemple.

"Presque tout le vinaigre du Nord de la France, dit Chaptal, se prépare a Orléans, et la fabrication y a acquis une telle célébrité, qu'on doit regarder les procédés qu'on y exécute comme les meilleurs. Voici à quoi ils se réduisent d'après MM. Prozet (1) et Parmentier.

"Dans les fabriques d'Orléans, on emploie des tonneaux qui contiennent à peu près 400 litres; on préfère ceux qui ont déjà servi, on les appelle mères de vinaigre.

" Ces tonneaux sont placés sur trois rangs, les uns sur les autres; ils sont percés à leur partie supérieure (sur la paroi verticale du fond qui est en avant) d'une ouverture de $0^{\mathrm{m}}, 055$ de diamètre, laquelle reste toujours ouverte.

" D'un autre côté, le vinaigrier tient le vin qu'il destine à l'acétification dans des tonneaux dans lesquels il a mis une couche de copeaux de hêtre, sur lesquels la lie fine se dépose et reste adhérente. C'est de ces tonneaux qu'il soutire le vin très clarifié pour le convertir en vinaigre.

"On commence par verser dans chaque mère (tonneau) 100 litres de bon vinaigre bouillant, et on l'y laisse séjourner pendant huit jours. On mêle ensuite 10 litres de vin dans chaque mère et on continue à en ajouter tous les huit jours une égale quantité, jusqu'à ce que les vaisseaux soient pleins. On laisse alors séjourner le vinaigre pendant quinze jours avant de le mettre en vente.

“ On ne vide jamais les mères qu'à moitié, et on les remplit successivement, ainsi que nous l'avons déjà dit, pour convertir du nouveau vin en vinaigre. 
"Pour juger si la mère travaille, les vinaigriers sont dans l'usage de plonger une douve dans le vinaigre et de la retirer aussitôt. Ils voient que la fermentation marche et est en grande activité lorsque le sommet mouillé de la douve présente de l'écume ou la fleur du vinaigre, et ils ajoutent plus ou moins de vin nouveau et à des intervalles plus ou moins rapprochés, selon que l'écume est plus ou moins considérable (1). "

Ce passage du Traité de chimie de Chaptal est très instructif par les réflexions qu'il suggère. Pas un mot de la matière visqueuse, et si tant est qu'elle existe dans les tonneaux, on ne s'en sert jamais comme d'un ferment acétique. Et Berzelius aurait dit sans doute : Le ferment, c'est le vinaigre ; car, pour monter un tonneau, on n'y verse à l'origine que du vinaigre, et même du vinaigre bouillant.

Aujourd'hui encore la pratique est la même; seulement, au lieu de rinaigre bouillant, on se sert de vinaigre ordinaire, mais avec la précaution de prendre le plus fort et le plus limpide possible, de telle sorte que l'on éloigne avec un grand soin tout dépòt, toute matière solide ou visqueuse; et, quand j'aurai donné la théorie exacte et complète de la fermentation acétique, on verra qu'il est utile en effet de n'employer au début que du vinaigre foṛt et limpide, et que la pratique plus ancienne du vinaigre bouillant était encore plus sûre.

Voilà donc un nourel appui à l'opinion de Berzelius sur le rỏle de la matière visqueuse. Bien plus, si nous remarquons que, dans les vinaigreries, on appelle du nom de mères de vinaigre les tonneaux euxmêmes qui le produisent, on est conduit à penser qu'il y a eu ici une confusion de langage lorsque l'on a appliqué le not mère de vinaigre à la matière visqueuse dont parlent tous les auteurs. Je me suis assuré, en effet, que les fabricants d'Orléans appliquent indistinctement le mot mère de vinaigre aux tonneaux et au dépót des tonneaux. Mais une chose qui m'a beaucoup surpris à l'origine de ces recherches, et alors que je ne connaissais pas encore la véritable théorie de tous les faits et de tous leurs accidents, telle que je l'expose dans ce Mémoire, c'est que, dans ces vinaigreries d'Orléans, on ignore pour ainsi dire l'existence de cette matière mucilagineuse dont tous les auteurs parlent. Il n'y en a jamais dans les tonneaux d'Orléans, et je me rappelle que c'est après aroir beaucoup insisté aupıès d'un intelligent fabricant de cette ville que j'ai pu le mettre sur la voie de l'existence de cette

1. Chaptal (J.-A.). Chimie appliquée aux arts. Paris, 1807, 4 vol. in-80. Tome IIJ, p. 157-159. - Voir ègalement l'article "Vinaigre n, tome X, p. 377-408 du Cours complet d'agriculture ou Dictionnaire universel d'agriculture de RozıER. Paris, 1781-1800, 10 vol. in-4. Note de l'Édition.) 
matière. Encore n'y suis-je parvenu qu’après avoir interrogé le plus ancien ouvrier de la vinaigrerie, qui raconta qu'on voyait en effet quelque chose de semblable dans des baquets où on avait abandonné du vinaigre, et aussi quand parfois une mère (tonneau) travaillait tellement mal que le vinaigre se pourrissait (1). En effet, je fus lientôt convaincu que le dépòt qui existe dans tous les tonneaux mères n'est pas du tout visqueux, que c'est une lie boueuse, délayée, et que l'on jette lorsqu'après un long temps, quelquefois dix à douze ans, cette lie s'est accumulée en trop grande quantité, et que le siphon ne peut plus soutirer du tonneau que du vinaigre trouble.

Cependant il faut dire que tous les vinaigriers croient que c'est dans ce dépôt que réside la cause du phénomène. Mais ils ne savent que s'en référer à l'usage et à la pratique séculaire du pays, si on leur demande pourquoi ils ne placent pas tout ou partie de ce dépôt dans les tonneaux lorsqu'il s'agit d'en mettre en train de nouveaux.

Tout ceci s'éclaircira bientòt. Mais n'oublions pas une dernière remarque au sujet de l'extrait précédemment cité de l'article de la Chimie de Chaptal. La mère, c'est-à-dire le tonneau, travaille bien, dit Chaptal, lorsqu'il y a de la fleur à la surface. Ne serait-ce donc pas là le ferment, la véritable mère? Non, dirait Berzelius; à la surface de toutes les matières organiques mortes exposées à l'air, on voit se développer de ces ébauches de végétation. Le vinaigre est une espèce particulière d'infusion végétale. Comme toutes les infusions, il se couvre de pellicules diverses ou bien il donne naissance à des animalcules. Et en effet, outre cette fleur, ne voit-on pas le vinaigre engendrer des myriades d'anguillules. Il n'est pas un tonneau d'une vinaigrerie quelconque, par le procédé d'Orléans, qui ne soit l'asile de quantités incalculables de ces petits êtres. N'a-t-on pas affirmé également que ces anguillules étaient le ferment du bon vinaigre?

Je viens de dire que les fleurs du vinaigre (ou d'autres analogues) étaient des ébauches de végétation. Il est intéressant, pour compléter l'historique que je trace en ce moment, de savoir à quelle époque l'idée s'en introduisit dans la science. Il y a lieu de penser que c'est à Chaptal qu'elle doit être attribuée.

“ Un phénomène, dit-il, qui a autant frappé qu'embarrassé les nombreux écrivains qui ont parlé des maladies du vin, c'est ce qu'on appelle les fleurs du vin. Elles se forment dans les tonneaux, mais surtout dans les bouteilles dont elles occupent le goulot: elles annoncent et précèdent constamment la dégénération acide du vin.

1. Chaptal ne parle pas du tout de cette matière visqueuse comme étant le ferment du vinaigre. 
Elles se manifestent dans presque toutes les liqueurs fermentées, et toujours plus ou moins abondamment, selon la quantité d'extractif qui existe dans la liqueur.

"Ces fleurs, que j'arais prises d'abord pour un précipité de tartre, ne sont plus à mes yeux qu'une végétation, un vraibyssus, qui appartient à cette substance fermentée. Il se réduit à presque rien par la dessiccation et n'offre à l'analyse qu'un peu d'hydrogène et beaucoup de carbone.

"Tous ces rudiments ou ébauches de végétation qui se développent dans tous les cas où une matière organique se décompose ne me paraissent pas devoir être assimilés à des plantes parfaites; ils ne sont pas susceptibles de reproduction, et ce n'est qu'une excroissance ou un arrangement symétrique des molécules de la matière, qui paraît plutòt dirigée par les simples lois de l'affinité que par celles de la vie. De semblables phénomènes s'observent dans toutes les décompositions des ètres organiques $(\mathbf{1})$. ’

Sans doute Chaptal aurait professé les mêmes idées à l'égard de la fleur du vinaigre.

Quoi qu'il en soit, au point où nous sommes arrivés de cette étude historique, c'est-à-dire vers 1830 , il n'est pas douteux que l'on ne sait rien de la véritable cause de l'acétification, et que l'opinion de Berzelius paraît être encore la meilleure.

En 1835, la question qui nous occupe aurait pu faire un pas décisif. Tout le monde sait que Cagniard de Latour découvrit à cette époque le fait du bourgeonnement de la levûre de bière, et qu'il introduisit dans la science cette vue, nouvelle alors, que c'était probablement par l'effet de sa végétation qu'elle agissait sur le sucre $\left({ }^{2}\right)$. Chaptal, et après lui Persoon et Desmazières $\left({ }^{3}\right)$, ayant reconnu que, dans la fermentation acétique, des êtres organisés prenaient naissance, anguillules et mycoderme, la science se trouvait invitée à appliquer à ces êtres la rue préconçue de Cagniard de Latour en ce qui concernait la levûre de biere, et à rechercher expérimentalement si ces êtres, les uns ou les autres, ou tous ensemble, participaient en quelque chose au phénomène. Au lieu de s'attacher à démontrer expérimentalement l'hypothèse de Cagniard de Latour, les partisans a priori de cette vue préconçue la regardèrent non seulement conme fondée en ce qui concerne la levûre de bière, mais ils l'appliquèrent en outre sans étude préalable

1. Chaptal (J.-A.). Traité sur les vins. Annales de chimie, XXXVI, an IX, p. 249-251.

2. Voir p. 51-126 du tome II des CEuvres DE Pasteur : Mémoire sur la fermentation alcoolique.

3. Voir la note 3 de la page 125 du présent volume. (Nates de l'Édition.) 
à la fermentation acétique. C'est ce que firent Turpin et Kützing. En un mot, ces savants renouvelèrent l'idée que j'ai exposée, et qui, comme nous l'avons vu, était déjà depuis longtemps dans la science, à savoir que c'était une matière visqueuse de la nature des végétaux inférieurs, appelée mère de vinaigre par certaines personnes, qui était le ferment acétique. C'était reproduire sans preuves une assertion très ancienne, combattue par Berzelius, mais cela n'ajoutait rien à ce que l'on savait déjà (1), et la vraie science ne doit attribuer aıcune valeur à ces sortes de généralisations et d'assertions anticipées. Les savants, habitués à une expérimentation rigoureuse, ne s'y trompèrent pas. " Il est des cas, sans doute, dit M. Dumas, où une intervention mystérieuse encore de quelques matières organiques peut faire penser que l'acétification se rattache aux fermentations proprement dites; mais tant qu'on n'aura pas montré les ferments dont il s'agit, isolés de toute autre matière et produisant les phénomènes qu'on leur attribue, il pourra rester des doutes sur la réalité de leur existence $\left(^{2}\right)$. " On ne pouvait mieux indiquer les desiderata de la science sur cette question.

D'ailleurs, il faut remarquer qu'à l'époque dont je parle l'étude de la fermentation acétique, étude très délicate comme toutes celles qui ont trait aux fermentations, s'était compliquée d'un principe entièrement nouveau et qui paraissait devoir éloigner toute idée d'une intervention vitale dans les phénomènes de l'acétification, et la faire rentrer dans le cercle des réactions chimiques ordinaires. Edmund Davy, en effet, depuis 1821 [1820], avait fait de l'acide acétique avec de l'alcool et du noir de platine, c'est-à-dire, comme Dobereiner et surtout M. Liebig le démontrèrent, par une influence de corps poreux capables de condenser l'oxygène.

Aussi M. Liebig, qui fut avec Berzelius l'adversaire le plus autorisé de l'hypothèse faite par Cagniard de Latour à la suite de son observation sur le bourgeonnement de la levûre de bière, M. Liebig, dis-je, développa bientôt des opinions qui fortifiaient celles de Berzelius, tout en différant d'elles sur quelques points.

Il est opportun de reproduire ici la théorie de l'acétification telle

1. Cela est si vrai que M. Turpin s'est même trompé sur la nature spécifique de la fleur du vinaigre. Il a décrit une fleur de vin (qui est en outre un peu de fantaisie), au lieu de la fleur du vinaigre qui en diffère tant. Voir la planche correspondante de son Mémoire intitulé : "Mémoire sur la cause et les effets de la fermentation alcoolique et acéteuse " et inséré au tome XVII, 1840 , p. 93-180 (avec 8 pl.) des Mémoires de l'Académie royale des sciences de l'Institut de France. Voir KützıNa [Recherches microscopiques sur le ferment et la mère de vinaigre, et de quelques autres formations qui en dépendent]. Répertoire de chimie scientifique et industrielle, III, 1838, p. 257-283 (28 fig.).

2. Dumas. Traité de chimie appliquée aux arts. Paris, 1828-1846, 8 vol. in- $8^{\circ}$. Tome VI, p. 341. (Note de l'Édition.) 
que l'a exposée dans son Traité de chimie organique l'illustre chimiste allemand (1).

“L'alcool pur ou étendu d'eau ne s'acidifie pas à l'air. Le vin, la bière, et en général les liqueurs fermentées qui, outre l'alcool, conticnnent des matières organiques étrangères, s'acidifient facilement au contact de l'air, à une certaine température. L'alcool pur étendu d'eau subit la même transformation quand on y ajoute certaines matières organiques, telles que de l'orge germée, du vin, du marc de raisin, du ferment, ou même du vinaigre déjà tout formé.

"En considérant l'ensemble des phénomènes, il ne peut pas y avoir le moindre doute à l'égard du rôle que jouent ces matières azotées dans l'acidification de l'alcool. Elles mettent l'alcool en état d'absorber l'oxygene, puisque à lui seul il ne possède pas cette faculté. L'acidification de l'alcool est absolument de même ordre que l'action qui provoque la formation de l'acide sulfurique dans les chambres de plomb; de la même manière que l'oxygène de l'air est transporté sur l'acide sulfureux par l'intermédiaire du bioxyde d'azote, de même aussi les substances organiques, en présence de l'esprit-de-vin, absorbent l'oxygène et le mettent dans un état particulier qui le rend susceptible l'être absorbé par l'alcool.... Les copeaux et la sciure de bois humides absorbent l'oxygène de l'air avec rapidité et pourrissent en donnant naissance à de l'acide carbonique et à une matière soluble. Cette propriété d'absorber l'oxygène reste la même quand on humecte le bois avec de l'alcool étendu d'eau; mais, dans ce cas, l'oxygène se porte sur l'alcool et non pas sur le bois, et on obtient ainsi de l'acide acétique.

"Le noir de platine très divisé se comporte de la même manière arec l'oxygène. La seule différence consiste en ce que l'oxygène qu'il condense ne l'altère pas, comme il altère les matières organiques. Quand on humecte le platine avec de l'alcool étendu d'eau, il cède l'oxygène condensé à l'hydrogène de ce dernier, d'où il résulte de l'eau et de l'aldéhyde qui passe à l'état d'acide acétique en présence d'un excès d'oxygène. En continuant à absorber de l'oxygène, le platine le cècle constamment à l'alcool sans éprouver lui-même la plus légère altération; les matières organiques, au contraire, prennent des formes différentes à la température élevée à laquelle l'acidification a lieu; il se produit dans la liqueur chaude, comme dans les eaux thermales, des végétations particulières qui se déposent en grande quantité au fond des vases, sous forme de masses blanches gélatineuses connues sous le nom de générateur ou mère du vinaigre....

1. Lıebıa (J.). Traité de chimie organique. Paris, 1840-1844, 3 vol, in-80. Tome Ior : Art. Acide acétique, p. 386-397. (Note de l'Édition.) 
“ Toutes les matières végétales ou parties de plantes, tous les fruits charnus, pris à l'état frais, se comportent avec l'oxygène comme le noir de platine; en présence de l'alcool étendu, ils entretiennent l'acidification, c'est-à-dire qu'ils absorbent l'oxygène et le cèdent à l'alcool.

“ L'effet que ces matières organiques produisent dans l'acte de l'acidification a été attribué à une force particulière à laquelle on a donné le nom de force catalytique. Cette force se manifeste, dit-on, par le simple contact de certaines matières.... Sans aucun doute on aurait également déduit la formation de l'acide sulfurique de l'influence catalytique, si le hasard n'avait pas dévoilé et mis dans son vrai jour le rôle que le deutoxyde d'azote joue dans cette action; en effet, ce gaz se colore en présence de l'oxygène et se décolore par le contact de l'eau, en abandonnant à l'acide sulfureux l'oxygène qu'il avait absorbé.

“ Ce qui précède suffit pour faire saisir les principes de la fabrication ordinaire du vinaigre $(\mathbf{1})$. »

Telle est la théorie de M. Liebig, qui était généralement adoptée lorsque j’ai publié les premiers résultats de mes recherches sur la fermentation acétique $\left({ }^{2}\right)$.

Toute influence de ferment organisé se trouve écartée. Si des végétations particulières apparaissent dans la fabrication, ce sont des matières analogues à celles qu'on rencontre dans les eaux thermales ou dans toutes les infusions. Elles sont le produit du phénomène, une suite occasionnelle des conditions dans lesquelles il se montre, mais elles n'interviennent pas dans sa manifestation. C'était, au fond, la mème opinion que celle de Berzelius.

\section{DEUXIĖME PARTIE}

\section{$\S$ I. - Description du mycoderma aceti (fleurs du vinaigre).} Róle de cette plante dans la fermentation acétique.

J'ai pour objet de démontrer dans ce Mémoire que la fermentation appelée acétique s'accomplit sous l'influence exclusive d'un être organisé agissant à la manière du noir de platine. Entre cette théorie

1. Liebrg. Loc. cit., p. 388-390. (Note de l'Édition.)

2. Cependant tous les chimistes ne partageaient pas ces vues théoriques, particulièrement en Angleterre. Rob. Thomson a publié, en 1852, une Note sur la nature et les effets de la mère du vinaigre, où il ne met pas en doute que, dans certains procédés de fabrication, le vinaigre est produit par cette plante. [Тномson (R.-D.). Notice of the vinegar plant. (Communicated march 17, 1852.) Proceedings of the Philosophical Society of Glasgow, III, 18481855, p. 238-241.] 
et la théorie ancienne que je viens d'exposer d'aprës M. Liebig, il y a cette différence fondamentale, qu'au lieu de placer la propriété de condensation et de transport de l'oxygène de l'air dans les copeaux, la sciure de bois, le terreau, les débris de végétaux, dans les diverses parties des plantes ou dans les matières azotées du vin, de la bière, de la levûre, etc., je crois qu'elle ne réside que dans un mycoderme, et que dans tous les cas où les matières précédentes, humectées d'alcool à une certaine température, ont donné lieu à une formation d'acide acétique, le mycoderne a pris naissance à l'insu de l'expérimentateur ${ }^{1}$. La différence des deux opinions, toute simple qu'elle puisse paraittre au premier abord, est au fond considérable, autant pour la théorie que pour les applications industrielles, et elle touche à une grave question, celle de la fixation de l'oxygène de l'air par les matières organiques mortes, dont je ferai le sujet d'une publication spéciale.

Le mycoderma aceti est une des plantes les plus simples que l'on puisse imaginer. Elle consiste essentiellement en chapelets d'articles, en général légèrement étranglés vers leur milieu, dỏnt le diamètre, un peu variable suivant les conditions dans lesquelles la plante s'est formée, est moyennement de 1 à 1,5 millième de millimètre. La longueur de l'article est un peu plus du double, et comme il est un peu étranglé en son milieu, on dirait quelquefois une réunion de deux petits globules, surtout lorsque l'étranglement est court; et quand il y a une couche, une pellicule un peu serrée de ces articles, on croirait avoir sous les yeux un amas de petits grains ou de petits globules. Il n'en est rien. Si l'on méconnaissait cette structure des articles du mycoderma aceti, on pourrait souvent confondre ce mycoderme avec des ferments en chapelets de grains de même diamètre qui en diffèrent cependant essentiellement par leur fonction chimique.

Le mode de multiplication de ces articles n'est pas douteux. Chacun d'eux s'étrangle de plus en plus, et donne deux nouveaux globules ou articles qui s'étranglent eux-mêmes en grandissant, et ainsi de suite. Beaucoup d'infusoires, les vibrions notamment, se reproduisent ainsi.

On peut composer des liqueurs qui provoquent le développement

1. Je n'ai pas fait d'expériences sur toutes ces matières, mais le mycoderma aceti et le mycoderma vini se forment avec tant de facilité partout où l'on rencontre de l'alcool mêlé à des substances qui sont plus ou moins des sources de phosphates et de matiéres azotées - ne fut-ce que par les poussières qui les recouvrent et qui suffiraient bien pour commencer le phénomène -, et il sera si bien prouvé, je le crois, par mes observations que c'est le mycoderma aceti qui intervient exclusivement dans les fermentations acétiques industrielles, qu'il est raisonnable de rejeter complétement l'idée de la possibilité de l'acétification à l'aide des corps poreux formés par des débris organiques queleonques, au moins jusqu'à ce que des expériences positives l'aient établie. A ma connaissance il n'en existe pas. 
de la plante avec une rapidité vraiment extraordinaire. Que l'on prenne, par exemple, un liquide formé de :

100 parties eau de levûre de bière (1), à 2, 3, 5 millièmes de matière dissoute, plus ou moins;

1 ou 2 parties d'acide acétique;

3 ou 4 parties d'alcool,

et que l'on sème à sa surface quelques taches de mycoderma aceti, à la température de $20^{\circ}$ environ, dès le lendemain ou le surlendemain, le plus souvent, la surface du liquide, quelle que soit son étendue, sera couverte d'un voile uni, formé exclusivement par les petits articles du mycoderme, en chapelets enchevêtrés. L’imagination se refuse à

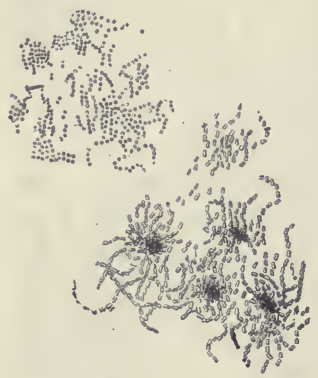

FIG. $1\left({ }^{2}\right)$. calculer le nombre des articles ainsi produits dans un espace de temps relativement très court.

La figure 1 représente le mycoderma aceti en voie de formation à la surface de la liqueur. Ce n'est point une figure de fantaisie, et la réalité est bien au-dessus d'un dessin, quelque soigné qu'il puisse être, pour la régularité et, j’ose dire, la beauté de ces petits chapelets.

On peut voir rayonner les chapelets d'articles dans toutes les directions à partir de divers centres. C'est airsi en effet que marche le développement de la plante. Seulement, il est difficile de s'en assurer dans des observations microscopiques ordinaires qui se font en trempant simplement l'extrémité d'une baguette de verre dans le liquide, et en déposant ensuite sur le porte-objet la petite portion du voile mycodermique qui est restée adhérente à la baguette. Cet essai permet bien de distinguer la forme des articles et leur multiplication en chapelets, surtout si l'on a soin de faire l'observation microscopique le pre-

1. Prendre de la levûre de bière en pâte, la faire bouillir dans de l'eau pendant un quart d'heure à la dose de 50 ou 100 grammes par litre d'eau, filtrer à clair ; c'est ce que j'appelle eau de levirre. En évaporant 100 centimètres cubes de la liqueur, desséchant dans une étuve à eau bouillante, on a la teneur des matières extractives dissoutes. Ce sont des substances albuminoïdes et autres, avec phosphates terreux et alcalins, qui, en général, offrent dans cette préparation un aliment azoté et minéral excellent pour la plupart des ferments, soit végétaux, soit animaux. La bière, le vin, le cidre, etc., renferment des principes analogues, principes que l'on appelait des ferments lorsque, disait-on, ils avaient subi, au contact de l'air, une altération de nature indéterminée. [Dans les Annales scientifiques de l'École Normale supérieure, Pasteur a ajoutẻ : “ J'ai déjả fait observer souvent que, selon moi, ce sont les aliments azotés et minéraux des ferments et rien de plus. "]

2. Dans l'opuscule " Études sur le vinaigre... ", Pasteur a donné une autre figure du mycoderma aceti. Elle est reproduite page $87 \mathrm{du}$ présent volume. (Note de l'Édition.) 
mier ou le second jour du développement, alors que les chapelets ne sont pas encore trop enchevêtrés. Lorsqu'on veut assister à la propagation des articles par rayonnement à partir de divers centres, voici l'artifice qu'il faut employer. On fait développer le mycoderme sur quelques centimètres cubes de liquide placés dans une petite cuve de verre dont le fond est formé par une lame de verre extrêmement mince. Lorsque la plante est en voie de multiplication, on enlève à l'aide d'une pipette la presque totalité du liquide. Le voile descend peu à peu sans se disloquer en restant toujours à la surface des dernières portions de la liqueur. Lorsqu'il n'y a plus qu'une couche de liquide d'une excessive minceur, on regarde le voile à travers le fond de la cuve, à l'aide d'un microscope de Nachet, dont l'objectif est en dessous de l'objet à étudier. On voit alors avec une grande netteté des amas d'articles d'où partent dans toutes les directions de charmants chapelets ( $\left.{ }^{1}\right)$.

Comment se procurer une première fois la semence de mycoderma aceti? Rien n'est plus facile. Le liquide dont j'ai donné tout à l'heure la composition, ou tout autre analogue, fournit constamment, après un temps plus ou moins long (deux, trois, quatre jours ou un peu plus), un voile de mycoderma aceti. On le place à cet effet dans un cristallisoir, couvert d'une lame de verre. Les poussières qui sont en suspension dans l'air, ou à la surface des parois du cristallisoir, ou dans les liquides mélangés, renferment toujours quelque semence pouvant amener le développement du mycoderma aceti. Il faudrait, pour que cela ne fút pas, prendre des précautions particulières, par exemple mélanger les liquides lorsqu'ils sont chauds, laver à l'eau bouillante le cristallisoir, etc., toutes manipulations qui tuent les germes des êtres inférieurs. Il n'est pas difficile de s'en convaincre, car si l'on prenait les précautions de propreté exagérée que j'indique, bien qu'on opérât au contact de l'air ordinaire, on verrait que l'on peut reculer beaucoup le moment de l'apparition spontanée de la plante ${ }^{(2)}$.

J'ai dit que des liquides dont la composition était analogue à celle de la liqueur artificielle dont j'ai parlé tout à l'heure pourraient servir' aussi bien que celle-ci à se procurer spontanément une première fois

1. Je crois qu'avec un peu de patience, et par l'emploi de ce mode d'observation, il serait facile, en maintenant l'œil au microscope pendant une demi-heure ou une heure, d'assister à la multiplication des articles par scissiparité.

On trouve dans l'Intellectual Observer de Londres (novembre 1863) une discussion sur la nature des mycodermes, par M. H. Slack. Je ne puis me ranger à l'opinion de l'auteur sur beaucoup de points, particulièrement en ce qui regarde les bacteriums comparés au mycoderma aceti.

2. J'ai souvent fait remarquer que les poussières qui sont à la surface des objets représentent toujours, en tant qu'il s'agit des poussières et germes en suspension dans l'air, un volume d'air très considèrable. 
le mycoderma aceti. Je citerai pour exemple un mélange de 1 volume de vin rouge ou blanc ordinaire, avec 2 volumes d'eau et 1 volume de vinaigre; ou bien encore 1 volume de bière, 1 volume d'eau et $\frac{1}{2}$ volume de vinaigre. Je parle ici de vinaigre de table qui renferme environ 7 pour 100 d'acide acétique. Au lieu de vinaigre de table, on pourrait se servir d'eau pure additionnée d'une quantité correspondante d'acide acétique cristallisable.

Les proportions de ces mélanges peuvent varier beaucoup en restant néanmoins dans de certaines limites. Ce qui doit être évité lorsqu'on veut obtenir spontanément le mycoderma aceti, ce sont d'une part les petits infusoires, bacteriums et autres, et le mycoderma vini. J'ai fait sur ce sujet un grand nombre d'expériences afin de rechercher quel était le milieu qui convenait le mieux au développement de ces deux mycodermes. Voici un aperçu de leurs résultats.

Le vin ordinaire, surtout le vin rouge et particulièrement le vin rouge nouveau, non étendu d'eau et sans addition d'acide acétique, ne donne que rarement le mycoderma aceti spontané. Il produit assez facilement, au contraire, le mycoderma vini. Il le produit plus facilement encore si l'on étend le vin de son volume d'eau. Le vin rouge ordinaire donne assez difficilement naissance au mycoderma aceti pour que j'aie vu souvent le mycoderma vini se former spontanément sur du vin à la surface duquel je n'avais pourtant semé que du mycoderma aceti, et bien que ce dernier eût pris déjà un commencement de développement, pénible il est vrai. Il est assez curieux mềne d'observer dans ce cas la marche de ces développements. Tandis que le mycoderma aceti se multiplie avec une grande lenteur, le mycoderma vini, de croissance plus rapide, envahit peu à peu la surface du liquide et refoule toutes les plages couvertes de mycoderma aceti, lequel s'épaissit progressivement, puis finit par tomber au fond du liquide en laissant toute la place à son voisin.

Mais les choses se passent autrement si le vin est additionné d'acide acétique, par exemple de son volume de vinaigre de force ordinaire. C'est alors le mycoderma aceti qui se développe de préférence, et on peut reproduire dans ces conditions l'expérience inverse de tout à l'heure, c'est-à-dire faire étouffer le mycoderma vini par son congénère.

Enfin on peut avoir des liqueurs qui offrent à la fois par développement spontané les deux mycodermes mêlés. Ainsi la bière étendue de son volume d'eau donne volontiers un mélange des deux mycodermes. Sans addition d'eau, le mycoderma vini est ordinairement le plus abondant. 
On empêche toujours les bacteriums de se montrer en acidulant un peu les liqueurs ( $\mathbf{1})$.

La figure 2 représente l'une des variétés du mycoderma vini pur.

La figure 3 le représente avec une petite différence d'aspect général et mêlé à quelques articles de mycoderma aceti $\left({ }^{2}\right)$.

Du développement mucilagineux du mycoderma aceti. — La figure 1 représente le mycoderma aceti tel qu'il s'offre à la surface d'un liquide dans les premiers temps de son développement sous l'influence d'articles de la plante déposés directement à la surface du liquide, ou sous l'influence des germes en suspension dans l'air. Dans ces deux cas, la plante se multiplie sous forme de voile d'apparence plus ou moins

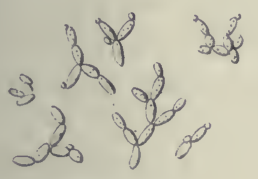

FIG. 2.

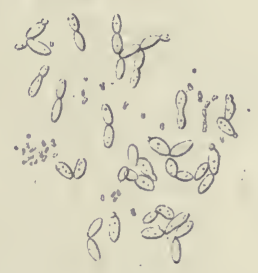

FIG. 3.

sèche, uni ou ridé, qui se laisse peu mouiller par le liquide sousjacent à cause des matières grasses propres à la plante $\left({ }^{3}\right)$. Dans les premiers jours, ce voile se déchire facilement. Une baguette de verre qu'on enfonce dans le liquide perce le voile, le troue, et en la retirant une partie du voile reste attachée à la baguette. Peu à peu, ce voile s'épaissit de plus en plus par la multiplication des chapelets d'articles qui, s'enchevêtrant dans toutes les directions, finissent par former une pellicule plus ou moins épaisse et difficile à déchirer. Une baguette de verre enfoncée sans effort dans le liquide ne perce plus le voile. En soulevant celui-ci en un de ses points, on entraîne les portions contiguës, sous forme d'une membrane grasse au toucher,

1. Il y a longtemps que j'ai constaté l'influence nuisible des acides, même à très petite dose, pour empêcher le développement des infusoires et favoriser celui des moisissures. Voir mon Mémoire sur les corpuscules organisés qui existent en suspension dans l'atmosphère. Annales des sciences naturelles, 40 sẻr., XVI (part. zool.), 1861, p. 5-98; Annales de chimie et de physique, 3* sér., LXIV, 1862, p. 5-110 [p. 210-294 du tome II des CEuvres DE Pasteur]. Voir aussi une Note d'un de mes élèves, M. Duclaux : Sur la germination des corpuscules qui existent en suspension dans l'atmosphère. Comptes rendus de l'Académie des sciences, LVI, 1863, p. 1225-1227.

2. Ces deux derniers alinẻas et les fig. 2 et 3 ont été supprimés dans l'opuscule "Études sur le vinaigre... ». (Note de l'Édition.)

3. J'ai reconnu par des épreuves directes, à l'aide de l'éther, que le mycoderma aceti renfermait des substances grasses au nombre de ses principes immédiats. 
glissante, et toujours assez difficile à mouiller. Dans ce cas, la plante n'est développée qu'à la surface. Si l'on enlève le voile, il ne reste que le liquide plus ou moins acétifié.

Il y a une autre forme très différente de développement de la plante et qu'il importe de bien connaître. On peut dire d'une manière générale que la culture prolongée du mycoderma aceti dans un milieu acétique quelconque finit toujours par le montrer sous la forme que je vais décrire. Mais souvent aussi on le voit naître de prime abord à cet état. La plante se présente sous la forme d'une matière mucilagineuse qui grandit peu à peu de manière à atteindre la surface, où elle offre des espèces de nodosités visqueuses qui se relient peu à peu les unes aux autres et constituent une sorte de peau humide, gonflée, gélatineuse et glissante. Elle finit par remplir tout le liquide. Son développement sous cette forme est, comme volume, et aussi comme poids, incomparablement supérieur à ce qu'il est dans le premier cas, dans l'état de voile membraneux non mouillé par le liquide et non submergé.

Jusqu'à présent ce n'est guère que sous cette forme que l'on a décrit le mycoderma aceti ou mère du vinaigre.

Au microscope ce sont toujours des articles, un peu moins étranglés peut-être, sensiblement de même dimension que les autres, mais reliés par un mucus translucide, qui, en vieillissant, prend l'aspect et la consistance d'une membrane homogène, d'une sorte de membrane animale. Sous l'influence de la combustion dont nous verrons le mycoderma aceti être le siège habituel, n'y aurait-il pas fusion, suture de la matière des articles? Je dois remarquer que ce mucus n'est pas exclusivement propre à la forme de développement dont je parle. Il est certain que, même dans l'état de voile membraneux, une sorte de matière glutineuse réunit les articles. La présence de cette matière se trahit, bien qu'elle soit invisible, par la disposition en chapelets que prennent les articles, alors même que ceux-ci sont disjoints et éloignés les uns des autres. On sait que les mucors et moisissures ont deux manières d'être fort distinctes, suivant qu'ils vivent à la surface des liquides ou dans leur intérieur. La forme mucilagineuse du mycoderma aceti est en quelque sorte la forme propre au mycelium de ce mucor.

Mais ce qui nous intéresse particulièrement, c'est de savoir dans quelle circonstance la plante prend l'aspect gélatineux et muqueux. Pourquoi n'est-elle pas toujours sous la forme d'un voile uni ou ridé? Ou, inversement, pourquoi n'est-elle pas toujours à l'état mucilagineux? J'ai reconnu que le mycoderma aceti se développe à l'état muqueux toutes les fois que la semence en est partout répandue dans la masse même de la liqueur, et qu'un voile plus ou moins rapidement 
formé ne soustrait pas l'oxygène et n'empêche pas la semence dispersée daus la masse du liquide de vivre sur le fond du vase ou dans l'intérieur mème de ce liquide. Il prend au contraire l'état de voile lorsqu'il provient de senınce déposée seulement à la surface.

Par exemple, dans toutes les expériences où l'on se sert de vinaigre brut, surtout un peu trouble, et qui renferme des articles du mycolerme flottant dans l'intérieur du liquide, même en quantité presque insensible à la vue, on peut être assuré que la plante se développera à l'état gélatineux(1). On empêchera cet effet si l'on porte pendant

1. Que l'on me permette de raconter ici les détails d'une visite que je reçus, le 27 mai 1863 , d'un habile fabricant d'Orléans, qui était venu me consulter sur un accident de sa fabrication.

" J'ai en travail présentement, me dit-il, un vin du Midi qui a provoqué le développement de ces matiéres gélatineuses dans les mères. " Et il me présentait en mème temps un flacon tout rempli de mycoderma aceti sous la forme mucilagineuse. " Ces matiéres, ajouta-t-il, entravent la fabrication. - C'est, répondis-je, une des formes de production du mycoderma aceti. ")

Le fabricant essaya de me prouver que ce devait être autre chose, tant cette forme du mycoderme est inconnue à Orléans, ainsi que je l'ai déjà fait remarquer. (Voir première Partie, \& II, p. 31.)

"Votre vin, continuai-je, doit être trouble et avoir subi dans le pays où vous l'avez acheté un commencement d'acétification qui n'a pu s'effectuer que par l'influence d'une pellicule de mycoderma aceti. Le vendeur n'a pas eu la précaution de coller le vin au départ, ni de le soutirer de façon à ne pas mêler dans sa masse les articles du voile de la surface. Ce sont ces articles qui lo troublent, et qui, dans les tonneaux mères, amènent la formation de ces masses gélatineuses s'opposant á une bonne marche de la fabrication. Il y a trop de germes du ferment en quelque sorte. Il ne faut pas qu'il y en ait dans tout l'intérieur du liquide. C'est une des raisons qui obligent dans votre industrie de filtrer avec soin le vin qu'on emploie et qui est souvent en partie altéré.

- C'est vrai, me dit le fabricant, le vin est trouble, et j'ai de la peine à l'éclaircir préalablement. Au surplus, voici un échantillon de ce vin. »

Il me montra un petit flacon d'un vin blanc qui était en effet tout trouble.

« Je vais vous faire voir, répliquai-je, que ce vin est déjà un peu aigri, très peu, puisque l'odorat ne l'accuse pas. "

J'évaporai doucement quelques centimètres cubes du vin dans une capsule, et à la fin de l'évaporation une odeur vive d'acide acẻtique se manifesta, ce qui n'arrive pas avec le vin pur.

* Examinons maintenant ce vin au microscope, et nous reconnaitrons qu'il est lout rempli de petits articles de mycoderma aceti, et que telle est la cause du trouble de la liqueur."

J'avais déjà antérieurement appris à ce fabricant à distinguer au microscope le mycoderma aceti.

Le résultat fut tel que je l'avais annoncé.

"Comment pourrais-je m'opposer au développement de ces matières gélatineuses?

- Vous pouvez essayer divers moyens. En faisant chauffer le vin et, déjá bien au-dessous de la chaleur de l'eau bouillante, vous détruirez la vitalité des articles du mycoderme. La filtration deviendra plus facile, et il n'y aura d'ailleurs plus à craindre le développement de ces articles, non plus, par suite, celui des matiéres gélatineuses. Un autre moyen plus économique consisterait a ajouter un peu de tanin au vin, puis une solution de colle forte, afin d'opérer un collage énergique qui précipiterait les articles de mycoderma aceti. Choisissez, en un mot, tel procédé qui vons conviendra, pourvu qu'il ait pour effet d'éloigner ou de faire périr les articles de mycoderme partout répandus dans le vin. "

J'ai voulu par ces détails montrer non seulement l'un des écueils de la fabrication, mais principalement confirmer, par un exemple pratique, l'exactitude de quelques-uns des résultats de ce Mémoire et la sûreté des principes qui y sont exposés. 
quelques instants le vinaigre à 50 ou $60^{\circ}(1)$, parce que l'on tuera ainsi tout germe de la plante renfermé dans le vinaigre.

Si la plante commence à se former à l'état de voile, et qu'on la veuille mucilagineuse, il suffira de disloquer le voile et de l'agiter pendant quelques instants dans le liquide afin qu'un certain nombre d'articles soient mouillés et restent au fond ou dans l'intérieur du liquide. C'est seulement dans le cas où un voile, se propageant à nouveau très rapidement, mettrait en œuvre pour son propre compte tout l'oxygène, que l'état mucilagineux de la plante ne se montrerait pas.

Aussi rien n'est plus facile, en suivant les indications précédentes, que de se procurer le mycoderme gélatineux en masses aussi considérables qu'on le désire et dans l'espace de quelques jours, surtout si l'on a la précaution d'employer un vinaigre faible qui convient beaucoup mieux que le vinaigre fort à la production du mycoderme sous la forme muqueuse. J'en donnerai des exemples dans le cours de ce Mémoire.

Bien que le mycoderma vini puisse se multiplier sur le fond des vases et complétement submergé, il n'offre jamais l'aspect gélatineux du mycoderma aceti.

Je vais maintenant rendre compte des expériences qui me portent à conclure que le mycoderma aceti est l'agent par excellence de l'acétification, et que, dans toutes les fermentations acétiques industrielles, il en est l'agent exclusif.

\section{§II. - Pas de mycoderme, pas d'acétification.}

Mes essais sur la fermentation acétique ont été extrêmement multipliés. Or, je puis affirmer que, dans aucune circonstance, un liquide alcoolique quelconque, plus ou moins chargé de matières dites albuminoïdes, extractives ou autres, ne m'a offert la moindre apparence d'acétification, tant qu'il n'y a pas eu développement de mycoderme. Vin naturel, vin étendu d'eau, vin étendu d'eau et d'acide acétique, bière, eau d'orge alcoolisée, mêlés ou non de telle ou telle proportion d'acide acétique, vin de jus de betteraves, eau de levûre de bière alcoolisée, eau de blé, eau d'écorce de divers arbres, jus de fruits bruts ou fermentés, tous ces liquides ne s'aigrissent jamais au contact de l'air par oxydation directe. Mais il n'en est aucun qui ne soit propre à donner naissance très rapidement, et souvent dans l'espace de vingt-

1. Dans le Mémoire des Annales scientifiques de l'École Normale supérieure, antérieur de quatre années à l'opuscule : "Études sur le vinaigre... ", Pasteur avait écrit : " 80 ou $90^{\circ}$. " (Note de l'Édition.) 
quatre heures, soit au mycoderma vini, soit surtout au mélange du mycoderma vini et du mycoderma aceti, soit aussi au mycoderma aceti pur, végétations qui ont la singulière propriété de fixer l'oxygène de l'air, de le condenser à la manière du noir de platine, en déterminant la combustion à un degré plus ou moins avancé des matières en dissolution, et notamment de l'alcool et de l'acide acétique.

Ce n'est pas à dire que si l'on expose au contact de l'air tous les liquides que je viens d'énumérer, ils n'y éprouvent pas du tout d'altération. Le lecteur pourra se convaincre, en lisant une Note insérée aux ('omptes rendus de l'Académie des sciences (avril 1863) [1], que j'ai mis hors de doute l'oxydation directe et variable des matières organiques, en dehors de l'influence de la multiplication des êtres inférieurs. Mais cette oxydation directe s'effectue avec une excessive lenteur, et elle donne lieu à des résultats bien différents de ceux que nous offre la fermentation acétique par le mycoderma aceti. Assurément, puisque le noir de platine agit sur l'oxygène et ultérieurement sur l'alcool lorsque celui-ci est présent, par un effet de corps poreux condensant les gaz et les vapeurs, on peut être porté à penser que des débris organiques solides, voire même des matières azotées dissoutes avides d'oxygène, pourraient bien également servir d'intermédiaire à l'oxydation de l'alcool, et autoriser des idées théoriques du genre de celles que M. Liebig a développées. Mais il ne s'agit pas de savoir ce qui arriverait dans telle ou telle hypothèse; qu'arrive-t-il en réalité? voilà ce qu'il importe de connaître. Eh bien! je n'ai jamais pu obtenir la moindre acétification des liquides alcooliques fermentés en dehors de la présence des mycodermes.

Le fait du noir de platine autorise bien des hypothèses, mais je ne connais pas d'exemple démontré d'acétification de l'alcool d'un liquide de fermentation par l'action d'un corps poreux non organisé (²). Quant à la nature de l'être organisé, je crois être en mesure de démontrer que, dans toute fermentation acétique de l'ordre des fermentations industrielles, soit par le procédé d'Orléans, soit par le procédé des copeaux, l'action résulte de la présence du mycoderma aceti développé spontanément dans les vaisseaux.

Dans ces études comme dans toutes celles qui concernent les fermentations, l'illusion est facile. La levûre de bière est quelquefois

1. Voir p. 165-171 du tome II des Euvvres de Pasteur : Examen du rôle attribué au gaz oxygéne atmosphérique dans la destruction des matiéres animales et végétales aprés la mort.

2. Dans les Annales scientifiques de ,l'École Normale supérieure, Pasteur a fait précéder cette phrase des mots : " Dans cet ordre de réactions, je ne regarde rien comme impossible. " (Notes de l'Édition.) 
utilisée pour acétifier des jus de betteraves fermentés, ou tout au moins, dit-on, il en faut pour mettre en train l'acétification, et il existe des procédés de fabrication recommandés par divers auteurs, où la levûre de bière est employée comme ferment. Fourcroy et Vauqueliu, d'autre part, acétifiaient le sucre avec de l'eau de froment, de l'eau de gluten, etc. (1). Des essais directs m'ont donné la conviction que ces substances n'agissaient que comme source d'aliments (azotés et phosphatés) pour le véritable ferment, qui se développait peu à peu de luimême et qui n'était autre que le mycoderma aceti. On peut laisser pendant plusieurs années la levûre de bière en contact avec des liquides fermentés et de l'air dans des vases en vidange, sans qu'il y ait la moindre acétification tant que le mycoderma aceti ne se montre pas. J'ai constaté des faits bien positifs et non douteux à ce sujet.

Lorsqu'il y a acétification après addition de levûre de bière, dire que la levûre est le ferment est une erreur pareille à celle que l'on commettrait en confondant les substances qui servent de nourriture à un végétal avec ce végétal même. Je ferai encore observer que, dans certains cas où le vin commence à s'acétifier dans des bouteilles en vidange, on serait quelquefois porté à croire qu'il y a eu acétification sans mycoderme, tant la pellicule de ce dernier est mince et à peine sensible. Le moindre mouvement de la bouteille peut en outre disloquer le voile, et il est difficile de le retrouver dans le vin à moins d'une étude microscopique délicate. Mais dans ces cas particuliers d'acétification en bouteille, il sera toujours facile de reconnaître dans le goulot au niveau du liquide, sur les parois du verre, un cercle grisâtre formé par le mycoderme, et que l'agitation du liquide fait difficilement disparaître. Quant à l'introduction de l'air, elle se fait par le bouchon.

\section{§ III. - Manière d'agì du mycoderma aceti.}

Première expérience. - Dans la fiole représentée figure 4, dont le volume total était de 2 lit. 862 , j’ai introduit, le 2 mars 1862 , à deux

1. On lit dans le Traité de chimie organique de Liebig [t. Ier, p. 390] : " En petit, on peut se procurer un vinaigre fort et agréable, en exposant pendant quelques semaines le mélange suivant à un endroit chaud : 100 parties d'eau, 13 parties d'eau-de-vie, 4 parties de miel et 1 partie de tartre cru; ou bien : 120 parties d'eau, 12 parties d'eau-de-vie, 3 parties de cassonade, 1 partie de tartre cru et $\frac{1}{2}$ partie de levûre.

"Pour fabriquer le vinaigre en grand, on se sert du moût de bière qui a déjà subi la fermentation alcoolique, et on l'expose dans des vases ouverts, avec un peu de levûre, dans des chambres chauffées jusqu'à ce que l'acidification soit complète. "

On sait que le tartre cru renferme toujours une proportion considérable de levure alcoolique de vin. C'est, suivant moi, la matière qui fournit au ferment ses aliments dans le cas où l'on n'emploie que du tartre cru, comme dans la première recette. 
heures, 101 centimètres cubes d'un liquide composé de 1 gr. 1 d'acide acétique cristallisable du commerce, 3 cc. 4 d'alcool absolu, et le complément à 101 centimètres cubes en eau de levíre. J'ai déjà dit 'Ju'un liquide ayant une composition de cette nature était éminemment propre au développement du mycoderma aceti. Après l'introduction du liquide, j'ai déposé à sa surface une quantité à peine appréciable de ce mycoderme (1). J'ai expliqué déjà que ce prélèvement et ce transport se font très facilement à l'aide d'une baguette de verre que l'on trempe

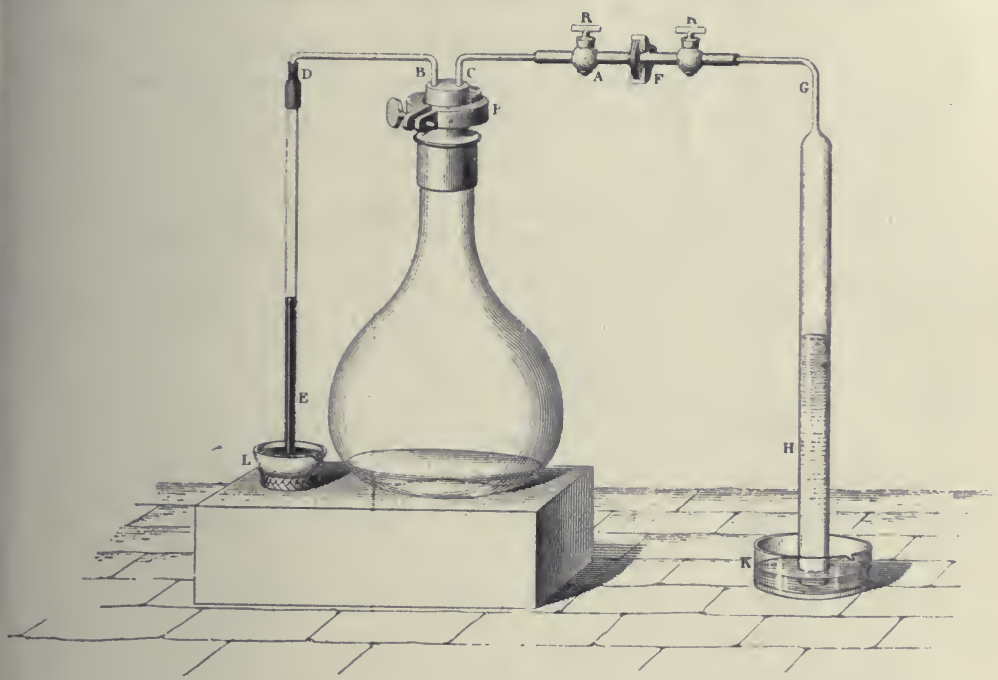

Fri. 4.

dans le liquide. En la retirant, un peu du voile s'y attache, et en la trempant ensuite dans le liquide frais, cette petite portion de voile se détache et s'étale à la surface. C'est ce que j'appelle la semence. Elle agit comme telle en effet $\left({ }^{2}\right)$. J'ai dit que le liquide et sa semence

1. Dans les Annales scientifiques de l'École Normale supérieuve : "Après l'introduction du liquide, je dépose à sa surface, par places, une quantité à peine appréciable de ce mycoderme prélevẻ dans un vase d'acétification à la surface duquel il y a un voile jeune formé par ce mycoderme. " (Note de l'Édition.)

2. Il n'est pas inutile d'en donner des preuves. D'une part, si l'on ne sème rien à la surface du liquide, il pourra se passer un temps considérable, quoique essentiellement variable, avant que l'on voie apparaître le mycoderma aceti. Dans ce cas la semence provient des poussières de l'air avec lequel le liquide a été en contact, ou des poussières des vases dans lesquels il a sẻjourné, poussières qui renferment ou ne renferment pas, selon les circonstances, le germe du mycoderme, ou quí le renferment plus ou moins vivace. Si elles ne le renferment pas, il ne se développe pas, et c'est là ce qui fait que souvent un liquide pareil déposé dans un flacon, même en vidange, ne s'aigrit pas. Avec semence ajoutée le développement a toujours 
avaient été placés dans la fiole le 2 mars, à deux heures. La pression barométrique était de $744^{\mathrm{mm}}, 6$. Aussitôt après, la garniture métallique $\mathrm{ABCDE}$ a été serrée fortement, à l'aide de la pince $\mathrm{P}$, à la garniture également métallique de la fiole. Le tube de verre DE, mastiqué en $\mathrm{D}$, plonge dans le godet $\mathrm{L}$ plein de mercure. Quant à la pièce FGH, j'en dirai l'usage plus tard. Présentement elle n'est pas encore adaptée à la garniture $\mathrm{AB}$.

Le 3 mars, toute la surface du liquide dans la fiole est couverte d'un joli voile très mince, uni, un peu terne, de mycoderma aceti. Dès que le voile se montre, on constate une absorption et une fixation d'oxygène qui, dans cette manière d'opérer, s'accuse et se mesure par l'ascension du mercure dans le tube ED.

Le 3 Mars.

$\begin{array}{cccc}\text { HEURES } & \begin{array}{c}\text { ÉLÉVATION } \\ \text { DU MERGURE }\end{array} & \begin{array}{c}\text { PRESSION } \\ \text { BAROMÉTRIQUE }\end{array} & \text { TEMPÉRATURE } \\ \text { h. } & \text { Cent. } & - & - \\ 12.35 & 11,6 & 738,5 & 25^{\circ} \\ 1.5 & 12,2 & " & " \\ 2.5 & 12,7 & " & " \\ 5.15 & 12,9 & " & " \\ \text { Minuit. } & 13,6 & " & "\end{array}$

Le 4 Mars.

$\begin{array}{lccc}9.0 \mathrm{M} . & 14,7 & 748,6 & 25 \\ 4.0 \mathrm{~s} . & 14,7 & »: & \text { 》 }\end{array}$

Le 5 Mars.

$\begin{array}{llll}9.0 & \text { м. } & 15,7 & 759,0\end{array}$

Ce tableau nous montre que l'absorption de l'oxygène, et par suite l'acétification de l'alcool, comme nous le verrons tout à l'heure en dosant l'acide acétique formé, était déjà considérable vingt-quatre heures après l'ensemencement, et que trente-six heures après environ elle était entièrement achevée, ce qui sera confirmé par l'analyse du gaz de la fiole. Cela donne une idée bien nette de la rapidité avec laquelle se fait le développement de la plante et de l'absorption de l'oxygène. On voit en outre que cette absorption qui correspondait

lieu, à moins que la semence ne soit morte, et il se déclare dans les vingt-quatre heures aux températures favorables. Enfin, ce qui prouve encore toute l'efficacité de la semence, c'est que le liquide dont je parle étant également très propre à nourrir le mycoderma vini, si l'on sème ce dernier, c'est du mycoderma vini que l'on récolte et non le mycoderma aceti. J'ai déjà fait remarquer néanmoins qu'il y a des cas où, tout en semant du mycoderma vini, on pourrait ne récolter que du mycoderma aceti. C'est qu'alors on aurait rendu la liqueur beaucoup plus propre au développement du mycoderma aceti qu'au développement de son congénère, et que la semence ajoutée, très lente à se multiplier ou même fanée par l'effet de la composition du liquide, ne se propagerait pas assez promptement à la surface pour 
encore, le 3 mars à midi, à une ascension de 6 millimètres de mercure par demi-heure, très appréciable par conséquent à l'œil nu dans l'intervalle de quelques minutes, n'était déjà plus que de 5 millimètres par heure entre 1 et 2 heures, de 2 millimètres seulement pour trois heures entre 2 et 5 heures. Il est évident d'ailleurs que cette ascension, nulle au début, ou, mieux, insensible tant qu'il n'y a pas de voile et seulement la semence, s'accélère peu à peu et retombe à zéro, par degré, au fur et à mesure de la soustraction du gaz oxygène.

Analyse du gaz de la fiole. - II fallait trouver le moyen de faire l'analyse du gaz de la fiole à un moment quelconque de l'expérience, si besoin était, et de manière à ne pas la troubler, c'est-à-dire sans disloquer le voile ni déranger la fiole de place. On y parvient facilement à l'aide du tube FGH qui n'est autre chose que le laboratoire de l'eudiomètre de M. Regnault. Après avoir été rempli de mercure, ce tube est approché de la fiole et réuni au robinet A à l'aide d'un collier à gorge. On ouvre alors le robinet $\mathrm{R}^{\prime}$, puis le robinet $\mathrm{R}$. Le gaz de la fiole passe aussitôt dans le tube FGH, en vertu de sa force élastique. On referme les robinets dès qu'on juge que la prise de gaz est suffisante pour l'analyse eudiométrique. Le tube FGH est ensuite séparé de la fiole et adapté à l'eudiomètre pour l'analyse du gaz. La fiole n'a pas été remuée pendant toute cette manipulation. Afin d'éviter la cause d'erreur tenant aux petites quantités d'air logées dans les robinets, je plaçais dans leurs gaînes de petits cylindres d'acier qui les remplissaient à peu près complétement sans s'opposer toutefois au-passage du gaz.

Dans l'expérience qui précède, le gaz de la fiole a été analysé le

empêcher le développement spontané du mycoderma aceti, c'est-à-dire le développement par les germes primitivement existants dans la liqueur. On arriverait, par exemple, à ce résultat, si l'on forçait dans la composition de notre liqueur la proportion d'acide acétique, en laissant la même ou en diminuant au contraire un peu celle de l'alcool. Cela tient uniquement à cette circonstance que le mycoderma aceti se plaît dans les liquides acétiques, tandis que le mycoderma vini s'accommode mieux des liquides un peu alcooliques et peu acides. A la rigueur, il s'accommoderait des liquides neutres s'il n'avait pas à redouter alors les infusoires qui s'opposent à son développement en prenant pour eux tout l'oxygène.

Si le lecteur réfléchit à ces observations et à beaucoup d'autres de la même nature, il se convaincra sans peine de la mobilité des résultats de toutes ces études sur les fermentations, mais en même temps il reconnaitra que, par des expériences suivies et raisonnées, on peut arriver á décourrir les causes générales déterminantes de la variation des résultats et s'en servir comme d'un guide sûr pour se rendre compte de cette mobilité apparente. Elle est toujours l'effet de conditions particulières, régies, dans leur influence sur la marche des phénomines, par des lois d'une fixité non douteuse.

C'est ce qui fait également que dans cet ordre d'études il n'est pas difficile de constater des faits particuliers, isolés, nouveaux ou paraissant l'être, tant ils sont nombreux et changeants. Mais si l'on n'en recherche pas la liaison avec le phénomène principal, si l'on n'établit pas que cette liaison existe, ou qu'elle n'existe pas, souvent, loin d'éclairer le sujet, on ne fait que l'obscurcir. Je pourrais en citer de nombreux exemples tirés de publications récentes. 
5 mars en suivant les indications que je viens de donner. Il était composé de:

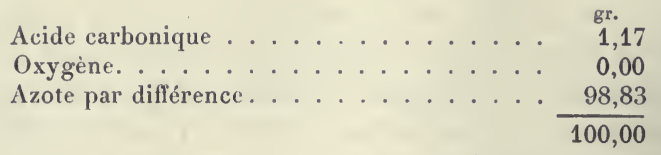

Tout l'oxygène arait donc disparu et il n'y avait qu'une très faible quantité de gaz acide carbonique. D'où provenait-elle? Il ne me paraît pas douteux qu'il faille l'attribuer à la vie de la plante qui, à la manière de la plupart des êtres inférieurs, absorbe du gaz oxygène et exhale du gaz carbonique. La proportion de gaz carbonique qui a pris naissance est bien en rapport avec celle des principes qui se sont assimilés pour nourrir le mycoderme dont le poids était extrêmement faible.

Je dois cependant faire observer dès à présent que la combustion dont la plante est le siège peut aller quelquefois jusqu'à la transformation de l'alcool en vapeur d'eau et en gaz acide carbonique. Il ne serait donc pas impossible qu'une fraction de l'acide carbonique eût une autre origine que celle qui résulterait de la modification des principes mis en œuvre par la vie de la plante pendant son développement. Cela est peu probable dans l'expérience que je viens de rapporter, tant est faible la proportion du gaz acide carbonique formé.

Le 5 mars, l'acidité totale du liquide a été trouvée égale à $2 \mathrm{gr} .2$ d'acide acétique, tandis qu'au moment où il a été placé dans la fiole le liquide renfermait seulement $1 \mathrm{gr} .1$ de cet acide. Si l'on calcule la quantité totale d'acide acétique qu'aurait dû former l'oxygène de la fiole en le supposant utilisé à changer l'alcool en acide acétique, la proportion de cet acide aurait dû être supérieure à la différence de 2 gr. 2 à 1 gr. 1. C'est qu'une partie de l'oxygène est employée à faire autre chose que de l'acide acétique : des produits neutres, de l'aldéhyde, etc... Mais l'acide acétique est le produit dominant. Cependant ce n'est pas le seul acide qui se forme. J'ai lieu de croire que l'acide succinique est toujours au nombre des produits de la fermentation acétique (1).

1. Voici le moyen de s'en assurer. Afin d'éviter les difficultés qu'amènerait nécessairement dans la recherche de l'acide succinique dû à la fermentation acétique la présence de celui que renferment naturellement le vin, la bière, le cidre, etc., il faut préparer du vinaigre à l'aide d'alcool pur et de phosphates, sans addition de liqueurs fermentées brutes. (Voiv le \& IV ci-après.)

Le vinaigre ainsi formé est évaporé : 100 centimètres cubes suffisent largement pour cet essai.

Le résidu renferme des matières extractives diverses que je n'ai point étudiées. Toutefois cette circonstance montre la complication de cette fermentation en apparence si simple. Il y a 
IV. - Acétification sans matière albuminoïde. - Développement du mycoderma aceti à l'aide de sels ammoniacaux et de phosphates alcalins et terreux. - Preuves évidentes de la nature organisée du ferment.

Quel a été le rôle des principes de l'eau de levûre dans l'expérience dont j'ai parlé au paragraphe précédent? On peut démontrer, quoique d'une manière indirecte, qu'ils ont fourni au mycoderme les aliments azotés et minéraux nécessaires à son développement.

Si l'on sème une trace impondérable de mycoderma aceti à la surface d'un liquide qui ne renferme d'autre matière azotée que du phosphate d'ammoniaque, la plante ne tarde pas à recouvrir toute la surface du liquide, empruntant son carbone à l'alcool ou à l'acide acétique, son azote à l'ammoniaque, ses principes minéraux aux phosphates, et l'acétification a lieu. Toutefois la plante n'a pas la même rigueur que dans le cas où elle a à son service des matières albuminoïdes. Le voile est moins ferme, plus délicat, plus sec, si je puis m'exprimer ainsi, quoique d'une continuité parfaite. La plante paraît renfermer moins de matières grasses que dans les circonstances ordinaires. Ainsi le voile se troue si l'on plonge une baguette de verre dans le liquide, et les bords déchirés ne se rejoignent pas quand on retire la baguette, circonstance qui ne se présente pas, en général, lor'squ'il s'agit d'un voile formé dans les conditions ordinaires.

Je prépare un liquide renfermant par litre, outre l'eau distillée :

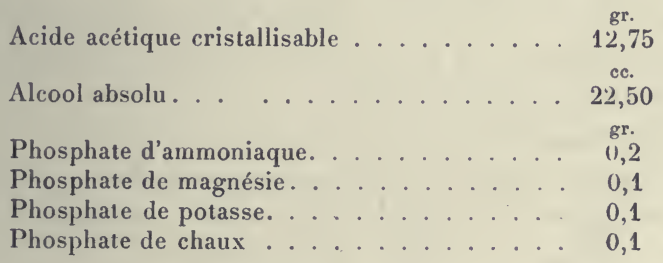

Ces proportions peuvent changer du reste dans des limites assez grandes.

Le 9 avril 1862, à 3 heures de l'après-midi, je place 2 litres de ce liquide dans une cuve en gutta-percha (de 45 centimètres de largeur sur

longtemps que j'ai fait observer que les fermentations étaient des actes chimiques aussi complexes que ceux de la rie.

Si l'on traite le résidu par un mélange d'alcool et d'éther, et qu'on abandonne la liqueur tiltrée á une évaporation spontanée, dẻs le lendemain on apercoit sur les parois du vase une quantité assez notable de cristaux d'acide succinique. 
50 de longueur), et je dépose à sa surface une trace de mycoderma aceti.

Le lendemain et le surlendemain, le développement de la plante n'est pas encore sensible. Le 12, toute la surface est couverte d'un voile doux, homogène, d'une minceur excessive, sans aucune solution de continuité. On aperçoit déjà sur le couvercle de verre qui recouvre la cuve une condensation de vapeur d'eau indiquant une élévation de température du liquide. L'odeur est acétique avec quelque chose d'agréable qui annonce des principes éthérés.

Le 12 , à 9 heures du matin, 1 litre du liquide renferme $21 \mathrm{gr.} 2$ d'acide acétique, au lieu de 12,75 qu'il y avait à l'origine. Le 12, à midi, il y en a 24,1 . Ainsi, en trois heures, il s'est formé 2 gr. 9 d'acide par litre, soit 5 gr. 8 pour les 2 litres. Ce serait une acétification de $46 \mathrm{gr} .4$ d'acide en vingt-quatre heures.

Le 12 , à midi, j'ai rajouté 70 centimètres cubes d'alcool à $90^{\circ}$. Ces additions d'alcool doivent toujours se faire avec ménagement. Si l'on verse de l'alcool à fort titre dans une cuve en acétification, sans précaution particulière, l'alcool, plus léger, se répand à la surface du liquide et tue le voile, quelquefois instantanément. Il faut retirer une portion du liquide de la cuve à l'aide d'un siphon sans déchirer le voile, ce qui est facile si le siphon plonge au fond de la cuve, parce que le voile descend sans se briser au fur et à mesure que le liquide s'écoule. On mêle l'alcool au liquide qui a été retiré de la cuve, et on rajoute ensuite la totalité de ce liquide à l'aide d'un entonnoir qui débite peu. Le voile se soulève également sans déchirure.

L'addition des 70 centimètres cubes d'alcool à $90^{\circ}$ a un peu ralenti l'acétification, qui avait repris le soir assez activement. Le voile continue de se développer. Le 13, il se montre tout plissé. Du 12 au 13, il s'est formé 40 grammes d'acide acétique. Le 13, après avoir constaté une odeur d'acétification des plus vives et une condensation considérable de vapeur d'eau, je rajoute 30 centimètres cubes d'alcool à $90^{\circ}$. Le 15, à 8 heures du matin, il y avait $126 \mathrm{gr} .8$ d'acide acétique dans la cuve et un volume total de 2 lit. 020 , ce qui correspond à 80 centimètres cubes d'évaporation. L'opération m'ayant paru terminée, parce que l'acétification n'avait été que de quelques grammes du 14 au 15, j'ai mis fin à l'essai. Le poids calculé d'acide acétique, correspondant au poids d'alcool employé, ajouté à celui de l'acide acétique cristallisable dissous à l'origine dans le liquide, forme un total de 165 grammes (1).

1. Dans les Annales scientifiques de l'École Normale supérieure, à la place de cette dernière phrase, on lit : " En transformant en acide acétique tout l'alcool employé et en l'ajoutant à l'acide acétique cristallisable dissous à l'origine dans le liquide, on aurait dù trouver 165 grammes d'acide acétique. " (Note de l'Édition.) 
La différence à 126 gr. 8 est de 38 gr. 2. C'est une perte de 23,2 pour 100 tant par évaporation que par déviation du phénomène chimique indiqué par l'équation

$$
\mathrm{C}^{4} \mathrm{H}^{6} \mathrm{O}^{2}+4 \mathrm{O}=2 \mathrm{HO}+\mathrm{C}^{4} \mathrm{H}^{4} \mathrm{O}^{4},
$$

équation qui ne se vérifie jamais complétement, parce que la combustion de l'alcool est plus complexe que ne l'indique cette équation et qu'il se forme, outre l'acide acétique, d'autres produits acides et neutres. Aussi l'odeur d'une cuve en fermentation acétique est toujours un peu mêlée, bien que celle de l'acide acétique domine. Je donnerai mème des exemples de combustion où tout l'alcool passe à l'état de ces produits suffocants qui provoquent le larmoiement et que fournit la combustion de l'alcool et de l'éther dans certaines circonstances, par exemple sous l'influence d'une spirale de platine incandescente dans une expérience bien connue.

En résumé, l'essai qui précède démontre avec une entière rigueur que le mycoderma aceti peut prendre naissance sans avoir à sa disposition d'autre aliment carboné que l'alcool ou l'acide acétique, ni d'autre aliment azoté et minéral que de l'ammoniaque et des phosphates cristallisables, et il faut en conclure que, dans tous les cas de fermentation acétique industrielle, les matières albuminoïdes, loin de constituer le ferment acétique, n'en sont que l'aliment. On sait qu'elles sont toujours associées à des phosphates. C'est toujours la condamnation de l'ancienne théorie des fermentations $\left.{ }^{(1}\right)$.

\section{\$. - Procédé des copeaux de hêtre.}

Le procédé d'acétification par les copeaux de hêtre, si répandu en France et en Allemagne depuis plus de vingt années déjà, a singulièrement accrédité les erreurs que je combats dans ce Mémoire. On sait que ce procédé consiste à faire écouler lentement dans des tonneaux remplis de copeaux de hêtre, rassemblés sans ordre ou disposés par assises après avoir été roulés comme des ressorts de montre, de

1. Dans les Annales scientifiques de l'École Normale supérieure : “ C'est toujours la condamnation de l'ancienne théorie des fermentations, et la confirmation des principes que j'ai établis dans mes recherclies antérieures, bien qu'il s'agisse présentement d'un ferment de combustion et non de désassociation comme dans le cas de la levùre de bière. "(Note de l'Edition.)

Les faits qui précédent prouvent surabondamment que l'assertion de Chaptal, rappelée en note à la page 26, est exagérée. Le vin le mieux dépouillé n'est pas privé de tout principe extractif, et, le serait-il, qu'il renfermerait encore des phosphates et des sels alcalins et terreux. Il est donc toujours propre à servir au développement du mycoderma aceti. Seulement il est d'autant moins propre à nourrir les mycodermes, et particulièrement le mycoderma vini, qu'il est plus dépouillé de ses principes extractifs. (Note de Pasteur.) 
l'alcool étendu d'eau de manière à ne plus marquer que 8 à $12^{\circ}$ à l'alcoomètre, et additionné de quelques millièmes d'acide acétique. Des ouvertures pratiquées dans la paroi du tonneau et dans un double fond sur lequel reposent les copeaux permettent l'accès de l'air qui monte dans le tonneau, comme il ferait dans une cheminée, en cédant tout ou partie de son oxygène à l'alcool pour le convertir en vinaigre.

Les copeaux, dit-on, agissent comme corps poreux, à la façon du noir de platine. Cette manière de voir parait d'autant plus certaine que, dans diverses fabriques, l'alcool que l'on emploie provient de flegmes, c'est-à-dire d'alcool de distillation qui ne renferme pas de substances albuminoïdes. Quant aux matières que les copeaux eux-mêmes pourraient céder au liquide, leur participation dans le phénomène est évidemment nulle, puisque ces copeaux ont une durée pour ainsi dire indéfinie. Ce n'est que tout à l'origine que l'on pourrait croire à une influence directe de quelques-uns de leurs principes solubles. Mais ce n'est là qu'un accident.

N'oublions pas toutefois de remarquer que la plupart des auteurs s'accordent à dire que la mise en train doit être faite avec addition de 1 à 2 millièmes de levûre de bière ou de vinaigre ordinaire ou de moût de bière.

Je démontrerai tout à l'heure que les copeaux n'ont qu'un ròle passif dans la fabrication. Ils permettent la division du liquide et ils servent de support au ferment qui est encore ici le mycoderma aceti sous la forme muqueuse. Je ne me dissimule pas cependant que les apparences sont tout à fait contraires à cette opinion. Que l'on se transporte, en effet, dans une fabrique marchant par le procédé allemand, et que l'on y examine les copeaux d'un tonneau en travail depuis plusieurs mois ou depuis plusieurs années, on les trouvera d'une propreté en apparence parfaite. On dirait qu'ils viennent d'être lavés avec beaucoup de soin. Mais vient-on à les racler avec une lame de couteau, et étudie-t-on la raclure au microscope, on ne tarde pas à reconnaître qu'un bon nombre portent à leur surface, au moins par places, une couche à peine sensible de mycoderma aceti, qui peut quelquefois se soulever en mince pellicule. Beaucoup de copeaux ne sont pas recouverts de mycoderme, même dans les tonneaux qui marchent le mieux. Je crois que ces copeaux sont tout à fait inutiles, si ce n'est pour diviser le liquide; et je m'explique les différences considérables que l'on observe entre l'activité du travail des tonneaux de diverses fabriques, ou même des tonneaux voisins dans une même fabrique, par ces lacunes plus ou moins prononcées dans le développement de la plante à la surface des copeaux. 
L'utilité de l'emploi des copeaux de hêtre tient si peu, selon moi, a leur nature propre, que je ne doute pas que l'on pourrait les remplacer par les inatières les plus diverses, voire même par des fragments de verre ou de porcelaine, à la seule condition toutefois que les substances dont on se servirait seraient propres à retenir adhérentes à leur surface le mycoderma aceti, ce qui ne serait peut-être pas le cas du verre ou de la porcelaine. Je ne cite ces corps que pour mieux rendre ma pensée et le peu de confiance que j'attache aux idées généralement admises par les chimistes et les fabricants.

Il ne faudrait pas croire néanmoins que l'on dût s'arranger de façon que la plante prît le plus de développement possible.

J'ai eu à ma disposition des copeaux, rassemblés depuis plusieurs années dans un grenier, que l'on avait dû mettre hors d'usage parce que le travail était devenu impossible par leur emploi. Le fabricant ne savait à quoi attribuer la mauvaise qualité de ces copeaux. Or, en les faisant détremper dans l'eau pendant quelques heures, je vis qu'ils étaient tous recouverts sur leurs deux faces d'une couche grasse au toucher (1) que je reconnus être le mycoderma aceti.

Dans une autre fabrique on avait dù vider des tonneaux, parce que le travail d'acétification s'était arrêté, et l'on avait trouvé, surtout à la partie inférieure, des masses gélatineuses qui n'étaient autre chose que de la mère de vinaigre.

Les faits que je viens de passer en revue n'étaient guère propres à éclairer la véritable cause des phénomènes. D'une part, on n'apercevait pas le mycoderme à la surface des copeaux lorsque le travail de la fabrique était régulier; d'autre part, il y avait quelques rares circonstances dans lesquelles on avait pu reconnaître que la mère du vinaigre, accidentellement fort développée, avait mis obstacle à l'acétification.

Mieux renseignés tout à l'heure sur la véritable théorie de l'opération, nous pourrons conclure que la plante ne doit pas prendre un développement exagéré. Il est certain que si elle se multiplie au point de boucher le passage de l'air dans les interstices des copeaux, la fermentation s'arrêtera forcément. Sans aller jusque-là, une trop grande abondance de mycoderme à la surface des copeaux peut rendre le travail d'acétification si actif que la perte d'alcool devient considérable, ou que la trop grande chaleur développée tue la plante. Dans les conditions normales, la perte en alcool est déjà fort sensible, souvent de 30 à 40 pour 100; c'est même lá l'écueil à éviter dans ce mode de fabrication.

1. Dans les Annales scientifíques de l'École Normale supérieure, Pasteur a ajouté "glissante ". (Note de l'Édition.) 
Mais j'ai hâte de démontrer expérimentalement la donnée fondamentale de la théorie que je viens d'exposer, à

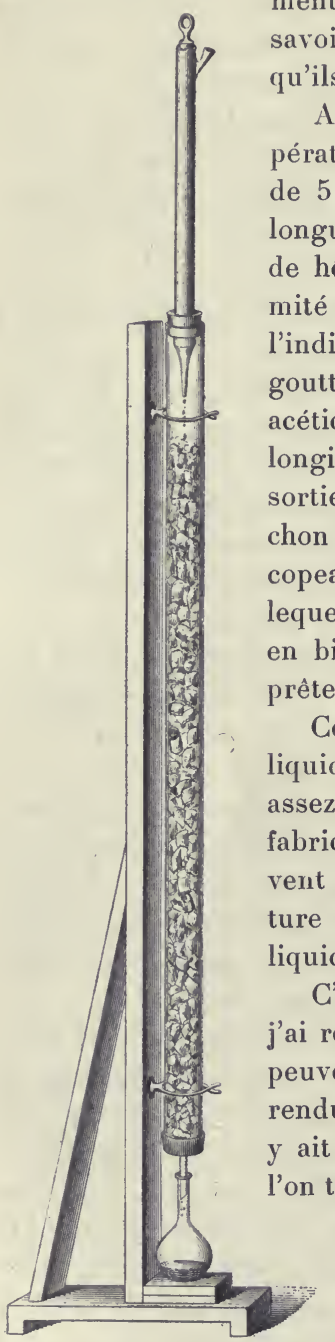

FIG. 5. savoir: que les copeaux n'ont d'effet utile qu'autant qu'ils sont recouverts de mycoderma aceti.

A cet effet, j'ai disposé dans une étuve, à la température de 28 à $30^{\circ}$, un tube de verre cylindrique de 5 à 6 centimètres de diamètre (fig. 5), d'une longueur de 1 mètre environ, rempli de copeaux de hêtre de fabrique. Un bouchon placé à l'extrémité supérieure porte une pipette disposée comme l'indique la figure, et qui laisse couler goutte à goutte, très lentement, un liquide alcoolique et acétique d'un titre acide déterminé. Une rainure longitudinale est pratiquée sur le bouchon pour la sortie de l'air qui entre par le tube fixé au bouchon de l'extrémité inférieure du gros tube à copeaux. Le petit tube, qui donne accès à l'air et par lequel s'écoule le liquide en expérience, est taillé en biseau, afin que la goutte de liquide toujours prête à tomber n'obstrue pas le passage de l'air.

Ces dispositions permettent un écoulement de liquide aussi lent qu'on le désire. Elles réalisent assez bien toutes les conditions du travail des fabriques. Afin de rechercher si les copeaux peuvent par eux-mêmes acétifier l'alcool à la température de $30^{\circ}$, il suffira de comparer le titre acide du liquide supérieur avec celui du liquide inférieur.

C'est par des expériences de cette nature que j'ai reconnu que des copeaux privés de mycoderme peuvent recevoir pendant plusieurs jours de l'alcool rendu acide par un peu d'acide acétique, sans qu'il y ait la moindre augmentation du titre acide que l'on trouve au contraire un peu diminué à la partie inférieure par suite de l'évaporation sous l'influence du courant d'air. Des liquides alcooliques et acétiques, mêlés de phosphates ou tenant en solution des matières albuminoïdes, se comportent de la même manière tant que la plante n'est pas née spontanément sur les copeaux, et souvent elle n'apparaît qu'au bout de plusieurs jours. Mais si l'on trempe les copeaux dans un liquide où il existe du mycoderma aceti 
a l'état muqueux, dont quelques parties restent attachées aux copeaux lorsqu'on les retire du liquide, puis que l'on fasse écouler sur ces copeaux un liquide alcoolique, dans tous les cas l'acétification se déclare sur-le-champ et persiste durant plusieurs jours, même après qu'on a remplacé le liquide albumineux ou phosphaté par un liquide alcoolique pur étendu d'eau distillée pure. Ce dernier fait est digne d'attention, car il prouve que la plante met un certain temps à perdre la structure qui lui donne son pouvoir acétifiant, alors même qu'on lui refuse des aliments appropriés à son développement.

J'ai confirmé ces résultats par des expériences qui me paraissent tout aussi démonstratives que les précédentes. En tendant une corde suivant l'axe d'un tube cylindrique en verre et laissant écouler le long de cette corde de l'alcool à titre très faible, je n'ai jamais vu l'alcool s'acétifier. Mais en trempant la corde dans un liquide en voie d'acétification recouvert de mycoderma aceti, lequel s'attache en partie à la corde lorsqu'on la retire, l'acétification se déclare dès qu'on fait écouler le long de la corde un liquide alcoolique. Si ce liquide n'est pas composé de façon à permettre le développement de la plante sur la corde, l'acétification se maintient pendant un certain temps jusqu'à ce que la plante soit morte, ou mieux jusqu'à ce qu'elle ait perdu la structure, le mode d'agrégation de ses parties qui lui donne sa vertu de fixation. de l'oxygène de l'air. Mais si le liquide alcoolique renferme des matières azotées et des phosphates, la plante se multiplie sur la corde, et son action chimique peut être longtemps prolongée.

Ces expériences établissent, ce me semble, l'absolue nécessité du mycoderma aceti à la surface des copeaux pour que l'acétification soit possible. Elles jetteront beaucoup de lumière sur la fabrication de l'acide acétique à l'aide des copeaux, fabrication qui ne laisse pas que d'ètre capricieuse.

Je suis disposé à croire que le travail est le meilleur lorsque le développement du mycoderme est assez faible pour que les copeaux paraissent au toucher n'en être pas recouverts. Le danger est qu'il y en ait trop peu, et qu'une grande partie des copeaux n'agissent pas. Toutefois il est probable qu'avec la dimension que l'on donne ordinairement aux tonneaux, il faut garder une certaine mesure; car si tous les copeaux intervenaient, l'action serait peut-être beaucoup trop énergique. Comment faut-il faire pour que le mycoderme existe dans la proportion convenable? Je crois qu'à cet égard le fabricant doit porter toute son attention sur la composition des liquides qu'il veut acétifier, c'est-à-dire sur la quantité et la qualité plus ou moins bien appropriée des matières qui peuvent servir d'aliments à la multiplication de la 
plante. Si l'on se sert du moût de bière, du vin, des jus d'orge ou de grains saccharifiés et fermentés, on se trouvera dans les conditions d'un développement facile et rapide de la plante. Le travail sera difficile, parce qu'il arrivera promptement à s'exagérer et peut-être à la combustion partielle de l'acide acétique. Avec des flegmes, au contraire, sans mélange de matière azotée ni de substances minérales, l'acétification ne tardera pas à devenir impossible, et même elle ne prendrait pas naissance si dès le début on avait fait usage d'un pareil liquide.

C'est entre ces deux extrêmes qu'il faut se tenir. Il doit y avoir constamment dans le liquide un peu de matière albuminoïde pour servir d'aliments à la plante, ou tout au moins un sel d'ammoniaque et des phosphates alcalins et terreux. S'il existe, comme je l'ai entendu dire, des fabriques où l'on n'utilise que des flegmes étendus d'eau pour alimenter les cuves, je ne doute pas que la plante ne trouve ses aliments dans les sels d'ammoniaque, dans les phosphates et peut-être aussi dans les matières organiques de l'eau commune que le fabricant ajoute forcément aux flegmes afin d'en diminuer le titre pour les ramener au degré voulu par l'acétification. Aussi je suis porté à croire que, dans ce cas, l'addition directe de phosphates rendrait de grands services.

Je n'hésite pas cependant à reconnaître que les considérations que je viens de présenter devraient être soumises à un contròle expérimental, et je l'aurais fait si j'avais pu disposer, dans une fabrique, de tonneaux d'acétification et les soumettre à des essais variés. C'est un travail facile que les industriels intelligents peuvent entreprendre sans peine dès qu'ils se seront familiarisés avec les principes que j'expose dans ce Mémoire. Il y va de l'intérêt de leur industrie. Il me semble que l'on peut aujourd'hui arriver à une sorte de perfection dans ce mode de fabrication par les copeaux de hêtre.

\section{$\S$ VI. - Combustion de l'acide acétique par le mycoderma aceti.}

On sait depuis très longtemps, car Van Helmont en parle déjà dans ses écrits (1), que le vinaigre abandonné à lui-même finit par se détruire complétement. Mais on ne saurait trouver dans les anciens auteurs rien de plus précis que ce qu'a écrit sur ce sujet l'illustre Scheele. Voici les remarques qu'il nous a laissées sur la manière de conserver le vinaigre :

"C'est une chose généralement connue que le vinaigre ne peut se

1. Les œuvres de J.-B. Van Helmont, traduction de Jean Le Conte. Lyon, 1671, in-4ㅇ. (Note de l'Édition.) 
conserver longtemps; qu'il s'altère au bout de quelques semaines, particulièrement dans les chaleurs de l'été; qu'il devient trouble et se couvre à la surface d'une viscosité épaisse, d'où il arrive que son acidité s'affaiblit de plus en plus et disparaît à la fin entièrement, au point qu'on est obligé de le jeter là.

"Il y a jusqu’à présent quatre procédés connus pour conserver le vinaigre.

" Le premier est de préparer un vinaigre très acide. De cette manière il se conserve à la vérité plusieurs années; mais comme il y a bien peu de personnes qui travaillent elles-mêmes leur vinaigre, et que la plupart se servent de celui qu'elles trouvent dans le commerce, cette méthode ne pourrait être utile qu'à un très petit nombre.

"Le second procédé consiste à le concentrer par la gelée. On fait un trou à la croûte de glace, et on met dans des bouteilles ce qui n'a pas été gelé. Cette opération est très sûre; mais on perd au moins la moitié du vinaigre, quoique la portion qui forme la croute de glace ne soit presque que de l'eau. Les gens économes n'en feront pas volontiers usage.

"Le troisième procédé est de tenir le vinaigre à l'abri de toute action de l'air, c'est-à-dire dans des bouteilles ou flacons bien bouchés, et qui soient toujours pleins. Le vinaigre se conserve très longtemps de cette inanière; cependant elle est peu en usage, sans doute parce qu'on serait obligé, aussitôt qu'on en aurait employé quelque peu, de remplir tout de suite la bouteille avec du vinaigre pareil et clair d'une autre bouteille, et que, celle-ci restant vide en partie et recevant l'air, le vinaigre y deviendrait trouble et gâté.

" Le quatrième procédé pour conserver le vinaigre est de le distiller; il se conserve alors plusieurs années, sans que l'air ni la chaleur lui causent aucune altération; mais comme il eșt plus cher, il n'y a pas d'apparence qu'on adopte cette méthode, surtout quand on connaîtra celle qui suit, et qui est la plus facile de toutes.

" Il suffit de jeter le vinaigre dans une marmite bien étamée, de le faire bouillir sur un feu vif un quart de minute, et d'en remplir ensuite des bouteilles avec précaution. Si l'on pensait que l'étamage fût dangereux pour la santé, on pourrait mettre le vinaigre dans une ou plusieurs bouteilles, et placer ces bouteilles dans une chaudière pleine d'eau sur le feu; quand l'eau aurait bouilli un petit moment, on retirerait les bouteilles.

" Le vinaigre ainsi cuit se conserve plusieurs années sans se troubler ni se corrompre, aussi bien à l'air libre que dans des bouteilles à demi-pleines; il remplacerait avantageusement le vinaigre commun chez les apothicaires, pour les vinaigres. composés qui deviennent 
bientôt troubles et perdent par conséquent toute leur acidité, à moins qu'on ne les prépare avec le vinaigre distillé (1). »

Il serait difficile de présenter des remarques plus justes au sujet de la conservation du vinaigre. Mais quelle est la cause de la disparition de l'acide acétique dans le vinaigre qui est exposé au contact de l'air?

Je vais démontrer que si le vinaigre perd sa force, c'est uniquement par l'effet d'une combustion lente, et que cette combustion est déterminée par le mycoderma aceti, qui, après avoir transformé l'alcool en acide acétique, porte l'oxygène de l'air sur cet acide lui-même, et le réduit complétement à l'état d'eau et d'acide carbonique.

Le 8 novembre 1861, je place, dans une grande fiole de verre de 4 lit. 700, 150 centimètres cubes d'un liquide composé de :

Eau contenant 5 grammes acide acétique cristallisable. . . 50 cc.
Eau de levûre de bière . . . . . . . . . . . . . . . . . . . . $50 " ~$
Eau pure. . . 50 "

puìs je sème à la surface du liquide une trace de mycoderma aceti non muqueux, en si petite quantité que la semence est presque invisible. Les jours suivants, développement lent et très peu vigoureux de la plante. La pellicule se disjoint par la moindre agitation. J'analyse le gaz de la fiole le 20 novembre. Il renferme 19,8 pour 100 d'acide carbonique et pas la moindre trace de gaz oxygène. L'absorption de ce dernier gaz a été de $1 \mathrm{gr}$. 306, et la proportion d'acide acétique de la liqueur avait diminué précisément dans le rapport de cette absorption et de la formation de l'acide carbonique. La pellicule, uniquement formée de mycoderma aceti, a pesé sèche 1 centigramme.

Cette expérience démontre deux choses : $1^{\circ}$ le mycoderma aceti peut vivre et se multiplier sur un vinaigre entièrement privé d'alcool; $2^{\circ}$ il fixe l'oxygène de l'air sur l'acide acétique en transformant son carbone en acide carbonique.

L'essai suivant conduit au même résultat, mais il prouve en outre que le mycoderma aceti, après avoir provoqué la combustion de l'acide acétique, peut agir de nouveau sur l'alcool, en le transformant en acide acétique.

Le 26 décembre 1861, je place, dans une fiole de 2 lit. 322, 150 centimètres cubes d'un liquide formé de :

Eau de levûre de bière. . . . . . . . $140 \mathrm{cc}$.

Eau tenant en dissolution 0 gr. 885 d'acide acétique pur . 10 »

1. Scheele. Mémoires de chimie. Dijon et Paris, 1785, in-12. [Seconde partie. XIX. Remarques sur la manière de conserver le vinaigre (tirées des Mémoires de l'Académie royale des sciences de Stockholm, année 1782), p. 137-140]. 
et je sème une trace de mycoderma aceti gélatineux. La température de l'étuve était de $25^{\circ}$ en moyenne. Le 27, pas de développement sensible de la semence. Le 28, taches mucilagineuses sur toute la surface. Le 29, il est plus développé encore $\left.{ }^{\mathbf{I}}\right)$.

Le 29, j'analyse le gaz. Il renferme déjà 17,15 pour 100 d'acide carbonique, et seulement 3,49 de gaz oxygène. Le 30 , il n'y a plus de graz oxygène, et la quantité d'acide acétique est réduite à 0 gr. 328 . Plus de $\frac{1}{2}$ gramme d'acide acétique a donc été brûlé.

Je renouvelle l'air de la fiole, puis j'ajoute au liquide 2 centimètres cubes d'alcool absolu, après les avoir mélangés à 10 centimètres cubes du liquide de la fiole retirés à l'aide d'un siphon, sans déchirer le voile. J'ai déjà fait observer que l'alcool, s'élevant par sa légèreté spécifique à la surface du liquide, tuait le voile. Il faut toujours le diluer avant de l'ajouter aux liqueurs.

Le 5 janvier, j'étudie de nouveau l'acidité du liquide de la fiole, et, au lieu de 0 gr. 328 d'acide, j'en trouve $1 \mathrm{gr}$. 740, c'est-à-dire deux fois plus qu'il n'y en avait dans le liquide à l'origine avant la première combustion.

En résumé, le mycoderma aceti a la propriété de porter l'oxygène de l'air sur l'alcool pour faire de l'acide acétique, et, tant qu'il y a de l'alcool, l'acide acétique n'éprouve pas de combustion complète; mais dès qu'il n'y a plus d'alcool dans le liquide, l'oxygène se fixe sur l'acide acétique et le transforme en eau et en acide carbonique. Replace-t-on de l'alcool dans la liqueur, le phénomène change : l'acide est respecté et l'alcool se transforme à nouveau en acide acétique.

Ces faits méritent au plus haut degré d'attirer l'attention. Ils nous offrent le curieux spectacle de petits organismes qui fixent l'oxygène de l'air, tantôt sur un principe (l'alcool), tantôt sur un autre (l'acide acétique), exclusivement sur le second si le premier est absent, exclusivement sur le premier malgré la présence du second, tant que le premier ne fait pas défaut.

Pourrait-on rencontrer un exemple de combustion plus voisin de la combustion respiratoire, qui s'effectue, elle aussi, par de petits organismes, les globules du sang? Nous voyons également dans ce dernier phénomène tel principe brûlé complétement et ramené à l'état d'eau et d'acide carbonique, tel autre s'arrêter à un degré de combustion intermédiaire, comme il arrive pour l'urée et l'acide urique.

Mais la comparaison peut aller plus loin, et de même que dans

1. On voit par cet exemple que la forme mucilagineuse de la plante se développe assez facilement sur un liquide acétique, même lorsqu'il est privé d'alcool. 
certaines circonstances les globules du sang deviennent malades et que les matériaux de l'économie ne sont plus comburés de la même façon, d'où résultent des produits d'excrétion divers, et par suite des désordres plus ou moins graves, de même nous allons voir nos petits organismes mycodermiques s'altérer dans certains cas si profondément, qu'ils ne pourront même plus porter la combustion de l'alcool jusqu'au terme acide acétique. Quelles importantes et trop souvent dangereuses modifications ne doit pas amener dans l'économie un changement de cet ordre s'appliquant aux globules du sang! Dans bien des maladies, c'est d'eux que doit procéder tout le mal.

$\S$ VII. - Altération spontanée dans la structure du mycoderma aceti. - L'alcool peut disparaître sans qu'il soit transformé préalablement en acide acétique.

On sait que dans l'oxydation de l'alcool ou de l'éther par le noir de platine, ou par le platine en fils maintenus incandescents dans des vapeurs de ces liquides, il prend naissance des produits à odeur suffocante et qui excitent le larmoiement au plus haut degré. Ces produits sont encore mal connus. Chose bien curieuse assurément! le mycoderma aceti peut également les fournir. J'en ai eu de nombreux exemples dans le cours de ces recherches. Ils ont toujours coïncidé avec une altération profonde du voile mycodermique, qui paraissait ne plus prendre de nourriture et perdre beaucoup de sa consistance naturelle. Au lieu de conserver son aspect ordinaire, qui a quelque chose d'un peu translucide, il devenait opaque, blanchâtre, blafard, se détachait des bords du vase et était prêt à tomber dans le liquide par lambeaux. On peut à volonté, pour ainsi dire, provoquer de tels changements dans le voile et dans sa manière d'agir sur l'alcool. D'ordinaire, ces changements se manifestent à la suite d'addition d'alcool au liquide en train de s'acétifier, surtout quand on n'a pas eu le soin de diluer l'alcool avant de l'introduire dans les vases.

Je vais donner un exemple de ces combustions dévoyées et toutes particulières de l'alcool. Reportons-nous à l'expérience de la page 48. Le 7 mars, j'ai introduit dans le liquide de la fiole 1 cc. 6 d'alcool absolu à $15^{\circ}$ délayé dans 40 ou 50 centimètres cubes du liquide en expérience, puis j'ai renouvelé par insufflation d'air nouveau le gaz de la fiole. Cette opération s'est faite à $1 \mathrm{~h} .40$. Voici les hauteurs du mercure dans le tube manométrique, hauteurs qui donnent une mesure de l'absorption de l'oxygène : 


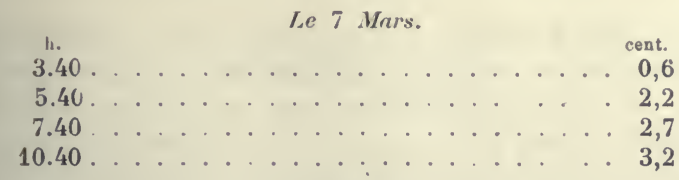

Le 8 Mars.

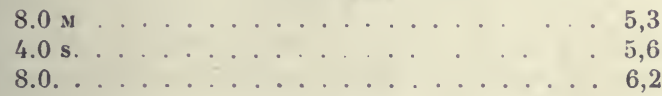

Le 9 Mars.

8.0 м ....................... 7,5

$11.0 \ldots \ldots \ldots \ldots, \ldots \ldots \ldots$

Le 10 Mars.

8.0 м. . . . . . . . . . . . . 8,4

Le 11 Mars.

Midi. . . . . . . . . . . 8,4.

On voit par ces résultats qu'après l'addition de l'alcool et pendant les deux premières heures, l'absorption d'oxygène a été assez rapide, puis elle a diminué en intensité et en vitesse, et a été s'affaiblissant de plus en plus les jours suivants. Pendant tout ce temps, du 7 au 11, le voile n'a paru prendre aucun développement. Le 11, j'ai ouvert la fiole. Le gaz qui y était contenu avait une odeur suffocante provoquant le larmoiement. Quant à la quantité totale d'acide contenue dans le liquide, je l'ai trouvée égale à $2 \mathrm{gr} .46$ au lieu de $2 \mathrm{gr} .2$ qu'elle était auparavant, ainsi qu'on l'a vu page 50. En d'autres termes, la quantité d'acide acétique formée n'était nullement en rapport avec la proportion d'oxygène fixée et accusée par l'ascension de la colonne de mercure. L'oxygène absorbé avait donc été employé à faire tout autre chose que de l'acide acétique, et notamment ces produits aldéhydiques à odeur suffocante.

Le 11 mar's, voulant reconnaître si le voile était mort et sans action possible sur l'oxygène et l'alcool, j'ai renouvelé l'air de la fiole, et j'ai rajouté sous le voile 100 centimètres cubes d'eau de levûre tenant en dissolution 3 centimètres cubes d'alcool à $90^{\circ}$. Aucune combustion quelconque ne s'est manifestée. Examiné su microscope, le voile était formé par les chapelets d'articles du mycoderma aceti, mais les articles paraissaient altérés, fanés, et çà et là on voyait des espèces de globules graisseux que j'ai retrouvés souvent dans des cas analogues.

L'addition au liquide alcoolique en voie d'acétification de substances diverses autres que l'alcool a souvent amené dans le mycoderma aceti le genre d'altération dont je parle; par exemple, lorsque j'ai ajouté à 
la liqueur de petites quantités d'esprit de bois. Le voile meurt, et les produits suffocants se montrent pendant les quelques jours où la plante, avant de périr complétement, est en quelque sorte malade.

Les expressions dont je me sers en ce moment pour caractériser l'état du voile mycodermique ne signifient pas du tout que je lui attribue une action physiologique. Je crois que sa fonction de transport de l'oxygène de l'air sur l'alcool, l'acide acétique, etc., tient à sa structure propre, et que c'est cette structure qui peut être modifiée par telle ou telle circonstance particulière et exceptionnelle.

$\S$ VIII. - Le mycoderma aceti submergé n'acétifie pas, alors même qu'il continue de viore et de se multiplier.

Nous avons reconnu qu'il était facile de suivre le progrès de l'acétification en disposant les expériences en vases clos de manière à pouvoir évaluer à chaque instant l'absorption de l'oxygène par la diminution de pression de l'air renfermé dans les vases.

Considérons dès lors un essai pareil à celui de la page 48. Le voile est formé, il fixe l'oxygène, et le mercure s'élève progressivement à vue d'œil dans le tube manométrique. Que l'on agite alors légèrement la fiole pour détacher le voile et le submerger : l'acétification accusée par l'ascension du mercure s'arrêtera sur-le-champ, et si le voile se reforme les jours suivants, ce qui arrivera à peu près inévitablement, l'acétification reprendra dès que la plante commencera à recouvrir la surface du liquide.

Deux circonstances sont réunies ici pour empêcher la continuation d'action de la plante dans les conditions précédentes. Sa structure physique change puisqu'elle est tout à coup recouverte par le liquide. En outre, elle n'a plus à son service que la très faible proportion d'oxygène qui est en dissolution dans le liquide. Il est mème très probable que cette faible proportion d'oxygène est exclusivement employée pour le développement ultérieur du mycoderme qui continue de vivre, quoique submergé, ainsi que j'ai déjà eu l'occasion de le dire en traitant de l'état muqueux du mycoderma aceti.

Je choisirai parmi les expériences que j'ai faites à ce sujet un exemple propre à montrer tout à la fois, et la possibilité du développement de la plante dans l'intérieur des liquides, et l'absence d'acétification dans ces conditions. Cet exemple prouvera également que le mycoderme détermine l'acétification, bien qu'à l'état muqueux, pourvu qu'il soit à la surface du liquide en contact avec l'air atmosphérique.

Le 15 mars 1862, je place dans une chambre-étuve, à la température 
de $22^{\prime}$ à $25^{\circ}$, une cuve de gutta-percha couverte d'une lame de verre, renfermant 2 litres d'un liquide composé de:

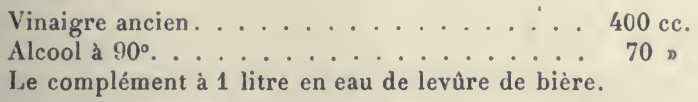

Cette eau de levûre renfermait $\frac{3}{1000}$ de son poids de matières solides empruntées à la levûre. Les 400 centimètres cubes de vinaigre renfermaient de nombreux articles de mycoderma aceti destinés à servir de semence.

Le 17, à midi, pas de voile, pas d'acétification. Le titre acide du liquide est le même qu'à l'origine, 1 gr. 09 pour 100 d'acide.

Le 18, le fond de la cuve est couvert d'un voile muqueux formant une sorte de peau continue quoique encore très peu épaisse. En passant sur le fond de la cuve une baguette de verre ou mieux de bois un peu rugueux, on soulève cette membrane. Il n'y a pas du tout de voile à la surface du liquide, mais çà et là cependant on aperçoit des gouttes translucides que l'on peut retirer sous la forme de larmes gélatineuses. Je mesure l'acidité du liquide. Elle est de 1,11 acide acétique pour 100.

Le 19, même état de développement de la plante dans l'intérieur du liquide et des noyaux muqueux de la surface. Titre acide, 1,25 pour 100.

Le 20, les taches muqueuses de la surface, plus nombreuses, se tiennent partout les unes aux autres sous forme d'une peau gélatineuse très translucide, encore peu consistante. Titre acide, 1,59 pour 100.

Le 21, commencement de voile ordinaire à la surface qui s'agrandit peu à peu le 21 et le 22. Le 22, le titre acide est de 4,4 pour 100 . L'acétification est terminée.

Cet exemple nous montre que l'acétification est, pour ainsi dire, nulle tant que la plante est submergée, bien qu'elle puisse être alors en voie de rapide développement. Il nous montre également qu'il y a acétification par la plante à l'état muqueux, mais bien moins active que dans le cas d'un voile superficiel, de consistance membraneuse un peu sèche, ou mieux légèrement humide et grasse en apparence; car c'est ce dernier état physique de la plante qui paraît le mieux convenir à une acétification rapide et avec le moins de perte possible. Dans l'exemple qui précède, la perte a été nulle en quelque sorte.

Il est facile de prévoir, d'après ce que je viens de rapporter, que la plante submergée et morte ne peut provoquer la moindre acétification. J'ai conservé bien longtemps au contact de l'air du mycoderma aceti en membranes gélatineuses dans des liquides alcooliques à faible 
titre, sans qu'il y eût fixation du gaz oxygène. Souvent, il est vrai, lorsque l'on suit longtemps de pareils essais, l'acétification se déclare. mais on peut être assuré de trouver alors à la surface du liquide un voile plus ou moins étendu, formé aux dépens de principes solubles fournis par la plante, qui peu à peu se seront répandus dans le liquide et en auront fait une solution appropriée au développement spontané du mycoderme. Il n'est même pas rare de voir dans ces circonstances le mycoderma vini se former de préférence.

Et si l'on a fait dissoudre du sucre dans la liqueur, ce sucre pourra fermenter lactiquement ou alcooliquement, sans doute parce que les ferments propres de ces nouvelles fermentations auront pu prendre naissance spontanément, à l'aide des principes de la mère du vinaigre leur servant d'aliments. On retombe alors dans ces modes d'expérience pratiqués autrefois par M. Colin, et plus récemment par d'autres chimistes, dans lesquels les fermentations sont déterminées par les matières azotées les plus diverses, sans que celles-ci agissent par elles-mêmes, mais seulement à titre d'aliments des véritables ferments.

\section{§ IX. - Le Mycoderma aceti envisagé comme parasite $d u$ mycoderma vini.}

Les principes solubles et insolubles du mycoderma vini peuvent devenir un aliment pour le mycoderma aceti dans certaines circonstances faciles à reproduire et qui me paraissent dignes d'intérêt au point de vue physiologique.

Je suppose que l'on fasse développer le mycoderma vini à la surface de vin pur ou étendu d'eau, de bière, etc., et que l'on enlève le liquide après le développement du voile mycodermique pour le remplacer par de l'eau distillée additionnée de quelques centièmes d'alcool pur. Cette manipulation peut s'effectuer facilement sans déchirer le voile de la plante. Dès que la substitution du nouveau liquide à l'ancien a eu lieu, l'acétification se manifeste et va croissant avec le temps.

Cette expérience est fort curieuse, mais il faut savoir en apprécier toutes les conditions pour ne pas l'interpréter d'une façon erronée.

J'ai reconnu que le mycoderma vini a la propriété de fixer l'oxygène de l'air sur l'alcool, sur l'acide acétique, sur les matières hydrocarbonées, les acides organiques, etc., à la manière du mycoderma aceti. Mais lorsqu'il provoque l'oxydation de l'alcool, il opère une véritable combustion de tous ses principes, c'est-à-dire que l'alcool se transforme en eau et en acide carbonique.

11 agit de même sur l'acide acétique. La combustion est complète. 
Dans l'expérience dont je viens de parler, avant de retirer de dessous le voile de mycoderma vini le liquide sous-jacent, l'alcool dissous se transformait donc en eau et en acide carbonique, et également l'acide acétique si le liquide en contenait.

D'autre part, lorsque le mycoderma aceti se trouve mêlé au mycoderma vini, tous deux agissent pour leur propre compte et comme s'ils etaient isolés. Le premier transforme l'alcool en acide acétique, ou brûle l'acide acétique s'il n'y a pas d'alcool, et le second brûle complétement soit l'alcool, soit l'acide acétique.

On peut donc obtenir les résultats les plus divers et souvent en apparence contradictoires. Si le mycoderma aceti est en faible proportion, l'effet du mycoderma vini sera prédominant, et l'acidité de la liqueur pourra diminuer, bien qu'il se forme constamment de nouvel acide acétique. Si le mycoderma aceti l'emporte, l'acidité du liquide s'accroîtra malgré la combustion partielle de l'acide acétique. Enfin les deux mycodermes peuvent se faire équilibre, et l'acidité dans ce cas peut ne pas changer de titre, le mycoderma vini brûlant une proportion d'acide équivalente à celle que forme le mycoderma aceti au fur et à mesure de son développement.

Ceci posé, revenons à l'expérience que j'indiquais tout à l'heure. Sur du vin, de la bière, etc., on a fait développer dans une cuve large et peu profonde le mycoderma vini en couche continue. A ce moment, d'après les faits que je viens de rappeler, l'alcool dissous se transforme en eau et en acide carbonique, et si le liquide contient en outre de l'acide acétique, il est également brûlé, de telle sorte que l'acidité de la liqueur diminue progressivement et de jour en jour. Enlevons alors le liquide à l'aide d'un siphon sans disloquer le voile, puis rajoutons de l'alcool à faible titre, sans mélange de matières azotées ni de phosphates (1). L'acétification de l'alcool, ai-je dit, se déclare aussitôt, et l'acidité de la liqueur augmente progressivement. Que se passe-t-il donc, et pourquoi cette inversion et cette opposition dans les phénomènes avant et après l'échange des liquides?

J'ai cru longtemps que, dans tous les cas, le mycoderma vini, privé d'aliments et se trouvant soumis à des conditions qui altéraient sa structure, ne pouvait plus porter la combustion de l'alcool qu'au terme acide acétique et vapeur d'eau, et non jusqu'à celui d'acide carbonique

1. Avant d'introduire l'alcool dilué sous le voile, rien n'est plus facile, si on le désire, de laver celui-ci par de l'eau pure et même à diverses reprises. Malgré ces lavages, il est toujours un peu acide. La plante sécrète des liquides á réaction acide tant que sa vie n'est pas totalernent éteinte. C'est déjả un caractère propre à la levưre de bière, qui présente de nombreuses analogies avec le mycoderma vini. 
et de vapeur d'eau qui lui est habituel. Mais ce n'est là au contraire qui l'accident et l'exception. Le plus souvent l'acétification n'est encor que l'effet du mycoderma aceti. Comment cela peut-il avoir lieu puisque j’ai supposé que le voile mycodermique était formé par l mycoderma vini?

Dans les conditions particulières dont je viens de parler, le myco derma aceti, dont il est très rare de ne pas rencontrer au moin quelques articles dans un voile quelconque de mycoderma vini, se multiplie aux dépens de ce dernier, qui lui sert de nourriture, avec une facilité extraordinaire; de là l'acétification de l'alcool. Observe-t-on au microscope le voile de mycoderma vini au moment de la mise en train de l'expérience, on le trouvera composé, je suppose, presque exclusivement d'articles de mycoderma vini. Il faudra, par exemple, chercher dans plusieurs champs de la goutte placée sur le porte-objet, pour rencontrer un ou deux articles de mycoderma aceti. Que l'on renouvelle cette épreuve le lendemain du jour où le premier liquide a été remplacé par de l'alcool pur étendu d'eau, et déjà partout se montreront un grand nombre d'articles de mycoderma aceti. Les jours suivants, rien qu'à' la vue simple, on pourra constater la disparition graduelle du voile primitivement épais et ridé du mycoderma vini, faisant place peu à peu au voile mince, léger, et de poids total beaucoup moindre, de mycoderma aceti, parce qu'il y a simultanément combustion de divers principes du mycoderma vini. La résorption des articles de ce mycoderme engendre en même temps des substances solubles plus lentes à être comburées et que l'on retrouve libres dans la liqueur. On y rencontre, par exemple, des matières qui réduisent avec la plus grande facilité, même à la température ordinaire, la liqueur de Fehling.

Il est vraiment très curieux d'assister à cette transformation et à cette nutrition d'un mycoderme par un autre, et cette circonstance me paraît mériter toute l'attention des physiologistes. Il y a là, à mon sens, l'image de la résorption d'un tissu par la production d'un autre, auquel le premier sert d'aliment, et mieux encore peut-être l'image de. la formation du pus et de ses globules à l'aide des matériaux du sang ou les principes des tissus voisins.

Quoi qu'il en soit, et c'est là principalement le fait sur lequel je désire appeler en ce moment l'attention du lecteur, dès que, par une circonstance quelconque, le mycoderma vini, si fréquent à la surface des liquides fermentés lorsqu'ils sont exposés au contact de l'air, vient à perdre sa vitalité propre, que des aliments appropriés lui font défaut par exemple, le mycoderma aceti l'envahit à la façon d'un parasite, vit 
fur lui et à còté de lui, en assimilant ses principes et en en comburant ine partie par l'effet de cette même faculté qui fait de ce mycoderme un agent de combustion partielle ou totale de l'alcool et de l'acide icétique.

\section{$\S \mathrm{X}$. - Des anguillules du vinaigre. Comment elles nuisent $\grave{a}$ l'acétification.}

Lorsque je visitai les vinaigreries d'Orléans, afin d'y contrỏler les résultats de mes expériences, les fabricants avec lesquels j'eus l'occasion de m'entretenir de leur industrie étaient persuadés que les anguillules que l'on trouve dans le vinaigre d'Orléans lorsqu'il n'a pas été convenablement filtré, et qui pullulent dans tous les tonneaux des celliers, sont nécessaires à la fabrication et à la bonne marche des phénomènes. C'est, comme je vais l'expliquer, une erreur grave, fort préjudiciable à l'industrie orléanaise et qu'il importe de faire disparaître (1). J'ai la persuasion que le travail des mères (tonneaux) dans le procédé d'Orléans est souvent entravé par la présence de ces animaux, dont le nombre, dans chaque tonneau d'une vinaigrerie par le procédé d'Orléans, est extraordinaire. Une partie des maladies auxquelles les mères sont sujettes, et qui entraînent de grandes pertes pour le fabricant, sont dues à ces animalcules.

Je vais essayer de faire comprendre leur influence nuisible en m'appuyant sur les principes que j'ai établis dans ce Mémoire.

Les anguillules ont besoin de gaz oxygène pour vivre. Les faits les plus vulgaires, tels que celui de la mort assez prompte des anguillules dans les flacons bouchés et remplis de vinaigre, me permettraient de le démontrer. Or, nous savons que l'acétification ne se produit qu'à la surface du liquide, dans un voile mince et frêle de mycoderma aceti qui se renouvelle sans cesse par parties à la suite de chaque addition de nouveau vin dans les tonneaux de la fabrique. Si nous supposons ce voile bien formé et en travail d'acétification active, tout l'oxygène qui arrive à la surface du liquide est mis en œuvre par la plante. Celle-ci en prive totalement les anguillules situées au-dessous d'elle et nageant dans les couches supérieures du vinaigre. Les anguillules se sentant alors dans l'impossibilité de respirer, et guidées par un de ces instincts dont les animaux à tous les degrés de l'échelle zoologique nous offrent de si curieux exemples, se réfugient sur les parois du

1. Il est bien entendu, cependant, que je ne préjuge pas ici la question de savoir jusqu'à quel point les anguillules pourraient modifier la saveur du vinaigre par les substanc ss qu'elles excrètent. 
tonneau, tout près du niyeau du liquide, où elles viennent former un couche humide, blanche, épaisse de plus d'un millimètre, haute d plusieurs centimètres, tout animée et grouillante. Là seulement ce petits êtres peuvent respirer. Mais on doit comprendre qu'ils n cèdent pas facilement la place au mycoderme. J'ai assisté maintes fois dans des expériences particulières, à une sorte de lutte qui s'établi entre eux et la plante. A mesure que celle-ci, suivant les lois de sor développement, s'étale peu à peu à la surface, les anguillules réunies au-dessous d'elle, et souvent par paquets, paraissent faire effort pour l'entraîner dans le liquide sous la forme de lambeaux chiffonnés. A cel état elle ne peut plus leur nuire, car nous avons reconnu que la plante submergée n'a plus qu'une action à peine sensible.

Je ne rapporterai que l'une de mes expériences. Les autres sont analogues et toutes faciles à reproduire (1).

Le 21 février 1862, j’ai mêlé, à 4 litres d'un liquide approprié à l'acétification et placé dans une cuve plate de gutta-percha, 100 centimètres cubes de vinaigre provenant d'un tonneau mère d'une vinaigrerie d'Orléans, chargé d'anguillules. Sans entrer ici dans le détail des particularités offertes par cette cuve, sous le rapport de l'acétification, j'arrive aux circonstances qui concernent plus particulièrement les anguillules et leur influence sur la marche de l'acétification. Pendant les mois de mars et d'avril, multiplication extraordinaire des anguillules, dont le nombre pouvait être évalué à quelques centaines de mille. Le 9 avril, j'enlève 2 litres de vinaigre et je rajoute 2 litres de vin. Le 11, pas de voile mycodermique à la surface du liquide. L'ancien est tombé en lambeaux au fond de la cuve. Les anguillules voyagent partout, distribuées dans les couches supérieures du liquide. Le 13, voile naissant de mycoderma aceti sur toute la surface, mais par taches, par lambeaux, avec des intervalles libres. En dessous et dans les portions découvertes, les anguillules voyagent encore et dans toutes les parties de la surface du liquide, au centre comme sur les bords. Mais le 14 au matin, au moment où j'arrive pour constater l'état des choses, tout est changé. Le voile uni et homogène se tient dans ses diverses parties, sans solutions de continuité. En outre, il n'y a plus

1. Lorsque j'ai commencé l'étude du rôle des anguillules dans la fabrication par le procédé d'Orléans, j'ai dû prier un fabricant de cette ville de m'envoyer du vinaigre qui contînt de ces animalcules.

Bien que mon laboratoire fùt rempli depuis plus d'une année de vases renfermant des liquides en voie d'acétification, je n'avais pas encore aperçu une seule anguillule. Cela n'empêchera pas, sans doute, les partisans endurcis de la génération spontanée des organismes inférieurs de penser que ces petits êtres peuvent venir au monde sans parents semblables à eux lorsqu'il y a concours de circonstances favorables. 
une seule anguillule dans le liquide, en aucun de ses points; mais, chose curieuse, les rebords de la cuve, plus haut que le niveau du voile et à partir de ce voile, sont recouverts d'une couche blanche jusque-là absente, et toute composée d'anguillules en mouvement, n'ayant d'autre liquide pour imbiber leurs tissus que celui qui monte de la cuve par capillarité dans l'intervalle de leurs corps sinueux.

Le 14, le 15, le 16, acétification très vive. Les anguillules sont toujours en couche grasse et remuante sur les parois verticales de la cuve. Le 17, nouveau changement. Le voile, qui avait épuisé à peu près son action les jours précédents et acétifié tout l'alcool, est tombé en lambeaux au fond de la cuve, et j'aperçois les anguillules qui, de toutes parts, émigrent dans le liquide. Les $18,19, \ldots, 25$ avril, les anguillules continuent de vivre et de se multiplier dans toutes les parties des couches liquides superficielles. Il n'y en a plus du tout sur les bords de la cuve.

Le 25 avril, je retire 2 litres du vinaigre rempli à profusion d'anguillules, et je rajoute 2 litres de vin, afin d'assister de nouveau à la succession des phénomènes dont je viens de parler.

Le 26, quelques traces de mycoderme apparaissent. Le 27, elles sont plus étendues en surface, et de nouvelles se sont formées. Mais, au-dessous de chacune de ces taches, je vois des paquets d'anguillules qui leur sont comme attachées et comme faisant effort pour entraîner ces portions de voile au fond du liquide. Le 28, même état des choses. Le 29, presque toutes les taches de mycoderma aceti ont disparu. N'est-on pas porté à croire, en présence de ces faits, à une sorte d'instinct chez les anguillules qui les porte à détruire la plante capable de les priver d'oxygène? Je ne voudrais rien exagérer, cependant. Je sais que l'homme est ami du merveilleux et s'y complaît volontiers. Il se pourrait que les efforts des anguillules, d'où résulte la destruction du voile, fussent simplement le résultat des mouvements que les anguillules effectuent naturellement pour se débarrasser des obstacles qui les gênent lorsque, par l'effet de la natation, elles se trouvent enchevêtrées accidentellement dans les replis du mycoderme. Peut-être aussi trouvent-elles dans les principes de la plante des aliments mieux appropriés à leur nutrition. La plante disparaîtrait, parce qu'elle servirait d'aliment aux anguillules. Ce qui est certain, c'est que le voile entraîné au fond du liquide par les mouvements des anguillules s'y présente très souvent sous la forme d'un précipité blanchâtre et pulvérulent, comme si les anguillules avaient séparé la matière glutineuse qui en relie les articles.

Quoi qu'il en soit, nous voyons avec quelle peine un voile de 
mycoderma aceti se multiplie dans certains cas en présence des anguillules. Que ces mêmes faits se réalisent dans un tonneau mère d'une vinaigrerie par le procédé d'Orléans, ce tonneau ne travaillera pas et sera dit malade ou tourné.

Continuons l'examen de notre cuve. Le 30 avril, même état des choses. Le $1^{\text {or }}$ mai, des taches nouvelles sont reformées et occupent une surface totale de 20 centimètres carrés environ. Le 2 mai, pas de développement nouveau des taches qui ont au-dessous d'elles des paquets d'anguillules que l'on dirait toujours occupées à les détruire. Le 3 , le 4 , rien de nouveau. Le 5 , j'aperçois dans un coin de la cuve un voile uni, bien formé, s'étendant sur toute la surface jusqu'au quart environ de la cuve. Or, déjà dans ce coin de la cuve les anguillules ont grimpé en couche épaisse sur les parois des rebords du vase. Peu à peu, les jours suivants, le voile continue de grandir, en chassant devant lui en quelque sorte les anguillules, qui se retirent peu à peu du liquide sans qu'il en reste trace dans le vinaigre de la cuve. Cette fois la plante a de nouveau pris le dessus et vaincu l'animalcule.

En résumé, et si l'on considère les phénomènes dans leur cause prochaine, lorsque le mycoderma aceti vient à se développer en couche continue à la surface d'un vinaigre rempli d'anguillules, celles-ci, se sentant privées de gaz oxygène sans lequel leur vie est impossible, émigrent et se réfugient sur les parois des bords de la cuve ou du tonneau. La plante met alors en œuvre à son profit tout l'oxygène qui arrive au contact de la surface du liquide. Sans doute ces anguillules sont très mal à l'aise sur ces parois du vase, hors du liquide, car si elles y trouvent l'oxygène indispensable à leur existence, elles n'y ont plus qu'en quantité beaucoup trop restreinte pour leur nombre les autres aliments que leur offre le liquide. Aussi, dès que la fixation de l'oxygène par la plante se ralentit ou s'épuise, elles rentrent dans le liquide en faisant tomber au fond la plante qui les gêne toujours en quelque chose, car nous savons qu'elle fixe l'oxygène sur l'acide acétique lorsqu'il n'y a plus d'alcool, très lentement il est vrai, si le vinaigre est fort.

Je n'ai pas besoin d'ajouter que tous les faits qui précèdent ou d'autres du même ordre se passent sans cesse dans les tonneaux des vinaigreries d'Orléans. Je l'ai vérifié jusque dans les plus minutieux détails.

Ces particularités curieuses de la fabrication de l'acide acétique par le procédé d'Orléans m'ont donné l'explication d'une pratique qu'emploient journellement les vinaigriers, afin de s'assurer de la marche des mères. Ils introduisent les doigts dans le tonneau par le 
trou d'air et tâtent avec l'index la paroi verticale du fond. S'ils sentent une humidité grasse, ils disent que le tonneau travaille bien. Ce quelque chose d'humide et de gras n'est autre chose que la couche d'anguillules réfugiées sur les parois du tonneau. C'est là en eflet un indice que la surface invisible du liquide doit être recouverte de mycolerma aceti en bonne voie de fixation de l'oxygène de l'air.

La condensation de vapeur d'eau sur les parois du tonneau non mouillées par le liquide est également un indice de travail régulier, parce qu'elle accuse une élévation de température des couches de niveau du vinaigre, et conséquemment un bon fonctionnement du voile mycodermique.

Dans tous les cas, on ne peut douter que la plante a constamment auprès d'elle, par la présence des anguillules, un ennemi qu'il faut combattre par tous les moyens possibles. Je sais que, depuis la publication de mes premiers travaux sur ce sujet, les industriels les plus éclairés d'Orléans ont fait revivre une pratique ancienne et tout à fait abandonnée, celle du soufrage des tonneaux de temps à autre. L'acide sulfureux tue les anguillules. Mais il faut prendre garde à l'emploi de ce moyen qui pourrait bien, dans certains cas, altérer la qualité du voile mycodermique.

En choisissant de préférence le moment où toutes les anguillules sont réfugiées sur les parois d'un tonneau, on pourrait les tuer en les privant d'air par la fermeture du trou d'air pendant un temps suffisant. La plante d'une part, les anguillules de l'autre, absorberaient assez. promptement la totalité de l'oxygène demeuré libre dans la partie vide du tonneau, ce qui aurait pour effet de faire périr les anguillules. Cette pratique très simple mériterait d'être essayée. Le voile du mycoderme ne s'altérerait pas sensiblement par la privation d'oxygène durant un certain laps de temps; car nous avons reconnu, pages 60-61 de ce Mémoire, que l'on a pu rajouter de l'alcool sous un voile, et continuer, à son aide, l'acétification, après que le vase eut été une première fois totalement privé d'oxygène.

$\S \mathrm{XI}$. - Application des résultats des paragraphes précédents(1).

Les faits d'observation que j’ai exposés dans le travail qui précède mont conduit à un nouveau procédé industriel de fabrication du

1. Ce paragraphe résume une Communication que j'ai faite à l'Académie des sciences en 1862 [Voir p. 13-20 du présent volume]. (Note de Pasteur.)

Ce paragraphe ne figure pas dans le texte des Annales scientifiques de l'École Normale supérieure. (Note de l'Édition.) 
vinaigre que j'ai communiqué à l'Académie des sciences en $1862{ }^{(1)}$.

Je sème le mycoderma aceti, ou fleur du vinaigre, à la surface d'un liquide formé d'eau ordinaire contenant 2 pour 100 de son volume d'alcool et 1 pour 100 d'acide acétique provenant d'une opération précédente, et en outre quelques dix-millièmes de phosphates alcalins et terreux, au nombre desquels doit se trouver le phosphate d'ammoniaque. Bien que ces seuls ingrédients puissent servir au développement du mycoderme, il vaut mieux lui fournir, comme je le dirai tout à l'heure, des liquides naturels qui renferment ces phosphates et qui contiennent en outre l'azote nécessaire à la vie du mycoderme sous la forme de matières azotées organiques albuminoïdes. La petite plante se développe et recouvre bientôt la surface du liquide sans qu'il y ait la moindre place vide. En même temps l'alcool s'acétifie. Dès que l'opération est bien en train, que la moitié, par exemple, de la quantité totale d'alcool employée à l'origine est transformée en acide acétique, on ajoute chaque jour de l'alcool par petites portions, ou mieux encore du vin ou de la bière alcoolisés, jusqu'à ce que le liquide ait reçu assez d'alcool pour que le vinaigre marque le titre commercial désiré. Tant que la plante peut provoquer l'acétification, on ajoute de l'alcool.

Lorsque son action commence à s'user, on laisse s'achever l'acétification de l'alcool qui reste encore dans le liquide. On soutire alors ce dernier, puis on met à part la plante qui par lavage peut donner un liquide un peu acide et azoté capable de servir ultérieurement.

La cuve est alors mise de nouveau en travail.

Il est indispensable de ne pas laisser la plante manquer d'alcool, parce que sa faculté de transport de l'oxygène s'appliquerait alors, d'une part à l'acide acétique qui se transformerait en eau et en acide carbonique, de l'autre à des principes volatils, mal déterminés, dont la soustraction rend le vinaigre fade et privé d'arome. En outre, la plante détournée de son habitude d'acétification n'y revient qu'avec une énergie beaucoup diminuée. Une autre précaution, non moins nécessaire, consiste à ne pas provoquer un trop grand développement de la plante; car son activité s'exalterait outre mesure, et l'acide acétique serait transformé partiellement en eau et en acide carbonique, lors même qu'il y aurait encore de l'alcool en dissolution dans le liquide.

Une cuve de 1 mètre carré de surface, renfermant 50 à 100 litres de liquide, fournit par jour l'équivalent de 5 à 6 litres de vinaigre. Un thermomètre donnant les dixièmes de degré, dont le réservoir plonge dans le liquide et dont la tige sort de la cuve par un trou pratiqué 
au couvercle, permet de suivre arec facilité la marche de l'opération.

Je pense que les meilleurs vases à employer sont des cuves de bois rondes ou carrées, peu profondes, analogues à celles qu'on emploie dans les brasseries pour refroidir la bière et munies de couvercles. Aux extrémités sont deux ouvertures de petites dimensions pour l'arrivée de l'air. Deux tubes de gutta-percha, fixés sur le fond de la cuve et percés latéralement de petits trous, servent à l'addition des liquides alcooliques sans qu'il soit nécessaire de soulever les planches du couvercle ou de déranger le voile de la surface.

Les plus grandes cuves que la place dont je disposais m'ait permis d'utiliser avaient 1 mètre carré de surface et 20 centimètres de profondeur. J'ajoute que les avantages du procédé ont été d'autant plus sensibles que j'ai employé des vases de plus grandes dimensions et que j'ai opéré à une plus basse température.

J'ai dit que le liquide à la surface duquel je sème le mycoderme devait tenir des phosphates en dissolution. Ils sont indispensables. Ce sont les aliments minéraux de la plante. Bien plus, si au nombre de ces phosphates se trouve celui d'ammoniaque, la plante emprunte à la base de ce sel tout l'azote dont elle a besoin; de telle sorte que l'on peut provoquer l'acétification complète d'un liquide alcoolique renfermant environ un dix-millième de chacun des sels suivants : phosphates d'ammoniaque, de potasse, de magnésie, ces derniers étant dissous à la faveur d'une petite quantité d'acide acétique, lequel fournit en même temps que l'alcool tout le carbone nécessaire à la plante.

Cependant, afin d'avoir un développement plus rapide et un état physique plus actif du mycoderme, il est bon d'ajouter au liquide à phosphates une petite quantité de matières albuminoïdes qui offrent l'azote et le carbone, et sans doute aussi une partie des phosphates sous une forme plus assinilable. J'emploie à cet effet soit de l'eau d'orge, soit de la bière, soit de l'eau de levûre, ou encore de l'eau de macération des radicelles d'orge germée... Le vin, le cidre, tous les liquides fermentés et même la plupart des jus naturels pourraient être utilisés. Mais afin que l'on comprenne bien le rôle de ces liquides organiques albumineux, et combien sont erronées les idées qui avaient cours dans la science sur la prétendue transformation en ferments des matières albuminoïdes par l'altération de ces dernières au contact de l'air, je répète que l'on peut facilement faire développer le mycoderma aceti et dans des conditions où il est capable d'acétifier de grandes quantités d'alcool, en lui fournissant uniquement, pour aliment azoté, de l'ammoniaque; pour aliment carboné, de l'acide acétique et de 
l'alcool; pour aliments minéraux, de l'acide phosphorique, uni aux principales bases alcalines et terreuses.

S’il s'agit de faire du vinaigre avec du vin, de la bière, des moûts de grains fermentés, il est inutile d'ajouter des phosphates. Ces liquides en contiennent naturellement dans des proportions et sous une forme mieux appropriées au développement du mycoderme qu'on ne peut les rencontrer dans un mélange artificiel. Veut-on transformer, par exemple, le vin en vinaigre, il suffira de le mêler à du vinaigre d'une opération précédente, de semer ensuite du mycoderme à la surface du mélange, en prélevant ce mycoderme sur une cuve en marche depuis quarante-huit heures ou dans une petite terrine où il aura été préparé directement à cet usage (1).

A la température de $15^{\circ}$, si la semence est bonne, il faut deux à trois jours au maximum pour que le mycoderme recouvre le liquide à la surface duquel il a été semé, quelles que soient les dimensions de la cuve. Par bonne semence, j'entends une plante jeune, en voie de multiplication, qui se présente au microscope sous la forme de longs chapelets d'articles et non d'amas de granulations, comme cela a lieu quand elle est un peu ancienne et qu'elle a déjà servi pendant plusieurs jours d'agent de combustion. Pour ce qui est de la quantité de la semence, un petit vase de 1 décimètre de diamètre, renfermant 100 centimètres cubes de liquide et recouvert de la plante, suffit pour ensemencer une cuve de 1 mètre carré de surface. On trempe dans ce vase l'extrémité d'une baguette de verre. Le voile du mycoderme s'y attache en partie, et lorsqu'on porte ensuite la baguette dans le liquide de la cuve, il s'en détache et reste à la surface du liquide à ensemencer. On répète cette manipulation tant qu'il y a une portion de voile à la surface du petit vase.

Dans une fabrique en travail, il y aurait toujours de la semence toute prête. Si l'on n'en a pas, il suffit d'abandonner au contact de l'air un liquide alcoolique et acétique de la nature de ceux dont j'ai parlë, pour y voir apparaître le mycoderme dont il s'agit.

Le procédé d'acétification dont je viens de parler offre divers avantages. L'opération se fait dans des cuves couvertes, à une température relativement basse. On dirige à son gré la fabrication. On est à l'abri

1. Dans la fabrique de MM. Breton-Lorion [voir p. 93], ces Messieurs opèrent par discontinuité, c'est-à-dire qu'après l'acétification d'une cuve, celle-ci est lavée et mise en train de nouveau. Ils ne rajoutent pas de vin pendant l'acétification des cuves. Cela m'a paru très préférable pour l'économie de la main-d'œuvre. Peut-être vaudrait-il mieux agir ainsi, même dans le cas où l'on voudrait monter une fabrique de vinaigre d'alcool, parce qu'il y a toujours à craindre, quand on rajoute du vin et surtout de l'alcool, une altération du voile, si l'on ne prend pas les précantions que j'ai indiquées. 
des inconvénients de la présence des anguillules. Les pertes sont beaucoup moindres que par le procédé des copeaux. Enfin l'acétification, disais-je à l'Académie des sciences en $1862\left({ }^{1}\right)$, est trois à quatre fois plus rapide que par le procédé d'Orléans, toutes choses égales d'ailleurs.

Aujourd'hui, d'après la communication qui m'a été faite par MM. Breton-Lorion, je puis assurer qu'elle est cinq fois plus rapide. Ce chiffre est éprouvé d'ailleurs, ainsi que je l'ai indiqué dans ma Conférence du 11 novembre (2), sur une fabrication de 12 à 15 hectolitres de vinaigre par jour.

1. Toir p. 13-20 du présent volume.

2. Il s'agit ici de la "Leçon sur le vinaigre de vin ", qui suit. (Notes de l'Édition.) 


\title{
LEÇON SUR LE VINAIGRE DE VIN \\ PROFESSÉE A ORLÉANS LE 11 NOVEMBRE 1867 (1)
}

\author{
PREMIÈRE PARTIE
}

Messieurs,

\section{M. le Maire d'Orléans et M. le Président de la Chambre de conı-} merce ayant appris que je m'étais occupé de la fermentation qui donne le vinaigre m'ont prié de vouloir bien venir exposer devant les fabricants de vinaigre de cette ville les résultats de mon travail.

1. Cette Leçon, suivie du Mémoire précédent sur la fermentation acétique, a été publiée par Pasteur sous forme d'opuscule intitulé : « Études sur le vinaigre, sa fabrication, ses maladies, moyens de les prévenir; nouvelles observations sur la conservation des vins par la chaleur. " Paris, 1868, Gauthier-Villars et Victor Masson et fils, vm-119 p. in-8 (avec 7 fig.). Cet opuscule était précédé de l'avertissement qui suit :

“ J'ai publiẻ en 1864, dans les Annales scientifiques de l'École Normale supérieure, un Mémoire sur la fermentation acétique, auquel on doit la connaissance exacte des principes de la fabrication des vinaigres de vin et d'alcool par les procédés connus sous les noms de procédé d'Orléans et de procédé allemand.

“ A diverses reprises, j'ai été sollicité de donner à ces études un genre de publicité qui les rendît accessibles à tous les négociants occupés de l'industrie des vinaigres. J'ai pu me convaincre récemment que les regrets touchant la publicité trop restreinte de mon travail étaient partagés par beaucoup de personnes; car j'ai été prié par M. le Maire et par M. le Président de la Chambre de commerce d'Orléans de vouloir bien exposer publiquement les résultats de mes recherches aux fabricants de cette ville, où l'industrie du vinaigre de vin est séculaire et jouit d'une réputation méritée. Je me suis empressé d'accepter cette invitation.

" Les circonstances que je viens de rappeler m'ont engagé á réunir dans une brochure mon Mémoire de 1864 et la Conférence que j'ai faite à Orléans, dans laquelle j'ai résumé sous une forme élémentaire les observations les plus importantes relatives à la fabrication du vinaigre de vin et l'indication des perfectionnements et des procédés nouveaux dont elle est susceptible.

" A propos de la conservation du vinaigre, je reviens sur les principes de la conservation des vins exposés dans mes Etudes sur le vin (*), et dont l'application par l'industrie prend chaque jour plus d'importance. Des appareils nouveaux fonctionnant sur une grande échelle se répandent de plus en plus, et le commerce acquiert la conviction que les vins les plus altérables possèdent après l'opération du chauffage préalable des propriétés de conservation inconnues autrefois, mème pour les meilleurs vins.

" Des vins qu'il fallait consommer sur place dans l'intervalle de la première année de leur

* Voir la seconde partie du présent volume. 
Je me suis rendu avec empressement à cette invitation en m'associant au désir qui l'a provoquée, celui d'ètre utile à une industrie qui est une des sources de la fortune de votre cité et de votre département.

Le fait fondamental sur lequel repose toute la fabrication du vinaigre de vin, le seul qui mérite le nom de vinaigre et dont je veuille vous entretenir ce soir, est connu dès la plus haute antiquité. Dans un pays vinicole, il n'est personne qui n'ait fait la remarque que le vin abandonné à lui-même dans des circonstances ordinaires, naturellement propres au maniement de cette boisson, se transforme fréquemment en vinaigre. Tel est le fait vulgaire que je me propose d'étudier scientifiquement dans cette conférence. Je chercherai ensuite à déduire, des connaissances que nous aurons acquises, les moyens d'améliorer '’'industrie du vinaigre de vin, industrie qui est née de l'observation de ce fait.

production peuvent se transporter aujourd'hui jusque dans les pays les plus éloignẻs du globe, naturels, avec toutes leurs qualitès hygiéniques, sans addition préalable d'alcool.

“ Des vins commençant à tourner ou à s'aigrir s'améliorent sur-le-champ par l'opération du chauffage et sont préservés de toute atteinte ultérieure de maladie quelconque.

"On avait craint que, pour les vins communs, le prix du chauffage fût trop élevé aujourd'hui il existe des appareils qui n'exigent pas une dépense de plus de 10 centimes par hectolitre, et qui peuvent chauffer jusqu'à 10 hectolitres à l'heure.

" Je puis donc assurer que le problème de la conservation des vins, qui a préoccupé les plus savants œenologues dans l'antiquité et de nos jours, est résolu aujourd'hui, aussi bien pratiquement que théoriquement. "

Pasteur présenta cet opuscule à l'Académie des sciences, dans la séance du 17 février 1868 (Comptes rendus de l'Académie des sciences, LXVI, p. 297-298) : "J'ai l'honneur, dit-il, de faire hommage à l'Acadẻmie d'une brochure que je publie sous ce titre : Etudes sur le vinaigre, sa fabrication, ses maladies, moyens de les prévenir; nouvelles observations sur la conservation des vins par la chaleur.

« Jai fait connaître antérieurement tous les principes scientifiques contenus dans cette brochure. La seule chose, en conséquence, qui puisse intéresser l'Académie dans l'opuscule dont j'ai l'honneur de lui faire hommage, consiste dans la mention de l'application qui a été faite sur une assez grande échelle des procédés industriels que j'ai dẻduits de ces principes.

"Le chauffage des vins, particulièrement des vins communs, qui, on le comprend, ont dì être éprouvés en premier lieu par l'industrie, a offert des avantages qui ont mème dépassé mes espérances. Quant au vinaigre, il existe à Orléans une fabrique établie d'après les indications de mes recherches, produisant en moyenne 15 hectolitres de vinaigre par jour et dont le travail est cinq fois plus rapide que par les anciennes pratiques, toutes choses égales. Cé chiffre m'a étẻ communiqué par MM. Breton-Lorion fréres, qui ont monté avec beauconp d'intelligence la fabrique dont je parle. "(Note de l'Édition.) 
Voici du vin qui s'est transformé en vinaigre après avoir été abandonné à lui-même durant quelques semaines.

Quelles sont les conditions qui ont déterminé cette transformation? Assurément il en est de particulières, car il ne faudrait pas croire que du vin abandonné à lui-même devienne toujours du vinaigre. Je couche horizontalement cette bouteille bouchée et pleine de vin. Quelle que soit la nature du vin, à quelque température qu'il soit exposé, dans aucune circonstance il ne se transformera en vinaigre. Tout au plus pourrait-il prendre une acidité faible, nullement comparable en intensité à celle du vinaigre, et dont la cause n'aurait d'ailleurs rien de commun avec celle de la transformation du vin en vinaigre.

\section{V}

C'est qu'une condition indispensable de transformation du vin en vinaigre réside dans la présence de l'air.

Lorsque du vin s'aigrit en bouteilles, soyez assurés que les bouteilles sont debout et plus ou moins en vidange, c'est-à-dire qu'il y a de l'air dans la bouteille, ne fût-ce que dans l'intervalle d'un traver's de doigt entre le bouchon et le niveau du liquide.

Comment cet air intervient-il dans l'acte chimique de la transformation du vin en vinaigre?

Je serai ,mieux compris dans ma réponse à cette question si je commence par vous donner une idée de la différence de nature du vin et du vinaigre.

Voici deux appareils distillatoires semblables. Dans l'un nous chauffons du vin, dans l'autre du vinaigre qui a été produit avec le vin du premier appareil. De part et d'autre, vous le voyez, nous avons recueilli dans le vase condenseur un liquide limpide et incolore, mais ces deux liquides ont des propriétés essentiellement différentes. Je chauffe dans cette soucoupe une portion de celui que le vin a fourni, et, dès que vous verrez apparaître des vapeurs, elles s'enflammeront au contact de la flamme de la lampe que je tiens à la main. Rien de pareil ne se manifestera dans cette autre soucoupe où je chauffe 
par comparaison le liquide provenant de la distillation du vinaigre.

Les anciens chimistes appelaient esprit toute matière volatile que I'on peut recueillir par la distillation : c'était la quintessence des choses. L'esprit-de-vin, qu'ils appelaient encore esprit ardent à cause de la propriété que possèdent ses vapeurs de s'enflammer au contact de l'air et d'un corps en combustion, porte le nom d'alcool lorsqu'on l'a débarrassé de toute l'eau à laquelle il est nécessairement mélangé par la distillation. On a donné le nom d'acide acétique à l'esprit du rinaigre quand il est privé d'eau.

L'alcool est toujours liquide. L'acide acétique peut cristalliser facilement quand on abaisse sa température.

L'esprit-de-vin n'altère en rien la couleur bleue de la teinture de tournesol. L'esprit de vinaigre, comme vous le voyez ici, la rougit sur-le-champ.

Lorsque du vin s'est transformé en vinaigre, l'alcool du vin est donc remplacé par une substance d'une nature toute différente, l'acide acétique. J'ajoute d'ailleurs que l'esprit de vinaigre n'est mélangé à aucune partie quelconque d'esprit-de-vin quand le vinaigre est bien achevé.

Telle est la différence essentielle entre un vin et le vinaigre provenant de ce vin : l'alcool a fait place à de l'acide acétique.

\section{I}

Mais la présence de l'air étant nécessaire à la transformation du vin en vinaigre, vous entrevoyez dès lors cette conséquence probable, que c'est l'air qui, en se fixant sur l'alcool du vin, doit changer cette substance en acide acétique.

C'est bien ainsi que les choses se passent; seulement ce ne sont pas tous les principes de l'air qui interviennent et qui se combinent à la fois à l'alcool du vin.

L'air atmosphérique résulte principalement du mélange de deux corps simples gazeux, l'azote et l'oxygène; l'azote y entre pour les $\frac{4}{5}$ du volume total et l'oxygène pour $\frac{1}{5}$ environ. Dans la transformation du vin en vinaigre, l'azote demeure inactif; l'oxygène seul entre en combinaison avec l'alcool. En d'autres termes, la transformation du vin en vinaigre est le résultat d'une oxydation; c'est une combustion sans flamme, une combustion lente, suivant l'expression consacrée.

Je vais mettre sous vos yeux quelques expériences simples et tout à fait démonstratives des assertions qui précèdent. 
Dans ce ballon de verre de 2 litres de capacité j’ai placé du vin dans les conditions propres à l'acétification. Entre autres précautions, j'ai eu soin de laisser un grand volume d'air, c'est-à-dire que le vin n'occupe qu'une petite fraction du volume du ballon. J'ai fermé le ballon à l'aide d'un excellent bouchon, et, pour être mieux assuré de sa fermeture, j'ai renversé le ballon et fait plonger le col et le bouchon dans l'eau. Si ce que j'ai avancé est vrai et que le vin se soit aigri, voici ce qui a dû se passer : l'oxygène de l'air contenu dans le vase s'est fixé sur l'alcool et il ne doit plus y avoir en ce moment dans le ballon que du gaz azote raréfié au lieu d'air ordinaire. En conséquence, si je débouche le ballon dans une cuve pleine d'eau, l'eau de la cuve rentrera brusquement. Je fais l'expérience, et vous voyez, en effet, l'eau se précipiter avec violence. Une mesure assez facile à faire montrerait qu'il en est rentré un volume précisément égal au cinquième du volume primitif de l'air.

Recueillons le gaz qui reste dans le ballon, et il ne me sera pas difficile de vous montrer : $1^{\circ}$ qu'une allumette enflammée s'y éteint comme si on la plongeait dans l'eau; $2^{\circ}$ qu'un oiseau y périt asphyxié sur-le-champ : ce gaz n'est plus que de l'azote.

\section{VII}

Nous sommes édifiés sur la nature chimique de la transformation du vin en vinaigre; c'est bien, comme je l'ai dit, un phénomène d'oxydation. Aussi vous ne serez pas surpris si, comparant les compositions de l'alcool et de l'acide acétique, nous trouvons que l'acide acétique est une substance plus riche en oxygène que l'alcool. Ces comparaisons si difficiles autrefois, qu'il eût été même impossible de faire pour le sujet qui nous occupe il y a soixante ans à peine, sont devenues un jeu par suite des progrès de l'analyse chimique.

Sur 100 parties en poids, l'alcool renferme :

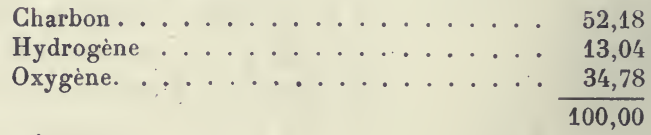

et l'acide acétique :

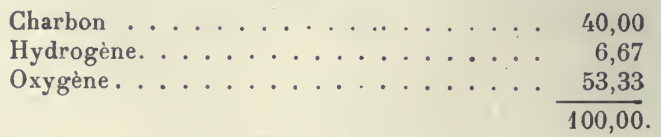


L'acide acétique contient donc plus de 53 pour 100 de son poids d'oxygène, tandis que l'alcool n'en renferme pas 35 pour 100. Neanmoins, l'acide acétique n'est pas le seul produit de l'oxydation de l'alcool; en d'autres termes, on ne saurait représenter l'acide acétique par de l'alcool et de l'oxygène : c'est que la transformation s'accompagne toujours de la production d'une certaine quantité d'eau. La réaction chimique complète peut s'exprimer ainsi :

46 parties en poids d'alcool, unies à 32 parties d'oxygène, forment 60 parties d'acide acétique et 18 parties d'eau.

Il résulte de ces données numériques qu'un vin qui renfermerait à la température de $15^{\circ} \mathrm{C}$. 10 pour 100 de son volume d'alcool, ce qui fait en poids $7 \mathrm{gr} .94$, parce que à $15^{\circ}$ un litre d'alconl pur pèse 794 grammes, fournirait un vinaigre contenant $\frac{60}{46} 7,94=10 \mathrm{gr} .36$ d'acide acétique. 10 pour 100 d'alcool dans le vin, l'évaluation étant faite en volume, correspondent donc à 10,36 pour 100 d'acide acétique en poids : c'est presque le même chiffre. Grâce à cette coïncidence et l'usage ayant prévalu d'évaluer l'alcool en centièmes du volume du vin et l'acide acétique en poids, on peut dire qu'un degré d'alcool doil faire très sensiblement un degré d'acide acétique. Un vin qui renferme $6,7,8, \ldots$ pour 100 d'alcool doit donner un vinaigre à $6.7,8, \ldots$ pour 100 d'acide acétique. A Orléans, la moyenne pour le bon vinaigre est 7 ou 7,5 pour 100 d'acide acétique.

Mais il ne faut pas oublier la convention tacite qui permet d'employer le langage qui précède. Le mot degré, quand il s'applique à la proportion d'alcool contenu dans le vin, n'a pas la même signification que le mot degré employé pour désigner la quantité d'acide acétique que renferme le vinaigre. Pour le vin l'évaluation de l'alcool se fait en volume à l'alcoomètre de Gay-Lussac, et pour le vinaigre l'évaluation de l'acide acétique se fait en poids au moyen d'une liqueur normale acétimétrique.

\section{VIII}

Revenons a l'explication du fait de la transformation du vin en vinaigre. En bornant nos connaissances à ce qui précède, il semblerait que de l'alcool étendu d'eau, exposé à l'air, devrait fournir de l'acide acétique : il n'en est rien cependant. Voici de l'eau pure alcoolisée au degré des vins ordinaires et qui est exposée au contact de l'air dans un vase non fermé; elle y séjournerait des années entières sans qu'il y eût jamais la moindre acétification. 
Quelle peut être la cause de la différence considérable que nous présentent sous ce rapport le vin naturel et l'eau pure alcoolisée? Pourquoi, dans les deux cas, l'oxygène de l'air ne se fixe-t-il pas également bien sur l'alcool? C'est qu'il existe dans le vin, a-t-on dit. quelque chose qui provoque l'union de l'oxygène de l'air avec l'alcool. L'eau alcoolisée est privée au contraire de cet intermédiaire.

Mais quelle est donc la substance qui peut avoir une influence pareille?

\section{IX}

Nous touchons ici à l'un des points les plus curieux de notre sujet, car il s'agit du principe même des fermentations, de cés phénomènes chimiques extraordinaires et mystérieux les plus dignes des méditations du savant aussi bien que de l'homme du monde.

On a donné le nom générique de fermentation à tous ces mouvements intestins qui s'accomplissent d'eux-mêmes après la mort dans tous les êtres organisés et en général dans toute matière qui a fait partie d'un être vivant.

Rappelons quelques-uns de ces phénomènes remarquables : le jus du raisin bouillonne dans la cuve de vendange par le dégagement du gaz acide carbonique, la pâte de farine se soulève et s'aigrit, le lait se caille, le sang se putréfie, la paille rassemblée devient du fumier, les feuilles et les plantes mortes enfouies dans la terre se transforment en terreau... Le caractère commun de toutes ces actions chimiques est la spontanéité. Elles sont l'œuvre du temps et des forces naturelles; la main de l'homme n'y intervient en quoi que ce soit. La raison en est simple: c'est une loi de l'univers que tout ce qui a vécu disparaisse. Il faut de toute nécessité que les matériaux des êtres vivants fassent retour, après leur mort, au sol et à l'atmosphère, sous forme de substances minérales ou gazeuses telles que la vapeur d'eau, le gaz carbonique, le gaz ammoniac, le gaz azote, principes simples et voyageurs que les mouvements de l'atmosphère peuvent transporter d'un pôle à l'autre et chez lesquels la vie peut aller à nouveau puiser les éléments de sa perpétuité indéfinie. C'est principalement par des actes de fermentation et de combustion lente que s'accomplit cette loi naturelle de la dissolution et du retour à l'état gazeux de tout ce qui a vécu.

L'acte chimique qui est le sujet de notre entretien n'est rien autre chose qu'un de ces phénomènes de fermentation et de combustion lente; c'est une des étapes naturelles de la destruction et de la gazéi- 
fication, dans certaines conditions déterminées, de la matière sucrée si abondanment répandue dans les plantes. En effet, le sucre du raisin fermente, et ses principes, sous leur forme nouvelle, composent le vin. Le vin à son tour, livré à lui-même, devient vinaigre; et, vous en serez témoins tout à l'heure, le vinaigre exposé au contact de l'air se transforme en eau et en gaz acide carbonique. A ce terme, l'œuvre de la mort et de la destruction qui la suit est achevée pour la matière sucrée; et ses principes élémentaires, le charbon, l'hydrogène et l'oxygène, ont repris la forme sous laquelle ils sont prêts à rentrer dans un nouveau cercle de vie.

\section{$\mathrm{X}$}

Quelle est donc la cause occasionnelle de tous ces phénomènes naturels de fermentations, de putréfactions et de combustions lentes?

A la fin du siècle dernier, un chiniste italien nommé Fabroni émit l'opinion, qu'il appuya d'observations diverses, que la fermentation vineuse, l'une des plus remarquables assurément, était due à la présence d'une matière d'origine végétale, mais dont les propriétés la rapprochent des substances animales, telles que l'albumine du blanc d'œuf, la fibrine de nos muscles. Il identifiait cette matière avec le gluten de la farine, et il la désignait sous le nom de principe végétoanimal. Tel était le ferment, et, selon lui, c'était parce qu'il y avait toujours de ce ferment en proportions plus ou moins grandes dans le raisin, que la vendange fermentait et devenait du vin (1).

La théorie de Fabroni a été appliquée par les chimistes modernes à toutes les fermentations. On prétendit que les matières albuminoïdes exposées au contact de l'air éprouvaient des altérations progressivement variables, et que sous leurs diverses modifications elles constituaient des ferments de diverses natures. Les fermentations étaient des effets de mouvements communiqués.

$\mathrm{XI}$

L'acétification faisant partie de la classe des phénomènes naturels qui offrent les caractères principaux des fermentations, on s'est empressé Jepuis longtemps de la soumettre à la théorie inaugurée par l'ouvrage de Fabroni.

1. Fabroni (A.). De l'art de faire le vin, avec tableaux et 13 figures. Traduit de l'italien par F.-R. Baud. Paris, an X, xII-220 p. in-80. (Note de l'Édition.) 
Si l'eau alcoolisée pure, a-t-on dit, ne peut s'acétifier au contact de l'air à la manière du vin, c'est que le vin renferme le principe végétoanimal, une des formes de la matière albuminoïde, qui, au contact de l'air, devient ferment acétique.

Une expérience curieuse, du genre de celles que Fabroni avait instituées pour la fermentation vineuse, paraissait appuyer cette opinion. Ajoutez, en effet, au mélange d'eau et d'alcool, tout à fait impropre à l'acétification, soit un peu de farine, soit un peu de sang, soit un peu de jus de viande, soit enfin une portion minime d'un jus végétal quelconque, et vous verrez la fermentation acétique prendre naissance pour ainsi dire d'une manière obligée.

\section{XII}

La théorie de Fabroni, telle que ce chimiste l'a exposée, ou l'expression plus moderne qui lui a été donnée dans notre siècle, sont à beaucoup d'égards inexactes. Sur le point capital, les observateurs ont été le jouet d'une illusion. Sans doute, il existe dans le vin, quand il s'aigrit, un -intermédiaire obligé de la fixation de l'oxygène de l'air, puisque, dans aucune circonstance, l'alcool pur, à un degré quelconque de dilution dans l'eau pure, ne peut se transformer en vinaigre. Mais cet intermédiaire obligé n'est point une substance albuminoïde morte : c'est une plante, de toutes les plantes la plus petite et la plus simple qui soit au monde, et qu'un botaniste, Persoon [d'après Kützing], a désignée, en 1822 , sous le nom de mycoderma aceti (1). On la connaissait avant lui sous la dénomination vulgaire de fleur du vinaigre.

Je projette ici sur ce tableau l'image de ce champignon agrandie à l'aide d'un microscope qu'éclaire la lumière électrique (fig. 1, p. 87). Vous le voyez formé d'articles plus ou moins étranglés, plus ou moins courts, quelquefois ressemblant à des granulations. Leur diamètre n'atteint pas le plus souvent 1 millième et demi de millimètre; ils sont joints les uns aux autres par une substance mucilagineuse presque invisible.

Je ne connais pas une seule circonstance bien étudiée dans laquelle du vin se soit transformé en vinaigre en dehors de la présence de ce mycoderme. Souvent il est des plus apparents, comme dans les vases qui sont sous vos yeux, où j'ai provoqué l'acétification la plus active ; quelquefois il est en voile si léger à la surface du vin, qu'on le croirait

1. Voir la note 3 de la p. 125 du présent volume. (Note de l'Édition.) 
absent : cela arrive particulièrement dans le cas où du vin s'aigrit lentement dans une bouteille debout, bien bouchée. L'accès de l'air n'étant possible que par les pores du bouchon ou parce que celui-ci ne ferme pas hermétiquement, il se fait avec une lenteur extrême; l'acétification est elle-même très retardée et difficile. Souvent alors le mycoderme se multiplie très péniblement et il est à peine visible; pour autant il n'est point absent. Videz un peu du liquide de la bouteille, et il vous sera

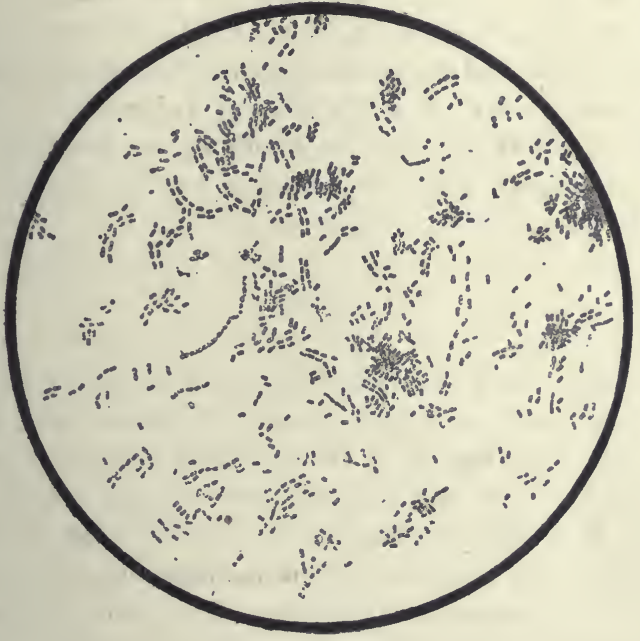

Fig. 1.

facile d'apercevoir sur les parois du goulot un petit cercle grisâtre d'une substance un peu grasse au toucher que vous reconnaîtrez au nicroscope pour le mycoderma aceti.

Je le répète donc, ce petit champignon est toujours présent à la surface d'un vin qui se transforme en vinaigre.

Mais est-ce bien là cet intermédiaire que nous cherchions tout à l'heure et dans lequel réside la propriété de fixation de l'oxygène de l'air sur l'alcool? Sa présence sur le vin, dans les conditions propres à l'acétification, n'est-elle pas l'effet d'une simple coïncidence? Ne sait-on pas que toutes les fois qu'une infusion de 'matière organique est exposée au contact de l'air elle se couvre de végétations cryptogamiques ou qu'elle est envahie par une foule d'animalcules? Le vinaigre n'est-il pas une infusion végétale particulière? 
Telle était, en effet, l'opinion générale, d'autant plus spécieuse ici que le vinaigre donne également asile à une foule de petits animaux bien connus sous le nom d'anguillules du vinaigre.

J'insiste sur ces détails afin de vous faire apprécier toutes les incertitudes de la méthode expérimentale, méthode si sûre néanmoins quand elle est sévèrement appliquée et à laquelle les sciences modernes doivent de si étonnants progrès. Le danger est toujours dans l'interprétation inexacte des faits. Les plus habiles y bronchent à chaque pas. Aussi le grand art consiste à instituer des expériences décisives, ne laissant aucune place à l'imagination de l'observateur. Au début des recherches expérimentales sur un sujet déterminé quelconque, l'imagination doit donner des ailes à la pensée. Au moment de conclure et d'interpréter les faits que les observations ont rassemblés, l'imagination doit au contraire être dominée et asservie par les résultats matériels des expériences.

\section{XIII}

Arrivons donc à ces preuves décisives en ce qui concerne l'erreur de la théorie ancienne des fermentations appliquée à la fermentation acétique, et en ce qui touche au véritable rôle du mycoderma aceti.

J'ai placé dans cette fiole de verre hermétiquement close du vin et de l'air, mais avec la précaution de chauffer le vin et de chauffer l'air. Je ne m'arrêterai pas aux détails de la manipulation qui n'auraient pas grand intérêt. L'observation établit que, dans ces conditions, jamais le vin ne se transforme en vinaigre. Je ne vois plus ici la possibilité de soutenir la théorie de la matière albuminoïde-ferment.

On pourrait objecter, il est vrai, qu'en chauffant le vin on a altéré la matière albuminoïde du vin et que c'est là ce qui s'oppose à ce qu'elle agisse comme ferment et qu'elle détermine la fixation de l'oxygène de l'air sur l'alcool.

Cette objection tombe devant l'expérience suivante : ouvrez la fiole; placez le vin qui a été chauffé au libre contact de l'air ordinaire, et l'acétification du vin pourra avoir lieu.

Voici des faits bien plus décisifs encore.

Nous avons dit que l'eau alcoolisée pure ne s'acétifiait jamais, à moins de mettre en sa présence une matière albuminoïde. Or, j’ai reconnu que l'on pouvait supprimer complétement cette matière albuminoïde et la remplacer par des substances salines cristallisables, phosphates alcalins et terreux auxquels on a adjoint le phosphate d'ammoniaque. Le mycoderme peut se développer quoique péniblement 
dans ces conditions, et l'alcool s'acétifie, surtout si l'on a acidulé le liquide par de l'acide acétique pur.

Qu'est-ce donc que les matières albuminoïdes du vin ? Évidemment elles ne sont pas le ferment, mais elles doivent être d'après l'expérience précédente et elles sont, en éffet, l'aliment du ferment, l'aliment du mycoderma aceti, notamment son aliment azoté.

\section{XIV}

Nous avons maintenant une connaissance complète de toutes les conditions de la transformation du vin en vinaigre. Aussi toutes les difficultés qui nous ont arrêté chemin faisant peuvent s'expliquer avec une facilité remarquable.

1. Dans ce vase oú il y a du vin chauffé préalablement et de l'air qui a été porté lui-même à une température élevée, le vin ne s'aigrit jamais! C'est parce qu'on a tué par l'élévation de température les germes du mycoderma aceti et ceux que le vin pouvait contenir et ceux qui pouvaient être en suspension dans l'air.

2. Dans ce vase où il y a du vin qui a été chauffé, mais exposé au libre contact de l'air ordinaire, le vin peut s'aigrir! C'est que si l'on a tué les germes du mycoderma aceti propres au vin, on n'empêche pas ceux qui peuvent être en suspension dans l'air de tomber dans le rin et d'y germer.

3. L'eau alcoolisée pure ne s'acétifie pas, bien que les germes en suspension dans l'air puissent y tomber, ou que le liquide ait pu en prendre aux poussières des vases qu'il a touchés! C'est que ces germes sont inféconds parce qu'ils n'ont pas d'aliments convenables à leur disposition.

4. Du vin en bouteille pleine et couchée ne s'acétifie pas! C'est que le mycoderma aceti ne peut se multiplier. L'air peut bien entrer par les pores du bouchon; mais le vin, rouge ou blanc, contient toujours des principes oxydables, des matières colorantes ou colorables qui s'emparent peu à peu de l'oxygène et n'en laissent pas du tout aux germes du mycoderme que le vin peut contenir et qu'il contient, en effet, le plus souvent. Quand une bouteille est debout, les conditions de l'oxydation sont tout autres : les germes de la surface sont entourés d'air. 
DEUXIÈME PARTIE

\section{XV}

J'arrive maintenant à la partie pratique de mon sujet.

Ce que nous venons d'exposer se résume dans quelques propositions très simples.

La formation du vinaigre est toujours précédée, sans aucune exception, du développement à la surface du vin d'une petite plante formée d'articles d'une ténuité extrême, mais dont l'accumulation donne lieu soit à un voile uni, léger, quelquefois à peine visible, soit à un voile chagriné, ridé, plus ou moins épais, gras au toucher, parce que la plante s'accompagne dans sa multiplication de matières grasses diverses.

Ce cryptogame jouit de la propriété singulière d'absorber, de condenser des quantités considérables de gaz oxygène et d'en provoquer la fixation sur l'alcool, ce qui transforme cette substance en acide acétique.

Cette petite production végétale n'a pas moins d'exigences que les grands végétaux; il lui faut pour vivre des aliments appropriés : le vin les lui offre en abondance.

Elle se plaît, si j'ose ainsi parler, dans les climats chauds; aussi, pour la cultiver dans nos régions tempérées, il est convenable de la placer dans des locaux chauffés artificiellement, surtout pendant l'hiver.

Le vin, ainsi que je viens de le rappeler, renferme tous les éléments nécessaires à la vie de ce mycoderme : matière azotée, phosphates de magnésie et de potasse. Mais ce sol, tout convenable qu'il.se montre, serait bien préférable encore s'il était rendu plus acide par l'acide acétique, car cette plante se plaît à la surface des liquides d'où s'exhalent des vapeurs d'acide acétique. Il faut d'ailleurs que vous sachiez qu'elle a un ennemi, sa mauvaise herbe à elle, le mycoderma vini, autrement dit la fleur $d u$ vin, dont je vais projeter l'image agrandie sur le tableau (fig. 2). Ces cellules bourgeonnantes se multiplient de préférence sur le vin dans son état naturel; c'est le sol qui leur convient le mieux. Elles ne sauraient prospérer au contraire sur les liquides rendus acides par l'acide acétique.

Cela posé, quoi de plus simple que de fabriquer du vinaigre de vin, ce vinaigre qui fait à juste titre la réputation de la fabrication orléanaise? 
Prenez du vin, et, après l'avoir mélangé avec du vinaigre déjà formé, semez à sa surface la plante ouvrière de la fabrication. A cet effet, comme je le pratique sous vos yeux, il suffit de prélever un peu du voile mycodermique dans un liquide qui en est recouvert et de le transporter, au moyen d'une spatule de bois sur laquelle on le recueille, a la surface du nouveau liquide à acétifier. Les matières grasses qu'il

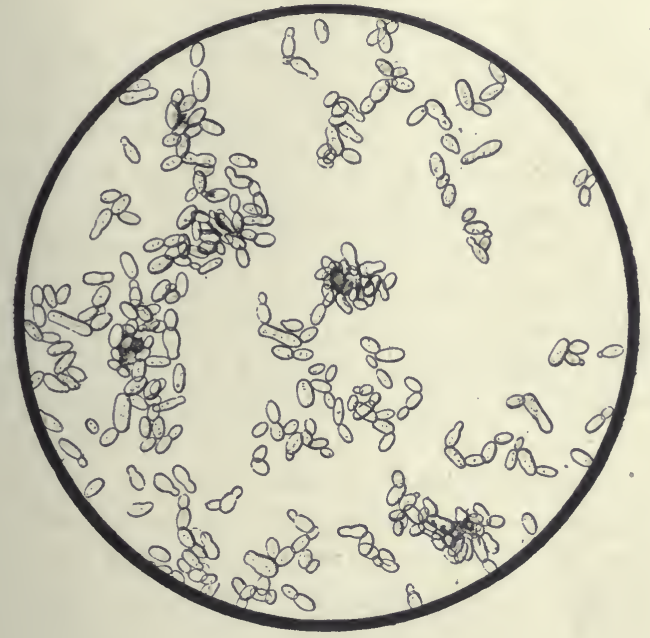

FIG. 2.

renferme s'opposant à ce qu'il soit facilement mouillé, il s'étale à la surface du liquide sans tomber au fond. Si nous opérons en été ou en hiver dans une pièce chauffée à 15 ou $20^{\circ} \mathrm{C}$., déjà après vingt-quatre ou quarante-huit heures au plus, le mycoderme couvrira toute la surface, tant est rapide et facile son développement, et en quelques jours tout le vin sera transformé en vinaigre. L'étendue de la surface du liquide est sans importance; ce qui a lieu pour une place a lieu pour la place voisine. Je me ferais fort de couvrir de mycoderma aceti, dans l'intervalle de quarante-huit heures, une surface de la grandeur de cette salle. 


\section{XVI}

Mais où trouver le mycoderme une première fois pour en semer, si l'on n'est pas à proximité d'une vinaigrerie? Rien de plus simple. Le mycoderma aceti est une de ces petites productions, dites spontanées, que l'on voit se former d'elles-mêmes à la surface des liquides appropriés à leur développement. Dans le vin, dans le vinaigre, en suspension dans l'air, partout, il existe des germes de cette petite plante. Voulez-vous donc vous procurer du mycoderme une première fois, il vous suffira de placer dans un endroit chaud un mélange de vin et de vinaigre. Dans l'intervalle de quelques jours vous verrez apparaître çà et là de petites taches grises, diffusant la lumière au lieu de la réfléchir à la manière du liquide voisin, lesquelles taches iront s'étendant progressivement et rapidement. C'est le mycoderma aceti, né spontanément, à l'aide des semences que le vin ou le vinaigre qui lui a été ajouté renfermaient, ou que l'air a déposées, comme on voit la terre des champs se couvrir d'herbes diverses par les semences naturellement éparses dans cette terre, ou que le vent ou les animaux y ont apportées. Jusque dans cette dernière circonstance la comparaison peut se poursuivre, car, aussitôt que vous placez dans un local chaud du vin et du vinaigre, il est remarquable combien souvent il faut peu de temps pour que l'on voie apparaître de petites mouches rougeâtres, habitants ordinaires des vinaigreries et de tous les lieux où des matières végétales s'aigrissent. Elles aussi avec leurs pattes, avec leurs suçoirs, elles peuvent apporter la semence de la vinaigrerie voisine.

\section{XVII}

Rien de plus simple que la disposition d'une vinaigrerie d'Orléans. Elle consiste essentiellement dans des rangées de tonneaux superposés, portant sur le fond vertical antérieur une ouverture circulaire de quelques centimètres de diamètre et un trou plus petit voisin, dit fausset, pour la sortie ou la rentrée de l'air quand la grande ouverture est bouchée par l'entonnoir à l'aide duquel on introduit le vin, ou par le siphon qui sert à retirer le vinaigre. Les tonneaux sont de la capacité de 230 litres, pleins à moitié. Le travail de main-d'œuvre consiste à entretenir dans la vinaigrerie une température convenable et à retirer 
tous les huit jours environ 8 à 10 litres de vinaigre que l'on remplace par 8 à 10 litres de vin.

La mise en train d'une mère, c'est-à-dire d'un tonneau nouveau, est toujours fort longue. Voici un aperçu du travail qu'elle nécessite. On introduit en premier lieu dans le tonneau 100 litres de très bon vinaigre, bien limpide, puis 2 litres de vin. Huit jours après on rajoute 3 litres de vin; encore huit jours après 4 ou 5 litres, plus ou moins, et ainsi de suite jusqu'à ce que le tonneau contienne environ 180 à 200 litres. On tire alors pour la première fois du vinaigre, de façon a ramener le volume du liquide dans le tonneau à 100 litres environ. C'est à partir de ce moment que la mère travaille et que l'on peut tirer tous les huit jours 10 litres de vinaigre et rajouter 10 litres de vin : c'est le maximum de travail d'un tonneau en huit jours. Souvent il arrive que les tonneaux fonctionnent mal et qu'il est nécessaire de diminuer leur production.

En résumé, un tonneau-mère de nouvelle mise en train ne marche bien qu'au bout de deux à trois mois, c'est-à-dire qu'il ne faut pas moins de temps avant qu'une vinaigrerie nouvellement installée puisse commencer à livrer du vinaigre au commerce.

\section{XVIII}

Lorsque je m'occupais, il y a quelques années, de l'étude de la fermentation acétique, j'ai mis au courant des résultats qui précèdent plusieurs fabricants de vinaigre d'Orléans. Parmi eux, il en est, MIM. Breton-Lorion, qui ont su mettre à profit ces connaissances nouvelles avec beaucoup d'intelligence. Leur maison a monté une fabrique spéciale qui déjà produit environ 12 à 15 hectolitres de vinaigre par jour, avec un matériel très restreint et en allant au moins cinq fois plus vite que par les anciennes pratiques, c'est-à-dire que, toutes choses égales et dans le même laps de temps, ils obtiennent 50 litres de vinaigre quand le procédé d'Orléans en fournit 10 seulement.

L'exposition de cette année au Champ de Mars de MM. Breton-Lorion était remarquable et peut-être n'a-t-elle pas été suffisamment distinguée par le Jury, car les expositions doivent récompenser particulièrement les industriels qui se sont montrés assez avisés pour introduire avec succès dans la grande pratique les résultats de la science. 


\section{XIX}

Je serais très incomplet, à divers égards, si je n'entrais ici dans quelques développements au sujet de ce que l'on pourrait appeler les maladies des vinaigres et des vinaigreries.

Un jour, M. Breton-Lorion m'apporta à Paris un flacon rempli de masses d'aspect gélatineux qui entravaient tout le travail de sa vinaigrerie et dont il ignorait la cause ainsi que le moyen de s'en préserver.

G'est le vin que vous employez en ce moment, dis-je à M. Breton, qui est la cause occasionnelle de cette maladie dans votre fabrique. Ce vin doit être trouble et avoir éprouvé chez le vendeur un commencement d'acétification. Je suis persuadé qu'il est rempli d'articles de mycoderma aceti. Je vais vous les montrer au microscope; puis, en évaporant dans une capsule de porcelaine quelques centimètres cubes de vin, vous sentirez à la fin de l'évaporation l'odeur vive et franche de l'acide acétique. Tout ceci fut vérifié et trouvé exact sur-le-champ.

Je me suis assuré, en effet, que les masses muqueuses et membraneuses dont je parle sont une des formes du développement du mycoderma aceti, particulièrement dans les cas où le mycoderme est submergé.

Les auteurs qui ont écrit sur le vinaigre prétendent que l'on trouve de telles masses gélatineuses au fond de tous les tonneaux dans les fabriques d'Orléans et que c'est là la vraie mère du vinaigre. La vérité est qu'elles y sont inconnues et que leur présence, comme vous venez de l'entendre, est l'indice assuré d'un trouble profond dans le travail de la vinaigrerie.

On donne facilement naissance à ces matières d'aspect gélatineux en seinant le mycoderme dans toute la masse du liquide et en l'empêchant de se produire sous forme de voile à la surface.

Je dirai tout à l'heure le moyen simple de prévenir cette maladie.

\section{XX}

Dans les vases où l'on conserve le vinaigre, soit dans les fabriques, soit dans les ménages ou chez les épiciers, il arrive fréquemment que le vinaigre se trouble et s'affaiblit d'une manière extraordinaire. Il finit même par tomber en putréfaction complète si l'on ne porte pas un prompt remède au mal. 
Il est facile de se rendre compte de cette altération du vinaigre. La cause qui la détermine est fort digne d'intérêt, car elle résulte d'une combustion tout à fait du même ordre que celle qui transforme le vin en vinaigre. Une question s'est peut-être présentée tout à l'heure à votre esprit lorsque j'ai démontré que l'acétification du vin résultait toujours de la présence d'un voile de mycoderma aceti développé spontanément ou par ensemencement préalable. Il est bien naturel, en effet, de se demander ce que devient le cryptogame lorsque l'acétification est terminée, c'est-à-dire quand tout l'alcool est devenu acide acétique.

Le plus souvent un changement profond se manifeste dans la structure du mycoderme, et il n'est pas rare de le voir tomber au fond des vases, mais il ne tarde pas à se reformer quoique péniblement.

Comment agit-il dans ces conditions nouvelles? Ne fonctionne-t-il plus comme un agent d'oxydation? Mes expériences ont démontré que la faculté comburante du mycoderme était loin d'ètre suspendue, mais qu'elle s'exerçait alors sur l'acide acétique lui-mème qui se brûle comme si on le jetait au feu, car il se transforme alors intégralement en eau et en gaz acide carbonique. Les principes éthérés et aromatiques qui constituent le bouquet du vinaigre de vin ne sont pas davantage épargnés. Ils disparaissent même en premier lieu, et, comme il en est parmi eux qui agissent assez vivement sur les muqueuses, on est surpris de la faiblesse apparente du vinaigre quand on le flaire après ce commencement de combustion effectuée. hors de la présence de l'alcool.

Il est donc indispensable de ne pas abandonner à elles-mêmes les cuves dont l'acétification, est terminée; le travail doit être surveillé arec soin sous ce rapport si l'on veut conserver au vinaigre sa force et son arome.

Je place ici sous vos yeux des vases où s'opère depuis plusieurs jours ce curieux phénomène de la combustion du vinaigre par le mycoderme qui l'a produit. Maintes fois dans mes expériences j'ai été jusqu'à faire disparaître intégralement l'acide acétique; c'est alors que la putréfaction se déclare. Tant qu'il y a dans le vinaigre une quantité sensible d'acide acétique, il est préservé de l'envahissement des animalcules de la putréfaction. Dès que l'acidité a disparu à peu près entièrement, il se comporte à la manière des infusions organiques neutres ou légèrement alcalines.

Les accidents dont je viens de parler peuvent être évités dans une vinaigrerie par une surveillance attentive et par l'habitude prise de déterminer la teneur en alcool des vins employés et la proportion 
d'acide acétique des vinaigres fabriqués, ce qui peut guider dans la connaissance du terme de l'opération. C'est au commerce principalement que ces accidents sont préjudiciables lorsqu'ils viennent à se produire dans les vases où le vinaigre est conservé; mais il est très facile - je reviendrai tout à l'heure sur ce perfectionnement si désirable - de prévenir la combustion des vinaigres dans les magasins où on les conserve, et chez les épiciers ou dans les ménages.

\section{X I}

Une troisième maladie bien autrement désastreuse pour les vinaigreries, parce qu'elle est endémique dans chacune d'elles, est due à la présence des anguillules; l'examen de ces petits êtres au microscope est fort curieux, car leur corps est transparent et l'on y distingue à l'aise tous les organes intérieurs. Dans l'impossibilité de les faire voir isolément à chacune des personnes qui m'écoutent, à l'aide d'un microscope ordinaire, je vais projeter sur cet écran leur image agrandie.

Ces anguillules se multiplient avec une rapidité extraordinaire; aussi n'y a-t-il pas un tonneau d'une vinaigrerie quelconque d'Orléans qui n'en contienne en nombre effrayant. L'ignorance était telle à leur égard, qu'on les considérait comme nécessaires à la fabrication; elles en sont au contraire un ennemi dangereux et permanent, et l'on doit chercher à s'en débarrasser le plus possible. Ce soin est d'ailleurs réclamé par la répugnance qu'inspire l'usage d'un liquide souillé par la présence de tels animaux, surtout quand on en a examiné une goutte au microscope.

Quant au rôle nuisible de ces petits êtres dans la fabrication du vinaigre, il me suffira, pour vous en rendre compte, de vous prouver que les anguillules ne peuvent vivre en dehors de l'action de l'air atmosphérique.

J'ai fait deux parts égales d'un vinaigre rempli d'anguillules : l'une d'elles a été placée dans ce flacon que j'ai rempli complétement de liquide et que j'ai bien bouché ensuite; l'autre a été mise dans un flacon semblable mais ouvert. Cette épreuve comparative a commencé depuis cinq jours et voici son résultat : dans le vase rempli et bouché toutes les anguillules sont mortes; elles continuent au contraire de se bien porter dans l'autre où elles ne sont pas distribuées dans toutes les couches, mais seulement vers le niveau supérieur du liquide; c'est là seulement qu'elles peuvent respirer à l'aise. 
Rapprochez ces observations de la nécessité de l'oxygène libre pour la vie des anguillules et de l'obligation corrélative de leur séjour dans les couches supérieures des liquides où elles vivent, de cet autre fait non moins avéré, que le vinaigre se forme par l'action du voile mycodermique superficiel, et vous comprendrez tout de suite que le mycoderme et les anguillules doivent se contrarier sans cesse dans les tonneaux des fabriques, puisque ces deux productions vivantes ont chacune un impérieux besoin du même aliment et qu'elles habitent le même lieu. Aussi, lorsque, pour un motif ou pour un autre, le voile mycodermique n'est pas formé dans un vaisseau ou qu'il tarde à se produire, les anguillules envahissent toutes les couches supérieures du liquide, absorbent l'oxygène et n'en laissent pas à la plante dont les germes ont par conséquent une grande peine à se développer. Réciproquement, lorsque le travail de l'acétification est en bonne voie, que le mycoderme a pris le dessus, il chasse progressivement devant lui les anguillules et finit par les reléguer jusque contre les parois où elles ne tardent pas à former une épaisseur en couronne blanchâtre toute mouvante et grouillante : c'est un fort curieux spectacle quand on l'examine á la loupe. Dans cette situation, leur ennemi, le mycoderme, ne peut plus leur nuire au mème degré; elles ont de l'air, mais certes elles ne sont point à leur aise et elles attendent là, avec impatience, le moment où elles pourront reprendre leur place dans le liquide et gêner à leur tour le mycoderme.

Je ne vois pas de moyen efficace pour détruire les anguillules dans les tonneaux des vinaigreries d'Orléans. La ferneture des ouvertures des tonneaux pendant un temps suffisant, le gaz acide sulfureux appliqué surtout au moment d'un travail actif du mycoderme lorsque les anguillules sont en masses pressées hors du liquide sur les parois des douves, peuvent avoir quelque utilité; mais ces remèdes n'ont rien de bien radical. Heureusement, en opérant, comme je l'ai dit, dans des cuves qui sont forcément nettoyées très souvent, rien n'est plus facile que de se préserver de ces petits animaux. lls n'auront jamais assez de temps pour se multiplier de façon à être nuisibles; on ne les verra même pas apparaître dans un travail bien dirigé. Cela est si vrai que, dans l'année où j'ai étudié cette question le la fermentation acétique, je n'ai pas vu apparaître d'anguillules dans mes cures, grandes ou petites, et que, le jour où j'ai voulu rechercher quel pouvait être le véritable ròle de ces êtres dans la fabrication, j'ai dû prier un vinaigrier de votre ville de vouloir bien m'envoyer un vinaigre qui en renfermât. A partir de ce moment, j'en ai eu à souhait, tant leur multiplication est facile. 


\section{XXII}

Il résulte des observations que je viens de présenter relativement aux altérations des vinaigres et aux difficultés accidentelles du travail des fabriques que le mycoderne et les anguillules sont les sources naturelles de ces imperfections. C'est quand le vin ou le vinaigre contiennent en suspension dans leur masse de nombreux germes actifs de mycoderma aceti que l'on voit se former des matières gélatiniformes gênantes pour la fabrication; ce sont les articles de mycoderma aceti associés au vinaigre marchand, principalement lorsqu'il est faible et mal éclairci, qui, venant à se multiplier, soit dans son intérieur ou à sa surface, le détruisent en provoquant la combustion de son principal élément, l'acide acétique. Enfin les anguillules, après avoir nui au travail de la vinaigrerie, deviennent un objet de dégoût dans la consommation de cette denrée.

Or, si nous nous reportons un instant aux résultats des études que j'ai publiées l'an dernier au sujet des maladies des vins, nous reconnaîtrons que, sous le rapport des causes des maladies qui l'affectent, le vin offre avec le vinaigre les plus grandes analogies, car j'ai démontré que toutes les principales maladies des vins sont également provoquées par le développement d'êtres organisés vivants de nature végétale.

Voici du vin de Bourgogne qui est devenu très amer. L'amertume est la maladie habituelle des grands vins de cette riche contrée; elle y est si fréquente qu'un des propriétaires de quelques-uns de ses crus les plus estimés, M. de Vergnette-Lamotte, m'écrivait, en 1864, afin de m'encourager dans mes recherches : "Si vous parvenez à prévenir l'amertume de nos grands vins, vous aurez donné des millions à la France. » J'y suis parvenu, en effet, et de la manière la plus simple : vous en serez témoins tout à l'heure. Mais en premier lieu constatons le mal et sa cause. Je vais vider dans cette carafe une bouteille de ce vin amer : vous voyez un vin tout trouble qui a perdu une partie de sa couleur primitive; un dépôt flottant qui était rassemblé au fond de la bouteille et qui est maintenant répandu dans toute la masse du vin lui donne cette opacité; au goût il offre une acidité et une amertume des plus désagréables. Prenons une goutte de ce vin et projetons son image agrandie sur cet écran à l'aide de notre microscope électrique; vous voyez que ce vin est rempli de petits filaments articulés : c'est la structure du cryptogame qui, corrélativement à son développement, produit l'amertume du vin. 
Les autres maladies des vins nous offriraient dans leurs causes des résultats du même ordre. Le temps me manque pour en placer les preuves sous vos yeux dans cet entretien; je renvoie les personnes que ce sujet intéresse à mes Études sur le vin (1).

\section{XXIII}

Comment prévenir toutes ces maladies des vins et des vinaigres?

De la manière la plus simple, car j'ai reconnu que toutes les végétations qui se plaisent dans le vin et dans le vinaigre, y compris les anguillules de ce dernier, périssent à une température de $55^{\circ}$ au plus. Portez du vin à cette température en tous les points de sa masse, et, par cette seule circonstance, il pourra se conserver sans altération ultérieurement, quand bien même il n'aurait été soumis à cette température que pendant quelques secondes, parce qu'à ce degré de chaleur, quand il s'agit du vin, toute vitalité est enlevée aux germes des cryptogames qui sont la source des maladies de cette boisson.

Ce que je dis du vin est également applicable au vinaigre. Les anguillules périssent et les articles du mycoderma aceti sont frappés de stérilité.

Je vous présentais tout à l'heure une bouteille de vin de Poinard devenu très amer et presque imbuvable. Afin d'éprouver l'action de la chaleur sur ce vin, j'avais eu soin de chauffer à $55^{\circ}$ un certain nombre de bouteilles du même vin. Voici l'une d'elles : je la vide dans une carafe, et vous voyez que le vin a conservé sa couleur et sa limpidité. En outre, à la dégustation, il n'a pas la moindre amertume.

Vous avez ici un nouvel exemple de cette vérité que, quand il s'agit de trouver un remède à un mal, une des premières conditions du succès est ordinairement de déterminer la vraie cause de ce mal ( $\left.{ }^{2}\right)$.

1. Pasteur. Etudes sur le vin. Ses maladies; causes qui les provoquent. Procédés nouveaux pour le conserver et pour le vieillir. Paris, 1866, in-80. Voir la seconde partie du présent volume. (Note de l'Édition.)

2. Cela est d'autant plus vrai dans le sujet qui nous occupe qu'Appert avait déjá exprimé autrefois la confiance que par son procédé de conserves on pourrait améliorer les vins, et, avant lui, Scheele avait appliqué ce même moyen au vinaigre ("). Mais le commerce n'avait donnè aucune attention à ce procédé de chauffage préalable.

(*) Voir a Études sur le vin ». Voir, en outre, mon Mémoire de 1864 sur la a Fermentation acétique [p. 23-77 du présent volume]. 


\section{XXIV}

Le chauffage préalable des bouteilles au bain-marie est des plus faciles.

Mais quel sera le moyen pratique de chauffer commodément et avec économie de grandes masses de vin? La solution de cette question intéressait au plus haut degré l'application du chauffage aux vins communs.

J'ai la satisfaction d'annoncer que ce problème a été résolu par l'industrie dans le courant de cette année de plusieurs manières différentes : à Béziers par MM. Giret et Vinas qui ont déjà chauffé 10 à 15.000 hectolitres, et qui. ont réuni des observations fort judicieuses sur le grand avantage du chauffage préalable, particulièrement en ce qui concerne les vins du Midi $\left(^{1}\right)$; à Narbonne par M. Raynal dont les appareils ont servi également à chauffer plusieurs milliers d'hectolitres (2). Je pourrais citer beaucoup d'autres négociants ou propriétaires de France, d'Espagne, d'Autriche et même des États-Unis.

Mais j'ai la bonne fortune d'avoir rencontré tout récemment et comme par hasard dans votre ville un négociant en vins très éclairé, M. Louis Rossignol, qui a imaginé de son còté une disposition des plus simples et fort économique $\left(^{3}\right)$. Je serais bien surpris si elle n'était adoptée par une foule de propriétaires et de négociants.

L'appareil de M. Rossignol a coûté 140 francs; il chauffe 6 hectolitres à l'heure, moyennant 10 à 12 centimes de dépense par hectolitre. Il serait d'ailleurs facile de le construire sur une échelle beaucoup plus grande. Comme vous pourrez vous assurer, quand vous le désirerez, des avantages que présente cet appareil, car M. Rossignol n'en fait point mystère et ne l'a point fait breveter, je vais le décrire avec détail. Déjà j'ai engagé diverses personnes à adopter cette disposition dont elles ne sont pas moins satisfaites que M. Rossignol.

\section{V}

L'appareil (fig. 3) se compose essentiellement d'un tonneau ee, dont on a enlevé un des fonds, lequel a été remplacé par une chaudière $k$ en

1. Voir p. $305-306$ du présent volume.

2. Voir p. 288-290 du présent volume.

3. Toir p. 286-288 du présent volume. (Notes de l'Édition.) 
cuivre, étamée extérieurement avec de l'étain pur et qui se prolonge a travers le tonneau par un tube ouvert à sa partie supérieure $h$. Le vin est placé dans te tonneau daus l'intervalle compris entre les douves et la chaudière; celle-ci est pleine d'eau et chauffée par un foyer en masonnerie à feu tournant. L'eau n'est jamais portée à l'ébullition; elle n'a guère que le degré de température du vin, température qui est donnée par le thermomètre $i$. La chaudière n'a pas besoin

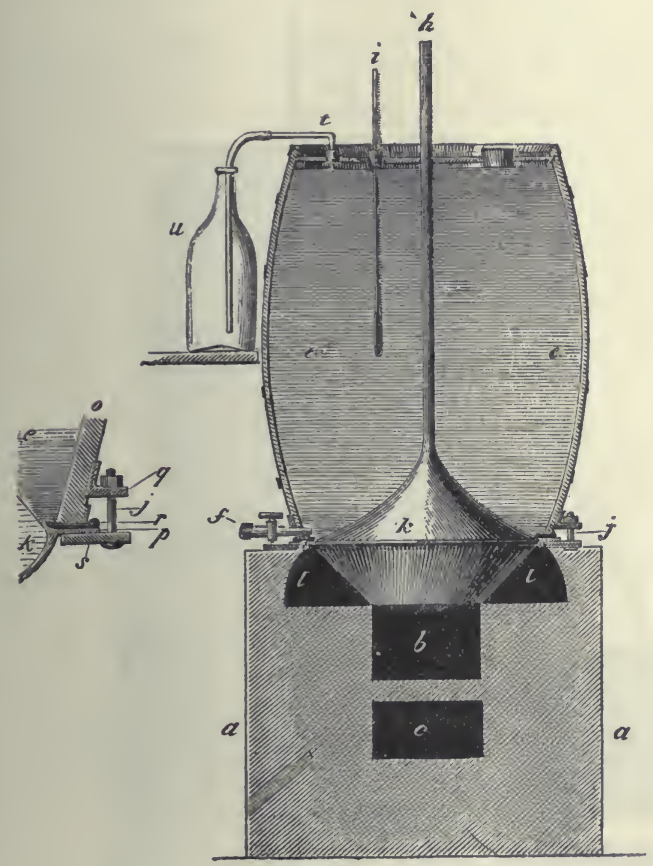

FIg. 3.

d'être vidée ni remplie à nouveau; c'est toujours la même eau qui sert. Le mieux est que le tube $h$ soit plein à moitié ou aux trois quarts de sa hauteur lorsque l'eau a atteint son maximum de température.

Un robinet placé à la partie inférieure du tonneau permet de soutirer le vin chaud et d'en remplir des fûts; à cet effet, on adapte au robinet un gros tube de caoutchouc, comme le représente la figure 4.

Dès que le tonneau est vide, on le remplit de nouveau afin de profiter de la chaleur acquise par le foyer et par l'eau de la chaudière dans l'opération précédente. 
Quand on doit suspendre pour un temps le chauffage, il est bon de remplir l'appareil de vin. Si l'intervalle entre deux opérations devait être fort long, d'une année par exemple, on pourrait de préférence remplir d'eau et chauffer celle-ci à l'origine, afin d'èviter qu'elle ne se corrompe ultérieurement.

La disposition adoptée par M. Rossignol pour relier le bas du tonneau à la chaudière, de façon à bien étancher l'appareil, est sûre et

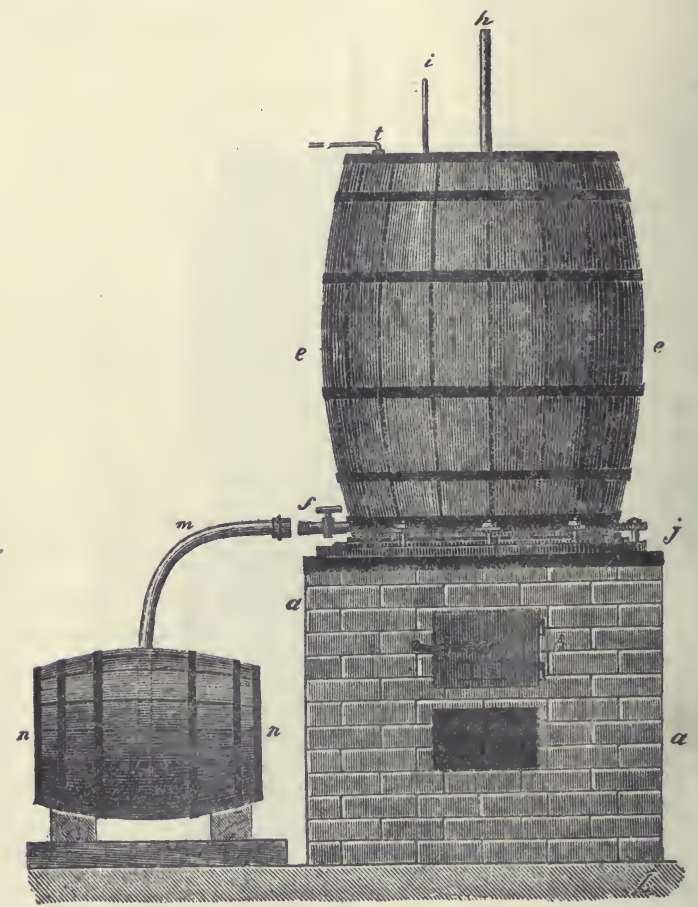

Fig. 4.

assez commode à pratiquer. Un cercle plat de cuivre étamé $p$ (fig. 3, p. 101) est soudé à la chaudière et fait saillie; il est compris entre deux autres cercles, l'un en fer assez fort $s$, l'autre en caoutchouc $r$, de 1 à 2 centimètres d'épaisseur environ. Le tonneau repose par la tranche de ses douves sur l'anneau de caoutchouc. Enfin un cercle de fer un peu encastré dans le bois des douves porte des équerres en fer, qui lui sont rivées de distance en distance, telles que $q$. Ces équerres sont traversées par des tiges de fer $j$, scellées au gros cercle $s$, et munies 
de boulons. En serrant ceux-ci on écrase par pression le caoutchouc entre le bois des douves et le cercle $p$ soudé à la chandière, ce qui donne une fermeture très hermétique $\left({ }^{4}\right)$.

On pourrait par diverses dispositions augmenter la surface des parois de la partie de la chaudière qui est en contact avec le vin et qui l'échauffe; je ne m'y arrête pas. Le feu tournant autour de la chaudière donne une grande économie de combustible.

Il serait désirable de faire reposer le cercle $s$ qui porte tout l'appareil sur une rangée de briques et de rendre la portion de chaudière qui est dans le foyer plus profonde; le caoutchouc s'échaufferait moins. D'ailleurs l'expérience montre qu'il peut résister très longtemps.

Le vin se dilatant par l'élévation de température, M. Rossignol ne remplit pas entièrement le tonneau avant le chauffage; il en résulte que le vin est mis en contact avec un certain volume d'air. Or, j'ai expliqué dans mes litudes sur le vin qu'il y a là un inconvénient à éviter dans tous les cas où l'on tient à ne pas altérer le vin dans sa couleur ou dans son gout par une oxydation brusque qui lui donne un vieillissement artificiel. On peut rechercher, comme on peut craindre, ce genre de vieillissement. Il est généralement préférable de l'éviter, d'autant plus qu'il s'accompagne ordinairement d'un goût de cuit, ce qui n'arrive jamais quand le vin est chauffé à l'abri de l'air pendant un temps très court. Le chauffage dans ces dernières conditions rend le vin inaltérable sans modifier sa couleur, si ce n'est qu'elle a plus de brillant, et sans modifier son goût qui n'est qu'un peu plus fondu, parce que la chaleur chasse un volume plus ou moins considérable de gaz acide carbonique tenu en dissolution dans le vin.

Le remplissage complet du tonneau pourrait avoir lieu si l'on fixait au fond supérieur un tube de verre ou de fer-blanc, afin de conduire le vin dû à la dilatation dans un vase voisin, comme je l'ai figuré.

Il y a une deuxième circonstance dans laquelle le vin pourrait éprouver l'influence d'une oxydation brusque; c'est après le transvasement dans les futs. Je n'entends point parler de l'action de l'air sur le vin pendant qu'il s'écoule en sortant du gros tube de caoutchouc (fig. 4). La rapidité avec laquelle les fûts se remplissent rend peu nui-

1. Au lieu d'encastrer dans le bois le cercle qui porte les équerres á boulons, il serait bien préférable de relier ce cercle à celui qui est au-dessus de la partie médiane et renflée du tonneau par quelques bandes de fer.

On pourrait également donner au tonneau la forme un peu conique d'une cuve. Cela aurait l'avantage de pouvoir agrandir la surface de chauffe des parois supérieures de la chaudière. Dans ce cas la pression exercée sur le cercle qui porte les équerres quand on serre les boulons n'aurait d'autre effet que de réunir plus fortement les douves, tout en opérant la fermeture hermétique par l'écrasement du cercle de caoutchouc. 
sible le contact de l'air et du vin dans cette opération; mais après que le fût a été rempli de vin chaud et bien bondé, il s'établit une vidange naturelle dans le tonneau par suite du refroidissement graduel du vin et un volume égal d'air s'insinue par les douves et leurs jointures. L'oxygène de cet air se dissout dans le vin et l'oxyde. M. Rossignol remplit les fûts refroidis avec du vin qui a été chauffé.

Si l'on juge utile d'éviter également l'action de cette nouvelle portion d'air, il sera facile de relier le fût, aussitòt après l'introduction lu vin chaud, avec un vase contenant du vin chaud ou du vin froid qui aura été chauffé antérieurement. La communication s'établira con:nodément à l'aide d'un tube de caoutchouc que l'on adaptera à un petit tube métallique dans un trou de fausset fixé près de la bonde. Après le refroidissement du fût qui se trouvera naturellement rempli de vin, on bouchera le trou de fausset avec une petite cheville de bois à la manière ordinaire.

Des fùts remplis de cette manière pourront voyager, traverser les mers, parcourir le monde sans que le vin y éprouve la moindre maladie. On peut juger dès lors de l'influence que cette pratique si simple et si peu dispendieuse aura inévitablement sur le commerce des vins de toutes les contrées vinicoles.

D'autres avantages non moins importants peut-être s'ajoutent à celui dont je parle. Le vin pourra rester aussi longtemps qu'on le voudra dans des fûts sans être soutiré. En outre, on pourra le conserver dans des celliers aussi bien et même avec plus d'avantages souvent que dans des caves.

Je suis persuadé que l'usage des caves, c'est-à-dire le séjour des vins à basse température, s'est répandu principalement par la nécessité d'éviter les maladies des vins. Que le vin se trouve placé dans des conditions de conservation indéfinie, et on pourra se passer des caves. J'en dirais autant des soutirages et des collages fréquents qui sont encore, à mon avis, des nécessités corrélatives de la facilité d'altération des vins.

J'ai le ferme espoir que par l'application du chauffage préalable on pourra modifier profondément toutes les anciennes pratiques de la vinification.

\section{XXVI}

Dans ce que je viens de dire, j’ai supposé que le vin mis en fûts, encore chaud et refroidi dans ces fûts, n'en sortait pour la première fois que pour être mis en bouteilles ou consommé, et que l'on ne s'inquié- 
tail ni des soutirages, ni des collages, ni des dépòts formés par l’oxydation lente. Il s'agit donc ici d'un mode tout nouveau de traitement des vins inconnu de la propriété et du commerce, et qui fournira des natures de vins dont on n'a pas idée aujourd'hui.

Mais il est naturel que rous me demandiez si le vin qui a subi l'opération du chauffage peut être manipulé à la manière ordinaire, soutiré, collé, etc. Yoici ma réponse à cette question. Il résulte des expériences consignées dans mes Études sur le vin que le vin peut reprendre dans ces manipulations au contact de l'air des germes d'altération, notamment ceux du mycoderma aceti et du mycoderma rini, mais ces effets sont relativement bien plus rares que lorsque le vin n'a pas subi l'opération du chauffage; cela tient à ce que les germes d'altération propres au vin existent surtout dans le vin lui-même. L'air en renferme peu relativement, de telle sorte que c'est déjà beaucoup faire que de garantir le vin contre le développement des germes des cryptogames naturellement contenus dans le vin.

Quoi qu'il en soit, il sera toujours préférable de faire les manipulations dont je parle et les coupages, si l'on en effectue, avant l'opération du chauffage.

C'est par les mêmes motifs que je suis porté à conseiller de ne pas donner aux appareils de chauffage le caractère de continuité, avec refroidissement du vin dans l'appareil même. La dépense du chauffage est si minime que cet avantage a peu d'intérêt. Il y a au contraire une utilité très grande à introduire le vin chaud dans les fùts où il devra être conservé ou voyager; car sa chaleur primitive sera facilement plus que suffisante pour détruire la vitalité de tous les germes des fùts.

Dans un essai fait avec l'appareil que j'ai décrit tout à l'heure, le vin avait $60^{\circ} \mathrm{C}$. dans le tonneau de l'appareil de chauffage et encore 58 a $59^{\circ}$ après que je l'eus transvasé dans un tonneau froid : il n'arait donc perdu que 1 à $2^{\circ} \mathrm{C}$. par le fait de ce transvasement $\left.{ }^{1}\right)$.

\section{XXVII}

M. Rossignol a déjả chauffé dans son appareil plus de cinq cents pièces de vin rouge ou blanc, particulièrement des vins de l'Orléanais, de la Charente et de la Gironde (Saint-Émilion). La conservation est

1. Toutefois j'aurais tort d'insister sur des dispositions que l'usage n'a pas encore suffisamment consacrées. C'est à l'industrie qu'il appartient de décider la question du chauffage avec ou sans discontinuité dans les appareils. 
parfaite, l'éclaircissement des vins très facile. Plus de vins tournés, gras ou aigris. Les vins les plus communs, les plus prompts à se troubler et à tourner, m’a dit M. Rossignol, restent clairs jusqu'au dernier litre, alors même que les débitants mettent quinze jours ou six semaines à vider un tonneau.

\section{XXVIII}

L'application du chauffage aux vins des vinaigreries n'offre pas moins d'avantages.

Un vin quelconque, limpide ou tout trouble, qui a été chauffé, devient beaucoup plus propre au travail de la vinaigrerie que le vin naturel. Enfin, si l'on chauffe le vinaigre après sa fabrication, il devient inaltérable parce qu'il est privé de germes actifs de mycoderma aceti et d'anguillules; son collage est facilité au plus haut degré; sa limpidité et sa couleur sont celles des vieux vinaigres.

Si l'on craignait une usure trop prompte dans l'appareil de M. Rossignol, on pourrait faire argenter extérieurement les parois de la chaudière $\left({ }^{1}\right)$.

\section{XXIX}

Tous les résultats que je viens d'avoir l'honneur de vous exposer sont forts encourageants.

Rien n'est plus agréable aux hommes voués à la car rière des sciences que d'accroître le nombre des découvertes, mais, quand l'utilité pratique de leurs observations est immédiate, leur joie est au comble. Aussi, permettez-moi de remercier publiquement, en terminant cet entretien, vos compatriotes, MM. Breton-Lorion et Rossignol, de m'avoir procuré la satisfaction d'assister à Orléans même aux applications des résultats de mes recherches sur le vin et sur le vinaigre.

Je ne désire plus qu'une chose, c'est qu'ils aient à Orléans et dans toute la France de nombreux imitateurs.

1. Lorsque le vin et le vinaigre ont été chauffés, ils doivent se refroidir dans leurs fûts avant d'ètre livrés au commerce. Ne pourrait-on pas profiter de leur chaleur pour chauffer la vinaigrerie? 


\section{NOTE SUR UN MÉMOIRE DE M. LIEBIG,}

RELATIF AUX FERMENTATIONS (1)

Dans la seconde partie de cette Note, Pasteur réfute les assertions de Liebig concernant la fermentation acétique. (Note de l'Édition.)

1. Comptes rendus de l'Académie des sciences, séance du 18 décembre 1871, LXXIII, p. 1119-1424. Voir tome II des Euvres de PASTEUR, p. 361-366. (Note de l'Édition.) 

ÉTUDES SUR LE VIN 



\title{
ÉTUDES SUR LE VIN
}

\section{SES MALADIES, GAUSES QUI LES PROVOQUENT}

\author{
PROCÉDÉS NOUVEAUX \\ POUR LE GONSERVER ET POUR LE VIEILLIR(1)
}

1. L'ouvrage portant ce titre eut deux éclitions :

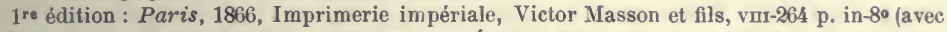
13 figures dont 11 en noir et 32 en couleur). - Études couronnées par le Comité central agricole de Sologne.

$2^{\circ}$ édition: Paris, 1873, Savy, rv-344 p. in- $8^{\circ}$ (avec 32 planches en couleur et 25 gravures en noir). - Etudes couronnées par le Comité central agricole de Sologne et par le jury de l'Exposition universelle de 1867.

Le texte que nous avons reproduit est celui de la deuxiéme édition. Nous avons mentionné les variantes entre les deux éditions. (Note de l'Édition.) 


\section{AVERTISSEMENT DE LA PREMIÉRE ÉDITION}

Au mois de juillet 1863, l'Empereur voulut bien m'encourager à porter mes recherches vers la connaissance des maladies des vins. Déja guidé par des observations de détail, que mes études relatives aux fermentations m'avaient suggérées, j'entrevoyais la possibilité d'un travail profitable sur ce sujet, auquel je me consacrai dès lors avec la pensée de son intérêt pour une des plus grandes productions agricoles de la France et le désir de répondre à la bienveillance d'un auguste patronage.

Aujourd'hui que je me décide à publier mes observations, afin de hâter les essais d'applications industrielles qui en découlent, je sens trop combien elles sont insuffisantes; nais j'ai l'espoir qu'elles pourront servir de base à des études plus approfondies.

Le 3 décembre 1865, j'eus l'honneur d'être reçu par l'Empereur au palais de Compiègne et d'exposer à Sa Majesté les résultats de mes recherches, en Lui remettant la lettre suivante, dont Elle a daigné autoriser la publication.

\section{Sire,}

Votre Majesté, préoccupée avec raison du prẻjudice que portent au commerce des vins de France les altérations auxquelles ils sont sujets, a daigné m'inviter, il y a deux ans, à rechercher les causes des maladies des vins et les moyens de les prévenir.

Depuis le jour où j'ai été honoré de cette importante mission, je n'ai cessé de m'y appliquer tout entier.

Les résultats auxquels je suis parvenu sont exposés dans l'ouvrage ci-joint, qui a pour titre : Études sur le vin. - Ses maladies; causes qui les provoquent. - Procédés nouveaux pour le conserver et pour le vieillir.

Si le temps, juge nécessaire et infaillible de toutes les productions 
de la science, consacre, comme je l'espère, l'exactitude de mon travail, j'aurai acquis, Sire, la satisfaction la plus enviable pour un savant, celle d'avoir servi utilement mon pays, en répondant à un désir de l'Empereur.

Je suis avec le plus profond respect,

$$
\begin{gathered}
\text { Sire, } \\
\text { de Votre Majesté, }
\end{gathered}
$$

le très humble et très fidèle serviteur et sujet.

L. Pasteur,

Membre de l'Académie des sciences. 


\section{PRÉFACE DE LA DEUXIĖME ÉDITION}

La première édition de cet ouvrage a paru en 1866. Deux années après, elle était épuisée. Engagé alors dans l'étude difficile de la maladie qui sévissait sur les vers à soie, à laquelle j'ai consacré six années d'un travail assidu, j'ai dô attendre jusqu'à ce jour pour une réimpression.

On trouvera dans cette édition quelques additions importantes : la description des nombreux appareils imaginés par l'industrie pour appliquer le procédé de chauffage préalable du vin dans le but d'en assurer la conservation; la constatation des résultats obtenus par cette application, et par quelques autres que j'avais déduites de mes premières études; l'influence du chauffage sur l'amélioration des vins; enfin, une réponse à une nouvelle réclamation de priorité qui s'est produite dans ces dernières années, et à laquelle j'ai donné peut-être une attention qu'elle ne méritait pas.

Les inventions heureuses sont ordinairement suivies de revendications plus ou moins vaines, dont le bon sens public finit toujours par faire justice.

Le chapitre relatif aux appareils à chauffage a été rédigé par un de mes anciens élèves et amis, M. Jules Raulin, qui est entré dans la carrière des sciences par un travail remarquable sur le mode de nutrition des mucédinées, auquel l'Académie des sciences vient de décerner l'un de ses prix le plus enviés, le prix de physiologie expérimentale. 


\section{PRENIĖRE PARTIE}

\section{GAUSES DES MALADIES DES VINS}

\section{INTRODUCTION}

La superficie du sol de la France plantée en vigne s'élève à plus de eux millions d'hectares, et elle s'accroît chaque année dans une proortion sensible. Ces deux millions d'hectares représentent annuelement environ cinquante millions d'hectolitres de vin, dont la valeur aoyenne dépasse 500 millions de francs. " La récolte du vin, dit haptal, est, après celle des céréales, la plus importante de toutes elles de la France "; et si l'on considère que, dans plusieurs de nos ontrées, le sol et le climat sont si bien appropriés à la culture de la igne que le seul département de l'Hérault produit plus de sept millions 'hectolitres de vin, trois fois plus que le royaume de Portugal (1), et [ue, grâce aux traités de commerce chaque jour plus nombreux entre a France et toutes les nations civilisées, les vins de France se transortent sur les principaux marchés du globe, on comprendra facilement [ue le vin peut devenir pour notre pays un objet de commerce d'une i grande valeur, qu'on aurait peine aujourd'hui à s'en faire une juste dèe $\left({ }^{2}\right)$.

1. Renseignement fourni par M. Pagézy, député de l'Hérault (1864).

2. Récolte des vins en 1864 :

\begin{tabular}{|c|c|c|c|c|c|}
\hline an & $474.540^{\mathrm{b}}$ & Dordogne & $792.803^{\mathrm{b}}$ & Lot-et-Garonne. & 965.219 \\
\hline .... & 178.133 & Doubs ...... & 149.424 & Lozère & 7.154 \\
\hline . . & 299.695 & Drôme. . . . . & 373.555 & Maine-et-Loire . & 715.429 \\
\hline Les (Basses-). . . & 57.498 & Eure. . & 11.877 & Manche .... & $n$ \\
\hline es (Hautes-). . . & 103.019 & Eure-et-Loir . . . : & 83.615 & Marne . . . . & 389.083 \\
\hline Maritimes... & 59.484 & stère. . . . . & 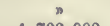 & Marne (Hante-). . & 404.111 \\
\hline$\cdots \cdot$ & 202. & & 1.702 .000 & Mayenne.... & 2.902 \\
\hline nnes. . . . . & 24.896 & Garonne (Haute-). . & 53 & irthe ..... & 705.714 \\
\hline ge..... & 51. & $\therefore \ldots$ & 1.30 & Meuse & 307.500 \\
\hline$\ldots$ & 29 & $\ldots .$. & & Morbihan .... & 24.073 \\
\hline & 1.50 & . & 7.12 & glle ..... & 300 \\
\hline ron..... & 33 & -Vilaine ... & 1. & Nièvre.... & 223.997 \\
\hline hes-du-Rhỏne. . & 419.300 & $\because \cdots$ & 23 & Nord. . . . . & $n$ \\
\hline dos. . . . . & & et-Loire... & & 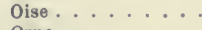 & 13.685 \\
\hline 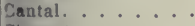 & 4.091 & $\cdots \cdot \ldots$ & 17 & Orne . . . . & $n$ \\
\hline ente. & 796.852 & $\cdots \cdot$ & 45 & -de-Calaie. ... & ” \\
\hline harente-Infórieure. . & 5.413 .170 & es....... & 19 & Dôme .... & 641.274 \\
\hline & 196.952 & t-Cher ... & 80 & Ses (Baeses-) . & 65.791 \\
\hline dèze & 223.225 & $\cdots \cdots$ & 856.477 & Pyrènées (Hautes-) . & 103.827 \\
\hline . . & 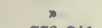 & Loire (Haute-) . . & 69.323 & Pyrénées-Orientales. & 439.874 \\
\hline -d'Or. & 776.341 & Loire-Inférieure . . & 2.45 & (as-). . . & 469.800 \\
\hline lu-Nord . . & $n$ & $\cdots \cdot$ & 87 & Rhin (Haut-) . . & 494.297 \\
\hline & & $\mathbf{L}$ & 467.500 & Rhône. . 舟 & 859.729 \\
\hline
\end{tabular}


Malheureusement les vins de France supportent difficilement le voyages prolongés. Ils sont sujets à de nombreuses maladies : l'acétifi cation, la pousse, la graisse, l'amer, etc.....; arrivés à leur destination ils se détériorent, et d'autant plus rapidement qu'ils sont livrés à de: mains plus ou moins inhabiles, dans des celliers mal disposés, privé: de ces mille soins qui font de l'élevage des vins un art où peu de personnes excellent, même en France.

Un négociant anglais très éclairé m'écrivait, à la date du 29 octobre 1863 : “ On s'étonne en France que le commerce des vins français n'ait pas pris plus d'extension en Angleterre depuis le traité de commerce. La raison en est assez simple. Tout d'abord nous avons accueilli ces vins avec empressement, mais on n'a pas tardé de faire la triste expérience que ce commerce mène à de grandes pertes, et à des embarras infinis à cause des maladies auxquelles ils sont sujets.

Tous les vins de table sont, en effet, susceptibles d'altération, et ceux des meilleurs crus sont souvent les plus délicats. Chaque année, par exemple, la maladie dite de l'amer détériore de grandes quantités des vins les plus exquis de la Bourgogne. Plus j'ai avancé dans cette étude des maladies des vins, plus je me suis convaincu que les pertes qu'elles occasionnent sont immenses.

Les propriétaires et les négociants affirment volontiers qu'ils n'ont que des vins irréprochables, et qu'ils savent par des soins intelligents éviter toute altération. Cette assertion est très ordinairement dictée par l'intérêt ou l'amour-propre. Je crois pouvoir assurer à mon tour, et cela donnera une idée de l'étendue du mal, qu'il n'y a peut-être pas une seule cave en France, chez le pauvre comme chez le riche, qui ne renferme quelque portion de vin plus ou moins altéré.

Préoccupé du préjudice que les maladies des vins portent au commerce de cette denrée, l'Empereur daigna m'encourager à diriger mes recherches sur cette importante question, afin de découvrir, s'il était possible, un moyen d'empêcher l'apparition de toutes ces maladies.

Le travail que je publie aujourd'hui a pour but de faire connaître les résultats de mes recherches. Si je ne me trompe, j'ai reconnu les véritables causes des diverses maladies des vins, et un moyen simple et pratique de les prévenir.

\begin{tabular}{|c|c|c|c|c|c|}
\hline Saône (Haute-) & $320.209^{\mathrm{h}}$ & Seine-et-Marne . & $315.410^{\mathrm{b}}$ & Vaucluse & $466.456^{\mathrm{t}}$ \\
\hline Saône-et-Loire. & 1.297 .128 & Seine-et-Oise & 409.472 & Vendée. & 729.858 \\
\hline arthe ... & 130.891 & Sèvres (Deux-) & 491.950 & Vienne & 615.320 \\
\hline avoie & 810.326 & Somme .... & " & Vienne (Haute-). & 24.201 \\
\hline avoie (Haute-). . . & 247.436 & Tarn & 436.145 & Vosges . & 896 \\
\hline 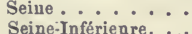 & 71.421 & $\begin{array}{l}\text { Tarn-et-Garonne } \\
\text { Var. }\end{array}$ & 320.918 & Yonne. & 8 \\
\hline ... & ” & $\operatorname{Var} \ldots$ & 886.852 & Total. & 3. \\
\hline
\end{tabular}

Je dois communication de ce tableau à $\mathbf{M}$. Teissonnière, négociant en vins, membre du conseil municipal de la ville de Paris. 


\section{OPINION ANCIENNE SUR LES GAUSES DES MALADIES DES VINS}

Les auteurs qui ont écrit sur le vin l'ont considéré jusqu'à présent comme un liquide dont les divers principes réagissent continûment les uns sur les autres par des actions mutuelles et lentes. Le vin, disent-ils, est toujours en travail. Lorsque la fermentation du moût de raisin est achevée, l'équilibre n'est pas établi encore entre les divers principes de la liqueur. Elle a besoin du temps pour se faire, pour que ces principes se fondent les uns dans les autres; et l'on ajoute, en termes non moins vagues, que, si ce développement des actions réciproques entre les substances qui composent le vin n'est pas régulier, le vin devient malade.

Par ces apparences d'explication du vieillissement et des maladies des vins, on ne fait qu'exprimer la différence bien connue qui existe entre le vin à ses divers âges, et le fait non moins avéré de ses altérations spontanées. Il y a eu cependant quelques essais de théorie au sujet des causes qui provoquent les maladies des vins. Je vais en indiquer l'origine et les principes.

Dans la seconde moitié du dernier siècle, toutes les questions relatives aux fermentations préoccupèrent vivement les esprits. En même temps que les maîtres de la science s'efforçaient d'apporter quelque lumière sur ces mystérieux phénomènes, bon nombre de sociétés savantes en proposèrent l'étude pour sujet de prix. Ce mouvement, auquel s'associa brillamment l'Académie des sciences, par divers travaux de ses membres, principalement par celui de Lavoisier sur la fermentation alcoolique $\left({ }^{1}\right)$, ne resta point stérile, même à l'étranger. Les recherches expérimentales qui méritent surtout d'être mentionnées ici sont celles de Fabroni, savant Italien, qui remporta le prix proposé en 1785 par l'Académie de Florence. Le sujet du prix consistait dans la découverte d'une théorie de la fermentation vineuse, confirmée par l'expérience et appliquée à la recherche des moyens propres à tirer de chaque espèce de moût, d'après la nature des principes qui le constituent, un vin doué des meilleures qualités, et principalement de celle d'être propre au transport et susceptible d'une longue conservation.

L'ouvrage de Fabroni a été traduit de l'italien et publié à Paris

1. Lavorsier. Traité élémentaire de chimie (seconde édition). Paris, 1793, 2 vol. in-8॰. (.Yote de l'Édition.) 
en 1801 (1), et, en outre, un Mémoire de cet auteur sur le même suje fut laissé par lui à la Société philomatique de Paris en 1798, après ur séjour qu'il fit en France, où il était venu par ordre de son gouver nement pour concourir à l'établissement du système des poids e mesures. Un résumé critique de ce Mémoire, dû à Fourcroy, fut insér dans le tome XXXI des Annales de chimie (2). C'est là qu'il convient de prendre l'expression de quelques-unes des idées de Fabroni, parce qu'elles y ont une date plus récente que dans son premier traité, et qu'elles s'y trouvent débarrassées des obscurités de l'hypothèse du phlogistique.

D'ailleurs, le seul point vraiment digne d'attention dans les observations de Fabroni, celui qui doit nous les rendre particulièrement recommandables, est relatif à la composition du ferment. Fabroni, en effet, est le premier qui ait reconnu que le ferment est de la nature des substances que nous appelons aujourd'hui albuminö̈des. Mais il est juste de rappeler que $M$. Thenard, dans un Mémoire bien connu, a beaucoup fait pour préciser cette opinion $\left({ }^{3}\right)$.

Fourcroy exprime ainsi l'une des propositions avancées par Fabroni :

“ La matière qui décompose le sucre dans l'effervescence vineuse est la substance végéto-animale; elle siège dans des utricules particulières, dans le raisin comme dans le blé. En écrasant le raisin on mêle cette matière glutineuse. (ce gluten) avec le sucre, comme si l'on versait un acide et un carbonate dans un vase; dès que les deux matières sont en contact, l'effervescence ou la fermentation y commence, comme cela a lieu dans toute autre opération de chimie $\left.{ }^{(4}\right)$. »

Laissons de côté les erreurs évidentes que cette proposition renferme. Elles étaient même, à divers égards, plus sensibles qu'il n'est dit ici par Fourcroy. Ce qui est digne de remarque, c'est l'assimilation ou l'identité établie par Fabroni entre le gluten et le ferment.

Par matière végéto-animale, Fabroni entend parler du gluten que Beccari, antérieurement, avait extrait de la farine. Fabroni rapporte en ces termes le mode de préparation de cette substance : “ Il ne s'agit que de former une masse de pâte épaisse, telle qu'on la prépare pour

1. Fabroni (A.). De l'art de faire le vin, ouvrage couronné par l'Académie royale d'économie de Florence, avec tableaux et 13 figures. Traduit de l'italien par F.-R. Baud. Paris, an X, xII-220 p. in-8.

2. Fourcroy. Notice d'un Mémoire du cit. Fabroni, sur les fermentations vineuse, putride, acéteuse, et sur l'éthérification, lu à la Société philomatique le 3 fructidor, an VII; et Réflexions sur la nature et les produits de ces phénomènes. Annales de chimie, XXXI, an VII, p. 299-327.

3. ThenafD. Mémoire sur la fermentation vineuse. Annales de chimie, XLVI, an XI, p. 294-320.

4. Fourcroy. Loc. cit., p. 301-302. (Notes de l'Édition.) 
faire le pain, et ensuite de la laver dans l'eau courante jusqu'à ce qu'elle cesse de la teindre en blanc. La partie tenace et glutineuse qui reste entre les mains est la substance végéto-animale (1). »

Fabroni savait, en outre, que ce principe végéto-animal existe dans la plupart des organes des végétaux et il rendait compte, par le fait de sa présence, d'expériences déjà connues de son temps, dans lesquelles on avait vu la fermentation s'établir par l'addition à l'eau sucrée de diverses substances végétales ou animales, expériences qui ont été, comme on le sait, variées à l'infini depuis trente à quarante ans. Ainsi le marquis de Bullion avait reconnu que l'on provoquait la fermentation du sucre en lui adjoignant des feuilles de vigne pilées (²). "Cette expérience, dit Fabroni, confirme ma manière de voir sur le fait que la matière végéto-animale a une grande part dans le prompt mouvement de la fermentation vineuse, car les feuilles ajoutées dans cette expérience, outre la partie mucilagineuse et résineuse, ont encore une matière analogue à la substance végéto-animale de la farine... Il a été démontré par Rouelle le jeune que dans les fécules vertes des plantes il existe une matière végéto-animale semblable en tout à celle que l'on a trouvée dans le blé(3). » Puis, à l'imitation du marquis de Bullion, il institue des expériences avec d'autres parties de plantes que les feuilles, par exemple avec les fleurs de sureau, et, s'il obtient une fermentation plus rapide qu'en se servant des feuilles d'oseille employées par le marquis de Bullion, il en attribue la cause à une proportion de matière albuminoïde plus forte dans les fleurs de sureau que dans les feuilles d'oseille.

Après ces détails, il est presque superflu d'ajouter que Fabroni a fait de nombreux essais de fermentation vineuse avec des mélanges d'eau sucrée, de tartre et de gluten, et que, conséquemment, au point de vue de cette fermentation, Fabroni se montre aussi avancé qu'on l'était de nos jours, avant mes recherches, en ce qui concerne les fermentations lactique, butyrique, etc.

1. FABRON. Loc. cit., p. 171. (Note de l'Édition.)

2. "J'ai mis à fermenter, pendant le mois d'août dernier, 120 pintes d'eau, 120 onces de sucre et une livre et demie de crème de tartre; le mélange est resté trois mois sans apparence de fermentation. J'ai jugé, d'après cette expérience, qu'il fallait autre chose que de l'eau, du sucre et du tartre pour obtenir la fermentation vineuse, et que la matière extractive résineuse était absolument nécessaire. J'ai donc ajouté à un mélange semblable au précédent 16 livres de feuilles de vigne pilées : le mélange a fermenté avec force pendant quinze jours; je l'ai ensuite distillé, et j'ai obtenu quatre pintes d'eau-de-vie. J'ai mis à fermenter la même quantité d'eau et de feuilles de vigne, sans sucre et sans tartre : le mélange a fermenté doucement, et je n'ai obtenu á la distillation que de l'eau acidulée. (Marquis de Bullion. [Sur les causes de la fermentation vineuse et sur les moyens de perfectionner la qualité des vins.] Journal de physique, XXIX, 1786, p. 3-7.) [Note de Pasteur.]

3. Fabroni. Loc. cit., p. 105. (Note de l'Édition.) 
Ses expériences étaient semblables à celles qui ont été pratiquées par les auteurs les plus modernes $\left({ }^{1}\right)$. On peut, à cet égard, consulter les importants travaux sur les fermentations de MM. Colin, Liebig, Fremy, Berthelot $\left({ }^{2}\right)$, et ceux de divers chimistes allemands résumés dans le Traité de chimie organique de M. Gerhardt $\left(^{3}\right)$.

Fabroni peut donc être considéré à juste titre comme le principal promoteur des idées modernes sur la nature du ferment. Lavoisier a éclairé la nature des fermentations prises du point de vue de la composition du corps fermentescible et de sa transformation sous l'action du ferment. Le travail de Fabroni, au contraire, bien qu'à une grande distance de celui de Lavoisier pour la rectitude et l'importance des résultats, a porté la lumière sur la nature du corps qui provoque la fermentation. Sur ces deux points, et si on laisse de côté la vue juste et féconde de Cagniard de Latour $\left(^{4}\right)$, qui considéra plus tard le ferment de la bière comme un être organisé, Lavoisier et Fabroni ont été aussi loin que les auteurs modernes.

Revenons à l'art de la vinification. A la suite des travaux théoriques de Lavoisier et de Fabroni, un progrès restait à accomplir. Il fallait éclairer les pratiques de la vinification de la connaissance des résultats de ces travaux; il fallait, en d'autres termes, s'attacher à composer un traité sur le vin ayant pour base le fait, établi par Lavoisier, de la

1. « Je fis un autre moùt artificiel avec les proportions suivantes :

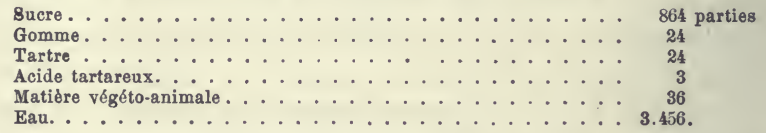

Je plaçai le tout à une chaleur variable depuis 22 jusqu'à 35 degrés Réaumur, dans laquelle je le laissai pendant six jours; ensuite, je modérai la chaleur jusqu'à 20 degrés, et, le jour d'après, c'est-à-dire le huitième, je vis la liqueur écumante et la fermentation établie; alors je la plaçai à une température constante de 12 degrés; mais, trouvant la fermentation trop diminuée, je la remis à son premier degré de chaleur, et je la vis à l'instant rétablie : j'obtins de ce moût une très agréable espèce de cidre. " (FABronr. Loc. cit., p. 104). [Note de Pasteur.]

2. Colrn. Mémoire sur la fermentation du sucre. Annales de chimie et de physique, 2• sér., XXVIII, 1825, p. 128-142. - Mémoire sur la fermentation. Ibid., XXX, 1825, p. 42-64.

Liebig. Sur les phénomènes de la fermentation et de la putréfaction, et sur les causes qui les provoquent. Annales de chimie et de physique, 2。 sér., LXXI, 1839, p. 147-195.

Boutron et Fremy. Recherches sur la fermentation lactique. Annales de chimie et de physique, 3’ sér., II, 1841, p. 257-274.

Berthelot (M.). Recherches sur la fermentation. Comptes rendus de l'Académie des sciences, XLIII, 1856, p. 238-239. - Sur la fermentation alcoolique. Ibid., XLIV, 1857, p. 702-706. - Remarques sur la fermentation alcoolique de la levûre de bière. Ibid., XLVIII, 1859 , p. $691-692$.

3. Gerhardt (Ch.). Traité de chimie organique. Paris, 1856, 4 vol. in- $8^{\circ}$.

4. Gagniard de Latour. Observations sur la fermentation du moùt de bière. L'Institut. 23 novembre 1836, IV, p. 389-390. - Mémoire sur la fermentation vipeuse. Annales de chimie et de physique, $2^{e}$ sér., LXVIII, 1838, p. 206-222. (Notes de l'Édition.) 
décomposition du sucre en alcool et en acide carbonique, et celui de l'influence des matières albuminoïdes dans l'acte de la fermentation selon les vues de Fabroni. C'est précisément ce que fit avec talent un chimiste habile, animé d'un grand zèle pour le bien public et fort versé dans toutes les applications de la chimie aux arts, où il voyait si justement l'une des sources principales de la fortune publique, je veux parler du comte Chaptal. Membre de l'Institut, conseiller d'État, et a la veille d'être appelé au ministère de l'Intérieur, Chaptal ne dédaigna pas de publier un traité sur l'Art de faire le vin, qu'on lit encore aujourd'hui avec le même intérêt et la même utilité que les ouvrages plus récents sur cette matière. C'est dans l'édition de 1807 que l'on trouve le premier essai de théorie sur la cause des maladies des vins ( $\left.{ }^{1}\right)$.

"Pour mieux comprendre, dit Chaptal, les dégénérations auxquelles les vins sont sujets, il faut rappeler quelques-uns des principes que nous avons déjả développés.

" La fermentation vineuse n'est due qu'à l'action réciproque entre le principe sucré et le ferment ou le principe végéto-animal.

" $1^{\circ}$. Si les deux principes de la fermentation se sont trouvés dans le moût dans des proportions convenables, ils ont dû être décomposés entièrement l'un et l'autre, et il ne doit exister, après la fermentation, ni principe sucré, ni ferment; dans ce cas, on ne doit craindre aucune dégénération ultérieure, puisqu'il ne se trouve dans le vin aucun germe de décomposition...

" $2^{\circ}$. Si le principe sucré prédomine dans le moût sur le principe régéto-animal ou ferment, ce dernier sera tout employé pour ne décomposer qu'une partie du sucre, et le vin conservera nécessairement un goût sucré...

"Les vins de cette nature peuvent être conservés sans altération aucune aussi longtemps qu'on peut le désirer...

" $3^{\circ}$. Mais si la levûre ou le ferment prédomine dans le moût sur le principe sucré, une partie du ferment suffira pour décomposer tout le sucre, et ce qui reste produit presque toutes les maladies propres au vin. En effet, ce principe de fermentation existant toujours dans le vin, ou bien il réagit sur les principes que contient la liqueur,

1. Le traité de $l$ Art de faire le vin, de Chaptal, a paru d'abord en 1799 [1800] dans les Annales de chimie et dans le Cours d'agriculture de l'abbẻ Rozier. Cette première édition parle des maladies des vins sans leur attribuer des causes bien déterminées. (Note de Pasteur.)

Chaptal. Traite sur les vins. Annales de chimie, XXXV, an VIII, p. 240-299; XXXVI. an IX, p. 3-49, 113-143 et 225-257; XXXVII, an IX, p. 3-37. - Art. VIN. In : Cours complet d'agriculture, ou Dictionnaire universel d'agriculture de Rozier. Paris, 1781-1800, 10 vol. in-40. Tome X, p. 284-378. - Lart de faire le vin. Paris, 1807, xix-368 p. in-80 (1 pl.). (Note de l'Édition.) 
et, dans ce cas, il produit une dégénération acide; ou bien il se dégage de la liqueur qui le retenait en dissolution, et lui donne alors une consistance sirupeuse qui produit le phénomène qu'on appelle graisser, filer, etc. ( $\left.{ }^{1}\right)$. "

Ce n'est pas le lieu de dire ce que ces opinions de Chaptal ont d'exagéré. Je me bornerai seulement à faire remarquer que la dernière, qui est relative aux causes des maladies des vins, règne encore dans la science. Les auteurs qui ont succédé à Chaptal n'en ont pas donné de plus certaine, et même ils n'ont fait que la reproduire sous des formes diverses. Elle est d'ailleurs bien en harmonie avec les théories de la fermentation dues à MM. Liebig ( $\left.{ }^{(2}\right)$ et Berzelius ( $\left.{ }^{3}\right)$ et que les travaux accomplis en France avaient paru confirmer.

En résumé, nous voyons qu'il a été admis jusqu'à présent que le vin est un liquide dont les principes réagissent sans cesse les uns sur les autres, qui se trouve constamment dans un état de travail moléculaire intestin, et que, lorsqu'il renferme une matière azotée de la nature du gluten, ou, comme on dit aujourd'hui, albuminoïde, celle-ci peut se modifier ou s'altérer par des causes inconnues et provoquer alors les diverses maladies du vin.

\section{OPINION NOUVELLE \\ SUR LES CAUSES DES MALADIES DES VINS ET DESCRIPTION DE CES MALADIES}

Les principes que j'expose dans cet ouvrage, et que'je crois avoir déduits d'une observation attentive des faits, sont tout autres que ceux que je viens de faire connaître.

En premier lieu, j'essayerai de montrer que le vin ne travaille pas de lui-même, à beaucoup près, autant qu'on le suppose. Sans doute, le vin étanit un mélange de diverses substances, parmi lesquelles il y a des acides et de l'alcool, il doit se former, avec le temps, des éthers particuliers, et des réactions du même ordre prennent peut-être naissance entre les autres principes également contenus dans le vin. Mais si l'on ne peut nier l'exactitude de tels'faits, parcel qu'ils sont établis sur des lois générales, confirmées et étendues par des travaux récents,

1. Chaptal. L'art de faire le vin. Paris, 1807 , in-80, p. 248-250.

2. Liebig. Traité de chimie olganique. Paris, 1840-1844, 3 vol. in-80. - Lettres sur la chimie considérée dans ses rapports avec l'industrie, l'agriculture et la physiologie. Paris, 1845, in-16. - Nouvelles lettres sur la chimie. Paris, 1852, in-16.

3. Berzelius (J.-J.). Traité de chimie. Paris, 1829-1883, 8 vol. in-8०. (Notes de l'Édition.) 
je crois que l'on en fait une fausse application lorsqu'on les veut faire servir à rendre compte du vieillissement des vins ou de leurs maladies, en un mot, des principaux changements de bonne ou de mauvaise nature dont ils sont le siège évident.

L'un des résultats principaux de mon travail est précisément d'établir que les variations qui s'observent dans les qualités du vin abandonné à lui-même, soit en tonneau, soit en bouteille, reconnaissent pour causes des influences extérieures à sa composition normale. Il résultera, je l'espère, de l'ensemble de mes observations et de mes expériences, que le vieillissement des vins réside essentiellement dans des phénomènes d'oxydation dus à l'oxygène de l'air, qui se dissout et pénètre dans le vin de diverses manières. J'établirai, en outre, qu'une deuxième source des changements propres au vin ne doit pas être cherchée dans l'action spontanée d'une matière albuminoïde, modifiée par des causes inconnues, mais dans la présence de régétations parasitaires microscopiques, qui trouvent dans le vin des conditions favorables à leur développement, et qui l'altèrent soit par soustraction de ce qu'elles lui enlèvent pour leur nourriture propre, soit principalement par la formation de nouveaux produits qui sont un effet même de la multiplication de ces parasites dans la masse du vin.

De là cette conséquence claire et précise qu'il doit suffire, pour prévenir les maladies des vins, de trouver le moyen de détruire la vitalité des germes des parasites qui les constituent, de façon à empêcher leur développement ultérieur.

Nous verrons combien il est facile d'atteindre ce but

MALADIE DE L'AGESCENCE DU VIN - VINS PIQUÉS, AIGRES, ETC.

Je commencerai par la plus conmune de toutes les maladies des vins, celle qui constitue le vin acide, le vin piqué, le vin aigre, etc.

"L'acescence du vin, dit Chaptal, est la maladie la plus commune, on peut même dire la plus naturelle, car elle est une suite de la fermentation spiritueuse.

"Pour connaître exactement cette maladie, il faut rappeler quelques principes, qui seuls peuvent nous fournir des lumières à ce sujet.

"Nous avons observé plusieurs fois que la fermentation du moût n'avait lieu que par le mélange du principe sucré avec le principe 
végéto-animal : or, ces deux principes peuvent exister dans le moût dans des proportions bien différentes. Lorsque le corps sucré est abondant, le principe végéto-animal est tout employé à le décomposer, et il ne suffit même pas; de sorte que le vin reste sucré et liquoreux sans qu'on doive craindre une dégénération acide. Lọrsqu'au contraire le principe végéto-animal est plus abondant que le principe sucré, ce dernier est décomposé avant que le premier soit tout absorbé; alors il reste du ferment dans le vin, lequel s'exerce sur les autres principes, se combine avec l'oxygène de l'air atmosphérique, et fait passer la liqueur à la dégénération acide...

“ On ne peut prévenir ce mauvais résultat, ajoute Chaptal, qu'en clarifiant, collant, soufrant et décantant le vin pour enlever tout le ferment qui y existe, ou bien en mêlant dans le vin du sucre ou du moût très sucré, pour continuer là fermentation spiritueuse, et employer tout le levain à produire de l'alcool(1). ”

Telle est l'application particulière faite par Chaptal de sa théorie générale des causes des maladies du vin à l'explication de l'acescence.

Le vin renferme de la matière albuminoïde; celle-ci, sous l'influence de circonstances diverses mal déterninées, mais au nombre desquelles on peut compter comme très efficace l'élévation de la température, devient propre à absorber l'oxygène de l'air et à acidifier l'alcool.

Une opinion semblable a été admise et mieux précisée plus tard par M. Liebig dans son Traité de chimie organique.

“ L'alcool pur ou étendu d'eau, dit M. Liebig, ne s'acidifie pas à l'air. Le vin, la bière, et en général les liqueurs fermentées, qui, outre l'alcool, contiennent des matières organiques étrangères, s'acidifient facilement au contact de l'air, à une certaine température. L'alcool pur étendu d'eau subit la même transformation quand on y ajoute certaines matières organiques, telles que de l'orge germée, du vin, du marc de raisin, du ferment, ou même du vinaigre déjà tout formé.

“ En considérant l'ensemble des phénomènes, il ne peut y avoir le moindre doute à l'égard du rôle que jouent ces matières azotées dans l'acidification de l'alcool. Elles mettent l'alcool en état d'absorber l'oxygène, puisque à lui seul il ne possède pas cette faculté. L'acidification de l'alcool est absolument de même ordre que l'action qui provoque la formation de l'acide sulfurique dans les chambres de plomb; de la même manière que l'oxygène de l'air est transporté sur l'acide sulfureux par l'intermédiaire du bioxyde d'azote, de même aussi les substances organiques, en présence de l'esprit-de-vin, 
absorbent l'oxygène et le mettent dans un état particulier qui le rend susceptible d'être absorbé par l'alcool (1). ”

J'ai démontré ailleurs $\left(^{2}\right)$ que cette manière de voir est tout à fait inacceptable, et que la fermentation appelée acétique s'accomplit sous l'influence exclusive d'un être organisé, agissant à la manière du noir de platine. Entre cette théorie et la théorie ancienne que je viens d'exposer d'après Chaptal et M. Liebig, il y a cette différence fondamentale, qu'au lieu de placer la propriété de condensation et de transport de l'oxygène de l'air dans les matières azotées du vin, de la bière, du cidre, de la levùre, etc., je prétends qu'elle ne réside que dans un mycoderme, et que, dans tous les cas où des matières organiques azotées, associées à l'alcool et exposées à une certaine température, ont donné lieu à la formation d'acide acétique, le mycoderme a pris naissance à l'insu de l'expérimentateur. La différence des deux opinions, toute simple qu'elle puisse paraître au premier moment, est au fond considérable, autant pour la théorie générale des fermentations que pour les applications industrielles.

Sans revenir sur les nombreuses preuves expérimentales renfermées dans mon Mémoire inséré dans les Annales scientifiques de l'École Normale, je dois néanmoins faire connaître les observations particulières sur lesquelles je m'appuie pour étendre à l'acescence du vin la conclusion la plus importante de ce Mémoire, savoir, qu'il n'y a jamais acescence d'un liquide alcoolique en dehors de la présence du champignon microscopique désigné sous le nom de mycoderma aceti.

Avant d'entrer dans le détail de ces observations, il est utile que je dise quelques mots de l'histoire de ce petit champignon et de diverses particularités de son développement.

Les botanistes micrographes attribuent à Persoon (1822), à Desmazières (1825), ou à Kützing (1838) (3), le mérite d'avoir décrit, comme productions de nature végétale, ces pellicules grasses que l'on voit se

1. Likbig. Traité de chimie organique. Paris, 18ł0-1844, 3 vol. in-80. Tome Ier, p. 388. (Note de l'Édition.)

2. Mémoire sur la fermentation acétique. Annales scientifques de l'École Normale supérieure, I, 1864, p. 113-158 (5 fig.), et surtout mes " Ettudes sur le vinaigre ", brochure in- 8 , Paris, Gauthier-Villars, 1868 [p. 23-77 du présent volume]. (Note de Pasteur.)

3. Persoon. Mycologia europæa. Erlangen, 1822, 3 vol. in-80 (fig. col.). - Il décrit, sectio prima, p. 96-97 : XLII. Mycoderma ollare, mesentericum, Lagena et pergameneum.

DEsmaztères (J.-B.). Recherches microscopiques et physiologiques sur le genre mycoderma. Annales des sciences naturelles (part. botanique), X, 1827, p. $42-67$ (1 pl.). - Il décrit le mycoderma cervisia, p. 59.

Kürzivg (F.). Recherches microscopiques sur le ferment et la mère de vinaigre, et de quelques autres formations qui en dépendent. Répertoire de chimie scientifique et industrielle, III, 1838, p. 257-283 (28 fig.). - Il parle p. 261 des algues du vinaigre (ulvina aceti). (Note de l'Édition.) 
former si facilement à la surface du vin, de la bière, du vinaigre; mais Chaptal avait, longtemps auparavant, assigné une nature végétale à ces pellicules.

"Un phénomène, dit Chaptal, qui a autant frappé qu’embarrassé les nombreux écrivains qui ont parlé des maladies du vin, c'est ce qu'on appelle les fleurs $d u$ vin. Elles se forment dans les tonneaux, mais surtout dans les bouteilles, dont elles occupent le goulot : elles annoncent et précèdent constamment la dégénération acide du vin. Elles se manifestent dans presque toutes les liqueurs fermentées, et toujours plus ou moins abondamment, selon la quantité d'extractif qui existe dans la liqueur...

«Ces fleurs, que j'avais prises d'abord pour un précipité de tartre, ne sont plus à mes yeux qu'une végétation, un vrai byssus, qui appartient à cette substance fermentée. Il se réduit à presque rien par la dessiccation et n'offre à l'analyse qu'un peu d'hydrogène et beaucoup de carbone.

“ Tous ces rudiments ou élbauches de végétation [qui se développent dans tous les cas où une matière organique se décompose] ne me paraissent pas devoir être assimilés à des plantes parfaites... De semblables phénomènes s'observent dans toutes les décompositions des êtres organiques (1). ”

Le mycoderma aceti est une des plantes les plus simples. La figure 1 le représente en voie de formation. Il consiste essentiellement en chapelets d'articles, en général légèrement étranglés vers leur milieu, dont le diamètre, un peu variable suivant les conditions dans lesquelles la plante s'est formée, est moyennement dans son jeune âge de 1,5 millième de millimètre. La longueur de l'article est un peu plus du double, et comme il est un peu étranglé en son milieu, on dirait quelquefois une réunion de deux petits globules, surtout lorsque l'étranglement est court; et, quand il y a une couche, une pellicule un peu serrée de ces articles, on croirait avoir sous les yeux un amas de petits grains ou de petits globules. Il n'en est rien. Si l'on méconnaissait cette structure des articles du mycoderma aceti, on pourrait souvent confondre ce mycoderme avec des ferments en chapelets de grains de même diamètre, qui en diffèrent cependant essentiellement par leur fonction chimique.

Le mode de multiplication de ces articles n'est pas douteux. Chacun d'eux s'étrangle de plus en plus, et donne deux nouveaux globules ou articles, qui s'étranglent eux-mêmes en grandissant, et ainsi de suite.

1. Ghaptal. Traité sur les vins. Annales de chimie, XXXVI, an IX, p. 249-251. (Note de l'Édition.) 
Beaucoup d'infusoires, les vibrions notamment, se reproduisent ainsi.

On peut composer des liqueurs qui provoquent le développenent de la plante avec une rapidité vraiment extraordinaire. Que l'on prenne, par exemple, un liquide formé de :

100 parties d'eau de levûre de bière( $\left(\mathfrak{I}^{2}\right)$, ou d'eau qu'on aura fait bouillir avec de la lie de vin;

1 ou 2 parties d'acide acétique;

3 ou 4 parties d'alcool,

et que l'on sème à sa surface quelques taches de mycoderma aceti, à la température de $20^{\circ}$ environ; dès le lendemain ou le surlendemain, le plus souvent, la surface du liquide, quelle qu'en soit l'étendue, sera couverte d'un voile uni, formé exclusivement par les petits articles du mycoderme en chapelets enchevêtrés. L'imagination se refuse à calculer le nombre des articles ainsi produits dans un espace de temps relativement très court.

Comment se procurer une première fois la semence de mycoderma acet $i$ ? Rien n'est plus facile. Le liquide dont je viens de donner la composition, ou tout autre analogue, fournit constamment, sans y rien semer préalablement, après un temps plus ou moins long (deux, trois, quatre jours ou un peu plus), un voile de mycoderma aceti. On le place à cet effet dans un cristallisoir couvert d'une lame de verre. Les poussières qui sont dans l'air, ou à la surface des parois du cristallisoir, ou dans les liquides mélangés, renferment toujours quelque semence pouvant amener le développement du petit champignon. Il faudrait, pour que cela n'êt pas lieu, prendre des précautions particulières, par exemple mélanger les liquides chauds, laver à l'eau bouillante le cristallisoir, etc., toutes manipulations qui tuent les germes des êtres inférieurs. Il n'est pas difficile de s'en convaincre, car, si l'on prend les précautions de propreté exagérée que j'indique, bien qu'on opère au contact de l'air ordinaire, on voit que l'on peut reculer, en quelque sorte à la volonté de l'opérateur, l'apparition spontanée de la plante.

Voici d'autres compositions de liqueurs très propres à fournir le

1. Prendre de lå levìre de bière en pâte (ou de la lie de vin), la faire bouillir dans de l'eau pendant un quart d'heure à la dose de 50 ou 100 grammes par litre d'eau, flltrer à clair : c'est ce que j'appelle eau de levure. En évaporant 100 centimètres cubes de la liqueur, dessèchant dans une étuve à eau bouillante, on a la teneur des matiẻres extractives dissoutes. Cé sont des substances albuminoïdes et autres, avec phosphates terreux et alcalins qui, en général, offrent dans cette préparation un aliment azoté et minéral excellent pour la plupart des ferments, soit végétaux, soit animaux. La bière, le vin, le cidre, etc., renferment des principes analogues. Ce sont ces principes que Chaptal et Liebig [Loc. cit.], adoptant les idées de Fabroni, considèrent par erreur comme étant des ferments. 
mycoderma aceti spontanément, c'est-à-dire sans semence ajoutée directement. Je citerai, par exemple, 1 volume de vin rouge ou blanc ordinaire, avec 2 volumes d'eau et 1 volume de vinaigre; ou bien encore 1 volume de bière, 1 volume d'eau et $\frac{1}{2}$ volume de vinaigre. Je parle ici de vinaigre de table, qui renferme environ 7 pour 100 d'acide acétique. Au lieu de vinaigre de table, on pourrait se servir d'eau pure additionnée d'une quantité d'acide acétique cristallisable correspondante.

Les proportions de ces mélanges peuvent être beaucoup modifiées, en restant néanmoins dans de certaines limites. Ce qui doit être évité lorsqu'on veut obtenir spontanément le mycoderma aceli, ce sont les petits infusoires, bacterium et autres, et surtout le mycoderma vini, production si connue sous la dénomination qu'employait tout à l'heure Chaptal, de fleurs du vin.

Le vin ordinaire, surtout le vin rouge et particulièrement le vin rouge nouveau, non étendu d'eau et sans addition d'acide acétique, ne donne que rarement le mycoderma aceti spontané. Il produit assez facilement, au contraire, le mycoderma vini. Il le produit plus facilement encore si l'on étend le vin de son volume d'eau.

Le vin rouge ordinaire donne assez difficilement naissance au mycoderma aceti pour que j'aie vu souvent le mycoderma vini se former spontanément sur du vin à la surface duquel je n'avais pourtant semé que du mycoderma aceti, et bien que ce dernier eût pris déjà un commencement de développement, pénible il est vrai. Il est assez curieux même d'observer dans ce cas la marche de ces végétations. Tandis que le mycoderma aceti se multiplie avec une grande lenteur, le mycoderma vini, de croissance plus rapide, envahit peu à peu la surface du liquide et refoule toutes les plages couvertes de mycoderma aceti, lequel s'épaissit progressivement, puis finit par tomber au fond du liquide en laissant toute la place à son voisin.

Mais les choses se passent autrement si le vin est additionné d'acide acétique, par exemple de son volume de vinaigre de force ordinaire. C'est alors le mycoderma aceti qui se développe de préférence, et l'on peut reproduire dans ces conditions, en sens inverse, l'expérience de tout à l'heure, c'est-à-dire faire étouffer le mycoderma vini par son congénère.

Enfin, on peut avoir des liqueurs qui offrent à la fois par développement spontané les deux mycodermes mêlés. Ainsi la bière étendue de son volume d'eau donne volontiers un mélange des deux mycodermes. Sans addition d'eau, le mycoderma vini est ordinairement le plus abondant. 
MALADIE DE L'ACESCENCE

(Vins piqués, aigires, etc.)

Fleurs du vinaiĝre /mycoderma aceti' . Le ferment est encore très jeune.

Fig. 1

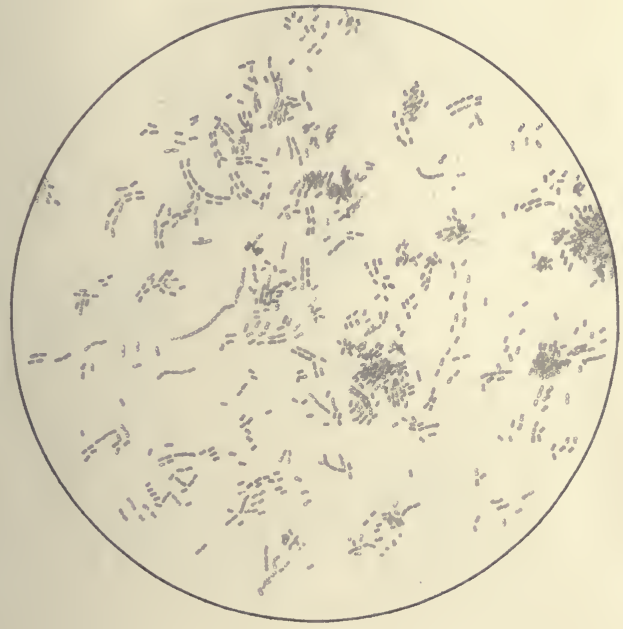

P. Luckerhwuer: ad. nat. det .

Inq. Girny-Gras Paris 

On empêche toujours les bacteriums de se montrer en acidulant un peu les liqueur's; aussi ne les voit-on jamais apparaître dans le vin.

La figure 2 représente l'image photographique d'une des variétés du mycoderma vini développée spontanément à la surface de vin rouge. Le mode de multiplication de la plante par bourgeonnement est bien évident sur les articles ou globules qui se trouvaient exactement au foyer. Le grossissement était de 460 en diamètre.

Lorsque j'eus acquis une connaissance suffisante des propriétés des deux mycodermes du vin et de leur manière d'agir en présence de l'oxygène, conformément aux résultats signalés dans une Note que j'ai insérée aux Comptes rendus de l'Académie au mois de février 1862 (1) et du Mémoire relatif à la fermentation acétique $\left(^{(2)}\right.$ que j'ai publié dans le tome I ${ }^{\text {er }}$ des Annales scientifiques de l'École Normale $\left({ }^{3}\right)$, je m'attachai à rechercher s'ils s'appliquaient fidèlement à toutes les circonstances r'elatives à la maladie de l'acescence du vin. C'est le point qu'il me reste à éclaircir.

L'une des localités où cette maladie est la plus fréquente est le Jura, notamment dans la région du vignoble très réputé d'Arbois, des Irsures, de Pupillin, etc. La connaissance que j'avais des lieux et l'obligeance des personnes $\left({ }^{4}\right)$ rendirent facile et plus fructueux le travail auquel je me livrai pendant les mois de septembre, octobre et novembre 1863.

1. Voir p. 7-12 du présent volume : Etudes sur les mycodermes. Rôle de ces plantes dans la fermentation acétique.

2. Voir p. $23-77$ du présent volume : Mémoire sur la fermentation acétique. (Notes de l'Édition.)

3. Ce Mémoire a été réimprimé dans mes "Études sur le vinaigre ". Paris, 1868, GauthierVillars. [Voir la note 1 de la page 23.]

4. Je dois adresser des remerciements particuliers á MM. Gallier, Charrière, Jules Vercel, Eugène Vuillame, et à la Société de viticulture d'Arbois, présidée par M. Parandier, inspecteur général des ponts et chaussées.

Je saisirai également l'occasion qui m'est offerte de témoigner ma gratitude envers le conseil municipal de la ville d'Arbois pour les intentions généreuses qu'il a manifestées à mon égard.

Mes expériences ont consisté quelquefois en analyses trés délicates, celles, par exemple, que je rapporterai sur la composition des gaz contenus dans le vin. On comprendra aisément les difficultés qu'elles ont dû rencontrer dans une ville où je ne pouvais trouver aucune des ressources d'un laboratoire, et où j'avais dû transporter de Paris les appareils de physique et de chimie les plus indispensables. Plusieurs personnes furent témoins de ces embarras matériels. Or, il arriva, tout à fait à mon insu, que le conseil municipal de la ville d'Arbois, sur la proposition du maire, M. le comte de Broissia, magistrat plein de zèle et de dévouement aux intérèts qui lui étaient confiés, décida qu'un local et une somme suffisante seraient mis à ma disposition pour la création d'un laboratoire à ma convenance. Je crus devoir décliner un lıonneur dont l'acceptation aurait trop engagé l'indépendance de mes études, mais je n'en garde pas moins une vive reconnaissance ì mes compatriotes, et je suis heureux de divulguer ici une démarche qui honore autant la science que les personnes qui en ont pris l'initiative iclairée. 
Je me transportai dans plusieurs caves et j'examinai sur place toutes les sortes de vins en tonneaux.

Voici très sommairement les pratiques ordinaires de la vinification dans le vignoble dont il s'agit.

Les raisins sont déposés dans une cuve qui a été amenée à la vigne même. Un ouvrier égrappe soigneusement tous les raisins, puis la vendange est conduite chez le propriétaire et vidée dans des tonneaux de petite ou de grande dimension, situés dans des caves assez profondes, avec voûtes de maçonnerie. Elle y fermente et y séjourne pendant six semaines ou deux mois. Alors on soutire le vin clair, on presse les marcs, dont la partie liquide est mise à part sous‘le nom de vin de pressurage. Le vin soutiré est placé dans des tonneaux que l'on ne remplit jamais entièrement. Pour un tonneau de 50 à 60 hectolitres, la vidange, mesurée en hauteur, est de 20 centimètres environ de la bonde au niveau du liquide. Elle est de 10 centimètres à peu près pour un tonneau de 500 à 600 litres. Le vin, après cette entonnaison, est abandonné, sans qu'on y touche, jusqu'au mois de février ou de mars. Alors il est soutiré, et de nouveau avec la précaution de laisser du vide dans les tonneaux, autant que la première fois.

Par suite de cet usage, qui consiste à ne pas remplir les tonneaux au moment des soutirages, le vin en tonneau, dans les localités qui m'occupent, est constamment couvert de fleur. Elle y forme une couche blanche, épaisse, sous laquelle le vin est généralement fort limpide.

Cela posé, l'observation microscopique m'a permis de constater que, toutes les fois qu'un vin était considéré, par un dégustateur habile, comme sain et non piqué, les fleurs étaient composées de mycoderma vini très pur (fig. 2). Au contraire, et sans aucune exception, les fleurs étaient un mélange de mycoderma vini et de mycoderma aceti lorsque le vin tournait à l'acide. La figure 3 représente cette association des deux mycodermes.

Les vins ordinaires, pour ainsi dire à tous les âges (il est vrai qu'on ne conserve ceux-ci que peu d'années) et les vins de choix, lorsqu'ils sont nouveaux, n'offrent guère que le mycoderma vini pur; mais les vins fins de ploussard (1), de trousseau, de ploussard et naturé blanc, vins qu'on laisse volontiers vieillir en tonneaux pendant cinq et six années, et souvent davantage, avant de les mettre en bouteilles, montrent assez souvent le mycoderma aceti dans la fleur qui les recouvre. D'ailleurs, le vin est d'autant plus piqué et tourné à l'aigre 
que la proportion du mycoderma aceti est plus grande. Le vin est tout i fait perdu, propre seulement à être transformé en vinaigre, dans le cas où le mycoderma aceti est seul développé.

Le mycoderme âgé perd beaucoup de sa netteté originelle. Il se montre au microscope sous l'aspect d'un amas de granulations où l'on ne retrouve plus la disposition en chapelets que représente la figure 1. La figure 4 rend assez bien cette nourelle apparence.

En multipliant ces recherches, il m'est arrivé fréquemment de constater la présence du mycoderma aceti en si faible quantité dans la lleur que son influence fâcheuse sur le vin n'était pas encore appréciable au goùt. Enfin la sûreté des indications microscopiques est telle que l'on peut fréquemment assigner à l'avance l'état du vin avant toute dégustation.

Il résulte de ce qui précède que Chaptal avait tort de dire d'une manière absolue que les fleurs annoncent toujours la dégénération acide du vin, puisque l'on voit dans le Jura des vins couverts de fleurs pendant des années sans qu'ils s'aigrissent, mais c'est à la condition que la fleur sera toujours formée de mycoderma vini pur. Or, ainsi que je le faisais remarquer tout à l'heure, la pureté de la fleur du vin tend à disparaître au fur et à mesure que le vin vieillit, que le vin se dépouille, pour employer une expression consacrée. Physiologiquement parlant, le vin perd de son aptitude à nourrir le mycoderma vini, lequel, se trouvant progressivement privé d'aliments appropriés, se fane, s'atrophie, et alors le mycoderma aceti apparaît et se multiplie avec une facilité d'autant plus grande qu'il puise assez longtemps sa première nourriture dans les cellules mêmes du mycoderma vini (1). On peut consulter pour cet objet le paragraphe IX de mon Némoire sur la fermentation acétique $\left({ }^{2}\right)$.

Il faut bien se convaincre, d'ailleurs, qu'il n'y a pas d'autre circonstance possible. Un vin en tonneau que l'on n'ouille pas tous les mois ne peut pas ne pas être couvert de fleur. Or, il n'y a guère que deux

1. L'aspect physique de la fleur change avec sa pureté, et l'on peut en quelque façon mettre cet aspect de la fleur en rapport avec sa nature et avec son action sur le vin. Les anciens agronomes avaient mème fait à ce sujet des remarques judicieuses. Pline [Histoire naturelle (Coll. Nisard), tome Ier, livre XIV, p. 540], dit : " La fleur du vin blanche est de bon augure; rouge, de mauvais, à moins que ce ne soit la couleur du vin. " On trouve dans les Géoponiques [de Cassianus Bassus] un passage plus exact et plus étendu sur le même objet. Il est certain que l'aspect velouté, d'un blanc un peu sec, du mycoderma vini pur et jeune change beaucoup, lorsque ce mycoderme se trouve associé à son congénére, le mycoderma aceti, lequel vit à ses dépens, lo fane, et permet son humectation et sa coloration par le vin, circonstance qui change entièrement l'apparence extérieure de la fleur. On pourrait, si on le désirait, apporter une certaine rigueur dans ces comparaisons, et en tirer quelques inductions sur la proportion du mélange des deux mycodermes.

2. Voir ce paragraphe p. 66-69 du présent volume. (Note de l'Édition.) 
espèces de fleurs possibles pour le vin : ce sont les précédentes. $\mathrm{S}$ donc le mycoderma vini ne se développe pas, ou mieux si, après s'ètr développé, il vient à se faner et à mourir, il faut nécessairement qu le vin se couvre de mycoderma aceti. La maladie de l'acescence fai alors les progrès les plus rapides.

Les personnes habituées aux soins de l'ouillage, prescrit ave raison dans la plupart des vignobles, seront bien surprises san doute d'apprendre que, dans le Jura, on éloigne au contraire systé matiquement cette pratique, et elles seront tentées de considére comme défectueux des usages si opposés à ceux qu'elles pratiquen avec succès sur les vins de leurs départements. N'est-il pas vraisem blable cependant que chaque localité est arrivée à une sorte de per fection relative dans les pratiques qu'elle s'impose? Je suis volontier porté à croire que les usages séculaires ont plus ou moins leur raisor d'être dans la nature même des choses. Si le Jura fait le vin et le soigne tout autrement que la Côte-d'Or, dont il lui serait si facile d'imiter les coutumes, n'est-ce pas la nature du vin qui l'exige? Le vins de ces deux départements sont de compositions très différentes Les cépages ne sont pas et ne peuvent pas être les mêmes. Le pinot de la Bourgogne communique aux grands vins de cette contrée ui bouquet particulier dont les vins du Jura sont privés. Ces dernier sont généralement beaucoup plus acides, tant à cause de la nature de cépages que par l'effet d'une maturité moindre à l'époque de la vendange. Un développement des fleurs, très nuisible en Bourgogne, ne pourrait-il donc pas, au contraire, se montrer sans mauvaise influence. utile même, dans le Jura? J'ai constaté un fait qui pourrait bien rendre raison de la nécessité de la pratique de l'ouillage en Bourgogne, et de son inutilité dans le Jura. C'est que la fleur spontanée des vins de Bourgogne est le plus souvent le mycoderma aceti, tandis que celle des vins du Jura, dans les premières années principalement, est formée par le mycoderma vini pur. Or, le mycoderma aceti doit être éloigné à tout prix, puisqu'il acétifie nécessairement le vin, tandis que le mycoderma vini est inoffensif à ce point de vue. Il s'empare de l'oxygène de l'air et le porte sur l'alcool à la manière du mycoderma aceti; mais. tandis que celui-ci fait de l'eau et de l'acide acétique, le mycoderma vini transforme l'alcool en eau et en acide carbonique. La combustion qu'il provoque étant complète, il ne dépose rien de nuisible dans le vin

L'étude comparative de la nature des fleurs à la surface des grands vins de Bourgogne et du Jura, ou de telle autre localité déterminée. 
eut se faire sans trop de dépense et commodément par le moyen des ins en bouteilles. J'ai réuni un certain nombre de bouteilles de vins e Pomard et de Volnay, et un nombre égal de bouteilles de bons vins rdinaires du Jura, toutes bien bouchées. Les bouchons peuvent même tre mastiqués. En laissant les bouteilles debout, il arrive ordinaiement que le vin, dans l'intervalle de quelques semaines, se couvre le fleurs dans le goulot des bouteilles. Or, on constate facilement que e mycoderma aceti apparaît de préférence dans les bouteilles de Bourgogne, et le mycoderma vini dans celles du Jura. Ce dernier résultat tant précisément le même dans le Jura pour les vins en tonneaux, il st vraisemblable que le fait que nous offre ici le bourgogne en pouteilles s'appliquerait également au bourgogne conservé en tonreaux, c'est-à-dire qu'il se couvrirait de préférence du mycoderma rceti. L'ouillage en Bourgogne, particulièrement pour les vins fins, est lonc une pratique nécessaire. Le Jura, au contraire, peut considérer ette pratique d'un œil indifférent. L'immunité toutefois n'est pas absolue, ainsi que je l'ai expliqué tout à l'heure. Elle dépend de l'âge hu vin et de sa qualité.

L'existence dans les vins de Bourgogne d'un bouquet spécial, que eux du Jura ne présentent pas, peut bien encore exiger l'absence de oute fleur, même du mycoderma vini pur, à la surface des vins de la Còte-d'Or. Le mycoderma vini peut déterminer en effet la combustion complète de quelques-un's de leurs principes volatils. Pareil inconvénient n'est guère à craindre pour les vins du Jura, puisqu'ils n'ont pas de bouquet spécial.

Si les faits qui précèdent démontrent que l'on peut, sans inconvénient sensible, laisser les vins du Jura en vidange à l'époque des soutirages et leur permettre de se couvrir de fleurs, ils ne prouvent pas que ces fleurs doivent leur être utiles. Mais il y a une circonstance digne d'intérêt, sur laquelle je puis, dès à présent, appeler l'attention. Lorsque j'examinerai la composition des gaz contenus dans le vin, nous reconnaîtrons que ce liquide, même exposé librement au contact de l'air, ne peut pas dissoudre la moindre trace d'oxygène, pour peu qu'il soit recouvert d'une pellicule de mycoderma vini. En d'autres termes, l'oxydation des principes du vin par l'oxygène de l'air est profondément modifiée par la présence du mycoderma vini, et, comme j'espère démontrer dans la deuxième partie de cet ouvrage que l'on ne peut pas impunément altérer les conditions de l'aération du vin, je suis porté à croire que la présence du mycoderma vini à la surface des vins du Jura (et sans doute cela pourrait se dire de plusieurs autres sortes de vins) entre comme élément utile dans les pratiques de la vinifi- 
cation de cette contrée, par les conditions spéciales dans lesquelle elle place le vin sous le rapport de l'aération.

En résumé, je ne me crois pas du tout autorisé, par les résultats d mes recherches, à conseiller aux propriétaires du Jura et de bieı d'autres localités d'adopter la pratique de l'ouillage; mais, si j'avai le bonheur que ce modeste ouvrage répandît l'usage des observation microscopiques parmi les personnes qui ont de grands intérêts dan le commerce des vins, je leur conseillerais de faire une étude trè: attentive de la nature de la fleur et de sa composition à chaque souti rage, et de suivre la pratique de l'ouillage dès que l'on s'apercevrai que le mycoderma vini perd de sa pureté, c'est-à-dire qu'il se montre associé, même au degré le plus faible, avec le mycoderma aceti.

Je reviens aux études microscopiques que j'ai faites dans les cave: d'Arbois. Leur utilité sera mieux appréciée si je m'attache exclusivement à celles qui concernent une sorte de vin fort estimé que l'on prépare dans le Jura, notamment dans le vignoble de Château-Châlons, sous les noms de vin jaune, vin de garde, vin de Château-Châlons, et qui a beaucoup d'analogie avec le vin de Madère sec.

Voici les procédés que l'on suit à peu près invariablement pour faire cet excellent vin.

Le cépage exclusivement employé est le savagnin ou naturé blanc. Tandis que la vendange principale du vignoble a lieu du $1^{\text {er }}$ au 15 octobre, la récolte du naturé ne commence qu'en novembre, et l'on attend même que les premières gelées aient un peu coti le grain du raisin. On égrappe à la vigne comme à l'ordinaire. La vendange est mise sous le pressoir dès qu'elle arrive. Le moût qui s'écoule est réuni dans des cuves découvertes, placées dans les celliers ou dans les caves selon l'emplacement du pressoir. La fermentation se déclare un peu plus tôt, un peu plus tard, d'après le degré de la température, généralement froide à cette époque de l'année. Une couche écumeuse, de couleur chocolat clair, monte à la surface, emportée par les premières bulles de gaz acide carbonique. On saisit le moment, souvent rapide et fugitif, où cette couche commence à se fendiller. C'est alors que le vin, toujours un peu trouble, est le plus éclairci. On le soutire par un robinet placé au-dessus du dépôt boueux du fond. Ce vin, ou mieux, ce clair, comme on l'appelle, eśt mis dans une cuve ouverte à côté de la première; le lendemain ou le surlendemain, la fermentation a ramené à la surface une deuxième couche de matière un peu épaisse, un nouveau soutirage est pratiqué. Quelquefois, cela dépend de l'épaisseur de la deuxième couche ou de l'année, on procède à un troisième soutirage après une nouvelle fermentation. Le soutirage, en temps convenable, empêche 
que la couche boueuse de la surface retombe et se mêle au liquide.

Le vin est mis ensuite en tonneau, où on le laisse indéfiniment, mềne sans le soutirer jamais, jusqu'à ce qu'il mange sa lie, expression volontiers employée par les vignerons. Le vin reste doux souvent pendant plusieurs années.

Tel est le mode de préparation du vin jaune, vin très remarquable au point de vue de l'application des principes de la science. Ce vin reste en tonneau pendant quinze ou vingt ans et même bien plus longtemps, sans ouillage, et, comme les tonneaux ont souvent une capacité de 10, 20 hectolitres, la vidange du tonneau s'élève quelquefois à 3 et 6 hectolitres. L'étude attentive de ce vin et de toutes les conditions de sa fabrication est une de celles qui m'ont le plus éclairé sur les propriétés générales des vins.

Représentons-nous la composition que doit avoir nécessairement le vin jaune bien fait. Sa préparation à une époque tardive, alors que le raisin a déjà subi les premiers froids de l'hiver, le soin que l'on met à éloigner les matières azotées du moût au moment de la fermentation des premiers jours, montrent assez que la fermentation ultérieure dans les tonneaux est toute particulière. Elle se rapproche extrêmement de ces cas de fermentation que j'ai examinés autrefois, dans lesquels le sucre est en grand excès relativement à la quantité de matière assimilable à l'état de ferment organisé actif, et où la proportion de glycérine et d'acide succinique formés est la plus élevée. Il en résulte que le vin jaune, dès son origine, est un vin dépouillé, un de ces vins dont Chaptal aurait dit qu'il y a excès du principe sucré sur le principe ferment, et que, par conséquent, ce vin ne doit pas être sujet aux maladies. Les choses sont telles, en effet, pour la plupart des maladies du vin. Elles n'atteignent pas le vin jaune. Mais si l'on se reporte pour un moment à l'un des chapitres de mon Mémoire, déjà cité, sur la fermentation acétique, chapitre intitulé : Acétification sans matière albuminoïde $\left(^{1}\right)$ où je démontre que le mycoderma aceti peut vivre, à la rigueur, et se multiplier sur des liqueurs de composition, pour ainsi dire, purement minérale, on comprendra facilement que la proposition de Chaptal ne saurait s'appliquer à la maladie de l'acescence. Or, le vin jaune, par son mode même de fabrication, qui exige une vidange prolongée, doit être fort sujet à contracter cette maladie. C'est, en effet, ce que j'ai pu constater, et, bien qu'au début de mes recherches je reçusse volontiers cette assurance que le vin jaune ne s'altérait pas, je ne tardai pas à reconnaitre que toutes les personnes qui habituellement

1. Voir ce chapitre p. 51-53 du présent volume. (Note de l'Édition.) 
préparent de tel vin en perdent fréquemment, et lorsque j'en vins aux observations microscopiques dans les caves, toutes celles-ci m'offrirent un ou plusieurs tonneaux de vin jaune plus ou moins aigri. Grâce à cette circonstance, j'ai pu examiner un grand nombre de tonneaux de vin blanc, façon de vin jaune, au point de vue de la relation nécessaire qui existe, suivant moi, entre la présence du mycoderma aceti et l'existence de la maladie de l'acescence du vin. Or, j'ai reconnu que, dans tous les cas où le vin m'a été signalé comme altéré, plus ou moins, il portait à sa surface, soit le mycoderma aceti seul, soit un mélange de mycoderma aceti et de l'une des variétés du mycoderma vini, variété caractérisée par cette circonstance, qu'elle a un aspect bien plus grêle que celle qui pousse sur les vins rouges ou blancs ordinaires. Elle est formée, en général, de globules sphériques et non d'articles plus ou moins rameux. Cette variété était seule développée et très pure toutes les fois que le vin jaune était sain.

Dans bien des cas, il m'est arrivé d'avertir utilement les propriétaires, à la suite d'un examen microscopique, de l'urgence qu'il y avait à éloigner du vin la pellicule de sa surface par un soutirage immédiat dans un tonneau très propre, que l'on remplirait complétement, en s'attachant à écarter le plus possible la moindre quantité de l'ancienne fleur.

Le grand prix du vin jaune, les soins qu'il exige, me firent consulter fréquemment sur les moyens que l'on pourrait mettre en pratique pour le guérir lorsqu'il a pris un commencement d'acescence. J'ai essayé un procédé fort simple et tout naturellement indiqué, qui a donné les meilleurs résultats : je veux parler de la saturation par la potasse caustique pure. A cet effet, après avoir déterminé exactement le titre acide du vin malade, et celui d'un vin analogue de bonne qualité, on sature la différence des deux titres acides par la potasse en solution concentrée et dosée. L'opération réussit toutes les fois que l'acidité due à l'acide acétique ne dépasse pas 2 grammes environ d'acide acétique par litre (1).

Je noterai cette circonstance, bien digne d'attention, que le bouquet des vins jaunes, bouquet souvent très prononcé et que masque l'odeur de l'acide acétique, n'est nullement altéré par un commencement d'acétification. Il reparaît après la saturation par la potasse. C'est sans doute parce que le bouquet des vins jaunes, comme je le démontrerai plus

1. Il faut bien que le moyen soit bon, car j'ai eu l'occasion de traiter de cette manière plus de 500 litres de vin jaune, par portions appartenant à divers propriétaires qui n'avaient sollicité le remẻde qu'après avoir constaté la guérison sur des échantillons. C'est seulement lorsque l'acescence est trop avancée que l'acétate de potasse communique au vin une saveur un peu pharmaceutique. 
MAL.ADIE DE L'ACESCENCE DU VIN

(Nycoderma vini et Nycoderma aceti réunis.)

La maladie est à son début: la fleur du vin commence à perdre de sa pureté.

Fig. 3

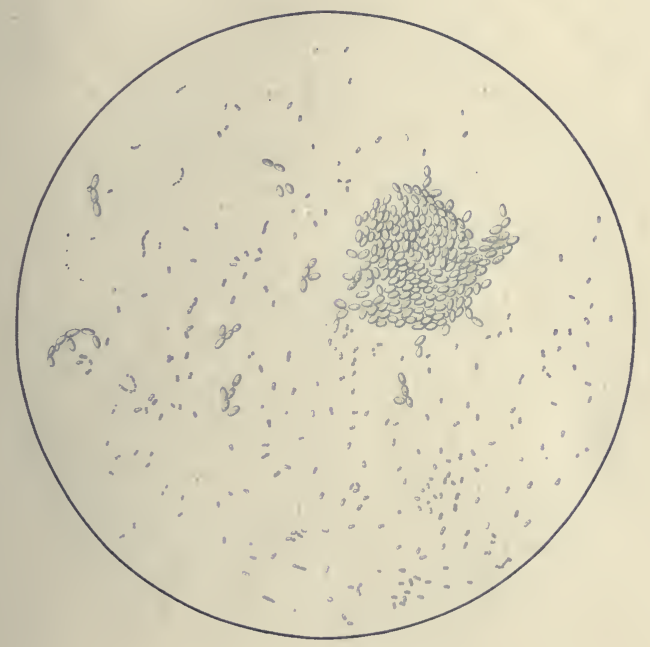



MALADIE DE L'ACESCENCE DU VIN

Mucouterma areti.)

- A cet état de ferment, le mal est dejjà très-avancé

Fig. 4

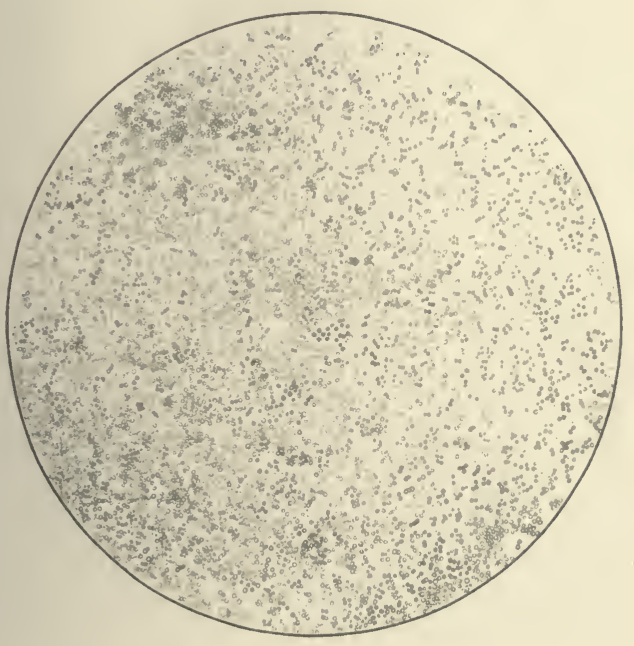



tard, est le résultat d'une oxydation, et que l'acétification, qui est également une oxydation, ne peut agir en sens inverse d'une action chimique de même ordre.

L'influence non douteuse de l'oxygène pour détruire certains principes odorants du vin encore mal connus, et qui contribuent à son arome, montre bien, si on la rapproche du fait que je signale relativement au bouquet du vin jaune, qu'il peut exister dans les vins des substances volatiles odorantes de natures très diverses. Les unes sont naturelles, propres aux cépages, d'autres sont acquises, et, parmi ces dernières, les plus importantes sont la conséquence de phénomènes d'oxydation. Je remets à la seconde partie de mon travail les preuves de cette opinion.

MALADIE DES VINS TOURNÉS, MONTÉS, QUI ONT LA POUSSE, ETC.

Lorsque la chaleur des mois de mai, juin, juillet, août, a pénétré suffisamment dans les caves ou dans les celliers et en a élevé la température de plusieurs degrés, il arrive fréquemment, èt dans tous les pays, que le vin tourne. Voici les caractères de cette maladie. Le vin est plus ou moins trouble, et, si on l'agite dans un tube de verre de 1 à 2 centimètres de diamètre, on y voit des ondes soyeuses se déplacer et se mouvoir en divers sens. Cela rappelle l'effet de certains précipités minéraux, notamment celui que montre le racémate de chaux. Le tonneau est-il bien fermé et plein, il n'est pas rare de voir des suintements aux joints des douves; les fonds mêmes du tonneau peuvent bomber. Si l'on pratique un fausset, le vin jaillit avec force et très loin. De là l'expression vulgaire : il a la pousse. Versé dans un verre, on aperçoit souvent sur les bords une couronne de très petites bulles à la surface du vin. Exposé à l'air, sa couleur change; elle se fonce; le trouble du vin paraît augmenter. La saveur est, en outre, plus ou moins altérée. Elle prend quelque chose de fade. L'abbé Rozier dit qu'on peut rendre un vin, même très généreux, semblable à un vin poussé, si on le bat et si on l'agite longtemps à l'air libre. Or, on sait que le vin qui a été soumis à l'action de l'air perd de sa force, ce que l'on exprime en disant qu'il s'évente. Rozier dit encore que la maladie de la pousse rend les vins plats, faibles et de mauvais goût( $\left(^{(1)}\right.$. Tous les auteurs qui ont

1. Rozier. De la fermentation des vins et de la meilleure manière de faire l'eau-de-vie. Lyon, 1770 , in-8 ${ }^{\circ}$, p. 15 . - Ouvrage médiocre, qui a remporté [en 1767] le prix proposé en 1766 par la Société d'agriculture de Limoges. 
écrit sur le vin tourné attribuent cette maladie à la lie qui remonte. Ils croient que le dépôt que l'on trouve, en quantité variable, au fond des tonneaux, se soulève et se répand dans toute la masse du vin.

Cette maladie est très fréquente. La moindre négligence dans les soutirages peut la provoquer. Certains vins blancs y sont également sujets, et aussi la bière et le cidré. Les expressions de bière tournée, de cidre tourné, sont bien connues.

Au mois de septembre 1858, j'eus l'occasion de constater dans plusieurs vins altérés du Jura un ferment très différent de la levûre alcoolique $d u$ vin, évidemment organisé, et qui offrait les plus grands rapports avec le ferment lactique. C'est alors que j'eus la première idée de rechercher si les maladies des vins étaient bien, comme on le croyait, des altérations spontanées, sans causes appréciables, une sorte de déviation du mouvement de ces réactions intestines auxquelles on attribuait le vieillissement graduel du vin. La présence constatée, dans un vin malade, de filaments organisés analogues à ces ferments que j'étudiais depuis deux ans et auxquels j'attribuais les fermentations proprement dites, ouvrait aux recherches sur le vin des aperçus nouveaux sur lesquels une circonstance particulière devait bientôt appeler l'atténtion.

Un grand propriétaire de vignobles de Montpellier avait vendu le 20 octobre 1861, après la récolte, du vin de bonne qualité, agréé par l'acheteur. Le 14 novembre, ce vin avait éprouvé une altération profonde. On avait cru d'abord que ce vin avait été additionné d'eau, conclusion que repoussaient d'une manière absolue l'honorabilité du propriétaire et la fidélité de ses employés. Le propriétaire s'empressa de consulter M. Balard, qui voulut bien m'inviter à examiner ce vin avec lui.

Tout de suite nous reconnûmes que ce vin altéré, et si fade que l'on pouvait croire à une falsification par addition d'eau, était précisément sous l'influence d'une fermentation spéciale de la nature de la fermentation lactique. M. Balard l'étudia avec sa sagacité ordinaire (la Note qu'il lut à l'Académie sur ce sujet est insérée au tome LIII des Comptes rendus de ses séances [1]); il ne tarda pas à reconnaître toute la fréquence de cette maladie dans le midi de la France.

Pendant les automnes de 1863 et de 1864, j'ai eu l'occasion d'examiner dans le Jura un grand nombre de vins tournés.

Telles sont les circonstances qui ont permis de constater que le trouble du vin tourné est dù, sans aucune exception, à la présence de

1. BaLARD. Sur une altération spontanée de certains vins. Comptes rendus de l'Académie des sciences, LIII, 1861, p. 1226-1230. Voir Document II, p. 483-487 du présent volume. (Note de l'Édition.) 
filaments d'une extrême ténuité, qui ont souvent moins de $\frac{1}{10(0) 1}$ de millimètre de diamètre, de longueurs très variables. La figure 5 représente l'apparence au microscope d'une goutte de vin tourné. Des filaments sont suspendus dans un liquide très limpide. Ce sont ces filaments qui donnent lieu, lorsque le vin est agité, à ces ondes soyeuses dont je parlais tout à l'heure. Quant au dépót du tonneau, ce n'est point du tout de la lie ordinaire, mais un amas de ces filaments, souvent très longs, tous enchevêtrés les uns dans les autres, formant ordinairement une masse noirâtre, glutineuse, qui se tient et se met en fils muqueux lorsqu'on la retire à l'aide d'un tube effilé plongeant jusqu'au fond du tonneau ou de la bouteille. Ce ferment s'accompagne, dans son action sur le vin, d'un dégagement de gaz acide carbonique que je crois sans mélange de gaz étranger (cela mérite cependant confirmation), et c'est là ce qui donne lieu au pétillement dans le verre et au phénomène de la pousse dont j'ai parlé. La pression augmente en effet dans le tonneau par suite de la production de ce gaz.

La maladie du tourné est donc constituée par une fermentation due à un ferment organisé spécial, et c'est sous l'influence du développement de ce parasite que la limpidité du vin, sa saveur et sa qualité éprouvent des changements si prononcés.

Je saisis de nouveau l'occasion qui m'est offerte de faire remarquer la grande utilité des observations microscopiques dans les soins que réclament les vins. Rien n'est plus facile que de reconnaître si un vin est prêt à prendre la maladie qui nous occupe. On ouvre le robinet adapté au tonneau; on rejette les premières portions du vin qui s'écoule, on en tire de nouveau un verre, qu'on laisse reposer quelques heures; puis, après décantation, on examine au microscope les dernières gouttes restées dans le verre. Si peu que le vin soit trouble, ces gouttes offrent de nombreux filaments. Le plus souvent même, l'examen attentif d'une goutte de vin, sans attendre qu'il ait déposé, suffit pour reconnaître s'il a éprouvé un commencement de maladie. L'examen du dépôt du tonneau n'est pas moins instructif, lorsqu'on le fait à divers intervalles. On òte la bonde et l'on plonge un tube à gaz un peu effilé à son extrémité, jusqu'à ce qu'il touche le fond, en s'en servant à la manière d'un tâte-vin. S'il y a de la fleur à la surface du vin, elle couvre les parois extérieures du tube lorsqu'on le retire du tonneau. Il faut essuyer cette fleur avec un linge et laisser perdre les premières portions du dépôt, puis observer au microscope. Si l'on n'avait pas la précaution d'essuyer le tube extérieurement, la fleur se mêlerait à la goutte que l'on doit examiner au microscope, et il pourrait en résulter des erreurs d'observation. Il est facile de juger de l'abondance plus ou 
moins grande du parasite dans le dépôt formé depuis le dernier soutirage ou depuis le dernier examen microscopique.

Le parasite dont il s'agit est un de ceux auxquels le vin donne le plus facilement asile et qui ont la plus grande influence sur sa composition. J'ai dit qu'il se montrait de préférence après les chaleurs des mois de juin, juillet, août. Il faut entendre que c'est à ce moment que le parasite se multiplie et envahit toute la masse du vin, mais je vais établir par de nombreuses observations

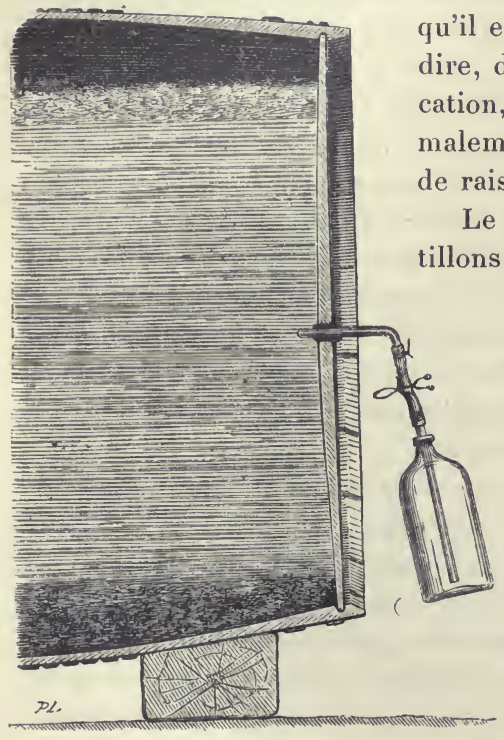

Fig. 6. qu'il existe à l'état de germe, pour ainsi dire, dès les premiers temps de la vinification, et qu'il accompagne presque normalement le ferment alcoolique du moût de raisin.

Le 21 novembre 1864, divers échantillons de vins rouges et blancs du Jura, de la récolte d'octobre, même année, ont été prélevés sur place, dans les caves, les vins étant encore sous le marc, non éclaircis, avant tout soutirage quelconque et en prenant la précaution de ne pas les exposer au contact de l'air. A cet effet, le vin s'écoulait des foudres (foudres de 40 à 60 hectolitres) dans des flacons de litre qui avaient été préalablement remplis de gaz carbonique. La figure 6 représente ce mode de prélèvement des échantillons. J'ai dit que dans le Jura la vendange, égrappée à la vigne, était amenée dans les caves et placée dans des tonneaux où elle fermente pendant six semaines environ. On pratique alors le premier soutirage, qui porte dans le pays le nom d'entonnaison. C'est avant ce soutirage que les échantillons ont été prélevés. Aussitôt après le remplissage des flacons, les bouchons étaient placés et serrés fortement, puis mastiqués. La vendange avait eu lieu du 10 au 20 octobre 1864. Ces vins ont été expédiés à Paris et examinés aussitôt après leur arrivée, c'est-à-dire dans les premiers jours de décembre 1864. Après agitation des flacons, ils étaient tous un peu troubles; par le repos le trouble tombait, et l'on voyait se rassembler sur le fond des vases un dépôt sensible. J'ai commencé par 
étudier ce dépôt au microscope avec beaucoup de soin. Un mot en premier lieu sur la nature de ces vins.

No 1. - Vin d'Arbois de tous plants. Ploussard dominant, et environ un quart de trousseau. Très bon ordinaire. Température du vin au moment de la prise d'échantillon, $11^{\circ}$.

$\mathrm{N}^{\circ}$ 2. - Vin d'Arbois de tous plants, aveć enfariné et plant maldoux dominant. Vin très ordinaire. $\mathrm{T}=8^{\circ}, 5$.

$\mathrm{N}^{\circ} 3$. - Vin d'Árbois presque uniquement formé par du ploussard des meilleures vignes de Pupillin. Vin très fin. $T=9^{\circ}, 5$.

$\mathrm{N}^{\circ}$ 4. - Vin d'Arbois de tous plants $\left({ }^{4}\right)$. Vin ordinaire. $\mathrm{T}=9^{\circ}$.

$\mathrm{N}^{\circ}$ 5. - Vin d'Arbois de ploussard à peu près pur. Vin assez fin.

$\mathrm{N}^{\circ}$ 6. - Vin d'Arbois de ploussard, valet noir et naturé. Très bon ordinaire. $\mathrm{T}=9^{\circ}, 5$.

No 7. - Vin d'Arbois, bon ordinaire, un peu moins fin que le $\mathrm{n}^{\circ} 5 . \mathrm{T}=9^{\circ}$.

No 8. - Vin blanc d'Arbois, du plan appelé melon. Vin blanc cuvé, c'est-à-dire que la vendange a été nise à fermenter dans les foudres à la manière de la vendange rouge. Le vin blanc non cuvé est celui qui est obtenu en faisant fermenter le moût que donne la vendange par l'action du pressoir. La vendange blanche du plan melon est ordinairement cuvée; celle du plant naturé ou savagnin est au contraire soumise au pressoir.

Voici le résumé des observations microscopiques propres aux dépôts de ces huit espèces de vins.

$N^{*}$ 1. - Belle levûre alcoolique de vin, de tailles diverses, de forme sphérique ou ovale, rarement sous forme allongée ou piriforme.

1. Je ferai remarquer que la température de la vendange qui a fourni ce vin a été élevée de 12 à $1 \%$, en portant à une température voisine de l'ébullition une partie du moùt de cette vendange. Voici le détail de l'opération :

Lorsque le foudre fut rempli aux trois quarts de vendange (il ne faut pas remplir entiérement, à cause de la grande augmentation du volume par la fermentation), on a soutiré par la cannelle * environ 30 litres de moût par 500 litres de vendange; puis, après avoir chauffé ce moût dans de grandes chaudières de cuivre, on l'a reversé dans le tonneau. Pour opérer le mélange de la partie chaude avec la partie froide, on a soutiré par la cannelle des seaux de mont que l'on a reversé par la bonde, un grand nombre de fois, jusqu'á ce que la température des couches supérieures de la vendange fut celle du mont arrivant par la cannelle. Cette expérience a été faite à titre d'essai pour faciliter la fermentation. Je ferai remarquer que la fermentation a dû être modifiée par une autre cause, sur laquelle j'aurai l'occasion de revenir, je veux parler de l'aération du moût par le fait du mélange des diverses portions de la vendange tel que je viens de le relater.

* La cannelle ou cannette est un robinet de bois ou de bronze qui est adapté à la partie inférieure du tonneau. Son condult serait bientôt obstrné par les pellicules des grains do raisin, si l'on n'avait la précaution d'entourer son orifice intérieur par une calotte formée d'un treillie d'osiers. 
Beaucoup de cristaux de bitartrate de potasse en lamelles aiguillées, associés à des cristaux prismatiques-octaédriques de tartrate de chaux. Enfin, de temps à autre, en déplaçant la lame de verre sur le porteobjet, un filament pareil à ceux de la figure 5 .

$N^{0} 2$. - Le dépôt a exactement l'aspect du $\mathrm{n}^{0} 1$ et renferme les mêmes éléments organiques ou minéraux; filaments du parasite aussi rares que dans le $n^{\circ} 1$.

№ 3. - Même dépôt; mêmes principes; mais ce dépòt se distingue tout de suite des précédents par une plus grande abondance des filaments du parasite. Il y en a toujours plusieurs dans chaque champ; dans les $n^{\text {os }} 1$ et 2 il fallait chercher dans plusieurs champs pour en trouver un seul.

$\mathrm{N}^{\circ}$ 4. - Même dépôt, mais avec absence complète de bitartrate de potasse; rares cristaux de tartrate de chaux; ici pas du tout de filaments. Il m'est arrivé quelquefois d'en soupçonner un, en cherchant attentivement dans une foule de champs distincts, mais je n'oserais rien affirmer. L'élévation initiale de la température de la vendange et son aération ne paraissent donc pas avoir provoqué le développement du parasite filiforme.

No 5 . - Même dépôt que dans le $\mathrm{n}^{\circ} 1$; peut-être quelques filaments de plus que dans les $n^{\text {os }} 1$ et 2 .

$\mathrm{N}^{\circ} 6$. - Même dépôt et toujours avec bitartrate en lamelles plus ou moins nettes, et des cristaux de tartrate de chaux. Des filaments du parasite à peu près comme dans le $n^{\circ} 3$, toujours plusieurs par champ.

No 7. - Ici les globules de levûre alcoolique paraissent vieux et fanés ( $\left.{ }^{1}\right)$. Pas de tartrate de chaux. Du bitartrate de potasse en aiguilles peu nettes. Des huit échantillons, c'est celui qui renferme le plus de filaments du parasite. Il y en a sensiblement plus que dans les $n^{\text {os }} 3$ et 6 , une dizaine par champ environ.

No 8. - Ici pas de filaments du parasite dans le dépôt, qui est formé d'une belle levûre alcoolique.

Ainsi, sur huit échantillons de vins examinés un mois seulement après la vendange, six, au moins, ont offert le parasite qui fait tourner le vin pendant les chaleurs de l'été. La vendange avait eu lieu du 10 au 20 octobre. Je rappelle que, dans le Jura, du moins dans le vignoble d'Arbois, la fermentation de la vendange a lieu dans des foudres couchés, sans que l'air y ait le moindre accès, parce que la portion vide du foudre est constamment remplie de gaz acide carbonique.

1. Il faut attribuer ce caractère de la levùre à la présence abondante du parasite filiforme. [Cette note de Pasteur n'existe pas dans la 1re édition.] 
Le vin renferme donc, le plus souvent dès l'origine, et pour ainsi dire normalement, les germes de-son altération ultérieure, et ici, par le mot germe, je n'entends point parler d'une cause vague et indéterminée dans sa nature, mais d'un objet visible et tangible qui a déjà tous les caractères d'une organisation complète et qui se multipliera à profusion dès que les conditions de son développement seront favorables ( $\left.{ }^{1}\right)$.

1. Il m'est arrivé de voir le ferment filiforme dont il est ici question se multiplier dans une fermentation alcoolique presque á l'égal du ferment levûre. Le 5 septembre 1863, j'ai mis à fermenter dans une bouteille de verre, munie d'un tube abducteur plongeant dans l'eau :

Mare de raisin (résidu de l'expression au pressoir de raisins frais) . . $1.573 \mathrm{gr}$.

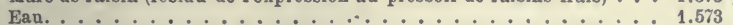

La fermentation, commencée dès le lendemain, a étẻ á la fois acide et alcoolique. La figure 7 représente l'aspect microscopique du ferment étudié le 19 septembre. On y voit que, sous le rapport du nombre des articles, le ferment filiforme était aussi multiplié que le ferment alcoolique. Je noterai, en passant, que ce dernier était en articles allongés, piriformes, souvent assez volumineux. C'est une des variétés du ferment alcoolique qui a sur le sucre une action plus lente, plus paresseuse que la levùre alcoolique ordinaire, et il est possible qu'il y ait eu lả une cause indirecte du plus facile développement du ferment filiforme. (Voir, au sujet des . variétés des levùres alcooliques, une Note que j'ai insérée dans le Bulletin de la. Soczété chimique de Paris pour le mois de juin 1862) [Quelques faits nouveaux au sujet des levûres alcooliques, tome II des [Euvres de PAsteur, p. 150-158.]

Le vin, très peu alcoolique, qui est résulté de cette fermentation, avait une acidité fort désagréable, et était très riche en acides volatils, dont il répandait même l'odeur.

Bien qu'il soit assez rare, sans doute, que les deux ferments dont je parle s'accompagnent dans de telles proportions relatives, il est pourtant nécessaire que l'attention soit éveillée sur

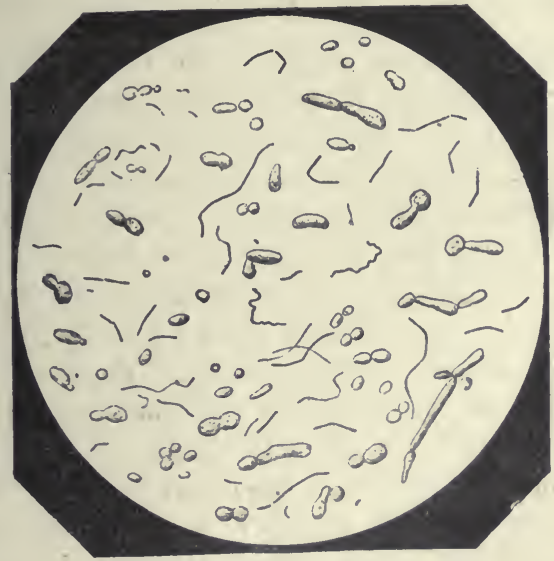

FIg. 7.

la possibilité d'un tel fait, qui rappelle ces fermentations de jus de betteraves á la fois lactiques ou mannitiques et alcooliques, qui sont désignées sous le nom de fermentations nitreuses, parce qu'elles donnent lieu à une décomposition des nitrates de la liqueur. J'ai fait remarquer 
Poursuivons cette étude. L'entonnaison, dans le Jura, se fait à la fin de novembre. Le premier soutirage a lieu ensuite au mois de mars, et le deuxième au mois de juillet ou d'août.

Le 20 juillet 1865, j'ai examiné au microscope onze dépôts de vins de la récolte de 1864, vins de la même nature que ceux dont je viens de parler. Tous étaient en foudres de 40 à 50 hectolitres et venaient d'être soutirés. Le premier soutirage avait eu lieu, selon l'usage, au mois de mars. Voici le résultat de l'examen microscopique :

Vin fin de ploussard. - Assez grand nombre de filaments dans chaque champ du microscope.

Vin commun de tous plants. - Le champ en est rempli.

Vin commun de tous plants. - Plusieurs par champ.

Vin bon ordinaire. - Pas du tout.

Vins de Montigny, des Arsures et d'Arbois mêlés. - Quelques-uns par champ.

Vin bon ordinaire. - Le champ en est rempli.

Vin ordinaire. - Rares filaments.

Vin très bon ordinaire. - Rares filaments.

Vins des Arsures, d'Arbois et de Montigny mêlés. - Plusieurs par champ.

Vin bon ordinaire. - Grand nombre.

Vin fin des Arsures. - Une foule dans chaque champ du microscope.

Il est manifeste par ces résultats que le parasite continue de se multiplier et d'agir après la fermentation originelle, et d'autant mieux, paraît-il, qu'il n'est plus associé au ferment alcoolique, puisque nous trouvons ici généralement bien plus de filaments du parasite que dans les huit vins encore sous le marc dont j’ai parlé en premier lieu.

Avant d'aller plus loin, je ferai tout de suite remarquer l'un des bons effets des soutirages. Ces onze sortes de vin étaient clairs et en bonne santé pour le propriétaire qui les possédait. Cependant nous voyons que le parasite s'était multiplié depuis l'entonnaison de novembre, mais cette multiplication n'affectait pas encore la masse du vin. De là une limpidité satisfaisante. Quant à la qualité accusée par la dégustation, on comprend très bien qu'elle n'ait pu paraître déjà altérée, puisque le parasite n'avait pris qu'un développement relativement faible; car un vin n'est réputé malade pour le propriétaire et

depuis longtemps [Note sur la fermentation nitreuse, tome II des [Euvres DE PAstÉUR, p. 37] que la cause de ces fermentations anormales est due précisément, comme dans le cas actuel, au développement parallèle et simultané du ferment alcoolique et de l'une des variétés du ferment lactique op du ferment visqueux. 
le consommateur qu'alors que les produits nouveaux répandus dans ce vin s'y trouvent en proportion suffisante. Jusque-là rien n'avertit de l'existence du mal. C'était le cas présentement; mais le microscope nous dit que le mal existait et avait dû commencer ses ravages. Aussi rien de plus rationnel que cette vieille coutume léguée par la sage expérience-de nos pères qui conseille de soutirer le vin en temps convenable pour en éloigner les dépôts.

Ceux-ci, en effet, sont tout prêts, je ne dirai pas à remonter dans le vin, l'expression serait impropre, mais à se multiplier dès que la température s'élèvera dans les celliers ou dans les caves.

Quand le développement du parasite est lent et pénible, il est naturel qu'on le rencontre de préférence dans le fond du tonneau, où il tombe en vertu de son poids; mais lorsque les conditions de son développement sont plus favorables, on le trouve partout dans la masse du vin. Il pourrait bien, dans certains cas exceptionnels, y être porté par des bulles de gaz qui le soulèveraient du fond du tonneau, et, dans ce cas, on pourrait dire, avec raison, que la lie remonte dans le vin.

Je me plais à rattacher aux explications de la science les usages techniques. Ils sont presque toujours le fruit d'observations justes. Bien que la nature de mes travaux ne m'ait pas souvent rapproché de l'application, il m'a été donné déjà maintes fois de reconnaître toute la vérité des pratiques de métier. Il arrive bien parfois que c'est la vérité de la légende, mêlée de merveilleux; mais si cette pointe de miracle ne vous rebute pas, et que vous veniez à considérer les faits en eux-mêmes, vous reconnaîtrez, à peu près invariablement, qu'un usage quelconque, lorsqu'il est généralement suivi, est le fruit d'une expérience raisonnée, qu'il y a quelque utilité à ne point s'en écarter, et que la connaissance des phénomènes naturels qui s'y rattachent n'est vraiment complète que lorsqu'on peut en donner scientifiquement l'explication. J'en citerai quelques exemples.

Je crois que, dans tous les pays et à toutes les époques, comme on en a la preuve dans les traditions recueillies par les agronomes latins, les vignerons ont établi une relation entre la vie du vin et celle de la vigne. Ils prétendent qu'au moment où le raisin fleurit, vers le 15 juin dans le Jura, le vin est en travail, et, également au mois d'aoùt, lorsque le raisin commence à mûrir. Volontiers ils croient à une influence mystérieuse entre ces diverses circonstances. Rien n'autorise à aller jusque-là. C'est à cette époque que la température des caves subit des variations, et telle est sans doute l'explication de la coïncidence dont je parle. Mais qu'importe que le paysan croie au mystère? ETUDES SUR LE VINAIGRE ET SUR LE VIN. 
C'est le fait seul qu'il faut considérer, parce qu'il sert de guide dans certaines pratiques de la vinification.

Les plus vieux écrits sur le vin recommandent le mois de mars pour le premier soutirage, et que le vent du nord souffle, non le vent du sud, qui est le vent de la pluie, au moins dans le Jura. Ne croyez pas à un préjugé ou à une routine aveugle. L'usage est ancien. Il est suivi généralement. Recherchez plutôt s'il n'est pas dans la nature des choses, tout bizarre qu'il vous paraisse. Pour moi, il me semble fort rationnel. Le vin, surtout le vin jeune, est sursaturé de gaz acide carbonique. Si le baromètre est très bas depuis plusieurs jours, le vin doit dégager de ce gaz. Il doit s'en élever de petites bulles du fond des tonneaux, capables d'emporter avec elles les parcelles solides les plus ténues des dépôts. Le vin sera donc moins limpide que si on le soutire par un temps de brise, alors que la pression atmosphérique tend à augmenter la solubilité des gaz dans les liquides. Telle est, je pense, l'origine de la pratique dont je parle.

Un vigneron me dit un jour : Nous croyons que le vent du nord colle le vin, et il ajouta: Dans tous les cas, il est bien sûr qu'il colle l'eau de la rivière. Rien n'est plus vrai en effet. La rivière de la Cuisance, qui traverse la ville d'Arbois, a sa source à quelques kilomètres seulement, dans les premières assises du calcaire jurassique. L'eau est chargée de carbonate de chaux dissous à la faveur du gaz acide carbonique. Par le vent de la pluie, l'eau de la rivière perd de sa limpidité. On distingue moins bien les cailloux qui forment son lit. Quelquefois on voit la mousse du fond se soulever. Qu'au contraire le vent du nord souffle, et l'on apercevrait une épingle à plusieurs pieds de profondeur. N'est-ce pas la confirmation de l'explication que je donnais tout à l'heure au sujet du vin et du conseil de soutirer de préférence par le vent du nord?

Mais revenons au parasite du vin.

Je disais, en commençant cet ouvrage, que le travail du vin, c'est-à-dire ces changements lents et progressifs qui surviennent avec l'âge dans ses propriétés, sont moins un effet d'actions chimiques intestines spontanées entre ses divers principes que le résultat tout extérieur, en quelque sorte, des parasites auxquels il donne asile, joint à l'influence de l'introduction graduelle de l'oxygène de l'air.

En ce qui concerne les parasites de la figure 5 , je vais montrer, non plus par l'examen au microscope, mais par une étude chimique, que ces petits filaments, dont nous venons de constater la présence dans la levûre alcoolique du moût de raisin, suffisent pour déterminer dans le vin une modification lente et progressive. On a constaté 
depuis longtemps que le vin renferme des quantités variables d'acide acétique, auquel il faut ajouter d'autres acides gras volatils, suivant les observations de M. Béchamp $\left.{ }^{(}\right)$. Or, nous allons reconnaître que ce n'est point à la fermentation normale qui produit le vin qu'il faut en attribuer la présence, mais à l'action des parasites dont il s'agit, pour la plus grande partie du moins.

Je trouve dans un traité sur les vins de M. Mulder $\left({ }^{2}\right)$ un tableau des proportions d'acide acétique que ce savant a rencontrées dans direrses sortes de vins. Je ne reproduirai que quelques termes de ce tableau.

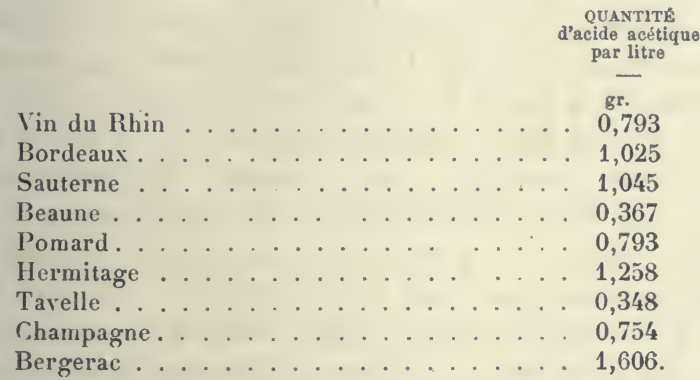

Ces nombres, nous allons le voir, sont tout à fait exagérés. Si le vin naturel n'est que le produit du ferment alcoolique propre au moût de raisin, il ne contient guère que 1 à 2 décigrammes d'acides volatils par litre. Je crois que, lorsque la proportion de ces acides dépasse ce chiffre, et c'est le cas le plus ordinaire, j'oserais même dire que cela est toujours ainsi pour les vins marchands, on peut être assuré que le vin a été sous l'influence des parasites, et il est possible de se rendre un compte assez exact des phases antérieures de la vie du vin à ce point de rue, par la détermination de la quantité des acides volatils qu'il renferme. J'espère même que, quand l'application de la chimie à l'industrie des vins sera plus répandue, on cherchera à connaître les altérations que les vins ont pu éprouver antérieurement, et qu'ils sont susceptibles d'éprouver encore, par la proportion des acides volatils qu'ils contiennent à un moment donné, par exemple au moment de leur mise en vente. Cette pratique mériterait toute l'attention du commerce.

1. BÉchasp (A.). Sur l'acide acétique et les acides gras volatils de la fermentation alcoolique. Comptes rendus de l'Académie des sciences, LVI, 1863, p. 969-972. (Note de l'Édition.)

2. Mulder. Chimie du vin. Rotterdam, 1855; Leipzig, 1857.

Voir aussi Ladrex. La chimie appliquée à la viticulture et à l'onologie. Paris, 1857, in-12, qui est un résumé clair et intéressant des principales connaissances à cette époque sur la vigne et le vin. 
Essayons, en effet, de déterminer la proportion des acides volatils de différents vins qui nous seront bien connus quant à l'influence qu'ils auront subie de la part du parasite (fig. 5).

Il ne faut pas espérer isoler complétement ces acides par la distillation. Les dernières portions d'acide acétique sont retenues opiniâtrément, et l'on doit craindre une altération des matières organiques du résidu du vin et le dégagement de l'acide succinique (1). La difficulté peut être levée de la manière suivante :

Un litre de vin est mis à distiller au bain de chlorure de calcium. On recueille d'abord $500 \mathrm{cc}$. de liquide exactement, puis $400 \mathrm{cc}$; on ajoute alors $400 \mathrm{cc}$. d'eau pure, et l'on recueille de nouveau par la distillation $400 \mathrm{cc}$. de liquide. L'expérience montre que le rapport des produits volatils, à partir de la troisième distillation, est à peu près celui de 2 à 1 entre deux distillations successives. Il est donc facile de déduire approximativement, des quantités d'acides volatils que renferment les 500 cc. recueillis en premier lieu et les 400 cc. recueillis ensuite à deux reprises, quelle est la proportion totale d'acide acétique renfermée dans 1 litre de vin.

Quant au dosage des acides volatils, évalués comme acide acétique pur, dans les liquides de distillation, il peut se faire à l'aide d'une solution d'eau de`chaux titrée. Voici quelques mesures prises en suivant cette marche :

Vin $n^{\circ} 1$, de la page 141.

Les 500 cc. ont exigé 26 cc. d'eau de chaux.

Les 400 cc. de la deuxième distillation ont exigé 44 cc. d'eau de chaux.

Les 400 cc. de la troisième distillation ont exigé sensiblement 20 cc. d'eau de chaux.

La quantité totale d'acide acétique contenue dans ce vin correspond donc à 26 cc. +44 cc. +20 cc. +10 cc. +5 cc. +2 cc. $5+1$ cc. $75+$ etc. d'eau de chaux. La somme de ces derniers nombres, non déduits de l'expérience directe, fait à peu près, et dans tous les cas il en sera de même, un nombre égal au troisième nombre déterminé expérimentalement. Le total général est donc sensiblement 26 cc. +44 cc. +20 cc. +20 cc. $=110$ cc. d'eau de chaux. Or, 27 cc. de cette eau de chaux

1. Il faudrait y joindre, selon MM. Berthelot et de Fleurieu, des acides éthérés [Sur le dosage de l'acide tartrique, de la potasse et de la crème de tartre contenus dans les liqueurs vineuses]. Annales de chimie et de physique, 4 sér., V, 1865, p. 177-264. - Voir, au sujet des acides volatils dans la fermentation, le Mémoire de M. Duclaux [Études relatives à l'absorption de l'ammoniaque et à la production d'acides gras volatils pendant la fermentation alcoolique]. Annales scientifiques de l'École Normale supérieure, II, 1865, p. 249-269. 
saturaient $0 \mathrm{gr}$. 06125 d'acide sulfurique ou $0 \mathrm{gr} .075$ d'acide acétique.

Les 110 cc. d'eau de chaux correspondent donc à 0 gr. 30 d'acide acétique par litrẹ de vin.

Vin $n^{\circ} 4$, de la page 141.

Les mèmes opérations sont effectuées.

Les 500 cc. ont exigé 18 cc. d'eau de chaux;

Les 400 cc. de la deuxième distillation ont exigé 28 cc.;

Les $400 \mathrm{cc}$. de la troisième distillation ont exigé $12 \mathrm{cc}$.

Le volume d'eau de chaux correspondant à l'acide acétique total est donc de $18 \mathrm{cc} .+28 \mathrm{cc} .+12 \mathrm{cc} .+12 \mathrm{cc} .=70 \mathrm{cc}$, , ce qui fait $0 \mathrm{gr} .19$ d'acide acétique par litre de vin.

Vin $n^{\circ} 7$, de la page 141 .

Mêınes opérations.

Ce vin renfermait $0 \mathrm{gr}$. 42 d'acide acétique par litre.

Mais considérons le vin $n^{\circ} 8$.

Les 500 cc. de la première distillation n'ont exigé que $17 \mathrm{cc}$. d'eaı de chaux pour leur saturation;

Les 400 cc. de la deuxième distillation ont exigé $20 \mathrm{cc}$;

Les $400 \mathrm{cc}$. de la troisième distillation ont exigé $10 \mathrm{cc}$.

Le volume total d'eau de chaux propre à saturer tout l'acide acétique contenu dans 1 litre de vin était donc égal à $17 \mathrm{cc} .+20 \mathrm{cc}$. +10 cc. +10 cc. $=57$ cc., ce qui équivaut à 0 gr. 16 d'acide acétique seulement par litre.

Il n'est pas douteux que les différences dans les proportions d'acides volatils entre ce $n^{0} 8$ et les $n^{0 s} 1,4$ et 7 doivent être rapportées presque exclusivement à celles qu'offraient leurs dépôts examinés au microscope. Mais il ne sera pas sans utilité d'en donner une preuve directe.

Le 4 janvier 1866, j’ai examiné de nouveau les dépôts de ces mêmes vins pris dans d'autres flacons que j'avais conservés soigneusement, et qui n'avaient jamais été ouverts depuis le jour où ils avaient été remplis, le 21 novembre 1864, c'est-à-dire depuis treize à quatorze mois environ. Ces vins étaient restés surchargés de gaz acide carbonique, très bien bouchés, et les bouchons mastiqués. Grâce à la fermeture et à la tension intérieure du gaz acide carbonique, il n'est pas rentré dans les flacons la moindre quantité d'air. Or, l'examen microscopique fait sur les dépôts des $\mathrm{n}^{\circ s} 1,2$, 4 et 7 a montré l'existence d'un nombre de filaments sensiblement plus grand que lors de la première observation qui avait été faite sur ces dépôts, 
observation relatée pages 141 et 142. Les figures $8,9,10$ et 11 donnent une idée de l'aspect du champ (1). J'ai alors déterminé de nouveau pour les $n^{\text {os }} 1$ et 4 les quantités d'acides volatils, et j'ai trouvé que le volume total d'eau de chaux (eau de mème dosage que la précédente) propre à saturer tout l'acide était :

Pour le $\mathrm{n}^{\circ} 1,43$ cc. +65 cc. +29 cc. +15 cc. +15 cc. $=167$ cc.;

Pour le $\mathrm{n}^{\circ} 4,38$ cc. +57 cc. +25 cc. +13 cc. +13 cc. $=146$ cc.

Ce qui équivaut à $0 \mathrm{gr}$. 46 et $0 \mathrm{gr}$. 40 d'acide acétique par litre de vin, proportions sensiblement plus élevées que celles qui existaient une année auparavant et qui étaient $0 \mathrm{gr} .30$ et $0 \mathrm{gr}$. 19. Cette différence ne peut s'expliquer que par la multiplication des filaments du parasite. Nul doute que j'aurais trouvé également bien plus d'acide acétique dans les vins $n^{\text {os }} 2$ et 7 , puisque les figures 9 et 11 accusent aussi une plus grande abondance du parasite depuis l'observation antérieure d'une année. Mais nous pouvons aller plus loin dans cet ordre de preuves.

J'ai fait observer précédemment que tous les vins en général, au fur et à mesure qu'ils prennent de l'âge, sont de plus en plus sous l'influence de productions parasites, alors même qu'ils ne sont pas encore considérés comme malades par les consommateurs. Il est donc vraisemblable que le vin marchand de une, deux, trois années d'âge renfermera une plus forte quantité d'acide acétique. C'est ce que l'expérience confirme. Voici l'essai de quelques vins choisis dans ces conditions :

Vin d'Arbois, bon ordinaire de 1863. - Étudié en 1865.

Un litre renferme $1 \mathrm{gr}$. 33 d'acide acétique.

Vin de Bordeaux, acheté en 1864, et vendu comme vin de 1859. Étudié en 1865.

Un litre renferme $1 \mathrm{gr} .08$ d'acide acétique.

Vin de Douby de 1854, envoyé par M. Terrel des Chênes $\left.{ }^{2}{ }^{2}\right)$ Beaujolais. - Étudié en 1865.

Un litre renferme $0 \mathrm{gr} .66$ d'acide acétique.

Vin de Bourgogne ordinaire de 1856. - Étudié en 1864.

Un litre renferme 0 gr. 80 d'acide acétique.

1. Je ferai remarquer, en passant, que nous avons ici la preuve certaine que le parasite de la figure 5 n'a pas du tout besoin de gaz oxygène pour se développer, puisqu'il s'est multiplié, dans cette occasion, absolument à l'abri de ce gaz.

2. Je saisis avec plaisir l'occasion qui m'est offerte de remercier M. Terrel des Chênes, auteur de divers écrits intéressants sur les maladies des vins, de son empressement à m'offrir ses services dans les études auxquelles je me suis livré. 
V'in des Arsures de 1859. - Étudié en 1864.

Un litre renferme $2 \mathrm{gr}$. 41 d'acide acétique. - Il est probable que ce dernier vin, qui n'avait été livré et mis en bouteille qu'au mois d'octobre 1863, avait éprouvé un commencement d'acétification par le mycoderma aceti développé à sa surface en tonneau.

Tous ces vins, sans exception, r'enfermaient des filaments. Il suffit de relever une des bouteilles, de la laisser reposer un jour ou deux, de décanter avec soin la presque totalité du vin et d'observer son dépòt au microscope, après l'avoir bien agité avec les 2 ou 3 centimètres cubes de liquide laissés à dessein au fond de la bouteille. Quelque faible que soit ce dépót, on voit un nombre variable de filaments qui se sont formés dans la bouteille ou qui proviennent du tonneau d'où le vin a èté tiré. Ainsi, la figure 12 représente le dépòt du vin de Douby de 1854 dont il a été parlé tout à l'heure. Je le répète, il est bien rare de trouver un vin rouge de table, commun ou de grand cru, bien naturel, qui soit exenıpt de parasites dans son dépôt. Cependant la figure 13 en offre un exemple. Elle représente le dépòt d'un vin de 1834, vin de qualité très supérieure. L'observation a été faite en 1865. Je reviendrai sur la nature de ces dépôts.

Ce que je désire surtout faire remarquer en ce moment, c'est que nous retombons ici pour des vins marchands, pris au hasard, sur des proportions d'acide acétique assez considérables et de l'ordre de celles que j'ai empruntées au tableau de M. Mulder (1).

Il n'est donc pas douteux que les quantités d'acide acétique trouvées par ce chimiste dans différents vins ne sont point naturelles et n'ont aucune signification propre. Elles sont l'effet d'une maladie du même ordre que la maladie de l'acescence, et dépendant d'une cause analogue.

L'acescence exige le contact de l'air. Elle est propre aux vins conservés en fûts. C'est elle, en grande partie du moins, qui a fait naître la pratique de l'ouillage, si nécessaire dans la plupart des vignobles. C'est elle encore qui a amené la pratique, non moins utile, de la conservation du vin en bouteilles couchées et non debout, parce que le vin dans des bouteilles debout, mème très bien bouchées, est sujet à l'acescence. Enfin, cette maladie exige le contact de l'air parce que son ferment ne peut vivre et agir qu'en présence de ce gaz. Mais à cóté de ce genre d'acescence, il y en a un autre dont les conditions diffèrent. Les vins en bouteilles couchées y sont sujets, aussi bien que ceux qui sont en fûts parfaitement ouillés. C'est que le ferment de 
cette maladie, qui est un ferment proprement dit, n'a pas du tout besoin de gaz oxygène libre pour vivre, ou pour agir. Aussi les vins les mieux soignés peuvent éprouver les effets de cette maladie. Il n'y a pas de pratique, aujourd'hui connue dans l'art de la vinification, qui puisse la prévenir sûrement. Cependant, comme son ferment se multiplie lentement, surtout à une basse température, et que, plus lourd que le vin, il tombe au fond des tonneaux, et que c'est là surtout qu'il agit, il est extrêmement utile, pour diminuer les inconvénients de cette maladie, de conserver les vins dans des caves à basse température, et de les soutirer vers l'époque des chaleurs. On les ịsole ainsi du dépòt qui les altère : on isole surtout le foyer du mal, et l'on oblige le végétal à se reformer avant qu'il puisse agir de nouveau. Telles sont, à mon avis, quelques-unes des principales circonstances qui ont amené l'usage des caves à basse température pour conserver le vin, et qui motivent la pratique si utile des soutirages, une ou deux fois par année.

Plus on réfléchira aux causes des maladies des vins, plus on se convaincra que l'art de la vinification, et les soins que l'expérience des siècles a proclamés nécessaires, ont principalement leur raison d'être dans les conditions mêmes de la vie et de la manière d'agir des parasites du vin, de telle sorte que, si l'on pouvait arriver à supprimer, par une opération pratique très simple, les causes des altérations spontanées des vins, on pourrait, sans nul doute, fonder un art nouveau de faire le vin, beaucoup moins dispendieux que celui qui est suivi depuis si longtemps, bien plus efficace surtout pour supprimer les pertes qu'occasionnent les maladies des vins, très propre par conséquent à l'extension du commerce de cette denrée:

Il est désirable que l'on atteigne ce but, car le vin peut être à bon droit considéré comme la plus saine, la plus hygiénique des boissons. Aussi, parmi celles qui sont connues aujourd'hui, c'est celle que l'homme recherche de préférence à toutes les autres, si peu que l'occasion lui ait été offerte de s'y habituer.

Ce serait ici le lieu d'examiner quels sont les principes immédiats du vin qui disparaissent, lorsque le vin tourne pour donner naissance à de nouveaux produits. M. Balard, dans la Note que j'ai citée précédemment $(1)$, et $M$. Béchamp $\left(^{2}\right)$ ont déjà traité cette question $\left({ }^{3}\right)$. Je m’en

1. Balard. Sur une altération spontanée de certains vins. Comptes rendus de l'Académie des sciences, LIII, 1861, p. 1226-1230.

2. Bёнамр (A.). Sur l'acide acétique et les acides gras volatils de la fermentation alcoolique. Ibid., LVI, 1863, p. 969-972. - Note sur l'acide acétique de la fermentation alcoolique. Ibid., p. 1086-1088. (Notes de l'Édition.)

3. M. Glénard, professeur de chimie à Lyon, s'était également occupé de ce sujet en 1862. [Glénard (A.). Note sur la fermentation tartrique du vin. Annales des sciences physiques 
MALADIE DES VINS TOURNÉS

Fig. 8

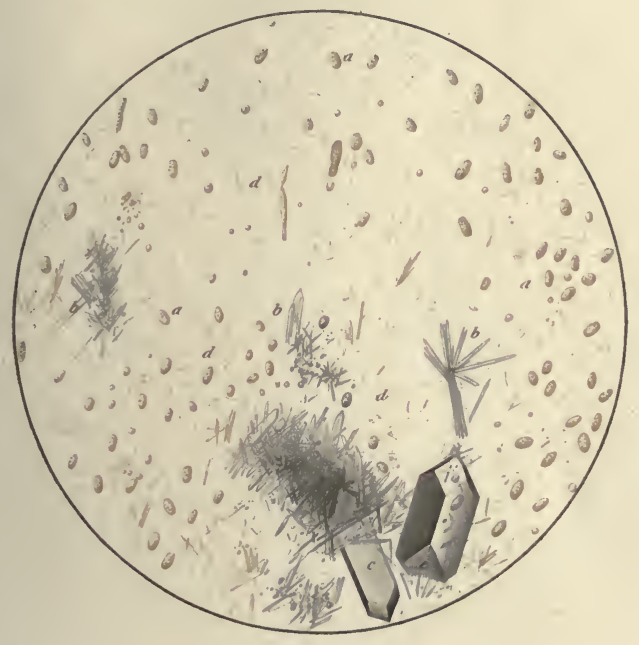

P. Lackerbouer ad nat det.

Imp. Geny Gras Paris

\section{$\frac{600}{1}$}

$a, a$. Ferment ordinaire alcoolique du vin

$b, b$. Cristaux aiguillés de bitartrate de potasse.

c, c. Cristaux de tartrate neutre de chaux.

$d, d$. Filaments du parasite qui détermine la maladie des vins tournés. 

MALADIE DH:S VINS TOLRNÉS

Fig. 9

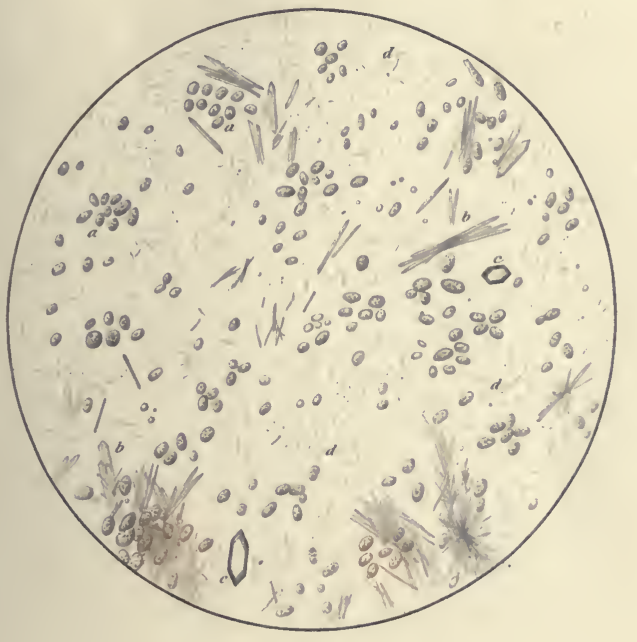

1. Lackerbauer, ad nat. del.

a. a. Ferment alcoolique ordinaire du vin.

$b . \zeta$. Cristaux aiguillés de bitartrate de potasse.

c. c. Cristaux de tartrate neutre de chaux.

d. d. Filaments du parasite qui determine la maladie des vins tournés. 

YALADIE DES VINS TOURNES

Fig. 11

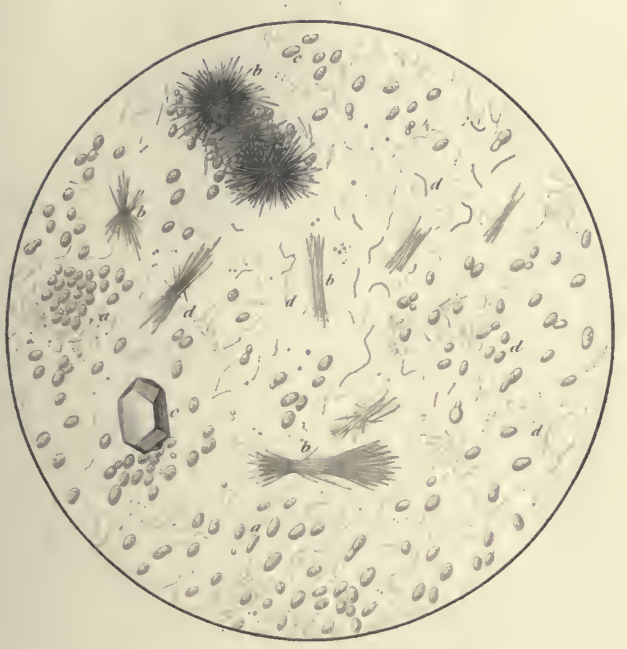

P.unterbauer ad nut ded.

Imp Pieny-Ginas Paris

$\frac{400}{1}$

a. a. Ferment alcoolique ordinatre du vin

b. b. Cristaux aiguillés de bitartrate de potasse

c. Cristaux de tartrate neutre de chaux.

d. d. Filaments du parasite qui determine la maladie du vin 

Fig. 12

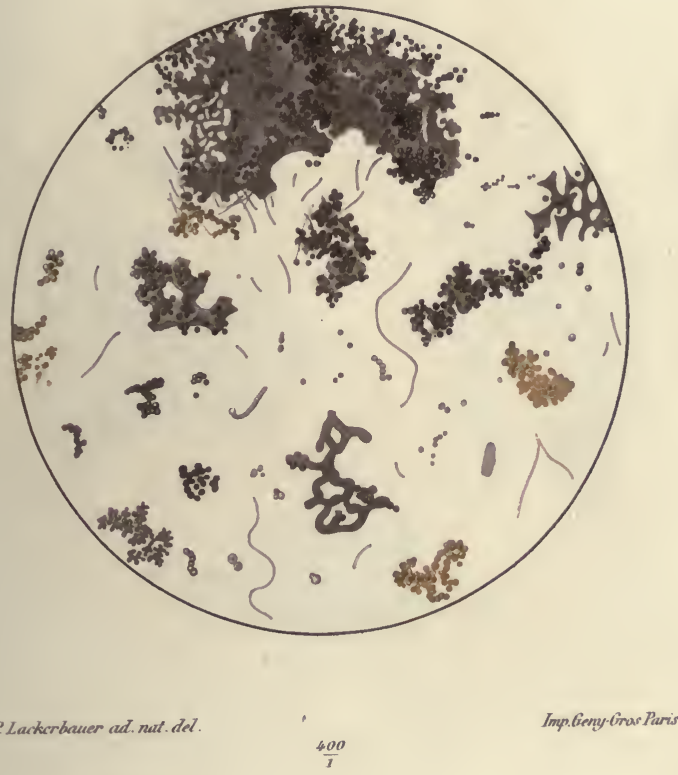



Fig. 13

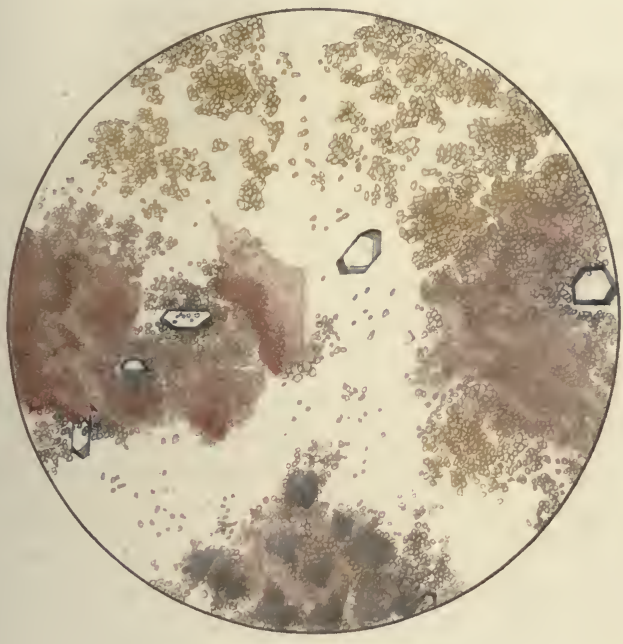

P. Lactierbiuer ad nat del 

suis occupé à mon tour, mais sans arriver à être satisfait de mes observations. Pour apprécier l'influence d'un ferment sur la nature des principes qu'un vin renferme, il est à peu près indispensable d'avoir a sa disposition une portion du même vin que le ferment n'aura pas du tout altérée, afin de procéder à une comparaison rigoureuse des deux échantillons. Cette condition est très difficile à réaliser et je n'y étais point parvenu à l'époque où je me livrais aux observations auxquelles je viens de faire allusion. Assurément on peut étudier un vin, le laisser s'altérer, puis reprendre à nouveau son analyse. C'est ce que j'ai tenté de faire. Mais cette marche est très peu sûre, et à peine qualitative, parce que nous ne connaissons pas encore de bons procédés de dosage des substances contenues dans le vin; de telle sorte que l'on doit toujours craindre que les différences constatées à long intervalle entre deux analyses d'un même vin tiennent à l'incertitude du mode d'analyse. Heureusement cette difficulté pourra être levée à l'avenir, grâce à un nouveau procédé de conservation du vin que je ferai connaître dans la troisième partie de cet ouvrage. Aussi ai-je commencé de nouvelles expériences sur les substances que les maladies introduisent dans les vins. J'ai pris diverses sortes de vins pouvant subir les maladies auxquelles ils sont sujets. A une partie de ces vins j'ai appliqué le procédé de conservation dont je parle. L'autre partie n'a pas été traitée et s'altère. Lorsque la maladie aura suffisamment exercé son influence, le vin malade sera comparé avec le même vin conservé. On sait combien ces comparaisons simultanées sont précieuses, même lorsqu'elles sont effectuées par des méthodes incertaines. Je donnerai ultérieurement, pour la maladie de l'amertume, un premier exemple de l'application de ce moyen d'étude aux effets que produisent les maladies des vins. (Voir l'Appendice.)

Je me bornerai en ce moment à soulever une question intéressante relative à la composition normale du vin et qui est liée au sujet dont je parle. Le vin renferme-t-il de l'acide lactique? A une époque où l'acide lactique passait pour être un produit de la fermentation alcoolique, la présence normale de l'acide lactique dans le vin était généralement admise. Mais, à la suite du Mémoire relatif à cette fermentation ( $\left.{ }^{1}\right)$, dans lequel j'ai montré que l'acide lactique n'existait, dans les liquides sucrés qui avaient éprouvé la fermentation alcoolique, qu'autant que cette fermentation avait été associée à une fermentation lactique proprement

et naturelles, d'agriculture et d'industrie... de Lyon (publiées par la Société d'agriculture de Lyon), 3e sér., VI, 1862, p. 141-160.]

1. Pasteur. Mémoire sur la fermentation alcoolique. Annales de chimie et de physique, 3. sẻr., LVIII, 1860, p. 323-426 (9 fig.). [ Toir ce Mémoire, tome II des CEuvres de Pasteur, p. 51-126.7 
dite, on a dû penser que la présence de l'acide lactique dans le vin n'était rien moins que prouvée, à moins que le raisin lui-même ne renfermât cet acide. Cependant, postérieurement à la connaissance des faits dont je parle, M. Balard a retiré directement de l'acide lactique de plusieurs espèces de vins, et notamment de vins qui n'avaient jamais été réputćs altérés ( ${ }^{1}$ ). L'acide lactique paraît donc être un principe immédiat propre à la nature du vin. Mais il ne faut pas se hâter de porter ce jugement. En effet, nous avons reconnu tout à l'heure que des vins, très sains en apparence, qui ne sont point du tout altérés pour le consommateur, peuvent être, chimiquement parlant, sensiblement malades, et que même il est bien difficile de trouver un vin rouge de table qui n'ait subi à un certain degré l'influence du ferment de la maladie deś vins tournés. Dès lors on doit se demander si l'acide lactique reconnu par M. Balard dans les vins qu'il a examinés n'était pas un produit accidentel, développé par l'influence d'un ferment parasite, comme il arrive pour les fermentations alcooliques ordinaires lorsqu'elles donnent naissance à cet acide. C'est encore un sujet d'études qu'il sera facile d'aborder en profitant du procédé de conservation des vins auquel je faisais allusion tout à l'heure. Je ne puis porter présentement un jugement assez autorisé sur la question dont je parle; cependant je dois dire qu'ayant recherché avec grand soin la présence de l'acide lactique dans les vins $n^{\text {os }} 4$ et 7 de la page 141 , je n'ai point trouvé cet acide dans un litre du vin $n^{\circ} 4$, mais j'en ai trouvé plusieurs décigrammes dans le $n^{\circ} 7$. Or, le vin $n^{\circ} 4$ s'était formé sous l'influence d'une fermentation alcoolique dont le ferment était sensiblement pur, tandis que le ferment alcoolique du vin $n^{\circ} 7$ était associé aux filaments propres au vin tourné, ainsi que je l'ai précédemment exposé. Ce résultat tendrait donc à faire penser que l'acide lactique n'existe dans le vin qu'autant que le vin a été soumis à l'influence du ferment filiforme (fig. 5).

On pourrait croire que je préjuge ici la question de la nature des filaments qui font tourner le vin, et que je les regarde comme identiques avec ceux qui composent le ferment de la fermentation lactique proprement dite. Mais il existe tant d'espèces distinctes parmi les ferments filamenteux qu'il faut être très circonspect dans ces sortes de questions. La formation de l'acide lactique ne suffit pas à décider celle-ci, car il peut se faire que divers ferments donnent lieu à une production d'acide lactique. Un seul principe ne peut servir à caractériser une fermentation.

Pour ce qui est de l'observation microscopique, le ferment des vins 
tournés offre les plus grandes ressemblances, il est vrai, avec le ferment lactique, surtout lorsqu'il a été agité, brisé et réduit en petits fils ou batonnets. Mais lorsqu'on l'étudie sur place, là où il a pris naissance, et sous ses divers aspects, on constate entre eux certaines différences qui consistent principalement en ce que le ferment des vins tournés est formé de longs filaments cylindriques flexibles sans étranglements bien apparents, de véritables fils non rameux, et dont les articulations ne sont pas toujours bien accusées. Le ferment lactique, au contraire, est formé d'articles courts, légèrement déprimés à leur milieu, de telle sorte que, sous un certain jour, on dirait une série de points, lorsque plusieurs articles sont réunis bout à bout.

Il ne faut pas exagérer toutefois la distinction des deux ferments d'après ce caractère. On le retrouve à quelque degré dans la plupart de ces productions, à cause du mode de multiplication par scissiparité qui leur est habituel. La nature d'un ferment ne peut être rigoureusement établie que par sa fonction physiologique, et nous ne connaissons pas encore suffisamment celle du ferment des vins tournés. Je suis même porté à croire que l'on réunit sous l'expression de vins tournés des maladies différentes auxquelles correspondent plus d'un ferment filiforme.

Les vins rouges ne sont pas seuls sujets à ce genre de maladie. Il arrive souvent que les vins de Champagne, ou les vins clairets et mousseux du Jura, prennent un goût de piqué très désagréable. J'ai reconnu que cette altération est produite par le parasite qui nous occupe. La bière elle-même est sujette à cette maladie. La figure 14 représente le ferment que j'ai observé dans une bière dite montée ou tournée. Le tonneau qui la renfermait, lorsque je l'ai examinée, offrait, en outre, à la surface du liquide une couche mycodermique formée de la réunion du mycoderma aceti et du mycoderma vini. De là le mélange de productions organisées qu'offre la figure. Une partie des mycodermes de la surface est tombée et s'est mêlée aux filaments qui ont fait tourner la bière.

C

MALAdIE DE LA GRAISSE. - VINS FILANTS, VINS HUILEUX.

Cette maladie, rare dans les vins rouges, est très fréquente dans les vins blancs, particulièrement dans les vins blancs faibles de divers vignobles. Tels sont, par exemple, les vins blancs du bassin de la Loire et de l'Orléanais. 
Les vins perdent leur limpidité naturelle, deviennent plats et fades, et, lorsqu'on les transvase, ils filent comme de l'huile.

La maladie se déclare dans les tonneaux, ou dans les bouteilles les mieux bouchées.

“ Pour concevoir, dit Chaptal, cette dégénération du vin, il faut se rappeler les principes que nous avons déjà développés sur la fermentation. J'ai observé que les deux principes nécessaires à la fermentation étaient le sucre et un ferment qui se rapproche de la nature du gluten animal. J'ai ajouté que, pour que la fermentation fût parfaite, il fallait qu'il existât une juste proportion entre ces deux substances. Si le gluten prédomine, il en reste une partie dans le vin, qui peut s'en dégager, et c'est cette substance qui forme la graisse dans les vins faibles $\left({ }^{1}\right)$. »)

M. François, pharmacien à Châlons-sur-Marne, qui a fondé sur l'emploi du tanin un remède très apprécié en Champagne pour prévenir cette maladie, a émis des idées analogues à celles de Chaptal. Le gluten de froment renfermerait une substance soluble dans l'alcool, identique avec celle que l'on peut extraire également par l'alcool des résidus de vins blancs gras. Le tanin précipite cette substance, qui, selon M. François, est la cause directe de la maladie (2).

Ce n'est pas le lieu de critiquer ces opinions. On peut bien prévoir, dans l'état actuel de la science, qu'elles sont erronées, mais il faut attendre le résultat des comparaisons dont je parlais tout à l'heure entre les vins malades et les mêmes vins conservés, afin d'être bien assuré de la nature des produits qui fournissent la graisse du vin.

La figure 15 représente le ferment des vins blancs filants. Ce sont des chapelets de petits globules sphériques dont le diamètre varie sensiblement suivant les espèces de vins atteints de cette maladie. Ceux de la figure appartenaient à un vin blanc nantais, de la nature de ceux qui servent à Orléans dans la fabrication du vinaigre. Ici les globules avaient moins de $\frac{1}{1000}$ de millimètre de diamètre.

Si le vin est devenu filant en bouteille, on trouve ce ferment au fond de la bouteille, ou en suspension dans la masse du vin. Dans ce dernier cas, la présence du ferment peut contribuer à la propriété filante du vin, parce que les chapelets enchevêtrés guident le jet liquide et font qu'on lui attribue plus de viscosité qu'il n'en possède réellement. C'est peut-être ce qui explique le fait reconnu par les anciens auteurs, Chaptal entre autres, que l'on peut corriger le mal « en

1. Ghaptal. L'art de faire le vin. Paris, 1807 , in-8 $8^{\circ}$, p. $218-250$. (Note de l'Édition.)

2. Françors. Mémoire sur la cause de la graisse des vins et sur le moyen de la détruire ou de la prévenir. Annales de chimie et de physique, XLVI, 1831, p. 212-217. 
agitant la bouteille pendant un quart d'heure, et la débouchant ensuite, pour laisser s'échapper le gaz et l'écume (1) 》. Le ferment s'accompagne d'une sorte de gelée qui peut bien aussi se concréter par l'agitation, effet propre également à diminuer la viscosité apparente. Cette matière mucilagineuse et les chapelets enchevêtrés du ferment forment quelquefois par leur réunion une véritable peau, glissante au toucher, entièrement analogue à la mère du vinaigre. J'ai observé cette forme de la maladie à Orléans sur un grand nombre de tonneaux de vin blanc de la maison Breton-Lorion. Ces tonneaux restés en vidange, et qui contenaient du vin filant, avaient tous à leur surface une peau membraneuse au lieu de la fleur ordinaire du mycoderma vini. A ne juger des choses que par l'aspect de cette pellicule, on aurait pu croire que le vin devait être transformé en vinaigre. Cependant il ne renfermait pas d'acide acétique, et l'observation microscopique m'a permis de reconnaître que la pellicule de la surface n'était point formée par le mycoderma aceti, mais qu'elle constituait une disposition particulière du développement du ferment des vins gras, due sans doute au contact de l'air et à la vidange. Ces peaux enfermées dans des bouteilles avec du vin blanc le rendaient, après un certain temps, extrêmement filant.

En résumé, la graisse des vins n'est point du toụt produite, comme on l'a admis jusqu'à présent, par la précipitation d'une substance glutineuse, plus ou moins analogue à certains principes du gluten du froment, se déposant dans le vin sous l'influence de causes inconnues. C'est une fermentation accessoire due au développement d'un parasite dont le germe doit être emprunté au raisin, et probablement à certains grains de raisin qui ont pourri sur le cep par l'effet de ce même parasite ou de l'une de ses variétés ou métamorphoses. Quelle profusion de germes de toute nature n'introduit-on pas dans une cuve de vendange! Que d'altérations diverses ne rencontre-t-on pas dans telle ou telle feuille, dans tel ou tel grain que mille causes ont pu entr'ouvrir, et qui ont été le siège de fermentations et de putréfactions de diverses natures! Et quel nombre effrayant de germes apportés par l'air et attachés dans la couche un peu cireuse de la surface extérieure des grains du raisin!

Que le vin par sa composition soit de nature à permettre le développement de quelques-uns de ces germes, et ceux-ci ne manqueront pas de se multiplier à un moment ou à un autre, selon les circonstances de température et d'aération de la liqueur.

Il y a deux classes de germes à jamais étouffés dans la cuve de

1. Chaptal. Art. Vin. In : Cours complet d'agriculture, ou Dictionnaire universel d'agriculture de Rozier. Paris, $1781-1800,10$ vol. in $-4^{\circ}$. Tome X, p. 358. 
vendange en fermentation et dans le vin qui en résulte. Ce sont, d'une part, tous ceux des infusoires, bactéries, kolpodes, anguillules, etc., et d'autre part toutes les spores des moisissures aériennes. Aucun infusoire n'apparaîtra dans le vin, parce que le vin est acide et que l'acidité les fait périr. Quant aux spores des moisissures, elles ne germeront pas, parce qu'elles ont besoin, elles et les êtres adultes qui doivent en provenir, de gaz oxygène pour vivre. Or, la cuve de vendange ou le foudre en fermentation sont des espaces absolument fermés à l'introduction de l'air. C'est un autre motif pour que les infusoires n'apparaissent pas. Quel genre de vie se montrera donc et à profusion? C'est celui qui est propre aux ferments, à ces êtres étranges qui peuvent vivre sans air, dans les profondeurs des matières organiques dont ils empruntent l'oxygène combiné, d'où résulte leur caractère de ferments, selon une théorie généraḷe de la fermentation à laquelle j'ai été conduit il y a quelques années, et qui me paraît de plus en plus l'expression des faits les mieux étudiés $\left({ }^{1}\right)$.

Encore ne verra-t-on apparaître que les ferments végétaux dont la vie peut s'accommoder d'une certaine proportion d'acide et d'alcool. Ainsi jamais de fermentation butyrique dans les vins, parce que les vibrions qui déterminent cette fermentation périssent dans les liquides acides. Ce seraient eux au contraire que l'on verrait se multiplier si l'on venait à ajouter dans la cuve de vendange une certaine quantité de chaux propre à rendre le liquide neutre.

Dans toutes ces études, si l'on perd de vue les conditions d'existence des êtres inférieurs, on ne voit que choses extraordinaires, et l'on s'imagine volontiers que l'on assiste à des créations variées, tandis que les lois générales trouvent ici, comme partout ailleurs, de simples et naturelles applications.

Je n'ai pas besoin de faire observer combien, au premier aspect, il y a d'analogie entre le ferment des vins filants et celui des vins tournés. Dans ces deux cas, l'apparence est celle de filaments, mais ceux de la maladie de la graisse sont des chapelets de grains, tandis que ceux de la maladie des vins tournés sont des chapelets d'articles, dont les articulations sont en général mal accusées. On les dirait pleins dans une grande longueur, le plus souvent du moins, car il n'y a ici rien de bien absolu. Ces distinctions deviendront plus claires dans la section suivante.

Lorsqu'on examine les dépôts des vins qui ont été filants ou qui le sont encore, mais après cessation de la fermentation qui les rend tels,

1. Voir tome II des (Euvres de Pasteur, p. 142-147 : Expériences et vues nouvelles sur la nature des fermentations. (Note de l'Édition.) 
en un mot, lorsque le ferment n'est plus en voie de se multiplier et d'agir, les grains des chápelets se disjoignent et on ne rencontre plus que des couples de petits grains sphériques, au lieu de chaînes de ces petits grains $\left(^{(1)}\right.$.

\author{
MALADIE DE L'AMERTUME. \\ DE L'AMER, DU GOUT DE VIEUx, ETC.
}

Voici une des maladies qui nuisent le plus au commerce des vins, particulièrement des vins vieux, qui sont toujours les vins des meilleurs crus, puisque l'on ne conserve que les vins les plus estimés. Tous les vins rouges, sans exception, sont sujets à cette maladie, mais elle atteint de préférence les vins les plus délicats de la Côte-d'Or et en général les vins des meilleurs crus. Il n'y a pas de contrée vinicole en France qui n'ait son coteau plus ou moins célèbre. Eh bien, c'est le vin de ce coteau qui deviendra amer avec les années. On pourrait dire que le vin de la plaine n'est jamais conservé assez longtemps pour que l'on sache s'il prendrait à son tour de l'amertume. Cela est vrai dans une certaine mesure. Mais il n'est pas douteux néanmoins que, toutes choses égales d'ailleurs, le rin commun ne soit bien moins sujet à l'amertume que le vin de qualité. Par contre, les vins communs sont plus sujets à tourner que les grands vins.

Je ne pourrais mieux faire, pour décrire la maladie de l'amertume des vins, que de reproduire ici une lettre intéressante qu'un habile œnologue, M. de Vergnette-Lamotte, a bien voulu m'adresser à la date du 27 avril 1864, à la suite d'une Communication que j'avais faite à l'Académie le 18 janvier précédent ( $\left.{ }^{2}\right)$ et dans laquelle j'avais décrit le ferment qui produit l'amertume des vins.

On trouvera cette lettre reproduite textuellement dans l'Appendice de cet ouvrage $\left({ }^{3}\right)$. J'en extrais les passages suivants :

“ Nous distinguons deux sortes d'amertume dans les vins : la première, celle qui les atteint de la deuxième à la troisième année de leur âge, et l'autre, que l'on rencontre dans les vins très vieux. Cette dernière maladie, à laquelle on peut plus spécialement donner le nom

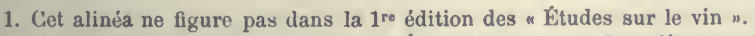

2. Toir p. 396-406 du présent volume : Études sur les vins. Deuxiéme partie : Des altérations spontanées ou maladies des vins, particulièrement dans le Jura.

3. Toir p. 363-370 du présent volume: Sur la maladie de l'amertume des grands vins de Bourgogne. I.ettre de M. de Vergnette-Lamotte á M. Pasteur. (Notes de l'Édition.) 
de goût de vieux, est loin de présenter autant de gravité que la première, en ce sens que les vins qu'elle atteint ont été et sont restés bons pendant de longues années, tandis que l'amertume proprement dite altère et détruit même complétement le vin dans ses premières années.

" Au début du mal, le vin commence par présenter une odeur sui generis; sa couleur est moins vive; au goût on le trouve fade; nos tonneliers disent que le vin doucïne. La saveur amère n'est pas encore prononcée, mais elle est imminente si l'on n'y prend garde. Tous ces caractères ne tardent pas à augmenter rapidement. Bientòt le vin devient amer, et l'on reconnaît à la dégustation un léger goût de fermentation dû à la présence de quelques traces d'acide carbonique. Enfin, la maladie peut s'aggraver encore, la matière colorante s'altère complétement, le tartre est décomposé (1) et le vin n'est plus buvable.

“ Il n'est pas nécessaire que les symptômes du mal soient aussi avancés que nous venons de le dire pour que nos vins perdent une grande partie de leur valeur. Que le bouquet soit altéré, que la franchise ne soit pas entière, et voilà un vin qui valait 500 francs la pièce, et qui n'en vaut plus que 100 , et une bouteille de romanée, qui, payée 15 francs, vaudra à peine 1 franc.

"L'amertume des vins est donc la maladie qui fait le plus de tort aux grands crus de la Bourgogne, ou mieux aux vins rouges de pinot de la Bourgogne et de la Champagne. L'amertume est pour nous la maladie organique des vins de pinot. C'est du reste la seule qu'ils aient à redouter... »

On lira avec intérêt dans la lettre de M. de Vergnette les procédés empiriques qu'il emploie pour se mettre autant que possible à l'abri de cette maladie de l'amertume. Chacun sera frappé du passage dans lequel M. de Vergnette proclame que, si l'on parvenait à trouver le moyen de prévenir cette maladie, on aurait donné des millions à la France : c'est dire toute l'importance de la recherche de la véritable cause de la maladie de l'amertume des vins de pinots.

Je ferai suivre ces renseignements, dus à M. de Vergnette, de quelques observations extraites d'une lettre qui m'a été adressée, à la date du $1^{\text {er }}$ mai 1865, par M. Boillot, maire de Volnay.

"Les vins fins de Volnay 1859 ont été généralement moins beaux et moins bons que ceux de 1858. Ils se sont également moins bien

1. En affirmant ici la décomposition du tartre, M. de Vergnette s'appuie sans doute sur les résultats du travail déjà cité de $M$. Glénard [Note sur la fermentation tartrique du vin. Annales des sciences physiques et naturelles, d'agriculture et d'industrie... de Lyon, $3^{\circ}$ sẻr., VI, 1862, p. 141-160]. On verra, dans l'Appendice de cet ouvrage, que ce sujet exige de nouvelles études. 
BIÈRE TOURNÉE

Fig . 14

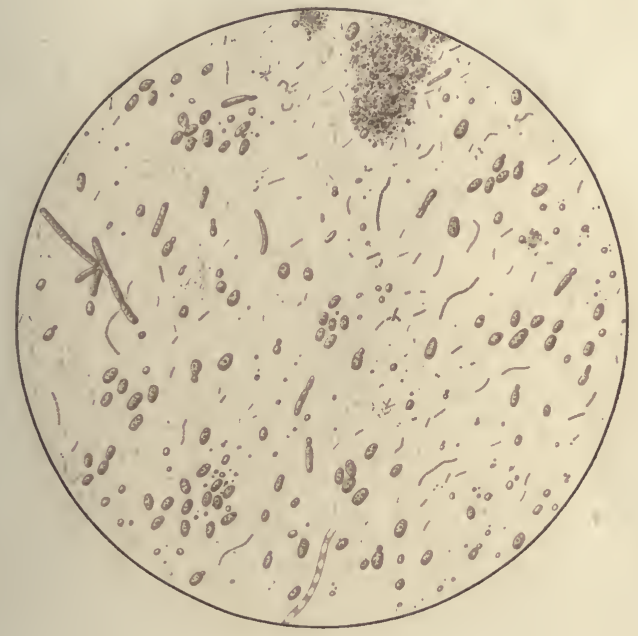



MAIADIE DE I.A GRAISSE

DES VINS BLANCS DE LA CHAMPAGNE, DE L'ORLEANAIS, ETC.

( VIs D'0ku.ŕans, très-filant.

Fiģ. 15

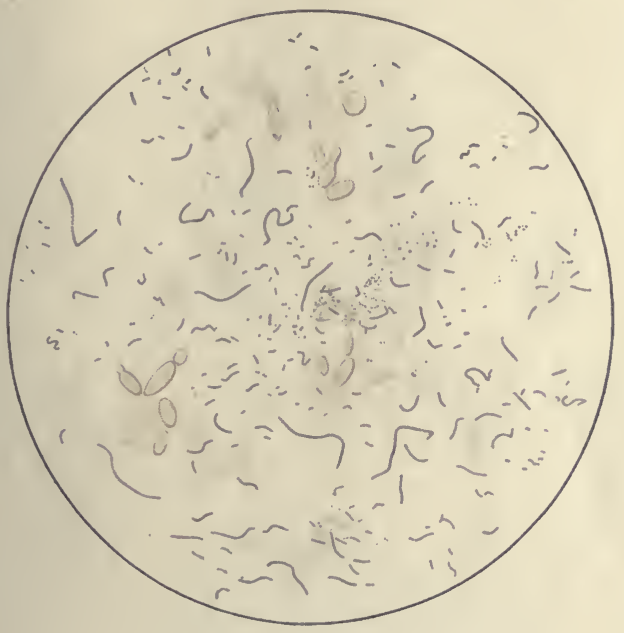

P. Lackerbuner, ad, nat, did.

Imp. Gieny. Gims Puris 

MALADIF, DE, L'ANERTUNE.

DES GRANDS VINS DE LA COTE-D'OR

(Vix de Volvay, 1859)

Fig . 16

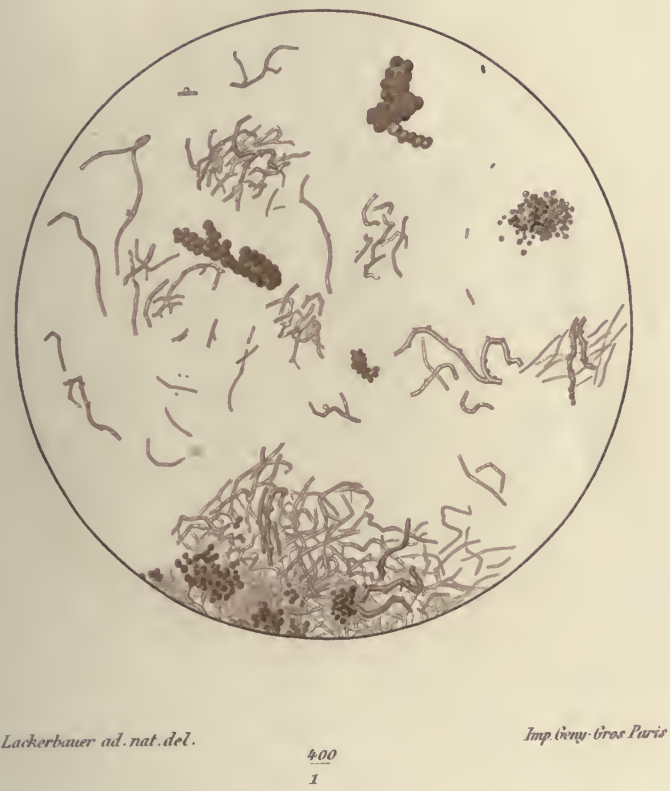



MALADIE DE L'AMERTUME

Vin de Bordeaux, vieux.

Le ferment est mêlé à des cristaux de tartre et à de la matière colorante.

Fig. 17

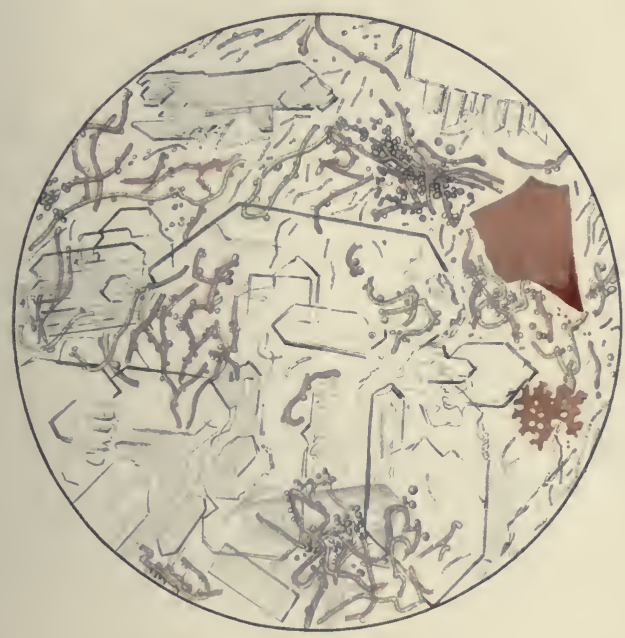

P.Lackerbauer ad nat. del.

Imp bieny-(imse Parir

$\frac{400}{1}$ 

conservés. J'en ai qui sont en bouteilles depuis deux ans environ (mis en bouteilles après cinq ans) et auxquels cette opération a été très funeste. Ils sont devenus troubles, puis des flocons se sont formés, et, en vidant la bouteille, les flocons arrivent et se mêlent au vin, qu'on ne peut obtenir très clair. Ce dépôt ne s'attache pas aux parois de la bouteille.

“Les vins de 1861 se sont conduits on ne peut plus mal ici et dans nos environs. Cette récolte a été désastreuse pour le commerce. Les $\frac{19}{20}$, sans exagération, se sont comportés comme je viens de le dire pour les 1859. Seulement les 1861 que j'ai encore ont beaucoup de dépôt adhérent à la bouteille, outre les flocons. Cependant ces vins de 1861 mis en bouteilles ici, et restés sur place, pour ainsi dire abandonnés, sont moins mauvais qu'il y a un an. Il est bien entendu que je ne parle que de vins très purs et naturels, sans mélange ni addition. "

Ces renseignements, joints à la lettre de M. de Vergnette, suffisent bien pour dire toute la fréquence de la maladie qui nous occupe et les pertes immenses qu'elle occasionne.

J'ai étudié une foule d'échantillons de vins amers, et il me sera aisé de démontrer que cette maladie est encore produite par un parasite, lequel se multiplie avec une merveilleuse facilité dans les grands vins de la Còte-d'Or, beaucoup plus difficilement dans les vins communs de Bourgogne, du Jura ou de Bordeaux, et que telle est l'explication des différences que la maladie présente dans son développement, suivant les localités et les natures de vins, bien que tous y soient sujets. C'est ainsi que, suivant les constitutions et les tempéraments, les maladies épidémiques atteignent de préférence ceux qui sont prédisposés à les contracter.

Je suppose que l'on ait entre les mains un vin devenu amer en bouteille, et dont l'amertume soit prononcée. Ce sera, si l'on veut, cette deuxième phase de l'amertume des grands vins de la Bourgogne dont M. de Vergnette parlait tout à l'heure, qui frappe le vin à un certain âge. Plaçons debout quelques bouteilles de ce vin, et, après quelques jours de repos, examinons le dépôt des bouteilles au microscope. Dans toutes, et quel que soit le vin, nous trouverons un élément commun, des espèces de branchages tout rameux, tout noueux, de diamètres plus ou moins larges, dans les rapports de 1 à 2 et à 3 , et quelquefois même davantage, plus ou moins articulés, incolores ou faiblement colorés en rouge, d'une teinte claire vive, ou d'une teinte brune très foncée. Ces filaments seront seuls et composeront tout le dépôt, ou bien ils seront associés à des lamelles de couleur uniforme, ou à des amas mamelonnés, ou à des cristaux. Les figures' 16 et 17, 
appartenant à des dépòts de vins amers de Bourgogne et de Bordeaux donnent des exemples de quelques-unes de ces particularités. Dan ces figures, les filaments branchus, contournés, représentent préci sément le parasite qui est la principale cause de l'altération que le vir a éprouvée. C'est ce que nous reconnaîtrons clairement dans la suite

La matière mamelonnée, malgré l'apparente organisation qu'ell présente quelquefois, n'est autre que la matière colorante du vin, qu s'est oxydée peu à peu par l'influence de l'oxygène de l'air, que le pores du bouchon laissent toujours introduire. Les petits bourgeons qu sont placés de distance en distance sur les filaments contournés n'on rien d'organisé. Ils n'appartiennent pas aux filaments. Ce sont tou simplement de petits nodules de cette matière colorante dont je parle rendue insoluble par l'oxydation ou par les altérations chimiques qu produit la vie du parasite. Enfin la différence de largeur des filament tient presque exclusivement à ce qu'ils sont plus ou moins recouverts suivant leur âge, par cette même matière. Ces déductions ne sont poin des idées préconçues. Elles sont démontrées par des faits positifs Ainsi, nous reconnaitrons tout à l'heure que l'on peut dissoudre 1 matière colorante mamelonnée et incrustante par les acides et l'alcool et que les filaments ont alors un diamètre réduit et un aspect tou autre, sans nodosités ni coloration quelconque. On comprend très biè que le parasite cesse d'agir, et perde, en partie du moins, sa vitalit ou mieux sa faculté de développement lorsqu'il s'incruste de matièr colorante. C'est ce qui arrive, et l'on voit très souvent l'amertum s'arrêter à un certain moment, diminuer même, sans doute parce qu le vin continue de vieillir, et s'améliore de nouveau comme vin nor malade. Cette amélioration relative fait croire souvent à une guérison mais elle n'est jamais bien réelle.

Ce qui précède s'applique au parasitè de l'amertume lorsqu'il es âgé et plus ou moins fané. Examinons-le lorsqu'il est en voie de déve loppement, très jeune.

Voici quelques indications au sujet de la figure 18.

M. Marey-Monge, grand propriétaire de vignes dans la Còte-d'Or m'adresse, le 10 mai 1865, vingt-cinq bouteilles de pomard 1848. Dan une lettre qu'il eut l'obligeance de m'écrire à cette époque, M. Marey Monge me donne les renseignements qui suivent, et qui ne sont pa sans intérêt pour le lecteur dans la question qui nous occupe. "No vins travaillent en août, plus ou moins, plus tôt ou plus tard, dans le bonnes comme dans les mauvaises années. Dans nos caves, cela n nous inquiète pas beaucoup, parce que nous soutirons en septembre En mars, nous soutirons encore, collons, resoutirons, et le vin es 
parfaitement clair. Pour le consommateur, c'est autre chose. Il se plaint, ne sait que faire; souvent il nous renvoie le vin, qui s'est bien conduit quelquefois pendant un ou deux ans. Vainement nous lui disons : Filtrez vos bouteilles, ou bien décantez-les dans un fût de bon goût, et collez, puis, quinze jours après, remettez en bouteilles. Il le fait quelquefois avec succès, mais le plus souvent il se démoralise.

" Des vins très bons, comme les 1854, deviennent quelquefois troubles, à la bouteille, comme de l'encre, et ils restent ainsi quatre, cinq ans, jusqu'à faire croire qu'ils sont perdus; puis un beau jour ils s'éclaircissent; le dépôt s'attache au verre; on les décante, et ils sont très bons. Ce serait donc rendre un immenșe service que de parvenir à supprimer le dépôt. ”

Dans une lettre subséquente :

“L'année 1848 était assez bonne; cependant, le vin nous a donné quelque désagrément de dépôt et d'amertume chez le consommateur. Chez nous, avec nos soutirages et collages, dont je vous parlais dans må dernière lettre, il s'est bien conduit. Le vin que je vous envoie a dix-sept ans. Il a été soutiré, à trois fois par an, cinquante et une fois. "

Les bouteilles de ce vin, mises debout pendant deux jours, présentaient toutes au fond de la bouteille un peu de dépôt flottant, très peu, puisqu'elles venaient d'être dépotées avant de m'être envoyées. Ce transvasement est pratiqué par tous les propriétaires lorsqu'ils expédient du vin en bouteilles afin qu'il arrive très limpide chez le consommateur. J'observe ce dépôt au microscope et j'y reconnais des filainents articulés. Ce sont ceux que l'on voit dans la figure, colorés, et de plus large diamètre. Je couche les bouteilles et je les conserve dans une cave très saine. Du mois de mai au mois de novembre, je reconnais que le dépôt augmente progressivement, et qu'en même temps il se forme sur les parois des bouteilles une couche uniforme brune, adhérente, très peu abondante. Le dépôt est donc de deux natures. Je l'étudie au microscope, et j'y reconnais les trois matières qu'indique le dessin de la figure 18 :

$1^{\circ}$ Des filaments très nombreux, plus ou moins nettement articulés, sensiblement plus gros que les filaments du vin tourné, sans coloration appréciable.

$2^{\circ}$ Quelques filaments de plus gros diamètre et colorés en rouge. Je répète qu'ils sont anciens et que leur formation a précédé le dernier transvasement du vin.

$3^{\circ}$ Une matière mamelonnée amorphe. C'est elle qui constitue le dépòt adhérent des parois. 
Les filaments incolores sont de récente formation. C'est tout ce qui a pris naissance du parasite de l'amertume depuis que le vin est arrivé à Paris.

L'altération dans la qualité du vin est certaine. J'en donnerai la preuve ultérieurement afin de ne pas anticiper sur des considérations d'un autre ordre. Comme cette altération, dans l'exemple particulier que je viens de prendre, est corrélative de deux sortes de dépôts, dépôt flottant cryptogamique, dépôt amorphe de matière colorante rendue insoluble par oxydation, on pourrait penser que l'amertume est liée peut-être à la présence du dépôt amorphe et non à celle du dépôt organisé.

L'une des preuves que l'on peut invoquer en faveur de l'absence de toute solidarité entre l'amertume et le dépôt de la matière colorante, c'est que, d'une part, le dépôt de matière colorante est souvent seul et qu'il n'est pas accompagné d'amertume, comme j'en donnerai des exemples divers ailleurs, et que, d'autre part, l'amertume existe et peut être très prononcée dans des cas où le dépôt est uniquement 'un dépôt flottant de parasites. Je citerai tout de suite une preuve de ce dernier fait.

Le 15 mars 1865, je reçois de M. de Vergnette-Lamotte 25 bouteilles de diverses sortes de vins, parmi lesquelles 3 bouteilles de vin de Pomard de 1863. Ce vin venait d'être soutiré. Chaque fût de 228 litres avait fourni 3 litres de dépôt. Le vin à son arrivée était très limpide, mais le dépôt $d u$ tonneau d'où le vin avait été tiré, dépôt que j'ai pu étudier, renfermait des filaments et de la matière amorphe en granulations confuses, et par conséquent le vin contenait des germes de cryptogames. Or, il arriva qu'au bout de six semaines déjà il était visible qu'un dépôt flottant organisé se formait dans les bouteilles. Trois mois après, il était abondant et uniquement composé du parasite de l'amertume, sans trace de matière colorante brune. Le vin avait conservé toute sa belle couleur. La figure 19 est la reproduction d'une photographie microscopique de ce ferment. L'organisation et le mode de reproduction du parasite sont ici bien évidents. La première impression est celle de fils plus ou moins enchevêtrés, puis on distingue dans ces fils des solutions de continuité qui forment articulation. C'est à ces places que les fils se brisent souvent sans se disjoindre, ce qui annonce l'existence aux articulations d'une matière plus molle qui soude les articles les uns aux autres. Si l'on s'arrêtait à cet examen, on pourrait croire que les articles s'allongent de plus en plus par une de leurs extrémités, comme les tiges des arbres. Mais, si l'on examine avec soin et de plus près l'image photographique, surtout pour un certain 
foyer du microscope, il sera visible que chaque article est formé lui-même en quelque sorte de sous-articles qui s'accusent par des renflements et rétrécissements alternativement clairs et obscurs. Cette structure me paraît indiquer avec évidence que l'allongement des fils se fait en chaque point de leur longueur, que ces articles se sousdivisent d'abord confusément, puis plus nettement au fur et à mesure qu'ils s'allongent. Ce serait le mode de division par scissiparité de beaucoup d'infusoires, très différent du mode de reproduction par bourgeonnement du mycoderma vini, si bien accusé dans la photographie, figure 2 .

Le vin de Pomard de 1863 dont je viens de parler était encore en fûts, ainsi que je l'ai fait observer, lorsque M. de Vergnette eut l'obligeance de m'en envoyer quelques bouteilles. Le moment n'était donc pas venu encore de le mettre en bouteilles. On pourrait dès lors penser que, la mise en bouteilles de l'échantillon que j'ai reçu ayant été prématurée, cela a facilité le développement du parasite de l'amertume. Il n'est pas douteux que l'époque de la mise en bouteilles d'un vin peut avoir une grande influence sur sa bonne conservation ultérieure. Tous les viticulteurs sont d'accord sur ce point, et j'ajoute que depuis mes recherches la science peut en donner une explication satisfaisante. Néanmoins l'amertume attaque tous les vins, quel que soit leur âge, et c'est bien plus avec la composition du vin qu'avec son âge qu'il faut compter, en général, toutes les fois qu'il s'agit des maladies qui peuvent l'affecter.

J'ai déjà cité du vin de Pomard qui, après dix-sept années d'àge, continuait de nourrir facilement le parasite de l'amertume, figure 18 (vin de M. Marey-Monge de 1848).

La figure 20 représente le ferment développé au bout de trente années. Voici la note du propriétaire relative au vin qui l'a fourni :

“ Ce vin est de 1822. Pendant trente années il a été parfait. Depuis dix ans il faiblit et prend un goût d'amertume. Aujourd'hui il est perdu comme vin de table. "M. de Vergnette, à qui ce vin avait été remis, ajoute dans sa lettre d'envoi :

“En vous envoyant ces échantillons, j'ai voulu appeler votre attention sur cette variété de vin passé à l'amer. Elle n'a, à mon avis, aucun rapport avec la maladie prompte et redoutable qui, dans l'intervalle d'une année, a détruit beaucoup de 1852 et de 1861. C'est cette dernière maladie, plus que la première, qui cause le plus de mal aux vignobles de la France. "

La note du propriétaire de ce vin, jointe à l'observation microscopique du dépôt, montre bien que le ferment de l'amer s'est développé 
ici après un laps de temps considérable. Pourquoi après ce laps de temps et pas plus tôt? C'est sans doute parce que la modification amenée par le temps dans ce vin, telle que l'oxydation de ses principes par l'oxygène de l'air, et dont je traiterai dans la deuxième partie de cet ouvrage, ou quelque circonstance accidentelle inconnue de température, etc. dans la cave où le vin était conservé, a disposé le vin à servir d'aliment au parasite. Enfin d'où venait donc le germe du parasite dans ces bouteilles depuis si longtemps saines et tout à coup malades? Ce germe existait depuis le jour de la mise en bouteilles, et provenait $\mathrm{du}$ tonneau au moment du soutirage. En effet, prenez le dépôt d'une bouteille de vin rouge quelconque, fût-il en bouteille depuis dix, quinze, vingt ans... et parfaitement conservé, vous y reconnaîtrez au microscope des filaments de parasites. On ne saurait dire souvent quelle est leur nature, si ce sont ceux de la maladie du vin tour'né, du vin amer, du vin gras, mais leur présence n'est pas douteuse, et l'on en trouve dès l'époque de la mise en bouteilles. En d'autres termes, le vin, par sa composition, par les soins dont on l'entoure, par la nature des vases ou des locaux qui servent à sa conservation, est plus ou moins apte à déterminer la multiplication des parasites qui peuvent l'altérer et dont il contient les germes.

Je pourrais citer bien des faits à l'appui de cette manière de voir.

Telle est, selon moi, la véritable explication des effets du vinage, des vins procédés, ou de la congélation artificielle appliquée aux vins. L'alcool est un des ennemis des parasites du vin. Tel vin qui renferme 10 ou 12 pour 100 d'alcool, et dans lequel le parasite de l'amertume se développe facilement, ne pourra plus que très difficilement faire vivre ce cryptogame si l'on a porté sa proportion d'alcool à $13,14,15$ pour 100 , tous les autres éléments du vin restant pourtant les mêmes.

Quant aux deux phases de la maladie de l'amer, elles ne constituent pas deux maladies différentes. C'est le même ferment qui les provoque, mais son développement se manifeste dans les premières années ou longtemps après, le vin ayant été très bon dans l'intervalle. Il est naturel que la maladie soit plus remarquée et jugée plus désastreuse lorsqu'elle détruit le vin avant qu'il soit livré au commerce et à la consommation.

On ne pourrait arguer de l'existence de deux maladies d'après la différence d'aspect du ferment lorsqu'on l'observe dans le vin jeune et dans le vin vieux. Dans le vin vieux, qui dépose toujours plus ou moins par suite d'une oxydation, le ferment change d'état, se colore et grossit, prend l'aspect de branches de bois mort, par le fait d'une sorte de teinture des filaments due à la matière colorante brune qui se 
précipite. L'explication que je donne des différences d'aspect du ferment jeune en voie de développement et du ferment très vieux et coloré ne peut être l'objet d'un doute. Il suffit de traiter ce dernier par l'alcool et les acides, et quelquefois par l'alcool seul, pour réduire le ferment au mème état qu'il possède lorsqu'il est de nouvelle formation. Sa coloration brune ou rouge (car elle est quelquefois d'un beau rouge) disparaît, et le diamètre apparent de ses filaments se trouve très notablement diminué et ramené au diamètre des filaments jeunes.

La figure 20 bis représente dans sa moitié gauche le dépôt du vin amer de 1822 dont j'ai parlé tout à l'heure, et dans sa moitié droite le même dépôt, mais préalablement traité par l'alcool ou par l'alcool et les acides, car il arrive quelquefois que la dissolution de la matière colorante exige l'emploi des acides. On voit que le diamètre des filaments a diminué considérablement, que ceux-ci ont perdu leur coloration, et qu'enfin ils ont pris assez sensiblement l'aspect du ferment de l'amertume, encore jeune, non coloré et en voie de développement.

J'ai avancé que les vins communs prenaient l'amertume bien plus difficilement que les vins fins. Ce fait est bien connu. Rien n'est plus facile à démontrer avec des vins de Bourgogne de gamay et de pinot. Ces derniers, dans l'intervalle de quelques mois, au moins tous ceux que j'ai eus à ma disposition et qui provenaient de la partie la plus méridionale de la Côte-d'Or, ont montré le développement rapide du ferment de l'aniertume, tandis que des vins de gamay de même année, de même localité, n'en ont pas fourni durant le même temps.

Je ne terminerai pas l'examen auquel je me suis livré sur l'amertume des vins sans faire remarquer que le vin, mis en vidange, prend souvent, par le seul fait de l'action de l'air, une amertume non douteuse. Celle-ci n'a rien à faire avec un développement cryptogamique. J'ai vérifié maintes fois que l'effet était dû uniquement à une action chimique. Cette amertume offre ceci de particulier, qu'elle disparaît si on supprime la vidange, et si l'on conserve le vin en bouteilles pleines pendant quelques semaines.

Le 16 novembre 1865, je mets en vidange une bouteille de vin de Pomard, conservé par le procédé que j'indiquerai ultérieurement, et qui a la propriété d'empêcher le plus souvent la naissance des fleurs à la surface du vin, même après qu'il a été mis en vidange sans précautions particulières. Le 23 novembre, le vin n'a pas du tout de fleurs : aucun cryptogame ne s'est développé ni à sa surface, ni dans le fond de la bouteille. Le vin a cependant un goût d'amertume prononcé. Je transvase le vin dans une bouteille plus petite, que je remplis et que je bouche bien. Le 27 décembre, c'est-à-dire un mois après environ, le 
vin, toujours très bien conservé, n'a plus la moindre amertume. Par une nouvelle vidange, elle s'est manifestée de nouveau tout aussi forte sans qu'il y eût davantage de cryptogame formé.

Pendant le travail de l'oxydation du vin, il peut donc se faire qu'une amertume se développe en dehors de toute présence d'organisme. C'est sans doute ce fait qui, étendu au cas de l'amertume proprement dite, aura fait croire à diverses personnes que la maladie de l'amertune résultait d'une décomposition de la matière colorante. Ce qui a pu induire encore en erreur et faire prendre l'effet pour la cause, c'est que la maladie de l'amer s'accompagne très souvent d'une altération notable de la matière colorante. Si l'on considère un vin dont un échantillon est parfaitement conservé et dont un autre est devenu amer, ou mieux a été sous l'influence des filaments dont nous venons de parler, on reconnaîtra, dans bien des cas, par la comparaison des couleurs dans deux verres de même dimension, que l'échantillon malade est d'une couleur moins vive, plus rouge, plus claire et moins agréable. Si l'on sature deux volumes égaux des deux échantillons par l'eau de chaux, les teintes du vin malade, variables avec les proportions du réactif, sont toujours plus pâles que celles du vin non malade. Cette différence est surtout accusée au moment de la neutralisation complète, et en outre le vin malade offre alors quelque chose de terne et de louche. Après la saturation du vin non malade, les flocons qui s'y déposent sont d'un violet bien plus foncé et bien plus franc que celui des flocons déposés dans le vin malade. Les choses se passent de la même façon, que le vin ait été privé ou non, préalablement, de son gaz acide carbonique dissous.

Il y aurait une question bien importante à élucider à propos de l'amertume du vin : c'est celle de la nature de son ferment comparée à celle du ferment qui provoque la maladie des vins tournés. Je ne serai en mesure de la résoudre que quand je connaîtrai exactement les fonctions physiologiques de ces ferments. Les différences physiques de ces ferments ne suffisent peut-être pas pour les distinguer. Les filaments du vin tourné sont plus fins que ceux du vin amer; leurs articulations moins sensibles, bien qu'elles existent et que le mode de reproduction soit le même dans les deux cas, et tel que je l'ai indiqué précédemment pour le parasite de la maladie de l'amertume. Les filaments du vin tourné enfin ne s'incrustent pas de matière colorante. On trouve souvent un mélange de ces filaments incolores, très fins, mêlés dans des vins vieux à des filaments volumineux et colorés, comme dans la figure 21. La figure 22 représente aussi cette association des deux sortes de filaments. Enfin ce ne sont pas les mêmes 
MALADIE. DE. I'AMERTUME.

DES GRANDS VINS DF. LA COTE-D'OR

(VIN De Pomard, 1848 .)

Fig. 18

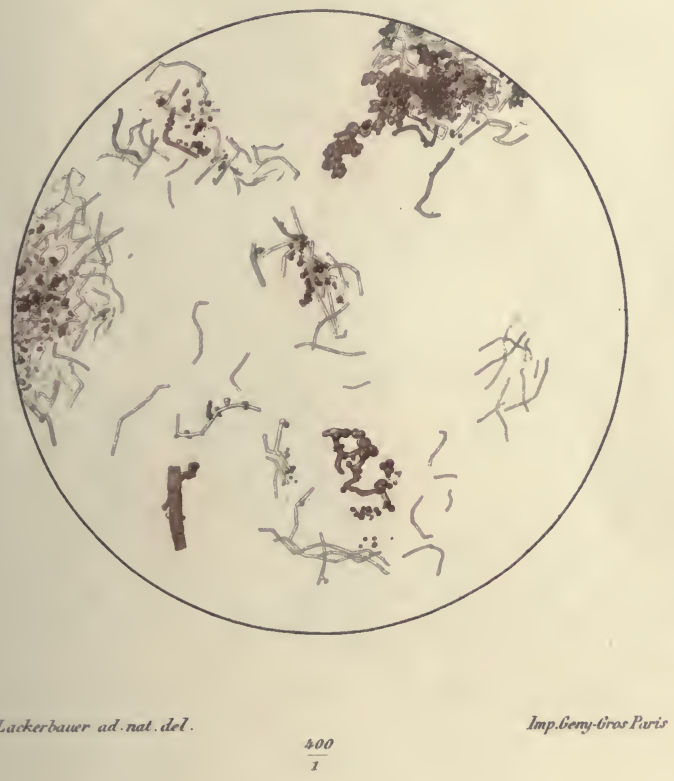



MALADIE DE L'AMERTUME

( Vis de PomaRd, 1863.)

Le ferment est jeune, en voie de développement et en pleine activité.

Fig. 19

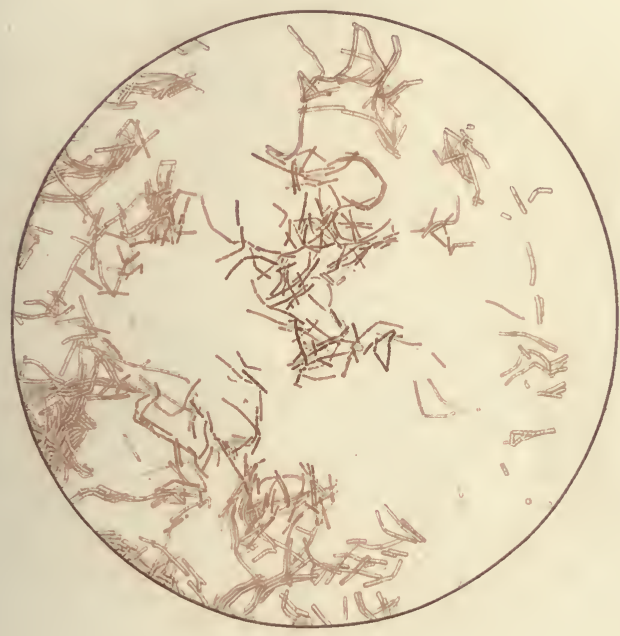

P Lackerbauer: ad. nat.del.

Imp limy-limar Paris

$\frac{400}{1}$ 

MALADIE DE L'AMEIRTUME.

Le ferment est mort depuis lonģtemps. Il est incruste de matière colorante et n'ag̉it plus.

Fig. 20

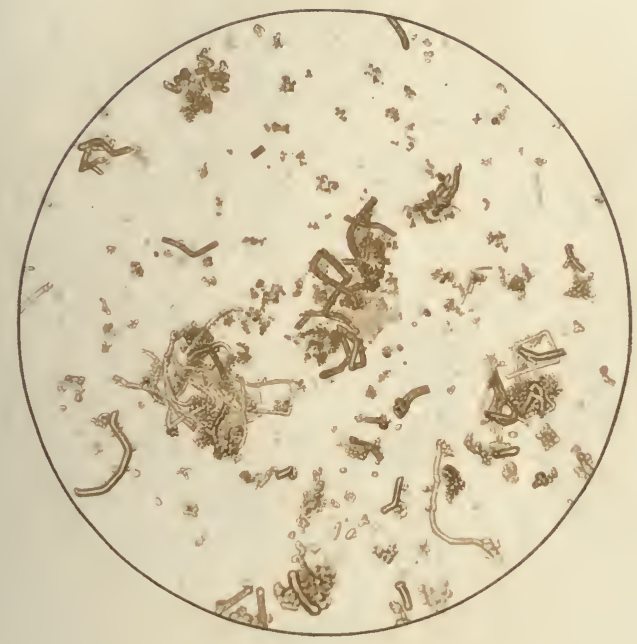

- P. Lackerbauer ad. nat. del.

Imp limy linas Paris 

MALADIE DE L'AMERTUME

Ferment très-ågé, terni et épaissi par la matière colorante.

Mème ferment débarrassé de la matière colorante.

Fig. 20 bis

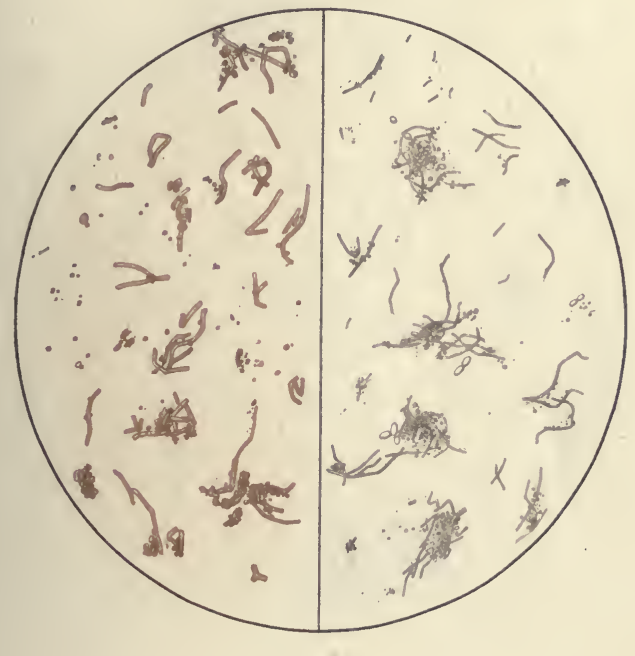

P Lackerbauer ad. nat. del.

Imp Gany-Grar Paris 



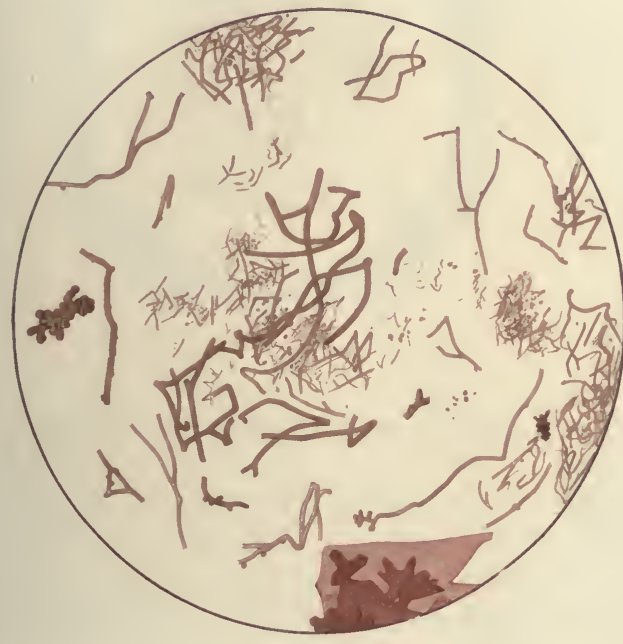



vins qui tournent et deviennent amers. Les vins communs tournent facilement. Les vins fins, au contraire, deviennent amers.

Si les filaments du vin tourné constituaient le même ferment que ceux des vins amers, on ne verrait pas pourquoi les vins communs qui tournent n'offriraient pas avec l'âge le ferment de l'amer, avec ses

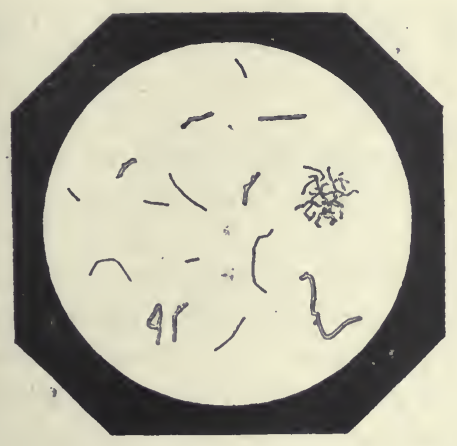

Fra. 22.

particularités de couleur, de volume, et ce caractère rameux et brisé du ferment de l'amer.

Enfin les viticulteurs ont toujours fait une distinction entre le vin qui tourne et le vin qui devient amer, bien que le vin qui tourne soit fade et un peu amer, caractères que l'on trouve dans les grands vins de Bourgogne lorsqu'ils deviennent malades dans leurs premières années.

Cependant je reconnais que la séparation des deux maladies des vins qui tournent et des vins qui passent à l'amertume réclamę encore de nouvelles preuves expérimentales. 


\title{
DE L'OXYGÈNE DE L'AIR DANS LA VINIFIGATION
}

\author{
DE L'INFLUENCE DE L'OXYGENE DE L'AIR \\ DANS LA VINIFICATION
}

Tout le monde connaît l'ingénieuse expérience par laquelle Gay-Lussac démontra ce que l'on avait longtemps pressenti et énoncé sans preuves, que l'oxygène de l'air est nécessaire à la fermentation du moût de raisin. Le jus sucré du raisin renfermé dans les grains encore réunis à la grappe qui les portait sur le cep ne fermente pas. Il était dès lors facile de prévoir que l'air, et dans l'air l'oxygène, est nécessaire à la fermentation du moût de raisin (1).

Gay-Lussac en donna la démonstration expérimentale. Après avoir écrasé des grains de raisin sous une éprouvette renversée pleine de mercure, il vit qu'ils ne fermentaient pas, soit seuls, soit au contact de divers gaz. L'addition d'une petite quantité de gaz oxygène déterminait au contraire la fermentation.

Voici le récit que fait Gay-Lussac (2) de l'expérience dont il s'agit, et comment elle lui fut suggérée :

“ En examinant les procédés de M. Appert pour la conservation des substances végétales et animales, j'avais remarqué avec surprise que du moût de raisin qui avait été conservé sans altération, pendant une année entière, entrait en fermentation quelques jours après avoir 'été

1. M. Chevreul s'exprime ainsi dans un article du Journal des savants relatif aux travaux du célèbre chimiste Stahl :

« Stahl avait bien apprécié la triple influence de l'air, de l'eau, et d'une certaine température pour la fermentation.

" Il devait à Bohn l'observation de la nécessité de l'air pour la fermentation du moût du suc de groseille, etc... car, hors du contact de l'atmosphère, ces sucs ne fermentent pas. Cette observation, qui remonte à Van Helmont, et qui fut reproduite par Mayow, en 1654, a été longtemps oubliée, car, en 1810, Gay-Lussac la reproduisit comme nouvelle, et encore aujourd'hui peu de personnes savent qu'elle remonte à plus de deux siècles. n [Ghevreur (E.). George Ernest Stahl. De 1660 à 1734. \& 6. Manière dont Stahl a envisagé la fermentation. Journal des savants, 1851, p. 175-176.]

2. Gay-Lussac. Extrait d'un Mémoire sur la fermentation (lu à l'Institut le 3 décembre 1810). Annales de chimie, LXXVI, 1810, p. 245-259. (Note de l'Édition.) 
transvasé. C'est même ainsi que M. Appert préparait des vins mousseux dans toutes les saisons de l'année. Ce fait m'a porté à soupçonner que l'air avait une certaine influence sur la fermentation... [p. 2'7].

“ En conséquence, j'ai pris une cloche, dans laquelle j'ai introduit de petites grappes de raisin parfaitement intactes, et après l'avoir renversée sous le mercure, je l'ai remplie cinq fois de suite de gaz hydrogène, pour chasser les plus petites portions d'air atmosphérique; après cela, j'ai écrasé le raisin dans la cloche au moyen d'une tige de fer, et je l'ai exposé à une température de 15 à $20^{\circ}$. Vingt-cinq jours après, la fermentation ne s'était pas manifestée, tandis qu'elle s'était déclarée le jour même dans du moût auquel j'avais ajouté un peu d'oxygène. Pour m'assurer que c'était à cause de l'absence de ce gaz que la fermentation ne s'était pas manifestée dans la première cloche, j'y ai introduit un peu d'oxygène, et peu de temps après elle a été très vive. J'ai remarqué dans ces deux dernières expériences que l'oxygène était absorbé presque complétement; mais je ne puis affirmer s'il s'est combiné avec le carbone ou avec l'hydrogène. J'ai observé un volume de gaz acide carbonique cent vingt fois plus considérable que celui du gaz oxygène que j'avais ajouté au moût de raisin; d'où il est évident que, si l'oxygène est nécessaire pour commencer la fermentation, il ne l'est point pour la continuer, et que la plus grande partie de l'acide carbonique produit est le résultat de l'action mutuelle des principes du ferment et de ceux de la matière sucrée. Dans une autre expérience du même genre que la précédente, la fermentation s'est déclarée au bout de vingt et un jours; mais le raisin était très avancé; d'ailleurs, une portion du même moût mis en contact avec un peu d'oxygène avait fermenté trente-six heures après avoir été préparé. Ainsi il est encore évident, par cette expérience, que le gaz oxygène favorise singulièrement le développement de la fermentation. " [p. 250-251.]

Puisque l'oxygène de l'air intervient dans la fermentation et que le sucre n'a que faire de ce gaz pour se transformer en alcool et en acide carbonique, il me paraît certain que c'est le ferment qui exige la présence de l'oxygène pour passer de l'état de germe à la forme cellulaire adulte, propre à se multiplier ensuite par bourgeonnement en dehors de toute influence de ce gaz. Dans l'expérience que je viens de rappeler, le ferment était à l'état de germe, soit sur les parois de l'éprouvette, soit dans les impuretés dont le mercure est souillé, soit à la surface des grains de raisin. Sous l'influence de l'oxygène, ce germe, encole inconnu dans sa véritable forme, devient celluleferment, à peu près comme une graine a besoin d'oxygène libre pour devenir petite plante ayant radicule et tigelle. C'est du moius l'explica- 
tion qui me parait la plus raisonnable du fait observé par Gay-Lussac( ${ }^{(1)}$.

Mais à cóté de cette influence de l'oxygène, sur laquelle il est inutile que je m'étende en ce moment, il en est une autre qui mérite d'être prise en sérieuse considération. Il existe dans le moût de raisin, comme dans la plupart des liquides propres aux organismes végétaux et animaux, des principes encore mal connus, extrêmement avides d'oxygène et qui se combinent directement avec cet élément. Ces principes sont certainement multiples déjà dans le moût et à plus forte raison dans le vin, où se trouvent en outre les matières colorantes de la pellicule des grains de raisin, elles-mêmes très avides d'oxygène.

Si l'on considère l'ensemble des pratiques de la vinification, on reconnaîtra que l'air atmosphérique en est, pour ainsi dire, exclu.

Les raisins sont jetés dans la cuve de vendange. Quelques-uns sont détachés de leur grappe, ou écrasés; un peu de jus s'écoule : l'air est présent; mais c'est en quantité bien faible comparativement au volume des raisins. Bientôt la fermentation se déclare; alors plus d'oxygène du tout et le liquide est constamment saturé de gaz acide carbonique. Le vin est soutiré rapidement, à gros jet, et on en remplit sur-le-champ des tonneaux. Le contact avec l'air pendant le soutirage ne dure qu'un instant. Une fermentation alcoolique lente continue dans les tonneaux, pendant laquelle le liquide est toujours sursaturé de gaz acide carbonique. Arrivent les soutirages. Alors le vin passe dans l'air, en jet plus ou moins volumineux, suivant le volume de la cannelle, pour être immédiatement transporté dans un autre tonneau. Il n'y a pas de temps d'arrêt, et en Bourgogne le soutirage se fait même à l'abri de l'air autant que possible.

La mise en bouteilles donne lieu encore à un contact obligé de l'air et du vin, mais toujours très rapide. A partir de ce moment, le vin n'a plus d'occasion d'être au contact de l'air. Joignons à cela la pratique habituelle de l'ouillage et celle du méchage, qui est assez fréquente, surtout pour les vins blancs. Si nous nous rappelons d'autre part le fait de l'évent, c'est-à-dire l'affadissement du vin lorsqu'il est placé au libre contact de l'air pendant plusieurs heures, il sera sensible pour tous que l'air a pu être considéré comme l'ennemi du vin, et que toutes les pratiques de la vinification invitent à adopter cette manière de voir.

Les rapports que présente l'oxygène de l'air dans son contact avec le vin ont été étudiés directement par M. Boussingault $\left({ }^{2}\right)$, qui a reconnu

1. Voir p. 427-429 du tome II des CEuvres de PAsteur.

2. Boussingault a communiqué ses résultats dans une leçon faite en 1859 au Conservatoire des Arts et Métiers. (Notes de l'Édition.) 
que le vin ne renfermait pas d'oxygène en dissolution, mais seulement de l'azote et du gaz acide carbonique. La conséquence naturelle de ce fait est qu'il existe dans le vin des principes très oxydables. II. Berthelot ( $\left.{ }^{4}\right)$ a non seulement confirmé l'exactitude de ce fait, mais il a, le premier à ma connaissance, rapporté judicieusement à l'influence d'une absorption 'd'oxygène la perte de qualité que le vin éprouve par la vidange. En d'autres termes, M. Berthelot a expliqué l'évent par le fait de l'absorption d'une certaine proportion de ce gaz. Il a émis, en outre, l'opinion fort exacte, à mon avis, que la vinosité, ou mieux la force du vin, n'est pas due seulement au principe alcoolique. Il y a certainement dans le vin une ou plusieurs substances qui lui donnent de la force indépendamment de l'alcool. J'ajoute que ces substances ne sont pas, toutes du moins (2), le produit de la fermentation ni de la vinification. Elles sont en partie formées (3) dans le grain de raisin, et il est très facile de reconnaître qu'il y a des raisins forts et des raisins faibles, comme il y a des vins forts et des vins faibles, circonstance dont il faudrait tenir grand compte dans le choix des cépages.

Parmi les cépages que l'on cultive dans le vignoble d'Arbois se trouvent le ploussard et le valet noir. Le 14 octobre 1863 j'ai récolté dans une vigne bien exposée au soleil des raisins de ces deux plants, d'une belle maturité. J'ai trouvé dans le moût de ces raisins : .

$$
\begin{aligned}
& \text { Valet noir }\left\{\begin{array}{r}
9 \text { gr. } 5 \text { d'acide par litre, évalué en acide tartrique. } \\
207 \text { gr. } 4 \text { de sucre. }
\end{array}\right. \\
& \text { Ploussard }\left\{\begin{array}{r}
8 \text { gr. } 7 \text { d'acide. } \\
223 \text { gr. } 2 \text { de sucre. }
\end{array}\right.
\end{aligned}
$$

Or, bien que le valet noir fût choisi dans ce cas particulier plus acide et moins sucré que le ploussard, en mangeant alternativement des grains de l'un et de l'autre cépage, il n'y avait aucune comparaison à faire entre les saveurs et l'impression générale sur le palais, et le plus doux et le plus sucré en apparence n'était pas le ploussard. Ce dernier a une force très supérieure au valet noir, toutes choses étant égales, et l'on se rend bien compte que le valet noir doit donner un vin beaucoup plus plat et en apparence moins acide que le vin de ploussard. Il ne serait pas difficile de trouver du valet noir plus sucré et plus acide que du ploussard et dont le vin, une fois fait, n'aurait

1. Berthelot (M.). Action de l'oxygène sur le vin. Comptes rendus de l'Académie des sciences, LVII, 1863, p. 795-797 et 983-985, et LVIII, 1864, p. 80-81. - Sur l'oxydation du vin. Ibid., p. 292-295.

2. Les mots " toutes du moins " ne figurent pas dans la $1^{\text {re }}$ édition.

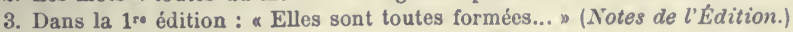


cependant ni la force, quoique plus riche en alcool, ni l'acidité apparente, quoique plus acide, du vin de ploussard.

Dans l'étude des cépages il faut donc envisager l'acidité habituelle et la proportion de sucre, et également la force, le corps du jus de leurs raisins, mots très vagues, mais qui se préciseront lorsque la science sera plus avancée. Il faut tenir grand compte assurément de l'acidité et de la proportion de sucre lorsqu'il s'agit de différences considérables s'exprimant, par exemple, par des moyennes respectives de 9 et 12 pour l'acidité, 180 et 220 pour le sucre; mais pour celles que je viens de comparer 8,7 et 9,5 en acidité, 207 et 223 en sucre, les vins peuvent n'en être pas très affectés. Cependant leurs qualités pourraient différer notablement parce qu'elles se trouveraient sous la dépendance d'autres principes que les acides et le sucre.

J'ai à mon tour étudié la question des rapports qui peuvent s'établir entre l'oxygène de l'air atmosphérique et le vin dans les diverses pratiques de la vinification. Tout en reconnaissant l'exactitude des faits signalés avant moi, tout en applaudissant à l'excellence de plusieurs des pratiques qui proscrivent le contact de l'air et du vin, j'ai été conduit cependant à envisager ce sujet sous un point de vue nouveau et que je crois plus vrai.

“ Les phénomènes que j’ai observés, dit M. Berthelot, prouvent avec quel soin le vin, une fois fait, doit être préservé de l'action de l'oxygène de l'air, puisque le contact prolongé de 10 centimètres cubes d'oxygène, c'est-à-dire 50 centimètres cubes d'air, suffit pour détruire le bouquet d'un litre de vin( $\left.{ }^{1}\right)$. ”

Un auteur qui a écrit un traité assez estimé sur les vins de France proclame qu'il n'y a pas de bon vin dans un vase qui n'est pas plein (2). En un mot, je le répète, l'oxygène a toujours été considéré comme l'ennemi du vin, ne fût-ce qu'à cause de son rôle dans l'acétification.

Mais la question est plus complexe, et je puis ajouter plus importante qu'on ne l'a pensé jusqu'à présent $\left({ }^{3}\right)$.

A l'époque où M. Berthelot faisait ses observations, qui corroboraient les idées des viticulteurs sur la nécessité de préserver le vin du contact de l'oxygène, j'ai été amené à considérer ce gaz, non comme nuisible, mais comme très utile au vin. Selon moi, c'est l'oxygène qui fait le vin; c'est par son influence que le vin vieillit; c'est lui qui

1. Berthelot. [Action de l'oxygène sur le vin.] Comptes rendus de l'Académie des sciences, LVII, 1863, p. 795-797.

2. Batilliat. Traité sur les vins de la France. Paris et Lyon, 1846, 352 p. in-8• (4 pl.).

3. Pasteur. [Études sur les vins. Première partie: De l'influence de l'oxygène de l'air dans la vinification.] Comptes rendus de l'Académie des sciences, LVII, 1863, p. 936-942. [Voir p. 389-395 du présent volume.] 
modifie les principes acerbes dı vin noureau et en fait disparaître le mauvais goût; c'est encore lui qui provoque les dépòts de bonne nature dans les tonneaux et dans les bouteilles, et loin, par exemple, qu'une absorption de quelques centimètres cubes de gaz oxygène par litre de vin use ce vin, lui enlève son bouquet et l'affaiblisse, je crois que le vin n'est pas arrivé à sa qualité et ne doit pas être mis en bouteille tant qu'il n'a pas absorbé une quantité d'oxygène bien supérieure à celle-ci.

Comment expliquer ces observations contradictoires? C'est qu'il faut distinguer avec un très grand soin l'action brusque et l'action lente de l'oxygène de l'air sur le vin. En outre, il n'est pas difficile de démontrer que les pratiques de la vinification, si ennemies qu'elles paraissent être de l'introduction du gaz oxygène dans le vin, sont éminemment propres à soumettre ce liquide à une aération progressive et lente, en même temps qu'elles s'opposent à une aération brusque et prolongée. J'ajoute que, s'il ne fallait pas s'armer constamment, dans les soins à donner au vin, contre les maladies auxquelles il est sujet, il y a beaucoup de pratiques dans l'art de faire le vin que l'on abandonnerait, parce qu'elles éloignent l'oxygène de l'air.

Il faut bien remarquer, en effet, que tel usage, celui de l'ouillage, par exemple, qui témoigne du soin que l'on apporte à éloigner la vidange, ne signifie pas d'une manière absolue, comme on le croit, que le vin doit être privé d'oxygène et qu'il n'y a pas de bon vin dans un vase qui n'est pas plein.

L'ouillage est commandé par la nécessité d'éviter les maladies du vin, et il atteint ce but par la gêne qu'il apporte dans le développement de certains parasites.

J'en dirai autant du méchage.

L'évent du vin doit être lui-mème envisagé avec plus de rigueur qu'on ne l'a fait. Il est bien vrai que la vidange affaiblit le vin, mais j'ai observé que cet effet change beaucoup avec le temps, si le vin, après avoir été éventé, est renfermé, à l'abri de l'air, en bouteilles pleines.

L'évent constitue donc un genre d'altération qui ne dure pas, a beaucoup près, avec son caractère originel, et ce fait aide à comprendre toute la différence qui doit exister entre l'aération brusque et l'aération lente du vin.

Pour développer les idées qui précèdent avec le soin qu'elles méritent, il est nécessaire que j'entre plus avant dans l'exposé des faits qui m'ont conduit à envisager l'action de l'oxygène de l'air sur le vin comme une action bienfaisante et indispensable. 


\section{ÉTUDE SUR LA NATURE DES GAZ CONTENUS DANS LE VIN ET DANS LE MOUT DE RAISIN}

Au point de vue qui m'occupe en ce moment, l'étude de la nature des gaz contenus dans le vin méritait une grande attention. Je me suis servi pour cet objet de l'appareil même qu'a imaginé M. Boussingault, en le modifiant légèrement, afin d'en rendre l'emploi plus sûr et plus pratique. Voici la manière d'opérer de M. Boussingault.

Un ballon de litre, muni d'un bouchon et d'une coiffe de caoutchouc,

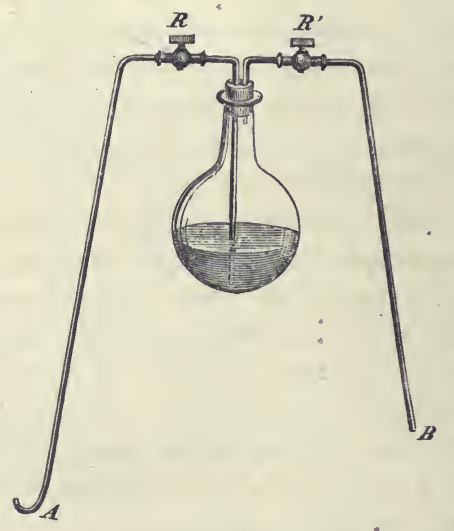

Fic. 23.

porte deux tubes du diamètre des tubes à gaz, comme l'indique la figure 23. Ces tubes sont très longs, garnis de robinets, et l'un d'eux est recourbé de façon à pouvoir s'engager sur une cuve à mercure, sous une éprouvette renversée pleine de liquide.

Rien de plus facile en échauffant un peu l'air du ballon, puis, le refroidissant pendant que l'un des tubes plonge dans l'eau et que le robinet de l'autre est fermé, d'introduire 300 à 400 centimètres cubes d'eau dans le ballon.

Alors le robinet $\mathrm{R}^{\prime}$ étant fermé, le robinet $\mathrm{R}$ ouvert et l'extrémité du tube recourbé engagée sous le mercure, on chasse rigoureusement tout l'air du ballon en portant à l'ébullition l'eau qui s'y trouve. Lorsque tout l'air a été chassé par la vapeur d'eau, on laisse refroidir le ballon, le mercure monte dans le tube, et l'on s'assure facilement, 
en surveillant la colonne de mercure après le refroidissement, que les robinets tiennent exactement le vide. Lorsque cette condition est remplie, on introduit dans le ballon un volume déterminé du liquide à éprouver en plongeant l'extrémité $\mathrm{B}$ du tube $\mathrm{R}^{\prime} \mathrm{B}$ dans ce liquide et en ouvrant le robinet $\mathrm{R}^{\prime}$.

Lorsque le liquide est introduit, on le fait bouillir, $\mathrm{R}^{\prime}$ étant fermé

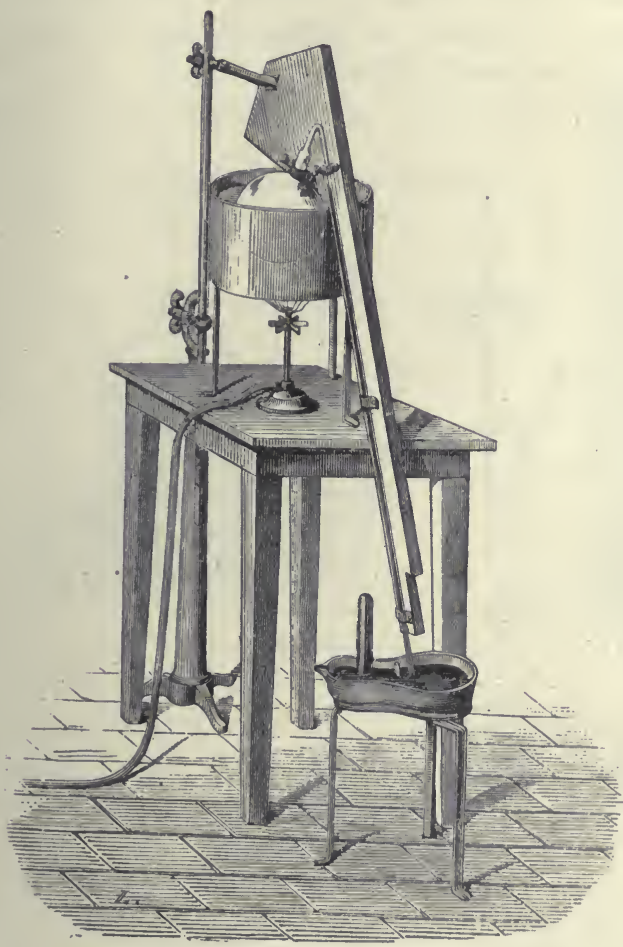

Fig. 24.

et $\mathrm{R}$ ouvert, et l'on recueille tout le gaz dans une éprouvette sur le mercure.

Ce procédé que j'ai appris à connaître dans une des excellentes leçons de M. Boussingault au Conservatoire des Arts et Métiers, leçon à laquelle j'assistais, est exactement celui que j'ai adopté; seulement j'ai supprimé les robinets et le bouchon de liège. J'avais trouvé trop de difficultés à rencontrer des robinets et un bouchon tenant le vide 
après une longue ébullition. Voici la disposition simple et sûre à laquelle je me suis arrêté.

Un ballon de litre, auquel on a soudé un long tulue de verre de 1 mètre recourbé, est fixé à l'aide de brides de cuir sur une planche découpée comme l'indique la figure 24. Un anneau de fer portant un appendice fixé avec des vis, à la planche soutient en outre le ballon. L'anneau de fer est entouré d'une bande de toile afin que le ballon repose mieux sur l'anneau. Le ballon est ainsi rendu très solide, très maniable, et d'un transport facile.

Le ballon est placé dans un bain de chlorure de calcium. Un vase

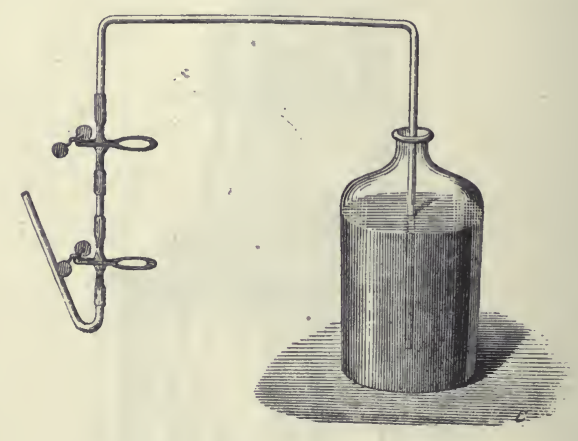

FIG. 25.

cylindrique de fer-blanc de quelques litres de capacité sert à contenir et à faire bouillir le bain de chlorure. Un trépied en fer porte le vase de fer-blanc, qui est chauffé par une lampe à gaz, ou sur un fourneau au charbon de bois, si le gaz fait défaut.

Pour soutenir la planche et son ballon, il suffit d'un support de métal à longue tige, dont la mâchoire s'engage dans un trou pratiqué dans la planche. En outre, la planche repose sur le bord même du vase de fer-blanc.

Le ballon est rempli d'eau au tiers et même un peu plus. Il n'y a pas d'inconvénient à ajouter 400 à 500 centimètres cubes d'eau. On fait bouillir rapidement cette eau. C'est seulement lorsqu'on arrive à la fin de l'évaporation qu'on fait plonger l'extrémité recourbée du tube de verre dans le mercure. Tandis que l'ébullition est vive, il n'y a pas à craindre la rentrée de l'air extérieur. Par le refroidissement le mercure remonte dans le tube et se fixe à une hauteur qui n'éprouve plus que les variations de la pression atmosphérique et de la température. 
On peut facilement transporter le ballon au loin, par exemple dans une cave. A cet effet, on ferme sous le mercure le caoutchouc placé à l'extrémité du tube, à l'aide d'un tube de verre plein, et au moment où le tube barométrique est un peu incliné, de façon que, en le relevant pour le transporter, il y ait pression du mercure de l'intérieur à l'extérieur sur le bouchon de verre. Pour plus de sûreté, on peut, en outre, adapter au caoutchouc une pince de Mohr. entre le bouchon de verre et l'extrémité du tube barométrique.

S'agit-il d'introduire du vin, placé dans une bouteille, dans un flacon ou dans un petit tonneau dont on peut ôter la bonde sans inconvénient, on prend un siphon (fig. 25), muni d'un tube de caoutchouc et d'un bout de tube de verre qui pourra s'engager dans le tube de caoutchouc fixé à l'extrémité du tube barométrique. Alors, après avoir rempli le siphon du vin à étudier, on le réunit au tube barométrique, tout en pinçant fortement avec les doigts, par son milieu, le tube de caoutchouc fixé à l'extrémité de ce tube, puis on desserre les pinces, et l'on incline doucement le ballon et son tube. Le liquide du flacon se précipite alors dans le ballon. On en introduit environ 200,300, 500 centimètres cubes, ou même davantage, suivant les conditions de l'expérience et de l'analyse ultérieure. Puis on pince de nouveau fortement avec les doigts le caoutchouc du

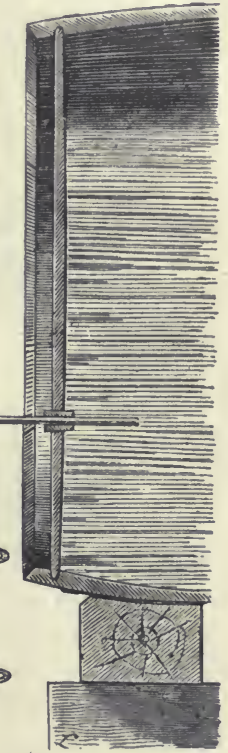

Frg. 26. tube barométrique, on détache le siphon, et on plonge dans le mercure l'extrémité du tube barométrique de façon a laisser s'équilibrer la pression intérieure par la rentrée du mercure dans le tube. Si l'on a à rapporter le ballon dans le laboratoire à distance, on replace le bouchon de verre pour fermer le tube barométrique avec les précautions que j'ai indiquées tout à l'heure.

Le ballon est alors introduit dans le bain de chlorure de calcium. On chauffe celui-ci, la pression augmente et l'on enlève sous le mercure le bouchon de verre qui ferme le tube barométrique. L'extrémité (le ce dernier a été préalablement ajustée dans la rainure d'une cuve à mercure en porcelaine, de façon à disposer facilement par-dessus une éprouvette renversée pleine de mercure. Lorsque tout le gaz est recueilli, il a passé en général très peu de liquide dans l'éprouvette, et 
dans la plupart des cas, lorsqu'il s'agit du vin, on peut sans erreur sensible transvaser le gaz dans un tube gradué en éloignant le liquide, avant l'introduction de la potasse. Ce liquide encore chaud renferme peu de gaz en dissolution.

Dans le cas où l'on veut recueillir sur place, dans une cave, du vin en tonneau, on adapte au tonneau un bouchon muni d'un tube de verre et d'un caoutchouc et d'un autre petit bout de tube avec caoutchouc, comme l'indique la figure 26 , et l'on procède ainsi qu'il a été dit plus haut pour l'introduction du vin dans le ballon.

La méthode que je viens de décrire pour recueillir les gaz dissous

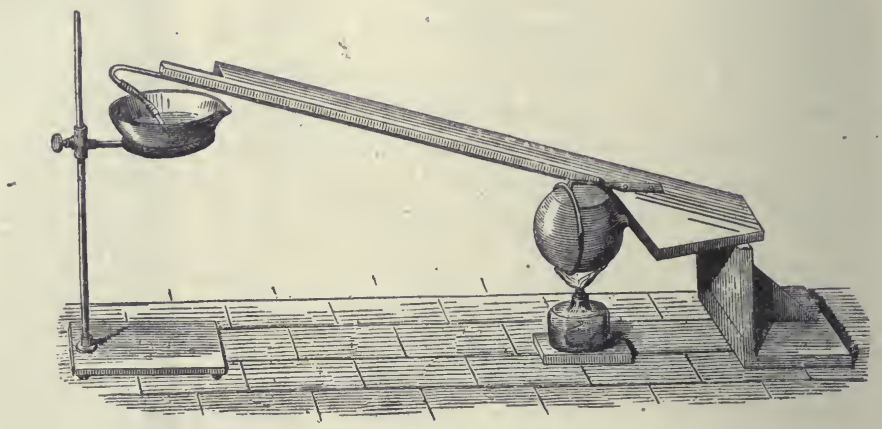

Fra. 27.

dans le vin et dans les liquides en général est assez commode. Le ballon et son tube n'ont point du tout la fragilité qu'on pourrait supposer. Quant à l'expulsion du liquide du ballon et de la petite quantité du mercure qu'il a chassé devant lui, rien de plus facile. Lorsque le gaz a été recueilli et que le ballon et le liquide sont encore très chauds, et au sortir même du bain de chlorure, on renverse le ballon dans la position de la figure 27, et l'on chauffe avec une lampe à alcool. Le liquide bout, et la vapeur, emprisonnée à sa surface à cause de la position du ballon, chasse le liquide et le mercure, si l'on a soin, au moment où l'ébullition se déclare, de relever un peu le ballon, afin que le mercure arrive dans le tube.

Le liquide est recueilli dans une capsule, et mesuré, en tenant compte de la portion qui a passé dans l'éprouvette avec le gaz. Il y a une petite perte de liquide due à ce que l'on recueille un liquide bouillant dont une partie se vaporise.

Dès que le liquide est entièrement chassé, on fait rentrer de l'eau 
dans le ballon, on le lave, et l'on chauffe de nouveau pour chasser l'eau de lavage par la vapeur surchauffée. Puis enfin on remplit de nouveau le ballon d'eau pour une nouvelle opération que l'on met tout de suite en train, ce qui se fait rapidement, puisque le bain de chlorure de calcium est encore très chaud.

Toutes ces manipulations sont assez faciles pour que j'aie pu les pratiquer à cent lieues de Paris (1), loin de tout laboratoire, dans un rez-de-chaussée, presque en plein air, et en allant recueillir le vin dans telle ou telle cave de la localité. Une petite cuve à mercure, d'un litre de capacité, quelques tubes gradués et quelques supports composaient le mobilier de ce laboratoire improvisé. Je ne dois pas oublier toutefois l'aide de quelques jeunes agrégés de l'École Normale, pleins d'intelligence et d'ardeur, et que l'amour seul de la science avait amenés avec moi (2).

Voici les résultats auxquels nous sommes parvenus :

\section{GAZ DU MOÛT}

I. Le 7 octobre 1864, récolte à la vigne de raisins blancs. (Cépage dit melon.) On les écrase à la main avec leurs grappes dans un seau, puis, après avoir pressé le tout dans un linge, on procède immédiatement à l'analyse.

Lorsqu'on opère avec le moût, il est bon de ne remplir le ballon qu'à moitié, afin que l'ébullition ultẹrieure du liquide ne donne pas une mousse gênante et qui puisse passer dans l'éprouvette destinée à recueillir les gaz.

Le volume total du moût a été mesuré à la fin de l'opération.

Volume total du moût. ........ $415 \mathrm{cc}$.

Gaz total ................... 33

Il y a dans l'éprouvette ......... 5 d'eau condensée.

Les 33 cc. de gaz renfermaient 4 cc. 6 d'azote et le reste en acide carbonique, sans trace de gaz oxygène. En supposant que les 5 cc. d'eau condensée et refroidie ont dissous leur volume de gaz acide carbanique, un litre de moût contenait:

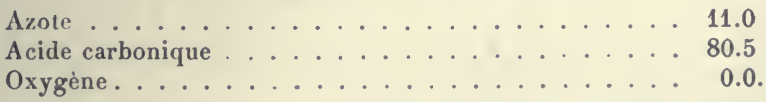

1. Arbois. (Note de l'Édition.)

2. Ce sont MM. Gernez, Lechartier, Raulin et Duclaux. Qu'ils veuillent bien recevoir ici l'expression publique de mes remerciements et de mon affection. 
II. Même cépage. On égrappe, puis on écrase les grains à la main et immédiatement on procède à l'analyse. Les grappes avaient été récoltées la veille.

Volume total du moùt. ........ 375 c.

Gaz total .................... 36

Il y a .................. 4 d'eau condensée.

Un litre de moût contenait :

Azute. ..................... 12.1

Acide carbonique . . . . . . . . . . . . . . 94.6

Oxygène..................... 0.0 .

III. Moùt du même cépage conservé depuis 48 heures au libre contact de l'air, dans un làrge cristallisoir, à une température de $9^{\circ}$. Un litre de moût renfermait:

Azote ..................... 12.2

Acide carbonique ................. 91.2

Oxygène . . . . . . . . . . . . . 0.0 .

IV. Moùt du cépage dit ploussard conservé 48 heures dans les mêmes conditions et toujours au libre contact de l'air :

Un litre renfermait 15 cc. 0 de gaz azote. Pas de trace d'oxygène. L'acide carbonique n'a pas été mesuré.

J'ai eu l'occasion d'examiner un moût qui était depuis sept jours dans une grande cuve ouverte, et qui n'avait pas encore fermenté à cause de la température basse où se trouvait la cuve. Il ne contenait pas du tout d'oxygène libre en dissolution. Sans doute le moût dissout de l'oxygène, mais, au fur et à mesure de sa dissolution, ce gaz se combine avec des principes oxydables. Il paraîtrait mème qu'il serait saturé de gaz azote, puisqu'il n'offre guère plus d'azote après avoir été conservé 48 heures exposé à l'air que lorsqu'il est récent.

La disparition du gaz oxygène n'est pas tellement rapide que l'on ne puisse avoir du moût tenant de l'oxygène en dissolution, mais il faut que le moût vienne d'être agité avec de l'air.

5 litres de moût ont été agités dans une grande bouteille de 10 litres avec leur volume d'air pendant une demi-heure. 50 centimètres cubes de gaz extraits du moût un quart d'heure après l'agitation ont laissé 13 centimètres cubes de gaz non absorbables par la potasse, lesquels renfermaient 20 pour 100 de gaz oxygène.

La même expérience répétée sur le même moût, en laissant reposer le liquide pendant une heure après l'agitation avec l'air, n'a plus fourni que 6 pour 100 d'oxygène dans le gaz privé d'acide carbonique. 
Enfin, en laissant du moût dans une bouteille bien bouchée en contact avec son volume d'air (à une température de $10^{\circ}$ afin de retarder la fermentation), l'air de la bouteille renfermait, au bout de 48 heures, près de 3 pour 100 de gaz carbonique, et 14 pour 100 de gaz oxygène seulement. On avait agité à deux reprises le moût avec l'air pendant une demi-heure. Chaque litre de moût avait donc absorbé environ 70 centimètres cubes de gaz oxygène. Cette expérience a été faite en 1863. J'ai essayé de la renouveler en 1864, mais j'ai trouvé alors des absorptions beaucoup moindres de gaz oxygène, sans que j'aie pu bien me rendre compte de la cause des différences. Je crois que la température ou un premier commencement insensible de fermentation ont une grande influence sur l'absorption du gaz oxygène.

Le $1^{\text {er }}$ octobre 1864, j'extrais du moût de ploussard de deux espèces de grappes, les unes bien mûres, les autres commençant à noircir, mais encore d'un rouge lie de vin. Je remplis à moitié avec ces moûts des tubes de 50 centimètres cubes de capacité. Le 3 octobre, c'est-àdire. 48 heures après, j'analyse l'air des tubes. Les tubes, fermés à la lampe, ont été placés dans une cave froide afin d'empêcher la fermentation de se déclarer.

\section{MOÛT DES RAISINS MÛRS}

Gaz total. . . . . . . . . . . . . 17,3

Après l'action de la potasse. . . . . . . . . . . 16,8

Après l'action de l'acide pyrogallique . . . . . . 13,6.

Cela répond à 2,9 pour 100 de gaz acide carbonique, et à 19,0 pour 100 d'oxygène dans le gaz restant.

\section{MOÛT DES RAISINS NON MÛRS}

Gaz total. . . . . . . . . . . . . . 18,8

Après l'action de la potasse. . . . . . . . . . . 18,3

Après l'action de l'acide pyrogallique. . . . . 14,9.

Cela répond à 2,7 pour 100 de gaz acide carbonique, et à 18,6 d'oxygène dans le gaz restant.

Le moût le moins mûr est donc moins oxydable que l'autre. Je ferai remarquer que ce résultat s'est soutenu dans deux autres séries d'expériences.

La combinaison de l'oxygène de l'air avec le moût modifie sa couleur. Le moût de raisins blancs, à peu près incolore dans le grain et au moment du pressurage, devient jaune brun en passant par les états intermédiaires. Le moût de raisins rouges renferme également des inatières incolores qui brunissent par le contact de l'air. Enfin l'odeur 
du moût récent, qui est faible et a quelque chose de vert, devient peu à peu, si le moût n'est pas filtré, agréable, éthérée, au moment où la fermentation commence, et cette odeur paraît être en rapport avec une aération lente du moût, car cet effet se produit principalement quand le moût a été exposé à l'air en grande surface (1).

Le moût de raisin renfermant des principes oxydables, et la fermentation étant plus propre par son caractère général à en augmenter le nombre qu'à les détruire, il est permis d'admettre que le vin sera lui-même un liquide très avide d'oxygène. Il est même facile de comprendre qu'il doit contenir des substances oxydables de natures diverses, car le moût en fournit probablement de plusieurs sortes, matières colorables par oxydation et autres, et la fermentation introduit de son còté les matières colorantes ou colorables de la pellicule qui sont très avides d'oxygène.

En résumé, le vin est un liquide que l'on n'expose pas à l'air, ou très peu, le moins possible, qui débute par être saturé de gaz acide carbonique, sans trace d'un autre gaz quelconque, par la nature même de la fermentation $\left({ }^{2}\right)$, et qui contient en outre des substances multiples très oxydables. Il résulte de là que toute circonstance qui sera propre à priver le vin du contact de l'oxygène, c'est-à-dire de l'air atmosphérique, ou qui, au contraire, le mettra en rapport avec ce gaz, doit mériter la plus sérieuse attention.

Pour m'assurer par l'expérience directe que le vin nouveau ne renferme pas la plus petite quantité de gaz oxygène, ni de gaz azote, et qu'il est saturé de gaz acide carbonique, j'ai transporté dans une cave l'appareil barométrique de la figure 24 , et, en opérant comme il a été dit à la page 179, j'y ai introduit du vin d'un des tonneaux.

Le gaz recueilli a été complétement absorbable par la potasse. Il ne renfermait pas du tout d'azote ni d'oxygène.

Une expérience de ce genre, faite le 19 novembre 1863, dans une cave d'Arbois, sur du vin de la récolte du mois d'octobre précédent, a fourni, à la température de $7^{\circ}, 1^{2}$ lit. 481 de gaz acide carbonique par litre, très pur.

1. Dans la $1^{\text {re }}$ édition ne figurent pas les mots " car cet effet... en grande surface ". (Note de l'Édition.)

2. Dans mon Mémoire sur la fermentation alcoolique, inséré dans les Annales de chimie et de physique pour l'année 1860 [Voir ce Mémoire p. 51-126 du tome II des CEuvres DE PASteur], j'ai indiqué la présence d'une quantité extrêmement faible d'azote mélangé au gaz acide carbonique des fermentations industrielles des distilleries de grains et de. betteraves. Mais l'absence absolue de ce gaz azote dans la fermentation du moût de raisin me fait craindre que le gaz azote que j'ai recueilli autrefois n'ait eu pour origine la solutión concentrée de potasse qui m'avait servi à absorber le gaz carbonique, bien que j'aie cru prendre toutes les précautions pour éloigner cette cause d'erreur, difficile á éviter complétement. 
Dans la même càre j'ai prélevé lé joưr suivant, par le même procédé, 250 cc. d'un vin de deux années, de la récolte de 1861. Il ne renfermait par litre que $200 \mathrm{cc}$. de gaz acide, carbonique, et $16 \mathrm{cc}$. de gaz azote, mesurés à la température de $12^{\circ}$, èt également sans trace d'oxygène. Ce vin n'avait été soutiré que deufois, en mars et en juillet 1862.

Sans aller plus loin, nous pouvons conclure de ces faits :

$1^{\circ}$ Que le vin nouveau ni le vin vieux ne renferment trace d'oxygène libre en dissolution;

$2^{\circ}$ Que le vin nouveau ne contient que du gaz acide carbonique pur;

$3^{\circ}$ Que le vin vieux contient bien moins de gaz acide carbonique que le vin nouveau, et du gaz azote en proportion sensible.

D'où provient le gaz azote qui est en dissolution dans le vin d'un certain âge? Nous allons reconnaitre d'abord que la moindre agitation du vin avec l'air, et cette agitatiōn est un des effets nécessaires des soutirages, amène immédiatement dans le vin, indépendamment d'autres causes non moins efficaces, une proportion sensible de gaz azote.

Le 20 novembre 1863, j'introduis 7 litres du vin nouveau dont j'ai parlé tout à l'heure, ne contenant ni azote, ni oxygène, dans une grande bouteille de 14 litres de capacité, et j'agite pendant quelques instants le vin et l'air contenus dans la bouteille, puis, une demi-heure après l'agitation, j'étudie la composition des gaz en dissolution dans le vin.

$520 \mathrm{cc}$. de vin ont laissé $10 \mathrm{cc}$. de gaz non absorbables par la potasse, lesquels ont fourni $7 \mathrm{cc} .5$ de gaz azote après l'action de l'acide pyrogallique. Un litre de vin avait donc absorbé par son contact avec l'air 14 cc. 5 de gaz azote et 4 cc. 7 de gaz oxygène.

J'ai placé alors 4 litres de ce vin aéré dans un grand flacon bien bouché. Le lendemain matin, $700 \mathrm{cc}$. de ce vin ont fourni $10 \mathrm{cc}$. 4 d'un gaz non absorbable par la potasse et ne contenant pas trace d'oxygène. L'oxygène était donc entré en combinaison avec certains principes oxydables contenus dans ce vin, conformément aux résultats des expériences de MM. Boussingault et Berthelot ${ }^{(1)}$.

Mais rapprochons-nous davantage d'un soutirage 'ordinaire. J'ai dit que le vin de 1861 ne contenait pas du tout de gaz oxygène, pas plus que le vin nouveau de 1863 , dont nous venons de parler. Je soutire au tonneau 4 litres de ce vin de 1861 dans une terrine, à l'aide d'une cannelle dont le jet est assez fort. Le soutirage a donc été très rapide. Aussitòt après, et sans plus de perte de temps qu'il n'en a fallu pour rapporter la terrine de la cave au rez-de-chaussée, je fais passer un 
certain volume de ce vin dans l'appareil barométrique. Or, le gaz contenu dans le vin renfermait 10,4 pour 100 de son volume de gaz oxygène après avoir été privé de son acide carbonique.

Voici d'autres faits relatifs à l'influence des soutirages sur le vin.

Le 21 novembre 1864, on remplit plusieurs tonneaux; de 60 litres de capacité environ, de vin de la récolte d'octobre, pris sous le marc. A cet effet, un gros tube de caoutchouc adapté à la cannelle du foudre vient se rendre jusqu'au fond du petit tonneau. Celui-ci se remplit dans l'intervalle de quelques instants. Lorsqu'il est tout à fait plein, on en retire avec un siphon exactement $300 \mathrm{cc}$. de vin. Cette précau. tion, peut-être inutile, a été prise afin que le tonneau pût supporter sans accident une élévation de température de quelques degrés.

Plusieurs tonneaux, remplis de cette façon, de vin pris sous marc, sont expédiés d'Arbois à Paris et sont conservés dans une pièce de rez-de-chaussée au nord, non chauffée.

Le 27 décembre, le gaz du vin est étudié pour un des tonneaux. On prélève $540 \mathrm{cc}$. de vin qui ont fourni $588 \mathrm{cc}$. de gaz à $12^{\circ}$ et $736^{\mathrm{mm}}$ de pression, lesquels ont laissé un résidu de gaz azote pur de 3 cc. 5 . Un litre de ce vin renfermait donc dans les conditions de l'expérience 1082 cc. de gaz acide carbonique et 6 cc. 5 de gaz azote.

On avait expédié en même temps à Paris le mème vin dans des flacons de litre bien bouchés. Le vin d'un de ces flacons, examiné le 27 décembre, renfermait 1229 cc. de gaz acide carbonique pur sans trace d'azote à la température de $11^{\circ}$.

La vidange du tonneau rempli le 21 novembre n'était pas moins de 810 cc. le 27 décembre, défalcation faite des 300 cc. enlevés le 21 novembre. C'était un tonneau de bois de chêne neuf.

Afin d'étudier l'effet des soutirages, je transvase, le 27 décembre, le vin de ce tonneau dans un autre tonneau de 60 litres, puis aussitôt après je remets le vin dans son premier tonneau. Le soutirage a été pratiqué avec un robinet de bronze dont l'ouverture de débit était de $0^{\mathrm{m}}, 01$ de diamètre.

Le lendemain, je détermine la composition du gaz dissous dans le vin. 500 cc. de vin ont fourni 290 cc. de gaz contenant 6 cc. 25 de gaz azote à $12^{\circ}$ et $749^{\mathrm{mm}}$ de pression. Température du vin $11^{\circ}$. Nulle trace de gaz oxygène. Ainsi, un litre de vin dans les conditions de l'expérience ne renfermait plus que 467 cc. 5 de gaz acide carbonique, au lieu de 1082 environ, et 12 cc. 5 de gaz azote, au lieu de 6,5.

L'influence des soutirages sur le vin nouveau ne sera pas moins bien indiquée par l'essai suivant :

Le 12 mai 1865, j'étudie la composition du gaz contenu dans le vin 
d'un autre tonneau de 60 litres, pareil au précédent et rempli à Arbois le même jour, c'est-à-dire le 21 novembre 1864, de vin pris sous marc. La température du vin était de $20^{\circ}$. La vidange, défalcation faite des 300 cc. enlevés à l'origine, n'était pas moins de 1 lit. 925 cc. $570 \mathrm{cc}$. de vin ont fourni $563 \mathrm{cc}$. de gaz à $19^{\circ}$ et $760^{\mathrm{mm}}$ de pression, qui n'ont laissé que 3 cc. 3 de résidu de gaz azote.

Ainsi, ce vin avait conservé une grande quantité de gaz acide carbonique, et ne s'était pas aéré. C'est évidemment que, la température du vin s'étant progressivement élevée depuis le mois de novembre 1864 jusqu'au mois de mai 1865 , le vin avait dégagé peu à peu de l'acide carbonique par les pores du bois. Il y avait eu constamment pression de l'intérieur à l'extérieur, et la partie vide elle-même du tonneau était pleine de gaz acide carbonique ayant une force élastique plus élevée que celle de l'atmosphère extérieure. L'air ne pénétrait pas dans cette partie vide, au fur et à mesure qu'elle se produisait par l'effet de l'évaporation et de l'humectation du bois, à cause de la tension du gaz acide carbonique intérieur.

C'est là un autre effet des premiers soutirages. Non seulement ils mettent le vin en contact avec l'air, ce qui amène une oxydation sulsséquente des divers principes, mais ils font dégager une quantité considérable de gaz acide carbonique. Ce gaz, en restant dans le vin, peut s'opposer à l'introduction de l'air par les pores du bois, à cause de sa tension intérieure, qui augmente au fur et à mesure que la température du vin s'élève.

Voyons maintenant ce qui arrive lorsque le vin est exposé librement au contact de l'air.

Le 30 septembre 1864, on place dans un cristallisoir trois litres de vin de la récolte de 1862 , que l'on vient de tirer à un grand foudre. Au bout de 24 heures, le gaz contenu dans le vin est analysé, et il renferme 25 pour 100 de gaz oxygène après l'absorption de l'acide carbonique. Ce dernier gaz était, du reste, en très petite quantité. Un litre de vin renfermait à très peu près $21 \mathrm{cc}$. de gaz carbonique, $18 \mathrm{cc}$. de gaz azote et $6 \mathrm{cc}$. de gaz oxygène $\left({ }^{1}\right)$.

Le vin dissout donc l'oxygène et l'azote de l'air avec une grande facilité. Mais, chose remarquable, dès que les fleurs du mycoderma vini apparaissent à la surface du vin, même par taches isolées, le vin,

1. J'ai déjà parlé de l'évent et de la disparition de ses effets lorsque le vin est remis en bouteilles pleines. Nous voyons, par l'expérience que je relate, que le vin exposé à l'air renferme du gaz oxygène en dissolution. Or, je pense qu'il doit y avoir une grande différence d'action physiologique sur les nerfs de la langue et du palais entre deux liquides identiques par leur composition, mais dont l'un contient du gaz oxygéne libre en dissolution, tandis que l'autre en est absolument privé. 
quoique exposé au contact de l'air, ne tient plus du tout d'oxygène en dissolution.

Le 30 septembre 1863, j'abandonne plusieurs litres de vin au contact de l'air dans un cristallisoir simplement recouvert d'une lame de verre. Cinq jours après, il s'est développé, par taches assez éloignées les unes des autres, une petite quantité de mycoderma vini sans mélange de mycoderma aceti. La surface totale du vin n'eût pas été recouverte au dixième si l'on eût rassemblé toutes les taches du mycoderme. Or, un litre de ce vin n'a fourni que 0 cc. 2 de gaz oxygène. L'oxygène disparaît donc dès que le mycoderma vini commence à se développer.

Il résulte, ce me semble, de ces faits une conséquence assez singulière relativement à la pratique de l'ouillage. Celle-ci consiste dans le soin que l'on met à supprimer la vidange qui se fait naturellement dans les tonneaux par évaporation: Ces tonneaux, remplis complétement au moment du soutirage, sont entretenus pleins par le vin qu'on y ajoute tous les mois. Mais j'ai fait observer qu'il y avait des vignobles où l'on conserve systématiquement la vidange. D'une part, les tonneaux ne sont pas remplis à l'époque des soutirages, et, de l'autre, on ne les ouille pas ultérieurement. Ne semble-t-il pas dès lors que l'ouillage correspond à la non-aération du vin et la pratique inverse à l'aération facile? Je suis porté à croire tout le contraire, à cause de l'intervention du mycoderma vini. En effet, si l'on n'ouille pas, on peut être assuré que le vin se couvrira de fleurs. Et il est bien entendu que je parle des cas où cette fleur est du mycoderma vini pur, car j'ai déjà dit que le vin se perd toutes les fois que, par sa nature, il donne lieu à un mélange de mycoderma vini et de mycoderma aceti, et à plus forte raison de mycoderma aceti pur. Le vin non ouillé étant recouvert de mycoderma vini, il faut en conclure, d'après le fait que j'ai cité tout à l'heure, que l'oxygène qui pénètre dans le tonneau, au fur et à mesure qu'il se vide par évaporation, est enlevé par la plante. Cet oxygène ne peut se dissoudre dans le vin, et, comme il pénètre très lentement dans le tonneau, nul doute qu'il ne soit utilisé principalement pour la vie du mycoderme, qui ne peut en être privé. Avec la pratique de l'ouillage les choses se passent bien différemment. Tout l'oxygène qui pénètre dans le tonneau peut se dissoudre dans le vin et entre en combinaison avec ses principes oxydables. Cette pratique de l'ouillage correspond donc bien plus que la pratique opposée à une introduction lente d'oxygène dans le vin.

En résumant les points principaux déjà traités dans ce chapitre, nous voyons que le moût du raisin et le vin sont des liquides fort 
remarquables lorsqu'on les envisage dans leurs rapports avec le gaz oxygène. Ils sont toujours privés d'oxygène libre, parce qu'ils sont très oxydables, et toujours prêts, par conséquent, à enlever à l'air une certaine proportion de ce gaz. Il est impossible de les exposer au contact de l'air sans qu'ils dissolvent de l'oxygène, qui bientôt disparaît, de telle sorte que la dissolution et l'oxydation peuvent recommencer sans cesse. Dès lors, si cette oxydation du vin méritait une attention sérieuse au point de vue de sa qualité, nous devrions conclure qu'il y a un grand intérêt à ne négliger aucune des circonstances, quelque fugitives qu'elles puissent paraître, dans lesquelles le vin peut recevoir un peu plus ou un peu moins de gaz oxygène.

Nous reconnaîtrons bientôt en effet toute l'importance de l'oxydation du vin. Il est donc indispensable d'envisager les pratiques de la vinification sous le rapport de la quantité d'oxygène qu'elles peuvent donner au vin.

Or, il n'en est aucune, pour ainsi dire, qui n'ait plus ou moins pour effet d'aérer le vin ou la vendange. Mais, de tous les usages, le plus considérable sous ce point de vue est sans contredit celui qui consiste à placer le vin dans des tonneaux de bois de chêne. Les parois d'un tonneau de bois donnent lieu à une évaporation active, variable avec l'épaisseur des douves, avec l'état du tonneau, avec la nature du vin et enfin avec la cave, son exposition, sa température et la distribution de ses courants d'air. Le vide intérieur qui provient de cette évaporation à la surface du bois est nécessairement rempli par de l'air dont l'oxygène disparaît au contact du vin. Nous pouvons donc avoir, par la mesure de l'ouillage, une première idée de la quantité de gaz oxygène que le vin absorbe en tomeau, même parfaitement bondé, et abstraction faite de toute exposition à l'air par les soutirages. Prenons comme exemple les grands vins de Bourgogne.

On sait que dans ce vignoble, lorsque la fermentation est terminée dans les cuves, le vin, mélangé avec une partie du vin de pressoir, est réuni dans des futailles où se continue la fermentation. Ces futailles sont des foudres, ou plus ordinairement des pièces de 228 litres, toujours de bois neuf. Le vin est soutiré trois fois la première année, en mars, mai et septembre, et deux fois les autres années, en juin et en octobre. Il reste en moyenne quatre ans en tonneau. Cette durée est très variable, selon les années, les crus, et aussi selon la capacité des tonneaux où le vin est conservé. Le clos-vougeot ne reste pas en moyenne moins de six ans en tonneau. Le chambertin, le romanée, le volnay, le pomard sont mis en bouteilles au bout de trois ou quatre ans.

Or, la vidange qui s'établit naturellement dans un tonneau de 
228 litres n'est pas moindre de $3 / 4$ de litre tous les vingt-cinq jours dans les caves de la Bourgogne. Je parle ici de vin d'une année, car dans la première année la vidange est plus considérable, parce que le bois du tonneau est neuf et que ses pores donnent lieu à une imbibition et à une évaporation plus actives. C'est aussi pour un motif semblable qu'après deux années la vidange n'est plus que de $1 / 2$ litre au lieu de $3 / 4$ de litre par vingt-cinq jours. Ainsi donc, une pièce de 228 litres donne près de 10 lit. 5 de vidange par année(1). Si la durée de la conservation $d u$ vin est de trois ans, cela ne fait pas moins de 35 lit. 5; cela équivaut à plus de $30 \mathrm{cc}$. de gaz oxygène par litre de vin pour les trois années, auxquels il faudrait ajouter celui qui a été amené par les soutirages, bien qu'en Bourgogne le soutirage se fasse, autant que possible, à l'abri de l'air.

Le vin est donc soumis constamment à l'action lente de l'oxygène, circonstance qui n'a point été assez remarquée, car il ne me paraît pas possible de douter, d'après les faits que j'exposerai tout à l'heure, que ce ne soit cette oxydation lente qui fasse vieillir le vin, qui lui enlève ses principes acerbes et provoque en grande partie les dépôts des tonneaux et des bouteilles. Le fait bien connu de l'évent, l'acétification par le contact de l'air, la formation des fleurs par la vidange, sont autant de circonstances qui ont fait admettre que l'air était l'ennemi du vin, et qui ont empêché de reconnaître ses bons effets. Pour moi, je considère que les faits les plus utiles et les plus nouveaux de mon travail se résument dans la connaissance de l'action malfaisante des cryptogames sur le vin, et de l'action bienfaisante de l'oxygène de l'air, lorsqu'il est employé avec ménagement.

1. Ces nombres, sur la vidange d'un tonneau de 228 litres, ont été recueillis par moi en Bourgogne auprès du tonnelier chef du Clos-Vougeot. Les suivants ont été déterminés, sous mes yeux, et à ma demande, par M. E. Vuillame, propriétaire à Arbois.

Deux tonneaux de vin blanc de $\mathbf{1 8 5 7}$, de 150 litres chacun, avaient été ouillés à la fin de juillet 1862, ainsi que cela était constaté par une étiquette apposée sur les tonneaux.

Le 26 novembre 1863 , c'est-à-dire après seize mois d'évaporation dans une très bonne cave voûtée et profonde, la vidange a été exactement de 7 litres pour chaque tonneau; 7 litres en seize mois pour un tonneau de 150 litres, c'est, en douze mois, 5 lit. 250.

Trois autres tonneaux de 150 litres du même vin blanc avaient été ouillés le 23 novembre 1861 . Le 26 novembre 1863, la vidange, mesurée à ma demande, a été de 9 litres pour chaque tonneau. Cela fait 4 lit. 500 par an.

Un tonneau de vin rouge de 500 litres avait été ouillé en juillet 1863 . Il y avait une vidange de 5 litres le 26 novembre 1863; cela équivaut, pour ce tonneau de 500 litres, seulement à 12 litres par an. Le tonneau était placé dans une cave profonde n'ayant qu'une ouverture au nord.

Enfin, j'apprends de MM. Gallier et Charrière, à Arbois, qu'ils ont eu, en cinq ans, 130 à 150 litres de vidange dans un tonneau de 18 hectolitres rempli de vin jaune.

La vidange par évaporation est done d'autant moindre que les tonneaux ont plus de capacité, que le bois est plus épais. La nature des caves n'influe pas moins. Les caves sont plus profondes, par exemple, dans le Jura qu'en Bourgogne. Anssi voyons-nous dans ce qui précède une vidange bien plus considérable en Bourgogne, toutes choses égales. 
Je démontrerai, en premier lieu, que le vin ne vieillit pas lorsqu'il est conservé à l'abri de l'air. J'ai dit précédemment qu'en novembre 1864 j'avais recueilli huit sortes de vin d'Arbois de diverses qualités, encore sous marc, et de façon qu'il n'y eût pas le moindre contact du vin avec l'air atmosphérique. Il y avait de chaque sorte dix flacons de litre. En ce moment(1) il reste encore plusieurs flacons de ces diverses espèces de vin dans l'état même où je les ai reçus en 1864. Or, ces vins de plus d'une année ont présentement la même couleur de vin nouveau qu'à l'origine, la mème saveur de vin vert et acerbe, et jusqu'à l'odeur et le goùt assez sensibles de levîre. Enfin il me paraît qu'ils n'ont pas éprouvé le moindre vieillissement. Ils ont été conservés dans une cave dont la température varie de 5 ou $6^{\circ}$ en hiver à 16 ou $17^{\circ}$ en été.

J'ai voulu savoir ce que deviendraient ces vins soumis à l'ardeur du soleil. Dans les idées actuelles cette exposition aurait dû les faire vieillir plus vite. J'ai rempli à peu près complétement des tubes de verre blanc, de la capacité de 100 cc. environ, en ne laissant libre que l'espace nécessaire pour que le vin ne fît pas éclater les tubes par dilatation au moment où ce vin serait exposé au soleil, puis, aussitôt après le remplissage, j'ai fermé les tubes à la lampe. Le contact du vin avec l'air est d'autant moins sensible dans ce transvasement que le vin, sursaturé de gaz acide carbonique, se couvre d'une atmosphère de ce gaz dans le tube de verré au fur et à mesure que celui-ci se remplit. Les tubes ont été préparés le 30 mai 1865, puis exposés au soleil sur une table devant une fenètre placée au midi. On sait combien ont été chauds les mois de juin et juillet 1865. Le 18 juillet, j'examine ces tubes et je déguste comparativement les vins qu'ils renferment avec le même vin, mais conservé à la cave, et qui, aujourd'hui, c'est-à-dire en janvier 1866, est encore du vin nouveau tel que le donne la fermentation qui suit la vendange. Or, il est très difficile de trouver, entre le vin de la cave et celui qui a été six semaines exposé au soleil, une différence quelconque. C'est la même couleur et le même goût. Chose remarquable, le vin exposé au soleil n'offre pas le moindre dépôt, et il est aussi vert et aussi âpre que le vin nouveau. Assurément, d'après ce que nous savons des réactions qui se passent entre les acides et l'alcool, réactions étudiées avec tant de persévérance dans ces dernières années par MM. Berthelot et Péan de Saint-Gilles (2),

1. « En ce moment n, c'est-á-dire au moment où fut rédigé le texte de la 1re édition des " Etudes sur lo vin ", en 1866. Dans la 2• édition, Pasteur n'a pas modifié le texte. (Note de l'Édition.)

2. Berthelot et Péan de Saint-Gilles. Recherches sur les affinités : de la combi- 
il a dû se former, et dans le vin de la cave et surtout dans le vin exposé au soleil, de petites quantités de produits éthérés nouveaux, dont la proportion pourra bien augmenter avec le temps; mais on voit, par ce qui précède, qu'à l'époque où les vins ont été examinés, ces changements intestins, auxquels on attribuait autrefois toutes les modifications que l'âge apporte dans les vins, n'étaient pas encore appréciables; et, tandis que ces mêmes vins, traités par l'art à la façon ordinaire dans des caves à basse température, avaient changé de couleur, avaient déposé sensiblement, et avaient pris déjà en partie les propriétés des vins vieux, ceux des tubes étaient restés ce qu'ils étaient le jour où on les avait tirés de dessous le marc après la vendange et la fermentation normale originelle. Or, il n'y a qu'une circonstance qui n'ait pas étë commune aux vins en tubes ou en flacons et aux mêmes vins manipulés dans la cave du vendeur suivant les pratiques ordinaires : c'est le contact de l'air, qui a existé dans ce dernier cas et qui a été évité ávec les plus grands soins dans le premier. La conséquence obligée de ces comparaisons, c'est que leș changements qui correspondent au fait exprimé par le mot de vieillissement du vin doivent être attribués principalement à l'absorption de l'oxygène de l'air et au dégagement de la plus grande partie du gaz acide carbonique dont le vin est sursaturé au moment du premier soutirage.

L'usage des tonneaux de bois, usage qui entraîne, comme je l'ai indiqué tout à l'heure, une aération lente et sensible du vin, est nécessité bien plus par les conditions du vieillissement du vin que par la commodité que peut présenter cette nature de vases pour le conserver.

Des vases imperméables de verre ou de terre cuite ne conviendraient pas. Le vin $\mathrm{y}$ resterâit vert à moins de très fréquents soutirages $\left(^{(1)}\right.$.

C'est pourquoi tout importe dans le choix d'un tonneau, sa capacité, l'épaisseur de ses douves, son état de plus ou moins grande incrustation par le tartre, sa position dans la cave, son exposition aux courants d'air, sa température. J'ai vu au Clos-Vougeot des foudres peints extérieurement afin, m'a-t-on dit, de mieux conserver le bois et

naison des acides envisagée d'une manière générale; influence de la température. Comptes rendus de l'Académie des sciences, LIV, 1862, p. 1263-1266. - Combinaison de divers acides avec un même alcool et de divers alcools avec un même acide. Ibid., LV, 1862, p. 39-43. (Note de l'Édition.)

1. L'usage des tonneaux dans l'art de faire le vin est des plus anciens. On lit dans Pline [Histoire naturelle (Coll. Nisard). Tome Ier, livre XIV] : « Les méthodes pour garder le vin sont très différentes : auprès des Alpes, on lo met dans des fûts de bois, que l'on cercle;... dans les contrées plus tempérées, on le met dans des vases de terre, qu'on enfonce dans le sol en tout ou en partie, suivant la température du lieu. » 
les cercles en fer. Mais il faut que l'on sache bien que cette peinture a pour effet de conserver au vin plus de vivacité et plus de verdeur, et, par exemple, je prétends que le vin conservé dans de tels fûts devrait être mis en bouteilles plus tard d'une année ou deux peut-être, toutes choses 'égales d'ailleurs, que le même vin conservé dans des fûts ordinaires. J'ai ouï dire que le commerce recherchait dans le Midi les vins verts, d'un caractère très jeune. Il faut dès lors soutirer le moins possible au contact de l'air et conserver le vin dans des futs d'une grande capacité. La grande abondance du vin dans cette partie de la France force d'ailleurs à agir ainsi. Par contre, si l'on veut, en Bourgogne et ailleurs, vieillir le vin plus vite, il faut le distribuer dans des fùts de petites dimensions. Je crois savoir que ces conséquences des idées théoriques que j'expose sont en parfaite harmonie avec les opinions des propriétaires les plus éclairés.

Il y a dans l'art de faire le vin une pratique qui est encore directement en rapport avec l'influence de l'oxygène de l'air sur le vin, je veux parler de la mise en bouteilles. Il faut aérer le vin lentement pour le vieillir, mais il ne faut pas que l'oxydation qui en résulte soit poussée trop loin. Elle affaiblirait trop le vin, elle l'userait, et elle enlèverait au vin rouge presque toute sa couleur. Aussi existe-t-il une époque, variable pour chaque sorte de vin et pour une même sorte avec l'année, à laquelle le vin doit passer d'un vase perméable dans un vase à peu près imperméable.

Mais il était nécessaire de confirmer le plus possible par des faits positifs les déductions auxquelles je suis conduit. C'est ce que j'ai tenté de faire par l'exposition directe au contact de l'air des vins dont j'ai parlé et en suivant les effets qui en résultaient. A côté des tubes scellés à la lampe, remplis de vin, j'avais placé des tubes de même capacité, mais non remplis et également scellés à la lampe, puis conservés, soit dans une cave à l'obscurité, soit au soleil. Les effets de l'air sont très différents, surtout par leur intensité après le même temps, suivant que les observations ont lieu à la lumière diffuse ou solaire ou dans l'obscurité.

Pour obtenir les mêmes résultats, il faut bien plus de temps à l'obscurité qu'à la lumière, et les effets, dans ces deux circonstances, ne sont pas toujours de même nature, principalement au début des expériences. Mais, dans tous les cas, l'action de l'air est considérable et elle se manifeste dès les premiers jours de l'expérience en s'accusant ensuite de plus en plus. Je suppose, bien entendu, que le vin n'est soumis dans ces essais qu'à l'action de l'air, et que les tubes dans lesquels il se développerait des nycodermes ou d'autres parasites ne 
font point partie des comparaisons établies. C'est là une difficulté de ce genre d'expérience, car on sait que le vin s'altère en vidange. Cette difficulté peut ne pas exister pour les tubes exposés au soleil par des motifs que j'indiquerai ultérieurement et, dans tous les cas, on peut opérer sur des vins auxquels on a fait subir le procédé de conservation que je décrirai dans la troisième partie de cet ouvrage.

Les figures 28 et 29 donnent une idée des résultats obtenus. Dans les tubes pleins, conservation à peu près intégrale de la couleur du vin (1), rouge ou blanc, et, comme je l'ai dit tout à l'heure, pas de changement appréciable de sa saveur; le vin conserve son goût de vin nouveau, et ne prend aucun bouquet particulier. Au contraire, le vin soumis à l'action de l'air donne lieu à un dépôt considérable. La teinte du vin blanc se fonce, celle du vin rouge s'éclaircit et finit par n'être plus que d'un brun rouge très faible. Enfin le vin perd sa saveur originelle, vieillit outre mesure, et prend au plus haut degré le goût des vins de rancio, s'il s'agit du vin rouge, et le goùt de madère, s'il s'agit du vin blanc.

Dans les premiers temps de l'expérience, le vin n'est qu'éventé, souvent fort désagréable. Le bourgogne prend fle l'amertume, perd son bouquet, sa couleur noircit. Mais ces effets sont passagers, et, dans tous les cas, pour bien apprécier l'influence de l'air, il faut ensuite conserver le vin pendant un 'mois ou deux en vases clos et remplis, parce qu'il s'opère alors des changements considérables, généralement favorables à la qualité du vin. Ce serait une grande erreur de croire que l'effet de l'oxygène se complète tout de suite. La première influence du gaz oxygène n'est paš l'influence durable, ce n'est pas celle qui sera constatée après un certain temps, si le vin est conservé à l'abri d'une oxydation nouvelle. Et c'est certainement ce qui explique la nécessité de laisser reposer un vin qui vient d'être mis en bouteilles, avant qu'on puisse juger de sa qualité. Le vin qui absorbe de l'oxygène, qui en tient en dissolution et qui est éventé, ne l'est plus, à beaucoup près, au même degré lorsque l'oxygène libre, présentement dans ce vin, est combiné chimiquement avec ceux des principes qui sont en état de le retenir ensuite indéfiniment, et que les dépôts dus à l'oxydation sont effectués. Aussi lorsque j'affirme que les vins, rouges ou blancs, exposés même au soleil, en vases clos et remplis, ne déposent pas du tout et n'éprouvent pas de changement de teinte sensible, j'entends

1. Un œil exercé constate une légère différence de teinte entre les vins des tubes pleins qui ont été maintenus á l'obscurité ou au soleil. C'est ce que j'ai essayé de rendre par la figure 30. On voit que dans le vin du tube qui a été exposé constamment à la lumière et au soleil la teinte est un peu moins rosée et un peu plus jaune brun que dans le vin du tube gardé dans l'obscurité complète. Mais là différence est très faible. 
parler, soit de vins qui ont été privès d'air absolument, tels que les vins nouveaux, soit de vins qui ont séjourné assez longtemps à l'abri de l'air. Un vin que l'on viendrait d'éventer et que l'on enfermerait en vases clos et remplis déposerait et changerait de teinte, mais ce serait sous l'influenee de l'oxygène de l'air qu'il aurait absorbé antérieurement et dont l'effet sur le vin n'était pas encore accompli. C'est ainsi que les dépôts des vins en bouteilles ne sont pas toujours produits par l'oxygène que le bouchon laisse pénétrer, mais bien par l'oxygène absorbé par le vin au moment du soutirage ou pendant qu'il était encore en tonneau. Mais, par le fait que j'ai signalé de l'absence absolue de dépòt dans un vin nouveau enfermé limpide en vases clos avant d'avoir reçu le contact de l'air, joint à celui du dépôt inévitable qui prend naissance dans le vin toutes les fois qu'il a absorbé de l'air, je me crois en droit de conclure rigoureusement :

$1^{\circ}$ Que tous les dépòts qui s'effectuent dans le vin non malade sont produits exclusivement par l'oxygène de l'air.

Je reviendrai sur les dépóts de tartre.

$2^{\circ}$ Que le vin ne changerait jamais de couleur s'il n'était pas soumis à cette mème influence de l'oxygène.

Enfin je conclus des changements si considérables de goût et de qualité qui accompagnent l'absoription du gaz oxygène de l'air par le vin et des dépòts qui en sont la suite, changements qui sont tous de l'ordre de ceux que l'on attendrait d'un vieillissement prolongé pendant une longue suite d'années dans les conditions ordinaires, et qui dans l'oxydation directe s'effectuent en quelques semaines, je conclus, dis-je, que le vieillissement et le développement des bouquets que l'on y recherche sont également et à peu près exclusivement produits par l'oxygène de l'air.

Il y a dans les vins des bouquets naturels et des bouquets acquis. Le bouquet des grands vins de Bourgogne existe sans doute dans le raisin de pinot lui-même, et il passe directement dans le vin, probablement même sans modification par la fermentation. Mais il y a des bouquets introduits par les procédés mêmes de la vinification. Tel est celui de ce vin de garde connu dans le Jura sous le nom de vin de ChâteauChâlons; tel est celui des vins qui servent à Cette à faire les vins dits vins d'imitation. Or, le bouquet des vins de Château-Châlons est si bien un effet d'oxydation dépendant du mode particulier de leur fabrication, que je suis arrivé à développer en quelques semaines, dans le vin blanc qui sert de base au vin de Château-Châlons, le bouquet de ce dernier vin.

Quelques semaines d'exposition à l'air et à la lumière produisent 
l'action de dix et vingt années de tonneau. Que le vin vieilli et rendu odorant avec cette rapidité d'action n'ait pas exactement les qualités requises par les dégustateurs pour les meilleurs vins de garde dont je parle et qui ont vingt et trente années de tonneau, c'est ce que je n'examine pas en ce moment. Il ne s'agit pas ici de nuances de goût, mais de ces grands effets de précipitation de matières, de changements de couleur, de développements de bouquets sui generis, et de cet ensemble de propriétés qui font dire qu'un vin est parfaitement dépouillé, inaltérable, incapable de déposer encore, et d'un âge très avancé. Je le répète, toutes ces modifications si profondes, que l'on met dix et vingt années à obtenir dans le Jura, et deux et trois années à Cette, on peut les déterminer en quelques semaines par l'effet direct de l'oxygène de l'air.

La combinaison de l'oxygène avec le vin, tel est donc, ce me semble, l'acte essentiel du vieillissement du vin.

J'ai dit qu'il y avait une grande différence dans l'intensité de l'action de l'oxygène de l'air sur les vins, suivant qu'elle s'effectuait à la lumière ou dans l'obscurité. Rien de plus sensible à l'aspect seul des tubes qui ont servi aux expériences; ainsi, la figure 31 représente le même vin (vin de la figure 30 ) exposé à l'action d'un volume d'air égal au volume du vin; mais l'un des tubes a été conservé dans l'obscurité, et l'autre à la lumière et au soleil.

L'analyse de l'air des tubes démontre ce fait avec plus d'évidence. Le 29 mars 1865, j'ai placé au soleil et dans une demi-obscurité des tubes de verre blanc remplis à moitié de vins de Bourgogne (pinot) de 1858 et de 1864. Un mois après environ, le 25 avril, j'ai analysé le gaz des tubes :

Vin de 1858. - Lumière diffuse un peu obscure, 10,4 pour 100 de gaz carbonique, et dans l'air restant après l'absorption de ce gaz carbonique, 17,9 pour 100 d'oxygène.

Vin de 1858. - Le même exposé au soleil, 10,4 pour 100 de gaz carbonique, et dans l'air restant après l'absorption de ce gaz, 12,7 pour 100 d'oxygène.

Vin de 1864. - Lumière diffuse un peu obscure, 10,9 pour 100 de gaz carbonique, et dans l'air restant après l'absorption de ce gaz, 17,6 pour 100 d'oxygène.

Vin de 1864. - Le même exposẻ au soleil, 15,0 pour 100 de gaz 
carbonique, et dans l'air restant après l'absorption de ce gaz, 12,4 pour 100 d'oxygène.

Les résultats'suivants montreront mieux encore toute la différence des phénomènes, et surtout la lenteur de l'absorption de l'oxygène dans l'obscurité complète.

Le $1^{\text {er }}$ juin 1865 , j'ai rempli à moitié des tubes de verre blanc avec du vin d'Arbois $\mathrm{n}^{\circ} 3$, dont il a été question, pour la première fois, page 141. Quelques-uns de ces tubes ont été maintenus dans une obscurité absolue, et d'autres en pleine lumière et recevant le soleil toutes les fois qu'il se montrait. Ce sont les tubes de la figure 31.

Le 9 janvier 1866, j’ai analysé le gaz des tubes.

Vin $n^{\circ} 3$. - Exposé au soleil, 49,1 pour 100 de gaz acide carbonique.

Le gaz restant après l'absorption de l'acide carbonique est de l'azote pur, sans trace d'oxygène.

Vin $n^{\circ} 3$. - Le même conservé dans l'obscurité, 41,1 pour 100 de gaz acide carbonique. L'air restant après l'absorption de l'acide carbonique renferme encore 12,4 pour 100 d'oxygène.

Ainsi, dans une obscurité complète les principes du vin se combinent très lentement avec le gaz oxygène.

L'abondance des dépôts, l'intensité de la couleur sont liées de la manière la plus directe avec l'absorption du gaz oxygène. J'ai essayé de représenter dans la figure 32 les rapports des teintes que prend un même vin lorsqu'il s'est combiné avec des quantités plus ou moins grandes de gaz oxygène. C'est le vin de la figure 30 , figure qui le représente dans sa teinte naturelle.

Ainsi, en règle générale, un vin rouge est d'autant plus décoloré qu'il a plus absorbé d'oxygène. Néanmoins je m'empresse de faire remarquer que les vins rouges d'Arbois exposés à l'air et dans l'obscurité ont commencé à prendre une nuance plus vive et plus foncée, mais c'était avant qu'un dépôt bien sensible fût formé. Cet effet est quelquefois très marqué. La couleur, généralement faible, des vins rouges d'Arbois prend alors quelque chose de la teinte bien plus foncée des vins de Bourgogne.

Quant aux vins blancs, l'oxydation, surtout dans l'obscurité, et alors même qu'il y a des dépòts abondants formés, a pour effet de donner plus de vivacité à la teinte, qui se dore et jaunit sensiblement. 
Bien que la matière colorante des vins rouges et une matière analogue dans les vins blancs éprouvent de la part du gaz oxygène les effets les plus sensibles, il ne faudrait pas croire que l'oxygène de l'air ne porte pas encore son action sur d'autres principes. Le phénomène est des plus compliqués. J'ai reconnu, par des épreuves répétées plusieurs fois, qu'une partie des acides était comme brûlée. Ainsi, le vin d'Arbois $n^{\circ} 5$, exposé à la lumière avec son volume d'air, a perdu du mois de juin au mois de novembre 12 pour 100 de son acidité totale. La proportion de sucre du vin est difficile à évaluer très exactement, mais il n'est pas douteux qu'elle ne soit sensiblement réduite par le fait de l'oxydation. Il y a des études intéressantes à faire dans cette direction. Le vin blanc m'a offert des résultats du même ordre.

Quant à la nature des dépôts qui prennent naissance dans les vins à la suite de l'absorption du gaz oxygène dans les expériences dont je viens de parler, il n'y a nul doute qu'elle ne soit la même que celle des dépôts que l'on trouve dans les tonneaux ou dans les bouteilles. Il y a plus, on constate dans ces dépôts des deux origines les mêmes variétés de structure physique. L'importance de la considération des dépôts qui se forment dans les vins m'engage à entrer ici dans quelques développements.

J'ai examiné avec attention les dépôts des vins. Je crois qu'il en existe de trois sortes seulement.

Une première sorte, bien connue, est due à des cristaux de bitartrate de potasse, de tartrate neutre de chaux ou d'un mélange de ces deux sels. On trouve plusieurs des formes des cristaux de tartrate neutre de chaux et de bitartrate de potasse dans quelques-unes des figures de cet ouvrage. Ces dépôts h'adhèrent pas aux parois des bouteilles, et sont assez lourds pour se rassembler sous un petit volume, par un repos de quelques minutes. Ce n'est que dans des cas exceptionnels, très peu fréquents, que le bitartrate de potasse est en cristaux légers et soyeux, très ténus, dont le dépôt exige un temps un peu plus long. Considérés sous le point de vue physique, ces dépôts de tartre sont peu gênants. Au point de vue chimique, leur influence sur la composition et les qualités du vin n'a, pour ainsi dire, aucune importance, tant elle est peu sensible.

Une deuxième sorte de dépòts, souvent confondue avec la précédente, mais qui en est tout à fait distincte, est due à ces matières de couleur brune ou violet foncé qui couvrent les parois des bouteilles, particulièrement dans la moitié qui regarde le sol, lorsque les bouteilles reposent couchées horizontalement. Ces dépôts sont constitués par de la matière colorante primitivement dissoute, et qui, peu à peu, 
est devenue insoluble par un effet d'oxydation. Elle se montre au microscope, suivant les cas, sous trois états physiques bien distincts :

$1^{\circ}$ Elle est en feuillets translucides, colorés en jaune brun plus ou moins foncé, quelquefois avec une nuance violette.

$2^{\circ}$ D'autres fois, la matière colorante se dépose en granulations, en petits amas amorphes, pressés les uns contre les autres et formant une' couche adhésive d'un rouge brun ou violet.

$3^{\circ}$ Ces granulations prennent souvent une structure si régulière que l'on croirrait avoir sous les yeux des cellules organisées, tant leur sphéricité est parfaite. Aussi diverses personnes qui ont essayé de reconnaître au microscope les ferments des maladies des vins ont été trompées par 'cette structure et ont pris ces globules pour des corps vivants.

La figure 33 représente un dépôt formé dans du vin rouge de Beaujolais de 1859 (commune de Villié) et observé en 1865, où l'on reconnaît l'existence de ces trọis manières d'être de la matière colorante, car ces trois états physiques se trouvent fréquemment rẻunis. Les feuillets translucides sont ordinairement recouverts, au moins par places, de granulations amorphes 'ou de celles d'apparence organisée. Ces'deux derniers états de la matière colorante sont souvent aussi associés l'un à l'autre en proportions variables.

Les dépôts dont je parle, quel que soit leur état, sont le plus ordinairement adhérents aux parois des vases, circonstance importante, parce qu'elle permet de tirer le vin clair jusqu'aux dernières gouttes.

Sous le rapport physique, cette deuxième sorte de dépôts est également peu gênante. Quant au changement de composition qui en résulte pour le 'vin, on peut dire que sa présence correspond généralement à une phase d'amélioration graduelle, bien qu'elle soit accompagnée d'une diminution progressive de la couleur, effet sans inconvénient, si ce dépôt n'est pas trop prononcé.

La troisième sorte de dépôts des vins est constituée par les cryptogames parasites que nous avons étudiés dans la première partie de cet ouvrage. Ces dépôts sont très gênants, physiquement parlant, puisqu'ils occasionnent de grandes pertes au moment des soutirages ou lors des transvasements des bouteilles. Ils sont encore plus dangereux que gênants tant par les principes qu'ils transforment que par les substances nouvelles qu'ils développent, d'où résulte la suppression des meilleures qualités des vins.

Cela posé, si l'on étudie les dépôts qui prennent naissance par l'action indirecte de l'air, dans les expériences avec les tubes dont j'ai parlé, on trouve qu'ils sont pareils à ceux de la deuxième sorte et 
qu'ils en reproduisent fidèlement les trois variétés : les granulations amorphes ou mamelonnées en couche adhésive contre les parois, les feuillets translucides unis ou chargés par places de petits amas mamelonnés, enfin ces petites boules sphériques ressemblant à des cellules vivantes.

La figure 34 représente, à un grossissement de 400 diamètres, un de ces dépôts dus à l'action directe de l'oxygène dans un vin rouge du Jura.

La figure 35, sur laquelle je reviendrai, représente aussi un de ces dépôts en feuillets colorés adhérents aux parois et que l'oxygène de l'air a seul déterminé. En comparant les figures 34 et 35 aux figures qui représentent des dépôts formés dans des vins naturels en bouteilles, il est facile de reconnaître que tous ces dépôts sont de même nature. Ce sont eux que l'on confond si souvent avec les dépôts de tartre, mais qui n'en contiennent pas le plus ordinairement, et que l'on retrouve en plus ou moins d'abondance dans toutes les bouteilles de vin vieux.

M. Batilliat, ancien pharmacien à Mâcon, a publié en 1846 un traité sur les vins de France, dans lequel il insiste particulièrement sur les matières colorantes du vin. Ses observations sont intéressantes. Malheureusement il a ignoré l'influence de l'oxygène sur ces matières, et il n'est pas possible de les étudier convenablement si l'on ne tient compte de cette circonstance qui en modifie sans cesse les propriétés. Quoi qu'il en soit, je trouve dans cet auteur un passage fort exact au sujet des dépôts qû́i se forment dans le vin conservé en bouteilles.

" Assez souvent, dit-il, il se forme dans les bouteilles contenant du vin rouge un dépôt, même en couches assez épaisses, que l'on désigne sous le nom de tartre... Cette lie contient quelquefois des cristaux de tartre, mais le plus fréquemment ce n'est presque que de la pourprite, qui tend sans cesse à se séparer du vin. »

L'auteur appelle du nom de pourprite et de rosite deux matières colorantes qu'il croit avoir isolées du vin rouge. Je ne partage pas du tout son opinion sur ce point.

" $\mathrm{Si}$, lorsque après avoir vidé ces bouteilles, on y introduit de l'esprit-de-vin, celui-ci en opère sur-le-champ la dissolution. Cette teinture est d'une belle couleur, mais plus ou moins foncée, selon l'âge des vins : dans les plus vieux, elle est moins pourprée. Cette dissolution... est de la pourprite presque pure lorsqu'elle est filtrée, attendu que l'alcool ne dissout ni le tartre ni les pellicules qui peuvent l'accompagner.

“ Si l'on veut recueillir la pourprite déposée dans les bouteilles, il 
ACTION DE L'OXY(GEXNE DE L'AIR SUR L.ES VINS ROUGKS

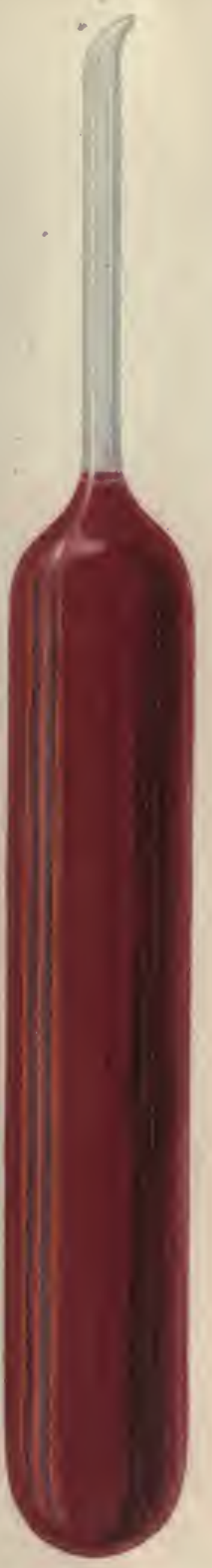

P. Lackerbaues ad nat pinx.
Fig̣. 28

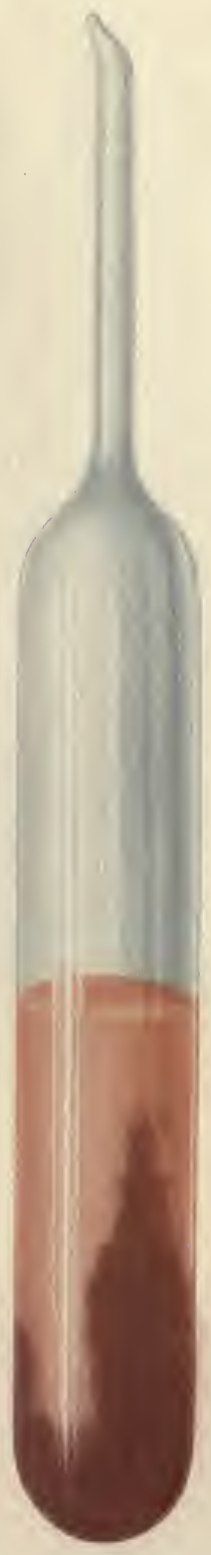

Imp lineny finos Pavis 

ACTION DEE L'OXYGÈNE

DE: I: AIR

SUR LES VINS BLANCS

Fig. 29

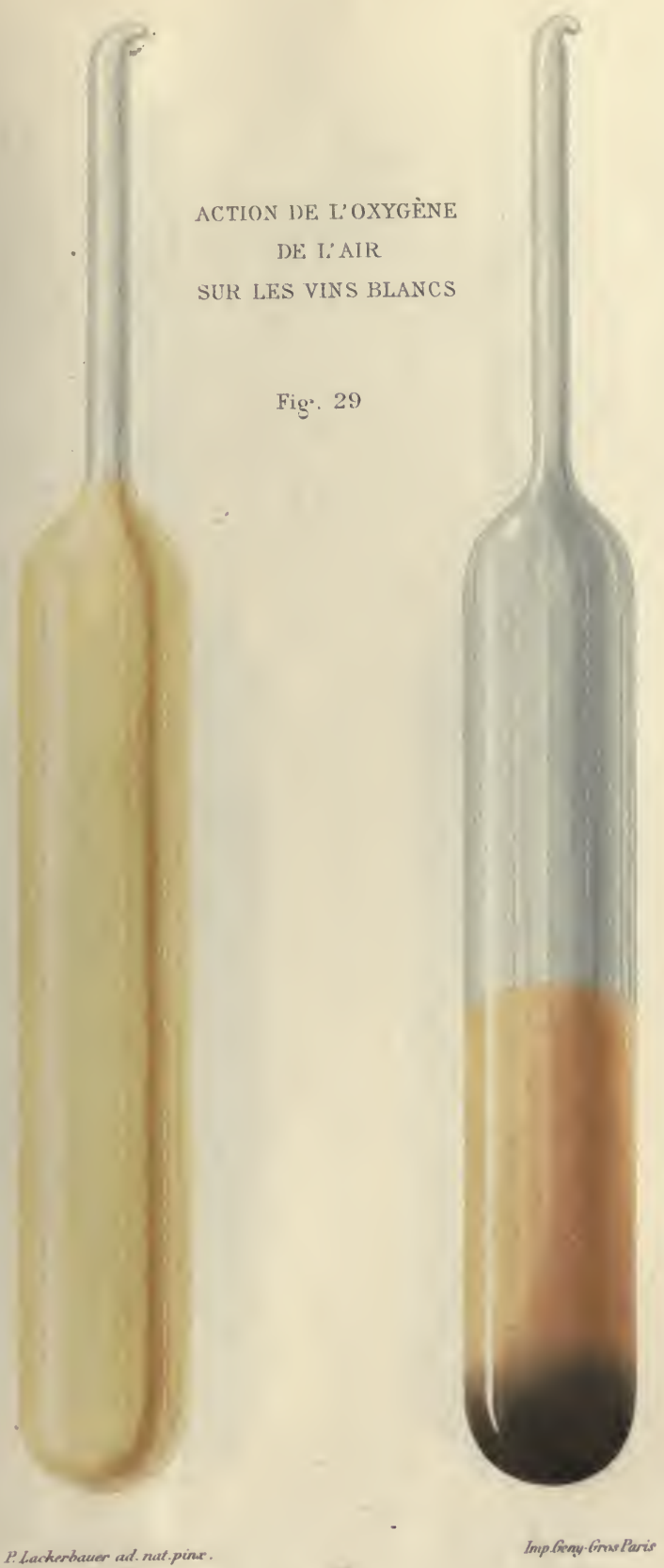

P. Lackerbaues ad nat pine. 



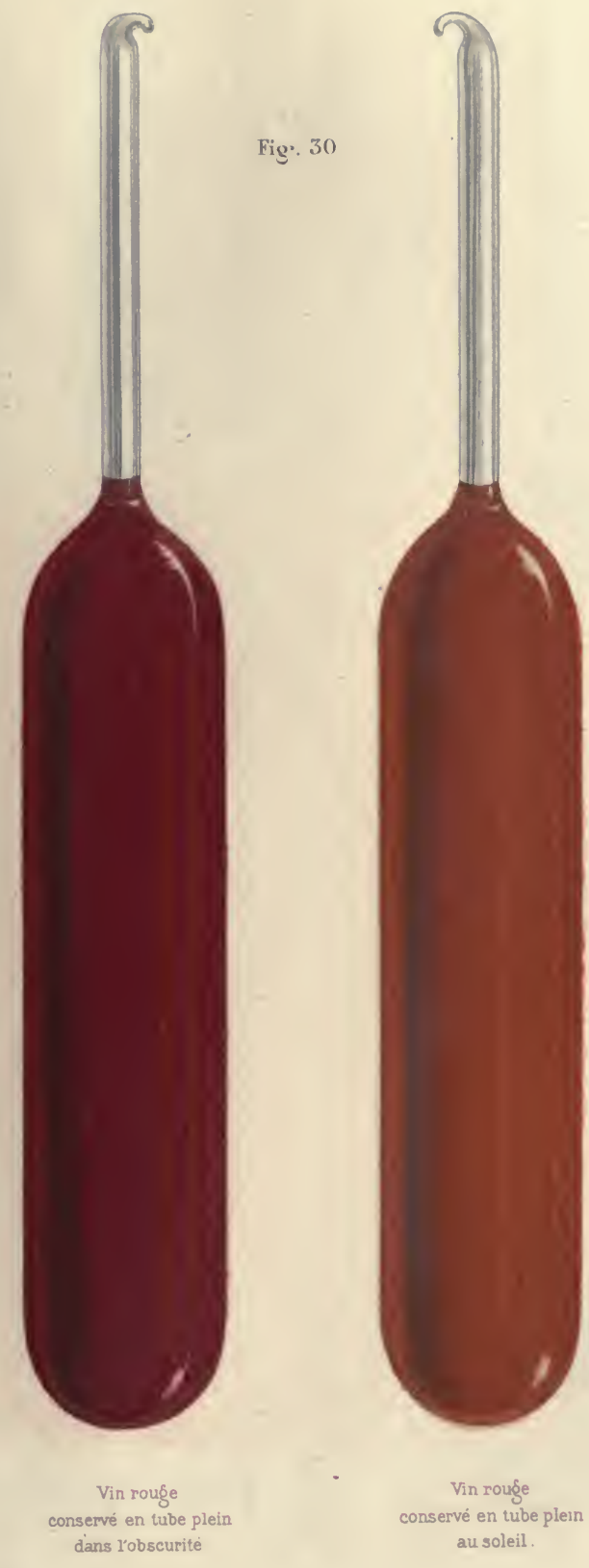





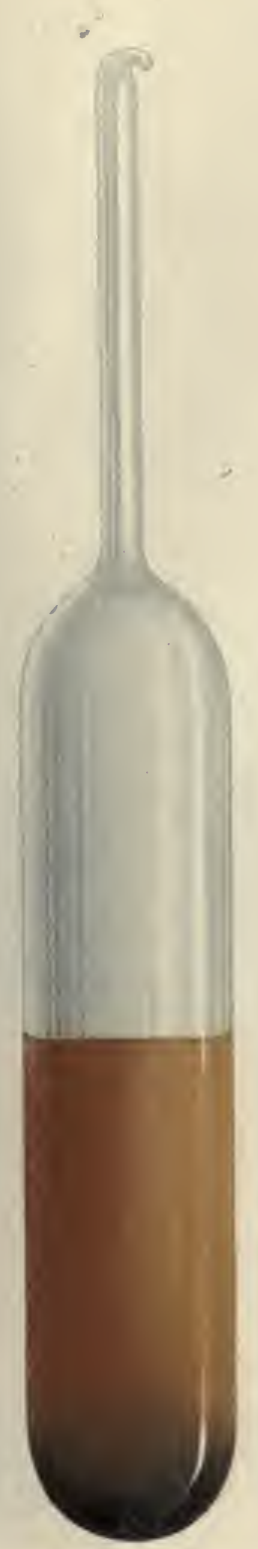

Vin rouge soumis à laction de l'air dans l'obscurité
Fig. 31

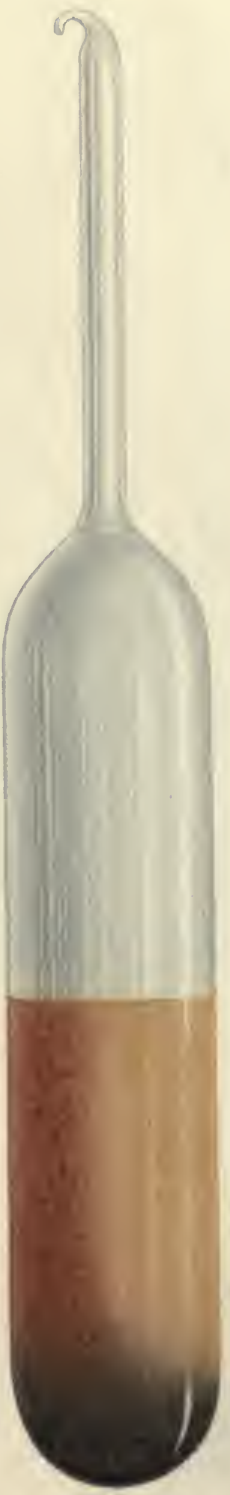

Vin rouģe lle mème soumis à laction de l'air au soleil 

ACTION DE L'OXYGì.NE DE L'AIR SUR LE VIN

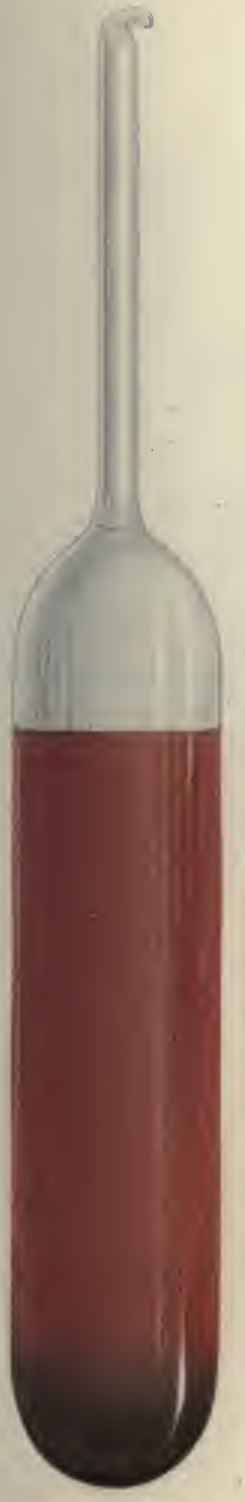

Maintenu à lobscurité

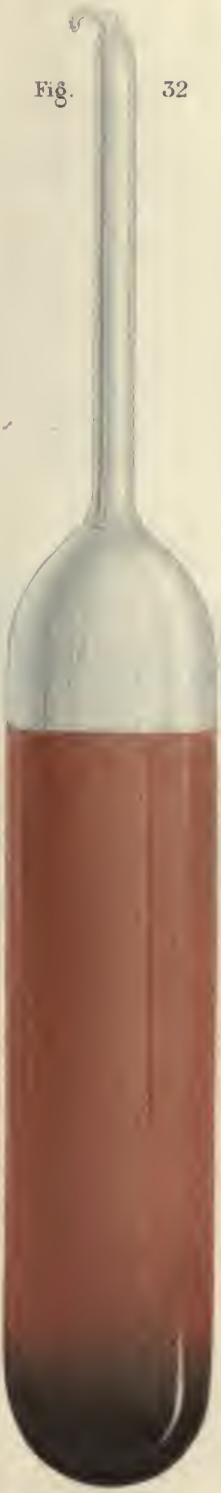

Maintenu au soleil

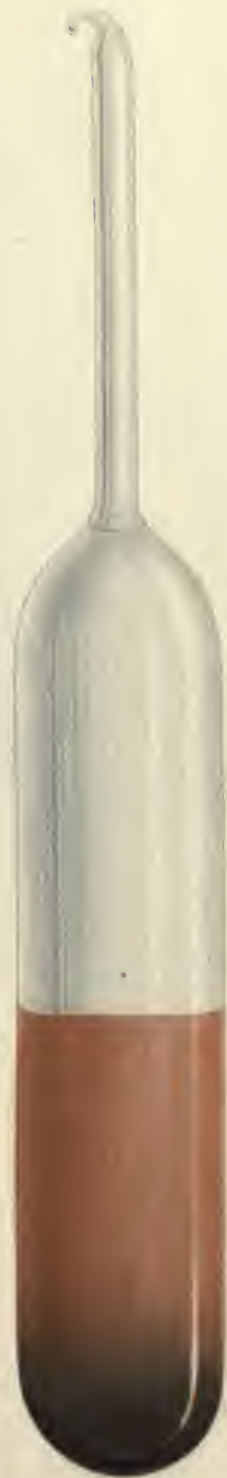

Maintenu à lobscurité 

DÉPÒT DE MATIÈRE COLORANTE

EN FFUILETS OU EN PETTS MAMELONS

Cette nature de dẹôts correspond g̨énéralement à un vieillissement très-sain .

Fig. 33

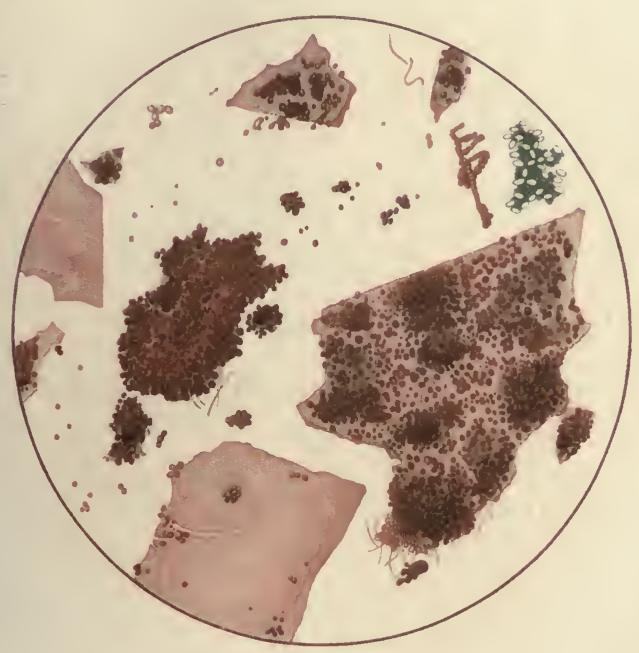

P. Lackerbauer ad nat. del.

Imp.tien̨y-Givur Rarip 

Fig.34

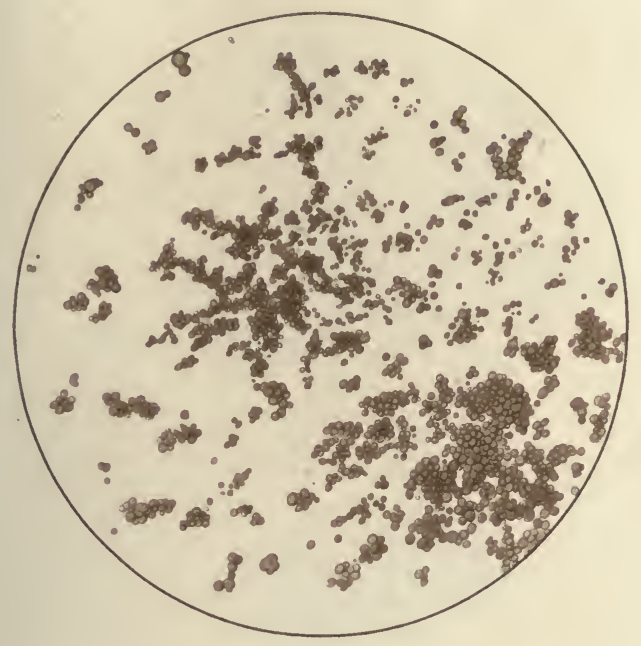

P. Lackerbuuer ad nat. del.

Imp. Gieny-(inves Paris 

DÉPÓT, PAR OXYDATION, DE LA MATIÈRE COLORANTE.

Dépôt dans un vim qui est resté en vidanģe, sans fleurs ni maladie quelconque.

Fig. 35

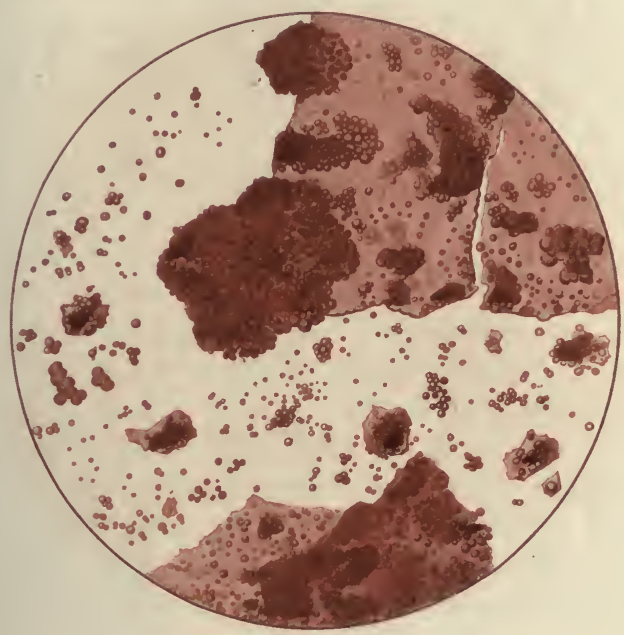

P. Lackerbauer ad. nat.del.

Imp.Geny-bros Paris 

faut le faire immédiatement après en avoir òté le vin, parce que, lorsqu'elle s'y dessèche, l'alcool n'en dissout qu'une partie, et l'eau ne peut plus la détacher. C'est ce qui rend si difficile le nettoyage des bouteilles... On doit donc les faire laver tout de suite (1). .)

Ces observations de M. Batilliat sont fort exactes. J'ajouterai seulement que cette matière rouge violacé, déposée sur les parois des bouteilles, ne peut pas être considérée comme une matière colorante pure. Ce n'est point un principe immédiat que l'on puisse regarder comme défini, mais une matière colorante plus ou moins oxydée, et dont les propriétés de coloration, de solubilité et de composition chimique varient progressivement avec l'intensité variable de l'oxydation. Ainsi, son insolubilité dans l'alcool après un certain temps n'est pas. un effet de dessiccation, comme le dit l'auteur que je vienş de citer, mais un effet d'oxydation. Plus la matière s'oxyde, plus elle devient difficilement soluble dans l'eau, dans l'alcool et dans les acides; plus également elle perd de sa coloration. Elle peut arriver ainsi progressivement au brun jaunâtre pâle. Les expériences dans les tubes dont j'ai parlé précédemment permettent de suivre toutes ces transformations progressives. On peut encore les étudier comparativement en faisant bouillir et évaporer du vin à l'abri et au contact de l'air. A l'abri de l'air, la matière colorante reste en dissolution, et par le refroidissement on n'a qu'un dépót de crème de tartre. Au contact de l'air, au contraire, la matière colorante s'oxyde, et par le refroidissement il se fait, principalement avec les vins riches en matière colorante et peu acides, une cristallisation de crème de tartre associée à un volumineux dépôt de matière colorante devenue insoluble dans l'eau et dans les acides faibles.

Je ne quitterai pas ce qui est relatif à l'action de l'oxygène de l'air sur le vin et aux causes de son vieillissement, sans parler des qualités particulières qu'acquièrent les vins qui ont voyagé, principalement dans les pays chauds. Je suis persuadé que les changements que l'on constate doivent être attribués bien plus à l'action de l'oxygène de l'air qu'à l'élévation de la température. Deux circonstances favorisent l'introduction de l'oxygène durant le voyage aux Indes ou en Amérique : une évaporation plus rapide à la surface des douves, et surtout les chocs du liquide contre les parois, agissant non comme agitation, mais comme cause de variations brusques et sans cesse répétées de la pression intérieure, d'où résultent une sortie des gaz azote et acide carbonique et une rentrée d'air à travers les pores du bois, bien plus

1. Batilliat. Traité sur les vins de la France. Paris et Lyon, 1846 , in-8º, p. 83-84. (Note de l'Édition.) 
actives que dans le cas où le vin est abandonné en repos dans une cave froide. L'expérience serait facile à faire : du vin renfermé dans des vases hermétiquement clos ne se modifierait pas sensiblement, ne prendrait pas le goût de cuit propre à ces vins et ne déposerait pas; et dans des bouteilles, l'effet serait beaucoup moins marqué que dans des tonneaux. J'ajoute que les vins portés à une température de 60,70 ou $80^{\circ}$ ne prennẹt pas le goût de cuit, comme on l'a publié souvent par erreur $\left.{ }^{1}\right)$, et ne déposent pas. La limpidité du vin est au contraire accrue par cette opération, excepté pour quelques vins très jeunes, encore en fermentation et môlés à de la levûre alcoolique.

1. Ces mots " comme on l'a publié souvent par erreur " ne figurent pas dans la 1re édition. (Note de l'Édition.) 
TROISIÈME PARTIE (1)

\section{CONSERVATION DES VINS}

\section{PROCÉDÉS EMPIRIQUES \\ PROPOSÉS POUR LA CONSERVATION DES VINS}

Si les observations consignées dans la première et dans la seconde partie de cet ouvrage sont exactes, elles démontrent que les maladies des vins sont corrélatives de la multiplication de végétations parasites, et qu'en l'absence de ces cryptoganes le vin vieillit sans altération, s'il est soumis lentement et progressivement à l'influence de l'oxygène de l'ail. Il faut considérer le vin comme une infusion organique d'une composition particulière. Toutes les infusions donnent asile à des êtres organisés microscopiques. Le vin se comporte de la même façon. Telle est l'origine des altération; spontanées auxquelles il est sujet.

Les maladies des vins devaient être et ont été en effet reconnues dés la plus haute antiquité, et l'empirisme a tout tenté pour essayer de les prévenir ${ }^{2}$. Ses efforts sont loin d'avoir élé stériles. Sans

1. Dans la 1ré édition, les cinq chapitres de la truisième purtie dəs "Études sur le vin" portaient les titres suivants : Nouveau procédé de conservation des vins. - Rapport de la Sinus-Commission chargée de constater les frésultats des expériences de M. Pasteur sur la co iservation des vius. - Observations au sujet du Rapport précédent. - Clıaufage du vin en houteilles. - Chauffage du vin en futt.

Dans la 2e édition, ces titres ont été clıangés, en raison des modifications introduites dans le texte. (Note de l'Édition.)

2. "Certains vins, au lever de la canicule, tournent dans les celliers, puis se rétablissent. La navigation les fait tourner; mais les vins qui résistent à l'agitation de la mer paraissent une fois plus vieux qu'ils ne le sont réellement. " (Pline. [Histoire naturelle (coll. Nisard), Paris. 18 i , 2 vol. in-10], t. I, p. 537.$)$

" On reconnaît que le vin tomne lorsqu'une lame de plomb qu'on y plonge change de conleur. Parmi les liquides, le vin offre la particularité de s'éventer ou de se changer en vinaigre; il y a des volumes sur les moyens d'y remédier. "(PLiNe, t. I, p. 539.)

"Il faut écarter les fumiers, les racines d'arbres, tout ce qui donne de l'odeur, laquelle passe très facilement au vin..., mettre des intervalles entre les pièces, de peur que les altérations ne se communiquent de l'une á l'autre, sorte de contagion qui est toujours très prompte. n (PLINE, t. I, p. 540.)

"On redoute aussi de voir les vases s'échauffer ou les couvercles suer. ” (PLiNE, t. I, p. 540.)

En effet, ces caractères physiques annonçaient que la fleur du vin était formée par le mycoderma aceti, qui, par l'active combustion qu'il détermine, écliaufait les couches supé- 
rappeler ici l'usage si fréquent de la poix résine et des aromates che les Grecs et les Romains (1), pour donner de la durée à leurs vins, on obtient de très bons effets de conservation par l'emploi du sucre : c'est le cas des vins liquoreux dont la conservation est si facile; par l'emploi de l'alcool : c'est le vinage, pratiqué avec succès, soit par addition de sucre à la vendange comme en Bourgogne, soit par addition directe d'alcool au vin comme dans le Midi; enfin par le gaz acide sulfureux, car le méchage des fûts est une des plus anciennes pratiques de l'art de faire le vin. Je laisserai de côté la pratique non moins ancienne du plâtrage, fort suivie encore dans le Midi, pour donner de la stabilité et de la limpidité au vin.

Il n'est pas difficile de démontrer que ces trois modes de conselvation $d u$ vin ne sont efficaces que parce que tous trois ont pour effet de gêner considérablement le développement des parasites du vin.

Pour la conservation des vins de table, on ne peut songer à l'emploi du sucre. L'action de l'acide sulfureux offre des inconvénients, et son effet n'a qu'une durée limitée. Le vinage est un des meilleurs procédés de conservation. Malheureusement les propriétés hygiéniques du vin, on ne saurait se le dissimuler, sont altérées par une augmentation un peu forte de son élément alcoolique. Plus un vin est riche en alcool, plus il s'éloigne des qualités que l'on recherche dans les vins de table, et plus en est restreinte la consommation. Il y aurait donc un grand intérêt pour l'extension du commerce des vins de France à pouvoir les exporter sans les viner (2).

rieures du vin, d'où résultait ụne évaporation, et par suite une humectation intérieure des parois au delà du niveau du liquide, et surtout du large couvercle de terre cuite qui recouvrait l'orifice des espèces de cylindres plus ou moins coniques dans lesquels on renfermait le vin.

1. On trouve dans les Géoponiques (extraits d'auteurs anciens, rassemblés vers le Ive siècle [par Cassianus Bassus]) l'indication de nombreux remèdes pour guérir les vins ou les empêcher de se gâter : plusieurs pourraient se justifier par les principes de la science moderne; ils prouvent, en somme, que cette question avait sérieusement préoccupé les anciens. (Note ajoutée à la deuxième édition.)

2. Mon savant confrère, M. Gay, m'a appris qu'au Chili on empêche quelquefois le vin de s'aigrir en ajoutant dans les fûts un morceau de viande.

Voici quelle me paraitrait être l'explication la plus plausible de ce fait :

Le vin en vidange est toujours recouvert forcément, soit de mycoderma vini, soit de mycoderma aceti, soit d'un mélange de ces deux mycodermes. Le mycoderma vini est peu ou pas nuisible; mais le mycoderma aceti, seul ou associẻ à son congénère, acétifie le vin très rapidement. D'autre part, plus le vin est âgé, plus il est dépouillé de ses principes albuminoïdes et extractifs, plus il a de tendance à donner asile à sa surface au mycoderma aceti. Plus il est jeune, au contraire, plus il est chargé de principes azotés, plus est facile le développement du mycoderma vini. Il résulte de ces faits positifs qu'un moyen d'empêcher le vin de s'aigrir pourrait consister à le rendre plus propre à nourrir et à donner naissance au mycoderma vini. Tel est probablement l'effet de l'addition de la viande. Voici ce qui se passe : le vin qui commence à s'aigrir porte à sa surface une pellicule plus ou moins développée de mycoderma aceti ou de mycoderma aceti mélangé à du mycoderma vini. Les substances 
* M. le professeur Scoutetten a présenté à l'Académie, en 1869, un Mémoire tendant à prouver que l'électricité améliore et conserve les vins (1) : les expériences qu'il cite ne prouvent point que le vin ait été préservé des maladies auxquelles il est sujet; elles ne sont point comparatives et tout à fait insuffisantes pour qu'on puisse attribuer à l'électricité l'amélioration obtenue dans quelques cas; enfin, elles ne paraissent nullement pratiques. Par l'action d'un courant électrique on doit donner lieu à des effets d'oxygénation qu'on aura rapportés à l'influence de l'électricité.

Le procédé de conservation des vins par la congélation préalable est connu depuis fort longtemps; mais il n'a pas toujours été regardé comme efficace : par exemple Fabroni, dans son traité " De l'art de faire le vin $\left({ }^{2}\right)$ ", s'exprime ainsi [p. 144] :

«Des auteurs ultramontains ont conseillé de remédier à l'excès de l'eau dans le vin en le concentrant par la gelée; mais Bucquet observe a ce sujet qu'alors on ne peut pas le conserver longtemps, et qu'il se convertit promptement en vinaigre. "

M. de Vergnette-Lamotte a le mérite d'avoir amené ce procédé à un état plus pratique : suivant cet œnologue, on peut exposer les tonneaux de vin à l'air libre pendant les froids rigoureux de l'hiver, ou, à défaut du froid naturel, soumettre ce liquide à l'action d'un mélange réfrigérant : de $0^{\circ} \dot{a}-6^{\circ}$, il se forme un précipité de tartre, de matières albuminoïdes, etc.; de $-6^{\circ}$ à $-12^{\circ}$, une partie du vin moins alcoolique que l'autre se congèle; on soutire, et la portion restée liquide se trouve enrichie en alcool.

La congélation pourrait donc produire avantageusement les effets du collage et du vinage, et, pår suite, améliorer le vin, tout en aidant à sa conservation; mais il est bien vrai, suivant l'assertion de Fabroni, que ce moyen de conservation du vin est loin d'être infaillible. Je possede une série de bouteilles de vin de Beaune qui, après avoir été concentrè par la gelée, a été expédié à San Francisco, et en a été

albuminoïdes et extractives introduites en dissolution dans le vin, par la viande, facilitent la multiplication du mycoderma vini, lequel pourra étouffer le mycoderma aceti, et partant l'acétification s'arrêtera. C'est une pratique qui revient à celle-ci : ajouter du vin trés jeune à du vin vieux qui s'aigrit, pour empêcher l'acétification de ce dernier. (Note ajoutée d la deuxième édition.)

"Le texte qui suit, jusqu'au ,chapitre intitulé : "Conservation du vin par le chauffage ” (p. 207), a été ajouté à la deuxième édition des "Études sur le vin ".

1. Scoutetren (H.). De la conservation et de l'amélioration deś vins par l'électricité. Comptes rendus de l'Académie des sciences, LXIX, 1869, p. 1121-1122. - Nouvelle Note sur l'amélioration et la conservation des vins par l'électricité. Ibid., LXX, 1870, p. 169.

2. Fabroni (A.). De l'art de faire le vin, ouvrage couronné par l'Académio royale de Florence, avec tableaux et 13 figures. Traduit de l'italien par F.-R. Baud. Paris, an X, $\mathrm{xII}-220$ p. in-80. (Notes de l'Édition.) 
renvoyé, parce qu'il avait contracté pendant le voyage la maladie de l'amer.

Quoi qu'il en soit, M. de Vergnette, dans le Mémoire qu'il a publié, en 1850, dans le recueil de la Société centrale d'agriculture ('), s'exprime ainsi :

“ En résumé, nous n'admettons pas que les vins doivent, pour être expédiés au dehors, subir aucun conditionnement qui entraîne avec lui l'addition de substances étrangères.

“ Pour nous, il n'est qu'une manière rationnelle d'améliorer les vins qui doivent faire de longs voyages, c'est de les concentrer par la congélation.

“ Ce procédé n'altère en rien leurs qualités.

“Soit au moyen de l'exposition des vins à l'air dans les hivers rigoureux, soit au moyen des mélanges frigorifiques, on sera toujours maître de congeler les vins au degré convenable. » [p. 524.]

Depuis la publication de mes travaux sur les maladies du vin et sa conservation facile par l'action de la chaleur, les idées de M. de Vergnette se sont profondément modifiées. Il a reconnu toute l'efficacité du chauffage préalable pour la conservation et l'amélioration des vins, et, éclairé par mes démonstrations expérimentales, il condamne aujourd'hui l'assertion que je viens de rappeler, savoir, qu'il n'existe d'autre procédé rationnel que la congélation pour permettre aux vins de voyager. Dans un livre intitulé : LE VIN, publié par cet œnologue postérieurement à mes travaux de 1864 et de $1865\left(^{2}\right)$, M. de Vergnette s'exprime ainsi :

“ Il n'en restera pas moins à l'œnologie ce grand fait, vrai en dehors de tout système, qu'un emploi rationnel de la chaleur contribue à la conservation des vins. Si on opère à une température qui ne dépasse pas $50^{\circ} \mathrm{C}$., et dans les conditions que nous avons spécifiées $\left({ }^{3}\right)$, on obtiendra du chauffage les meilleurs résultats pour les grands vins. En définitive, ce procédé les préservera des maladies qui les altèrent. » [p. 292.]

Cette opinion de M. de Vergnette, qu'il a empruntée à mes travaux, est très exacte, excepté sur un point : c'est qu'il n'est pas du tout nécessaire de ne pas dépasser $50^{\circ}$ dans le chauffage rapide, le seul

1. Vergnette-Lanotte (A. de). De l'exportation des vins de Bourgogne dans les pays chauds. Mémoires dagriculture... publiés par la Société nationale et centrale d'agriculture, année 1850, p. 513-524.

2. Vergnette-Lamotte (A. de). Le vin. Paris (1867). Librairie agricole, $384 \mathrm{p}$. in-12 (3 pl. col. et 29 fig.). (Notes de l'Édition.)

3. Il faudrait dire : dans les conditions que M. Pasteur a spécifiées, qui sont celles d'un chauffage trẻs rapide, car les conditions spécifiées par M. de Vergnette sont celles d'un chauffage d'une durée de deux mois. 
efficace et que j'aie conseillé. Même pour les vins les plus délicats, on pourrait porter la température de $55^{\circ}$ à $60^{\circ}$, et même $65^{\circ}$; mais j'ai démontré que celle de $55^{\circ}$ est suffisante en général et, à certains égards, préférable.

\section{CONSERVATION DU VIN PAR LE CHAUFFAGE HISTORIQUE DE LA QUESTION}

La connaissance des causes des maladies des vins nous donne des vues très nettes sur les conditions à remplir pour leur conservation. Tout le problème se réduit à s'opposer au développement des parasites. Mes premières tentatives ont eu pour objet l'addition au vin de substances sans odeur, inoffensives, et ayant, à la manière de l'acide sulfureux, des propriétés désoxydantes énergiques. Les inductions sur lesquelles je m'appuyais dans le choix de telles substances sont peut-être contestables, et je ne m'étonne pas que leur emploi ne m'ait guère réussi.

J'ai obtenu, au contraire, d'excellents effets d'une pratique aussi simple que peu dispendieuse, et qui offre le grand avantage de ne nécessiter l'addition d'aucune substance étrangère. Pour détruire toute vitalité dans les germes des parasites du vin, il suffit de porter le vin pendant quelques instants à une température de 50 à $60^{\circ}(\mathbf{1})$. J'ai reconnu, en outre, que le vin n'était jamais altéré par cette opération préalable, et, comme rien n'empêche qu'il subisse ensuite l'action graduelle de l'oxygène de l'air, source à peu près exclusive, selon moi, de son amélioration avec le temps, ainsi que je l'ai exposé dans la seconde partie de cet ouvrage, il est sensible que ce procédé réunit les conditions les plus avantageuses(2).

Je ne dois pas omettre de relater ici les faits antérieurs qui pou-

1. La température de 50 á $60^{\circ}$ ne suffit pas toujours pour tuer la levûre ou ferment alcoolique du vin, pas plus que les parasites qui engendrent ses maladies. Si le vin est doux, sucré, pour être assuré qu'après le chauffage il n'éprouve plus aucune fermentation alcoolique complémentaire, il faut élever la température à plus de $60^{\circ}$, et d'autant plus que le vin est plus sucré, moins acide, en un mot plus rapproché de la composition du jus naturel du raisin. Aussi, dans le brevet que j'ai déposé le 11 avril 1865 [voir le texte de ce brevet p. $410-411$ du présent volume], j'ai indiqué la température comprise entre 60 et $100^{\circ}$ comme propre à la conservation des vins, quelle que soit leur nature. (Note ajoutée a la deuxième édition.)

2. Le texte qui suit, jusqu'à a Les pages qui précèdent... " (p. 215), se trouve une vingtaine de pages plus loin dans la $1^{\text {re }}$ édition, où il constitue la fin du chapitre intitulé : $\alpha$ Chauf-

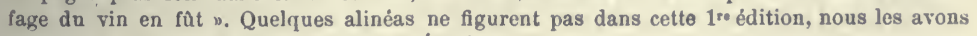
marqués ici d'un astérisque. (Note de l'Édition.) 
vaient mettre sur la voie d'un tel procédé, ainsi que ceux qui pouvaient en éloigner.

De tout temps l'emploi de la chaleur, sous diverses formes, a été mêlé aux pratiques de la vinification. On trouve dans les agronomes latins les procédés de conservation et de préparation utilisés par les Romains et les Grecs. Columelle( $\left.{ }^{1}\right)$, le plus exact d'entre eux, nous apprend que, pour donner au vin de la durée, on ajoutait à la vendange des proportions, variables suivant sa qualité, de moût cuit réduit à la moitié ou aux deux tiers, dans lequel, à la fin de la cuisson, on avait fait infuser de l'iris, de la myrrhe, de la cannelle, de la poix résine et d'autres ingrédients analogues. C'était, pour le dire en passant, un véritable vinage à la cuve, joint à une conservation par antiseptiques. Columelle reconnaît d'ailleurs que le vin de première qualité est celui qui n'a pas besoin d'être frelaté, c'est-à-dire additionné des substances précédentes, pour durer longtemps; et il ajoute : “ Nous croyons qu'il ne faut absolument y mettre aucune mixtion qui puisse en altérer le goût naturel, parce que ce qui peut plaire sans le secours de l'art est supérieur à tout $\left({ }^{2}\right)$. ”

Entre autres procédés pour conserver le moût de raisin, Columelle donne le suivant : "Dans les terroirs où le vin a coutume de s'aigrir, il faut, dès qu'on aura cueilli et foulé le raisin, et avant d'en porter le marc au pressoir, avoir soin de verser le moût dans un panier, et d'y ajouter un dixième d'eau douce tirée d'un puits creusé dans le terroir même; enfin de le cuire jusqu'à ce qu'il soit diminué d'une quantité pareille à celle de l'eau qu'on y a ajoutée; ensuite, lorsqu'il sera refroidi, on le versera dans des vases que l'on recouvrira et que l'on bouchera; à l'aide de ces soins, il se conservera plus longtemps sans s'altérer en aucune façon $\left({ }^{3}\right)$. »

Fabroni enseigne que, dans quelques endroits de l'Espagne, on cuit encore la totalité du moût qu'on veut changer en vin ( $\left.{ }^{4}\right)$.

L'abbé Rozier rapporte, d'après Belon, que les vins de Crète étaient portés à la température de l'ébullition lorsqu'ils devaient passer la $\operatorname{mer}\left({ }^{5}\right)$.

La chaleur du soleil intervenait aussi assez fréquemment dans les pratiques de la vinification.

1. Columelle. De l'agriculture. In : Les agronomes latins (collection Nisard). Paris, 1844, gr. in-8 ${ }^{\circ}$, p. 169-517, et notamment \& XVI-XLV du livre XIIe, p. 463-479.

2. Columelle. Loc. cit., \& XIX, p. 465.

3. Columelle. Loc. cit., \& XXVI, p. 471. (Notes de l'Édition.)

4. Fabroni. De l'art de faire le vin. Paris, an X, in-80, p. 146.

5. Rozier. De la fermentation des vins et de la meilleure manière de faire l'eau-de-vie. Lyon, $1770,166 \mathrm{p}$. in-80 (3 pl.). 
“ En Grèce, dit Pline, le vin qu'on nomme ßios (vie), et qui s'emploie dans plusieurs maladies, est très célèbre à juste titre. Il se prépare de la façon suivante : le raisin, cueilli un peu avant la maturité, est séché a un soleil vif; on le tourne trois fois par jour pendant trois jours, le quatrième on le presse; on met le vin dans des pièces, et on-le laisse vieillir au soleil (1). »

Caton (2) a enseigné le moyen de faire du vin de Cos avec du vin d'Italie : il faut, outre la préparation indiquée (cette préparation consistait essentiellement dans une forte addition d'eau de mer au vin), le laisser se faire pendant quatre ans au soleil.

Enfin on trouve dans Pline ce passage remarquable, qui prouve que la fabrication suivie à Cette pour vieillir le vin est bien ancienne : “ En Campanie, dit-il, on expose les meilleurs vins en plein air, on regarde comme très avantageux que les vaisseaux qui les renferment soient frappés du soleil, de la lune, de la pluie et des vents $\left({ }^{3}\right)$. »

Le vinaigre est trop voisin du vin pour que je ne rappelle pas ici le procédé proposé par l'illustre Scheele $\left(^{4}\right)$ à la fin du siècle dernier pour conserver sûrement ce liquide.

"Il suffit, dit Scheele, de jeter le vinaigre dans une marmite bien étamée, de le faire bouillir sur un feu vif un quart de minute, et d'en remplir ensuite des bouteilles avec précaution. Si l'on pensait que l'étamage fût dangereux pour la santé, on pourrait mettre le vinaigre dans une ou plusieurs bouteilles, et placer ces bouteilles dans une chaudière pleine d'eau sur le feu; quand l'eau aurait bouilli un petit moment, on retirerait les bouteilles.

" Le vinaigre ainsi cuit se conserve plusieurs années, sans se troubler ni se corrompre, aussi bien à l'air libre que dans des bouteilles à demi pleines. »

* Le vinaigre a tant de rapports avec le vin, par son origine et ses qualités, que cette expérience conduisait directement à l'application de la chaleur à la conservation du vin.

C'est la méthode qu'Appert a mise plus tard en pratique avec tant

1. Pline. Histoire naturelle (coll. Nisard). Paris, 1848,2 vol. in-4º. Tome Ior, livre XIV, p. 531.

2. Gaton (M.-P.). Économie rurale. In : Les agronomes latins (coll. Nisard). Paris, 1814, in-40, p. 32. Pasteur a dû prendre cette référence dans Pline. Le texte de Pline doit être erroné. Celui de Caton porte en effet : « Laissez bien mùrir sur tiges le raisin que vous destinez à la fabrication du vin de Cos. Lorsqu'une fois il aura été alternativement exposé à la pluie et à la sécheresse, récoltez-le et exposez-le au soleil pendant deux jours, ou a l'air pendant trois jours, si le temps n'est pas pluvieux. (Et ponito in sole biduum aut triduum sub dio, si pluvice non erunt.) [Note de l'Édition.]

3. Pline. Loc. cit., p. 540 .

4. Scheele. Mémoires de chimie. Dijon et Paris, 1785, 2 vol. in-12. Seconde partie. XIX. Remarques sur la maniére de conserver le vinaigre, p. 137-140. (Note de l'Édition.) 
de succès pour la conservation d'une foule de substances alimentaires, méthode que l'on trouve également en germe dans les expériences de Needham et de Spallanzani au sujet des générations dites spontanées, ainsi que je l'ai fait remarquer ailleurs (1).

Lorsque j'ai publié les premiers résultats de mes expériences sur la conservation possible du vin par le chauffage préalable, il était évident que je ne faisais que donner une application nouvelle de la méthode d'Appert, mais j'ignorais absolument qu'Appert eût songé longtemps avant moi à cette même application. C'est en me livrant à des recherches historiques à l'occasion de l'ouvrage dont je publie aujourd'hui la $2^{\text {e }}$ édition que j'ai rencontré accidentellement les observations d'Appert. Elles étaient restées si complétement dans l'oubli jusqu'au jour où je m'empressai de les faire connaître dans une Note insérée aux Comptes rendus de l'Académie des sciences (décembre 1865)[2] qu'ayant eu à soutenir un débat de priorité avec diverses personnes au sujet de mes propres recherches, il ne vint à l'esprit d'aucune d'entre elles de m'opposer la publication d'Appert ( ${ }^{3}$ ). C'est néanmoins cet habile industriel qui, le premier, a nettement indiqué la possibilité de conserver le vin par l'application préalable de la chaleur. Pourtant il est juste de faire remarquer que le fait sur lequel Appęrt s'appuyait ne prouvait pas du tout que sa méthode fût réellement bonne pour le vin. Les affirmations d'Appert ont dû paraître très exagérées, et telle est, sans doute, la cause de l'oubli dans lequel elles sont tombées.

En effet, Appert raconte (4) qu'ayant envoyé à Saint-Domingue quelques bouteilles de vin de Beaune préalablement chauflées au bainmarie à $70^{\circ}$, deux seulement revinrent en France, et que, les ayant comparées alors : $1^{\circ}$ avec une bouteille du même vin resté au Havre; $2^{\circ}$ avec une autre bouteille du mème vin également, resté dans sa cave, et toutes deux n'ayant pas subi l'opération du chauffage, le vin de la bouteille conservé chez lui avait un goût de vert très marqué; que le vin ren-

1. Voir p. 212-215 du tome II des Geunres de Pasteur: Mémoire sur les corpuscules organisés qui existent dans l'atmosphère.

2. Voir p. $425-426$ du présent volume : Note sur l'emploi de la chaleur comme moyen de conservation du vin.

3. Appert (Ch.). L'art de conserver, pendant plusieurs années, toutes les substances animales et végétales. Paris, 1810, vir- $226 \mathrm{p}$. in- $8^{\circ}$ (fig.). - La $3^{\circ}$ édition de cet ouvrage est intitulée : Le livre de tous les ménages, ou l'art de conserver, pendant plusieurs années, toutes les substances animales et végétales. Paris, 1813 , xuvur-176 p. in-8 (fig.). - La $5^{\circ}$ édition, revue par Prieur-Appert et Gannal, a pour titre : Le livre de tous les ménages. In Collection A. Carême : Le Conservateur, Paris, 1842, in-8, p. 1-166.

4. Appert. Le livre de tous les ménages (5॰ édition), p. 105-108: Procédé pour la conservation des vins dont la délicatesse ne permet ni le transport par mer, ni l'emmagasinage dans beaucoup de caves. (Notes de l'Édition.) 
voyé du Havre s'était fait, et conservait son arome, mais que la supériorité de celui qui était revenu de Saint-Domingue était considérable ; que rien n'égalait sa finesse, son bouquet; que la délicatesse de son goût lui prêtait deux feuilles de plus qu'à celui du Havre, et trois années au moins de plus qu'à celui de sa cave( $\left.{ }^{1}\right)$.

En réalité, Appert ne signalait pas du tout comme vin altéré ou malade le vin des deux bouteilles restées en France. Tout lecteur a dû faire la remarque qu'il n'y avait pas à s'étonner que le vin qui avait été à Saint-Domingue et qui était revenu d'un si long voyage dût avoir plus de qualité que le même vin resté en France, puisqu'il est bien avéré depuis longtemps que les voyages améliorent beaucoup le vin toutes les fois qu'ils ne sont pas une cause d'altération.

L'assertion d'Appert sur la conservation du vin par le chauffage préalable devait donc être attribuée bien plus ả la confiance qu'il avait dans la généralité des applications de sa méthode qu'à la rigueur de ses observations, qui étaient en effet bien insuffisantes.

* C'est sans doute ce qui explique pourquoi, tandis que le procédé des conserves d'Appert est devenu populaire, le procédé qu'il proposa pour conserver le vin tomba dans l'oubli.

* Pourtant les idées d'Appert sur le sujet qui nous occupe germèrent dans l'esprit de quelques praticiens éclairés, car en 1827, 1828 et 1829, J.-A. Gervais prit un brevet( $\left.{ }^{2}\right)$ et publia deux brochures $\left({ }^{(3)}\right.$ dans lesquelles il parle de l'emploi de la chaleur pour améliorer le vin (4).

Il décrit même un appareil de chauffage ingénieux dont il sera question plus loin.

* Voici comment il formule ses résultats :

" Dans mon brevet, j’ai déjà dit que, par les effets de mon procédé : $1^{\circ}$ les acides sont émoussés; $2^{\circ}$ l'action du ferment est paralysée : $3^{\circ}$ celle de l'air atmosphérique ainsi que les autres causes fermentescibles sont détruites; $4^{\circ}$ les principes aromatiques sont mieux développés; $5^{\circ}$ la verdeur du vin est corrigée; $6^{\circ}$ enfin la chaleur appliquée sur les vins, à un très haut degré, a la propriété de dilater

1. Toir dans l'Appendice, p. 362-363, le texte même d'Appert.

2. Amélioration des vins, des eaux-de-vie et autres liqueurs vineuses, en les faisant passer dans des tuyaux aplatis qui sont en contact avec l'eau chaude. (Gervais, brevet lu 1 it a oùt 1827 .)

3. Gervais. Mémoire sur les avantages d'un procédé pour perfectionner le mout des fruits et pour clarifier, améliorer et conserver les vins et autres liqueurs, par l'application de la chaleur, inventé et perfectionné par J.-A. Gervais. Paris, 1827, 29 p. in-8 (1 pl.), et Paris, 1828, 30 p. in-80 (1 pl.). (Note de l'Édition.)

4. D'aprés Gervais, Cadet de Vaux [L'art œenologique réduit à la simplicité de la nature, par la science et l'expérience. Paris, 1823, in-16, p. 141-142 (Vin soumis à un degré de chaleur élevé)] parle de l'amélioration des vins de Bordeaux, lorsqu'on les expose dans un four graduellement échauffé. 
les parties aqueuses qu'ils contiennent (ce qui les rend plus pénétrables), et de donner à leurs principes essentiels et spiritueux une action plus pénétrante; en sorte que, par l'effet de cette double conséquence, on obtient en peu de temps leur combinaison intime, tandis qu'il fallait l'attendre pendant plusieurs années d'une fermentation insensible, qui était souvent devancée ou suivie d'une décomposition inattendue. Par l'effet de cette combinaison dans les corps hétérogènes, d'autres principes surabondants contenus dans le vin se précipitent en se collant aux parois du vaisseau, ce qui rend le vin plus fin, plus dépouillé et plus délicat(1).»

* Les résultats annoncés par Gervais démontrent qu'il avait appliqué avec confiance, en praticien, la méthode d'Appert, sans se rendre bien compte de ses effets, sans faire une étude expérimentale et méthodique des phénomènes.

Pour moi, le mérite que je revendique est d'avoir prouvé la vertu très réelle de la méthode d'Appert appliquée au vin, par des démonstrations expérimentales rigoureuses, et à l'aide de principes scientifiquement déduits; je ne doute pas que mes études n'aient pour conséquence de mettre en lumière ce qu'il y a de vrai et d'utilement applicable dans les effets de la chaleur sur le vin et dans les tentatives des ånciens et des modernes sur ce sujet, tout en faisant justice des exagérations et des erreurs auxquelles elles sont mêlées.

* C'est bien à tort, par exemple, que l'on a confondu le procédé de chauffage dont je parle avec certaines pratiques importées d'Espagne dans le Midi et appliquées à Mèze depuis une époque assez reculée. Là le vin est chauffé au contact de l'air à une température douce de 25 à $30^{\circ}$, puis graduellement plus élevée, pendant huit, quinze et vingt jours, dans le but avoué de donner au vin la teinte de vin vieux, d'en modifier le goût; ensuite il est refroidi, mis dans des tonneaux sans précaution, souvent mêlé avec du vin nouveau. Il est manifeste que la chaleur n'a ici pour effet que d'aider à l'action de l'oxygène de l'air sur les principes colorants ou autres du vin, et qu'indépendamment de toute théorie, cette pratique diffère essentiellement du chauffage à l'abri de l'air vers $60^{\circ}$ pendant quelques instants.

* A fortiori mon procédé diffère-t-il des pratiques de Cette pour vieillir le vin. Ici on expose les tonneaux de vin au soleil, à toutes les intempéries, dans de grands magasins pendant un an, dix-huit mois, deux ans et plus : la température, en été, doit varier de 25 à $35^{\circ}$. Le négociant, par cette opération, n'a pour but que de vieillir son vin,

1. Gervars. Mémoire... Paris, 1827 , in- $8^{\circ}$, p. 17-18. (Note de l'Édition.) 
d'en modifier le goût. Lä chaleur n'a d'autre effet que d'activer l'évaporation, et de permettre à l'oxygène de pénétrer plus rapidement à travers les douves du tonneau. Or, c'est cet agent qui fait vieillir le vin, ainsi que je l'ai établi dans la première partie de cet ouvrage.

L'historique que je trace en ce moment serait incomplet si je ne résumais un Mémoire intéressant de M. de Vergnette-Lamotte dans lequel cet habile viticulteur a fait précisément des essais semblables à ceux d'Appert, mais dont il n'a point saisi la véritable signification, ce qui a dû contribuer encore à cet oubli, que je regrettais tout à l'heure, dans lequel on a laissé la méthode proposée par Appert ( $\left.{ }^{1}\right)$.

Le Mémoire auquel je fais allusion est inséré au recueil des travaux de la Société d'agriculture de Paris pour l'année $1850\left({ }^{2}\right)$.

En voici textuellement les conclusions déjà reproduites en partie tout à l'heure :

"En résumé, nous n'admettons pas que les vins doivent, pour être expédiés au dehors, subir aucun conditionnement qui entraîne avec lui l'addition de substances étrangères.

“Pour nous, il n'est qu'une manière rationnelle d'améliorer les vins qui doivent faire de longs voyages, c'est de les concentrer par la congélation. Ce procédé n'altère en rien leurs qualités.

"Soit au moyen de l'exposition des vins à l'air dans les hivers rigoureux, soit au moyen des mélanges frigorifiques, on sera toujours maître de congeler les vins au degré convenable.

"Les vins qui ont voyagé dans les pays chauds présentent tous les caractères des vins que l'on soumet artificiellement, dans les limites

1. Dans la Note que je cite plus loin (voir le renvoi de la page 240), adressée á l'Académie dans la séance du 12 mars 1866, IJ. de Vergnette [Conservation des vins par l'emploi de la chaleur. Comptes rendus de l'Académie des sciences, LXII, 1866, p. 596-602] dit avoir eu connaissance des essais d'Appert dès l'année 1840 , et il me blàme de les avoir ignorés. Je tiens à faire observer que j'ai été induit en erreur précisément par M. de Vergnette lui-mème, qui s'exprime ainsi dans son travail de 1850 :

" J'ai observé, il y a quelques années, un fait assez important. Souvent obligé, dans le moment de la récolte, de conserver, par la méthode Appert, des moûts destinés à des expériences qui ne pouvaient être faites que plus tard, J'AI AUSSI APPLiQUÉ CE PROCÉDí A DES VINS DE DIFFERENTES QUALITÉs. "

Tel est le passage qui m'a fait dire, dans ma lettre au Moniteur vinicole [Voir cette lettre p. 343-361 du présent volume] que M. de Vergnette était la personne qui avait pour la première fois appliqué la chaleur au vin (voir l'Appendice). J'ai reconnu depuis cette inexactitude par quelques lignes insérées aux Comptes rendus de l'Académie du 4 décembre 1865 [Note sur l'emploi de la chaleur comme moyen de conservation du vin. Comptes rendus de l'Académie des sciences, LXI, 1865, p. 979, et p. 425-426 du présent volume], et M. de Vergnette n'a fait que confirmer ma rectification dans sa Note postérieure du 12 mars 1866 [Conservation des vins par l'emploi de la chaleur. Ibid., LXII, 1866, p. 596-602].

2. Vergnette-Lamotte (A. de). De l'exportation des vins de Bourgogne dans les pays chands. Mémoires d"agriculture... publiés par la Socièté nationale et centrale d'agriculture, année 1850, p. 524 . (Note de l'Édition.) 
de 60 à $70^{\circ} \mathrm{C}$., à la chaleur d'un four ou à celle d'un bain-marie. Si, après avoir soumis à cette épreuve quelques échantillons des vins que l'on veut exporter, on reconnaît qu'ils y ont rësisté, on pourra, en toute sécurité, les expédier; dans le cas contraire, on devra s'en abstenir. "

M. de Vergnette attribuait, comme on le voit, à la chaleur une action maladive dans tous les cas où le vin n'était pas assez robuste de sa nature. Le chauffage, selon lui, pouvait indiquer surtout si un vin est propre à l'exportation. Il y est propre, si la chaleur né l'altère pas.

Il ressort clairement de la lecture attentive du travail de M. de Vergnette, que cet onologue ne rapportait pas la conservation du vin, après qu'il avait été chauffé, à l'opération même du chauffage, mais à la composition du vin, à son état robuste, à sa bonne constitution.

Ces principes sont tout à fait en contradiction avec l'expérience. Jamais un vin ne s'altère par l'application de la chaleur dans les conditions indiquées par Appert, et c'est précisément lorsqu'il est d'une santé douteuse qu'il faut lui faire subir l'opération du chauffage, car elle ne l'altère pas plus que s'il était d'une santé robuste, et, d'autre part, elle l'empêche de s'altérer ultérieurement. En d'autres termes, j'ai démöntré clairement qu'il faut rapporter exclusivement la conservation du vin à l'opération du chauffage, et nullement à sa constitution.

C'est ce qui m'a permis de fonder sur l'opération du chauffage un procédé pratique de conservation bien différent de celui de la congélation, auquel M. de Vergnette s'était arrêté (1) , et de démontrer l'excellence de la méthode d'Appert, appliquée dans les conditions que j'ai fait connaître le premier.

Du reste, le véritable état de la question de la conservation des vins, notamment des vins de Bourgogne, au moment où j'ai abordé mes études, ne saurait être mieux exposé que par la lettre déjà citée de M. de Vergnette, qu'il m'a fait l'honneur de m'écrire à la date du

1. Dans la $1^{\text {re }}$ édition des "Etudes sur le vin ", à ce texte était ajoutėe la note suivante :

« Le procédé de conservation des vins par la congélation préalable est connu depuis fort longtemps, mais M. de Vergnette a le mérite de l'avoir amené à un état pratique. Il s'en faut qu'il l'ait toujours été. Par exemple Fabroni, dans son traité "De l'art de faire le vin » [Paris, an $\mathrm{X}$, in- $\left.8^{\circ}\right]$, s'exprime ainsi [p. 144]:

" Des auteurs ultramontains ont conseillé de remédier à l'excès de l'eau dans le vin en le concentrant par la gelée; mais Bucquet observe à ce sujet qu'alors on ne peut pas le conserver longtemps, et qu'il se convertit promptement en vinaigre."

" Il est bien vrai que ce moyen de conservation du vin est loin d'être infaillible. Je possède une série de bouteilles de vin de Beaune qui, après avoir été concentré par la gelée, a été expédiẻ à San Francisco, et en a été renvoyé parce qu'il avait contracté pendant le voyage la maladie de l'amer. "(Note de l'Édition.) 
27 avril 1864 et que l'on trouvera dans l'Appendice de cet ouvrage (1). II. de Vergnette signale avec force toute l'importance qu'aurait pour la France la découverte d'un moyen pratique et sûr de conservation des grands vins de la Côte-d'Or ou des autres vignobles. Dans cette lettre, comme dans son Mémoire de 1850 (2), M. de. Vergnette s'arrête à la pratique de la congélation ou à celle du méchage, et ne fait aucune allusion à l'emploi de la chaleur.

Je reproduis également, parmi les documents placés à la fin de cet ouvrage, une lettre que j'ai adressée au Moniteur vinicole $\left(^{3}\right)$ à l'occasion de divers articles où la question du chauffage des vins avait été présentée sans être bien comprise des personnes qui en avaient parlé. Je n'ai rien à changer à cette lettre, sinon qu'Appert ne doit pas être cité seulement pour la découverte d'une méthode dont mon procédé n'était qu'une extension, mais comme étant la personne qui, la première, a affirmé qu'on obtiendrait de bons effets de la chaleur comme moyen de conservation du vin $\left({ }^{4}\right)$.

Les pages qui précèdent, dans lesquelles je crois juger avec impartialité l'affirmation d'Appert et les observations de M. de Vergnette-Lamotte concernant l'action de la chaleur sur les vins, sont extraites textuellement de la première édition de cet ouvrage. Je n'aurais rien à y changer, si une réclamation de priorité soulevée par M. de Vergnette-Lamotte ne m'obligeait de les développer. Voici à quelle occasion cette réclamation s'est produite.

Le 23 août 1869, M. le maréchal Vaillant, président du Conseil général de la Còte-d'Or, lut à cette assemblée une notice $\left.{ }^{5}\right)$ propre à intéresser les membres du Conseil. Elle était relative aux résultats des études que j'avais publiées sur les vins, leur conservation facile par le chauffage, et la fabrication du vinaigre.

“M. Pasteur, disait le maréchai, a reconnu que les maladies, auxquelles est exposé le précieux liquide qui nous occupe, sont engendrées par le

1. Voir p. 363-370 du présent volume: Sur la maladie de l'amertume des grands vins de Bourgogne.

2. Veronette-LAмотte (A. de). De l'exportation des vins de Bourgogne dans les pays chauds. Mémoires d'agriculture... publiés par la Société nationale et centrale d'agriculture, année 1850 , p. 513-524.

3. Voir p. 343-361 du présent volume : Sur le procédé de conservation des vins par le chauffage préalable. Lettre au Moniteur vinicole.

4. Le texte qui suit jusqu'au chapitre intitulé " Démonstration expérimentale des bons

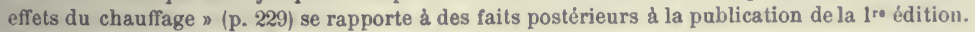
Il ne figure donc pas dans cette édition.

5. Vaitlant. Chauffage des vins et confection du vinaigre, p. 1-4 d'une brochure publice à Dijon (1869), 12 p. in-12, qui renferme aussi le " Rapport de la Commission », reproduit p. 253-256 du présent volume. (Notes de l'Édition.) 
développement et la multiplication de champignons microscopiques dont les germes existent, mais à des degrés différents, dans tous les vins, qu'ils soient communs ou de grands crus : de là, cette conséquence naturelle que, si l'on parvenait à s'opposer efficacement à la germination de ces petits êtres parasites, on assurerait la conservation de tous les vins. Le moyen, heureusement, a été trouvé par M. Pasteur; heureusement aussi, il consiste en une opération pratique des plus simples et des moins coûteuses.

“ Des expêriences aussi multipliées que précises ont démontré qu'il suffisait de porter le vin, ne fût-ce que pendant une minute, à la température de $55^{\circ} \mathrm{C}$. pour enlever aux germes des parasites dont il s'agit leur faculté de reproduction.

"A l'origine, une question était douteuse : l'emploi du procédé dont il s'agit n'altérerait-il pas ces délicatesses et ce bouquet des grands vins qui ont porté si loin la réputation de nos crus, et fait donner à notre département un nom si exceptionnellement enviable?...

“ Aujourd'hui, toute incertitude a disparu. Des constatations récentes et rigoureuses viennent d'établir que, alors même qu'on serait assuré qu'un grand vin de la Côte-d'Or, abandonné naturellement à lui-même à partir du moment de sa mise en bouteille, n'éprouverait aucune altération, la pratique d'un chauffage préalable serait encore avantageuse, car il est avéré aujourd'hui que le vin non seulement se conserve par l'effet de cette opération du chauffage, mais qu'il vieillit et s'améliore dans des conditions plus sûres que si on ne l'avait pas chauffé.

“ Par suite de l'opération dont nous parlons, les vins n'ont jamais de dépôt flośtant; le dépôt, quand il existe, est toujours adhérent; en outre, sa couleur s'avive et s'exalte; enfin, il y a suppression absolue de cette maladie de l'amertume, qui a été de tout temps si fatale à nos grands vins. L'opération du vinage, soit à la cuve par addition de sucre, soit au vin même par addition d'alcool, devient superflue. »

M. Thenard, présent à la séance du Conseil, crut devoir contredire sur un point les paroles du maréchal et déclarer que l'invention de la méthode du chauffage pour la conservation des vins était due à Appert et à M. de Vergnette-Lamotte, son ami, propriétaire de vignes à Beaune et à Pomard, Côte-d'Or.

Les droits d'Appert dans la question, on vient de le voir, avaient été exposés par moi-même dans la première édition de cet ouvrage et aussi quelques mois auparavant, devant l'Académie des sciences, dans sa séance du 4 décembre $1865\left(^{1}\right)$. J'avais également rendu justice à M. de Vergnette dans les termes qu'on vient de lire. Sur l'invitation du maréchal Vaillant et du Conseil, M. Thenard rédigea par écrit ses observations, qui furent insérẻes au procès-verbal de la séance du Conseil général, du 23 août 1869.

1. Voir p. 425-426 du présent volume: Note sur l'emploi de la chaleur comme moyen de conservation du vin. (Note de l'Édition.) 


\section{Voici textuellement"la Note de M. Thenard (').}

“ Ce n'est pas, comme il a été dit, M. Pasteur qui a inventé l'art de chauffer les vins pour prévenir leur altération ultérieure.

“ Dès avant Appert, c'est-à-dire avant 1810, cette méthode paraît avoir été pratiquée en Bourgogne. Est-ce pour les vieillir ou les conserver? Nul ne peut répondre exactement.

" Mais ce qui est constant, e'est qu'en ce qui touche la conservation, Appert a publié le procédé.

"Ses expériences sont authentiques; il prit des vins en bouteilles, en chauffa une partie à $75^{\circ}$ et laissa l'autre à l'état naturel, puis il emballa le tout dans la mème caisse, l'expédia en Amérique et la fit revenir.

« $A u$ retour, les vins non chauffés étaient plus ou moins altérés; les autres, au contraire, n'étaient en rien modifiés. D'où Appert conclut que, par le chauffage préalable et en vase clos à $75^{\circ}$, les vins étaient préservés des altérations occasionnées par les voyages.

«Or, il y a quinze ou seize ans, M. de Vergnette-Lamotte, que ses travaux en œnologie ont placé à la tête de cette branche de la science, reprenant les expériences d'Appert, mais opérant sur des vins très fins, reconnut que, si les vins de Bourgogne, chauffés à $75^{\circ}$, ne s'altéraient pas ultérieurement, l'action même du chauffage les rend si secs et si durs, qu'en tournant au goût de certains vins du Midi, ils perdent leurs plus précieuses qualités de finesse et de bouquet. En sorte que, malgré cette plus grande stabilité, il borna l'application de sa méthode aux vins communs devant être placés dans des conditions très défavorables, et, à l'oceasion, à quelques vins blancs fins.

“ La question en était donc là quand M. Pasteur, il y a quatre ans environ, prit un brevet pour la conservation des vins par le chauffage préalable cntre 65 et $75^{\circ}\left({ }^{2}\right)$. Mais moins de deux ans après $\left({ }^{3}\right)$, et sans connaitre le brevet Pasteur, qui n'était pas encore dénoncé, M. de Vergnette présenta à l'Académie des sciences un Mémoire où il annonçait qu'après un chauflage préalable variant entre 42 et $52^{\circ}$, qui n'altérait pas nos vins les plus fins, ceux-ci se conservaient aussi bien que si on les eût chauffés à $75^{\circ}$.

" En sorte que, par cette modification, le principe dénoncé par Appert d'abord, qui jusque-là n'était applicable qu'à des vins de basse qualité, se généralisait en devenant applicable aux vins les plus délicats.

"Depuis, qu'a fait M. Pasteur? Il a successivement abaissé les limites de température; si bien que, de 75 à $65^{\circ}$, il est arrivé à $55^{\circ}$; c'est-à-dire qu'il a de plus en plus confirmé les observations de M. de VergnetteLamotte, et que, pour peu qu'il tombe encore de $3^{\circ}$, il les confirmera tout à fait.

“ C'est là un service qu'il ne faut pas méconnaître, car', dans la science, toute constatation par un habile expérimentateur d'un fait considérable, mais encore douteux, bien qu'il ait été énoncé par un autre expérimentateur

1. Cette Note a paru le 28 août dans le journal Le Bien public de Dijon, et le 9 septembre suivant dans le Journal d'agriculture pratique [1869, II, p. 389-390].

2. Voir le texte du brevet p. 410-411 et la note 1 de la p. 207. (Note de l'Édition.)

3. C'est trois semaines et non deux ans, comme le dit $M$. Thenard, peu au courant de son sujet. 
si éminent qu'il soit, est un service; mais ce n'est pas une invention, c'est une constatation, et, en la circonstance, c'est tout ce qu'a fait M. Pasteur.

“ Les seuls inventeurs sont donc les prédécesseurs d'Appert, qui ont entrevu le fait, Appert, qui, par des expériences exactes, l'a mis en évidence, et M. de Vergnette-Lamotte, qui l'a utilement précisé.

"Quant à M. Pasteur, dans un livre digne de sa juste célébrité, oì sa part d'originalité reste considérable, il n'en a donné qu'une théorie rationnelle, mais il n'est pas plus l'inventeur $d u$ fait pratique que ne le serait du labourage celni qui donnerait une théorie nouvelle de la charrue, si ingénieuse qu'elle soit. »

Je protestai immédiatement devant l'Académie des sciences (1) contre cette Note si partiale et si erronée. Dans la discussion qui suivit, M. Thenard se borna à des affirmations que je réfutai (2) en m'appuyant sur des textes. Dans les premiers mois de l'année 1872, M. Thenard revint encore sur les prétentions de son ami, M. de Vergnette, peut-être á contre-cœur; mais il fut provoqué à prendre la parole devant l'Académie par une insinuation adroite de M. Fremy, qui était alors engagé dans une discussion fort embarrassante pour lui, mais qu'il avait lui-même soulevée à tort à propos d'un débat entre M. Liebig et moi sur la nature des fermentations. Cette fois, la réclamation de MM. Thenard et de Vergnette fut traitée principalement par mon savant maître,' M. Balard, avec cette impartialité et cette précision qui sont les caractères distinctifs de son esprit éminent. M. Balard lut à l'Académie, dans la séance du 26 février 1872 , la Note suivante :

Sur l'invention de la méthode de conservation des vins par le chauffage. Note de M. Balard. (Comptes rendus de l'Académie des sciences, séance du 26 février 1872, LXXIV, p. 561-569.)

“ Dans la séance du 29 janvier dernier $\left({ }^{3}\right)$, notre confrère, M. Thenard, a répété sur la conservation des vins ce qu'il avait déjà dit à l'Académie en $1869\left(^{4}\right)$, et affirmé de nouveau « qu'à M. Pasteur appartenait la théorie de

1. Pasteur. Note au sujet d'une réclamation de M. Paul Thenard, relativement au chauffage des vins. Comptes rendus de l'Académie des sciences, séance du 13 septembre 1869, LXIX, p. 645, et p. 438-439 du présent volume.

2. Pasteur. Note relative aux Communications de M. de Vergnette-Lamotte et de M. P. Thenard. Ibid., séance du 25 octobre 1869, LXIX, p. 905-911. - Réponse à la dernière Note de M. P. Thenard sur le chauffage des vins. Ibid., séance du 8 novembre 1869, LXIX, p. 973-974. Voir p. 439-446 et p. 447-448 du présent volume.

3 et 4. Thenard (P.). Observations relatives aux procédés de conservation des vins par le chauffage. Comptes rendus de l'Académie des sciences, LXXIV, 1872, p. 298. - Réponse à la Note lue par M. Pasteur dans la séance du 13 septembre 1869, sur les droits á l'invention de la conservation des vins par le chauffage préalable. Ibid., LXIX, 1869, p. 748-749. (Notes de l'Édition.) 
cette opération, mais qué c'était à Appert et à M. de Vergnette-Lamotte qu'étaient dus les faits sur lesquels elle était fondée. »

" J'aurais voulu, dans la séance suivante, faire une réponse et établir que c'était bien à M. Pasteur seul qu’appartenait cette découverte; mais les travaux de l'Académie m'ont forcé à renvoyer ma Communication, de séance en séance, jusqu'aujourd'hui. Je ne regrette pas, du reste, ce retard; il me permettra de répondre en même temps à notre confrère M. Thenard, ainsi qu'à M. de Vergnette lui-même.

“Dans la première édition de son traité, Appert( $\left(^{1}\right)$, avant toute expérience directe, avait présenté le chauffage comme devant faciliter l'exportation des vins. Plus tard, il raconte, dans une de ses dernières éditions [la $\left.5^{\circ}\right]$ comment il a essayé de vérifier la justesse de ses prévisions. Après avoir décrit la manière dont il fit chauffer aı bain-marie à $70^{\circ}$ des bouteilles de vin dont une partie resta au Havre et l'autre fut remise à des capitaines au long cours, tandis qu'il conservait dans sa cave quelques bouteilles telles qu'il les avait reçues de Beaune, il ajoute :

a J'attendis plus de deux ans le retour de mes bouteilles; de six que mon commettant avait expédiées au long cours, deux seules revinrent de Saint-Domingue. Très curieux, comme on se l'imagine bien, de connaitre le résultat d'une expérience aussi importante, je m'empressai de soumettre une de ces bouteilles à la dégustation d'un habile connaisseur. Il la compara avec deux autres, savoir : une qui était restée dans la cave de mon correspondant du Havre, et qu'il venait de me renvoyer récemment, et une de celles que j'avais conservees intactes. Le résultat de cette triple comparaison fut extraordinaire, et démontra que ce vin, originairement le même, présentait trois qualités essentiellement différentes.

" La bouteille conservée chez moi, et qui n'avait pas subi de préparation, avait un goût de vert très marqué; le vin renvoyé du Havre s'était fait et conservait son arome; mais la supériorité de celui revenu de Saint-Domingue était infinie : rien n'égalait sa finesse et son bouquet; la délicatesse de son goût lui prêtait deux feuilles de plus qu'à celui du Havre, et au moins trois de plus qu'au mien. Un an après, j'eus la satisfaction de réitérer cette expérience avec le mème succès $\left({ }^{2}\right)$.

"Il faudrait, pour conclure de ces expériences que c'est $\Lambda$ ppert qui a appris à conserver les vins par la chaleur, confondre deux choses bien distinctes : leur amélioration et leur conservation. Le vin n'est pas en effet, comme les autres substances alimentaires fraîches, nécessairement altérable : le plus souvent, il s'améliore en vieillissant; mais il éprouve parfois des altérations profondes qu'on appelle des maladies. Il devient louche, désagréablement sapide, souvent impotable. Conserver les vins, c'est prévenir ces altérations chez ceux qui auraient été naturellement susceptibles de les éprouver. Or, rien dans l'expérience d'Appert ne prouve que la chalenr ait eu cette efficacité. Il eùt fallu pour cette preuve que le vin sur lequel se faisait l'expérience fùt altérable. Mais il ne l'était pas, puisqu'il s'est conservé aussi bien que celui qui avait été chauffé. On voit donc comment MM. Fremy, Thenard et de Vergnette-Lamotte, qui répétent que la découverte est due à $\Lambda$ ppert, sont loin de la vérité. Ce qu'il avait

1. Appert. L'art de conserver, pendant plusieurs années, toutes les substances animales et végétales (1 $1^{\text {r* }}$ édition). Paris, 1810 , in- $8^{\circ}$ (fig.).

2. Appent. Le livre de tous les ménages (50 édition, revue par Prieur-Appert et Gannal). Paris, 1842, in-80, p. 106-107. (Notes de l'Édition.) 
prouvé, e'est que la chaleur apportait dans les vins chauffés une amélioration que le voyage au long cours rendait plus sensible. Aussi, tandis que les procédés pour la fabrication des conserves se répandaient dans le monde entier, et que l'on continuait à recourir au transport dans l'Inde pour améliorer la qualité des vins, l'emploi de la chaleur pour leur conservation proprement dite est resté sans usage, malgré les améliorations dans le mode de chauffage introduites par M. Gervais de Paris ( ${ }^{1}$ ), dont II. le docteur Bart a rappelé de nouveau le travail.

“ Si, en s'appuyant sur les travaux dont je viens de parler, on avait eu quelque tendance à employer le chauffage, on en aurait d'ailleurs été détourné par les expériences de M. de Vergnette-Lamotte, qui publia, en 1850, un Mémoire intitulé : de l'Exportation des vins de Bourgogne dans les pays chauds $\left({ }^{2}\right)$. M. de Vergnette croyait à cette époque, comme la plupart des œnologues, que la bonne conservation d'un vin dépendait des proportions dans lesquelles s'y trouraient ses éléments : l'eau, l'alcool, le tanin, l'acide tartrique, etc. Le vin dans lequel la nature avait mis entre ces matières diverses une pondération convenable était un vin susceptible de conservation, un vin normal.

“ C'est d'une manière incidente que M. de Vergnettc parla, en 1850, du chauffage des vins.

“... Ne peut-on pas, dit-il, s'assurer a priori si les vins résistent aux fatigues qui résultent de leur envoi dans les pays chauds?

" J'ai observé, il y a quelques années, un fait assez important, qui contribuera singulièrement à éclairer la question. Souvent obligé, dans le moment de la récolte, de conserver, par la méthode d'Appert, des moûts destinés à des expériences qui ne pouvaient être faites que plus tard, j'ai aussi appliqué ce procédé à des vins de différentes qualités.

“ En 1840, des vins de cette récolte avaient été mis en bouteilles au décuvage : après avoir été bouchés, ficelés et exposés au bain-marie à une température de 70 degrés C., ils furent descendus à la cave et oubliés. En 1846 (alors que la plupart des vins de 1840, dont les raisins furent grêlés, avaient subi une maladie à laquelle plusieurs succombèrent), quelques bouteilles de ce vin se trouvèrent sous ma main avec leur étiquette, et je constatai, avec une remarquable satisfaction, qu'il était dans le meilleur état de conservation; seulement il avait contracté ce goût de cuit que nous rencontrons dans les vins qui ont voyagé dans les pays chauds. Il s'était dépouillé de sa matière colorante bleue. Plus sec, plus vieux qu'un vin de six ans ne devait l'être, il avait tous les caractères que nous avons signalés dans le vin no 1 .

"Nous avons répété cette expérience sur d'autres vins, à l'époque de leur mise en bouteilles, et toujours nous avons réussi, en faisant varier la température du bain-marie de 50 à 75 degrés C., à prẻserver de toute altération ultérieure les vins de qualité soumis à ces essais. Il n'en était pas de même pour ceux qui, d'une santé douteuse, ne présentaient pas cette composition normale sans laquelle les vins ne se conservent pas. Dans ce cas, ils ne résistent pas à cette épreuve. Nous verrons plus tard quel parti on peut tirer de ces observations. "

"Que le lecteur veuille bien relire avec une scrupuleuse attention ces deux dernières phrases, sur lesquelles je reviendrai tout à l'heure, et qui sont capitales dans le débat.

1. Gervars. Mémoire sur les avantages d'un procédé pour perfectionner le moût des fruits et pour clarifier, améliorer et conserver les vins et autres liqueurs, par l'application de la. chaleur, inventé et perfectionné par J.-A. Gervais. Paris, 1827,29 p. in-8 $(1$ pl.).

2. Mémoires d'agriculture... publiés par la Société nationale et centrale d'agriculture, année 1850, p. 513-524. (Notes de l'Édition.) 
“ Après avoir blâmé lès coupages adoptés à Bordeaux, et insisté sur la nécessité de n'introduire dans les vins rien d'étranger, M. de Vergnette ajoute, comme conclusion qui étonnera peut-être l'Académie :

"Il nous paraît donc hors de doute que le seul moyen auquel nous devions avoir recours en Bourgogne pour la préparation des grands vins destinés à l'exportation consiste à les concentrer au moyen de la gelée. "

“ Ayant décrit le procédé de congélation qui, conseillé par d'anciens œnologues, a été étudié par M. de Vergnette avec beaucoup de soin, il continue ainsi :

"Nous savons d'ailleurs que les voyages dans les pays chauds produisent sur les vins les mêmes effets que la chaleur d'un bain-marie ou d'un four dans les limites de 60 à $70^{\circ} \mathrm{C}$. Si donc, après avoir soumis à la congélation les vins qui doivent être exportés, nous en exposons, dès qu'ils sont devenus assez limpides pour être tirés en bouteilles, un échantillon à l'action de la chaleur, nous pourrons, dans le cas où ils résistent à cette épreuve, si l'on se rappelle ce que nous avons dit plus haut, en conclure qu'ils résisteront aussi aux fatigues des plus longs voyages...

“En résumé, pour nous, il n'est qu une manière rationnelle d'améliorer les vins qui doivent faire de longs voyages : c'est de les concentrer par la congélation.

“... Les vins qui ont voyagé dans les pays chauds présentent tous les caractères des vins que l'on soumet artificiellement, dans les limites de 60 à $70^{\circ} \mathrm{C}$., à la chaleur d'un four ou à celle d'un bain-marie. Si, après avoir soumis à cette épreuve quelques échantillons des vins que l'on veut exporter, on reconnait qu'ils y ont résisté, on pourra, en toute sécurité, les expédier; dans le cas contraire, on devra s'en abstenir ( $\left.{ }^{(}\right)$. "

“ Ces citations montrent, ce me semble, jusqu'à l'évidence que, pour M. de Vergnette, en 1850, la chaleur n'était pas un moyen de conservation des vins; il la regardait au contraire comme ayant une action altérante. Exaltant leurs dispositions maladives, elle atteignait les vins faibles et échouait dans son action sur les vins robustes. De là l'idée que cette chaleur pourrait être employée comme une épreuve permettant de distinguer, entre deux vins soumis également à la congélation, ceux pour lesquels ce préservatif n'aurait pas suffi de ceux que cette congélation aurait rendus assez résistants pour qu'on pût les expédier dans les pays chauds.

“ En disant, d'ailleurs, que les vins d'une santé douteuse ne se conservent pas et qu'ils ne résistent pas à cette épreuve, il n'engageait, certes, pas à employer un remède qui pouvait devenir pire que le mal.

“Quand au commencement de l'année 1864, M. Pasteur (2) annonça que les altérations des vins étaient corrélatives de la présence et de la multiplication de végétaux microscopiques, M. de Vergnette-Lamotte, comprenant l'importance de la voie nouvelle dans laquelle notre confrère venait d'entrer, s'empressa, en le félicitant, de lui faire part des pratiques routinières suivies en Bourgogne pour cette conservation. Il ajoutait, en terminant une très longue lettre $\left({ }^{3}\right)$ :

1. Vergnette-Lamotte (A. de). De l'exportation des vins de Bourgogne dans les pays chauds. Mémoires d'agriculture... publiés par la Société nationale et centrale d'agriculture, année 1850 , p. 513-524.

2. Voir p. 396-406 du présent volume : Études sur les vins. Deuxiéme partie : Des altérations spontanées ou maladies des vins, particuliẻrement dans le Jura.

3. Voir p. 363-370 du présent volume. (Notes de l'Édition.) 
"Vous voyez, Monsieur, que tous les moyens que j'indique pour le traitement des vins menacés ou malades sont des moyens empiriques qui ne sont en rien basés sur les causes connues du mal. Il ne pouvait en être autrement. Ces causes, Monsieur, vous les avez trouvées, et, permettez-moi de vous le dire, vous devez à la France viticole un travail sur le ferment de l'amer aussi complet que celui que vous avez publié sur le ferment alcoolique...

“ Ce qu'il nous faut aujourd'hui, c'est d'être guidés par le raisonnement seul dans toutes les opérations que demande le traitement des vins dans les caves. Alors plus de vins malades, et vous aurez donné des millions à la France." "

"Chacun peut apprécier si, sous la plume d'un grand propriétaire de vignobles, récoltant des vins de prix, c'était là un compliment banal, comme le dit aujourd'hui M. de Vergnette, ou l'expression sincère des sentiments qu'il éprouvait en songeant que, la cause du mal étant connue, on pouvait espérer en découvrir le remède.

" Le 4 avril 1865, M. Pasteur, en faisant connaître à M. de Vergnette les observations qu'il avait faites sur quelques vins, au sujet desquels celui-ci l'avait consulté, après lui avoir annoncé que tous les vins vieux qu'il a envoyés sont malades et lui avoir donné de graves doutes sur ses vins nouveaux, ajoute (1) :

" Voici une nouvelle importante et qui vous fera plaisir :

" J'ai.la ferme conviction que je suis en possession d'un moyen très pratique et sûr, capable de prévenir toutes les maladies de vos grands vins. Vous pourrez les conserver aussi longtemps que vous le désirerez. Je voudrais avoir sur ce point l'appui de votre observation la plus scrupuleuse et la plus directe. Voici dès lors le service que je réclame de votre obligeance et de votre dévouement à la solution qui me préoccupe.

“Vous auriez la bonté de m'envoyer diverses sortes de vins, choisis parmi les plus altérable's de la Bourgogne... Je traiterais moitié ou trois quarts du nombre de ces bouteilles par mon procédé, et je vous les renverrais soigneusement étiquetées et parafées avec cette indication : Ce vin ne s'altérera plus.

"Vous les déposeriez tout auprès d'un nombre égal de ces bouteilles mises en réserve, et dans six mois, dans un an, dans deux ans..., vous dégusteriez comparativement ces vins... De mon côté, je garderais quelques-unes de ces bouteilles dans les mêmes conditions et dans le même but." "

\section{( M. de Vergnette répond le 8 avril :}

“ Je suis tout disposé à donner mon concours à vos expériences en vous adressant du vin de mes récoltes. Voici seulement un point sur lequel je désirerais être fixé.

"Pouvez-vous opérer sur des vins de la qualité des $\mathrm{n}^{\mathrm{os}} 12,18,21,19$ ?

"Nos vins vieux ont votre ferment, à ce qu'il parait, mais j'espère que vous vous trompez sur nos vins nouveaux."

\section{« Le 11 avril, M. Pasteur lui répond :}

“ Je m'empresse de vous remercier et de vous informer que je puis opérer sur des vins de la qualité des $n^{\circ} 12,18,21,19$. Mon procédé n'a pas pour effet de guérir des vins malades, mais il arrête le mal lorsqu'il existe et le prévient absolument lorsqu'il n'existe pas. Ce n'est pas un remède aux vins altérés, mais un préservatif, et, appliqué aux vins déjà altérés plus ou moins, il empêche la continuation de la maladie. Si vous m'envoyez les vins $n^{\text {os }} 12,18,21,19$, je vous les renverrai dans un état tel, qu'ils resteront ce qu'ils sont, plutôt meilleurs que moins bons, et qu'ils ne deviendront jamais amers. "

« Et le même jour, dans un document publié depuis dans nos Comptes 
rendus (1), il résume en ces termes le résultat de ses études alors presque complètes :

"J'ai reconnu que les maladies ou altérations spontanées des vins sont produites par des êtres microscopiques, dont les germes existent dans le vin avant qu'il devienne malade.

"Le vin ne s'altère pas si ces germes sont tués. Un moyen simple et pratique de faire périr ces germes consiste à porter le vin à une température comprise entre 60 et $100^{\circ}$.

"Je déclare prendre un brevet d'invention pour l'application de ce procédé. Il empêche toutes les fermentations irrégulières des vins, quelle que soit leur nature, sans altérer la qualité du vin (\%) "

“Dans une Communication faite plus tard à l'Académie, M. Pasteur a montré que le minimum de la tempèrature nécessaire pour la conservation des vins pouvait être abaissé jusqu'à $50^{\circ}\left({ }^{3}\right)$.

“ En voyant M. de Vergnette engager M. Pasteur à s'occuper de cette question, continuer à correspondre avec lui, solliciter son jugement sur les altérations des vins qu'il lui envoyait, le visiter dans son laboratoire, apprendre de lui, le 15 févricr 1865, à reconnaître au microscope les êtres vivants, causes de la maladie, qui aurait pensé qu'il poursuivait lui-même, sáns en laisser rien transpirer, la solution du même problème?

“ On est bien obligé de l'admettre, pourtant; car ce n'était pas sans doute un plan d'expériences, mais des faits réellement observés qu'il présentait à l'Académie, quand, devenu notre correspondant, trois semaines après la prise de date de M. Pasteur qui était encore ignorée, il publiait un Mémoire sur l'amélioration et la conservation des vins par la chaleur (4).

«Renonçant à la congélation, adoptant probablement l'idée que la cause du mal tenait à des êtres vivants, que M. Pasteur lui avait appris à distinguer, il essayait aussi de les tuer par la chaleur, dont il avait fait, en 1850, l'emploi que j’ai apprécié.

“ Le procédé de M. de Vergnette ne s'applique qu'aux vins en bouteilles et consiste " à les empiler au grenier pendant les mois de juillet " et d'août, ou à les exposer, pendant deux mois, dans une étuve dont la “ température ne dépasse pas $50^{\circ}$. Après ce traitement, les vins sont “ descendus à la cave et conservés, comme de coutume, jusqu'à ce qu'on " les livre à la consommation.")

« Si M. de Vergnette était présent à notre séance, je lui demanderais cependant s'il a mis fréquemment en pratique son procédé; mais, à son défaut, notre confrère M. Thenard peut nous dire s'il a dans ses caves beau-

1. Voir p. 409-412 du présent volume : Procédé pratique de conservation et d'amélioration les vins. (Note de l'Édition.)

2. Ce brevet fut pris par M. Pasteur, quand ses idées sur la conservation des vins furent bien arrètées, afin de se mettre en garde contre les frelons de l'industrie. Il l'a laissé volontairement tomber dans le domaine public, et ceux qui parlent avec un certain dédain de cette maniére de s'assurer la propriété d'une découverte industrielle peuvent en faire dès lors usage kratuitement. (Note de M. Balard.) [Voir p. 410-411 du présent volume le texte de ce brevet.]

3. Voir p. 418-422 du présent volume : Nouvelles observations au sujet de la conservation des vins. Dans cette Communication Pasteur dit : "Il suffit que la masse du vin ait été portée quelques minutes seulement á la température de 60 a $70^{\circ}$ pour que le vin ait acquis une résistance extraordinaire a toutes les maladies qui peuvent l'atteindre... J'ajouterai que mes dernières expériences me permettent d'espérer que le maximum de la température à atteindre pourra ètre abaissé à $45^{\circ}$, sans que l'on puisse toutefois descendre plus bas. »

4. Veronette-Lamotte (A. de). Des effets de la chaleur pour la conservalion et l'amélioration des vins. Comptes rendus de l'Académie des sciences, LX, 1865, p. 895-89.). (Notes de l'Édition.) 
coup de vin exposé pendant deux mois à l'étuve, et si le climat de la Bourgogne et l'été de 1864 permettent de supposer que, dans un grenier couvert de tuiles et non de vitrages, la température puisse s'élever jusqu'à 45 ou $50^{\circ}$. Je voudrais aussi savoir de lui ce qu'il pense des assertions contradictoires de M. de Vergnette et de M. Pasteur sur le fait de l'amélioration de la qualité du vin par cette méthode. M. de Vergnette assure que son procédé conserve et améliore le vin; M. Pasteur prétend qu'il aurait pour résultat nécessaire d'altérer les vins fins de la Bourgogne. Mais c'est à l'expérience et aux dégustateurs à prononcer sur l'influence comparative d'une température de $60^{\circ}$ agissant pendant un instant, et celle d'une température maximum de $50^{\circ}$ prolongée. pendant deux mois, la seule chose, à mon avis, que M. de Vergnette puisse réclamer dans la question de la conservation du vin par le chauffage.

"Quant à l'utilisation pratique des deux procédés, je ne pense pas qu'on puisse hésiter entre celui qui exige du vin en bouteilles, une étuve, deux mois de chaleur, et un autre qui n'a besoin que d'une minute de chauffage, qui peut s'appliquer à bas prix aux vins conservés dans d'immenses tonneaux, et qui a déjà rendu à l'agriculture et au commerce des vins des services réels.

“ On pouvait croire qu'à la fin de ces débats de 1865, la question que je cherche à élucider était claire pour tout le monde, et c'est ainsi qu'en pensait, à l'Exposition de 1867, le jury pour la classe d'agriculture, qui décernait à M. Pasteur un Grand Prix pour la conservation des vins (1). Mais, en 1869, à la suite d'une allocution de notre confrère le maréchal Vaillant au Conseil général de la Côte-d'Or, sur l'utilité du procédé Pasteur, notre confrère M. Thenard, soutenant de nouveau que c'était à M. de VergnetteLamotte que revenait la priorité, donna lieu â de nouveaux débats $(\mathbf{2})$.

( M. Pasteur, en partant pour Trieste $(3)$, les croyait terminés; il n'en était pas ainsi cependant. Ils se prolongèrent pendant son absence, et ce n'est que tout récemment qu'il a eu connaissance de la Note communiquée à l'Académie, le 22 novembre 1869, par M. de Vergnette-Lamotte ( ${ }^{4}$ ).

" Dans cette Note, comme dans celle que renferme le Compte rendu précédent, comme dans toutes les autres, M. de Vergnette ne se sert que d'un seul argument : la reproduction du passage relatif au chauffage des vins en 1850 , qu'il cite avec plus ou moins d'extension, mais jamais en entier. Dans celle de 1869, par exemple, rappelant ce qu'il avait publié en 1850, " quinze ans avant les premiers travaux de M. Pasteur sur le chauffage ", il se contente de reproduire cette seule phrase :

“ Nous avons répété cette expérience sur d'autres vins, à l'époque de leur mise en bouteilles, et toujours nous avons réussi, en faisant varier la température du bain-marie de 50 à $75^{\circ} \mathrm{C}$., à préserver les vins de qualité soumis à ces essais de toute altération ultérieure." "

1. Moniteur universel, n 183, 2 juillet 1867 : Grand Prix, à M. Pasteur, Paris. Procédé de conservation des vins par le chauffage.

2. Voir, à ce sujet, p. 215-218 et p. 439-453 du présent volume.

3. Pasteur partit á cette époque pour la villa Vicentina, près de Trieste, afin d'y faire une application en grand de son procédé de grainage en vue de prévenir la maladie des vers à soie.

4. Vergnette-Lamotte (A. de). Note en réponse à la dernière Communication de M. Pasteur sur le chauffage des vins. Comptes rendus de l'Académie des sciences, LXIX, 1869, p. 1048-1050. (Notes de l'Édition.) 


\section{Et il ajoute :}

"Cette citation si précise répond, - l'Académie voudra bien me l'accorder, je l'espère, - à toutes les attaques qui ont été dirigées contre moi. "

"Je ne crois pas que l'Académie puisse lui faire cette concession. Sa citation, précise dans ce qu'elle contient, n'est pas suffisante. Il aurait fallu, pour cela, y joindre la phrase suivante :

“ Il n'en était pas de même pour ceux qui, d'une santé douteuse, ne présentaient point cette composition normale sans laquelle les vins ne se conservent pas. Dans ce cas, ils ne résistent pas à cette épreuve, etc. ”

« Eh bien, la découverte de M. Pasteur, c'est que, contrairement à cette assertion de M. de Vergnette, tous les vins peuvent subir l'action de la chaleur sans s'altérer, et qu'une minute de chauffage assure la conservation d'un vin quelconque; que le vin le plus faible, le plus disposé à tourner à l'aigre, à la graisse, à l'état visqueux, à l'amer, est garanti des altérations qu'il aurait pu éprouver. Grâce à elle, l'ouvrier, le paysan, si peu soigneux pour leur vin, pourront le laisser presque impunément en vidange, en lui conservant les qualités d'un liquide sain et agréable.

“ M. Pasteur n'a donc pas seulement le mérite si restreint que lui accorde M. Thenard; il est réellement l'inventeur, le propagateur convaincu de la méthode de conservation des vins par la chaleur; et si notre pays, grâce à ces pratiques, voit la richesse publique s'augmenter par l'exportation de nos vins ordinaires, les plus altérables, d'un bas prix et susceptibles d'être consommés par la partie la plus nombreuse des peuples qui ne cultivent pas la vigne, e'est à lui qu'en toute justice on doit en rapporter l'honneur.

“ Je prie, en terminant, l'Académie d'excuser l'étendue de cette Communication (1); j'espère qu'elle voudra bien se rappeler que je ne suis pas entré spontanément dans cette discussion de priorité introduite dès les premiers jours dans le débat important qui s'agite devant nous. Cette discussion pouvait paraître, au premier aspect, une chose incidente, et n'avant pour la science qu'un intérêt restreint. Elle se rattache cependant, de la manière la plus intime, au fond même du débat, puisque ces altérations des vins font partie des fermentations proprement dites de II. Pasteur, qui sont en cause en ce moment. Amené sur ce terrain malgré moi, j'ai cru devoir traiter la question d'une manière complète, en m'efforçant de la rendre assez claire pour que ce débat ne pût plus reparaîtrc dans nos Comptes rendus, où il a, à diverses époques, occupé déjà trop de place.

“Dans la Communication que je viens de faire, j'ai eu surtout pour but d'exposer les faits. C'est, bien entendu, sur eux que j’ai fondé mes convictions; mais je n'ai pas l'espérance de la voir partagée par ceux qui, depuis longtemps déjà, ont eu et soutenu une opinion contraire. S’ils jugent convenable de continuer ce débat spécial, je ne les y suivrai pas; il est clos en ce qui me concerne, et je ne demanderai de nouveau la parole sur ce sujet

1. Ce développement, qui avait été d'abord rédigé sous forme de Note, n'a pas été lu à l'Académie. (Note de Balard.) 
que dans le cas où l'on contesterait les documents que je reproduis et les faits sur lesquels je m'appuie. »'

A cette argumentation complète et sévère, MM. Thenard (1) et de Vergnette $\left(^{2}\right)$ ne répondirent encore que par des affirmations, sans recourir aux textes originaux, et par des dissertations sur la pratique de la congélation des vins, qui était hors de cause.

" Les expériences d'Appert sont authentiques, avait dit M. Thenard, il prit des vins en bouteille, en chauffa une partie i $75^{\circ}$ et laissa l'autre i l'état naturel..... Au retour les vins non chauffés (qui étaient restés en France et non expédiés avec les bouteilles chauffées, comme le dit par erreur M. Thenard) étaient plus ou moins altérés; les autres, au contraire, n'étaient en rien modifiés $\left(^{3}\right)$. "C'est une erreur. Les vins chauffés avaient été améliorés, dit Appert, et les vins non chauffés n'avaient éprouvé aucune altération; ils avaient conservé leur verdeur primitive, sans contracteraucune maladie. Par son expérience, Appert n'avait donc rien prouvé, quant à l'efficacité du chauffage contre le développement des maladies des vins. C'est, du reste, ce que M. de Vergnétte lui-même a reconnu : " M. Pasteur, dit-il, a fait remarquer avecljustesse que l'indication d'Appert était insuffisante, puisqu'il ne dit nulle part si les vins de même qualité non chauffés par lui asaient ou non été malades. ”(De Vergnetre. Le vin, 2e édit., 1869, p. 255.)

Poursuivońs l'examen de la Note de M. Thenard, en la mettant en regard de la critique de M. Balard. " Il y a quinze ou seize ans, dit M. Thenard, M. de Vergnette-Lamotte, reprenant les expériences d'Appert, mais opérant sur des vins très fins, reconnut que, si les vins de Bourgogne, chauffés à $75^{\circ}$, ne s'altéraient pas ultérieurement, l'action même du chauffage les rend si secs et si durs, qu'en tournant au goût de certains vins du Midi, ils perdent leurs plus précieuses qualités de finesse et de bouquet; en sorte que, malgré cette plus grande stabilité, il borna l'application de sa méthode aux vins communs devant être placés dans des conditions très défavorables, et, à l'occasion, à quelques vins blancs fins. ”

1. ThenaRd (P.). Observations relatives aux procédés de conservation des vins par le chauffage. Comptes rendus de l'Académie des sciences, LXXIV, 1872, p. 293. - Réponse à la Note de M. Balard sur la prioritẻ d'invention du chaufiage des vins. Ibid., p. 569-570. Réponse á une Communication de M. Pasteur (sur la conservation des vins). Ibid., p. 848.

2. Vergnette-Lamotte (A. de). Ob́servations relatives aux procédés de conservation des vins par le chauffage. Ibid., p. 589-540. - Observations relatives à la réponse faite par M. Pasteu. á propos de la conservation des vins. Ibid., p. 843-845.

3. Thenard (P.). [Réclamation de M. Thenard, au Conseil général de la Côte-d'Or.] Journal d'agriculture pratique, 1869, II, p. 389-390. Voir cette Note p. 217-218 du présent volume. (Notes de l'Édition.) 
Il n'y a rien de cela "du tout dans le travail de M. de Vergnette de 1850, le seul qu'il ait publié avant mes recherches, et où il ait parlé de vins chauffés. Nulle part, il n'y est dit qu'il faille borner l'application de la méthode d'Appert aux vins communs. M. de Vergnette distingue, dans ce travail, les vins en deux classes : $1^{\circ}$ ceux qui ont une santé robuste et qui se conservent naturellement sans conditionnement préalable quelconque; $2^{\circ}$ ceux qui sont d'une santé douteuse, qui ne présentent pas la composition normale sans laquelle les vins ne se conservent pas. La chaleur, dit M. de Vergnette, n'altère pas les premiers, et tous les autres, au contraire, ne résistent pas à son épreuve. Les premiers sont hors de cause, puisqu'ils se conservent naturellement; les seconds s'altèrent selon lui, et bien plus, séance tenante, par le chauffage d'un échantillon; IL x'y AVait donc poun M. DE Vergasette aucune sorte de vin a laquelle ox dût appliquer le chauffage ex vue de la conservation. Aussi le Mémoire dont je parle se termine par ces mots : EN RÉSUMÉ, PoUr Nous IL N'EST QU'UNE

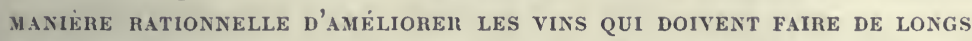
Voyages, C'est de Les concentrer Par LA CONGÉlation. Quant à l'expérience que M. de Vergnette rapporte sur le vin blanc, c'est, mot pour mot, l'expérience d'Appert, avec cette circonstance toutefois, que II. de Vergnette, qui aujourd'hui exalte Appert afin de diminuer le mérite de mes travaux, n'a pas cité Appert en 1850, sinon pour le dépouiller puisqu'il se borne à dire : J'ai aussi appliqué au vin ce qu'Appert avait fait pour les moûts.

Au reste, le savant défenseur de M. de Vergnette ne s'est pas assez préoccupé de se mettre d'accord avec son client, car, dans une Note présentée à l'Académie, le 12 mars 1866, M. de Vergnette s'exprime ainsi :

"Voyons maintenant d'abord ce que deviennent les vins qui ont été soumis au procédé Appert... La plupart des vins de table, ceux de la deuxième catégorie, ne résistent pas, au point de vue œnologique, à ce traitement; ils deviennent secs, vieillardent, et ne tardent pas a se décolorer.

" Mais les vins qui, sans exception, perdent leur valeur, si faible qu'elle soit, lorsqu'on les traite par le procédé Appert, sont les vins communs de la troisième catégorie, tant ils se décolorent, deviennent secs et acides $\left({ }^{1}\right)$. "

Et M. Thenard dit de M. de Vergnette : Il borna l'application de la méthode d'Appert aux.x vins communs devant être placés dans des condi-

1. Vergnetre-Lamotte (A. de). Conservation des vins par l'emploi de la chaleur. Comptes rendus de l'Académie des sciences, LXII, 1866, p. 596-602. (Note de l'Édition.) 
tions très défavorables. "C'est exactement le contraire que proclame M. de Vergnette.

M. Thenard dit ensuite : "La question en était là, quand M. Pasteur, il y a quatre ans environ, prit un brevet pour la conservation des vins par le chauffage préalable entre 65 et $75^{\circ}$; mais moins de deux ans après (lisez : trois semaines), et sans connaitre le brevet Pasteur, qui n'était pas encore dénoncé, M. de Vergnette présenta à l'Académie des sciences un Mémoire où il annonçait qu'après un chauffage préaláble variant entre 42 et $52^{\circ}$, qui n'altérait pas nos vins les plus fins, ceux-ci se conservaient aussi bien que si on les eût chauffés à $75^{\circ}(1)$. »

Tout cela est encore erroné et incomplet. D'une part, le travail auquel M. Thenard fait allusion est postérieur de trois semaines à la prise de date de mes résultats, le 11 avril 1865, et par conséquent il ne peut primer le mien; d'autre part, voici textuellement la fin de celte Communication de M. de Vergnette du $1^{\text {er }}$ mai 1865 :

“ A défaut d'une étuve... on mettra les vins en bouteilles au mois de juillet, en ne choisissant jamais que des vins âgés de deux ans au moins, les fûts qui les contenaient étant jusqu'à ce moment restés dans lą cave. Les bouteilles ne seront point bouchées à l'aiguille, mais cependant à la mécanique. Après le tirage, les bouteilles seront transportées et empilées au grenier. Elles y resteront deux mois, et les vins seront ensuite descendus en cave pour y être conservés comme de coutume jusqu'à ce qu'on les livre à la consommation (2). ”

C'est à défaut d'une étuve à $50^{\circ}$ que M. de Vergnette conseille l'emploi du grenier, ce qui est une autre grave méprise, car la température d'un grenier en été, surtout en Bourgogne, n'atteint jamais $50^{\circ}$ dans un tas de bouteilles empilées, pas même $40^{\circ}$.

Pourquoi donc M. Thenard omet-il de dire que M. de Vergnette chauffe les vins PENDANT DEUx mois dans un grenier ou dans une étuve à $50^{\circ}$ ? Moi, je les porte, ne fût-ce qu'une minute, à $60^{\circ}$. Les deux procédés ne sont-ils pas, de fait, entièrement distincts, outre que le mien a précédé l'autre? Mais il y a plus; mon procédé est d'une application facile et sûre; non seulement il conserve les vins les plus fins comme les plus communs, il permet en outre leur vieillissement et leur amélioration dans les meilleures conditions. Je déclare au contraire

1. Thenard (P.). Journal d'agriculture pratique, 1869, II, p. $389-390$ et p. 217-218 du présent volume.

2. Vergnette-Lamotte (A. de). Des effets de la chaleur pour la conservation et l'amélioration des vins. Comptes rendus de l'Académie des sciences, LX, 1865, p. 895-899. (Notes de l'Édition.) 
que tous les vins, sans exception, souffriraient considẻrablement par une exposition de deux mois dans une étuve de 42 à $52^{\circ}$. Ce procédé n'a jamais été appliqué par M. de Vergnette ni par personne d'une manière suivie aux vins fins de la Bourgogne. Il leur enlèverait complétement leurs qualités les plus précieuses et les rendrait malades pour la plupart.

Voici une dernière citation empruntée à la Note de M. Thenard : "Depuis, qu'a fait M. Pasteur? Il a successivement abaissé les limites de température; si bien que, de 75 à $65^{\circ}$, il est arrivé à $55^{\circ}$; c'est-à-dire qu'il a de plus en plus confirmé les observations de M. de VergnetteLamotte, et que, pour peu qu'il tombe encore de $3^{\circ}$, il les confirmera tout a fait (1). )

Tout cela encore est erroné; l'exposition rapide à la température minima de $60^{\circ}$, que j'ai indiquée le premier, convient à tous les vins fins ou communs, excepté aux vins très liquoreux qui ont peu fermenté. C'est par pure curiosité scientifique que j'ai dû essayer des températures inférieures, notamment celle de 55 à $60^{\circ}$, et j'ai reconnu, en effet, que la température de $55^{\circ}$ était suffisante et encore c'est à la condition de tenir les bouteilles couchées. Cette température ne tue pas complétement les germes du mycoderma aceti, mais, je le répète, la température de $50^{\circ}$ Pendant deux mois qui forme le procédé de M. de Vergnette, dont il a toute la priorité, donnerait les plus mauvais résultats. En résumé, de toutes les assertions de la Note de M. Thenard, reproduites plus ou moins par M. de Vergnette, aucune ne reste debout $\left({ }^{2}\right)$.

\section{DÉMONSTRATION EXPÉRIMENTALE DES BONS EFFETS DU CHAUFFAGE}

J'ai hâte d'arriver à la démonstration expérimentale des effets de la chaleur sur le vin que j'ai indiqués précédemment.

Le 15 mars 1865, je reçois de M. de Vergnette-Lamotte 25 bouteilles comprenant des échantillons des vins suivants :

№ 12. - Vin de pinot (Beaune 1858), non transvasé avant l'envoi.

No 18. - Vin de pinot (Pomard 1858), non transvasé avant l'envoi.

No 19. - Vin de pinot (Pomard 1862), transvasé avant l'envoi.

No 21. - Vin de pinot (Pomard 1863), transvasé avant l'envoi.

1. Thenard (P.). Loc. cit.

2. Voir p. $425-460$ du présent volume les documents relatifs à la question de priorité de l'invention de la méthode du chanffage pour conserver les vins. (Notes de l'Édition.) 
Après avoir laissé en repos les bouteilles pendant quarante-huit heures, je décante le vin avec un grand soin, à l'aide d'un siphon qui débite peu, et en laissant dans chacune des bouteilles seulement 1 ou 2 centimètres cubes de liquide. J'agite alors la bouteille de façon à délayer, dans le peu de liquide qui y est resté, le faible dépôt que l'on trouve presque toujours au fond d'une bouteille de vin bien reposée. L'examen microscopique me montre dans tous les dépôts les filaments dont il a été question dans la première partie de cet ouvrage, plus ou moins nombreux suivant la nature du vin, mais présents partout. Cette observation prouve que les vins dont il s'agit renferment dans leur intérieur des germes de maladie. Je chauffe alors sans la déboucher une bouteille de cháque sorte de vin, vers $60^{\circ}$, puis, après le refroidissement, je place ces bouteilles à côté d'autres bouteilles non chauffées du même vin, et je les abandonne dans une cave dont la température varie en été de 13 à $17^{\circ}$. L'examen des bouteilles était fait tous les quinze jours, sans les déboucher, en élevant la bouteille et regardant dans la gouttière du fond placée entre l'œil et la lumière, afin de constater s'il se formait un dépót. En moins de six semaines, particulièrement pour le $n^{0} 21$, il était visible qu'un dépôt flottant commençait à se former, et il a augmenté progressivement. Mais ce dépôt, aujourd'hui si abondant dans toutes les bouteilles qui n'ont pas été chauffées, est absolument absent dans toutes celles qui ont été portées à une température de $65^{\circ}$ environ. A l'heure où j'écris ces lignes $\left({ }^{(}\right)$, les bouteilles qui n'ont pas été chauffées, et pour les quatre sortes de vins, offrent un dépôt si considérable, qu'il s'élève à plus de $0^{\mathrm{m}}, 02$ et $0^{\mathrm{m}}, 03$ en hauteur dans la gouttière des bouteilles, et si l'on agite le vin il est trouble dans toute sa masse. Enfin, le vin est très sensiblement malade, amer, bien moins agréable à boire que le même vin qui a été chauffé, et qui n'a pas éprouvé du tout de dépréciation.

Si l'on examine les dépôts au microscope, on reconnaît qu'ils sont organisés, avec mélange, dans certains cas, d'un peu de matière colorante ou colorable oxydée et devenue insoluble par le fait même de cette oxydation. La figure 19 représente le dépôt du vin $\mathrm{n}^{\circ} 21$, et la figure 36 le dépòt du vin $\mathrm{n}^{\circ} 12$.

Voici d'autres preuves qui s'appliquent particulièrement au développement des mycoderma vini et aceti.

Le $1^{\text {er }}$ mars 1865 , je fais chauffer 20 bouteilles bien bouchées d'un vin nouveau du Jura, à une température de $70^{\circ}$, et après refroidissement je les laisse debout à côté de 20 autres bouteilles du même vin 
non chauffé préalablement. Quinze jours après, il y a dans les goulots de toutes les bouteilles non chauffées, à la surface du vin, des fleurs de mycoderma vini. Aujourd'hui encore, les bouteilles qui avaient été chauffées, et qui sont restées debout depuis le mois de mars, n'ont pas la moindre trace de fleurs. Mais, bien plus, on peut mettre en vidange les bouteilles de vin chauffé et les abandonner à elles-mêmes, rebouchées avec le même bouchon, à moitié pleines, sans que le plus souvent elles se couvrent de fleurs. Je n'ai jamais vu de vin de table, grand vin ou vin commun, qui, dans de telles conditions, ne se courrît de fleurs et ne s'altérât.

Il n'y a de différence entre les divers vins que dans l'époque plus ou moins tardive de l'apparition des fleurs, et dans l'espèce des fleurs qui prennent naissance, parce que la facilité plus ou moins grande du développement des mycodermes et leur nature dépendent beaucoup de la composition du vin. J'en ai donné des exemples et j'en ajouterai d'autres tout à l'heure. On peut également consulter à cet égard les faits que j'ai consignés dans le Mémoire que j'ai inséré dans les Annales scientifiques de l'École Normale, relatif à la fermentation acétique (1).

J'ai fait suivre ces études d'autres études analogues, dans lesquelles j'ai reconnu qu'alors même qu'une maladie est en pleine activité dans un vin, l'application de la chaleur l'arrête au point où elle est arrivée.

Enfin, je m'appliquai à rechercher, sur un grand nombre de sortes de vins, si la chaleur ne faisait pas subir au vin, comme on le croyait généralement, des modifications particulières; en d'autres termes, si la couleur du vin, sa limpidité, sa saveur, son bouquet, ne recevraient pas, du fait du chauflage préalable, une atteinte qui restreindrait singulièrement l'utilité de la pratique que j'entrevoyais.

Après bien des épreuves favorables à la pratique du chauffage, et dans lesquelles j'avais provoqué le jugement de personnes du monde, j’ai pensé que jé devais avoir recours à des courtiers et à des négociants, très exercés à saisir dans les vins les moindres nuances de qualités.

M. Hemmet, syndic de la Compagnie des courtiers de Paris, et II. Teissonnière, membre du Conseil municipal de Paris, qui dirige un comınerce de vins considérable, ont mis à me servir dans cette circonstance une obligeance dont je m'empresse de les remercier publiquement.

Le 26 octobre 1865 , ils ont bien voulu, à ma demande, déguster les cinq sortes de vins suivants :

1. Voir p. 23-77 du présent volume : Mémoire sur la fermentation acétique. (Note de l'Edition.) 
I. Vin d'Arbois, bon ordinaire de 1863 : bouteilles chauffées à $75^{\circ}$, le 5 avril 1865 ; bouteilles du même vin non chauffées.

II. Vin de coupage acheté à l'entrepôt de Paris : bouteilles chauffées, le 11 juin 1865 , à $65^{\circ}$; bouteilles du même vin non chauffées.

III. Vin du Cher, vieux, acheté à l'entrepôt de Paris : bouteilles chauffées, le 11 juin 1865 , à $65^{\circ}$; bouteilles du même vin non chauffées.

IV. Vin de Pomard de 1863, livré par M. Marey-Monge : bouteilles chauffées à $60^{\circ}$, fin juillet; bouteilles du même vin non chauffées.

V. Vin de Gevrey-Chambertin de 1859, acheté chez le propriétaire au prix de 5 francs la bouteille : bouteilles chauffées, le 16 mai, à $65^{\circ}$; bouteilles du même vin non chauffées.

Voici l'appréciation écrite et textuelle de ces messieurs :

- Vin d'Arbois. - Le chauffé est supérieur au non chauffé. Pas de différence sensible dans la couleur. Elle est plus vive dans le vin chauffé. Pas de dépòt sensible ni dans l'un ni dans l'autre.

Vin de coupage. - Le chauffé est supérieur au non chauffé. Même nuance de couleur, mais plus vive dans le chauffé. Déjà dépôt faible, mais sensible dans le vin non chauffé. Pas du tout de dépòt dans le vin chauffé. La bouteille, retournée et agitée, offre le vin aussi limpide qu'auparavant.

Vin du Cher. - Le chauffé est supérieur au non chauffé. Mème nuance de couleur dans tous deux, mais elle est plus vive et plus agréable dans le chauffé. Pas du tout de dépôt dans le chauffé. Il commence dans le non chauffé, assez pour troubler légèrement le vin lorsqu'on retourne et qu'on agite la bouteille.

Vin de Pomard. - Le chauffé est supérieur au non chauffé. La couleur est la même, mais toujours plus vive dans le chauffé. La limpidité du vin chauffé est parfaite; pas encore de dépôt du tout. Le non chauffé offre un dépôt considérable et flottant, qui, examiné au microscope, montre des fils très longs, d'autres très petits, et enfin des granulations sphériques. Il a un goût d'amertume qui ne se retrouve que très faiblement dans le vin chauffé. 
MAI.ADIE DE L'AMERTEYE:

VIN dF Beace. 1858.

Fig. 36

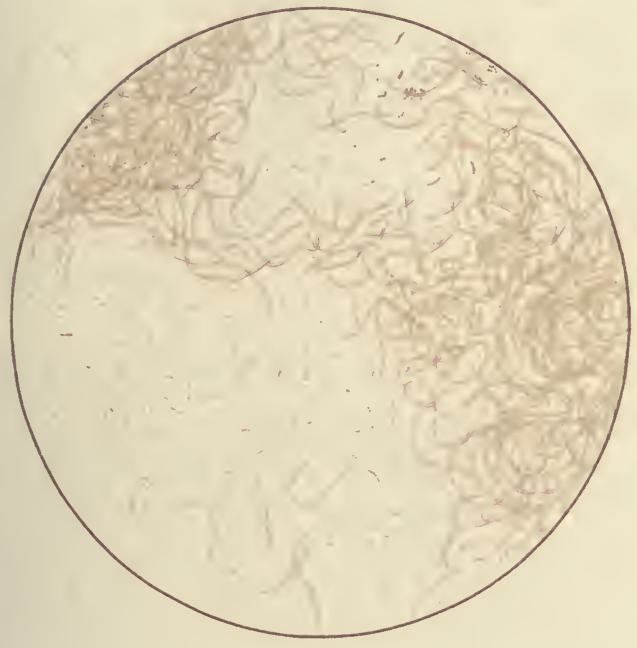

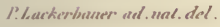



l'in de Chambertin. - Limpidité très grande et même couleur dans les deux cas. Autant de finesse et de bon goût dans le chauffé que dans le non chauffé, avec légère maigreur de plus dans le chauffé.

Ces mêmes vins seront dégustés dans les années suivantes, autant que cela sera possible par les mêmes personnes, et je m'empresserai d'en faire connaître le résultat ( $\left.{ }^{1}\right)$.

MM. Henmet et Teissonnière, frappés de l'importance des résultats qu'ils venaient de constater, voulurent bien me donner le conseil de les faire juger de façon qu'ils pussent être portés ultérieurement à la connaissance du public sous le couvert d'une plus grande autorité de la part des juges. Je m'empressai de suivre ce conseil, aussi modeste de la part des personnes qui me le donnaient, qu'il était obligeant pour moi.

En conséquence, j’adressai, le 28 octobre 1865, la lettre suivante à M. Lanquetin, président de la Commission représentative du commerce des vins en gros de Paris :

\section{“ Mossievr le Président,}

"Depuis plus de deux ans je m'occupe de l'étude des maladies des vins, de leurs causes et des moyens de les prévenir. Mes recherches m'ont conduit à un procédé simple et pratique de conservation que je serais heureux de faire juger par les personnes les plus compétentes en cette matière. L'avis le plus autorisé que je puisse solliciter est sans contredit celui de la Commission préposée aux intérêts du commerce des vins dans Paris, que vous avez l'honneur de présider.

" Ce procédé, que je désirerais faire apprécier d'abord et exclusivement pour les vins en bouteilles, consiste à élever la température du vin à l'abri de l'air jusqu'à un degré qui peut varier avec les diverses natures de vins, mais qui est compris entre les limites de 50 à $65^{\circ}$ environ.

" Si vous approuvez ma demande, monsieur le Président, je vous serai obligé de provoquer immédiatement les travaux de la Commission. "

Le lendemain, je reçus une réponse très obligeante, qui m'informait de la nomination prochaine d'une Sous-Commission ayant pour mandat de se mettre en communication avec moi, et de faire un premier rapport qui serait soumis à la Commission représentative.

1. Voir les dégustations faites en 1869 et en 1872 , p. 253-256 et p. $878-381$ du présent volume. (Note de l'Édition.) 
Les jeudis 16 et 23 novembre, la Sous-Commission procéda à la dégustation de vingt et une sortes de vins de diverses origines, conservés dans une cave très saine, dont la température varie pendant l'été de $13^{\circ}$ à $17^{\circ}$ environ. Les bouteilles chauffées et non chauffées avaient toujours été dans les mêmes conditions et placées les unes à còté des autres soigneusement étiquetées.

Voici le rapport de la Sous-Commission, composée de :

MM. Teissonnik̀re, membre du Conseil municipal de Paris, viceprésident de la Commission représentative;

Brazier jeune, négociant en vins ;

L. Gélerier, négociant en vins;

Cherrier, négociant en vins;

Delaleu, négociant en vins.

Par suite de votre décision, la Sous-Commission que vous avez nommée sur le désir exprimé par M. Pasteur, membre de l'Institut, dans sa lettre du 28 octobre 1865, s'est rendue, les 16 et 23 novembre à l'École Normale, à l'effet de constater par la dégustation les résultats obtenus par ce savant, qui s'occupe d'une manière toute spéciale des maladies des vins et de leurs causes.

Appréciation, par la dégustation, DES ÉCHANTILlons Soumis a LA SOUS-Conmission.

I. - Vin rovge en vidange (1/2 de la bouteille) Depuis cine mois.

(Coupage de vin au litre vendu dans Paris.)

Le vin non chauffé est couvert de fleurs, trouble, d'un goût défectueux.

Le vin chauffé est limpide, d'une couleur brique, a un goût de rancio très avancé, mais n'est pas aigre. Il y a à sa surface une pelli- 
cule légère formée par la matière colorante, mais pas de fleurs, et sur les parois un abondant dépòt adhérent.

\section{II. - Vix de la vente au litre daxs Paris.}

(Bouteilles debout depuis le mois de mars.)

Le vin chauffé ne dépose pas, est parfaitement conservé. Le chauffage a développé un très léger goût de rancio.

Le vin non chauffé est couvert de fleurs. Il a déposé sans que cependant son goût ait subi d'altération sensible.

$$
\text { III. - VIX dE LIE. }
$$

(Bouteilles debout depuis le 11 juin.)

Le vin non chauffé est supérieur en goût: Sa couleur est plus vive. Le dépót plus apparent au fond de la bouteille.

Le vin chauffé a un gont de chauffé très léger, une teinte plus vieille. C'est un vin plus avancé. Le dépòt au fond de la bouteille est insignifiant.

$$
\text { IV. - Vin de Chixon, } 1864 .
$$

(Bouteilles debout depuis le 11 juin.)

Le vin chauffé est parfaitement conservé. Sa limpidité est parfaite. Le goût n'a subi aucune variation par l'action de la chaleur. Résultat excellent.

Le vin non chauffé est presque décomposé. Il y a un grand dépôt au fond de la bouteille. Le goût du vin est fermenté et amer.

$$
\text { V. - Vix du Cher, } 1863 .
$$

(Bouteilles debout depuis le 11 juin.)

Même résultat que pour le précédent. Le vin chauffé a gagné en couleur. Son goût s'est aminci, mais il est bon. Le vin est resté limpide. Il n'y a pas de dépòt au fond de la bouteille.

Le vin non chauffé a perdu de la couleur. Son goût malade est resté le même qu'au moment de la mise en bouteille. Il y a un fort dépôt.

$$
\begin{aligned}
& \text { VI. - Vix gris. Vix façox Tavel. } \\
& \text { (Bouteilles debout.) }
\end{aligned}
$$

Il n'y a pas de fleurs, ni sur le vin chauffé, ni sur le vin non chauffé.

Le vin chauffé est trouble, mais sans dépòt au fond de la bouteille. Son goût est défectueux. 
Le vin non chauffé est très limpide. Il a légèrement déposé. Il est de bon goût.

Noтء. Cette sorte de vin ayant déjà subi une préparation, et sa couleur n'étant pas entièrement naturelle, il n'y a peut-être pas lieu de s'étonner du résultat. (Note de la Commission.)

$$
\begin{aligned}
& \text { VII. - VIN DE Montagne, } 1864 . \\
& \text { (Bouteilles debout.) }
\end{aligned}
$$

Le vin chauffé est supérieur. Il a plus de couleur et de limpidité, la bouteille non remuée. Il est plus trouble lorsque la bouteille a été agitée. Il est bon de goût, a gagné en qualité.

Le vin non chauffé est trouble, il s'est altéré et a déposé beaucoup. Ce vin, agité, est un peu moins trouble que l'autre.

$$
\text { VIII. - Vix de moxtagne, } 1864 .
$$

Dépôt similaire dans le vin chauffé et non chauffé.

Le vin chauffé est légèrement trouble. Il a vieilli au goût sans que sa couleur rouge soit détériorée; il est un peu plus maigre au goût.

Le vin non chauffé a des fleurs, mais il est bon de goût. Il est supérieur à l'autre malgré les fleurs.

$$
\begin{gathered}
\text { IX. - VIn D'ArboIs, } 1863 . \\
\text { (Chauffé le } 19 \text { mai. - Bouteilles couchées:) }
\end{gathered}
$$

Il n'y a aucun dépòt dans les bouteilles. Les deux vins sont également bien conservés comme limpidité. Le vin non chauffé est supérieur. Il a conservé son goût.

Le vin chauffé a séché et a perdu de sa finesse.

$$
\text { X. - Vin d'Anвois, } 1859 .
$$

(Chauffé le 27 avril. - Bouteilles couchées.)

Il n'y a aucun dépôt ni dans le vin chauffé ni dans celui qui ne l'a pas été. Le résultat est le même que le précédent. Le vin non chauffé est supérieur. Le vin chauffé est plus sec; il a une tendance légère à l'amertume.

$$
\begin{aligned}
& \text { XI. - Pomard, 1863, Marey-Monge. } \\
& \text { (Chauffé fin juillet.) }
\end{aligned}
$$

Le vin non chauffé qui était debout est décomposé. Il est mauvais. Il y a un grand dépôt flottant au fond de la bouteille. La fleur a 
formé cordon autour du goulot, et le vin est louche et a la couleur brique.

Le vin chauffé qui était debout comme le précédent est très limpide. Il a une jolie couleur de vin vieux. Son goût est bon, mais il a perdu de son velouté.

Le vin non chauffẻ qui est resté couché a beaucoup déposé; teint pas bon. Il a la couleur brique et est louche.

Le vin chauffé qui est resté couché est très limpide. Il a une jolie couleur. C'est un vin très sain. Il a le goût plein, 'velouté, et n'a subi aucune altération.

\section{XII. - Pomard, 1848, Marey-Moxge.}

(Bouteilles couchées.)

Le vin non chauffé est légèrement trouble et amer. Il a beaucoup déposé. C'est un vin malade.

Le vin chauffé a légèrement déposé. Il a le goût vieux, très vieux, mais sans amertume. Il est très limpide et très bon comparativement au précédent.

\section{XiII. - Pomard, 1858, Vergnette-Lamotte. \\ (Chauffé le 27 avril. - Bouteilles couchées.)}

Le vin non chauffé est assez bon, a un grand dépôt, et il est plus léger en couleur que le vin chauffé. Vin malade.

Le vin chauffé est excellent, incomparablement meilleur que le précédent, n'a pas du tout déposé, et donne une idée du vin lorsqu'il est le meilleur.

\section{XIV. - Volnay, 1858, phemière cuvée. \\ (Chauffé le 9 mai. - Bouteilles couchées.)}

A la comparaison du vin chaulfé avec celui qui ne l'a pas été, les opinions sont d'abord partagées.

Le vin non chauffé est cependant trouvé supérieur parce qu'on trouve au vin chauffé un goût de cuit. Il n'y a aucun dépòt dans les bouteilles.

Nота. Il est essentiel de noter que, pour toutes les dégustations précédentes, les dégustateurs savaient à l'avance qu'ils avaient affaire à du vin chauffé ou à du vin non chauffé. Pour toutes les dégustations suivantes, ils l'ont. ignoré; M. Pasteur écrivait au fur et à mesure, et avant la dégustation, la nature du vin, sur un papier qui a été ensuite confronté avec les résultats des dégustations. Celles-ci étaient également consignées par écrit au fur et à mesure qu'elles avaient lieu. (Note de la Commission.) 
XV. - Vin de la vente au litre dans Paris (cachet javie).

(Chauffé le 14 mars. - Bouteilles couchées.)

Le vin non chauffé est aigre et amer. Il y a au fond de la bouteille un fort dépôt. Il a perdu un peu en couleur.

Le vin chauffé est bon, sans dépôt au fond de la bouteille et il a conservé sa couleur.

XVI. - Vin de Bourgogne (Saxs autre indication d'onigine). (Chauffé depuis plusieurs mois. - Bouteilles couchées.)

Trois dégustateurs contre un trouvent au vin non chauflé une supériorité incontestable sous le rapport du développement du bouquet. Le vin est limpide. Il a le goût de vin très vieux, qu'il est en effet.

Les trois dégustateurs trouvent le vin chauffé inférieur en ce sens que le bouquet se dégage moins. Ce vin est également très limpide. Il paraît plus sec.

\section{XVII. - Vin de Nuits, 1861, Pheniène cuvée.}

(Chauffé le 22 mai. - Bouteilles couchées.)

Le vin chauffé a une nuance de plus que le non chauffé. Il est parfaitement conservé, incontestablement supérieur au non chauffé, qui a une tendance assez prononcée à l'amertume. Fort dépòt dans le vin non chauffé, pas du tout dans le vin chauffé.

\section{XVIII. - Vis d'Arbois, 1859 (c'est le vis ${ }^{\circ} \mathrm{X}$ ). (Chauffé le 27 avril. - Bouteilles couchées.)}

Les avis sur la supériorité sont partagés. Le vin chauffè est légèrement moins nuancé que le vin non chauffé.

\section{XIX. - Vin de Montagne.}

(Chauffé dans les premiers jours de juin. - Bouteilles debout.)

Différence imperceptible pour le goût entre le vin chauffé et le vin non chauffé. Le vin chauffé a une teinte légèrement plus foncée. Limpidité parfaite dans les deux vins. Pas de dépôt sensible ni dans l'un ni dans l'autre.

$$
\text { XX. - Vin de Nuits, 1858, Ganay. }
$$

Le vin chauffé est supérieur. Il est beaucoup meilleur et a une teinte légèrement moins prononcée. 
XXI. - VIN dE COUPAGE.

(Chauffé en mai. - Bouteilles couchées.)

Le vin non chauffé est inférieur, quoique bien conservé.

Trois dégustateurs contre un préfèrent le vin chauffé.

Tous les vins chauffés dont il est question ci-dessus ont été portés à des températures qui, pour les diverses sortes de vins, ont varié de 50 à 70 ou $75^{\circ}$.

Le compte rendu des dégustations qui précèdent a démontré à la Commission que le procédé de M. Pasteur a pour résultat de maintenir limpide le vin qui s'y trouve soumis, et de lui conserver généralement son goût et sa couleur. Toutefois la Commission a remarqué que l'opération du chauffage produisait sur les vins communs provenant de mélanges un léger amaigrissement et un faible goût de cuit $\left(^{1}\right)$, qui se reproduit dans quelques vins de montagne.

En résulte-t-il que l'on puisse dire à la dégustation, sans que l'on fasse immédiatement la comparaison du vin chauffé avec celui qui ne l'a pas été, que le premier a été chauffé? Nous ne le croyons pas, parce qu'il n'y a qu'une nuance de goût imperceptible.

En résumé, et tout en réservant leur opinion sur l'influence que le temps pourra avoir sur les qualités relatives des vins qu'ils ont comparés, les membres de la Commission ont constaté que cette opération prévient surtout les maladies qui sont les causes de l'altération des vins, et qu'elle peut même les guérir. En ce qui concerne les différences de goût qui ont été remarquées dans les comparaisons des vins chauffés avec les mêmes vins qui ne l'avaient pas été, et qui étaient restés sains, il faut convenir qu'elles sont si faibles qu'elles échapperaient aux neuf dixièmes des consommateurs, que le temps pourrait peut-être les faire disparaître, qu'assurément l'imagination n'est pas sans avoir une très grande influence sur la dégustation, puisqu'ils s'y sont trompés eux-mêmes.

La Commission pense que, pour apprécier d'une manière définitive le système employé par M. Pasteur, il y aura lieu, ainsi qu'il en a exprimé le désir à la Commission, de procéder à la dégustation ultérieure des vins précédents, qui n'ont encore que quelques mois depuis l'époque du chauffage.

1. La Commission croit utile de faire remarquer que le mot cuit, dont elle s'est servi pour. exprimer le goût particulier qu'elle a signalé sur quelques vins chauffés, ne rend peut-être pas d'une façon bien précise l'idée qu'elle a voulu exprimer.

Il aurait peut-être mieux valu dire le goùt de chauffé, mais en excluant toutefois l'idée du goût de fumée ou de brûlé, qu'entraine avec lui le mot de chauffé. 
Nous ne saurions trop faire l'éloge du procédé de M. Pasteur. Il nous paraît pratique en ce qui concerne son application aux vins en bouteilles, car il est peu coûteux, et il le serait d'autant moins qu'il s'appliquerait à de plus grandes quantités.

Les membres de la Sous-Commission,

\author{
Signé Teissonnière, \\ Célerier, \\ Brazier, \\ Cherrier, \\ Delaleu.
}

Observations aU sujet du rapport précédent.

Il me reste à compléter ce rapport par des observations sur la nature des vins qui ont été examinés par la Commission et sur la véritable signification des jugements qu'elle a formulés.

Je ferai remarquer, en premier lieu, que j'ai soumis à la Commission tous les vins que j'avais mis à l'épreuve, au moins tous ceux dont il me restait des échantillons, sans distinction des conditions plus ou moins favorables de la pratique de l'opération. Ainsi, à l'origine, je chauffais le vin jusqu'à $75^{\circ}$. Peu à peu j'ai diminué la température en m'assurant, par exemple, que l'on pouvait nême descendre à 50 ou $55^{\circ}$, et peut-être un peu au-dessous de $50^{\circ}$. Or, il n'est pas douteux que, si la température de 50 à $55^{\circ}$ est suffisante pour tuer les germes des parasites, elle sera moins capable d'altérer le vin, son bouquet, sa couleur, etc..... qu'une température de 70 à $75^{\circ}$. D'ailleurs la question d'économie conseille l'emploi de la température la plus basse possible (1).

1. Les lignes qui précèdent étaient écrites lorsque j'ai lu, dans les Comptes rendus de l'Académie des sciences (séance du 12 mars 1866) [LXII, p. 596-602 : Conservation des vins par l'emploi de la chaleur], une Note de M. de Vergnette-Lamotte, dont la partialité et les erreurs m'ont surpris. Je ne relèverai qu'un détail. Il est dit dans cette Note que, depuis le $1^{\text {er }}$ mai 1865 , je me suis rapproché du procédé proposé par cet œnologue pour améliorer les vins, parce que, après avoir chauffẻ le vin à $70^{\circ}$ et $75^{\circ}$, j'ai cherché si une température de $60^{\circ}$, de $55^{\circ}$, et même inférieure, pourrait être assez élevée pour tuer les germes des parasites du vin. Je rappellerai que ce procédé de M. de Vergnette, du 1 $1^{\text {er }}$ mai 1865 , est ainsi résumé par lui, Comptes rendus de l'Académie des sciences, LX, 1865, p. 898 [Des effets de la chaleur pour la conservation et l'amélioration des vins] :

"On mettra les vins en bouteilles au mois de juillet, en ne choisissant jamais que des vins âgés de deux ans au moins, les fûts qui les contenaient étant jusqu'à ce moment restés dans la cave.

" Après le tirage, les bouteilles seront transportées et empilées au grenier. Elles y resteront deux mois, et les vins seront ensuite descendus en cave pour y être conservés, comme de coutume, jusqu'à ce qu'on les livre à la consommation. ”

Quoi de plus naturellement indiqué, que de rechercher si une température de $60^{\circ}$, de $55^{\circ}$, 
A l'origine également j'ai fait chauffer des vins pris sans précaution dans une cave quelconque, et je m'inquiétais peu du remplissage plus ou moins parfait des bouteilles. Mais j'ai reconnu qu'il est préférable d'opérer sur des bouteilles pleines ou presque pleines. Si donc je n'avais soumis à la Commission que des vins traités, si je puis m'exprimer ainsi, dans les conditions du procédé définitif, son jugement aurait pu être encore plus favorable.

Tel qu'il est, ce jugement est très satisfaisant.

En effet, $1^{\circ}$ dans aucun cas le vin chauffé n'est devenu malade et n'a offert le moindre dépôt de mauvaise nature;

$2^{\circ}$ En laissant de côté le vin I, qui était un vin en vidange (et sur lequel je reviendrai), le rapport constate que, sur les vingt sortes de vins restants, dix sortes parmi les non chauffés ont commencé à s'altérer, dont cinq sortes en vins communs et cinq en vins des grands crus de Bourgogne. Ces dix sortes où les échantillons non chauffés sont altérés sont comprises sous les chiffres I, IV, V, VII, XI, XII, $\mathrm{XIII}, \mathrm{XV}, \mathrm{XVII}, \mathrm{XX}$.

$3^{\circ}$ Pour les dix sortes restantes le rapport de la Commission est fort curieux et très instructif si on le rapproche des remarques dont je vais l'accompagner.

Je ferai d'abord observer que, pour les vins III, VI, VIII, IX, X, $\mathrm{XIV}$, les membres de la Commission ont donné la préférence aux échantillons non chauffés. Mais je m'empresse de dire que l'on se tromperait singulièrement si l'on pensait que la différence constatée entre les couples d'échantillons de ces six sortes de vins est de même ordre que celle des neuf sortes dont j'ai parlé antérieurement. Pour ces neuf sortes de vins dans lesquelles il y a une altération du vin non chauffé, la différence de qualité est considérable entre les échantillons chauffés et ceux qui ne l'ont pas été. Quelquefois même le vin non chauffé était si malade qu'on avait de la répugnance à le boire, et, dans tous les cas, après agitation de la bouteille, c'est-à-dire lorsqu'on avait

et mème inférieure, suffirait pour tuer les germes des parasites du vin, après que j'avais constaté que la température de $70^{\circ}$ avait cette vertu? Il n'y a pas de rapport entre ces expériences et celles qui consistent á porter le vin de Bourgogne au grenier pendant deux mois, en juillet et en aont. Je pense me̊me que ce dernier procédé serait très propre à rendre malarle le vin de Bourgogne. J'ai la conviction que des bouteilles empilées dans un grenier en Bourgogne ne prennent jamais une température supérieure à 30 et quelques degrés. M. de Vergnette a mal imité, selon moi, une pratique de plusieurs départements du Midi, où quelques personnes exposent le vin au grenier pendant un mois ou deux; mais c'est sur les tuiles qu'elles le placent, et non dans le grenier.

M. de Vergnette était plus dans le vrai lorsqu'il signalait sa Note du $1^{\circ \circ}$ mai $1865\left({ }^{\circ}\right)$ comme inspirée par les résultats de mes recherches sur les maladies des vins.

* Vergnetre-Lamotre (A. de). Des effots de la chaleur pour la conservation et l'amélioration du vin. Comptes rendus de l'Académie des sciences, séance du 1or mai 1865, LX, 895-899. (Note de l'B́dition.) 
disséminé le dépôt flottant dans toute la masse, le vin était très sensiblement trouble. Au contraire, la différence des échantillons dans les six sortes dont je viens de parler était si faible, qu'en ce qui me concerne il m'était impossible de l'apprécier, et que beaucoup de personnes donnaient la préférence aux échantillons chauffés, contrairement à l'avis des membres de la Commission. D'ailleurs il faut prendre l'expression des différences constatées dans le rapport dans le résumé général qui le termine.

" En résulte-t-il, lit-on dans le rapport, que l'on puisse dire à la dégustation, sans que l'on fasse inmmédiatement la comparaison du vin chauffé avec celui qui ne l'a pas été, que le premier a été chauffé? Nous ne le croyons pas, parce qu'il n'y a qu'une nuance de goût imperceptible. »

Et plus loin :

" En ce qui concerne les différences de goût qui ont été remarquées dans les comparaisons des vins chauffés avec les mêmes vins qui ne l'araient pas été et qui étaient restés sains, il faut convenir qu'elles sont si faibles qu'elles échapperaient aux neuf dixièmes des consommateurs, que le temps pourrait peut-être les faire disparaître, qu'assurément l'imagination n'est pas sans avoir une très grande influence sur la dégustation, puisqu'ils (les membres de la Commission) s'y sont trompés eux-mêmes. »

Mais voici une circonstance bien plus démonstrative de cette influence de l'imagination sur la dégustation. J'ai dit en commençant que la Commission avait procédé à la dégustation des vins que je lui ai soumis, les jeudis 16 et 23 novembre 1865 .

Or, habitué que j'étais à faire déguster les échantillons des vins chauffés et non chauffés par des personnes du monde, et à recueillir des indications presque toujours plus favorables au vin chauffé qu'au vin non chauffé, je fus surpris de voir que les membres de la Commission avaient donné plusieurs fois, dans leur première réunion, une préférence au vin non chauffé, dans les cas, bien entendu, où le vin non chauffé ne s'était pas altéré du tout, et avait vieilli à la manière des vins qui vieillissent en s'améliorant progressivement. Dès lors, je pensai qu'il avait pu exister a priori dans l'esprit du plus grand nombre des membres de la Commission une certaine prévention contre l'opération du chauffage, prévention de laquelle serait résultée la préférence dont je parle le jour de leur première réunion.

Je proposai donc à la Commission, au commencement de sa deuxième séance du 23 novembre, de vouloir bien me permettre de ne plus lui indiquer par avance, comme je l'avais fait dans la première 
Héance, la nature des deux échantillons placés en même temps entre les mains de chacun de ses membres.

La Commission, qui n'avait comme moi que le désir de connaître la rérité, s'empressa de se ranger à cet avis. Or, nous voyons par les termes dı lapport que, dans la seconde séance, dans tous les cas où les vins non chauffés ne se sont pas altérés, il y a eu incertitude chez les membres de la Commission sur la préférence à donner aux vins chauffés ou non chauffés. Les avis ont été partagés pour les vins XVI, XVIII, XIX et XXI.

Iais il y a plus. Il est à remarquer que le vin XVIII était précijément le vin $\mathrm{X}$ de la première séance. Or, dans cette première séance, la Commission avait jugé le non chauffé supérieur. Enfin je dois dire fue c'est ce même vin d'Arbois qui avait été dégusté le 26 octobre par IIM. Hemmet et Teissonnière, et pour lequel la préférence avait été lonnée au contraire, ce jour-là, à l'échantillon chauffé.

Enfin, voulant m'assurer par une épreuve péremptoire de l'influence te l'imagination sur la constatation de ces nuances de goût dont nous arlons entre des vins de qualités presque identiques, j'ai usé, à l'égard Ie la Commission, d'une petite supercherie qu'elle a bien voulu me ardonner, et à laquelle elle a pris soin elle-mème de faire allusion lans son rapport.

La Commission venait d'être habituée à constater des différences, jetites ou grandes, entre les deux échantillons que j'offrais simultahément à chacun de ses membres. Il était dès lors facile de prévoir fue si, à son insu, je la priais de déguster comparativement deux ichantillons tout à fait identiques, mais qu'elle croirait différents, arce qu'elle ne serait pas avertie et qu'elle venait de prendre l'habiude de juger toujours des choses distinctes, elle se laisserait aller par rreur d'imagination à croire encore à des différences réelles.

En conséquence, sans avoir rien dit ni rien fait qui pût éveiller des ;oupçons, je remis entre les mains de chacun des membres de la Commission, dans des verres séparés, le même vin, sortant immédiaement de la méme bouteille. Or, chacun des membres accusa une diffé-ence entre les deux échantillons soumis à son appréciation. Et néannoins, je puis assurer que tous les membres de la Commission avaient ine sûreté d'appréciation que l'on a peine à admettre lorsqu'on n'en a ras soi-même constaté les effets. J'en juge par l'impossibilité où j'étais l'apprécier des différences que je savais devoir être réelles, et sur esquelles tous les membres de la Commission n'hésitaient pas à se rrononcer dans le même seus, alors même que chacun d'eux était tenu le consigner son opinion par écrit, et que le jugement était donné en fuelque sorte au scrutin secret. 
Le vin $n^{\circ}$ I du rapport mérite une mention spéciale. Il s'agit d'ur vin rouge très ordinaire, d'un de ces vins appelés vins de coupage du commerce de vins en détail dans Paris.

Le 3 juin 1865, j'ai mis en vidange des bouteilles de ce vin et d'autres vins analogues, les uns non chauffés et les autres qui avaient été chauffés préalablement de 50 à $55^{\circ}$, et plusieurs même un peu au-dessous de $50^{\circ}$. La vidange était à moitié de la bouteille. Or, le 16 novembre 1865, j'ai pu soumettre à la Commission une série de couples de bouteilles dont les chauffées n'offraient pas la moindre altération. Bien entendu, le vin de toutes les autres bouteilles qui n'avaient pas été chauffées était couvert de fleurs, généralement en couche épaisse, parce que les vins communs donnent naissance de préférence au mycoderma vini. Le vin y était, pour ainsi dire, non potable et décomposé. Au contraire, comme le constate le rapport, les échantillons qui avaient été chauffés et qui s'étaient conservés n'avaient pas de fleurs, n'étaient pas aigres, étaient très limpides, d'une belle couleur brique, et avaient un goût de rancio très appréciable. La matière colorante; devenue insoluble par l'oxygène de l'air, s'était déposée sur les parois en couche adhérente, que l'on pouvait détacher en larges feuillets de couleur brune plus ou moins foncée, absolument comme il arrive pour les vins en bouteilles très âgés et bien conservés. Il aurait peut-être fallu quinze et vingt années d'âge à ce même vin pour prendre en bouteille l'état de vin vieux qu'il avait contracté ici dans l'intervalle de cinq à six mois. Ainsi le vin qui a été porté à la température de 50 à $60^{\circ}$ est devenu si robuste, qu'il se montre le plus souvent inaltérable, bien qu'il soit mis en vidange. J'ai multiplié à l'infini ce genre d'expériences. Je n'en rapporte point les résultats, parce qu'ils sont absolument du même ordre que celui que je viens de rappeler avec l'autorité que lui donne d'ailleurs le rapport des membres de la Commission du commerce des vins dans Paris.

Si l'on veut se rendre compte des diverses circonstances que présentent les expériences dont je parle, il faut se reporter à celles que j'ai faites pour montrer l'inanité des observations invoquées à l'appui de la doctrine des générations spontanées. Les germes des végétations propres à l'infusion organique acide qui constitue le vin étant détruits par la chaleur, le vin exposé à un volume limité d'air, comme il arrive lorsqu'on met en vidange une bouteille de vin, ne peut plus s'altérer que par la propagation des germes tenús en suspension dans ce volume d'air, et si ce volume d'air n'en contient pas de la nature de ceux qui peuvent se développer dans le vin, ce liquide restera absolument intact 
ot soumis seulement à l'action chimique directe de l'oxygène de l'air. C'est précisément ce qui arrive, et, neuf fois sur dix au moins, le vin qui a été chauffé, mis ensuite en vidange, n'éprouve pas la moindre acidification, alors même qu'on l'expose pendant des mois entiers dans une étuve de 30 à $35^{\circ}$.

La nature de ce genre d'expériences et l'intérêt qu'elles présentent dans l'étude du vin n'échapperont à personne. On n'avait pas eu encore l'occasion de voir du vin exposé au contact de l'air pendant un temps très long sans qu'il éprouvât d'altération. Les expériences dont je viens de parler réalisent ces conditions toutes particulières, et elles sont très instructives, parce qu'elles nous apprennent que le vin vieillit alors outre mesure en très peu de temps, et qu'il prend, autant que sa composition le lui permet, les qualités des vins estimés du midi de la France et de l'Espagne. J'espère que la connaissance de ce fait deviendra la source d applications utiles.

Il me reste à faire connaître la nature des dépòts qui se sont formés dans les vins dont il est question dans le rapport de la Commission.

La figure 35 représente le dépôt adhẻrent de l'échantillon de vin chauffé $\mathrm{n}^{\circ} \mathrm{I}$, conservé en vidange sans autre modification que celle qu'a déterminée l'oxygène de l'air. On voit que ce dépòt est en feuillets translucides ou en mamelons plus ou moins régulièrement sphériques, mamelons isolés ou réunis sur les feuillets, comme il arrive lorsque le vin dépose et vieillit sans éprouver d'altération.

La figure 37 représente le dépôt du vin $\mathrm{n}^{\circ} \mathrm{V}$, non chauffé. (Vin du Cher.) Ce vin avait été mis en bouteilles le 10 juin 1865. Le 11 juin, moitié avait été chauffée. Toutes les bouteilles chauffées s'étaient bien conservées, et n'avaient pas donné le moindre dépôt, tandis que toutes celles qui n'avaient pas été chauffées offraient, le 16 novembre, un dépòt considérable de $0^{\mathrm{m}}, 01$ de hauteur environ, dépót flottant et presque entièrement organisé, comme l'indique la figure. Ce dépòt était formé de filaments de deux diamètres, tous très longs, ressemblant à des paquets de filasse. Il paraissait muqueux, se tirait en fils gluants du fond de la bouteille, effet que l'on remarque assez souvent dans les dépóts des vins tournés, parce que tous les fils sont enchevêtrés les uns dans les autres et forment des amas qui se tiennent. Les gros filaments étaient-ils le parasite de la maladie de l'amer? Je l'ignore.

Le dépòt du vin de Chinon, $\mathrm{n}^{\circ} \mathrm{IV}$, était pareil à celui-ci.

La figure 38 représente le dépôt d'une des bouteilles non chauffées du vin de Pomard, Marey-Monge, de 1863, n XI. Ce vin m'a été envoyé à 
la fin de juillet de 1865. Il avait été mis en bouteilles à Pomard, dans le. caves de M. Marey-Monge, et était, à son arrivée à Paris, d'une limpidité parfaite. Il y en avait 200 bouteilles. Cent ont été chauffées, les cent autres ont été laissées telles qu'elles avaient été expédiées de Pomard. Peu à peu un dépòt flottant s'est développé dans toutes les bouteilles non chauffées. Présentement (janvier 1866) il n'en est pas une seule qui ne renferme plus de 50 à 60 centimètres cubes d'un tel dépôt, et le vin est sensiblement altéré. Or, il n'y a pas une seule des bouteilles chauffées qui montre le moindre dépòt flottant, et le vin me paraît être meilleur qu'au monınt oủ je l'ai reçu. Il a donc vieilli dans de bonnes conditions depuis cinq ou six mois, ainsi que le constate d'ailleurs le rapport même des experts.

Parmi les bouteilles chauffées et non chauffées, plusieurs des deux sortes ont été laissées debout et bien bouchées. Dans l'intervalle de quelques semaines, le mycoderma aceti, sans mélange de mycoderma vini, s'était montré à la surface du vin dans le goulot de toutes les bouteilles non chauffées, de telle sorte que le vin de ces bouteilles a éprouvé deux maladies simultanément, celle de l'acescence et celle de l'amertume. Aussi les experts ont-ils trouvé que ce vin des bouteilles debout non chauffées était décomposé.

Il faut remarquer ici que le ferment de l'amer s'est multiplié, dans ces bouteilles debout, avec la même facilité que dans les bouteilles couchées. Or, il est évident, si l'on se reporte aux résultats des expériences de mon Mémoire sur la fermentation acétique, que tout l'oxygène qui pénétrait dans les bouteilles à travers les pores des bouchons et qui venait alimenter le mycoderma aceti était absorbé par ce parasite, et que le ferment de l'amer, développé au fond de la bouteille, a vécu absolument à l'abri du contact du gaz oxygène. Ceci confirme, et par une preuve sans réplique, ce que j'ai dit sur la vie de quelques-uns des parasites du vin. Aussi me trompai-je, lorsqu'à l'origine de mes recherches sur les moyens de prévenir les maladies des vins, j'eus l'idée de recourir à l'emploi de substances avides d'oxygène pour m'opposer au développement des germes de ces parasites. Je suis très porté à croire que l'acide sulfureux agit de deux manières sur le développement des êtres inférieurs, non seulement comme substance désoxydante, mais aussi comme substance antiseptique odorante. Je ne vois pas bien à quoi correspond chimiquement et physiologiquement pour la vie d'un être inférieur la qualité de substance odorante; mais il est certain qu'il y a très souvent dans le fait d'avoir de l'odeur une vertu antiseptique propre. En d'autres termes, si l'acide sulfureux, sans rien perdre de son affinité pour l'oxygène, était privé tout à coup 
de volatilité, je crois qu'il n'aurait plus, à beaucoup près, les mêmes qualités antiseptiques (1).

Je ferai remarquer en terminant, pour ce qui concerne la figure 38 , que le dépôt de la bouteille qui a servi à faire le dessin de cette figure n'était pas formé par le parasite de l'amer tout à fait pur. Il était associé à un autre ferment en petits grains sphériques, sur la nature duquel je ne pourrais me prononcer. Les quelques autres bouteilles dont j'ai examiné les dépòts au microscope ne m'ont paru offrir que le ferment de l'amertume.

La figure 18 représente le dépòt du vin $11^{\circ} \mathrm{XII}$, vin de Pomard, 1848, Marey-Monge. Il en a été déjà question ailleur's. Je n'y reviendrai pas.

La figure 39 représente le dépôt du vin non chauffé $\mathrm{n}^{\circ}$ XVII, vin de Nuits, $1^{\text {ro }}$ cuvée de 1861 . Ce vin a été mis généreusement à ma disposition par M. le maire de Nuits. Il était accompagné de la note suivante, à la date du 17 mai 1865 : "Ce vin est bon et d'un premier cru, mais d'une année qui ne présente pas grande chance de conservation. " On voit en effet que, du mois de mai au mois de novembre 1865 , c'est-à-dire dans l'intervalle de six mois seulement, un dépôt notable s'est formé dans les bouteilles non chauffées, avec tendance prononcée à l'amertume, tandis que le mème vin qui a été chauffé s'est très bien conservé, et se trouve aujourd'hui très supérieur au non chauffé, et sans dépòt flottant.

En présence de tant de résultats si probants et que je pourrais multiplier, je ne doute pas que tous les propriétaires des grands crus de la Bourgogne n'adoptent le procédé de conservation que je propose, procédé si facile à appliquer et si peu dispendieux.

Tous les négociants qui font le commerce du vin au litre dans les grandes villes ne devraient pas être moins empressés.

Je regrette de n'avoir pas eu l'occasion d'opérer plus souvent sur les vins de Bordeaux. Mes relations avec ce centre de production ont été fort restreintes. Cependant je puis assurer, par quatre ou cinq essais sur des vins de divers âges et qualités, que le résultat est tout aussi favorable que sur les vins de l'est et du midi de la France. J'espère d'ailleurs que les essais tentés en ce moment par divers producteurs de ce pays, sur les indications qu'ils m'ont demandées, suppléeront bientòt à l'insuffisance de mes propres recherches.

1. M. Victor Jodin [Études sur quelques propriétés de l'acide formique. Comptes rendus de l'Académie des sciences, LXI, 1865, p. 1179-1181] a communiqué récemment à l'Académie des expériences intéressantes sur l'acide formique, desquelles il résulterait que cet acide ne peut servir d'aliment carboné aux moisissures. Je suis porté à croire que cet acide est un antiseptique, non par nature, mais parce qu'il est odorant. Je donne cette appréciation pour faire mieux comprendre ma pensée au sujet des propriétés de l'acide sulfureux. 
L'effet du procédé, en ce qui concerne les vins du Midi, peut être apprécié par les faits que le rapport constate au sujet des vins de montagne, de coupage, etc. J'ai d'ailleurs obtenu de très bons résultats en opérant sur des vins du Midi purs, non mélangés à d'autres vins (1).

Chaque année les preuves à l'appui de la théorie que je soutiens se sont multipliées: il est superflu de dire que le nombre des appareils pour le chauffage industriel du vin augmente tous les jours, et que des milliers d'expériences faites en grand sont venues attester la justesse de mes vues.

Parmi les nombreux exemples que je pourrais citer, j'en choisirai quelques-uns qui empruntent à l'autorité des personnes qui les ont fournis une valeur toute spéciale.

En 1868, M. de Lapparent, directeur des constructions navales, a adressé au ministre de la marine un rapport sur les travaux d'une Cómmission chargée d'apprécier mon procédé de chauffage au point de vue pratique ${ }^{(2)}$.

Je cite textuellement :

“ Première question: Les procédés de chauffage préconisés par M. Pasteur, pour prévenir les maladies des vins, paraissent-ils décidément assez efficaces pour qu'il convienne d'en conseiller, dès maintenant, l'application aux vins de campagne, destinés soit aux bâtiments de la flotte, soit aux colonies?

“ Cette question a été résolue à l'unanimité, dans le sens de l'affirmative, et voici les faits qui ont servi à former l'opinion de la Commission :

" $1^{\circ}[$ Ce sont] toutes les expériences faites sur les vins en bouteilles par M. Pasteur et rapportées dans le grand ouvrage qu'il a publié sous le titre d'Études sur le vin. La Commission a pu véritier, chez M. Pasteur lui-même, la parfaite exactitude de quelques-unes de ces expériences. Ainsi, en 1863, un riche et savant viticulteur de la Côte-d'Or, M. Marey-Monge, avait adressé un certain nombre de bouteilles à M. Pasteur, celui-ci en chauffa la moitié, laissant l'autre moitié à l'état naturel. Une bouteille de chaque tas a été soumise, en mars dernier, à la Commission, qui a trouvé le vin chauffé parfaitement conservé, tandis que le non chauffé avait un goût très prononcé d'amertume, qui est la maladie spéciale aux grands vins de Bourgogne. En plaçant une goutte de ce vin sous l'objectif du microscope, M. Pasteur fit voir à la Commission le parasite particulier à l'amertume, tel qu'il est décrit dans les planches de son ouvrage. La Commission remarqua, en outre, dans le laboratoire de M. Pasteur, une bouteille debout, vide aux deux tiers, close simplement par un bouchon de liège, et dont l'étiquette

1. Le texte qui suit jusqu'au chapitre intitulé "Manière de conduire les expériences" (p. 261) ne figure pas dans la 1re édition des "Études sur le vin ".

2. Lapparent. Rapport [á S. Exc. le ministre de la marine et des colonies] sur la conservation des viris. Revue maritime et coloniale, XXIV, 1868, p. 124-133, et Paris, 1868, brochure de 11 p. in-12. (Notes de l'Édition.) 
MALADIE DES VINS TOURNE'S, MONTÉS, ETC.

VIN DU CheK.

Fig. 37

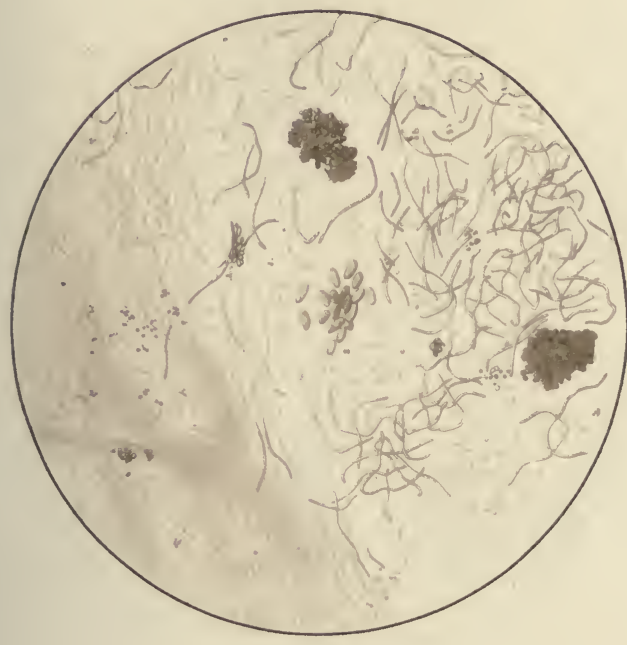

PLackerbauer ad nat. del.

Imp bieny Binus Ruris

$\frac{400}{7}$ 

MALADIE IDE L'AMERTUME

Vin dF. Nuits, 1" cuvee, 1861.

Fig̉. 39

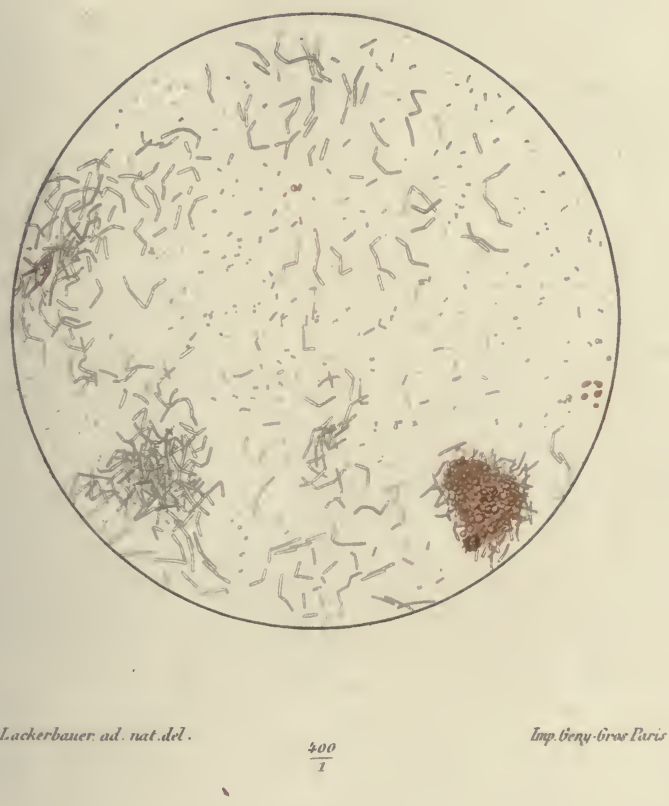



annonçait qu'on avait commencé à la mettre en vidange le 3 juin 1865. Le vin, très ordinaire, puisqu'il n'avait coùté que $0 \mathrm{fr}$. 45 le litre, avait pris la couleur particulière aux vins vieux, mais ne manifestait, à la dégustation, aucun caractère d'acidité ou d'amertume. Dans les mêmes circonstances, uII pareil vin, non chauffé, aurait passé à l'aigre en quelques jours.

“ $2^{\circ}$ Les procédés de M. Pasteur, dont celui-ci n'avait fait usage que pour les vins en bouteilles, sont depuis bientot deux années appliqués en grand, par des négociants intelligents, sur divers points de la France, notamment à Orléans, Béziers et Narbonne. Dans la première de ces villes, la Commission a pu, grâce à la parfaite obligeance de M. Rossignol, voir fonctionner l'appareil imaginé par cet habile négociant, et avec lequel il a déjà chauffé 3.000 hectolitres de vin environ. Cet appareil consiste en une barrique de 6 hectolitres, dont un fond a été enlevé et remplacé par une chaudière en cuivre étamé, terminée par un long tube. Le fond de la chaudière, pleine d'eau, est placé sur un fourneau, et c'est l'eau qui transmet sa chaleur au vin qui remplit le tonneau. Quand le thermomètre indique la température voulue, on cesse le feu et on vide le vin chauffé dans la barrique où il doit être conservé. Interrogé sur la valeur du procédé, M. Rossignol a répondu que tout ce qu'il pouvait dire, c'est que, depuis qu'il expédiait des vins soumis au chauffage à ses clients, il n'avait pas reçu d'eux le moindre reproche, tandis qu'antérieurement les plaintes étaient assez fréquentes.

“A Béziers, le chauffage du vin s'exécute sur une grande échelle, chez plusieurs propriétaires ou négociants, à l'aide du puissant et ingénieux appareil inventé par MM. Giret et Vinas. Cet appareil comprend deux organes, l'un appelé le caléfacteur, l'autre le réfrigérant. Le vin, préalablement élevé à une hauteur convenable, à l'aide d'une pompe aspirante et foulante, pénètre dans le réfrigérant, à sa base, s'élève jusqu'au sommet et passe de là dans le caléfacteur, où il est chauffé au bain-marie; ensuite il retourne à la partic supérieure du réfrigérant et, en descendant, communique une partie de sa chaleur au vin froid qui monte et dont il n'est séparé que par une mince paroi. L'un des inventeurs, M. Giret, a fait goûter aux membres en mission du vin de sa dernière récolte, qu'il avait fait chauffer, parce qu'il menaçait de tourner à l'aigre. Ce vin est encore très potable. Il y a plus, la petite perte qui se fait toujours, lorsqu'on remplit une bouteille au robinet, est recueillie dans une baille placée au-dessous de ce robinet. Lorsque la Sous-Commission s'est présentée dans les chais de M. Giret, le vin contenu dans cette baille représentait la perte d'une semaine. A la dégustation, ce vin a paru, naturellement, plus plat que celui du foudre, mais sans aucune saveur acide. M. Giret déclara que, s'il n'avait pas été chauffé, il aurait passẻ au vinaigre en moins de vingt-quatre heures. Enfin, un négociant de Béziers a eu l'heureuse idée d'acheter tous les vins qui avaient un commencement de maladie, de couper, pour ainsi dire, celle-ci par le chauffage et de mêler ce vin chauffé avec une certaine quantité de bon vin. On dit qu'il produit, de cette manière, une boisson très recherchée, et sur laquelle il réalise de fort beaux bénéfices.

"Ces faits confirment ceux qui ont été observés dans quelques-uns de nos ports militaires, Brest et Rochefort, en particulier, et qui méritent d'être signalés. 
“ A Brest, une Commission spéciale divisa en deux parties une barrique de 500 litres, dont une moitié seulement fut chauffée à une température de $63^{\circ}$. Puis, les deux vins, ayant été introduits dans des barriques bien conditionnées et scellées, furent placés sur le vaisseau le Jean-Bart, et firent la campagne de 1866, qui dura dix mois. Au retour du bâtiment, la Commission, après avoir reconnu l'état parfait de conservation extérieure des deux barriques, constata :

" $1^{\circ}$ Que le vin chauffé était limpide, doux, moelleux, avec cette jolie couleur de rancio particulière aux vins vieux; qu'en un mot il était parfaitement en état d'être délivré de nouveau comme vin de campagne;

“ $2^{\circ}$ Que le vin non chauffé était également limpide, mais plus couvert, avec une saveur astringente passant à l'acide; que ce vin était encore buvable, mais qu'il convenait de le consommer de suite, si on voulait éviter qu'il ne se perdit entièrement.

"L'expérience faite à Rochefort est encore plus curieuse et plus concluante : on introduisit les deux vins, chauffé et non chauffé, chacun dans un flacon d'une capacité de 10 litres et qui fut rempli à moitié. Chaque flacon fut clos par un bouchon de liège traversé par un tube en verre à deux boules, qui mettait l'intérieur du flacon en communication avec l'air extérieur, tout en évitant l'introduction des poussières. Le flacon contenant le vin chauffé fut enfin placé dans la vinaigrerie de Rochefort, où il séjourna pendant quatorze jours. A l'issue de cet intervalle, la Commission ayant constaté que le vin n'avait éprouvé aucune altération, on plaça, à côté du premier, le flacon de vin non chauffé et on laissa s'écouler encore une semaine. Au bout de ce temps, on reconnut que le vin non chauffé avait déjà contracté une saveur acide très prononcée, tandis que le vin chauffé était toujours inaltéré!

"Enfin, la Commission a fait elle-même une expérience sur le vin chauffé devant elle, à Orléans. On retira de deux bouteilles, contenant l'une du vin chauffé, l'autre du mème vin non chauffé, la valeur de deux verres, et on replaça les bouchons. Au bout de trois jours, un voile très sensible s'était formé sur le vin non chauffé. On constata au microscope que ce voile n'était encore formé que de fleurs de vin (mycoderma vini), mais qui ne tardèrent pas à dégénèrer en fleurs de vinaigre (mycoderma aceti). Aujourd'hui, ce vin est devenu imbuvable, tandis que le vin chauffé, quoique ayant perdu quelque chose de sa force et de ses qualités, à cause de son contact prolongé avec l'air, n'accuse aucune trace d'acidité et est encore très potable.

“De tout ce qui précède, il résulte évidemment qu'il y a un avantage considérable à chauffer les vins qui doivent voyager et aller dans des parages où l'élévation de la température, I'absence de magasins convenables et le défaut de soins les exposent à des altérations qui les privent, pour le moins, de ces qualités hygiéniques et fortifiantes qu'on doit attendre de cette excellente boisson. 》

Chaque année depuis cette époque, M. de Lapparent a fait chauffer ses vins à l'aide de son petit appareil (roir plus loin [p. 294-295] l'article 
des appareils à chauffage), et aujourd'hui il se déclare complétement satisfait des résultats qu'il obtient.

Mais il affirme que les vins de la marine chauffés à Toulon, en 1868, et expédiés aux colonies, tout en se maintenant à l'abri des maladies, ont contracté un goût « douceâtre et comme pharmaceutique qui déplaît aux équipages ".

Ce vin était du vin très commun, fait de mélanges divers, fortement viné; aussi M. de Lapparent n'hésite pas à regarder cette particularité comnie l'effet propre du vinage, car, dit-il, “j'ai envoyé des vins non vinés en Cochinchine, qui sont revenus excellents ».

S'il en était ainsi, la pratique du chaufrage ne s'appliquerait qu'imparfaitement aux vins alcoolisés par le vinage; toutefois il faut remarquer qu'une seule expérience est insuffisante pour conclure, et que l'appareil à chauffage qui servit aux expériences de Toulon ne remplissait que très imparfaitement les conditions qu'on doit attendre d'une opération bien faite, comme on le verra dans la description de cet appareil (voir l'article des appareils à chauffage). M. de Lapparent était lui-même convaincu de ces inconvénients; mais la nécessité d'opérer immédiatement sur un nombre considérable d'hectolitres (50 par heure environ) ne permit pas de recourir à un appareil plus satisfaisant; c'est donc à l'expérience à prononcer sur ce point.

M. Maurial, rédacteur d'articles scientifiques dans le Moniteur vinicole, très compétent en matière de dégustation de vins, avait tout d'abord combattu mon procédé; je l'ai invité, le 9 juillet 1869, à venir apprécier les résultats de mes expériences, et voici en quels termes il décrit ses impressions ( $\left.{ }^{1}\right)$ :

“M. Pasteur m'a conduit dans un sous-sol de l'Ecole Normale, où se trouvent rangés les vins expérimentés et leurs pareils non chauffés; nous avons choisi, d'après les indications recueillies aux légendes écrites sur diverses tablettes accrochées aux murs ou aux casiers, plusieurs sortes de vins qu'on a apportés dans la salle à manger, où devait avoir lieu la dégustation.

"Nous avons commencé par un vin de Pomard de 1863, récolté par M. Marey-Monge. Il avait été chauffé le 18 juillet 1865, ayant déjà déposé. Le vin chauffé présente une couleur relativement belle et brillante; son goût laisse à désirer, mais il est buvable. Le même vin non chauffé est amer, de couleur livide; c'est un vin perdu.

" Lc deuxième vin est du vougeot-Echézeaux antérieur à 1863, sans date plus précise; il a été chauffé en 1867. Le vin non chauffé a une légère pointe d'acidité, un goût prononcé d'amertume, sa couleur est un peu terne.

1. Voir le Moniteur vinicole du 17 juillet 1869 . 
Le vin chauffé a une couleur splendide, un bouquet délicieux et très prononcé; c'est bien du vrai rubis et quel moelleux!

“ La troisième dégustation a porté sur les vins de Volnay 1863 et 1864, récoltés par M. X... Le premier est très remarquable de finesse, de bouquet; c'est bien le délicieux grand cru de la Bourgogne. Le second a un peu plus de corps, une nuance en moins de finesse. Le vin chauffé l'emporte, quoique de bien peu, sur le vin non chauffé, par la perfection des qualités, mais surtout poứr la franchise et l'intensité de la couleur.

“ Ici se présente un incident qu'il est très utile de noter. M. Pasteur m'avait dit, avant de goùter le volnay 1863, qu'il ne faisait pas de différence entre le vin chauffé et celui qui ne l'avait pas été. Ayant goûté et comparé, j'ai remarqué que le vin chauffé avait une couleur plus vive, plus foncée, et qu'il était plus moelleux. M. Pasteur a été de cet avis après dégustation.

“ Mais le côté intéressant de cette contradiction apparente des deux appréciations de l'honorable savant, c'est qu'il n'avait pas comparé ces deux bouteilles du même vin depuis un an, et qu'il est évident que le vin chauffé a conservé toutes ses riches propriétés, tandis que son semblable, non chauffé, en avait perdu quelques-unes. Je crois avoir remarqué, au reste, que l'éminent maitre a trouvé des démarcations sur tous les vins goutés plus accentuées à cette dernière dégustation qu'à celle qui l'a précédée.

“ Un autre vin de Pomard 1861, de M. Marey-Monge, arrivé avec un dépôt très marqué, a été chauffé en janvier 1867. L'échantillon qui a été chauffé ne s'est pas bien rétabli sous le rapport du goût; mais il a conservé une bonne et limpide couleur. Le pareil non chanffé a une couleur terne et un goût aigrelet.

" Un vin de gamay, de la Côte-d'Or, de 1858, chauffé en juillet 1865, a conservé toutes ses qualités; corsé et de franc goût. Ce vin non chauffé est très âcre et un peu terne.

“ Voilà tous les vins de Bourgogne que nous avons appréciés. Je n'hésite pas à déclarer que l'expérience me semble héroïquement concluante en faveur du chauffage. Ce que je redoutais le plus dans les effets de cette pratique, c'était l'altération des principes vitaux, garantie de la perfectibilité dans les vins. Je craignais que ce précieux liquide fùt réduit à l'état de monie, et qu'il n'arrivât guère au delà de l'état dans lequel l'opération du chauffage le laissait.

"Pleinement rassuré aujourd'hui à cet égard, je suis convaincu qu'appliqué comme moyen préventif, le chauffage des vins peut rendre les plus grands services à la Bourgogne. C'est dans ce procédé que les Bourguignons trouveront la solidité nécessaire à leurs excellents vins pour leur transport dans tous les pays étrangers. Les effets généraux les plus tranchés que le chauffage opère sur les vins que je viens d'énumérer sont l'intensité de la couleur, la limpidité, le brillant, le moelleux et la conservation à l'abri de toute altération. "

Quelques jours après, le 11 août 1869, MM. les membres de la Commission syndicale des vins de Paris, se rendant à mon invitation, voulurent bien déguster les vins chauffés et non chauffés que je conserve depuis trois ou quatre années. 


\section{Voici le rapport de la Commission $\left({ }^{1}\right)$ :}

Étaient présents : MI. Teissonnière, président de la chambre syndicale; Célerier, vice-président; Mathieu, Brazier, Allain.

M. Desvignes, négociant en vins, s'était adjoint à la Commission.

Étaient en outre présents, mais sans prendre part à la dégustation : MIN. Dumas, sénateur; de Lapparent, directeur des constructions navales au ministère de la marine, président de la Commission pour la conservation des vins.

Afin d'éviter que le jugement des membres de la Commission ne fût influencé, soit par la connaissance préalable de la nature des vins à déguster, soit par des opinions individuelles, on résolut d'adopter les règles suivantes : le vin chauffé et le même vin non chauffé étaient versés, en mème quantité, dans deux séries de verres semblables, hors de la présence des dégustateurs, excepté toutefois en ce qui concernait le membre faisant fonction de secrétaire. Le vote avait lieu au scrutin secret. Une des sortes de vin, le vin chauffé par exemple, était dans la main droite, le vin non chauffé dans la main gauche, ou inversement, ce que le secrétaire seul savait à l'avance, ainsi que les personnes étrangères à la dégustation. Le bulletin de vote indiquait si la préférence avait été donnẻe au verre de la main droite ou à celui de la main gauche.

Voici les résultats de la dégustation pour chaque sorte de vin et le jugement définitif porté par la Commission :

Vin récolté daxs l'Hérault, fourni par M. Teissonnière.

Chauffage en décembre 1866.

Vin de Charente (récolte de 1865), fourni par M. Durouchoux. Chauffage en décembre 1866.

VIN DE Coupage, fourni par M. Durouchoux.

Chauffage en décembre 1866.

VIN ORDINAIRE, fourni par M. Teissonnière.

Chauffage en décembre 1866.
Majorité de 4 contre 2 pour le vin non chauffé.

Unanimité pour le vin chauffé. Dépot adhérent dans le vin chauffé, non adhérent dans le vin non chauffé.

Unanimité pour le vin chauffé. Les dépots sont similaires.

(Le vin non chauffé ayant un goût de bouchon prononcé, l'expérience est annulée quant à la dégustation.) Le dépot du vin chauffé est tout à fait adhérent, l'autre l'est beaucoup moins.

1. Ce rapport et les commentaires qui suivent ont fait l'objet d'une Note présentée par Pasteur à l'Académie des sciences, dans la séance du 6 septembre 1869 , sous le titre : De la pratique du chauffage pour la conservation et l'amélioration des vins (Comptes rendus de l'Académie des sciences, LXIX, 1869, p. 577-581). Cette Note débute ainsi : J'ai l'honneur de déposer sur le bureau de l'Académie la copie d'un rapport intitulé : Dégustation des vins chauffés et des mêmes vins non chauffés par les membres de la Commission syndicale des vins de Paris, chez M. Pasteur, le 11 aoat 1869. "(Note de l'Édition.) 
Vin ordinalre, de M. Teissonnière.

Vin de coupage, fourni par M. Anthoine.

Chauffage le $1^{\text {er }}$ juin 1865.

(Les bouteilles étaient debout.)

Vin de coupage, de M. Anthoine. Chauffage le $1^{\text {er }}$ juin 1865.

(Les bouteilles étaient debout.)

Vin x 21, de Pomard (voir page 229), fourni par M. de Vergnette-Lamotte.

Chauffage en avril 1865.

Vin de Ponard de 1861, fourni par M. Marey-Monge. (Procédé à 24 kilogrammes de sucre par pièce.)

Charffage en décembre 1866.

Vin de Pomard de 1862, fourni par M. Marey-Monge. (Procédé à 24 kilogrammes de sucre par pièce.) Chauffage en décembre 1866.

Vin de Volnay de 1863, fourni par M. Boillot, maire de Volnay. (Procédé à 5 kilogrammes de sucre par pièce.) Mis en bouteilles en octobre 1866.

Chauffage en décembre 1866.

Vin de Volsay de 1864, fourni par M. Boillot, maire de Volnay. (Procédé à 5 kilogrammes de sucre par pièce.) Mis en bouteilles en octobre 1865.

Chauffage en décembre 1866.

Vin de Volyay de 1865, fourni par M. Boillot, maire de Volnay. Mis en bouteilles en octobre 1866 . Chauffage en décembre 1866.
Majorité de 5 contre 1 pour le vin chauffé.-Les dépots sont similaires.

Unanimité pour le vin chauffé. Le vin non chauffé est amer et décomposé. - Dépôt adhérent pour le vin chauffé.

3 votes pour le vin chauffé et 3 pour le vin non chauffé. - Dépot adhérent pour le vin chauffé. Fleurs à la surface du vin non chauffé.

Unanimité pour le vin chauffé, dont la couleur est mieux conservée. - Dépot presque nul dans lc vin chauffé; assez considérable dans le vin non chauffé, et très flottant.

Unanimité pour le vin chauffé, dont la couleur est bien mieux conservée. - Dépôt plus considérable dans le vin non chauffé.

Unanimité pour le vin chauffé. La couleur est mieux conservée. Dépôts dans les mêmes conditions que les précédents.

Unanimité pour le vin chauffé. Ces deux vins sont parfaitement conservés l'un et l'autre. - Le dépot est presque nul de part et d'autre.

Majorité de 4 voix contre 1 pour le vin chauffé. - Aucune espèce de dépot dans le vin chauffé; le vin non chauffé commence à donner un dépôt, mais qui est encore insignifiant. Ces deux vins sont bien conservés l'un et l'autre.

Majorité de 4 voix contre 2 pour le vin chauffé. - Aucun dépot dans le vin chauffé, tandis que le vin non chauffé a formé une lentille. Ces deux vins sont parfaitement conservés l'un et l'autre. 
Vix de Beaune de 1857, Marey-Monge. Chauffage en 1866.
Majorité de 5 contre 1 pour le vin non chauffé, qui a cependant un léger dépot, tandis quele vin chauffé n'en a pas. Selon M. Pasteur, le chauffage, qui a eu lieu neuf ans après la récolte, a été fait beaucoup trop tard après la récolte et la mise en bouteilles.

Vix de Volxay de 1862, fourni par M. Boillot, maire de Volnay. Mis en bouteilles en juillet 1864 .

Chauffage en décembre 1866.

Vis d'Échézeacx-Vougeot de 1862. Chauffage en 1866.

Vix blayc de Pique-Poule, fourni par M. Teissonnière.

Chauffage en novembre 1866.

Vix blaxc d'Anbois.

Chauffage en avril 1865.

Vix blaxc d'Anbois malade, dont on a arrêté la maladie par le chauffage en décembre 1866.
Unanimité pour le vin chauffé, qui est en parfait état de conservation et sans dépot, tandis que le vin non chauffé est trouble, avec un dépot abondant.

Unanimité pour le vin chauffé, qui n'a qu'un léger dépot adhérent. Le vin non chauffé est louche par un commencement de dépót flottant.

Majorité de 5 contre 1 pour le vin chauffé. - Le vin non chauffé a un léger dépôt flottant.

Unanimité pour le vin chauffé, qui est limpide comme de l'eau-de-vie. - Le vin non chauffé est au contraire un peu louche.

Unanimité pour le vin chauffé. Le vin chauffé est limpide; il n'est pas mauvais, mais il n'est pas redevenu bon. - Le vin non chauffé est trouble et mauvais; la maladie n'a fait qu'empirer.

\section{Conclusions du rapport.}

11 est impossible de nier, en raison de l'exposé qui précède, l'immense résultat obtenu par le chauffage sur les vins en bouteilles, au point de vue de leur conservation.

I,e temps écoulé depuis le chauffage ne permet plus aucun doute sur son efficacité. Son effet est surtout incontestablement préventif : il détruit les germes des maladies auxquelles les vins sont généralement sujets, sans pour cela nuire au développement de leurs qualités.

Tous les vins chauffés sont bons; il n'y a d'altération ni dans leur goutt, ni dans la couleur; leur limpidité est parfaite; ils sont, en conséquence, dans toutes les conditions désirables pour donner satisfaction aux consom- 
mateurs. Il n'y a rien de plus à dire, croyons-nous, pour témoigner toute notre confiance dans la valeur du procédé de M. Pasteur.

Nous croyons ce procédé parfaitement pratique et peu coûteux, surtout si on l'applique sur de grandes quantités.

Je n'ai que peu de mots à ajouter à ce rapport pour en marquer toute l'importance : il acquiert une valeur plus grande, en un sens, que le rapport de 1865 , parce que, en 1869 , le procédé du chauffage a été soumis à une épreuve de trois ou quatre années, tandis que les vins dégustés en 1865 par la première Commission ne subissaient que depuis quelques mois les effets du chauffage $\left(^{1}\right)$.

Lorsque j’annonçai le résultat de mes expériences sur le chauffage, personne n'en put nier l'exactitude; mais les uns prétendirent que le développement des parasites était nécessaire, à un certain degré, pour le.vieillissement des vins; qu'en conséquence la pratique du chauffage nuirait au développement naturel de leurs qualités; les autres affirmèrent que les vins communs devenaient secs, maigres, qu'en un mot ils s'altéraient; que, pour les vins fins, cette pratique leur enlevait leur parfum et ces qualités exquises qui en font tout le prix. J'ai laissé passer sans réponse ces contradictions téméraires, longuement développées devant l'Académie (2). Je pressentais toute leur exagération, et le temps m'était nécessaire comme élément d'un jugement définitif.

Le rapport qu'on vient de lire, émanant des hommes les plus autorisés dans la question, fait justice des erreurs dont je viens de parler. Inaltérabilité du vin, conservation parfaite de sa couleur, limpidité brillante, absence de dépóts ou dépôts adhérents, supériorité constante

1. Dans la Note présentée à l'Académie des sciences, la phrase : " il acquiert.... les effets du chauffage " est remplacée par la suivante : "L'Académie se rappellera peut-être qu'en 1864 j'ai démontré que les maladies des vins étaient occasionnées par la présence et le développement de parasites microscopiques; qu'en 1865 j'ai [reconnu qu'il suffisait de porter le vin à une température de $55^{\circ}$ environ ${ }^{*}$, ne fût-ce que pendant quelques instants, pour détruire la vitalité des germes de ces parasites et leurs fonctions de reproduction. Il résultait évidemment de ces faits que, par un chauffage préalable, on peut préserver les vins de toute altération ultérieure. " (Note de l'Édition.)

2. " Un vin vieillit et s'améliore par une influence analogue à celle qui peut le gâter...

" La cause qui fait vieillir les vins est une fermentation provoquée par des organismes qui succèdent au ferment alcoolique proprement dit.

"Tout le secret de l'art de faire vieillir les vins et de les empêcher de se gâter' sera donc, dans l'avenir, de favoriser la production des organismes bienfaisants. " (BRснамP. [Sur la cause qui fait vieillir les vins]. Comptes rendus de $l$ Académie des sciences, LXI, 1865, p. 411.)

" La plupart des vins de table, ceux que produit surtout la France, que leur provenance soit de la Bourgogne, du Bordelais ou de la còte du Rhône, ne résistent pas à ce traitement, au point de vue œnologique; ils deviennent secs, vieillardent, et ne tardent pas à se décolorer...

" Mais des vins qui, sans exception, perdent leur valeur sont les vins communs, tant ils se décolorent et deviennent secs et acides. " (DE VERGNeTtE-LAMOTTE [Conservation des vins par l'emploi de la chaleur]. Ibid., LXII, 1866, p. 599.) [Note de Pasteur.]

* Quand le vin est resté sucré, le chauffage doit être porté à quelques degrés de plus, $60^{\circ}$ environ. Ce terme est nécessaire pour tuer le germe du ferment alcoolique. (Note de Pasteur.) 
du vin qui a été chauffé sur le même vin qui ne l'a pas été, ALORS мลेме QUE LE VIN NON CIIAUfHÉ Ne S'EST PAS ALTÉHÉ; grande infériorité du vinage par rapport au chauffage pour la conservation du vin : telles sont les qualités et les améliorations qui ont été proclamées unanimement par les dégustateurs, et qui assurent à la pratique du chauliage préalable un immense avenir en tout ce qui concerne le commerce et l'élevage des vins.

Il résulte encore du rapport de la Commission que, dans la construction et l'emploi des appareils de chaufiage en grand, déjà fort multipliés en ce moment, il est indispensable de réaliser les conditions du chauffage en bouteilles, c'est-à-dire d'éviter autant que possible le contact de l'air. J'ai toujours particulièrement insisté sur ce point; car l'oxygène peut développer le goût de cuit, altérer et rendre peu solide la couleur. Toutefois on peut profiter de sa présence pour communiquer au vin une couleur et des qualités qu'il n'acquerrait pas hors de son influence ${ }^{(1)}$.

J'invite le lecteur a lire attentivement dans l'Appendice le procèsverbal d'une nouvelle dégustation de vingt-quatre sortes de vin, faite dans non laboratoire par les membres de la Commission syndicale des vins de Paris en juillet $1872\left({ }^{2}\right)$, au moment où cette nouvelle édition de mes Études sur le vin était sous presse. Cette nouvelle dégustation ne laisse plus aucun doute sur l'amélioration des vins par la pratique du chauffage : Non seulement le chauffage en bouteilles, et d'une manière plus générale le chauffage à l'abri de l'air, empèche toute détérioration des vins communs et en général de tous les vins susceptibles de dépérir avec le temps; il améliore en outre la qualité de tous les vins, même les plus fins.

On connaît la compétence de $\mathrm{M}$. Terrel des Chênes en ce qui concerne l'œnologie. Voici comment il s'exprime sur le chauffage dı vin, dans une brochure intitulée la Suprématie viticole de la France $\left.{ }^{3}\right)$ :

"Le chauffage du vin a toutes mes préférences, et je ne les lui ai accordées qu'après avoir acquis l'entière conviction de son excellence, conviction basée sur l'étude la plus approfondie et sur les faits les plus certains et les plus décisifs.

1. La Note présentée à l'Académie des sciences se termine ici par cette phrase :

" Avant de terminer cette Note, la reconnaissance n'impose le devoir de rappeler que les recherehes dont je viens de présenter les résultats ont été entreprises, à l'origine, sur l'invitation de l'Empereur." "

2. Voir p. 375-381 du présent volume : De l'amélioration des vins par le chauffage (Extrait des Comptes rendus de l'Académie des sciences, séance du 5 aoùt 1872).

3. Terrel Des Chenes (E.). De la suprématie viticole de la France et des mojens de la consolider. (Communication faite au Congrẻs agricole de Valence, séance du 29 avril 18\%0). Lyon, 1870, Impr. A. Vingtrinier, 30 p. in-8 . (Notes de l'Édition.) 
" Aucun de vous ne l'ignore : le chauffage est une opération par laquelle au moyen d'appareils imaginés à cet effet, on élève rapidement les vins une température donnée, pour les ramener non moins rapidement à leu température première, ou peu s'en faut. Quels changements a subis le vir pendant les quelques secondes qu'a duré l'opération? Pas un atome étranger n'a été introduit dans le liquide; pas un atome ne lui a éte soustrait. It a éprouvé instantanément les effets d'une chaleur que l'on peu faire varier de 50 à $75^{\circ} \mathrm{C}$.; rien de plus, rien de moins. Et quels sont ces effets? Les voici : après l'entier refroidissement du vin chauffé, il faut être bon dégustateur pour le distinguer de son pareil non chauffé.

" Dans ce cas on constate :

"Que le bouquet est plus développé et que le principe alcoolique semble exalté;

«Que la couleur est plus franche et plus veloutée;

"Que la verdeur et l'âpreté ont en partie disparu;

"Qu'il y a plus de maturité 'sans vieillissement.

" En revanche, le vin non chauffé a conservé son goút de fruit que le vin chauffé a perdu en totalité ou en partie...

"Enfin, dans les nombreuses dégustations que j'ai provoquées ou auxquelles j'ai assisté, j'ai, le plus souvent, entendu les hommes les plus experts conclure ainsi : "Vraiment la différence est bien peu de chose. »)

“ Et pourtant, entre ces deux vins si peu dissemblables qu'on a peine à les distinguer, la différence est immense; elle est capitale, décisive; l'un est devenu inaltérable, c'est le vin chauffé; l'autre reste exposé à toutes les maladies des vins, c'est celui qui n'a pas été chauffé...

" Lorsqu'un fait aussi considérable, aussi extraordinaire est avancé, il faut en administrer la preuve aussitôt. Les preuves? Elles surabondent...

"Permettez-moi de vous citer les conclusions d'un rapport de la Société agricole de Lombardie, sur les essais faits en Italie. Ici les vins chauffés et leurs pareils non chauffés ont été soumis à une épreuve que je regarde comme plus décisive encore que celle de trois ou quatre ans de garde dans une cave : une navigation en mer de cent vingt-six jours. Voici les conclusions en question :

“ Du jugement qui précède résulte ce qui suit :

" Sur vingt sortes de vins italiens, treize ont résisté à la navigation en " parfait état de conservation, sans avoir subi aucune préparation.

" Les vins chauffés selon le système Pasteur ont tous indistinctement " résisté à la navigation.

“ Parmi les qualités qui se sont conservées inaltérées sans préparation " aucune, les vins chauffés ont été pour la très grande partie trouvés meil" leurs que ceux non chauffés.

" Pour une seule espèce, le vin noir d'Acqui, le vin non chauffé a été " trouvé notablement plus agréable que le vin chauffé. " (Bullettino dell' agricoltura. Milan, 24 avril 1869.)

" Je n'ai pas le détail de ce qui a été fait en Hongrie, mais je sais que le chauffage n'y a pas donné des résultats moins remarquables.

" La force de conservation communiquée aux vins par le chauffage est si 
extraordinaire, que j'ose à peine vous parler des faits rigoureusement constatés ou controlés par moi.

" Le 12 janvier, j’ai vidé à moitié une bouteille de vin de 1868 chauffé et une autre bouteille, extraite de la même pièce, mais non chauffée. Les deux ont été exposées en cet état, et débouchées, sur une fenêtre de cave. Dégustées par plusieurs vignerons au bout d'un mois, la première, vin chauffé, a été trouvée intacte; la seconde, vin non chauffé, était fortement piquée. Après deux mois, état parfait du vin dans la première; décomposition dans la seconde. Enfin, à une dernière dégustation, peu de jours avant ma venue à Valence, c'est-à-dire après trois mois et demi, le vin chauffé était toujours bon; l'autre n'existait plus comme vin.

"Un de mes amis, grand négociant en vins et président d'un comice voisin du mien, a eu la curiosité de pousser un semblable essai jusqu'à quatorze mois de durée. Il m'affirmait récemment que le vin chauffé n'était pas altéré après un aussi long temps, il avait seulement été affaibli par la perte d'une partie de son alcool, qui s'évapore, ainsi que vous le savez, beaucoup plus rapidement que l'eau.

" Il n'est done plus permis d'en douter : le chauffage est le moyen décisif, d'une efficacité constante et absolue, qui prévient les maladies des vins et assure leur conservation en les améliorant (1)."

Voici encore un passage de cet opuscule que je demande la permission de citer :

“ Un vigneron californien écrivait, au mois d'août 1869, au Monthly Statistics de New-York :

"Si la vinification, en Californie, ne peut pas se vanter d'une longue " expérience, du moins elle n'a pas de vieux préjugés à vaincre et n'est en " aucune façon éloignée d'adopter les connaissances nouvelles qui sont " démontrées. Aussi les vignerons de Californie lisent, avec autant de profit " que d'avidité, vos grands chimistes du vin, depuis Lavoisier jusqu'a "Pasteur. Pasteur est aussi populaire parmi les viticulteurs de Californie “ que le président des États-Unis et, s'il était ici, ils le nommeraient à un " grand emploi.

“ Aussitôt que je reçus un exemplaire de ses Études sur le vin, pour lui " rendre honneur, je chauffai 20.000 gallons (910 hectolitres) de vin en un " seul lot, selon son procédé; et tout ce qu'il avait prédit de ses effets fut " vérifié. Conformément à ses instructions, les producteurs de vin de Cali" fornie, hardiment et à intervalles réguliers, saturent d'air les moûts “ pendant la fermentation tumultueuse, maintenant ainsi une oxydation " prolongée qui complète promptement la fermentation avec le succès le " plus décidé (2). "

A travers les continents et les mers j'adresse mes bien sincères remercîments à cet honnête vigneron de Californie, dont je regrette de ne pas connaître le nom.

1. Terrel des Chênes. Loc. cit., p. 22-27.

2. Terrel des Chenes. Loc. rit., 'p. 9. (Notes de l'Édition.) 
Il est beau de voir l'habitant d'un pays où la vigne n'existait pas il y a vingt ans proclamer aujourd'hui que, pour rendre honneur à une découverte française, il a mis en expérience, d'un seul coup, près de 100.000 litres de vin! Aussi ces hommes marchent à pas de géants tandis que nous posons timidement un pied devant l'autre, plus occupés souvent à dénigrer qu'à honorer les services rendus.

Nous extrayons encore d'une lettre adressée par M. Terrel des Chênes au Moniteur vinicole, en décembre 1871, les passages suivants relatifs aux résultats du chauffage des vins en Hongrie :

“Tous les producteurs, sans exception, se plaignent des fermentations latentes et successives qu'éprouvent les vins de Tokay, pendant dix ans et plus après leur confection; fermentations qui amènent inévitablement des dépóts, obligent à de nombreuses décantations, et enfin déplaisent aux consommateurs et nuisent à la vente. C'était le cas ou jamais d'essayer d'arrêter ces fermentations par le chauffage. En admettant que la pasteurisation (car le mot est fait ẹt est devenu allemand depuis plusieurs années), en supposant, dis-je, que la pasteurisation fit perdre au tokay un peu de sa délicatesse, jamais elle ne lui serait aussi nuisible que ces malheureuses fermentations. Je choisis, en conséquence, un vin d'un des premiers crus de Tokay, du vin de Tallya, 1866, du $\mathrm{D}^{\mathrm{r}}$ J. Szabó (1866 est l'une des plus grandes années de la Hongrie), et je le chauffai à $62^{\circ} \mathrm{C}$., exagérant à dessein le degré de la pasteurisation, afin que les effets en fussent plus marqués et plus décisifs. J'avoue que je redoutais un échec, et j'entends par là quelques petites pertes, de ce je ne sais quoi de délicat et d'exquis qui est le caractère éminent du tokay.

"Trois demi-bouteilles furent d'abord décantées et chauffées; trois autres furent décantées avec le plus grand soin et gardées à l'état naturel; les premières marquées II, les secondes marquées I. Un billet indiquant les marques données au vin pasteurisé et au non pasteurisé fut mis sous enveloppe cachetée. Cela fait, pendant les deux jours que le grand œnotherme (1) opéra, dans les caves de M. Franz Schopt, de Pesth, la pasteurisation des vins rouges et blancs en fûts, les échantillons de tokay chauffé et non chauffé furent dégustés par les marchands et les viticulteurs venus pour assister aux opérations qui avaient lieu sous la surveillance du ministère hongrois de l'agriculture. Chaque dégustateur, après avoir goûté, écrivait, sur un tableau préparé pour cela, s'il donnait la préférence à l'échantillon I ou à l'échantillon II. La dégustation terminée, on rompit l'enveloppe, et l'on vit alors que la marque II appartenait à l'exemplaire chauffé. On compta les votants, et les votes exprimés et signés s'il vous plaît, et il se trouva que, sur 39 dégustateurs qui avaient consenti à signer leur opinion, 33 avaient préféré l'exemplaire II. Notez que la dégustation avait lieu quatre jours seulement après la pasteurisation, c'est-à-dire au moment où le vin n'était pas encore reposé.

1. Nom donné par M. Terrel des Chênes à šon appareil de chauffage des vins. (Note de l'Édition.) 
"Le ministère hongrois va publier dans les journaux un compte rendu de nos opérations, celle-là comprise. Je vous l'enverrai pour que vous le teniez à la disposition des adversaires du chauffage. Permettez-moi d'ajouter en passant que la plupart des vins de Tokay ont 18 à 20 pour 100 d'alcool, ce qui ne les empêche pas de fermenter, ni de se troubler. Que pourrait faire là une addition dé... ou... pour 100 d'alcool? ”

II. Chiozza, grand propriétaire de vignes dans le Frioul autrichien, qui a longtemps professé la chimie industrielle à Milan, et qui est connu dans le monde savant par des travaux de chimie estimés, a obtenu du chauffage à l'abri de l'air des résultats excellents sur les vins du Frioul qui sont généralement très altérables. M. Chiozza se loue beaucoup de l'application de ce procédé pour l'amélioration de ses vins.

En résumé, aujourd'hui l'épreuve est décisive : le procédé du chauffage, dont je revendique la démonstration expérimentale, est applicable aux vins soit en fûts, soit en bouteilles; il suffit de chauffer ce vin de 55 à $60^{\circ}$ pour qu'il soit désormais à l'abri de toute maladie.

Ce traitement n'altère nullement les qualités précieuses de ce liquide, qu'il s'adresse aux vins fins ou aux vins communs; il n'en altère ni la couleur, ni le goût, ni le bouquet, ni les nuances les plus délicates du vieillissement, qu'il rend au contraire plus régulier, à tel point que, lors même que le vin non chauffé reste inaltéré, le vin chauffé se montre encore, avec le temps, supérieur.

\section{MANIÈRE DE CONDUIRE LES EXPÉRIENGES}

11 me reste à faire connaitre les moyens de chauffage que j'ai adoptés dans mes expériences. Je les donne à titre de renseignement, car l'industrie saurait mieux faire. Il ne s'agissait pour moi que d'essais sur une bien petite échelle et de la constatation de résultats scientifiques.

Chauffage du vin en bouteilles. - Le chauffage du vin en bouteilles se fait avec une grande facilité et à très peu de frais. On peut le pratiquer sur le vin qu'on vient de mettre en bouteilles, et cela est préférable (1), ou sur le vin qui est en bouteilles depuis longtemps, qu'il soit sain ou malade. Seulement, lorsqu'on sera obligé d'opérer sur le vin qui est depuis longtemps en bouteilles, il sera bon de séparer les dépôts en transvasant le vin dans de nouvelles bouteilles, après avoir

1. Les mots $\alpha$ et cela est préférable » ont été ajoutés á la 2 édition des "Etudes sur le vin ". (Note de l'Édition.) 
relevé les anciennes et les avoir laissées debout quarante-huit heures pour donner au dépôt flottant le temps de se rassembler.

Je suppose donc que du vin vienne d'être mis en bouteilles. On a bouché à l'aiguille ou autrement, à la mécanique ou non. On ficelle chaque bouteille, puis on les porte dans un bain-marie. La figure 40 reproduit cèlui qui m'a servi. Afin de manier plus facilement les bouteilles, elles étaient placées dans un panier à bouteilles en fer. L'eau doit s'élever jusqu'à la cordeline. Il ne m'est pas arrivé de noyer complétement les bouteilles. Je ne crois pas qu'il y aurait inconvénient à le faire, pourvu qu'il n'y eût pas de temps d'arrêt ni de refroidis-

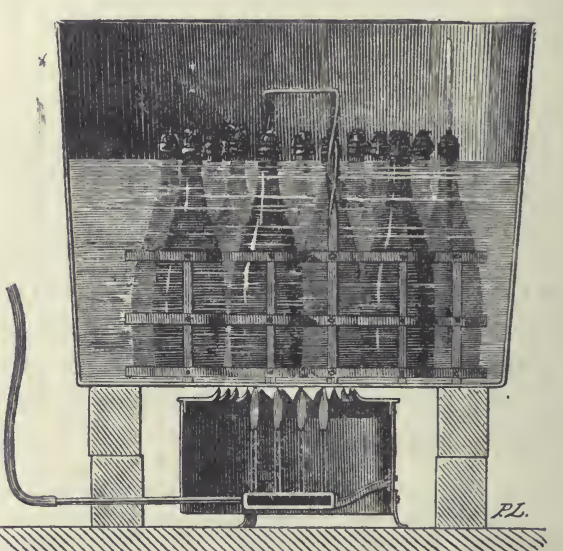

Fig. 40.

sement partiel pendant le chauffage, qui exposerait à faire entrer un peu d'eau dans, les bouteilles.

Parmi les bouteilles, on en place une pleine d'eau, à la partie inférieure de laquelle plonge la boule d'un thermometre. Quand celui-ci marque le degré voulu, par exemple $60^{\circ}$, on retire le panier. Il ne faut pas en remettre un autre tout de suite : l'eau trop chaude pourrait faire briser les bouteilles froides. On retire une portion de l'eau chaude et l'on abaisse un peu le degré de celle qui reste en ajoutant de l'eau froide. Mieux encore, on a commencé par chauffer les bouteilles du deuxième panier, afin de pouvoir les placer sans retard dans l'eau chaude qui vient de servir, et ainsi de suite.

La dilatation du vin pendant son échauffement tend à faire sortir le bouchon, mais la ficelle (ou le fil de fer) le retient, et le vin suinte 
entre le bouchon et les parois intérieures du goulot. Pendant le refroidissement des bouteilles, le volume du vin diminue, on frappe sur les bouchons pour les renfoncer, on òte la ficelle et l'on met le vin en cave, ou dans un cellier quelconque, au rez-de-chaussée ou au premier étage, à l'ombre ou au soleil. Il n'y a pas à craindre que ces diverses manières de le conserver le rendent malade; elles n'auront d'influence que sur son mode de vieillissement, sur sa couleur, etc.

Il sera toujours utile de conserver quelques bouteilles du même vin non chauffé, afin de pouvoir les comparer à longs intervalles, si on le désire, avec le vin des bouteilles qui auront été chauffées. Les bouteilles pourront être conservées debout, jamais il ne s'y formera de fleurs; mais peut-être le vin perd-il un peu de sa finesse dans ces conditions, si le bouchon se dessèche et laisse trop facilement pénétrer l'ail' extérieur.

De nouvelles expériences m'ont appris que certains vins s'améliorent considérablement quand on laisse les bouteilles debout un temps convenable, temps qui doit être étudié pour chaque sorte de vin. Quand on laisse l'aération se prolonger à travers les pores du bouchon, le vin peut se décolorer plus ou moins complétement et même prendre un goût de cuit. Dans le cas où les bouteilles doivent ètre placées debout, il faut également avoir la précaution de les chauffer au moins à $60^{\circ}$ et que, pour toutes, le vin, pendant l'échauffement, vienne toucher le bouchon en se dilatant, ce qui arrive toujours si les bouteilles sont convenablement remplies au moment de la mise en bouteilles. La température de $55^{\circ}$, je l'ai éprouvé plusieurs fois, n'est pas suffisante pour tuer les germes des moisissures répandus sur les bouchons, non plus que le mycoderma aceti, qui peut acétifier le vin si les bouteilles ne sont pas couchées (1).

Chauffage du vin en füt. - J'ai pratiqué le chauffage des vins en fût en suivant la disposition qu'indique la figure 41. Le tonneau est placé dans un bain-marie. Le niveau de l'eau est distant de quelques centimètres de la bonde, qui est simplement posée sur son ouverture sans être serrėe. L'eau du bain est portée à $80^{\circ}$. L'ébullition donnerait trop de vapeur d'eau et une perte inutile de chaleur. Lorsqu'on juge que le vin peut être près de la température de 55 à $60^{\circ}$, on ôte la bonde et on plonge un thermomètre, que l'on retire aussitôt après, pour continuer s'il y a lieu. Le vin de dilatation s'écoule par le trou de la bonde, puisque la bonde n'est pas serrée. Il serait facile de disposer les choses pour ne pas perdre ce vin.

1. Cet alinéa ne figure pas dans la 1 re édition des a Etudes sur le vin " (Note de l'Édition.) 
Industriellement parlant, ce procédé de chauffage n'est ni bon, ni pratique. Je ne m'en suis servi que pour constater scientifiquement les effets de conservation dus au chauffage, qui ont été très remarquables (1).

Pour un tonneau de 30 litres, l'eau du bain-marie étant à 70 ou $80^{\circ}$, i) fallait de cinq à six heures pour que le vin arrivât à la température de $60^{\circ}$.

Lorsqu'on avait atteint la température voulue, on retirait le tonneau,

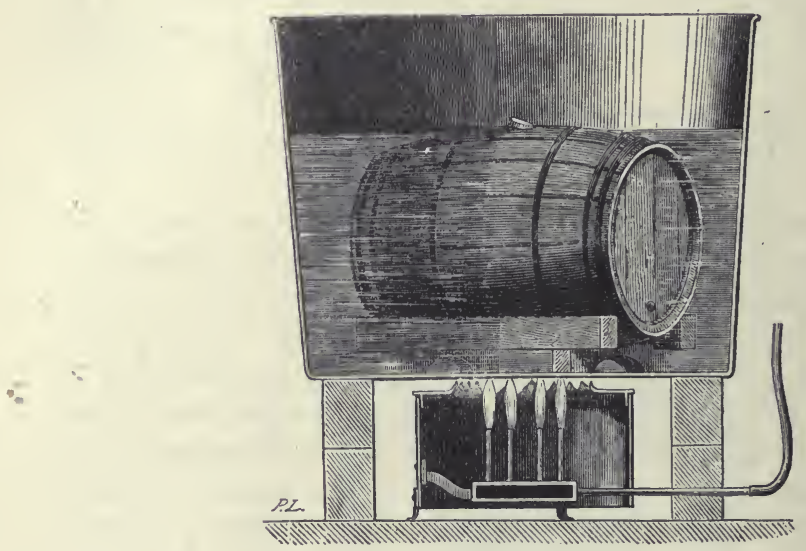

Fig. 41.

on frappait la bonde, et on portait le tonneau à la cave ou dans un local quelconque.

Le résultat a été excellent comme conservation. J'ai abandonné du mois d'avril au mois de décembre, en plein air, sur une terrasse, du côté du nord, des tonneaux de vins rouge et blanc ainsi préparés; dans aućun d'eux il n'y a eu la moindre acétification, ni fleurs, ni maladies quelconques. Le vin reste très limpide et dépose de la matière colorante amorphe suivant les principes que j'ai exposés; mais il est inutile d'opérer des soutirages. Ce genre de dépôt ne nuit pas au vin (2).

Lorsqu'on veut déguster le vin et savoir s'il est propre à la consomination, il suffit de pratiquer un fausset.

Dans les cas où ce vin chauffé en fût a été mis en bouteilles, celles-ci

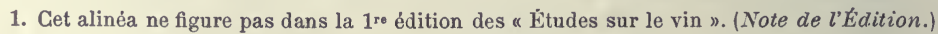

2. Le seul inconvénient grave que j'aie remarqué dans mes essais, et qu'il serait facile, je pense, d'éviter, c'est que le vin a pris plusieurs fois un léger goût de bois. Il aurait fallu laisser séjourner de l'eau chaude dans les tonneaux avant de les chauffer pleins de vin. 
ne m'ont pas paru avoir besoin d'être chauffées de nouveau pour que le vin s'y conserve sans altération. Cependant il faut qu'elles soient couchées. En les laissant debout, bon nombre prennent des fleurs, dont elles reçoivent le germe au moment de la mise en bouteilles; ce germe peut se trouver aussi sur les parois des bouteilles ou sur les bouchons. Mais je n'ai pas vu se former les parasites filiformes, sans doute parce que les germes de ces derniers ferments sont moins répandus que ceux des mycodermes et se trouvent principalement dans le vin naturel. Dans tous les cas, s'il y avait altération, elle ne serait pas générale et ne s'appliquerait qu'à quelques bouteilles isolées. Cependant, je n'aurais pas osé porter un jugement définitif sur la non nécessité d'un nouveau chauffage du vin après la mise en bouteilles, lorsqu'il a été chauffé en fût, en me fondant uniquement sur mes expériences personnelles trop peu nombreuses. Mais aujourd'hui des centaines d'expériences industrielles ont prononcé : elles ont démontré qu'un nouveau chauffage n'est pas nécessaire $\left(^{(1)}\right.$.

Une ou deux fois, dans mes essais, le vin que j'avais chauffé en fût est devenu louche, parce que les tonneaux dont je m'étais servi étaient en mauvais état, et que le vin avait éprouvé, pendant son refroidissement et par une fissure, l'action directe et brusque de l'oxygène de l'air. L'action directe de l'air, pour une certaine proportion d'air, amène fréquemment ce résultat sur les vins rouges. Cet effet s'accompagne en outre d'une amertume du vin assez sensible. Il est facile d'éviter cet inconvénient.

Il me reste à faire connaitre un mode de chauffage et d'aération des vins blancs et rouges qui rendra peut-être de grands services au commerce des vins de France et d'Algérie dans la fabrication des vins d'imitation.

Dans des bonbonnes de verre placez le vin naturel, ou viné à un degré voulu, et additionné, s'il est nécessaire, de vin doux ou de sucre, en proportion convenable, pour que le vin ait ultérieurement le degré de douceur que l'on peut désirer, s'il s'agit d'obtenir des vins plus ou moins liquoreux. Les bonbonnes ne sont pas remplies, afin que l'oxygène de l'air qui y sera laissé oxyde le vin, le fasse déposer et lui communique les bouquets et saveurs dont j'ai parlé précédemment, à l'occasion des expériences en tubes.

Voici ce qui se passe lorsque les bonbonnes sont exposées à toute

1. Dans la $1^{\text {ro }}$ édition, la fin de cet alinéa était remplacée par les lignes suivantes : « Cependant, je n'oserais pas encore porter un jugement définitif sur la non nécessité d'un nouveau chauffage du vin après la mise en bouteilles, lorsqu'il a été chauffẻ en fût. L'expérience prononcera. Celle qui m'est personnelle n'a peut-être pas une durée suffisante. "(Note de l'Édition.) 
l'ardeur du soleil, très bien bouchées. La température, surtout dans l'air de ces bonbonnes, est portée à plus de $50^{\circ}$, parce que la chaleur des rayons obscurs s'y accumule rapidement. Il en résulte que les germes des mycodermes sont tués, de telle sorte que le vin devient inaltérable. Il n'y a pas d'acétification possible. En outre, en quelques semaines, il a absorbé l'oxygène et s'est dépouillé complétement. Alors on débouche le vase sans le remuer, et l'on met le vin qui y est contenu en bouteilles à l'aide d'un siphon. Le vin, très limpide, a pris les principaux caractères d'un vin très vieux, et se trouve madérisé à un degré marqué. Il est devenu, en outre, pour ainsi dire, inaltérable et incapable de donner lieu au moindre dépôt. J'ai la confiance qu'en suivant ces indications, que l'expérience pourra modifier sur quelques points, on arrivera à abréger considérablement la fabrication de Cette, en. évitant toute déperdition par consumé ou vidange naturelle des tonneaux, et toute détérioration des vases servant à exposer le vin au soleil, deux circonstances qui conduisent à de grandes pertes avec les procédés de fabrication qui sont suivis à Cette et dans d'autres villes. Cependant c'est à l'expérience de prononcer définitivement sur la - valeur de ces nouvelles pratiques. Pour moi, j'ai préparé en un mois, sans la moindre dépense, du vin jaune, façon Château-Châlons, que l'on aurait mis bien des années à obtenir tel par les procédés qui sont en usage dans le Jura.

Depuis que ces lignes ont été écrites, c'est-à-dire depuis la publication de la première édition du présent ouvrage, j'ai appris qu'on avait appliqué en Espagne, sur une grande échelle, les procédés dont je viens de parler : dans des vases de verre à moitié pleins, on expose le vin au soleil pendant un ou plusieurs jours, suivant la demande de la couleur. Ces faits m'ont été communiqués en 1869 par M. Florès Domonte. J'espère que nos négociants du Midi sauront comprendre également toute l'importance d'essais de cette nature sur les diverses sortes de vins qui peuvent s'y prêter avec tant de succès, selon moi.

\section{APPAREILS INDUSTRIELS POUR LE CHAUFFAGE DU VIN (1)}

Rien ne démontre mieux les progrès de la question du chauffage des vins dans l'esprit des praticiens que les récompenses proposées

1. Article rédigé par M. J. Raulin, docteur ès sciences, ancien élève de l'École Normale. (Note de Pasteur.)

Cet article, ajouté à la $2^{\circ}$ édition des "Etudes sur le vin ", contient 14 nouvelles figures d'appareils (fig. 43 et fig. 45 à 57). Il renferme, sous forme de citations de Pasteur, quelques passages qui, dans la $1^{\text {re }}$ édition, faisaient partie du chapitre précédent. (Note de l'Édition.) 
par les Commissions de plusieurs concours agricoles pour les meilleurs appareils de chauffage, et surtout la décision prise par la Société d'encouragement pour l'industrie nationale, dans sa séance du 20 février 1867. Les termes mêmes de cette décision méritent d'être cités :

"Prix de 3.000 francs pour les meilleurs appareils ou procédés fonctionnant pratiquement et commercialement pour la conservation les vins tant en vue du transport qu'en vue du débit.

“M. Pasteur, de l'Académie des sciences, a donné une théorie excellente des causes qui président aux altérations des vins et des moyens qui peuvent les prévenir. Il a fait connaître les conditions pratiques des manipulations à effectuer pour garantir cette conservation.

“ Reste leur emploi. Il peut être compris à deux points de vue : appliqué au lieu de production, appliqué au lieu de consommation.

"Le producteur trouve dans ces procédés un moyen certain de garantir d'altération, pendant le voyage, les vins qu'il expédie, et de leur assurer, en conséquence, une valeur qu'ils ne sauraient atteindre tant qu'ils ne peuvent pas supporter les transports et aller chercher les consommateurs lointains. Il est donc du plus haut intérêt, pour beaucoup de nos pays vignobles, d'avoir à proxinité des caves, ou dans les caves mênes, un appareil d'un emploi économique permettant de porter le vin à la température nécessaire à sa conservation.

“ Il ne l'est pas moins d'étudier avec soin une organisation qui perınettrait, dans les villes, de faire subir, à volonté, une opération de la mème nature aux vins, au moment de leur arrivée.

“ Elle ouvrirait au débit français des conditions spéciales tout à fait nouvelles, puisque le vin pourrait se conserver sans altération dans les appartements pendant des mois entiers en bouteilles, ou même pendant plusieurs jours en vidange.

"Les vins les plus légers reçoivent, en effet, de l'application de la chaleur, les qualités de garde naturellement propres aux vins alcooliques.

“ L'application de l'une ou de l'autre de ces méthodes ou même leur emploi simultané n'exerçant aucune influence sur le prix des vins, puisque la dépense doit s'élever tout au plus à quelques millièmes de leur valeur, il en résulterait un bien inappréciable pour le producteur, pour le trafic et pour le consommateur. Cependant, comme il s'agit seulement d'appliquer des moyens connus, la Société a dû mesurer la valeur de ses prix, non à l'importance de la question, mais à la difficulté.

" Un prix de 3.000 francs sera accordé à la personne qui aura 
imaginé et mis en usage, en grand, les meilleurs appareils de chauffage et de conservation des vins $\left({ }^{1}\right)$. "

Le chauffage des vins peut s'effectuer, soit sur les vins en futts, soit sur les vins en bouteilles; M. Pasteur, dans la première édition de son ouvrage sur le Vin [p. 166], a insisté sur les avantages pratiques du second mode de chauffage :

" Le chauffage du vin après la mise en bouteille, dit M. Pasteur, est si facile, si peu dispendieux, et rend un tel service à la conservation du vin, que je ne comprendrais pas qu'il ne fût pas généralement appliqué par les négociants ou les propriétaires au moment où ils expédient ce vin. A combien de difficultés, d'ennuis, de réclamations de toutes sortes ne s'exposent-ils pas? Combien de dépenses de main-d'œuvre et de pertess n'éviteraient-ils pas à eux et à leurs clients? Le commerce des vins en bouteilles acquerrait une sûreté et une facilité extrêmes. Qu'on veuille bien relire les extraits que j'ai rapportés des lettres de MM. de Vergnette-Lamotte, Marey-Monge, Boillot $\left({ }^{2}\right)$, et j'aurais pu multiplier beaucoup ce genre d'informations, - qu'on veuille bien méditer particulièrement le rapport de la Commission du commerce des vins dans Paris (3), qui a constaté la détérioration, après quelques mois seulement, de dix sur vingt sortes de vins que j'avais mis à l'épreuve, et l'on se convaincra de l'immense avantage de la pratique que je préconise en ce moment. J'ai la conviction qu'elle peut donner des millions à la France, pour me servir des expressions que j'ai déjà rappelées d'une des personnes les plus autorisées dans ces matières, M. de Vergnette (4). "

Aujourd'hui, ces conseils conservent toute leur autoritè.

Le commerce des vins en bouteilles est considérable et s'accroît tous les jours, surtout dans les grandes villes; les vins en bouteilles sont généralement destinés à être conservés longtemps, durée qui accroît pour eux les chances de maladie, enfin les vins conservés longtemps en bouteilles sont ordinairement les vins de qualité, les plus précieux, ceux auxquels précisément on a le plus d'intérêt à appliquer le chauffage.

D'ailleurs, et c'est l'opinion très fondée de M. Pasteur, le chauffage des vins en bouteilles bien fermées, et au bain-marie, réalise les conditions les plus favorables au succès de cette opération :

1. Bulletin de la Socièté d'encouragement pour l'industrie nationale, 2• sér., XIV, 1867, p. 212-2I3. (Note de l'Édition.)

2. Voir p. 159, 162-163, 160 du présent volume.

3. Voir p. 234-240 du présent volume.

4. Voir p. 363-370 du présent volume la lettre de M. de Vergnette-Lamotte. 
D'une part, en chauffant le vin dans le vase même hermétiquement clos, où il est conservé ultérieurement, on est certain de tuer absolument tous les germes et de n'en laisser rentrer aucun : dès lors la conservation indéfinie du liquide est assurée.

D'autre part, dans ces conditions, on n'a pas à craindre que quelques parties du vin soient élevées à une température de beaucoup supérieure à $60^{\circ}$, et le vin, une fois chauffé, est ramené promptement à la température ambiante; il ne subit le contact de l'oxygène de l'air, ni pendant l'opération du chauffage, ni avant cette opération, ni pendant ou après le refroidissement; en un mot, il est écarté aussi peu que possible de son état habituel de conservation, et on prévoit que cette condition est nécessaire pour que les qualités d'un liquide aussi délicat ne soient pas émoussées.

L'expérience a pleinement justifié ces prévisions : qu'on relise avec attention les rapports des Commissions de 1865 et de 1869, et surtout de $1872\left({ }^{1}\right)$, qui avaient trait exclusivement à des vins chauffés en bouteilles, et l'on se convaincra que, dans ces conditions, le vin a résisté absolument à la maladie, et que ni son goût, ni son bouquet n'ont èté altérés; que le vieillissement, loin d'être entravé, s'est souvent effectué plus régulièrement, que les dépôts se sont mieux formés, que la couleur, loin de se perdre, a été plutôt avivée.

Et pourtant, faut-il le dire, les praticiens n'ont pas encore profité de ces enseignements : jusqu'à présent, on n'a guère chauffé dans l'industrie que les vins en tonneaux. Pourquoi? C'est, d'une part, que le chauffage en fùt est si facile, si peu dispendieux, qu'on le préfère au chauffage en bouteilles, supérieur par ses résultats; d'autre part, l'idée du chauffage des vins, jusqu'à présent, a surtout fait des progrès chez le producteur, plus attentif aux soins que réclame le vin que le commerçant des villes ou le consommateur, plus expert dans l'art de traiter un vin qu'il connaît parfaitement, et désireux de maintenir la réputation de ses produits. Or, le producteur traite généralement le vin en tonneaux, non en bouteilles.

Pourtant, le chauffage en bouteilles mérite une sérieuse attention; l'invention d'appareils commodes, appropriés aux cas les plus usuels, contribuerait, je pense, à répandre cette utile pratique.

II. Pasteur, dans la première édition de cet ouvrage, a donné à l'industrie d'utiles indications à ce sujet:

" Comment, se demande-t-il, pourrait-on opérer dans l'industrie sur une grande quantité de bouteilles?

1. Voir p. 234, 253 et 378 du présent volume. 
"Le bain-marie que représente la figure 40 (page 262) peut être agrandi, mais je crois que le meilleur système, s'il n'offrait pas d'inconvénients cachés (et je n'en soupçonne pas), consisterait dans l'emploi d'une grande cuve à étages de planches percées de trous pour laisser circuler l'eau facilement entre les bouteilles. Celles-ci seraient réunies sur ces planches et noyées entièrement dans l'eau de la cuve, que l'on échaufferait progressivement avec de la vapeur d'eau arrivant directement dans la cuve ou circulant dans des serpentins. Je répète que je ne vois pas d'inconvénient à noyer les bouteilles complétement s'il y a constamment pression de dedans au dehors, effet inévitable avec une élévation progressive de la température de l'eau de la cuve. Pourtant c'est à l'expérience de prononcer.

"Un autre système consisterait à chauffer les bouteilles empilées dans un cabinet-étuve, où l'on ferait arriver de la vapeur d'eau, ou de l'air chaud, ou des tuyaux remplis d'eau chaude qui échaufferaient l'air et qu'on distribuerait après des essais préalables de façon à obtenir en tous les points de l'étuve la température nécessaire. Celle-ci serait toujours indiquée par des bouteilles remplies d'eau avec thermomètres dans l'intérieur et graduations visibles au dehors.

“Dans mes premiers essais, je me suis servi d'une étuve à air chaud. C'était une caisse en bois à trois ou quatre étages; une plaque de tôle était placée à la partie inférieure et chauffée en dessous par le gaz.

" J'ai voulu agrandir cette étuve et lui donner la forme qu'indique la figure 42. Celle-ci, pouvant contenir 200 bouteilles, m'a encore rendu des services, mais elle avait le désavantage de donner des températures inégales en divers points d'un même plateau. Tandis que certaines bouteilles sont portées à $50^{\circ}$, d'autres le sont à 55 ou $60^{\circ}{ }^{(1)}$. La différence de température à divers étages n'a pas beaucoup d'inconvénients dès qu'on s'est assuré du degré que l'on atteint pour une pression déterminée d'arrivée de gaz. Comme, pour la facilité de la charge des plateaux, ceux-ci étaient portés par un arbre central et vertical pouvant tourner, on remédiait à la différence de température en divers points d'un même plateau en faisant tourner le système des plateaux d'un certain angle de demi-heure en demi-heure.

"Dans le Midi, on pourrait, je pense, se servir d'une étuve chauffée par les rayons du soleil. On sait qu'avec une double ou triple enveloppe vitrée on peut facilement porter l'air intérieur à plus de $100^{\circ}$ [p. 163-166]. "

M. Hervé Mangon, dans son rapport à la Société d'encouragement, 


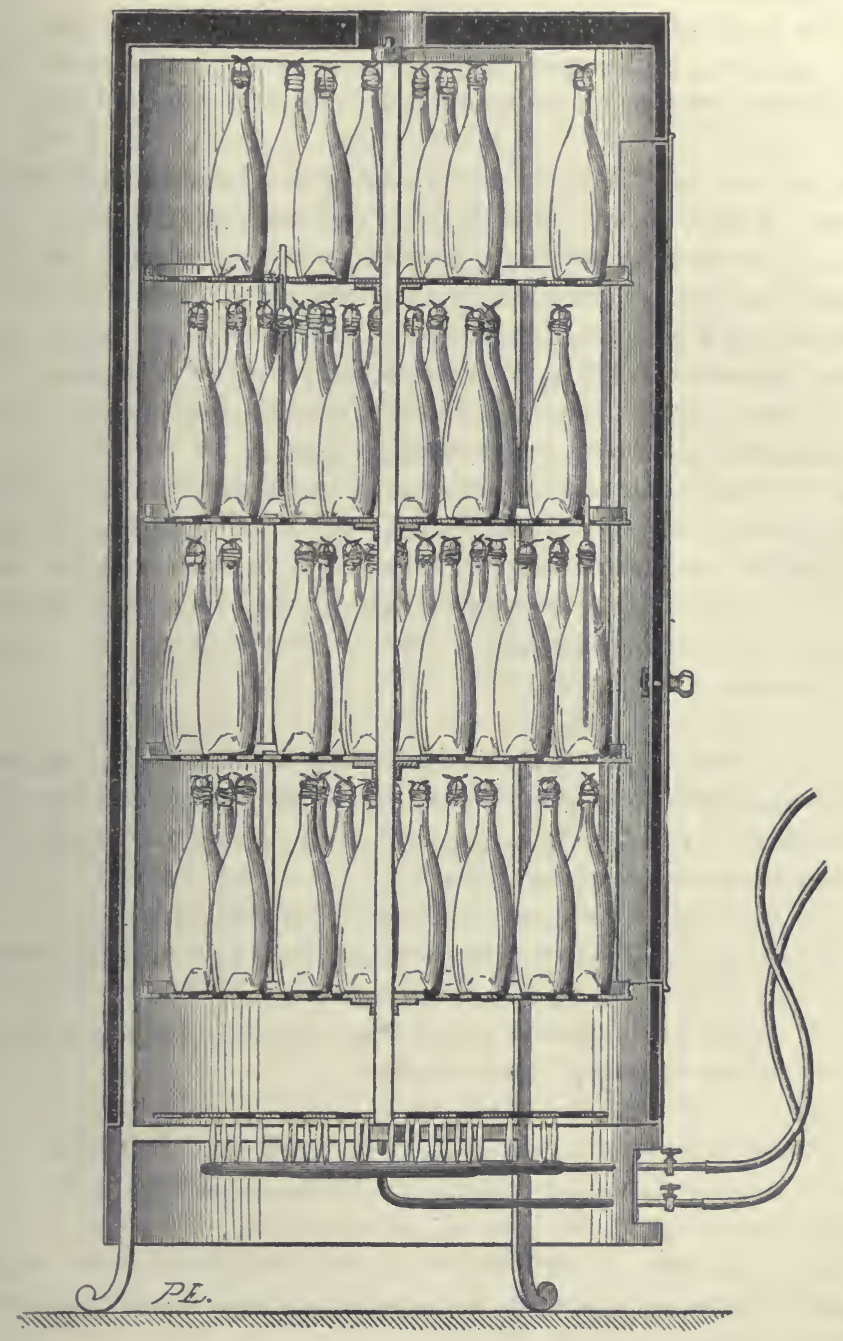

Fig. 42. 
sur le prix proposé pour le meilleur appareil à chauffage du vin, s'exprime ainsi $\left({ }^{(1)}\right)$ :

"Le chauffage des vins en bouteilles, appelé probablement à rendre de grands services pour la conservation des vins fins, s'effectue sans difficulté dans un simple bain-marie, quand on opère en petit.

“Pour chauffer à peu de frais un grand nombre de bouteilles par jour, il conviendrait, sans doute, d'organiser le travail d'une manière continue. Les bouteilles, placées verticalement dans une chaîne à godets sans fin, entreraient par une extrémité d'une chaudière longue et assez peu profonde pour ne pas mouiller les bouchons, et sortiraient par l'autre extrémité après avoir subi l'action de la chaleur.

"Rien de plus simple, d'ailleurs, que les dispositions de détail qui permettraient de réaliser cet arrangement. »

Cette idée ingénieuse paraîtrait se prêter facilement aux besoins de l'industrie : on pourrait même faire sortir les bouteilles du côté de la chaudière où elles entrent, et disposer le foyer sous l'autre extrémité de la chaudière : les bouteilles qui ont subi l'action de la chaleur se refroidiraient ainsi en cédant leur chaleur à celles qui entrent dans l'appareil.

C'est donc le chauffage en bouteilles, le système le plus parfait de tous, qui doit nous guider dans la recherche des conditions que le chauffage du vin en tonneaux doit réaliser autant que possible. Ces conditions sont de trois ordres :

$1^{\circ}$ Garantir le vin contre toute maladie ultérieure;

$2^{\circ}$ Ne pas modifier par le chauffage les propriétés naturelles de ce liquide ;

$3^{\circ}$ Donner à l'appareil à chauffage certaines qualités économiques que réclame la pratique industrielle.

$1^{\circ}$ Pour assurer la conservation du vin, il faut que toutes les parties du liquide atteignent au moins $55^{\circ}$ pendant quelques instants (et une température plus élevée pour certains vins, voir page 207), afin de tuer les germes de tous les organismes, et il faut éviter autant que possible que les vases ou l'air extérieur introduisent à nouveau des germes dans le liquide refroidi.

$2^{\circ} \mathrm{Si}$ l'on veut modifier le moins possible les propriétés du vin, on

1. Mangon (Hervé). Rapport sur le Concours pour les meilleurs appareils de chauffage et de conservation des vins. (Prix : 3.000 francs.) Bulletin de la Société d'encouragement pour l'industrie nationale, 2 e sér., XVII, 1870, p. 422-430. (Note de l'Édition.) 
doit veiller à ce que certaines parties du vin ne soient pas portées à une température trop élevée, qu'elles ne dépassent pas $65^{\circ}$ en général, et que l'action de la chaleur ne dure que quelques instants; on doit maintenir sur le liquide chaud une pression assez grande; enfin, et c'est là la condition la plus essentielle, on doit éviter le contact de l'oxygène avec le liquide soit avant, soit après l'application de la chaleur, mais surtout pendant que le liquide est encore chaud. Si le vin était soumis à une température trop élevée ou trop durable, il serait à craindre que la finesse, que le bouquet du liquide n'en fût altéré. Si la pression qui s'exerce sur le liquide chaud était trop faible, et la température trop élevée, certains principes volatils pourraient en se dégageant du liquide en modifier les propriétés. Si l'on introduisait en grande quantité, par le fait du chauffage, de l'oxygène dans le vin, on apporterait des modifications profondes à sa couleur, à son bouquet, à son vieillissement, comme M. Pasteur l'a démontré dans la deuxième partie de ce livre, et si l'oxygène agissait sur le vin encore chaud, l'effet serait alors très prononcé, il s'y développerait en particulier un goût de cuit, d'autant plus appréciable et plus durable que la température serait plus élevée.

$3^{\circ}$ Pour que le procédé du chauffage se fasse accepter de l'industrie, il faut des appareils d'un usage simple et commode, faciles à construire, à visiter intérieurement et à réparer, qui puissent se monter et se démonter rapidement, qui ne mettent pas le liquide en contact avec un métal attaquable par lui; enfin, toutes choses égales d'ailleurs, on devra préférer l'appareil qui, pour un même nombre d'hectolitres chauffés à l'heure, sera d'un prix moins élevé, consommera dans le même temps moins de combustible, exigera moins de main-d'œuvre, et présentera le plus petit volume. La question de volume, pour les grands appareils, a son importance, car le volume est d'ordinaire en rapport avec la capacité du foyer, par suite, avec la quantité de charbon brûlé, avec l'emplacement nécessaire au fonctionnement de l'appareil, avec le poids de l'appareil et, par suite, avec la faculté de le transporter, de le monter, de le démonter, de le réparer, etc., et, dans une certaine mesure, avec son prix de revient.

Un appareil à chauffage ne peut guère réaliser au plus haut degré toutes ces conditions dont plusieurs sont jusqu'à un certain point opposées : aussi, parmi les nombreux appareils déjà proposés par divers inventeurs serait-il fort difficile ou même fort inexact de faire un choix absolu et exclusif; plusieurs se recommandent par des qualités précieuses, mais diverses, et la préférence pour tel ou tel appareil doit être surtout déterminée par les circonstances où l'on se trouve 
placé et les conditions que l'on tient à réaliser principalement dans le chauffage.

A peine est-il besoin de dire qu'on n'a imaginé aucun appareil pour chauffer le vin à feu nu : la haute température à laquelle serait porté le vin en contact avec le foyer a fait renoncer à ce mode de chauffage, qui ne remplirait pas les conditions du deuxième genre dont il a été question plus haut, page 272 .

Aussi tout appareil à chauffer le vin comprend nécessairement trois parties (fig. 43):

10 Une boîte à feu A;

$2^{\circ}$ Une caisse à vin $\mathrm{C}$;

$3^{\circ}$ Une caisse B à liquide (ordinairement de l'eau) destiné à transmettre en la modérant la chaleur de $\mathrm{A}$ à $\mathrm{C}$.

Quelque variée que soit la forme de ces organes, nous les retrou-

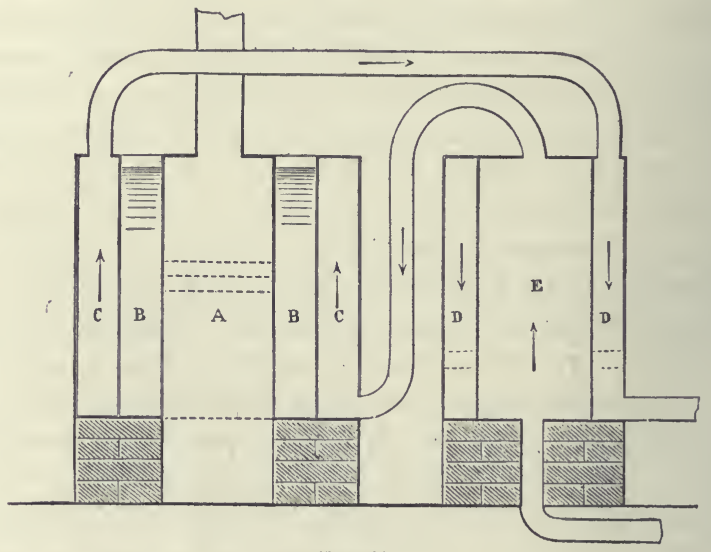

Fig. 43.

verons toujours dans les appareils décrits plus loin, mais avec des modifications très diverses :

Tantôt l'eau remplit complétement la boîte B, et le vin contenu dans C reçoit sa chaleur du liquide en mouvement; tantôt une partie de $B$ est occupée par la vapeur d'eau, qui retombe dans le bain-marie après avoir cédé son calorique au vin.

On peut procéder de deux manières pour faire passer le vin dans l'appareil à chauffage : ou bien on remplit tout le vase $\mathrm{C}$ de vin froid, qu'on amène graduellement à $60^{\circ}$, et alors on l'envoie, une fois chauffé dans toute sa masse, dans les fûts (et comme cas particulier, nous 
considérerons le cas oủ le vase $\mathrm{C}$ serait le fût lui-mème qui contient le vin à chauffer); ou bien le vin, arrivant froid dans ce vase d'une manière continue, en sort constamment à $60^{\prime \prime}$, avec une vitesse convenable, et de là se rend dans les tonneaux. Mais, dans ce dernier cas, la pratique admet deux manières de procéder : ou bien le vin arrive chaud directement dans les fûts, au sortir de l'appareil, ou bien il passe auparavant dans une boîte $D$, où il se refroidit en cédant sa chaleur au vin froid qui arrive dans l'appareil à chauffage par la caisse E.

En somme, il existe plusieurs genres d'appareils à chauffage :

Sous le rapport du mode de chauffage, on distingue les appareils où le vin est chauffé par la vapeur; ceux où il est chauffé au bainmarie.

Sous le rapport du mode de circulation du vin, on distingue les appareils à travail intermittent, et les appareils à circulation continue; en outre, ces derniers peuvent être munis ou non d'un réfrigérant.

L'industrie ne paraît pas très empressée d'adopter le chauffage par la vapeur: sans doute, dans certains cas particuliers, un industriel peut trouver commode d'utiliser un générateur à vapenr, de transporter à distance le calorique d'un foyer fixe, et d'improviser une machine à chauffer, puissante, qu'il utilise pour d'autres opérations; mais, en général, et toujours lorsqu'il s'agit de faire choix d'une machine spéciale à chauffer le vin, l'industrie a raison de préférer le bain-marie à la vapeur: On doit craindre, en effet, avec la vapeur, que la portion du vin la plus voisine du tuyau d'arrivée de la vapeur ne soit portée à une température trop élevée, et la finesse du liquide altérée, comme il paraît résulter de l'expérience. En outre, l'emploi de la vapeur - dans le cas général - est loin d'être économique : Supposons, en effet, la boîte à eau à demi remplie de liquide, fermée, et chauffant le vin par l'intermédiaire de la vapeur sous pression; la température de ce liquide sera supérieure à $100^{\circ}$. Supposons au contraire le bain-marie complétement plein d'eau, communiquant avec l'atmosphère, et chauffant directement le vin par le liquide lui-mème; la température de ce liquide ne dépassera pas $100^{\circ}$, à condition qu'il circule librement dans l'appareil : or, dans le second cas, l'eau absorbera une plus grande portion de la chaleur du foyer que dans le premier. Mais tout le calorique absorbé par l'eau est ensuite transmis au vin. Le chauffage au bain-marie sera donc, toutes choses égales d'ailleurs, et en général, plus rapide et plus économique que le chauffage par la vapeur.

Moins parfaits à bien des égards que les appareils à circulation continue, les appareils intermittents ne sont pas toujours à dédaigner, 
là où l'économie d'espace et de combustible est comptée pour peu de chose, mais où les moyens de fabrication des appareils sont restreints. Dans ces conditions, on peut recourir à un genre d'appareil intermittent très simple : un fourneau ordinaire, une chaudière, un serpentin de forme simple, une cuve en bois pour contenir le vin, c'est-à-dire 'les éléments qui rentrent partout dans la fabrication ordinaire, peuvent i.tre ajustés pour composer un appareil intermittent qui sera, on le conçoit, très facile à organiser et très facile à réparer. En outre, ce genre d'appareil n'exige, dans la direction du travail, aucune pré('ision; l'ouvrier n'a qu'à remplir et vider des tonneaux et jeter de temps en temps du charbon dans le fourneau, opérations que le premier ouvrier venu est habitué à faire; il peut mème, pendant le chauffage du vin, vaquer à d'autres occupations, sans que l'opération soit compromise : à ces caractères on reconnaît un genre d'appareils capables de rendre de très bons services dans la petite industrie agricole, à la campagne, chez le propriétaire.

Dans le chauffage des vins, comme dans toutes les opérations industrielles, les appareils à travail continu conviennent principalement à la grande industrie : bien que la conduite des appareils à chauffage à circulation continue exige plus de soins et de précision que les appareils intermittents (et dans le cas dont nous parlons ce n'est pas un obstacle réel), ils donneront, étant bien dirigés, de meilleurs résultats au point de vue de la qualité du produit que les appareils intermittents, car dans les premiers le vin subira moins longtemps l'action de la chaleur, sera moins longtemps exposé à l'action de l'oxygène de l'air, pendant qu'il reste à une température élevée : par suite, ses principes seront moins modifiés et la perte de produits volatils sera moindre, les qualités du liquide seront donc moins altérées.

D'autre part, considérons deux appareils, l'un intermittent, l'autre continu, de même volume, de structure aussi comparable que possible, de même foyer, c'est-à-dire dépensant à l'heure la même quantité de combustible; le premier fournira moins d'hectolitres de vin chauffé, en vingt-quatre heures, que le second, car il exige des temps d'arrêts nécessaires pour vider et remplir la cuve; en outre, sa caisse à vin doit être beaucoup plus volumineuse que celle d'un appareil continu; par compensation, et à égalité de volume total, sa caisse à eau sera moins spacieuse et, par suite, les surfaces de chauffe moins étendues, ce qui diminuera notablement le rendement. D'ailleurs un appareil continu, fournissant par jour le même nombre d'hectolitres de vin qu'un appareil intermittent de structure analogue, ne sera pas, on le conçoit, 
d'un prix sensiblement plus élevé, n'exigera pas plus de main-d'œuvre. En résumé, les appareils continus sont donc préférables au point de vue de l'économie.

C'est surtout pour les appareils à circulation continue propres à la grande industrie que le côté économique acquiert de l'intérêt; le problème consiste à déterminer le rendement par heure d'un appareil dont les éléments sont connus : il ressort directement du calcul et ne réclame pas nécessairement le secours de l'expérience.

Je traiterai la question dans un cas théorique simple dont se rapprochent plus ou moins les divers cas de la pratique : on verra facilement comment on pourrait diriger les calculs pour chaque appareil, en tenant compte des diverses causes d'erreur que je négligerai, et la formule à laquelle je serai conduit donnera, sans être rigoureuse, une idée suffisante de l'influence des divers éléments d'un appareil sur son rendement.

Reprenons l'appareil figuré page 274́. Appelons V le volume de gaz produit dans l'unité de temps par la combustion du charbon : ce volume, pour un courant d'air convenablement réglé, dépend du poids de charbon brâlé dans l'unité de temps, lequel peut se déduire des dimensions de la grille du foyer, et la température $T^{\prime}$ de ce gaz, au moment de sa production, peut être également connue. Supposons d'autre part que la température de ce gaz, aux divers points d'une même couche horizontale de la boîte $A$, reste la même, c'est-à-dire que la mobilité du gaz soit parfaite; admettons aussi que les courants du bain-marie $B$ soient assez rapides pour que la température de ce bain soit constante en tous ses points. Négligeons les pertes de chaleur par rayonnement extérieur et par le contact de l'air, et toutes les condensations de vapeur ou variations de volume du gaz qui se produisent dans le cylindre A par suite de la variation de la température.

Divisons ce cylindre A en tranches très minces et égales. Exprimons que la quantité de chaleur perdue par une de ces tranches gazeuses, pendant qu'elle vient prendre la place de la couche immédiatement supérieure, est proportionnelle à l'excès de température de cette tranche sur la température du bain-marie, nous aurons l'équation :

$$
c s \varepsilon \Delta \mathrm{T}=-k p \varepsilon \Delta \theta(\mathrm{T}-t) .
$$

$c$ est la chaleur spécifique du gaz rapportée au volume; $k$, une constante qui dépend du coefficient de conductibilité de la paroi du cylindre A et de la nature des milieux en contact avec elle; $s$, la section du cylindre; $p$, son périmètre; $\varepsilon$, la hauteur de la tranche; $\Delta \theta$, le temps que met cette tranche pour venir remplacer la suivante; $\Delta \mathrm{T}$, la varia- 
tion de sa température pendant ce temps; T, la température de la tranche; $t$, la température du bain-marie.

D'où en intégrant :

$$
\mathrm{T}-t=\mathrm{B} e-\frac{k p}{c s} \theta .
$$

En appelant $T^{\prime}$ et $T^{\prime \prime}$ les températures des couches inférieures et supérieures du cylindre A, en désignant par $v$ la vitesse d'ascension du gaz ehaud, par $\mathrm{H}$ la hauteur du cylindre A, en déterminant la constante $B$ de l'équation précédente, en remarquant d'ailleurs que l'on a $s v=\mathrm{V}$, et transformant, on obtient l'équation :

$$
\frac{T^{\prime \prime}-t}{T^{\prime}-t}=c-\frac{l p \mathrm{H}}{c \mathrm{~V}} \text {. }
$$

Un calcul semblable, appliqué à l'échange du calorique entre les vases $\mathrm{B}$ et $\mathrm{C}$, donnera :

$$
\frac{\mathrm{T}_{2}-t}{\mathrm{~T}_{1}-t}=e^{-\frac{h^{\prime} p^{\prime} \mathrm{H}}{c^{\prime} \mathbf{V}^{\prime}}},
$$

équation dans laquelle $T_{1}$ et $T_{2}$ désignent la température du vin à son entrée dans $\mathrm{C}$ et à sa sortie; $p^{\prime}$, le périmètre extérieur du cylindre à eau; $V^{\prime}$, le volume du vin chauffé dans l'unité de temps et $c^{\prime}$, la chaleur spécifique du vin.

En exprimant que toute la chaleur perdue par le gaz central est transmise au vin, on a :

$$
c \mathrm{~V}\left(\mathrm{~T}^{\prime}-\mathrm{T}^{\prime \prime}\right)=c^{\prime} \mathrm{V}^{\prime}\left(\mathrm{T}_{2}-\mathrm{T}_{4}\right) .
$$

En éliminant $\mathrm{T}^{\prime \prime}$ et $t$ entre ces trois équations, on aura finalement :

$$
\frac{\mathrm{T}^{\prime}-\mathrm{T}_{4}}{\mathrm{~T}_{2}-\mathrm{T}_{4}}=\frac{c^{\prime} \mathrm{V}^{\prime}}{c \mathrm{~V}} \frac{1}{1-e^{-\frac{k p \mathrm{H}}{c \mathrm{~V}}}}+\frac{1}{1-e^{-\frac{k^{\prime} p^{\prime} \mathrm{H}}{c^{\prime} \mathrm{V}^{\prime}}}}
$$

équation qui donne $\mathrm{V}^{\prime}$, rendement de l'appareil dans l'unité de temps.

Cette formule peut conduire à quelques conséquences pratiques d'un certain intérêt :

Considérons divers appareils construits sur le même modèle et géométriquement semblables, mais de grandeurs différentes : il est facile de voir, par cette équation, que $\mathrm{V}$ étant à peu près proportionnel à la section du foyer, par suite au carré des dimensions linéaires de l'appareil, il en sera de même de V', c'est-à-dire que le débit de l'appareil dans l'unité de temps variera comme le carré des dimensions linéaires et sera à peu près proportionnel à la quantité de combustible dépensée. 
Comparons d'autre part les rendements d'appareils égaux en volume, mais de structure différente : la discussion de la formule précédente nous apprend que, si $\mathrm{V}$ reste constant, les surfaces $p \mathrm{H}, p^{\prime} \mathrm{H}^{\prime}$ étant seules variables, le volume $\mathrm{V}^{\prime}$ de vin chauffé dans l'unité de temps variera dans le même sens, en sorte que le rendement de l'appareil, à égale quantité de charbon brûlé, et dans le même temps, sera d'autant plus élevé que les surfaces de chauffe auront plus de développement. Si, au contraire, les surfaces de chauffe $p \mathrm{H}$ et $p^{\prime} \mathrm{H}^{\prime}$ étant constantes, la quantité $\mathrm{V}$ augmente, $\mathrm{V}^{\prime \prime}$ croîtra dans le même sens, mais le rapport $\frac{\mathrm{V}^{\prime}}{\mathrm{V}}$ diminuera, c'est-à-dire qu'en augnentant les dimensions du foyer seul, et par suite la quantité de charbon brûlé dans le même temps, on obtient un rendement plus grand par heure, mais la dépense en combustible par hectolitre de vin chauffé est plus considérable.

Dans les premiers essais de M. Pasteur sur le chauffage, le vin restait pendant une demi-heure ou une heure vers $60^{\circ}$ : c'était à l'expérience à dire si cette durée ne pouvait pas être amoindrie, ou si ce temps était absolument nécessaire pour tuer les germes. Or, on a construit des appareils à circulation continue munis de réfrigérants (fig. 43, page 274), dans lesquels le vin chauffé, incessamment refroidi par le vin qui entre dans l'appareil, ne reste vers $60^{\circ}$ que pendant une ou deux minutes, et il ne paraît pas que cette modification influe d'une manière fâcheuse sur sa conservation.

Pourtant il est nécessaire, dans ce cas, de donner plus d'attention au nettoyage des tonneaux, de les laver avec soin à l'eau bouillante, d'y brûler du soufre, etc., car il est à craindre que le,vin, y arrivant froid, n'y trouve des germes actifs qui détruisent les effets du chauffage. Il est également nécessaire de surveiller avec plus de soin le thermomètre de l'appareil à chauffage, car si quelques litres de vin n'atteignaient pas la température à laquelle les germes sont tués, ils suffiraient pour porter dans toute la masse du vin des germes de maladie.

Si l'on évite ces dangers, il est manifeste que l'emploi d'un réfrigérant réunit plusieurs avantages : Le vin ne subit l'action de la chaleur que pendant un temps très court; et il ne reçoit pas le contact de l'air pendant qu'il est encore chaud, conditions excellentes pour la conservation des qualités précieuses de ce liquide. (Voir page 273.) Au point de vue économique, on chauffe par heure un plus grand nombre d'hectolitres avec le mème appareil muni d'un réfrigérant sans dépenser plus de combustible.

Il est facile de déterminer par le calcul le nombre de degrés dont 
le réfrigérant refroidit le vin chauffé, et le rapport du rendement de l'appareil muni de son réfrigérant au rendement de l'appareil sans réfrigérant :

Appelons $\mathrm{T}$ et $\mathrm{T}$, les températures du vin à son entrée dans le réfrigérant $\mathrm{E}$ et à son entrée dans le caléfacteur $\mathrm{C}_{3} ; \mathrm{T}_{2}$ et $\mathrm{T}_{2}$ les températures du vin au sortir du caléfacteur et au sortir du réfrigérant pour se rendre dans les tonneaux (fig. 43, page 274).

Remarquons d'abord que le vin qui s'échauffe en $\mathrm{E}$ de $\mathrm{T}$ à $\mathrm{T}_{1}$ cède sa chaleur à un égal volume de vin qui se refroidit en $\mathrm{D}$ de $\mathrm{T}_{2}$ à $\mathrm{T}_{3}$, en sorte que l'on a :

$$
\mathrm{T}_{1}-\mathrm{T}=\mathrm{T}_{2}-\mathrm{T}_{3}
$$

ou :

$$
\mathrm{T}_{2}-\mathrm{T}_{4}=\mathrm{T}_{3}-\mathrm{T} \text {. }
$$

Les différences de température dans une même section des deux cylindres $\mathrm{D}$ et $\mathrm{E}$ sont donc égales à la partie inférieure et à la partie supérieure de ces deux cylindres; on verrait aisément que cette différence de température est aussi constante dans une section quelconque des deux cylindres.

Si donc on exprime que la chaleur perdue par une tranche mince du liquide du cylindre $\mathrm{D}$, pendant qu'il parcourt la hauteur $\mathrm{H}^{\prime}$ de ce cylindre, est proportionnelle à l'excès constant de la température de cette tranche sur la tranche correspondante du cylindre E, on aura une équation de la forme :

$$
c^{\prime} \varepsilon^{\prime}\left(\mathrm{T}_{2}-\mathrm{T}_{\mathrm{3}}\right)=k^{\prime \prime} p^{\prime \prime} \varepsilon \theta\left(\mathrm{T}_{\mathrm{3}}-\mathrm{T}\right),
$$

équation dans laquelle $c^{\prime}, \varepsilon, s^{\prime}, k^{\prime \prime}, p^{\prime \prime}$, désignent des éléments analogues à ceux qui sont représentés par les mêmes lettres dans l'équation (1), et $\theta$ le temps que met le liquide à parcourir la hauteur $\mathrm{H}^{\prime}$.

En désignant par $\iota^{\prime}$ la vitesse du vin dans le cylindre D, par V" le rendement de l'appareil dans l'unité de temps, et en remarquant que l'on a : $v^{\prime} \theta=\mathrm{H}^{\prime}$ et $s^{\prime} v^{\prime}=\mathrm{V}^{\prime \prime}$, et en transformant l'équation précédente, on obtient :

$$
\mathrm{T}_{2}-\mathrm{T}_{3}=\left(\mathrm{T}_{2}-\mathrm{T}\right) \frac{\frac{k^{\prime \prime} p^{\prime \prime} \mathrm{H}^{\prime}}{c^{\prime} \mathrm{V}^{\prime \prime}}}{1+\frac{k^{\prime \prime} p^{\prime \prime} \mathrm{H}^{\prime}}{c^{\prime} \mathrm{V}^{\prime \prime}}} .
$$

Cette équation sera prise simultanément avec l'équation (6) et avec l'équation (5) appliquée aux données de l'appareil muni de son réfrigérant, entre lesquelles on éliminera $T_{1}$, et ces trois équations donneront $T_{2}-T_{2}$, qui mesure le refroidissement du vin par le réfrigérant, et $V^{\prime \prime}$ le rendement de l'appareil avec réfrigérant; l'équation (5) appliquée 
au caléfacteur seul donnera $V^{\prime}$ rendement de l'appareil sans réfrigérant; on aura ainsi le rapport $\frac{\mathrm{V}^{\prime \prime}}{\mathrm{V}^{\prime}}$.

On peut du reste avoir plus simplement la valeur approchée du rapport $\frac{\mathrm{V}^{\prime \prime}}{\mathrm{V}^{\prime}}$, si l'on remarque que les gaz chauds de la boîte à feu cèdent au vin des quantités totales de chaleur peu différentes, soit qu'on emploie le réfrigérant, soit qu'on le supprime. C'est ainsi qu'on obtient l'équation approchée :

$$
\frac{V^{\prime \prime}}{V^{\prime}}=\frac{T_{3}-T}{T_{2}-T_{1}} .
$$

En combinant cette équation avec les équations (6) et (8), on peut éliminer $T_{1}$, obtenir $\frac{V^{\prime \prime}}{V^{\prime}}$ et $T_{2}-T_{3}$ en fonction d'éléments connus et de $V^{\prime}$ qui est donné par l'équation (5) appliquée au caléfacteur sans réfrigérant, et se convaincre que le refroidissement du vin par le réfrigérant, de même que le rapport des rendements de l'appareil, avec ou sans réfrigérant, dépendent essentiellement de la surface $p^{\prime \prime} \mathrm{H}^{\prime}$ de la boîte $\mathrm{E}$ du réfrigérant et augmentent avec elle.

A peine le procédé de la conservation des vins par la chaleur fut-il connu, que divers praticiens proposèrent à M. Pasteur des procédés industriels pour le chauffage des vins en fûts, ou lui demandèrent des conseils à cet égard : preuve incontestable de l'intérêt général qui s'attachait à la question.

Voici ce que M. Pasteur dit à ce sujet dans la première édition de cet ouvrage :

"Plusieurs personnes ont bien voulu me communiquer leurs idées sur des procédés divers. Je les prie de recevoir mes remercîments et mes excuses si le temps m'a manqué pour répondre à toutes les lettres qui me sont parvenues. Je crois que chacun fera bien de mettre à l'épreuve le dispositif qu'il aura imaginé, afin que l'expérience juge en dernier ressort. M. H. Marès, surtout, m'a communiqué récemment des idées qui me paraissent pratiques. J'ai hâte de voir les vins naturels du Midi, non vinés, transportés sur tous les marchés. La France, grâce au procédé de conservation par le chauffage préalable, pourrait alimenter de vin le monde entier [note 1, p. 169-170 de la $1^{\text {re }}$ édition]. "

"Le chauffage en fût pratiqué dans des bains-marie (voir page 263) ne me paraît pas être du tout le mode à adopter définitivement. Il faut un procédé qui puisse s'appliquer facilement à des quantités considé- 
rables de vin. Les essais dont j'ai parlé ont été faits sur de petits fûts de trente litres, et n'avaient d'autre but que de donner de premières indications [p. 169 de la $1^{\text {re }}$ édition]. »

Et ailleurs :

“ Beaucoup de personnes me demandent d'indiquer le moyen qui me paraitrait le plus pratique pour l'application en grand du procédé de conservation que j'ai déduit de mes études sur les causes des maladies des vins, consistant dans une élévation préalable de la température à $50^{\circ}$ environ.

" J'ai déjà dit que c'était à l'industrie et au commerce de faire cette recherche. Pour moi, si j'avais à pratiquer des essais $\square$ sur une grande échelle, voici le mode de chauffage que je voudrais tenter tout d'abord: soit un générateur de vapeur, grand ou petit, suivant les besoins; que l'on visse ou que l'on adapte, par un moyen quelconque, sur le tube de sortie de la vapeur, un tube serpentin avec branche de retour pareil à celui de la figure 44 . Il serait en cuivre, ou mieux en cuivre argenté extérieurement. Introduisez ce tube dans le tonneau, par l'ouverture de la bonde, et faites glisser le bouchon $a b$ de façon à couvrir l'orifice sans le fermer hermétiquement, pour que le vin de dilatation puisse s'échapperau besoin. La vapeur, en circulant dans le serpentin, échauffera le vin, et elle sortira par l'orifice $o$, d'où elle Fra. 44. pourra se rendre dans un autre serpentin pareil, placé dans un tonneau voisin, et ainsi de suite; ou bien elle viendra échauffer l'eau d'une caisse en tôle, formant bain-marie, pour le chauffage du vin en bouteilles.

"Que l'on imagine, dans une filature, les bassines à dévider les cocons remplacées par des tonneaux, et le tube à robinet d'admission de la vapeur communiquant avec les serpentins dont je parle, et l'on comprendra toute la facilité de l'opération du chauffage.

" Sans doute il ne faut pas que la vapeur se condense directement dans le vin. Pourtant, il ne faudrait pas rejeter a priori un tel procédé. Il est possible que, pour les vins communs, ce soit la plus simple et la plus économique des méthodes, car je ne pense pas que l'on puisse nuire ainsi sensiblement à la qualité de tels vins, tant il faudrait un faible poids de vapeur pour atteindre la température voulue [note additionnelle, p. 262 de la $1^{\text {re }}$ édition]. »

En 1868, le $\mathrm{D}^{\mathrm{r}}$ Antonio Pacinotti, de Bologne, a essayé de réaliser 
l'idée, émise par M. Pasteur, du chauffage direct du vin dans les tonneaux, par une disposition assez singulière : concevons une sorte de petit fourneau métallique, surmonté d'un tube assez élevé pour dégager les produits de la combustion; un second tube, moins élevé que le premier, communique avec la partie inférieure de ce fourneau et amène l'air nécessaire à la combustion; un manchon contenant de l'eau pour servir de bain-marie enveloppe le tout. On descend ce petit appareil dans le tonneau par une ouverture pratiquée supérieurement; on jette le combustible par l'ouverture du premier tuyau, et la température du vin s'élève peu à peu : tel est à peu près le procédé imaginé par le Dr Pacinotti.

Très simple et peu conteux, puisque son prix est de 25 francs, très économique en apparence au point de vue de la main-d'œuvre et du combustible, cet appareil est réellement très défectueux sous le rapport du rendement à l'heure, car il exige toute une journée pour chauffer vers $50^{\circ}$ un tonneau de six barils, inconvénient capital qui tient à l'exiguïté du foyer et des surfaces de chauffe.

M. Charles Tellier, ingénieur civil à Paris, a réalisé l'idée de M. Pasteur d'une façon plus pratique. La partie spéciale de son appareil (fig. 45) consiste en un serpentin en cuivre $S$, étamé extérieurement et contourné en hélice, dans l'intérieur duquel est un autre tube de section beaucoup plus petite. Cet appareil étant introduit par l'ouverture de la bonde dans un tonneau de vin $\mathrm{T}$, on fait communiquer le tube intérieur du serpentin, ouvert inférieurement, par le tube $a$, avec un générateur à vapeur F; le gros tube extérieur, qui est fermé inférieurement, communique, par le tube $e$, arec un broc $\mathrm{V}$ de capacité connue. On ouvre le robinet du tube $a$ : la vapeur se rend dans le serpentin S, s'y condense, et l'eau de condensation se rend dans le broc V. Lorsqu'on y a recueilli un volume d'eau déterminé, le vin du tonneau est chauffé à point. Le chauffage terminé, on adapte à l'ouverture de la bonde du tonneau un vase cylindrique en fer-blanc terminé inférieurement par une tubulure. Sur ce cylindre, on applique un entonnoir muni d'un long tube qui pénètre dans le liquide du tonneau, en passant dans la tubulure. On verse dans l'entonnoir le vin qu'on a été obligé d'enlever du tonneau pour permettre au serpentin d'y pénétrer et à la dilatation du liquide de s'effectuer. Ce liquide froid se mêle au liquide chaud du tonneau, en y pénétrant par le tube plongeur, pendant que le liquide chaud du tonneau remonte dans le cylindre extérieur. Le vin une fois refroidi, on retire l'entonnoir et on met la bonde. Quant au réservoir A, représenté sur la figure, tantòt il sert à 
alimenter la chaudière, tantôt il fonctionne comme appareil de sûreté, ‘à l'aide de tubes $p, p$.

Il est facile, en tenant compte des pertes de calorique,, de com

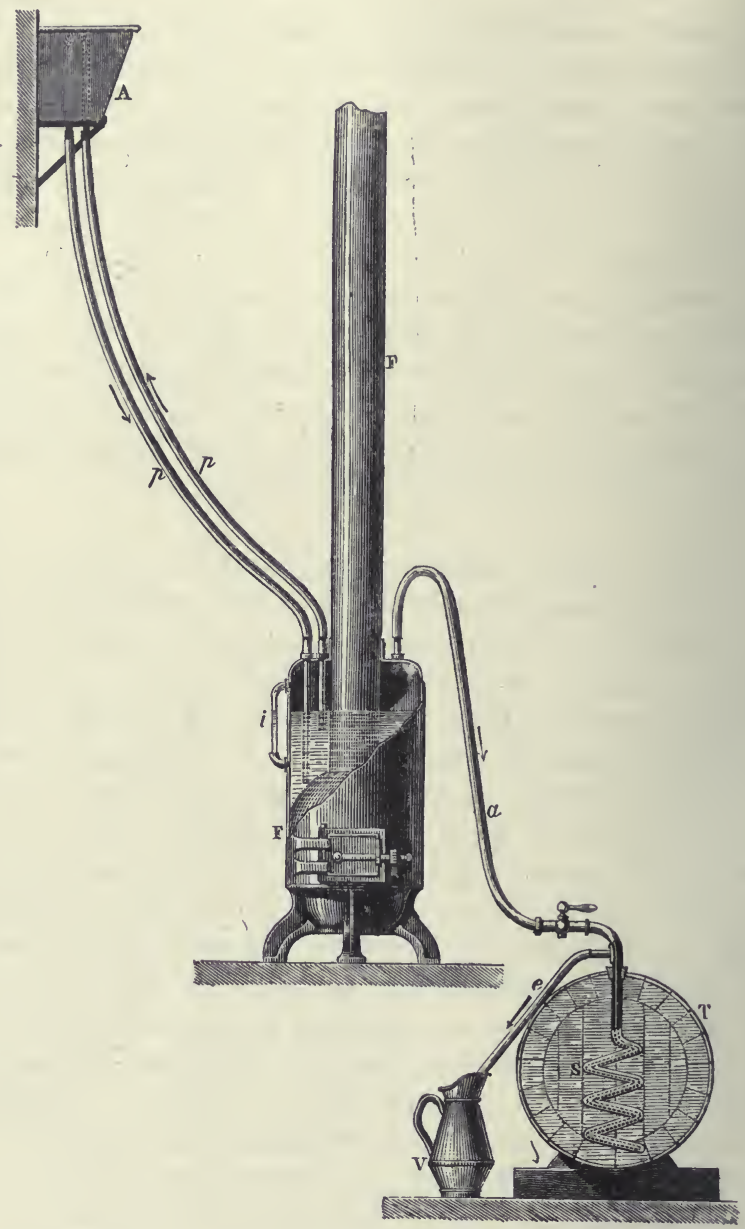

Échelle : $1 / 25^{\circ}$.

Fig. 45. - Appareil de M. Gh. Tellię, chauffant 228 litres à l'heure.

prendre que, suivant l'assertion de l'auteur, une barrique de 228 litres, prise à $10^{\circ}$, doit atteindre $53^{\circ}$ environ, lorsqu'un broc de 20 litres est 
rempli d'eau de condensation. Un appareil capable de chauffer en une heure cette barrique consomme environ 5 kilogrammes de charbon, dont la dépense, à raison de 3 francs les 100 kilogrammes, est d'environ 15 centimes; l'appareil complet, avec la chaudière et les accessoires, coûte 275 francs (1).

Cet appareil présente les inconvénients que nous avons signalés dans les appareils chauffés directement par la vapeur (p. 275). Il offre les avantages et les inconvénients généraux propres aux appareils intermittents (p. 275), avec quelques particularités : il est d'un prix très modéré, si l'on possède déjà un générateur à vapeur, auquel on puisse adapter le serpentin. Il évite les transvasements, qui nécessitent de la main-d'œuvre, et sont une cause d'aération du liquide, et quelquefois une cause d'erreur par suite de l'introduction possible des germes dans le vin refroidi. Le cylindre à entonnoir a pour effet d'empêcher la vidange, et, par suite, l'aération du liquide dans le tonneau pendant qu'il se refroidit. Pourtant, bien que le vin paraisse chauffé à l'abri de l'air, il y a réellement contact du liquide chaud et de l'oxygène de l'air par les douves du tonneau, et l'on sait que, dans ces conditions, l'aération modifie notablement les propriétés du vin (p. 273). La disposition ingénieuse du serpentin, que l'on introduit dans le tonneau à la manière d'une vis, permet d'obtenir une surface de chauffe assez appréciable; mais, quoi que l'on fasse, la surface de ce serpentin est toujours assez réduite, et le rendement par heure, eu égard au volume, ou par kilogramme de charbon brûlé, est relativement faible. Enfin, l'emploi d'un vase de capacité déterminée pour recueillir l'eau de condensation de la vapeur dispense de l'observation du thermomètre pendant le chauffage. Le réservoir régulateur $A$, dont nous avons expliqué l'usage, est également fort commode.

Dans les appareils que nous allons décrire, comme dans ceux qui précèdent, le chauffage est encore intermittent; mais le vin, au lieu d'être chauffé dans son fût, subit l'action de la chaleur dans une cuve spéciale où il est transvasé tout exprès pour cette opération.

L'idée de ce mode de chauffage a été indiquée par M. Pasteur dans la première édition de ses Études sur le vin [p. 169]:

"Je crois, dit-il, que le mieux serait de chauffer le vin, à l'abri de l'air, dans de grandes cuves, par la vapeur d'eau circulant dans des serpentins, à la manière de MM. Privas et Thomas (voir à l'Appendice de set ouvrage [p. 343-361] ma lettre au Moniteur vinicole); puis, lorsque

1. Les nombres cités dans ce chapitre, relativement au rendement et au prix des appareils, reposent sur les indications fournies par les inventeurs eux-mêmes. 
le vin serait chaud et porté par exemple à 60 ou $65^{\circ}$, on en remplirait les pièces, où il se refroidirait; mais la teinpérature à laquelle le vin aurait été porté en cuve serait telle qu'après le remplissage des pièces le vin y aurait encore une température maximum supérieure a $50^{\circ}$, ou mieux supérieure à la température minimum suffisante pour détruire la vitalité des geimes que ces tonneaux pourraient contenir. »

Ces appareils de MM. Privas et Thomas ont beaucoup d'analogie avec l'appareil Hrck employé en Belgique pour vieillir les vins et les eaux-de-vie : ce dernier pourrait également être appliqué au chauffage du vin par le procédé Pasteur. M. Vincent Fialla, près de Vienne (Autriche), constririt également un appareil du même genre qui fonctionne en Autriche pour pasteuriser le vin (comme disent les Allemands), preuve incontestable du progrès de la méthode nouvelle à l'étranger.

Tous ces appareils, que je ne décrirai pas en détail, se ressemblent; le vin est contenu dans une cuve chauffée, à l'aide de serpentins, par la vapeur issue d'un générateur. Les remarques que j'ai faites sur les appareils chauffés par la vapeur leur sont généralement applicables.

L'appareil de M. Rossignol, négociant en vins à Orléans, est aussi un appareil intermittent, "mais chauffé directement au bain-marie :

Cet appareil (fig. 46) se compose de trois parties : $1^{\circ}$ un fourneau $F$, qui ne diffère en rien des fourneaux ordinaires de l'industrie; $2^{\circ}$ une chaudière évasée en cuivre $\mathrm{C}$, surmontée d'un couvercle qui lui est soudé et qui se prolonge par un tube droit $\mathrm{H}$, ouvert à son extrémité; cet appareil est rempli d'eau servant de bain-marie, jusqu'à la moitié du tube; $3^{\circ}$ une cuve, ou un tonneau en bois $\mathrm{T}$, dont le fond a été scié, et qui repose par ce fond sur le bord du couvercle de la chaudière; il est fixé hermétiquement à ce couvercle par un mécanisme simple : le bord du couvercle $a$ dépasse la chaudière de 3 à 4 centimètres; au-dessous de lui est une rondelle en fer forgé $i$, et, au-dessus, une rondelle de caoutchouc, sur laquelle repose le bord du tonneau; un cercle de fer entoure le bord du tonneau, et est muni de pattes en fer $e$, qui se relient par de forts boulons à la rondelle inférieure. C'est l'espace compris entre l'extérieur de la chaudière $\mathrm{C}$ et l'intérieur du tonneau $\mathrm{T}$ qui sert à recevoir le vin; aussi a-t-on pris la précaution d'étamer toute cette portion de la chaudière qui doit être en contact avec le vin. Un thermomètre $t$ sert à indiquer la température du vin; un vase $\mathrm{E}$ avec tube sert de trop-plein et permet au liquide de remplir l'appareil, en lui laissant la liberté de se dilater par la chaleur.

Un simple coup d'œil jeté sur la figure suffit à faire comprendre 
comment fonctionne cet appareil. Il chauffe 6 hectolitres en une heure, dépense 10 centimes de combustible par hectolitre, et coûte 140 francs.

Il possède naturellement les inconvénients et les avantages généraux des appareils intermittents à circulation d'eau chaude (p. 275). Voici quels sont ses caractères spéciaux : comme dans l'appareil

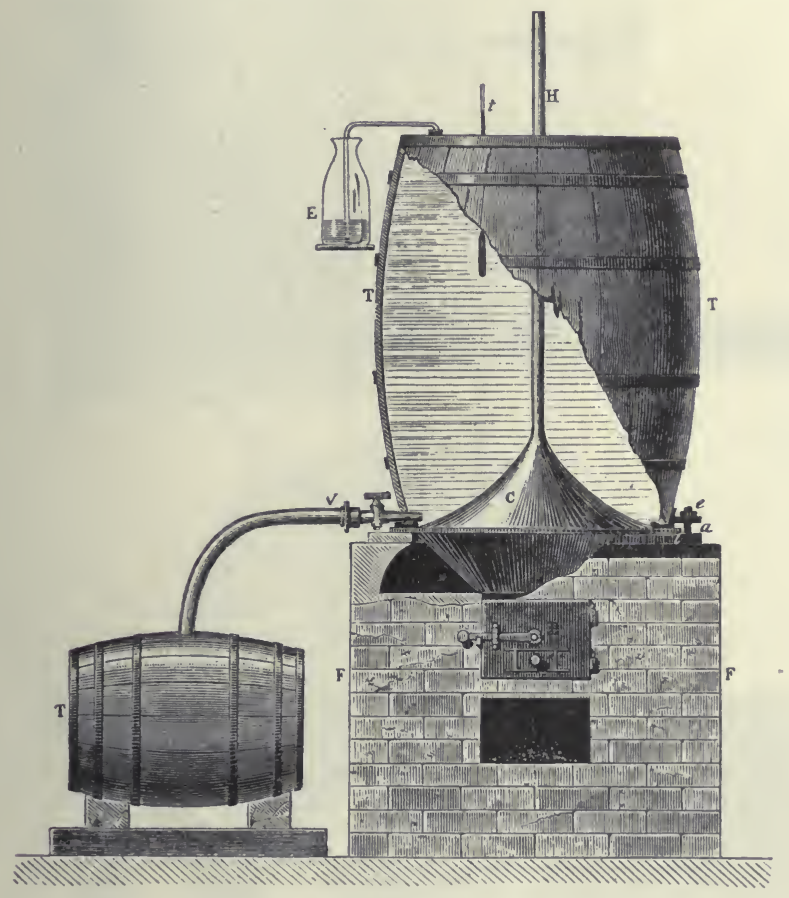

Échelle : $1 / 25^{\circ}$.

Frc. 46. - Appareil de Mr. Rossignol, chauffant 6 hectolitres à l'heure.

Tellier, le vin est chauffé dans un vase en bois, c'est-à-dire poreux, il n'est donc pas à l'abri du contact de l'oxygène de l'air pendant le chauffage, dans des conditions où cette aération agit énergiquement sur les propriétés du vin. Cet appareil présente, comme ceux dont il va être question, l'inconvénient des transvasements du vin, cause d'aération qu'évite le chauffage direct en tonneau. Au point de vue économique, il exige un peu plus de main-d'œuvre que l'appareil précédent, mais il est d'un prix moins élevé; comme lui, il a un rendement faible, 
parce que la surface de chauffe et la surface de séparation du bain-marie et $\mathrm{du}$ vin sont peu développées. Il est d'ailleurs simple et facile à construire.

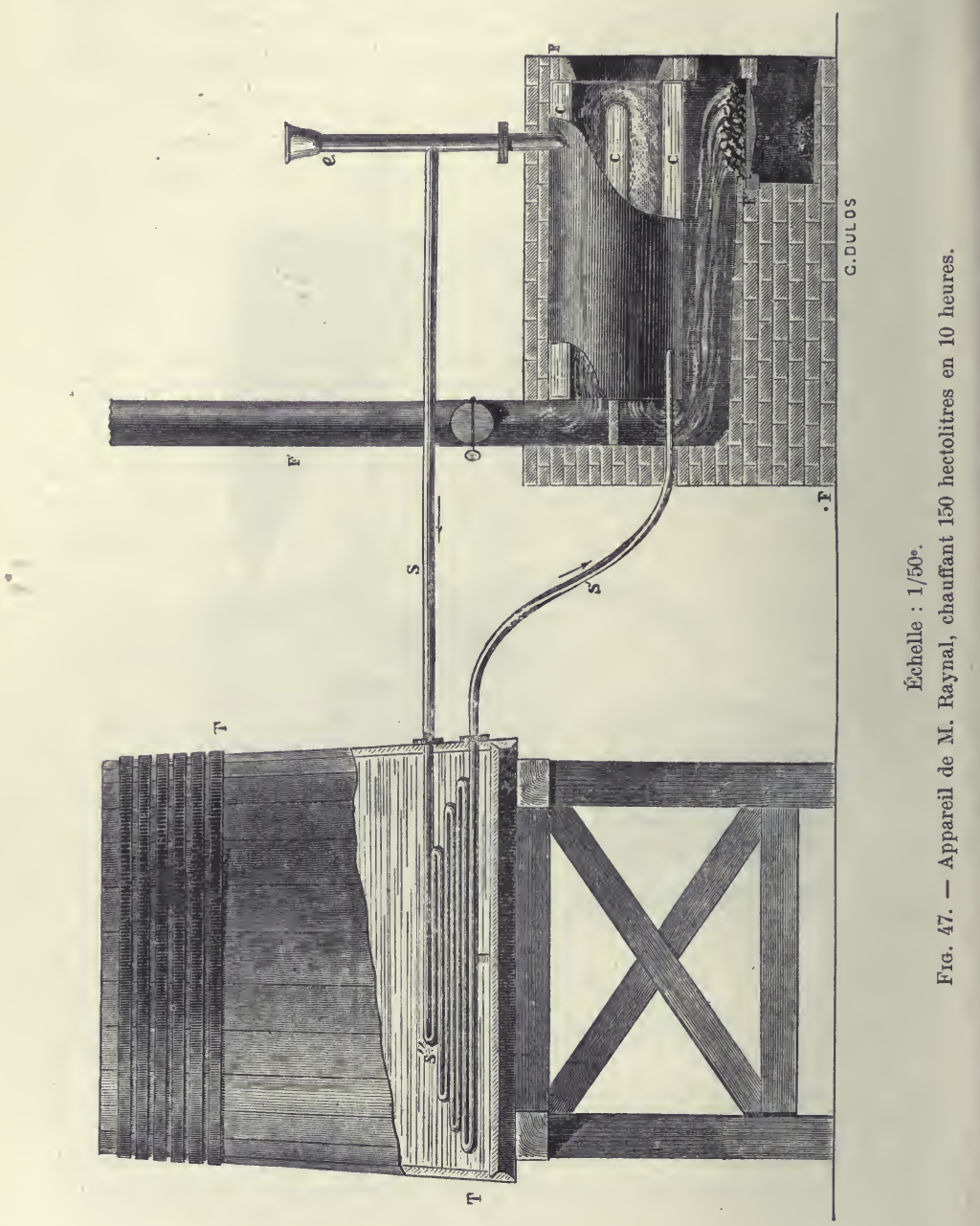

M. Raynal, de Narbonne, a, depuis 1866, construit des appareils intermittents, à circulation d'eau chaude, dont les dimensions sont appropriées à la grande industrie. 
Les figures 47 et 48 donnent plusieurs vues de ces appareils dans

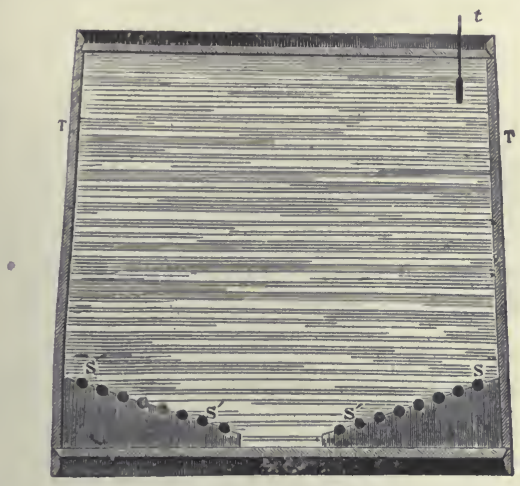

Coupe verticale.

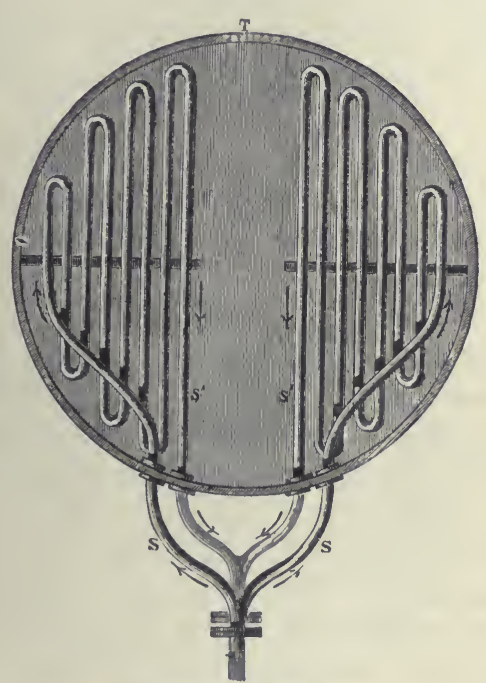

Projection horizontale.

FIG. 48. - Cuve de l'appareil Raynal.

lesquels nous retrouvons encore les trois parties essentielles de tout appareil à chauffage :

$1^{\circ}$ Une grande cuve en bois $\mathrm{T}$ destinée à recevoir le vin à chauffer; elle est fermée à la partie supérieure et munie d'un thermomètre $t$; 
$2^{\circ}$ Une chaudière annulaire $\mathrm{C}$, formée de deux cylindres concentriques et de deux lames parallèles, suivant l'axe, reliées au cylindre intérieur; cette chaudière communique supérieurement, à l'aide d'un tube bifurqué, avec deux serpentins S, S, placés sur le fond de la cuve à vin et soutenus à l'aide de fortes planches : ceux-ci viennent, par leur partie inférieure $S^{\prime}, S^{\prime}$, se confondre en un seul tube, qui de nouveau va rejoindre la chaudière vers sa partie inférieure;

$3^{\circ}$ Un fourneau $\mathrm{F}$ dans lequel la chaudière est encastrée; les gaz de la combustion enveloppant la chaudière parcourent le circuit indiqué sur la figure 47 et s'échappent en $F^{\prime \prime}$.

Lorsqu'on veut chauffer du vin, la chaudière et les serpentins doivent être complétement remplis d'eau par l'entonnoir $e$. La cuve T est remplie de vin jusqu'à la partie supérieure. Lorsque le thermomètre atteint $55^{\circ}$, on éteint le feu et on transvase le vin chaud dans les fûts.

M. Raynal a fabriqué, jusqu'ici, un certain nombre de ces appareils de diverses grandeurs :

Appareils à cuves de 500 hectolitres, prix. . . . . . 1,900 fr.

\begin{tabular}{|c|c|c|}
\hline & 150 & - \\
\hline & 60 à 70 & - \\
\hline
\end{tabular}

L'appareil de 150 hectolitres dépense, pendant le temps du chauffage, qui est de dix heures, 120 kilogrammes de houille, ce qui, en prenant pour base le prix de 3 francs par 100 kilogrammes de houille, représente une dépense de 2 cent. 5 de combustible par hectolitre de vin.

Cet appareil est du même genre que l'appareil de M. Rossignol : comme lui, il donne lieu à l'aération inhérente au chauffage dans une cuve en bois. Il ne présente aucune difficulté réelle de construction. Un peu moins simple de forme que l'appareil Rossignol, il a aussi un plus grand rendement, sous le même volume, soit dans le même temps, soit à égale quantité de charbon brûlé. La surface de chauffe et la surface de contact du bain-marie et du vin sont, en effet, plus étendues dans l'appareil Raynal. Il est facile à visiter intérieurement et à nettoyer, grâce à une porte pratiquée dans la partie supérieure de la cuve à vin.

Les appareils à circulation continue doivent spécialement nous intéresser, parce que, comme nous l'avons dit plus haut, ils sont éminemment propres à la grande industrie.

Je ne mentionne qu'en passant un appareil à circulation continue chauffé par la vapeur, imaginé en 1866, par M. Holderer, de Strasbourg : j'en donnerai une idée suffisante, en disant qu'il n'est autre qu'un de 
ces alambics de laboratoire servant à distiller de l'eau, avec un tube de retour pour ramener l'eau distillée dans la chaudière, et un couvercle

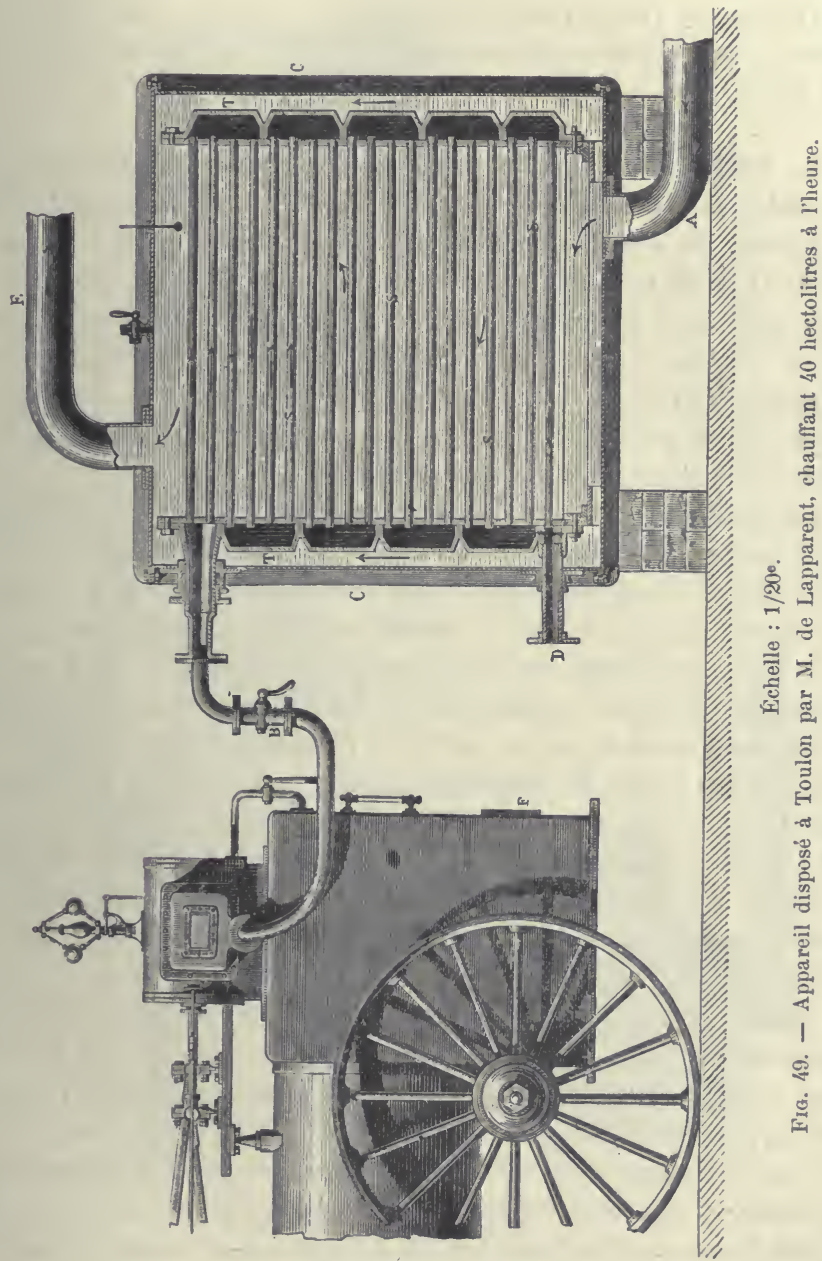

pour fermer le réfrigérant qui est muni d'un thermomètre; le vin circule de bas en haut dans le réfrigérant de l'alambic, et s'échauffe, en condensant la vapeur d'eau du serpentin.

M. Beaume, professeur au lycée d'Orléans, a chauffé en 1867 de 
petites quantités de vin, avec un appareil analogue, aussi simple et aussi peu coûteux que possible.

Les alambics que l'on voit transporter dans le midi de la France, de village en village, pour distiller les vins, ne pourraient-ils pas recevoir une modification analogue, et servir utilement à deux usages à la fois?

En 1868, M. de Lapparent (1), directeur des constructions navales au ministère de la marine, voulut faire dans le port de Toulon une expérience de chauffage en grand sur les vins destinés à la marine de l'État. Il avait besoin d'une machine d'une grande puissance; il eut l'heureuse idée de combiner des appareils qu'il avait sous la main, et qui se trouvent dans tous les ports : il se servit d'une locomobile dont la vapeur était lancée dans l'appareil réfrigérant de M. Perroy, officier supérieur du génie maritime, appareil habituellement employé à bord des navires pour distiller l'eau de mer (fig. 49).

Le réfrigérant CC de M. Perroy consiste en une caisse métallique, renfermant un serpentin formé d'une série de tubes droits très nombreux SS, qui aboutissent par leurs extrémités à des cavités TT. La vapeur du générateur $\mathrm{F}$ entre dans le serpentin multiple par le tube B, en parcourt les tubes successivement de haut en bas, s'y condense peu à peu, et l'eau de condensation s'écoule au dehors en D; le vin, entrant en A par le bas de la caisse C, s'élève verticalement en baignant les tubes du serpentin et sort par la partie supérieure en $\mathrm{E}$ pour se rendre au tonneau. Un thermomètre, dont le réservoir plonge dans la partie supérieure de la caìsse, indique la température du vin à la sortie. Un robinet adapté, non loin du thermomètre, au tuyau de sortie, sert à régler l'écoulement continu du vin, de telle sorte que le thermomètre marque toujours de 55 à $60^{\circ}$.

Dans cet appareil, comme dans tous les appareils à circulation continue, le vin doit être soumis à une pression un peu forte, si l'on 'veut éviter un dégagement du gaz acide carbonique par l'action de la chaleur, qui produirait des irrégularités dans l'écoulement du liquide.

On peut estimer que cet appareil chauffe environ 40 hectolitres de vin à l'heure et consomme pendant ce temps 45 kilogrammes de charbon, ce qui, à raison de 3 francs les 100 kilogrammes, constitue une dépense de 3 à 4 centimes par hectolitre.

Il présente les inconvénients généraux assez graves des appareils à

1. Lapparent (de). Rapport à S. Exc. le Ministre de la marine et des colonies sur la conservation des vins. Revue maritime et coloniale, XXIV, 1868, p. 124-133, et Paris, 1868, brochure de $11 \mathrm{p}$. in-12. (Note de l'Édition.) 
vapeur (p. 275). Il n'offre plus, comme les appareils intermittents à cuve de bois, l'inconvénient d'aérer le vin pendant le chauffage; comme eux et comme tous les appareils à circulation continue_sans réfrigérant, il

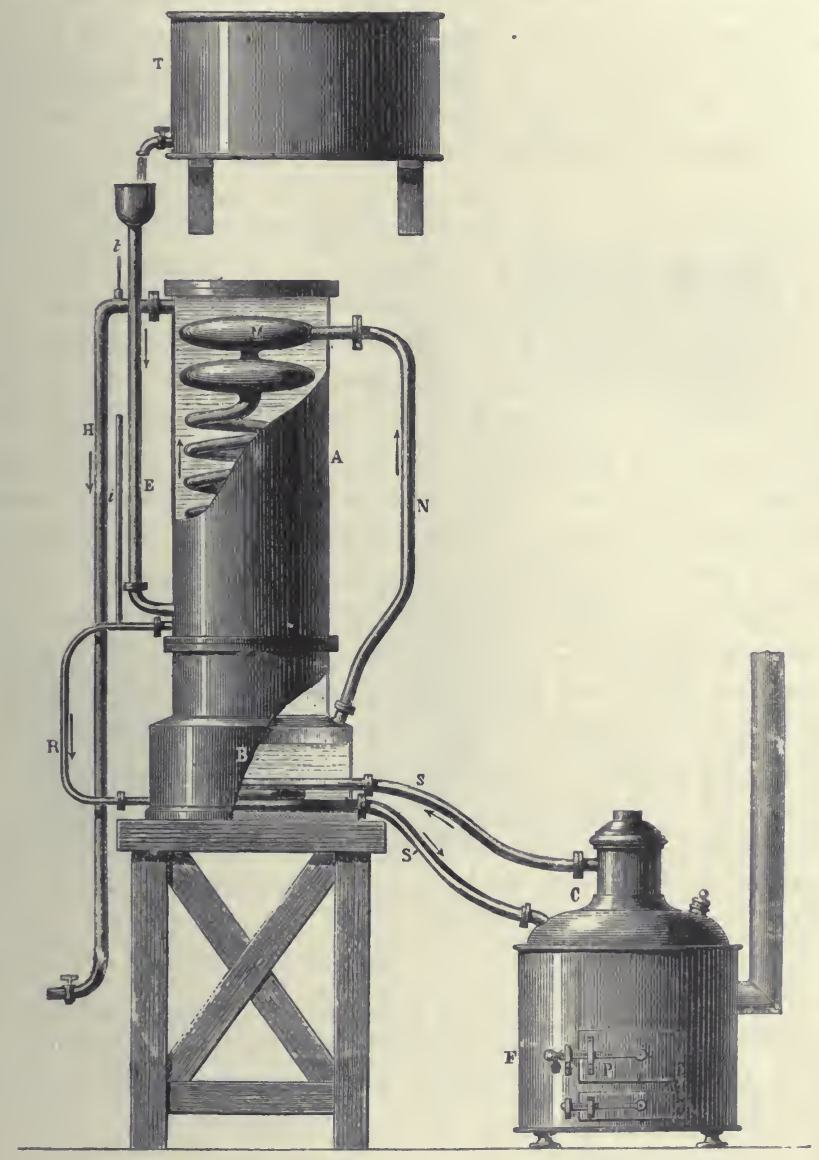

Fig. 50. - Appareil de M. Sourdeval.

envoie directement le vin encore chaud dans les fûts, où ce liquide s'aère, tant par l'air du tonneau, au moment de son arrivée, que par l'air ambiant qui pénètre à travers les douves, et cela à une température à laquelle l'oxygène agit fortement sur les principes du vin (voir p. 273). Ce serait un tort de le faire construire tout exprès pour le chauffage 
du vin; mais, là où il est construit d'avance pour d'autres usages, on peut utilement l'appliquer au chauffage, surtout au chauffage en grande quantité des vins communs. Il a un rendement relativement assez fort, parce que les surfaces sont considérables; il est remarquable par la grandeur des effets obtenus; mais nous décrirons plus loin des appareils chauffés au bain-marie, qui donnent des résultats meilleurs au point de vue de la qualité du produit, avec un rendement aussi fort ou mème supérieur, toutes choses égales d'ailleurs.

L'appareil imaginé par M. Sourdeval repose sur une idée ingénieuse : c'est encore un appareil à chauffage par la vapeur, mais par la vapeur d'esprit de bois en libre communication avec l'air ambiant, qui dans ces conditions bout à $65^{\circ}$ : dès lors on n'a pas à craindre que les parties du vin immédiatement en contact avec la vapeur soient portées à des températures capables d'altérer les qualités du liquide : c'est là un avantage de cet appareil sur les précédents. On peut dire encore que l'emploi de ce liquide dispense en partie de l'observation constante du thermomètre, puisque le vin ne dépasse jamais la température à laquelle il doit être chauffé; mais ce dernier avantage est très léger, car, puisqu'on est obligé de surveiller le thermomètre pour qu'il ne descende pas trop bas, il n'en coûte pas plus de le surveiller également pour qu'il ne monte pas trop haut. Signalons aussi l'inconvénient que présente dans la pratique l'emploi d'un liquide de nature spéciale, volatil et inflammable, la complication inévitable d'un appareil à deux liquides, la perte de calorique, etc.

L'esprit de bois est contenu dans un réservoir B, et chauffé par un serpentin $\mathrm{S} \mathrm{S}^{\prime}$, où circule de la vapeur d'eau produite par une autre chaudière $\mathrm{C}$.

La vapeur de l'alcool se rend dans un serpentin M par le tube $\mathrm{N}$ et une fois condensée revient au réservoir B par le tube R. Le tube $i$ met le réservoir à alcool en communication avec l'atmosphère.

Le vin froid arrive du réservoir $T$, par le tube $\mathrm{E}$, dans le bas du cylindre A, et sort par le tube $\mathrm{H}$ pour se rendre dans la futaille.

Le plus simple des appareils à chauffage à circulation continue, à l'aide d'un bain-marie, est un petit appareil, à l'usage des propriétaires qui n'ont à chauffer qu'un petit nombre d'hectolitres (1), que M. de Lapparent a fait construire en 1867; il se compose (fig. 51):

$1^{\circ} \mathrm{D}^{\prime} u n$ fourneau $\mathrm{F}$ en forte tôle, surmonté d'un cylindre $\mathrm{F}^{\prime}$ pour la

1. Depuis cette époque, M. Faucon, propriétaire à Gravéson (Bouches-du-Rhône), a décrit un appareil à l'aide duquel il chauffe ses vins, et qui rappelle celui de M. de Lapparent. 
circulation de l'air chaud qui se rend ensuite dans la cheminée $\mathrm{F}^{\prime \prime}$; la surface de chauffe est augmentée par de larges tuyaux $a a$, à section elliptique, qui traversent le cylindre transversalement à diverses hauteurs;

$2^{\circ}$ D'une caisse cylindrique $\mathrm{C}$, destinée à contenir l'eau du bainmarie, qui entoure le cylindre intérieur;

$3^{\circ}$ D'un serpentin en plomb $\mathrm{S}$, doublé intérieurement d'étain, qui reçoit, par sa partie supérieure, le vin du réservoir $\mathrm{T}$; le liquide parcourt le serpentin de haut en bas et sort par un tube latéral pour se

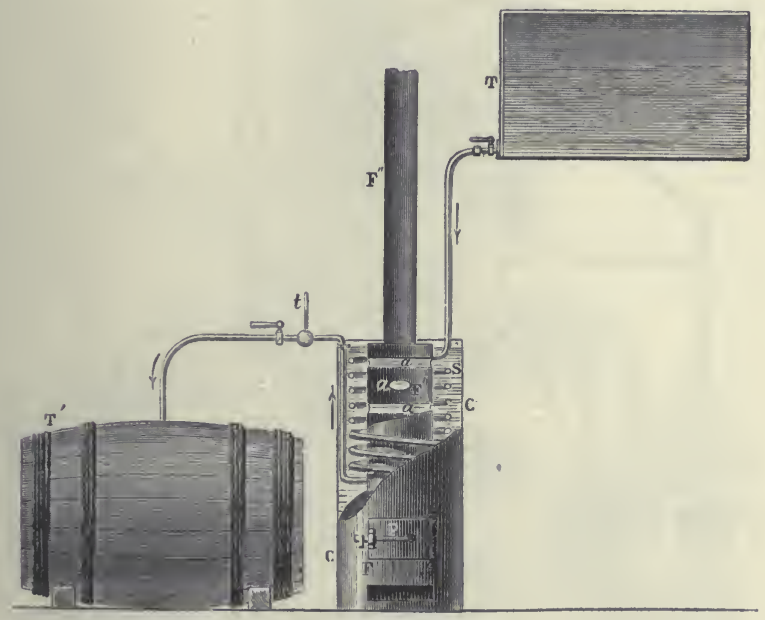

Échelle : 1/25.

Fig. 51. - Appareil de M. de Lapparent, chauffant 1 hectolitre 1/2 à l'heure.

rendre dans le tonneau $\mathrm{T}^{\prime}$. A la sortie, il rencontre une boule où plonge un thermomètre $t$ qui indique la température.

Cet appareil présente les propriétés générales des appareils à circulation continue sans réfrigérant (p. 276). Il est portatif, de construction assez simple, facile à réparer, d'un prix peu élevé. Mais la surface de chauffe n'est pas très étendue; le serpentin a un faible développement en surface, une conductibilité médiocre : de là un rendement faible, comme le prouvent les nombres suivants :

Un appareil de 40 centimètres de diamètre sur 80 centimètres de hauteur, coûtant 120 francs, fournit 1 hectol. 4 par heure; un appareil de 50 centimètres de diamètre, coûtant 180 francs, donne 2 hectolitres; un appareil de 60 centimètres donne 3 hectolitres à l'heure. 
C'est à Gervais (1), à la date de 1827, que remonte la première idée des appareils à circulation continue et chauffés au bain-marie, dans lesquels le vin froid est utilisé pour refroidir le vin chauffé.

Son appareil, comme l'indique la figure 52, n'a aucune valeur au point de vue pratique et industriel; mais il fait très bien comprendre comment fonctionnent tous les appareils munis de réfrigérants.

$1^{\circ}$ RR est le réfrigérant: le vin froid, sortant par le robinet de droite du tonneau $T$, parcourt le tube intérieur $a$ du réfrigérant pour se rendre

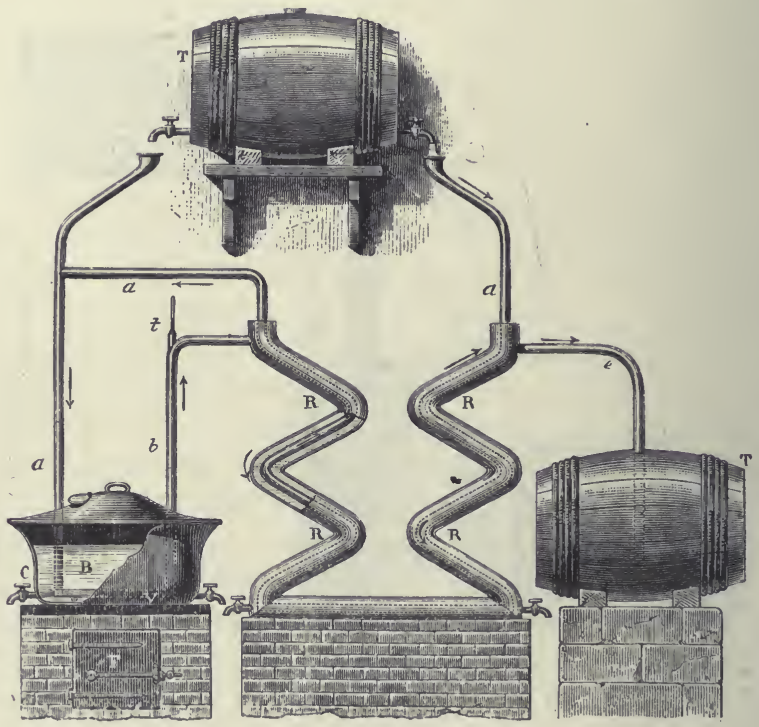

Fra. 52. - Appareil Gervais.

au caléfacteur $\mathrm{C}$, pendant que le vin chaud, sortant en $b$ du caléfacteur, va en sens inverse par le tube extérieur du réfrigérant pour se rendre au tonneau $\mathrm{T}^{\prime}$.

$2^{\circ} \mathrm{C}$ est le caléfacteur : une chaudière B, contenant de l'eau, est chauffée par le foyer $\mathrm{F}$. Le vin froid, arrivant par le tuyau $a$, traverse la caisse V, formée de deux lames de cuivre, soudées par leurs bords;

1. Gervais (J.-A.). Mémoire sur les avantages d'un procédé pour perfectionner le moût des fruits et pour clarifier, améliorer et conserver les vins et autres liqueurs, par l'application de la chaleur, inventé et perfectionné par J.-A. Gervais. Paris, 1827, 29 p. in-8॰ (1 pl.). (Note de l'Édition.) 
il y.prend une température déterminée, indiquée à la sortie par le thermomètre $t$ et se rend au réfrigérant par le tube $b$.

On peut aussi se passer du réfrigérant : il suffit de fermer le robinet

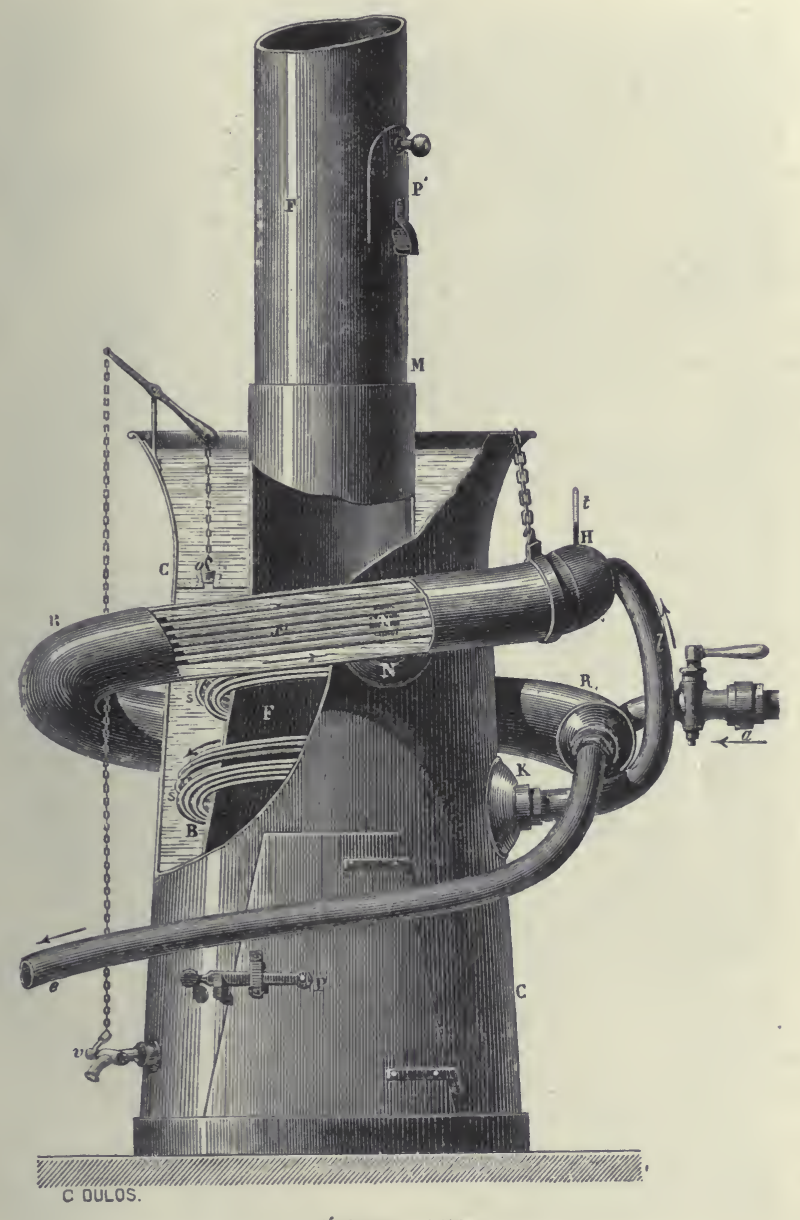

Échelle : $1 / 10^{\circ}$.

Fıa. 53. - Appareil de M. Terrel des Chènes, chauffant 10 hectolitres à l'heure.

de droite et d'ouvrir le robinet de gauche du tonneau $\mathrm{T}$ : le vin arrive directement par le tube $a$ dans la chaudière ( $\left.{ }^{(}\right)$.

1. M. Velten, à Marseille, a installé dans sa brasserie pour le chauffage de ses bières des appareils qui consistent essentiellement en deux cuves avec serpentin intérieur et remplies 
Les trois appareils que nous allons décrire sont à circulation continue, à bain-marie, avec réfrigérant.

L'appareil de M. Terrel des Chênes date de 1868.

Le caléfacteur se compose (fig. 53):

$1^{\circ}$ D'une boîte à feu centrale $\mathrm{F}$ en forme de tronc de cône; le foyer en occupe la partie inférieure. On introduit le combustible d'abord par une porte latérale P; et, lorsque l'appareil est en marche, par une petite porte $\mathrm{P}^{\prime}$, pratiquée dans le tuyau de la cheminée. Un registre sert à modérer le tirage de la cheminée;

$2^{\circ}$ D'un bain-marie B, qui occupe tout l'espace compris entre la boîte à feu et le cylindre extérieur. En $v$ est un robinet de vidange. Au-dessus du bain est un réservoir ouvert à l'air libre, constamment rémpli d'eau, séparé du bain-marie par une cloison horizontale, et communiquant avec lui par une soupape $o$ attachée à un levier. Ce levier lui-même est relié au robinet $\varphi$, à l'aide d'une chaîne : lorsque par une cause accidentelle le bain atteint une température trop élevée, les gaz sortent par la soupape $o$, l'eau rentre, et le bain est ramené à la tempé" rature normale en même temps qu'il s'alimente. Si, pour une cause quelconque, on est obligé d'arrêter pendant quelque temps la marche de l'appareil et que la température du bain s'élève trop, on obtient le même résultat en ouvrant le robinet $v$ qui force la soupape $o$ à s'ouvrir : l'eau froide, que l'on a soin d'entretenir dans le réservoir ouvert, pénètre alors dans le bain-marie, qu'elle refroidit;

$3^{\circ}$ D'un serpentin $s s$, destiné à la circulation du vin : ce serpentin est formé de 40 petits tubes en cuivre de 4 millimètres de diamètre intérieur, qui viennent tous aboutir, d'une part à la bouche $\mathrm{N}$, d'autre part à la bouche $K$, après avoir fait près de deux fois le tour du bainmarie.

Le réfrigérant R R est formé d'un très gros tuyau (fig. 53), qui entoure le caléfacteur et qui contient dans son intérieur 40 petits tubes parallèles $s^{\prime}$ de 4 millimètres de diamètre, semblables à ceux du caléfacteur. Ces tubes aboutissent, d'une part à une boîte $H$, où plonge un thermomètre $t$ pour indiquer la température, d'autre part à une cavité, en $R$, à l'autre extrémité du gros tube.

Voici comment le vin circule dans l'appareil à chauffage pendant qu'il fonctionne :

Le vin froid arrive par le tube $a$, pénètre en $\mathrm{R}$ dans le gros manchon

d'eau : l'une est chauffée par un foyer; de l'eau froide passe dans l'autre cuve; le vin circule d'abord dans le serpentin de la première, où il s'échauffe, puis dans le serpentin de la deuxième, où il se refroidit. 
qui constitue le réfrigérant, circule dans ce manchon, en sort en $\mathrm{N}^{\prime}$ par une tubulure, pour pénétrer de suite dans le caléfacteur en $\mathbf{N}$. parcourt

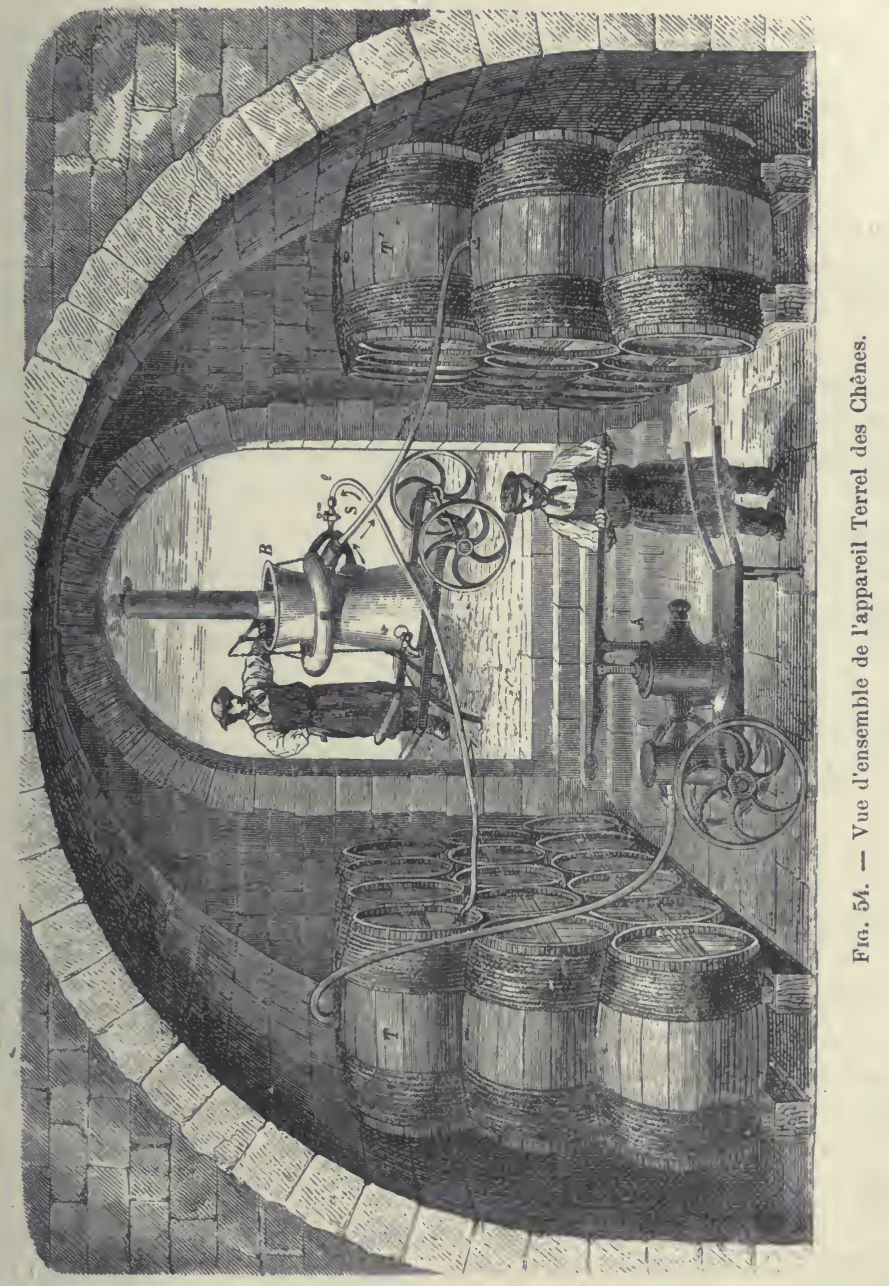

les 40 tubes $s s$ du caléfacteur, vient sortir en K, rentre par le tube $l$ dans le réfrigérant, parcourt les 40 petits tubes $s^{\prime} s^{\prime}$ du réfrigérant, pour se rendre au dehors de l'appareil à chauffage par le tube $e$.

La figure 54 donne une vue d'ensemble de l'appareil complet et de 
la manière dont il fonctionne. L'appareil à chauffage est représenté en B à l'entrée d'une cave; il est porté sur une brouette et peut être déplacé par un seul homme; une pompe à air A, également portée sur une brouette, sert à comprimer de l'air à la partie supérieure du tonneau T dont on veut chauffer le vin; un tube adapté à la partie inférieure de ce tonneau envoie le vin en $e$ dans l'appareil à chauffage $\mathrm{B}$; un autre tube $\mathrm{S}$ dirige le vin chauffé de l'appareil dans un tonneau vide $\mathrm{T}^{\prime}$.

Pour faire marcher l'appareil, on emplit d'eau le bain-marie, on lance le vin dans l'appareil en exerçant une pression avec la pompe; puis, lorsque le bain-marie paraît assez chaud, on ouvre légèrement le robinet $S$; le thermomètre monte; dès qu'il atteint $60^{\circ}$, par exemple, on ouvre davantage le robinet, et c'est alors seulement qu'on reçoit le vin dans le tonneau vide. Un homme fait manœuvrer la pompe, pendant qu'un autre soigne l'appareil à chauffage et règle l'écoulement du vin à l'aide du robinet, en surveillant le thermomètre.

Lorsque, l'opération terminée, on veut nettoyer l'appareil, on dévisse la soupape $o$ (fig. 53) et à sa place on adapte l'extrémité du tube $e$; un courant de vapeur traverse alors tout l'appareil en sens inverse de la

- marche du vin, et entraîne les dépôts qui ont pu se former dans les tuyaux.

Voici des nombres qui donneront une idée des résultats économiques de cet appareil :

\begin{tabular}{|c|c|c|}
\hline & $\begin{array}{c}\text { PRIX } \\
\text { avec tous } \\
\text { les accessoires. }\end{array}$ & $\begin{array}{l}\text { NOMBRE } \\
\text { d'hectolitres chauffés } \\
\text { à l'heure à } 60^{\circ} \text {. }\end{array}$ \\
\hline & $1.200 \mathrm{fr}$. & 10 \\
\hline en. & 450 & 5 \\
\hline etit appareil... & 220 & moins de 1 hectol. \\
\hline
\end{tabular}

Le grand appareil prenant le vin vers $15^{\circ}$, et le portant à $60^{\circ}$, le refroidit vers $32^{\circ}$. Il dépense 5 kilogrammes de charbon par heure, soit 1 centime 1/2 par hectolitre; son diamètre à la base est de $0^{\mathrm{m}}, 50$, sa hauteur totale 2 mètres. Le poids total de l'appareil avec la pompe et les accessoires ne dépasse pas 230 kilogrammes.

Cet appareil présente les propriétés générales des appareils à bainmarie, à circulation continue avec réfrigérants (p. 279).

Il est très remarquable par un rendement à l'heure considérable, eu égard à son volume : ce n'est pas que les surfaces en soient très développées, puisque la surface de chauffe du grand modèle n'atteint que 0 mètre carré 75 , et que la surface des 40 petits tubes n'atteint pas 1 mètre carré; mais la boîte à feu a un volume considérable, égal aux $\frac{6}{10}$ du volume total du caléfacteur : dès lors le volume $\mathrm{V}$ des gaz de la combustion produit dans une heure est très grand, d'où résulte 
un fort rendement à l'heure (p. 279), avec une dépense en charbon un peu plus forte que si les surfaces se développaient davantage aux dépens de la capacité de la boîte à feu. Aussi est-ce un appareil commode, très portatif, et dont la manœuvre est facilitée par diverses pièces accessoires ingénieusement combinées; il est essentiellement applicable à l'industrie agricole (1). Peut-être cependant n'est-il pas très facile de le faire réparer par un ouvrier peu expérimenté, à cause des particularités de construction qu'il présente. Peut-être aussi la faible capacité du bain-marie et le petit diamètre des tubes où circule le vin sont-ils un obstacle à la parfaite régularité du fonctionnement de l'appareil; enfin il serait à désirer que les surfaces internes des petits tubes où circule le vin pussent être étamées avec soin $\left({ }^{2}\right)$.

MM. Perrier frères ont construit, depuis 1869, des appareils du même genre. Le caléfacteur se compose (fig. 55) :

$1^{\circ}$ D'un foyer $\mathrm{P}$ surmonté de tubes droits F F F, qui communiquent avec la cheminée de dégagement $\mathrm{G}$;

$2^{\circ}$ D'un bain-marie $\mathrm{C}$ de forme cylindrique, qui entoure complétement les tubes et le foyer;

$3^{\circ}$ D'un serpentin $S^{\prime}$ qui communique inférieurement arec le cylindre central M.

La partie principale du réfrigérant $R$ est un serpentin $S$ semblable au serpentin $\mathrm{S}^{\prime}$. Ce serpentin est compris entre deux cylindres, de sorte que l'espace compris entre ses spires forme un deuxième serpentin parallèle au premier.

1. M. Terrel des Chênes fait remarquer avec raison qu'on pourrait, en enlevant le réfrigérant, utiliser le caléfacteur pour réchauffer vers $25^{\circ}$ le moût de raisin en fermentation lorsque la température est trop basse, et activer ainsi la fermentation. Des essais qu'il a faits en Hongrie lui ont donné de bons résultats avec une dépense insignifiante.

2. Pasteur écrivit à M. Terrel des Chênes qui lui avait fait connaître l'appareil dont il vient d'être question :

« Alais, le 4 mai 1868.

« Monsieur, je reçois votre lettre à Alais (Gard) où j'ai continué mes études sur les maladies des vers á soie. Je vous félicite bien de vous occuper de la question qui m'a occupé moi-même et d'avoir imaginé un appareil dont vous êtes très satisfait ce qui doit ètre la preuve de son efficacité. Votre offre gracieuse d'associer mon nom au vôtre m'a fort tonchú mais vous connaissez mon éloignement pour tout ce qui franchit la limite scientifique dans les questions auxquelles j'ai consacré mes efforts. Permettez-moi donc de refuser votre aimable invitation.

La dénomination œnotherme me paraît fort bien choisie et en $\mathbf{y}$ ajoutant votre nom seul vous agirez avec justice et de façon à recommander votre appareil comme il le mérite d'aprẻs tous les avantages que vous m'indiquez.

« Je regrette bien de ne pouvoir causer avec vous plus longuement. Je ne saurais vous dire combien je suis occupé en ce moment.

"Veuillez agréer, etc. "

Signé: L. Pasteur. (Note de l'Édition.) 
Pour mettre l'appareil en marche, on remplit le cylindre C d'eau par l'entonnoir $e$. On allume le feu. Le vin, amené à l'aide d'une pompe ou de tout autre moyen dans le réservoir T, est chassé par sa

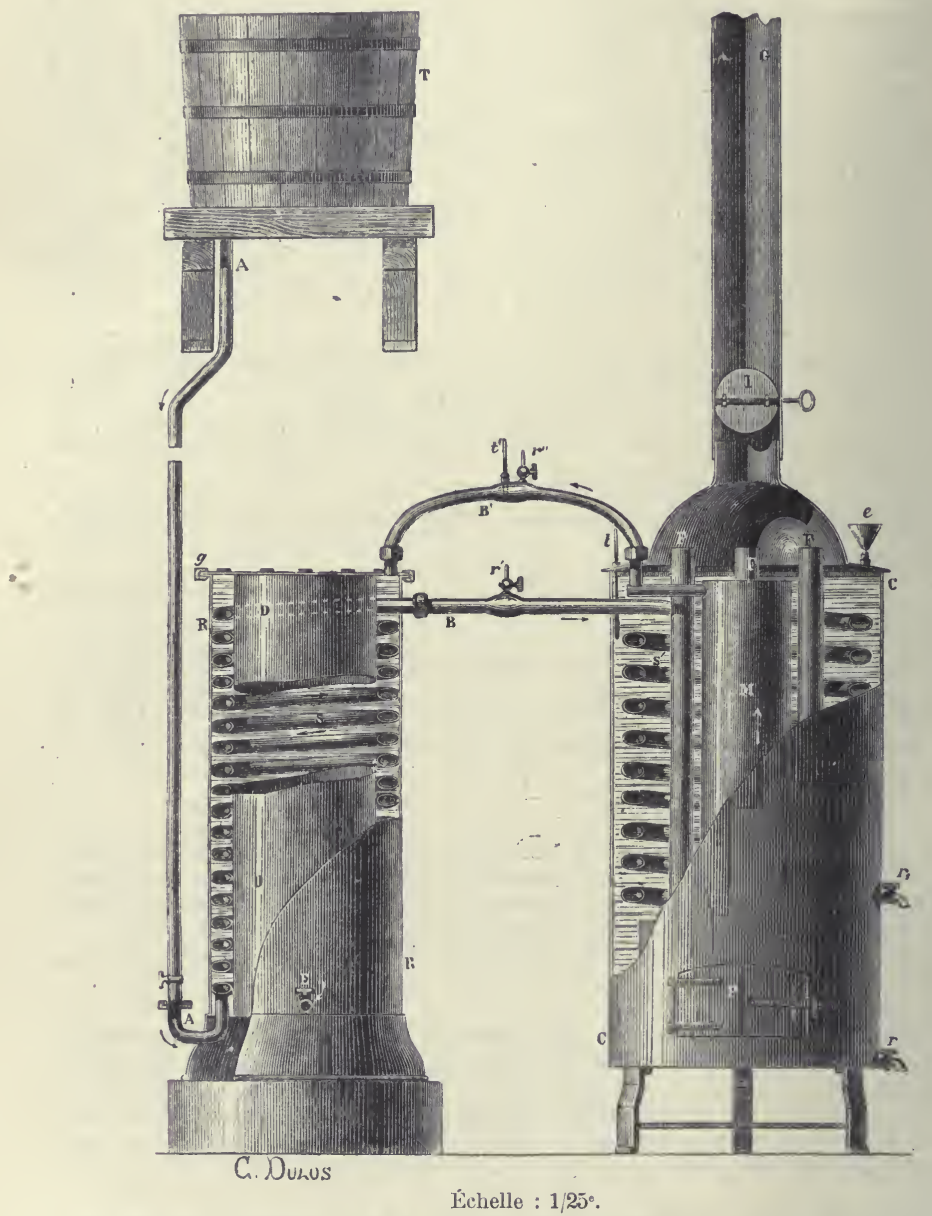

FIG. 55. - Appareil de MM. Perrier frères, chauffant 15 hectolitres à l'heure.

propre pression dans l'appareil, pourvu qu'on ouvre le robinet $\mathrm{A}$ et les deux robinets $r^{\prime} r^{\prime \prime}$ qui servent à laisser échapper l'air : il pénètre en $A$ dans le serpentin $\mathrm{S}$, passe de là dans le serpentin $\mathrm{S}^{\prime}$ par le tube de 
communication B; puis il monte dans la colonne M; celle-ci remplie, on ferme le robinet $r^{\prime}$; le liquide redescend alors entre les spires du serpentin du réfrigérant; ces spires étant remplies, on ferme le robinet $r$ ".

Lorsque l'eau du bain-marie paraît suffisamment chaude, on ouvre légèrement le robinet $\mathrm{E}$; le thermomètre $t^{\prime}$ monte ; quand il atteint $60^{\circ}$, en ouvrant plus ou moins le robinet $\mathrm{E}$, on le maintient à cette température; mais, comme les premières portions du vin qui sortent n'ont pas subi l'action de la chaleur, on ne recueille le vin dans les futs que lorsqu'on a laissé écouler une portion de vin correspondant au volume compris entre les spires du serpentin $\mathrm{S}$ du réfrigérant. Les flèches marquées sur la figure indiquent suffisamment la marche du vin.

L'opération terminée, on ouv're les robinets $\mathrm{E}, r_{1}, r^{\prime}, r^{\prime \prime}$ et on dévisse le tube en A pour vider complétement de vin le caléfacteur et le réfrigérant, après avoir eu soin d'éteindre le feu; on vide le bain-marie par le robinet $r$.

Quelques nombres donneront une idée du rendement de ce système d'appareils :

\begin{tabular}{|c|c|c|}
\hline $\begin{array}{l}\text { APPAREILS } \\
\text { chauffant } \& 60^{\circ}\end{array}$ & $\begin{array}{c}\text { PRIX } \\
\text { en francs }\end{array}$ & $\begin{array}{c}\text { DIAMÈTRE } \\
\text { du cylindre } \\
\text { du calefacteur } \\
\text { en centimètres }\end{array}$ \\
\hline - & - & - \\
\hline 2 hect. à l'heure & $»$ & 30 \\
\hline - & 500 & 35 \\
\hline - & 800 & 50 \\
\hline - & 1.200 & 60 \\
\hline - & 1.600 & 85 \\
\hline 30 & $n$ & 94 \\
\hline 50 & ” & 115 \\
\hline
\end{tabular}

L'appareil de 30 hectolitres est à serpentin double, celui de 50 à serpentin triple.

Le vin, entrant dans ces appareils a $15^{\circ}$ et chauffé à $60^{\circ}$, se refroidit à $27^{\circ}$; la dépense en combustible ne dépasse pas un centime par hectolitre pour les appareils de 10 hectolitres à l'heure et au-dessus.

Cet appareil, à égal rendement, est d'un prix un peu plus élevé que l'appareil Terrel des Chènes; il produit un peu moins dans le même temps, à volume égal, bien que les surfaces de chauffe y soient plus considérables: l'appareil de MM. Pẹrrier de 10 hectolitres à l'heure, par exemple, est plus volumineux que l'appareil de M. Terrel des Chènes, d'un égal rendement; dans le premier cependant, la surface de la boîte a feu est d'environ $1^{\mathrm{m}}, 50$; la surface du serpentin du caléfacteur atteint 2 mètres; celle du serpentin du réfrigérant $2^{\mathrm{m}}, 50$ environ; elles dépassent donc sensiblement les surfaces corres- 
pondantes de l'appareil Terrel des Chênes. Cette différence dans les résultats tient au volume de la boîte à feu qui est relativement

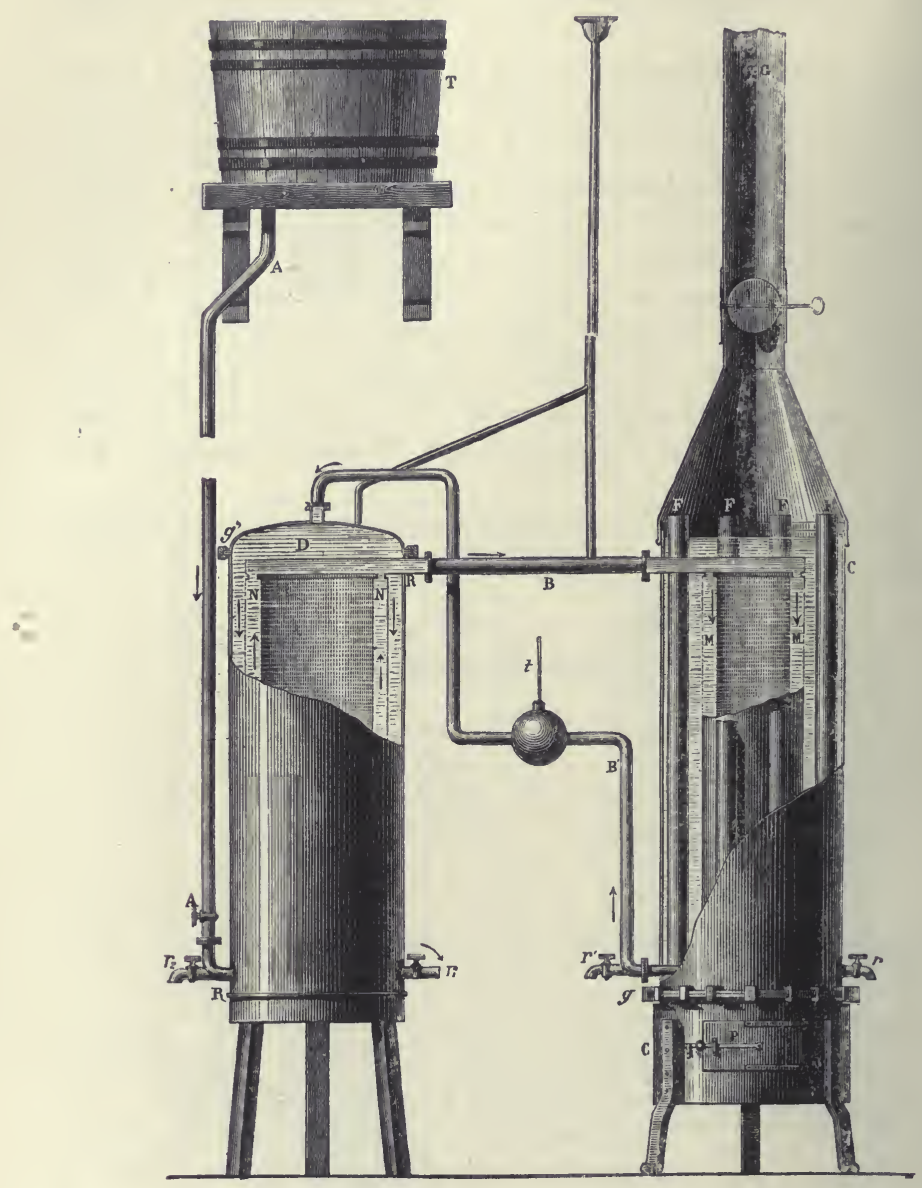

Échelle : $1 / 25^{e}$.

Fig. 56. - Appareil de MM. Giret et Vinas, chauffant 10 hectolitres á l'heure.

moindre dans l'appareil Perrier que dans l'appareil qui précède : de là un rendement à l'heure moins considérable, mais aussi une petite économie de combustible par hectolitre chauffé (p. 279).

Dans l'appareil de MM. Perrier, la grande capacité du bain-marie, 
le volume assez grand du serpentin qui contient le vin chaud, la section assez forte des deux serpentins évitent les irrégularités du chauffage. La boîte centrale M de grande capacité, où le vin se rend avant d'aller au réfrigérant, contribue encore à cette régularité, en mêlant toutes les parties du vin chauffé, leur faisant prendre la température convenable, et les maintenant à cette température pendant assez de temps pour qu'il n'y ait aucun doute sur la destruction des germes. Quant au réfrigérant de l'appareil Perrier, il est facile, tant par les résultats obtenus que par le calcul des surfaces, de s'assurer qu'il est très énergique. Le diamètre assez fort des serpentins où circule le vin permet de les étamer avec soin, de les nettoyer et de les réparer assez facilement.

L'appareil de MM. Giret et Vinas, de Béziers (fig. 56), a beaucoup d'analogie avec celui de MM. Perrier, et pour la forme et pour les propriétés; il date de 1866.

La boîte à feu $\mathrm{P}$ avec tubes $\mathrm{F} F$ du caléfacteur $\mathrm{C}$ est identique pour la forme à celle de l'appareil précédent; il en est de même du bain-marie $\mathrm{C}$; mais le cylindre du bain-marie est fixé sur le foyer à l'aide de deux rebords entre lesquels est une bande de toile trempée dans de la colle de farine : ces deux rebords sont pressés par des pinces en fer $g$; de sorte que ce cylindre peut se démonter facilement. La caisse M M où circule le vin a une forme simple qu'il importe de remarquer; elle est formée de deux cylindres concentriques reliés en haut et en bas par deux rondelles annulaires.

Le réfrigérant $\mathrm{R} R$ est formé d'un cylindre contenant une caisse intérieure $\mathrm{N} \mathrm{N}$, identique à la précédente. Le couvercle du cylindre extérieur est mobile et fixé au cylindre par une disposition $g^{\prime}$ semblable à celle qui relie le foyer du caléfacteur au bain-marie, c'està-dire à l'aide de rebords et de pinces en fer. Toutes les surfaces en contact avec le vin sont étamées.

Le vin sort du réservoir $\mathrm{T}$ par le tube A pour se rendre dans la caisse N N, qu'il parcourt de bas en haut; puis il passe par le tube B dans la caisse M M, sort en $B^{\prime}$ après avoir été chauffé, rencontre le thermomètre $t$ qui en indique la température maxima, repasse dans le cylindre $\mathrm{D}$, où il se refroidit en parcourant de haut en bas la boîte extérieure, et sort en $r_{i}$ pour se rendre au tonneau.

Les robinets $r, r, r$, servent à vider l'appareil après l'opération.

Les tubes terminés par un entonnoir qui prennent naissance en $B$ et en $\mathrm{D}$ servent au dégagement de l'air et des gaz.

Les nombres suivants donneront une idée de la valeur pratique de cet appareil : 

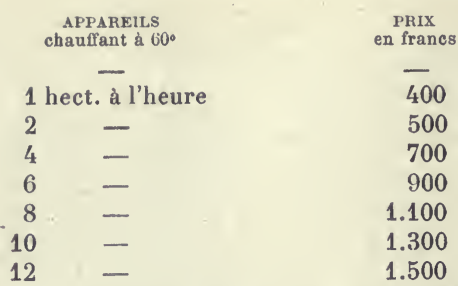

DIAMÈTKE

du caléfacteur

en centimètres

Cet appareil, avons-nous dit, èst très comparable au précédent par sa forme, la grandeur relative de ses surfaces, la disposition de ses diverses parties; aussi les prix, les rendements, les dépenses en combustible sont très analogues de part et d'autre.

L'effet du réfrigérant doit être un peu moindre ici que dans l'appareil Perrier, parce que la surface de séparation du vin qui entre et du vin qui sort est notablement moindre; d'autre part, la portion du liquide en mouvement en contact avec la surface métallique se renouvelle moins rapidement dans une colonne verticale que dans un tube sinueux; à égalité de surface, le serpentin agira donc plus énergiquement que les surfaces cylindriques. Mais, d'autre part, il y a moins de résistances à la circulation du vin dans les boîtes de l'appareil de MM. Giret et Vinas que dans les serpentins de l'appareil de MM. Perrier, à cause des sinuosités que présentent ces serpentins. L'appareil de MM. Giret et Vinas, de construction simple, se démonte très facilement; l'intérieur peut être visité sans trop de peine; les surfaces peuvent être étamées à nouveau toutes les fois qu'il est nécessaire; ces boîtes intérieures formées de cylindres concentriques qui distinguent cet appareil nous paraissent donc heureusement imaginées.

Les trois appareils dont nous venons de parler sont essentiellement industriels; chacun offre des avantages particuliers, mais différents ; aussi ont-ils été généralement appréciés des praticiens, comme le prouvent les récompenses qu'ils ont obtenues dans divers concours : celui de MM. Giret et Vinas en particulier a obtenu en 1870 le prix de 3000 francs proposé par la Société d'encouragement pour « les meilleurs appareils de chauffage et de conservation des vins (1) ». L'appareil de MM. Perrier a obtenu un prix au concours agricole d'Aix et un autre à celui de Narbonne en 1869. Trois médailles d'or ont été décernées dans diverses expositions agricoles à celui de M. Terrel des Chênes. 
Il ne faudrait donc pas chercher à s'écarter beaucoup de la disposition de ces appareils dans les perfectionnements qu'on tenterait de réaliser. Toutefois ils paraissent encore susceptibles de recevoir quelques améliorations.

En premier lieu, ils ne satisfont peut-être pas assez exactement à la condition de ne pas aérer le vin par l'opération du chauffage. Dans les appareils de MM. Perrier, Giret et Vinas, le vin subit le contact de l'air dans le tonneau qui se vide, dans la cuve qui le reçoit, dans le tonneau qui s'emplit. M. Terrel des Chênes, à l'aide de la pompe de son appareil, supprime l'emploi de la cuve intermédiaire et l'aération qui en est la suite; mais l'air comprimé agit alors plus énergiquement sur le vin du tonneau en vidange.

Je lis dans une lettre de M. de Lapparent, adressée à M. Pasteur à la date du 14 septembre 1869, un passage fort judicieux qui indique bien la valeur de ce desideratum et suggère pour y remédier une idée simple, qui mériterait d'être appliquée :

“ Les derniers essais auxquels j'ai assisté chez vous m'ont définitirement donné la conviction qu'il fallait opérer en grand, comme vous l'avez fait en petit et en bouteilles : c'est-à-dire chauffer complétement à l'abri du contact de l'air et refroidir le vin immédiatement. Il est vrai que vos bouteilles n'ont pas été refroidies; mais, vu leur peu de volume, le refroidissement s'y faisait infiniment plus vite qu'il n'a lieu avec une barrique...

“D'après cela, aucun des appareils que j'ai vus fonctionner ne me semble satisfaisant...

"Je crois que celui que je combine en ce moment, et que je proposerai au ministre à mon retour, remplira toutes les conditions. Je projette de prendre à Toulon le vin dans le foudre même, de l'envoyer dans l'appareil, là où vous l'avez vu établi, de le refroidir après échauffement et de le renvoyer dans le foudre où il devra être conservé. Ma force motrice sera l'acide carbonique comprimé à 1 atmosphère au plus. J'ai été faire fonctionner l'appareil de M. Foussat, à Montluçon. Il est admirablement combiné et je ne doute pas un instant du succès.

"Seulement je veux m'assurer de la quantité d'acide carbonique qui pourra pénétrer dans le vin. Dans tous les cas, ce ne serait pas un mal; d'ailleurs, comme vous le faites observer dans votre ouvrage, le fait du chauffage trop élevé est de fondre le vin, en chassant l'acide carbonique qu'il renferme. C'est peut-être pour cela que nos matelots le trouvent trop doux. Il pourrait donc se faire qu'il y eât avantage à rendre un peu de ce gaz piquant au vin. »

D'après l'idée de M. de Lapparent, il faudrait donc supprimer le réser: 
voir des appareils Perrier, et Giret et Vinas, ainsi que la pompe d l'appareil Terrel des Chênes, et remplacer l'air des tonneaux par l'acid carbonique artificiel, en produisant $c$

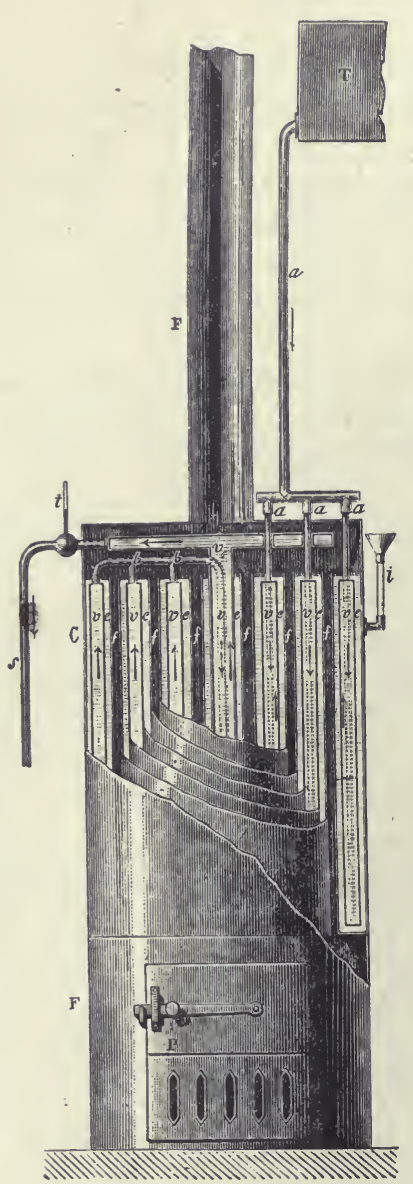

Échelle : 1/8.

Fig. 57. - Appareil de M. Raulin, chauffant environ 2 hectolitres à l'heure. gaz en vase clos, et le faisant agir pa sa propre pression pour chasser le vit dans l'appareil à chauffage : le ga servirait ainsi tout à la fois à pro téger le vin contre le contact de l'air et à le faire mouvoir, et acceśsoiré ment à empêcher le dégagement de l'acide nécessaire à sa constitution La dépense serait sans doute ur peu augmentée, mais très faiblement puisqu'une portion de la main-d'œuvre serait supprimée.

Il importe encore, dans des appareils de ce genre, que les surfaces de chauffe et les surfaces de refroidissement soient aussi considérables que possible, sous un volume déterminé, afin qu'un appareil de petites dimensions puisse fournir un fort rendement; car le rendement d'un appareil dépend principalement, nous l'avons vu, de l'étendue des surfaces; mais en même temps ces surfaces doivent être de forme simple, elles doivent se concilier avec une fabrication peu compliquée de l'appareil, un démontage rapide et des réparations faciles à exécuter; elles doivent présenter peu de sinuosités et ne point former de passages trop étroits, afin que les liquides y circulent facilement. J'ai pensé que sous ce rapport les appareils à chauffage qui existent pourraient encore recevoir quelques améliorations. Je me suis donc demandé quelle serait la forme de surface la plus simple et capable de présenter sous un volume déterminé le développement maximum, et j'ai cru résoudre la question en adoptant, pour la caisse à air chaud, pour le bain-marie, 
pour la caisse à vin, et aussi pour les caisses du réfrigérant, des boîtes annulaires formées par une série de cylindres concentriques.

J'ai fait construire un petit appareil de ce genre (fig. 57); il est en cuivre, et les surfaces en contact avec le vin sont étamées; il se compose principalement de quatre systèmes de boîtes concentriques ve, à peu près semblables. Chacun est formé d'un vase annulaire $e$ ouvert par en haut, fermé inférieurement, qui contient un vase plus étroit $v$, mais de même forme, fermé aux deux extrémités. Les vases ouverts servent de bain-marie, les vases fermés sont les caisses à vin; le foyer est en F ; l'air chaud qui s'en échappe circule dans les intervalles ff qui séparent ces systèmes de boîtes et se rend dans la cheminée $\mathrm{F}$. Le vin froid entre à la fois dans trois des boîtes à vin par les tubes $a$ qui pénètrent jusqu'au fond, et sort par les tubes $b$ pour se rendre dans la boîte centrale $v$, où ses direrses parties se mêlent et prennent la température de $60^{\circ}$. De là il s'écoule dans le fût par le tube $s$. Si l'on voulait adapter à cet appareil un réfrigérant, il suffirait de l'entourer d'une boîte annulaire, fermée supérieurement par une rondelle mobile, qui en contiendrait une autre plus petite hermétiquement fermée : le vin froid entrerait dans l'appareil en passant par une de ces boîtes, le rin chauffé en sortirait par l'autre.

Pour donner une idée du développement des surfaces de ce genre d'appareil, je dirai que l'appareil dont je parle, qui a un diamètre de 28 centimètres, a une surface de chauffe égale à $1^{\mathrm{m}}, 50$, et que la surface des boîtes à vin a à peu près la même étendue; il peut chauffer par heure environ 2 hectolitres de vin.

Je ferai encore remarquer qu'en général dans les appareils appartenant à un même type, mais de grandeurs différentes, les surfaces croissent comme les carrés des dimensions linéaires, tandis que, dans ce système, elles croissent comme les cubes de ces dimensions: le rendement de grands appareils construits sur le modèle du précédent sera donc encore proportionnellement plus considérable que celui du petit appareil dont je parle.

La simplicité de forme des boîtes de cet appareil, leur volume relativement grand empêchent toute obstruction, toute irrégularité dans le chauffage. Les tubes d'arrivée et de sortie du vin s'adaptant aux boîtes à vin, à l'aide de caoutchouc, l'appareil tout entier peut être démonté en un instant, nettoyé très facilement. Il peut être aussi visité intérieurement, et facilement étamé à nouveau; les fuites se réparent sans difficulté, puisque les diverses pièces séparées forment autant de boîtes simples, qu'on peut remplir d'eau pour vérifier si elles sont parfaitement étanches. 
M. V. Regnault, de l'Institut, a combiné pour le chauffage des vins en fûts une disposition d'appareil qu'il emploie avec succès dans ses propriétés du département de l'Ain, et dont je regrette de ne pas connaître les détails.

Si l'illustre physicien veut bien porter son attention sur cette application de principes scientifiques sur lesquels il est plus compétent que personne, on peut espérer que la pratique vinicole ne tardera pas de posséder un appareil propre à remplir toutes les conditions exigées pour le succès de l'opération du chauffage des vins. 


\section{APPENDICE}

\section{NOTES ET DOCUMENTS}

On a réuni dans les notes suivantes quelques documents qui serviront de complément à diverses questions traitées précédemment.

\section{Dosage de L'ACidité TOtale dU MOÛt de RAISiN.}

Je me suis servi d'eau de chaux titrée à l'aide d'une solution normale d'acide sulfurique ou d'acide oxalique. L'eau de chaux est un peu plus chargée en hiver qu'en été. Il en faut environ 27 centimètres cubes pour saturer $0 \mathrm{gr}$. 06125 d'acide sulfurique, lesquels équivalent à 0 gr. 0750 d'acide acétique, à 0 gr. 09375 d'acide tartrique, à 0 gr. 2350 de bitartrate de potasse.

On prélève 10 centimètres cubes de moût avec une pipette graduée; on les place dans un verre à pied sans addition de teinture de tournesol. Le moût le plus incolore, provenant des raisins rouges ou blancs, renferme toujours des matières colorables sous l'influence de la plus minime quantité d'alcali ajoutée en excès. On verse alors l'eau de chaux à l'aide d'une burette décime que l'on tient de la main gauche pendant qu'on agite avec la main droite, jusqu'au changement de teinte de la couleur, ou jusqu'à l'apparition d'une teinte jaune verdâtre, si le liquide était primitivement incolore. Il faut aller rapidement sans tâtonner jusqu'à la nouvelle coloration, et retrancher une ou deux gouttes du chiffre marqué par la burette. Au moment du changement de teinte, il ne se fait aucun dépót, ni floconneux, ni cristallin. Ce n'est qu'au bout de quelques ninutes, ou mieux d'une demi-heure à une heure, que la liqueur se trouble en laissant déposer des cristaux grenus de tartrate neutre de chaux, ou plus rarement de tartromalate de chaux, sel formé d'une combinaison de 1 équivalent de tartrate de chaux avec 1 équivalent de malate de cette base, unis à 16 équivalents 
d'eau. Le microscope permet de distinguer très nettement ces deux genres de sels.

Si, pendant l'addition même de l'eau de chaux, la liqueur se troublait par la précipitation de petits cristaux de tartrate de chaux, l'essai acidimétrique n'en serait pas moins exact. Il ne faudrait donner aucune attention à ce dépôt. Souvent la coloration du liquide ne s'en aperçoit que mieux. Mais ce cas est rare si l'essai ne traîne pas en longueur.

Le papier de tournesol rouge est un réactif infidèle pour assigner la fin de l'essai. En effet, il arrive constamment que le papier, qu'il faut dans tous les cas choisir très sensible, commence à bleuir et à donner par conséquent des signes d'alcalinité bien avant qu'il y ait un excès réel d'eau de chaux accusé par la coloration du liquide. Cela tient à ce que les solutions des tartrate et malate de chaux ont, comme l'acétate de cette base, une réaction alcaline.

J'ai supposé que le moût avait été filtré à clair. Si on devait l'employer à l'état brut et trouble, on pourrait être embarrassé d'assigner le moment où l'épreuve est achevée. Dans ce cas, il faut ajouter une quantité d'eau de chaux insuffisante pour la saturation, en allant, par exemple, jusqu'à ce que la liqueur manifeste un premier commencement d'alcalinité au papier rouge sensible. Puis on filtre et on prélève 10 centimètres cubes de la liqueur claire, auxquels on ajoute goutte par goutte de l'eau de chaux jusqu'au changement de teinte. Une proportion indique facilement ce que l'on aurait dû ajouter au volume total de la liqueur. Exemple : 10 centimètres cubes d'acide sulfurique Péligot au dixième exigent 27 cc. 5 d'eau de chaux. Il en résulte que 27 cc. 5 de cette eau de chaux équivalent à 0,09375 d'acide tartrique $\mathrm{C}^{8} \mathrm{H}^{4} \mathrm{O}^{10}, 2 \mathrm{HO}$. J'essaye avec cette eau de chaux un moût trouble; après addition de 22 cc. 8 d'eau de chaux, soupçon éloigné d'alcalinité. Pour 24 cc. 3 l'alcalinité est très sensible. Je filtre et je prélève 10 centimètres cubes pour lesquels il faut ajouter 8 gouttes d'eau de chaux afin de faire virer la teinte. Pour le volume total de la liqueur, en tenant compte du volume des gouttes, il eût fallu ajouter 1 cc. 2 d'eau de chaux. 10 centimètres cubes de ce moût exigeaient donc 25 cc. 5 d'eau de chaux pour leur saturation; 1 litre de ce moût renfermait par suite l'équivalent de $\frac{0,09375.100}{27,5} \cdot 25,5=8$ gr. 69 d'acide tartrique, en supposant hypothétiquement que tout l'acide du moût est de l'acide tartrique.

Lorsqu'on opère sur du moût préalablement filtré, comme on va d'un trait jusqu'au changement de teinte, la lecture sur la burette donne immédiatement le volume de l'eau de chaux nécessaire à la saturation de 10 centimètres cubes de moût. Ce volume, multiplié par 
le rapport $\frac{9,375}{27,5}$, indique l'équivalent au litre d'acide tartrique. Le nombre 27,5 change d'ailleurs avec le titre de l'eau de chaux. C'est le nombre de centimètres cubes d'eau de chaux nécessaire pour saturer $0 \mathrm{gr} .06125$ d'acide sulfurique de formule $\mathrm{SO}^{3}, \mathrm{HO}$.

Dosage de L'acidité totale du vix.

La détermination du titre acide du vin se fait de la même manière; seulement il est impossible, du moins très incertain, de s'en rapporter ici à un changement de teinte, surtout lorsqu'il s'agit de vin rouge. On peut commettre d'assez graves erreurs, parce que le changement de teinte précède de beaucoup l'alcalinité. Il est surtout très sensible au moment de cette première alcalinité de la liqueur qui ne correspond encore qu'aux sels de chaux dissous et déjà en partie formés à l'état neutre. Le véritable terme de l'essai, celui qui correspond au premier excès d'eau de chaux, est accusé invariablement, quel que soit le vin, par un trouble floconneux qui se rassemble très vite en flocons de couleur foncée nageant dans toute la liqueur. Tant qu'on n'a pas atteint cette limite, on peut être assuré que tous les acides ne sont pas saturés. Les moûts ne donnent pas lieu à un pareil dépôt.

Il arrive très rarement qu'il se forme des précipités de sel de chaux pendant l'essai, avant l'apparition des flocons. Si cette circonstance se présente, on peut presque toujours, quand on a l'habitude de ces sortes d'essais, reconnaître auquel des deux précipités l'on a affaire. En tout cas, on pourrait filtrer et chercher, comme il a été dit tout à l'heure, le nombre de gouttes nécessaire pour saturer un volume déterminé du liquide filtré. Dans cette liqueur filtrée, les flocons amorphes apparaîtront avant qu'un nouveau précipité cristallin de sel de chaux se montre.

J'ai insisté un peu longuement sur ces essais acidimétriques, parce que je n'ai point vu dans les auteurs d'indications précises à ce sujet, et que, si l'on n'a pas soin de suivre celles qui précèdent, on peut commettre des erreurs sensibles. D'ailleurs, dans l'étude des changements qui peuvent survenir spontanément dans un vin, il est sourent indispensable de déterminer avec une grande précision son équivalent acide.

Une dernière précaution, qu'il est bon de ne pas omettre, consiste, après avoir mesuré les 10 centimètres cubes de vin sur lesquels on veut opérer, à placer le verre qui les contient dans le vide de la machine pneumatique, afin de chasser la presque totalité du gaz acide carbo- 
nique. Cela est surtout utile quand il s'agit des vins nouveaux et également des vins montés, qui sont toujours plus ou moins chargés de gaz acide carbonique, principalement dans les cas où la maladie est actuelle ou récente.

\section{Dosage dU SUChe dU MOÛt de RaIsin.}

Le dosage du sucre dans le moût se fait assez exactement à l'aide de la liqueur cuivrique alcaline. L'une des meilleures recettes pour préparer cette liqueur est celle qui a été indiquée par M. Fehling :

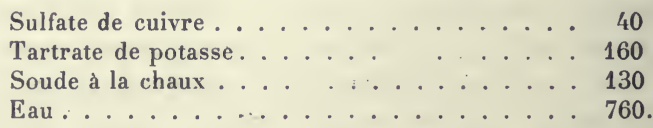

On place 10 ou 20 centimètres cubes de cette liqueur dans un petit ballon de 100 centimètres cubes environ, en ajoutant 1 ou 2 centimètres cubes de potasse assez concentrée pour rendre plus rapide la décomposition ultérieure du sucre. Puis, après avoir porté à l'ébullition ce liquide sur la flamme d'une lampe à alcool, on ajoute peu à peu la liqueur sucrée à l'aide d'une burette décime placée dans la main droite, tandis qu'on tient dans la main gauche le ballon par les branches d'une pince de bois munie de bouchons échancrés, serrant bien le ballon par son col afin qu'il ne puisse obéir à de faux mouvements.

Après chaque addition nouvelle du liquide sucré, on examine la teinte, de la liqueur éclaircie en regardant sur ses bords par transmission une feuille de papier blanc. Il faut aller jusqu'à la décoloration et s'arrêter au moment où l'addition d'une ou deux gouttes nouvelles fait virer à une teinte jaune. Il faut se défier de la réflexion de la couleur bleue du ciel, qui, se mêlant à une couleur un peu jaunâtre de la liqueur, fait souvent prolonger l'opération au delà de sa vraie limite.

La liqueur de cuivre a été titrée préalablement au moyen d'une solution normale de sucre préparée avec $10 \mathrm{gr} .000$ de sucre candi dissous dans un litre d'eau après interversion par l'acide chlorhydrique.

J'ai essayé à diverses reprises si le moût de raisin renfermait du sucre cristallisable, non interverti. J'ai toujours trouvé le même titre avant et après l'interversion par les acides, avec une très légère différence en plus après l'interversion, différence qui ne dépasse pas $\frac{1}{100}$.

Lorsque l'on opère sur du moût de raisin, il faut l'étendre beaucoup avant de le faire agir sur la liqueur cupropotassique. Il serait trop 
chargé de sucre comparativement à la proportion de cuivre dissous. Le mieux est de porter 10 centimètres cubes de moût à 200 centimètres cubes par addition d'eau ordinaire. C'est ce moût au $\frac{1}{20}$ qui est mis dans la burette décime.

\section{Nouveau procédé de dosage de l'acide tartrique (1).}

On peut doser assez approximativement la creme de tartre contenue dans un vin, en réduisant un litre de vin, environ à 50 centimètres cubes, ou mieux jusqu'à formation de pellicule cristalline à la surface du liquide chaud, et laissant cristalliser pendant 24 ou 48 heures. On décante alors l'eau mère et on lave les cristaux à deux ou trois reprises avec une eau saturée de bitartrate de potasse. On dessèche les cristaux dans leur capsule, qui a été tarée à l'avance. On n'a ainsi qu'une approximation de la quantité de crème de tartre que le vin peut fournir, mais il ne faudrait pas négliger de recourir à cet essai comme contrôle d'autres essais, bien que ces derniers parussent plus précis.

MM. Berthelot et de Fleurieu ont publié récemment un Mémoire étendu sur le dosage de l'acide tartrique et de la potasse dans le vin (2). J'y renvoie le lecteur pour une foule de détails intéressants, et pour l'application du procédé de dosage qui leur est propre, lequel consiste essentiellement dans la précipitation de la crème de tartre par un mélange d'alcool et d'éther à volumes égaux. Après 24 ou 48 heures, la crème de tartre, qui s'est précipitée, est recueillie, et son titre acide déterminé à l'aide d'une solution dosée d'eau de baryte. Le dosage du bitartrate de potasse effectué par le procédé de MM. Berthelot et de Fleurieu est une épreuve utile. Mais je dois dire, après l'avoir essayée sur une foule d'échantillons, qu'elle me paraît très défectueuse, en ce sens qu'elle conduit à un résultat le plus souvent de beaucoup plus faible que le dosage direct par cristallisation de la crème de tartre, après évaporation d'un litre de vin. La différence s'élève au quart, au tiers, à la moitié, et même davantage, du poids le plus élevé.

Je ne saurais assigner avec précision quelles sont les causes d'erreur du procédé de MM. Berthelot et de Fleurieu. Je crois cependant que

1. Voir aussi sur la même question : Sur le dosage de l'acide tartrique dans les vins. Bulletin de la Société chimique de Paris, nouv. sér., I, 1864, p. 449, et p. 407-408 du présent volume. (Note de l'Édition.)

2. Berthelot et Fleurueu (A. de). [Sur le dosage de l'acide tartrique, de la potasse et de la crème de tartre contenus dans les liqueurs vineuses.] Annales de chimie et de physique, $4^{\circ}$ sér., V, 1865, p. 177-264. 
l'une des plus sensibles est la suivante. Lorsqu'on précipite le bitartrate de potasse du vin par un mélange d'alcool et d'éther, il se dépose en même temps une proportion variable, suivant les cas, de tartrate de chaux, parce que tous les vins renferment de la chaux. Cette précipitation de sels de chaux n'a pas lieu du tout, excepté dans des cas tout à fait exceptionnels (pour les vins plâtrés, par exemple), lorsqu'on fait cristalliser la crème de tartre par évaporation d'un litre de vin. La crème de tartre n'est accompagnée que de matière colorante en précipité léger, facile à éloigner par le lavage. Le tartrate de chaux qui pourrait se former est relativement très soluble dans l'eau mère acide du vin évaporé. Il y' est bien plus soluble que le bitartrate de potasse, de telle sorte que, s'il y a excès de potasse dans l'eau mère, par rapport à la quantité d'acide tartrique total pouvant passer à l'état de bitartrate, c'est à l'état de bitartrate seulement que se déposera l'acide tartrique. Au contraire, le tartrate de chaux est peut-être plus insoluble que le bitartrate de potasse dans une liqueur éthéro-alcoolique. M. Berthelot signale en passant dans son Mémoire la cause d'erreur que j'indique; mais il n'y insiste pas autant qu'elle le mérite.

- J'avais besoin, dans mes recherches, d'un procédé de dosage qui permît une comparaison délicate des quantités d'acide tartrique renfermées dans un vin à deux époques de son existence en quelque sorte, dans un vin altéré, par exemple, comparé au même vin non altéré. Voici comment j'opère : à 20 centimètres cubes de vin j'ajoute une quantité d'acide tartrique gauche correspondant, par exemple, à 3 grammes de bitartrate de potasse droit ordinaire (1). Puis j'ajoute la quantité d'eau de chaux nécessaire pour saturer les 20 centimètres cubes de vin, quantité qui a été déterminée par un essai acidimétrique préalable. Il se précipite du racémate de chaux. Si la quantité d'eau de chaux ajoutée ne suffisait pas pour précipiter tout le racémate possible, il faudrait y joindre quelques gouttes de chlorure de calcium. Après quelques minutes d'attente, je filtre, et je prélève deux portions séparées à peu près égales, 15 centimètres cubes environ, de la liqueur toujours très limpide qui a passé au filtre. Dans une des portions, que j’appellerai le verre de droite, j'ajoute 2 gouttes d'une solution de tartrate droit

1. Je me sers d'une solution renfermant 10 grammes de tartrate gauche d'ammoniaque par litre. Il est facile de calculer le volume de cette liqueur nécessaire pour transformer en racémate tout l'acide tartrique contenu dans 20 centimètres cubes de vin.

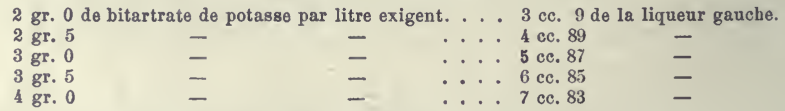

et pour une quantitè $t$ de bitartrate $\mathrm{V}=2 t \frac{184}{188} ;$ soit $t=2 \mathrm{gr} .8, \mathrm{~V}=5$ cc. 48. 
d'ammoniaque au $\frac{1}{100}$ ( 1 gramme dans 100 centimètres cubes d'eau distillée), et, dans le verre de gauche, j'ajoute 2 gouttes d'une solution de tartrate gauche d'ammoniaque également au $\frac{1}{100}$. Trois cas peuvent se présenter. Après un quart d'heure, une heure, et même davantage, car il est toujours utile de conserver les verres un temps assez long, il se fait un précipité dans le verre de droite, ou dans le verre de gauche, ou pas du tout de précipité ni à droite ni à gauche. Il n'arrive pas que le précipité se fasse à droite et à gauche, à moins que quelque circonstance accidentelle ne se présente. S'il y a précipité à droite, c'est que la liqueur qui a passé au filtre renferme du tartrate gauche. Il n'y a donc pas dans le vin en acide tartrique l'équivalent de 3 grammes de bitartrate de potasse. Si le précipité s'est formé à gauche, il y a du tartrate droit dans la liqueur filtrée, et l'on conclut que le vin renferme en acide tartrique l'équivalent de plus de 3 grammes de bitartrate de potasse. Enfin, s'il n'y a de précipité ni à droite ni à gauche, c'est que le vin renferme à très peu près l'équivalent de 3 grammes de bitartrate par litre.

Supposons que le deuxième cas se soit présenté, c'est-à-dire que la liqueur qui passe au filtre renferme du tartrate droit; on procédera à un nouvel essai tout semblable, avec cette seule différence que l'on ajoutera aux 20 centimètres cubes de vin l'équivalent en acide tartrique gauche de $3 \mathrm{gr} .5$ de bitartrate de potasse par litre. Mêmes essais ultérieurs, conclusion analogue..., et l'on arrivera ainsi beaucoup plus vite qu'on ne pourrait l'imaginer au premier abord, en moins d'une heure, par exemple, à resserrer suffisamment les limites entre lesquelles se trouve comprise la quantité totale d'acide tartrique de la liqueur, de façon à la connaître facilement à moins d'un décigramme ou de cinq centigrammes par litre.

Le grand avantage de cette méthode est de pouvoir comparer dans l'intervalle d'une heure au plus, et avec rigueur, deux bouteilles d'un mème vin, dont l'une est restée saine, tandis que l'autre est suspecte d'altération, de les comparer, dis-je, sous le rapport de la proportion de l'acide tartrique qu'elles renferment. On peut s'assurer de cette manière si le ferment propre à la maladie dont il s'agit a porté son action sur l'acide tartrique.

Je vais en donner un exemple pour le vin de Pomard de 1863, de M. Marey-Monge, portant le $\mathrm{n}^{\circ} \mathrm{XI}$ dans le rapport de la Commission du commerce des vins, page 236 , et dont la figure 10 représente le dépòt pour la portion non chauffée, en voie d'altération.

J'ai dit que 100 bouteilles de ce vin avaient été chauffées de 50 à $60^{\circ}$ à la fin de juillet 1865; que les 100 autres bouteilles sont restées 
telles que je les avais recues, placées dans la même cave que les premières; que celles-ci ont donné asile au parasite de l'amertume des grands vins de Bourgogne, qu'enfin, en janvier 1866, un dépôt considérable, qui n'est pas moindre, à la décantation, que le dixième du contenu de la bouteille se réunit au fond de chaque bouteille lorsqu'on les redresse. Le vin qui a été chauffé n'offre pas de dépôt, et il n'a fait que s'améliorer, tandis que le vin non chauffé a perdu considérablement de sa valeur.

L'altération chimique des principes du vin n'est pas moins évidente. J'ai déterminé comparativement l'acidité des deux vins.

10 centimètres cubes de vin chauffé exigent pour la saturation 16 cc. 7 d'eau de chaux, dont 29 centimètres cubes saturent 0 gr. 075 d'acide acétique.

10 centimètres cubes de vin non chauffé en exigent 20 cc. 5 .

La différence est de 3 cc. 8 , ce qui correspond à une augmentation d'acidité totale, par le fait du parasite, égale a $0 \mathrm{gr} .98$, évaluation faite en équivalent d'acide acétique.

J'ai déterminé ensuite la proportion relative des acides volatils de ces deux vins, en suivant les indications que j'ai données ailleurs, c'est-à-dire en distillant un litre de vin, en recueillant exactement 500 centimètres cubes de liquide, puis 400 centimètres cubes $(\mathrm{A})$, puis encore 400 centimètres cubes $(B)$, après avoir ajouté dans la cornue 400 centimètres cubes d'eau pure. On cherche ensuite les quantités d'eau de chaux qui sont nécessaires pour saturer les différentes portions que l'on a recueillies.

J'ai trouvé ainsi :

Vin chauffé ... $\begin{array}{r}\text { Les } 500 \text { centimètres cubes ont exigé } 108 \text { centimètres } \\ \text { cubes d'eau de chaux dont } 27 \text { centimètres cubes }\end{array}$ saturaient $0 \mathrm{gr}$. 075 d'acide acétique.

Vin chauffé... $\begin{aligned} & \text { Les } 400 \text { centimètres cubes (A) ont exigé } 157 \text { centi- } \\ & \text { mètres cubes d'eau de chaux dont } 27 \text { centimètres } \\ & \text { cubes saturaient } 0 \text { gr. } 075 \text { d'acide acétique. } \\ & \text { Les } 400 \text { centimètres cubes (B) en ont exigé } 64 \text { centi- } \\ & \text { mètres cubes. }\end{aligned}$

| Les 500 centimètres cubes ont exigé 133 centimètres

Vin non chauffé. $\left\{\begin{array}{l}\text { cubes d'eau de chaux dont } 27 \text { centimètres cubes satu- } \\ \text { raient } 0 \text { gr. } 075 \text { d'acide acétique. } \\ \text { Les } 400 \text { centimètres cubes (A) en ont exigé } 233 \text { centi- } \\ \text { mètres cubes. } \\ \text { Les } 400 \text { centimètres cubes (B) en ont exigé } 90 \text { centi- } \\ \text { mètres cubes. }\end{array}\right.$

Si l'on se reporte à ce que j'ai dit page 148, on verra que l'on peut admettre assez approximativement qu'un litre de vin chauffé renfermait 
une quantité totale d'acide acétique égale à celle que satureraient $108 \mathrm{cc}$. +157 cc. +64 cc. +64 cc. $=393$ centimètres cubes d'eau de chaux, ce qui correspond à $1 \mathrm{gr} .1$ d'acide acétique, et qu'au contraire un litre de vin non chauffé renfermait une quantité totale d'acide acétique égale a celle que satureraient 133 cc. +233 cc. +90 cc. +90 cc. $=546$ centimètres cubes d'eau de chaux, volume qui correspond à 1 gr. 5 d'acide acétique.

La différence dans les proportions des acides volatils étant de $0 \mathrm{gr} .4$ d'acide acétique et celle de l'acidité totale étant égale à $0 \mathrm{gr} .98$, on voit que le parasite de l'amertume développe des acides fixes aussi bien que des acides volatils.

Étudions maintenant les proportions de l'acide tartrique du vin sain et du vin altéré, afin de voir si l'altération a porté sur ce principe.

Vin chauffé ... $\begin{aligned} & \text { Pour } 5 \text { cc. } 5 \text { de liqueur gauche correspondant à } 2 \mathrm{gr} .8 \\ & \text { de bitartrate par litre, trouble dans le verre de gauche. } \\ & \text { Pour } 5 \text { cc. } 9 \text { de liqueur gauche correspondant à } 3 \text { gr. } 0 \\ & \text { de bitartrate par litre, trouble dans le verre de droite. }\end{aligned}$

Vin non chauffé. $\left\{\begin{array}{c}\text { Pour } 5 \text { cc. } 3 \text { et } 5 \text { cc. } 9 \text { je trouve exactement les mêmes } \\ \text { indications. }\end{array}\right.$

En conséquence, les deux vins renferment chacun la même quantité d'acide tartrique, qui équivaut à $2 \mathrm{gr} .9$ de bitartrate, à moins de $0 \mathrm{gr} .1$ par litre.

Le ferment de l'amertume n'a donc pas porté son action, au moins dans cette circonstance, sur l'acide tartrique, mais sur quelque autre produit, puisque l'altération a été telle qu'il s'est formé environ 1 gramme d'acide par litre dans le vin malade, du mois de juillet 1865 au mois de janvier 1866 .

Ce résultat est d'autant plus digne d'attention qu'un habile chimiste de Lyon, M. Glénard, ayant eu l'occasion d'étudier en 1862 un vin malade de 1859 , tourné à l'amer, suivant l'expression des dégustateurs, n'y a plus trouvé de tartre, tandis que le vin qui commençait à s'altérer en renfermait $2 \mathrm{gr} .7$ par litre.

M. Glénard a retiré de ce vin malade des quantités considérables d'acide acétique, fait conforme, dit-il, à celui qui a été observé depuis longtemps par M. Nöllner dans la fermentation de l'acide tartrique( $\left.{ }^{1}\right)$. On sait, depuis les recherches exactes de M. Nicklès, que l'acide de Nöllner n'était point de l'acide acétique, mais un isomère de cet acide.

Comment concilier mes observations avec celles de M. Glénard?

1. Glénard (A.). [Note sur la fermentation tartrique du vin.] Annales des sciences physiques et naturelles, d'agriculture et d'industrie... publiées par la Société d'agriculture de Lyon, 3" sér., VI, 1862, p. 141-160. 
Je l'ignore. Il se peut que les dégustateurs aient mal caractérisé la maladie dont se trouvait affecté le vin étudié par ce chimiste, que ce vin ait été tourné et non amer. On a depuis longtemps reconnu dans le Midi que les parois intérieures des tonneaux se nettoient, c'est-à-dire que le tartre disparaît, lorsque le vin tourne. Ce fait a été confirmé expérimentalement par M. Béchamp $\left(^{(1)}\right.$, qui a bien reconnu en outre que l'acide volatil formé n'était point de l'acide acétique $\left(^{2}\right)$. Si les conjectures que j'émets au sujet de la différence des résultats obtenus par M. Glénard et par moi étaient fondées, il y aurait là une preuve nouvelle de la différence spécifique des ferments des maladies du tourné et de l'amer.

Quelle serait donc la substance, ou mieux l'une des substances qui joueraient le rôle de matières fermentescibles, lorsqu'un vin passe à l'amertume? En comparant les quantités de glycérine dans des vins de Bourgogne amers et dans les mêmes vins non amers, j'ai trouvé sensiblement moins de glycérine dans le vin amer. Cependant la différence ne suffisait pas pour rendre compte de la différence d'acidité des vins malades et des vins bien portants.

J'ai repris le dosage de l'acide tartrique dans ce vin (qui renfermait un peu plus de potasse qu'il n'en fallait pour faire du bitartrate de potasse avec tout l'acide tartrique) par le procédé de MM. Berthelot et de Fleurieu, et j'ai trouvé :

Sans addition de potasse ......... 1 gr. 8

Avec addition de potasse. ......... 1 gr. $8(3)$.

Il faut ajouter $0 \mathrm{gr} .1$ pour la cause d'erreur que signalent les auteurs au sujet de la solubilité de la crème de tartre dans la liqueur éthéro-alcoolique, soit donc $1 \mathrm{gr} .9$ de bitartrate de potasse par litre. La différence est de 1 gr. 0 sur 2 gr. 9, plus de 30 pour 100.

Le résultat du dosage par l'acide tartrique gauche est généralement

1. BẼchamp (A.). Sur les variations dans la quantité de certains principes immédiats du vin, et sur les transformations que ces principes subissent par suite de certaines altérations spontanées. Comptes rendus de l'Académie des sciences, LIV, 1862, p. 1148-1152.

2. Ве́снамp (A.). Sur l'acide acétique et les acides gras volatils de la fermentation alcoolique. Ibid., LVI, 1863, p. 969, 1086 et 1231. (Notes de l'Édition.)

3. Cet essai a été fait en suivant exactement les prescriptions du Mémoire de M M. Berthelot et de Fleurieu, à la page 190, sous la rubrique Deuxième essai (essai principal), c'est-à-dire que j'ai saturé 10 centimètres cubes de vin par la potasse en solution concentrée, puis j'ai ajouté 40 centimètres cubes de vin, et j'ai prélevé sur les 50 centimètres cubes $12 \mathrm{cc} .5$ auxquels j'ai ajouté 25 centimètres cubes du mélange d'alcool et d'éther.

Dans l'essai sans addition de potasse, j'ai ajouté à 20 centimètres cubes de vin 100 centimètres cubes du mélange d'alcool et d'éther.

Dans un troisième essai fait avec 10 centimètres cubes de vin et 20 centimètres cubes seulement du mélange éthéro-alcoolique, je n'ai obtenu que lcs $\frac{40}{43}$ de $1 \mathrm{gr} .8$ de bitartrate de potasse par litre. 
le même que celui que donne l'évaporation directe d'un litre de vin. Cependant je dois dire que, si l'on pouvait tenir compte exactement de la quantité de bitartrate qui reste dans l'eau mère, on trouverait un peu plus de bitartrate par l'évaporation que par l'autre moyen, ce qui me fait penser que, dans le procédé par l'acide tartrique gauche, jobtiens un minimum de la quantité, ce qui éloigne encore plus de la vérité les résultats du dosage par le mélange d'alcool et d'éther.

Je dois ajouter en terminant que MM. Berthelot et de Fleurieu ont signalé, comme une des causes de la différence entre les quantités de bitartrate fournies par leur procédé et l'évaporation directe, la présence dans le vin de proportions plus ou moins grandes d'acide éthyltartrique que la chaleur décomposerait. Mais doit-on admettre qu'un vin, dans lequel il y a plus de potasse qu'il n'en faut pour transformer en bitartrate tout l'acide tartrique, donne lieu, avec le temps, à de l'acide éthyltartrique? n'est-il pas vraisemblable que cette formation d'un produit éthéré doit s'appliquer plutôt aux autres acides? Enfin, comment le procédé de dosage par le tartrate gauche donnerait-il lieu à une décomposition de l'acide éthyltartrique du même ordre que celle qu'occasionne l'ébullition? comment expliquer, si cette décomposition n'a pas lieu dans l'emploi du tartrate gauche, l'accord sensible qui existe entre le procédé de dosage par ce tartrate, et celui par évaporation directe?

* Le vin de Pomard de 1863, de M. Marey-Monge, dont il vient d'être question (page 317 et suivantes), a été soumis à nouveau à l'analyse en juillet 1872. Le vin chauffé a conservé sa couleur naturelle; le vin non chauffé, d'un jaune rougeâtre, est en grande partie décoloré.

Le vin chauffé a un dépôt adhérent. Le vin non chauffé a un dépôt flottant considérable. Le microscope permet de découvrir dans le vin chauffé de petites granulations amorphes de matière colorante, et çà et là à peine un ou deux petits articles organisés par champ, ceux-là mêmes qui existaient à l'origine et auxquels le chauffage a retiré toute propriété de développement ultérieur: ce vin, chauffé deux années seulement après la récolte, avait déjà certainement subi un commencement d'altération peu sensible au gout, mais visible au microscope. Au contraire, dans le vin non chauffé, le champ du microscope est rempli de gros filaments imprégnés de matière colorante et çà et là on distingue au milieu d'eux de petits filaments très nets qui paraissent

- Les paragraphes suivants jusqu'au chapitre "De l'influence de l'aération sur la fermentation des moûts " ont été ajoutés à la deuxième édition des "Etudes sur le vin ". (Note de l'Édition.)' 
encore vivants; ces deux espèces de filaments sont semblables à ceux que montre la figure 21.

Au goùt, le vin chauffé est bien conservé; le vin non chauffé a pris une acidité et une amertume très désagréables : il est complétement perdu. (Voir [pages 378-381] le rapport de la Chambre syndicale sur la dégustation du 10 juillet 1872.)

Ces caractères sont évidemment corrélatifs d'altérations chimiques profondes.

Pour les découvrir, j'ai d'abord dosé l'alcool de ces deux vins et j'ai trouvé, toutes corrections faites, dans le vin chauffé : 11,3 pour 100 d'alcool, et dans le vin non chauffé : 11,1 pour 100, nombres aussi identiques que possible, qui prouvent que l'altération du vin n'a point porté sur l'alcool.

J'ai principalement étudié par comparaison les acides de ces deux vins :

10 centimètres cubes de vin chauffé ont exigé pour la saturation 15 cc. 6 d'une eau de chaux dont 21 cc. 8 saturaient 0 gr. 0591 d'acide acétique; 10 centimètres cubes de vin non chauffé en ont exigé 24 centimètres cubes.

La différence est de 8 cc. 4 qui correspondent à une augmentation totale par litre, par le fait du parasite, égale à $2 \mathrm{gr} .28$ évalués en acide acétique : il y a donc encore eu dans ce vin accroissement d'acidité depuis 1866.

Mais l'acidité totale du vin chauffé n'a pas varié sensiblement depuis le mois de janvier 1866, car on trouve par le calcul que 10 centimètres cubes de ce vin en 1872 auraient exigé pour la saturation 16 cc. 35 de l'eau de chaux dont le même vin a exigé en 1866 16 cc. 7.

J'ai déterminé la proportion relative des acides volatils, en distillant un litre de liquide (voir page 318 ); j'ai trouvé :

\footnotetext{
Vin chauffé .. $\left\{\begin{array}{l}\text { Les } 500 \text { premiers centimètres cubes ont exigé } 105 \text { cc. } 4 \\ \text { d'eau de chaux dont } 23 \text { cc. } 2 \text { saturent } 0 \text { gr. } 0591 \\ \text { d'acide acétique. } \\ \text { Les } 400 \text { centimètres cubes (A) ont été saturés par } \\ 180 \text { centimètres cubes d'eau de chaux. } \\ \text { Les } 400 \text { centimètres cubes }(B) \text { par } 72 \text { cc. } 7 \text { d'eau de } \\ \text { chaux. }\end{array}\right.$ Vin non chauffé. $\left\{\begin{array}{l}\text { Les } 500 \text { centimètres cubes ont exigé } 217 \text { centimètres } \\ \text { cubes d'eau de chaux. } \\ \text { Les } 400 \text { centimètres cubes (A) ont exigé } 318 \text { centi- } \\ \text { mètres cubes d'eau de chaux. } \\ \text { Les } 400 \text { (B) } 126 \text { centimètres cubes d'eau de chaux. }\end{array}\right.$
} 
Un litre de vin chauffé renfermait donc une quantité totale d'acide acétique égale à celle que satureraient $105 \mathrm{cc} .4+180 \mathrm{cc} .+72 \mathrm{cc} .7$ +72 cc. $7=430$ cc. 8 d'eau de chaux, ce qui correspond à 1 gr. 1 d'acide acétique. Au contraire, un litre de vin non chauffé renfermait une quantité d'acide capable de saturer : 217 cc. +318 cc. +126 cc. +126 cc. $=787$ cc., volume correspondant à 2 grammes d'acide acétique.

Si l'on se reporte à l'analyse de la page 319 , on voit que depuis 1866 la proportion d'acides volatils n'a pas varié dans le vin chauffé. L'augmentation, par l'influence du parasite, étant de $0 \mathrm{gr} .9$ en acides volatils, et de $2 \mathrm{gr} .28$ en acide total, il en résulte que le parasite de l'amertume développe des acides fixes aussi bien que des acides volatils.

On voit également que, depuis 1866 jusqu'à 1872, les acides fixes et les acides volatils se sont développés à peu près dans le même rapport dans le vin non chauffé que depuis 1865 jusqu'à 1866, ce qui tendrait à prouver que la fermentation n'a pas changé de caractère; mais la vitesse de l'altération s'est beaucoup ralentie dans la deuxième période.

Examinons encore les variations de l'acide tartrique :

Par l'évaporation directe (voir page 315) on a trouvé :

Vin chauffé, 2 gr. 5 de bitartrate de potasse par litre;

Vin non chauffé, 1 gr. 8 de bitartrate de potasse par litre.

Par précipitation, à l'état de racémate de chaux, on trouve :

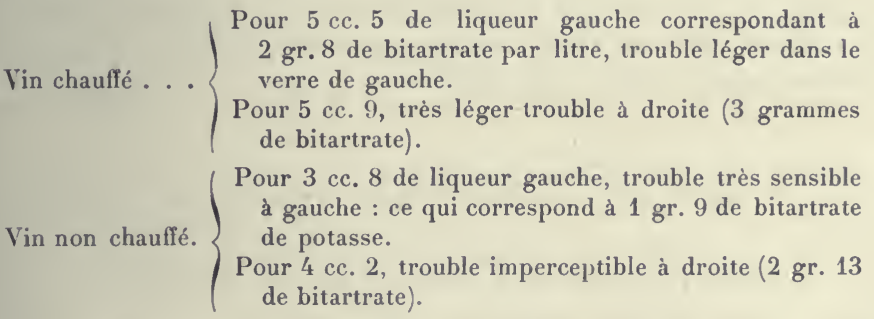

Ces résultats concordent assez bien avec ceux obtenus par évaporation directe.

Dans le vin chauffé, l'acide tartrique est encore demeuré invariable depuis 1866. Mais, dans le vin non chauffé, tandis que, de 1865 à 1866, l'acide tartrique était resté inattaqué, dans la deuxième période il a participé à la fermentation et a disparu en proportion notable équivalant à peu près à 0 gr. 8 de bitartrate par litre, ou à 0 gr. 47 d'acide tartrique. 
Pourquoi la fermentation du vin non chauffé a-t-elle atteint l'acide tartrique dans la deuxième période, de 1866 à 1872, et non dans la première, de 1865 à 1866 ? Deux hypothèses sont possibles : ou bien la fermentation a changé de caractère avec le temps; au ferment de l'amertume aurait succédé avec le temps le ferment du tourné comme l'indiquerait le mélange des deux sortes de filaments (page 321). C'est en effet l'acicle tartrique qui paraît principalement attaqué quand le vin tourne (page 320). Ou bien le ferment de l'amertume, après s'être porté sur un certain principe $d u$ vin, se serait enfin nourri aux dépens de l'acide tartrique, le premier venant à manquer. Je pencherais plutôt pour cette dernière hypothèse.

Mais outre l'acide tartrique, sur quels principes le ferment de l'amer a-t-il porté son action dans le vin non chauffé pendant ces deux périodes? La matière colorante est sans doute un de ces principes, puisque celle-ci a disparu de la dissolution, - non par l'action de l'oxygène de l'air, - mais vraisemblablement par la fermentation. On est tenté d'admettre que l'organisme vivant a agi sur le glucoside de la matière colorante du vin comme sur une matière fermentescible,

- d'où est résultée la précipitation d'une autre partie de la matière colorante elle-même.

Quoi qu'il en soit de cette hypothèse, l'analyse du vin dont il s'agit a prouvé que la glycérine intervient pour une forte part dans la fermentation de l'amertume, car le rapport des poids de glycérine observés dans un litre de vin chauffé et dans le même vin non chauffé est $\frac{6 \text { gr. } 10}{2 \text { gr. } 68}$, fait qui confirme la remarque que j'ai faite sur la diminution de glycérine dans des vins de Bourgogne moins amers que celui de M. Marey-Monge. (Voir page 320.)

\section{De L'influence de L'AÉRATion SUR LA FERMentation des môtts.}

J'ai constaté que, lorsque le moût est exposé au contact de l'air en grande surface pendant plusieurs heures, ou agité avec de l'air, opération facile à pratiquer à l'aide d'un soufflet dont la douille est munie d'un tube qui plonge dans la cuve ou dans le tonneau, ou par tout autre moyen, la fermentation du moût est incomparablement plus active que celle du même moût non aéré, et la différence varie avec l'intensité de l'aération. Il est digne d'attention, en outre, que l'aération peut produire des effets aussi sensibles, alors même qu'on l'effectue pendant la fermentation, lorsque le liquide est déjà chargé d'acide carbonique et de levûre alcoolique. 
Les expériences suivantes ne laisseront pas de doute à ce sujet, mais elles montreront, d'autre part, que l'activité plus grande de la fermentation pendant les premiers jours n'est pas durable, qu'elle fait bientòt place à un ralentissement très marqué, et que, si l'on n'aère pas de nouveau, le mont primitivement non aéré finit quelquefois par prendre le dessus.

Le 29 septembre 1864, j'ai rempli de moût de ploussard deux bouteilles de 2 litres. Ce moût, extrait la veille et renfermé après l'action du pressoir dans les bouteilles, contenait l'équivalent de $9 \mathrm{gr} .3$ d'acide tartrique par litre et $200 \mathrm{gr}$. 4 de sucre. Une des bouteilles fut aérée le 29, en insufflant de l'air avec un soufflet muni d'un tube de verre courbé à angle droit, et dont l'extrémité plongeait dans le moût. L'aération dura une heure. On adapta ensuite des tubes abducteurs aux bouteilles.

Le 30 septembre, commencement de fermentation dans la bouteille aérée. Rien d'apparent dans l'autre.

Le $1^{\text {er }}$ octobre, la fermentation commence dans la bouteille non aérée. J'appellerai A la bouteille aérée, B l'autre.

Voici le tableau comparatif du nombre des bulles de gaz acide carbonique par minute :

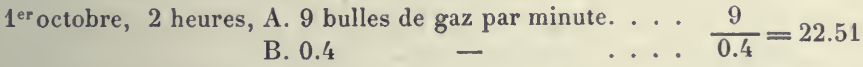
2 octobre, 11 heures, A. 15
B. 1.25
$\cdots \frac{15}{1.25}=12$
3 octobre, 8 heures, A. 24
$\cdots \frac{24}{4}=6$
B. 4
$-$
$-\quad \cdots \frac{40}{10}=4$
4 octobre, 9 heures, A. 40
B. 10

On détermine les quantités de sucre. A ne renferme plus que 169 gr. 3 de sucre par litre, et B en contient encore 196 gr. 4 . Il en a donc fermenté $31 \mathrm{gr} .1$ dans la première, et seulement $4 \mathrm{gr}$. 0 dans l'autre.

5 octobre, 1 heure, A. 28 bulles par minute $\ldots \ldots \frac{28}{16.5}=1.69$

6 octobre, 8 heures, A. 20.5

B. 16.5

$\ldots \ldots \frac{20.5}{16.5}=1.24$

7 octobre, 9 heures, A. 17

8 octobre, 10 heures; A. 15

8 octobre, 10 heures; A. 15
B. 11

-

$\ldots \ldots \frac{17}{13}=1.30$

$-\quad \ldots \ldots \frac{15}{11}=1.36$ 


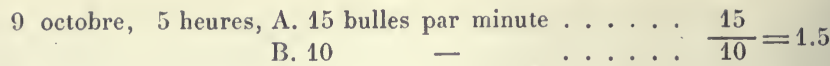

10 octobre, 11 heures, A. $10.5 \quad-\quad \cdots \cdots \cdot \frac{10.5}{7}=1.5$

11 octobre, 5 heures, A. $11.5 \quad-\ldots \ldots \frac{11.5}{7.5}=1.53$.

Il résulte de ces comparaisons qu'encore bien que le moût aéré fermente plus vite que celui qui n'est pas aéré, la différence, qui est considérable à l'origine, va diminuant peu à peu, et, dans d'autres cas, j'ai constaté même que le moût non aéré reprend le dessus.

Le 13 octobre, j'ai déterminé de nouveau l'acidité des deux moûts.

A renfermait $9 \mathrm{gr} .7$ en équivalent d'acide tartrique par litre, et B, $9 \mathrm{gr} .9$, au lieu de 9 gr. 3 qu'il contenait à l'origine.

Ainsi, d'une part, l'acidité des moûts a augmenté pendant la fermentation, et, d'autre part, le moût qui avait été aéré a moins gagné en acidité par la fermentation que le moût non aéré. Ces résultats sont dignes d'attention, et tous deux m'ont paru constants d'après d'autres essais analogues. A l'aération du moût correspondrait donc un

- moyen d'apporter quelque changement dans les proportions des principes résultant de la fermentation. Il y a lieu de penser, puisque la fermentation du moût aéré fournit moins d'acide que celle du moût non aéré, qu'elle introduit également moins de glycérine; car il résulte des expériences consignées dans mon Mémoire sur la fermentation alcoolique $\left(^{1}\right)$ que la proportion de glycérine augmente ou diminue avec celle de l'acide succinique. Il ne faudrait pas croire, d'ailleurs, que ces différences tiennent au poids de gaz oxygène que l'aération peut fixer sur les principes du moût. C'est à une constitution propre de la levûre qui prend naissance qu'il faut les attribuer. La levûre formée dans un liquide où il y a de l'oxygène, en dissolution ou en combinaison instable et assimilable par elle, est fort différente par ses propriétés physiologiques de celle qui se multiplie dès l'origine à l'abri de l'oxygène, bien que, sous le rapport de l'aspect au microscope, il ne soit pas toujours facile de les distinguer.

Si le lecteur veut bien se reporter à une Communication que j'ai faite à l'Académie en 1861, intitulée Expériences et vues nouvelles sur la nature des fermentations (2), il pourra se convaincre que, lorsque le moût de raisin est exposé au contact de l'air, le ferment se multiplie

1. Voir p. 51-126 du tome II des CEuvres de Pasteur : Mémoire sur la fermentation alcoolique.

2. Voir p. 142-147 du tome II des CEuvres De Pasteur. (Notes de l'Édition.) 
avec une grande rapidité, et que, si on le considère en lui-même, abstraction faite du poids qui s'en est formé pour un poids donné de sucre décomposé durant sa production, c'est un ferment des plus énergiques, lorsqu'on le fait agir ensuite sur le sucre à l'abri de l'air. Mais nous venons de reconnaître que l'activité de ce ferment ne dure pas, qu'elle s'épuise très vite.

Il résulte de ces faits que l'on peut modifier considérablement une variété déterminée d'un ferment alcoolique, changer ses propriétés physiologiques, par le seul fait d'un changement dans les conditions de son développement. Les différences sont telles que l'on pourrait croire à des espèces distinctes.

Il faut donc être très sobre de déductions sur la nature spécifique des ferments, alors même que l'on constate des modifications importantes dans leur manière d'agir.

Je crois qu'il serait fort utile de mettre en rapport, avec les conditions de l'aération des moûts, les particularités de la fermentation des bières par les levûres dites supérieure ou inférieure, et que l'on éclairerait beaucoup la fabrication des deux sortes de produits que ces levûres permettent d'obtenir.

\section{Application de l'á́ration a la production de la mousse dans le vin de Champagne.}

Je fus consulté un jour par deux fabricants de vin de Champagne sur la production de la mousse dans ce vin, sur les difficultés de sa fermentation, tantôt trop lente, tantôt trop rapide, etc.

Je donnai à ces fabricants le conseil d'activer la fermentation par l'aération préalable. Quelques mois après, ils m'adressèrent, à la date du 16 octobre 1865, une lettre dont j'extrais le passage-suivant :

"Nous avons l'honneur de venir vous donner le résultat d'un essai que nous avons fait, d'après votre conseil, lorsque nous avons mis en bouteilles notre vin de 1864 .

"L'expérience consistait à aérer le vin avant la mise en bouteilles, ce que nous avons fait, sur vos indications, en roulant pendant une demi-heure une pièce de vin à demi pleine. Le résultat a confirmé complétement vos prévisions : le vin, traité de la sorte, est devenu grand-mousseux en huit jours, tandis qu'il a fallu trois semaines à du vin mis en bouteilles sans cette opération pour arriver à une bonne mousse ordinaire. Au bout de quinze jours, une bouteille de chaque sorte, débouchée sans explosion, a donné lęs résultats suivants : vin 
aéré, la bouteille se vide aux trois quarts, et c'est une des plus grandes mousses possibles; vin ordinaire, la bouteille se vide à 8 centilitres seulement.

“La mousse du vin aéré est aussi restée jusqu'à présent sensiblement plus forte que celle de l'autre. Le dépót est sec et se détache bien. "

Voilà un exemple frappant de l'influence de l'oxygène de l'air sur le développement de la levûre alcoolique, et dont les fabricants de vins de Champagne pourront tirer d'autant plus de profit que la proportion de ferment développé, lorsqu'il y a aération, étant plus grande, le vin doit se mieux dépouiller et être moins sujet, je pense, à une fermentation ultérieure : cependant il faut que la pratique décide ( $\left.{ }^{1}\right)$.

Mais il ne faudrait pas croire que l'aération des moûts se borne à modifier les conditions de la fermentation. Elle influe sur la qualité ultérieure du vin, et, ce qui confirme tout à fait les principes que j'ai exposés sur la cause du vieillissement des vins, elle a pour résultat de le vieillir.

J'ai démontré, dans la seconde partie de cet ouvrage, que l'agent essentiel du vieillissement du vin est l'oxygène de l'air. Or, il est remarquable que le vieillissement par aération peut précéder en quelque sorte la fabrication du vin. Le 5 octobre 1864, j’ai étendu sur le bac à refroidir d'une brasserie 335 litres de vendange égrappée, arrivant de la vigne, et l'y ai laissée trois jours, en renouvelant matin et soir les surfaces à l'aide d'un râteau. Puis cette vendange a été mise en tonneau. Une autre portion de 400 litres de la même vendange a été mise à fermenter dans un tonneau voisin, sans aération préalable. Les deux vins que ces vendanges ont fournis différaient notablement : celui de la vendange aérée était du vin déjà fait, comparé à l'autre. Il n'avait point la verdeur de ce dernier. Enfin, abstraction faite de l'acide carbonique, ce n'était pas du vin nouveau : il était, dès l'entonnaison, bon à boire.

C'est ici le lieu de rappeler une méthode très curieuse de faire le vin, usitée en Lorraine, peu répandue aujourd'hui, mais qui a été remise en honneur en 1856 devant la Société centrale d'agriculture de

1. Puisque l'occasion m'est offerte de parler du vin de Champagne, je ferai remarquer que l'on pourrait conserver avec la plus grande facilité, par le procédé du chauffage préalable à $50^{\circ}$, le vin encore sucré des bonnes années qui doit servir à élever. le degré des vins de moindre qualité des années suivantes.

Le chauffage s'oppose à la fermentation alcoolique ultérieure des moûts éclaircis à la suite d'un commencement de fermentation.

La conservation d'un moût sucré au degré que l'on désire peut devenir une source nouvelle d'applications pour la préparation des vins de liqueur. 
Nancy, par MI. Henrion-Barbezan ( ${ }^{(1)}$, et, en 1863, par M. Nicklès (2), dans un article inséré dans le Journal de pharmacie et de chimie. On ne sait à quelle époque elle remonte. Elle consiste essentiellement dans un brassage de la vendange, sans interruption pendant quarante-huit heures, avec des pelles; puis on fait fermenter, et le reste des opérations de la vinification a lieu comme à l'ordinaire. Or, M. HenrionBarbezan assure que, toutes les fois qu'il a fait brasser une partie de sa vendange, le vin résultant a été et plus alcoolique et plus agréable que le vin de la vendange non brassée ou non pellée; car on appelle ce vin, en Lorraine, vin de pelle.

Sans doute cette pratique du brassage, si elle a la valeur qui lui est attribuée par M. Henrion-Barbezan, ne s'est point répandue à cause de l'impossibilité qu'il y aurait, en temps de vendange surtout, de faire brasser, pendant quarante-huit heures, à quatre ouvriers par bouge, comme le recommande ce cultivateur éclairé. Mais, d'après les essais que j'ai rapportés dans cette Note, il n'y a pas à douter que ce brassage de la vendange n'est qu'un moyen d'aération, et qu'en conséquence on pourrait le remplacer par une insufflation d'air à l'aide de procédés plus simples et plus économiques.

En résumé, je ne saurais trop répéter ici que tout importe dans les pratiques de la vinification lorsqu'elles ont pour conséquence de modifier en quoi que ce soit l'aération de la vendange ou du vin. Et il faut bien remarquer qu'il y a une foule de circonstances auxquelles on ne donne aucune attention à l'ordinaire, dans lesquelles néanmoins il y a intervention de l'oxygène de l'air.

Par exemple, le vin est apporté dans les cuveries et versé tout de suite dans les cuves de fermentation, ou bien il est cylindré, c'està-dire écrasé au-dessus de la cuve à l'aide de deux cylindres cannelés, desquels le moût s'écoule par minces filets. Il est de toute évidence que, dans le second cas, le moût s'aère bien plus que dans le premier. A coup sûr, selon moi, le vin du propriétaire qui aura suivi cette dernière pratique de l'écrasement de tous les grains au contact de l'air différera de celui du propriétaire qui aura cuvé sans cylindrer, toutes choses égales d'ailleurs. Le premier vin sera plus fait, moins vert, moins vif. Il n'y a pas jusqu'à la distance des cylindres à la cuve qui n'aurait une importance sensible, surtout s'il s'agit de vins très délicats.

Ce que je dis ici de cylindres broyeurs, je puis le répéter en ce qui

1. Mémoire sur la fabrication du vin, lu dans la séance du 6 septembre 1857 de la Société centrale d'agriculture de Nancy, par M. Henrion-Barbezan, président de la section d'œnologie. Nancy, 11 p. et 1 tabl. in-80.

2. Nicklès. Sur la fabrication d'un vin particulier connu sous le nom de vin de pelle. Journal de pharmacie et de chimie, 3e sér., XLIV, 1863, p. 393-397. (Notes de l'Édition.) 
concerne une autre pratique que j'ai vu appliquer au Clos-Vougeot, et qui consiste à placer les raisins sur le tablier du pressoir et à les faire piétiner par des hommes avant de les mettre dans la cuve de fermentation. Cette opération doit appeler toute l'attention de ceux qui l'adoptent. Il faủt qu'ils étudient la durée qu'elle doit avoir, la température extérièure pendant laquelle on la pratique, l'écrasement plus ou moins achevé, etc., parce que l'oxygène de l'air est présent et agit. Je crois même qu'il faudrait la mettre en rapport avec l'état de maturité des raisins, avec ía nature des cépages, et même avec les exigences du commerce des vinș.

Enfin, pour citer une dernière circonstance, insignifiante en apparence, mais où l'action de l'air intervient encore nécessairement, je signalerai le filet de moût qui s'écoule du pressoir. Il n'est pas du tout indifférent que le moût soit reçu dans une cuve largement ouverte, où il séjournera plus ou moins de temps, ou qu'il soit conduit immédiatement par des tubes à l'abri de l'air dans des tonneaux.

Bref, tout le travail de la vinification doit être étudié dans ses rapports avec l'air atmosphérique. Je ne fais d'ailleurs que signaler un - principe sans dire comment il faut l'appliquer. Le sujet est trop complexe, et ce qui est bon pour un vin peut être mauvais pour un autre. C'est à la propriété et au commerce qu'il appartient de déterminer la mesure dans laquelle il faut suivre les indications de la science. Je désire ne pas tomber dans cette faute assez commune, dont les traités sur les vins offrent tant d'exemples, qui consiste à établir des opinions définitives ou des pratiques nouvelles sur la foi d'observations isolées et incomplètes.

\section{Note SUR LE cépage APPelé enfariné.}

Singularité de Sa maturation.

Le plant enfariné est propre au vignoble du Jura et particulièrement au vignoble d'Arbois. C'est un des cépages qui renferment le plus d'acide et le moins de sucre. On l'estime néanmoins à cause de l'abondance de son produit et de sa force de résistance contre l'intempérie des saisons.

Au point de vue scientifique, il mérite quelque attention, parce que l'acidité de ce cépage ne diminue pas toujours avec sa maturité, et que le sucre n'augmente pas non plus nécessairement avec elle (1).

1. Je tiens de M. Ladrey que M. Fleurot, habile pharmacien de Dijon, a dẻjả constaté des faits analogues sur un cépage de la Bourgogne. 
Voici des mesures que j'ai prises en 1863 et en 1864.

ANXÉE 1863.

Récolte du 16 septembre.

On choisit les grappes les plus mûres. Elles paraissent être aussi mùres que ce cépage peut les donner.

Acide total en équivalent tartriquc. . . . . . . . . . 23,1

Sucre. . . . . . . . . . . . . . . 153,9

Récolte du 19 septembre.

On fait trois lots.

$1^{\circ}$ Grains les plus mûrs choisis parmi les plus noirs :

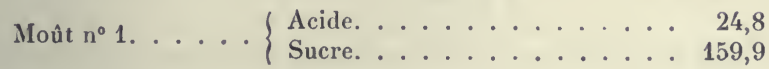

$2^{\circ}$ Grains rouges sans apparence de noir :

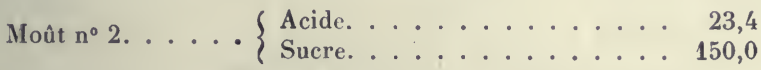

$3^{\circ}$ Grains intermédiaires, chacun des grains en partie noir, en partie rouge :

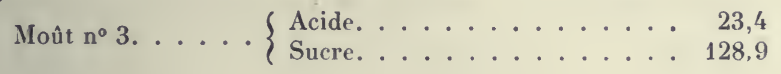

AxxÉE 1864.

Récolte du 27 septembre.

On fait trois lots.

10 Grains noirs les plus mûrs :

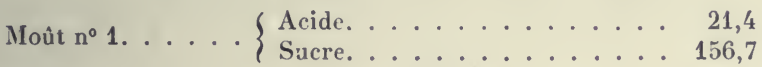

$2^{\circ}$ Grains rouges commençant à noircir :

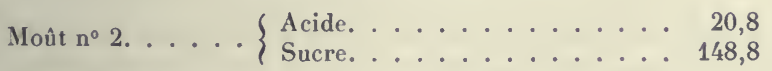

$3^{\circ}$ Grains verts commençant à devenir roses :

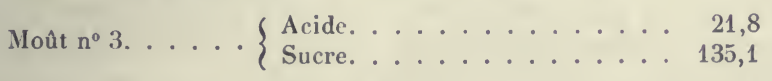

Récolte du 28 septembre.

On fait quatre lots.

$1^{\circ}$ Grappes les plus noires dont on éloigne tous les grains avec 
apparence de rouge mêlé; c'est le maximum de maturité pour le 28 septembre, à en juger d'après la couleur :

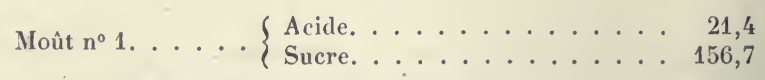

$2^{\circ}$ Grains sans mélange de noir, tous d'un rouge violacé; pas de vert dans la teinte :

$$
\text { İoût no } 2 \ldots \ldots\left\{\begin{array}{l}
\text { Acide. } \ldots \ldots \ldots \ldots \ldots \\
\text { Sucre. } \ldots \ldots \ldots \ldots
\end{array}\right.
$$

$3^{\circ}$ Grains intermédiaires, c'est-à-dire les noirs non très noirs et les rouges noirs :

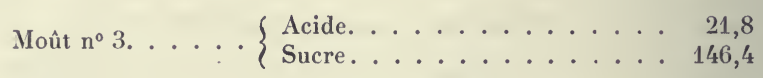

$4^{\circ}$ Grains tout verts et ceux d'un vert qui commence à rougir :

$$
\text { Moût no } 4 \ldots \ldots\left\{\begin{array}{l}
\text { Acide. } \ldots \ldots \ldots \ldots \ldots \\
\text { Sucre. } \ldots \ldots \ldots \ldots
\end{array}\right.
$$

Récolte du 30 septembre.

On fait trois lots.

$1^{\circ}$ Grains à surface noire, près de la queue comme à l'opposé :

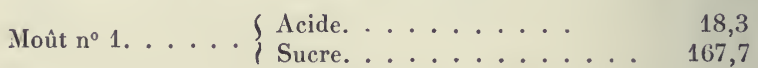

$2^{\circ}$ Grains rouges près de la queue et noirs à l'opposé :

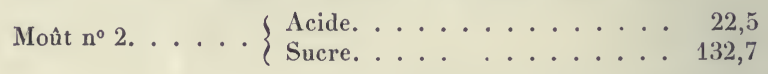

$3^{\circ}$ Grains rouge violacé, sans apparence sensible de noir à l'opposé de la queue :

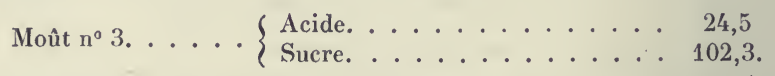

En jetant les yeux sur ces tableaux, nous constatons ce résultat, très digne d'attention, offert par les récoltes du 19 septembre 1863 et du 27 septembre 1864, que l'acidité du grain rouge et du grain partiellement rouge et noir est moindre que celle du grain noir. Pendant la maturation, l'acidité augmente donc au lieu de diminuer, du moins à un certain moment de la maturation. Ce fait n'est peut-être pas d'accord, au moins dans l'état actuel de nos connaissances, avec l'idée qui attribuerait l'origine du sucre à une transformation des acides tartrique et malique. 
Les récoltes du 28 et du 30 septembre 1864 ne présentent pas ce résultat, mais cela a tenu peut-être au mode de triage. Quoi qu'il en soit, toutes les récoltes nous montrent le fait curieux de la faible variation de l'acidité comparée à celle des quantités de sucre.

La récolte du 28 septembre offre un autre résultat très singulier et qui ne correspond pas du tout à une erreur de mesure, ainsi que je m'en suis assuré au moment même où je l'ai constaté. Le $\mathrm{n}^{\circ} 2$ de cette récolte à grains rouges renferme moins de sucre que le $n^{\circ} 4$, qui correspond aux grains beaucoup moins avancés, puisqu'ils étaient verts, ou d'un vert teinté de rouge. Il semble donc qu'il y ait eu ici diminution du sucre par la maturité, comme tout à l'heure il y avait augmentation de l'acidité. Les grains rouges, $\mathrm{n}^{\circ} 2$, de la récolte du 19 septembre ont offert bien plus de sucre que les rouges $n^{\circ} 2$ du 30 septembre. Ils étaient un peu plus avancés et d'une autre vigne.

Enfin nous pouvons déduire de notre tableau cette autre observation que l'enfariné mûr de 1863 était plus acide et un peu moins sucré que celui de 1864 .

On est conduit à se demander s'il n'y aurait pas dans l'enfariné deux minima pour l'acidité. Les grains verts en mûrissant deviendraient moins acides, puis, en mûrissant davantage, ils prendraient plus d'acide, et en mûrissant davantage encore, l'acidité diminuerait de nouveau. Tout ceci demande des recherches plus approfondies. Je ne veux qu'éveiller l'attention des jeunes chimistes qui désireraient s'en occuper

INdication d'UNe méthode pour Étudier les principaux acides du ViN.

Il serait bien utile également de rechercher les variations des quantités des deux acides tartrique et malique pendant la maturation du raisin.

Il n'est pas difficile d'extraire tous les acides contenus dans le moût du raisin par le moyen suivant : le moût, réduit d'abord par évaporation au cinquième de son volume, est agité, avec un mélange d'alcool et d'éther, à diverses reprises, puis on laisse reposer et l'on décante le liquide alcoolique éthéré. On ajoute de celui-ci une nouvelle portion, que l'on décante à son tour, au bout de vingt-quatre heures, et ainsi de suite jusqu'à ce que le moût ne cède plus d'acides. Il ne contient plus alors que du bitartrate de potasse, du tartrate neutre de chaux et des sels alcalins neutres. Tous les liquides alcooliques sont évaporés. Les premiers peuvent l'être séparément. Ils renferment très peu de sucre. 
Après l'évaporation, on sature par l'eau de chaux et l'on évapore de nouveau. La première cristallisation est ordinairement du tartrate de chaux pur en petite quantité, puis, après une nouvelle évaporation, on a une cristallisation abondante de tartromalate de chaux, sel hydraté, formé d'un équivalent de tartrate neutre et d'un équivalent de malate neutre de chaux. Il est quelquefois en fines aiguilles groupées en houppes, mais, plus souvent, il est grenu en lames rhombiques. Enfin, la troisième cristallisation est du malate neutre de chaux pur. L'eau mère renferme les mêmes sels, avec un autre sel de chaux en petite quantité, que je n'ai pas étudié encore suffisamment. Pour séparer ces sels de chaux du sirop sucré qui les empêche de cristalliser, on étend d'eau et l'on fait fermenter le sucre rapidement par une addition suffisante de levûre de bière. Le vin est évaporé et les sels de chaux cristallisent.

Je réduis 5 litres de moût d'enfariné à 1 litre par l'évaporation. L'acidité du moût déterminée à l'avance avait indiqué que les 5 litres exigeaient 27 lit. 650 d'eau de chaux représentant $33 \mathrm{gr} .08$ de chaux pour leur saturation.

Le résidu des deux premiers traitements par le mélange d'alcool et d'éther à volumes égaux a exigé pour sa saturation 14 lit. 925 d'eau de chaux représentant 17 gr. 412 de chaux caustique. Une première cristallisation a fourni après vingt-quatre heures 6 gr. 550 de tartrate neutre de chaux pur. Par évaporation il s'est formé une nouvelle cristallisation de tartromalate de chaux pur pesant $16 \mathrm{gr}$. 730. Une nouvelle évaporation a fourni $6 \mathrm{gr} .42 \mathrm{du}$ même sel, dont une portion était en mamelons aiguillés. Enfin une nouvelle cristallisation, formée cette fois par évaporation au bain-marie, était formée de malate neutre de chaux pur pesant $21 \mathrm{gr} .89$. L'eau mère était sirupeuse, peu abondante, ressemblant à de la mélasse. En l'étendant d'eau jusqu'au volume de 250 centimètres cubes environ, et en la mêlant à deux fois son volume d'alcool à $90^{\circ}$, on obtient un précipité amorphe très abondant, qui est formé en majeure partie de malate de chaux; son poids s'élevait à 6 gr. 15. Le liquide alcoolique total renfermait seulement $0 \mathrm{gr} .715$ de chaux, probablement à l'état de malate de chaux. Mais dans le précipité par l'alcool se trouvait une petite quantité de sel de chaux insoluble dans l'eau chaude, où il se rassemblait en masse poisseuse, devenant très dure par le refroidissement. C'est l'acide de ce sel de chaux qui devrait être étudié, afin de savoir s'il a déjà été signalé dans le vin.

En résumé, nous pouvons reconnaître dès à présent que le moût de raisin, au moins ce moût d'enfariné, ne contient guère que des acides tartrique et malique, et vraisemblablement pas d'acide lactique, puisque 
l'eau mère alcoolique, qui devrait tenir en dissolution la plus grande partie de l'acide lactique à l'état de lactate de chaux, ne renferme qu'une petite quantité de cette base.

En réunissant toute la chaux des différentes cristallisations obtenues et y joignant celle qui reste dissoute dans l'eau mère alcoolique, il est facile de s'assurer que l'on retrouve à très peu près les $17 \mathrm{gr} .412$ de chaux que renfermaient les 14 lit. 925 employés à la saturation des acides.

Je n'ai pas isolé avec le même soin les sels de chaux fournis par les troisième, quatrième, cinquième traitements, à l'aide du mélange d'alcool et d'éther, mais j'ai lieu de croire qu'ils ne m'auraient offert que ceux dont je viens de parler. J'ai voulu plutôt indiquer un procédé d'extraction des principaux acides du vin par la préparation plus facile de ceux du moût que faire connaître exactement ces acides et leurs proportions, si variables d'ailleurs avec les cépages et la maturité.

J'ai obtenu des résultats de même ordre avec le moût de ploussard. Les acides principaux sont encore le tartrique et le malique.

\section{Note SUR Le CÉPAge APPELE ploussard.}

Le plant de ploussard est un des plus estimés du vignoble d'Arbois. J'ai suivi sa maturité en 1863 et en 1864 par le dosage des quantités d'acide et de sucre; on verra par le tableau suivant combien elles diffèrent de celles du plant enfariné.

ANNÉE 1863.

Récolte du 7 septembre.

La récolte est partagée en grains les plus noirs, grains lie de vin (c'est-à-dire rouges ou rouges avec noir commençant), et grains verts commençant à devenir rouges.

Poids des grains les plus mûrs, 9 kil. 433.

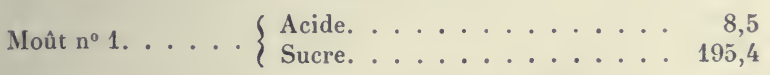

Poids des grains lie de vin ou rouges, 3 kil. 862.

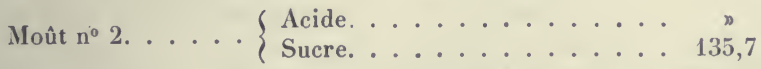

Poids des grains verts rougissant, 0 kil. 200.

Moût $n^{\circ} 3 \ldots \ldots\left\{\begin{array}{l}\text { Acide. } \ldots \ldots \ldots \ldots \ldots \\ \text { Sucre. } \ldots \ldots \ldots \ldots\end{array}\right.$ 
Même récolte.

On avait mis à part quelques grappes, les plus mûres, que l'on a pressées séparément. Elles pesaient 0 kil. 300.

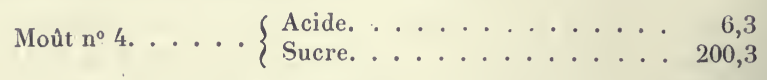

\section{Récolte du 16 septembre.}

On met à part :

Les grains les plus noirs choisis un à un comme étant les plus mûrs dans les grappes très mûres.

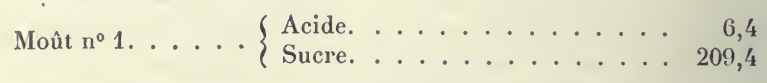

Les intermédiaires entre le rouge et le noir de la maturité, c'està-dire qu'on éloigne d'un certain nombre de grappes tous les grains verts, rouges et noirs, pour ne garder que ceux qui sont à moitié mûrs.

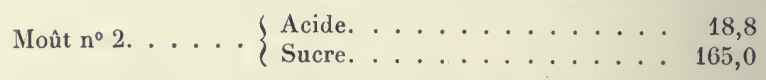

Les grains rouges, dits ici grains lie de vin. Ce sont des grains bien rouges, où l'on ne voit plus de teinte verte et pas encore de teinte noire.

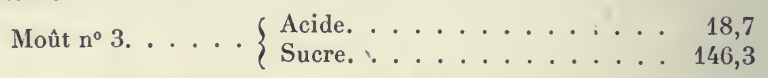

Les grains verts commençant à offrir une teinte rose.

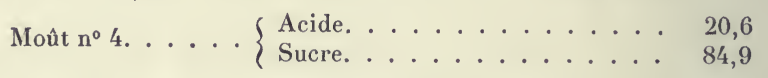

\section{Récolte du 18 septembre.}

Grains les plus noirs choisis un à un comme étant les plus mûrs dans les grappes les plus mûres.

Acide. . . . . . . . . . . . . . . 6, 6

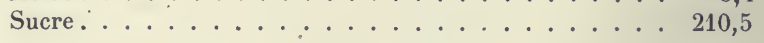

ANNÉe 1864.

Récolte du 27 septembre.

Grains les plus noirs choisis un à un comme étant les plus mûrs dans les grappes les plus mûres.

Acide . . . . . . . . . . . . . . . . 8,8

Sucre . . . . . . . . . . . . . . 215,0 
Récolte du 28 septembre.

Même essai, en prenant la précaution d'aller récolter les grappes les plus mûres dans la localité qui passe dans le pays pour donner le meilleur vin et la plus grande maturité.

Même triage.

Acide

Sucre.

221,5

Pour la récolte du 16 septembre 1863, il manque un terme de comparaison, celui des grains mûrs, non choisis parmi les plus mûrs, c'està-dire le terme correspondant au $n^{\circ} 1$ de la récolte du 7 septembre. Il aurait donné sensiblement 8 grammes d'acide et 200 de sucre par litre. Je supposerai ce terme intercalé parmi ceux de la récolte du 16 septembre.

En rapprochant les $\mathrm{n}^{\text {os }} 4,3$ et 2 de cette récolte du 16 septembre, on voit qu'en 1863 la maturation de ce cépage consistait principalement, pour les grains verts et rouges, à prendre du sucre. Mais pour les grains plus avancés, la maturité s'accuse au contraire par une diminution de l'acidité. C'est très sensible quand on passe de la première maturité à une maturité plus grande; en effet, en passant du $n^{\circ} 4$ au $n^{\circ} 3$, c'est-à-dire lorsque le raisin vert à peine rosé devient rouge, pour une diminution d'acide représentée par 2 grammes, le gain en sucre est de plus de 60 grammes par litre. D'autre part, le grain rouge, en devenant en partie noir, n'a perdu qu'une quantité insignifiante d'acide en gagnant près de 20 grammes de sucre. Ce dernier résultat a cependant quelque chose d'un peu exceptionnel. En général, on trouve plus de différence que cela dans l'acidité pour des sortes de grains compris dans les dénominations des $\mathrm{n}^{\text {os }} 2$ et 3 .

Nous voyons, au contraire, que le grain déjà noir en partie, aux trois quarts inûr, perd beaucoup d'acide en devenant noir sans que la quantité de sucre augmente en proportion. Pour une diminution d'acide représentée par 10 grammes environ, il y a augmentation de 35 grammes de sucre. Et si l'on passe des grains noirs aux grains choisis parmi les plus noirs, ou, ce qui revient au même, des grains noirs et qui viennent d'atteindre cette maturité, aux grains déjả depuis longtemps noirs, on trouve que le sucre augmente très peu et que l'acide diminue sensiblement. C'est ce qui résulte surtout de la comparaison du $\mathrm{n}^{0} 1$ et $d u n^{0} 4$ de la récolte du 7 septembre, et aussi de celle du $n^{0} 1$ du 7 septembre avec celle du $\mathrm{n}^{\circ} 1$ du 16 septembre.

Il y a en quelque sorte deux espèces de maturation; l'une qui se. ÉTUDES SUR LE VINAIGRE ET SUR LE VIN. 
traduit de préférence par une production de sucre, et l'autre par une diminution d'acidité. La maturation par augmentation de sucre serait propre au grain tant qu'il n'est pas noir; plus tard, ce serait le tour de la maturation par diminution de l'acidité. Elle correspondrait à une maturité plus avancée.

Il est facile de reconnaître en outre, par les nombres du tableau, que la maturité du ploussard offre, ou du moins a offert, en 1863, une sorte de limite qu'elle avait peine à dépasser. Il paraitrait donc que les grains, après avoir atteint cette maturité, peuvent rester sur le cep sans amélioration sensible. Gagnent-ils sous d'autres rapports, d'autres principes sont-ils modifiés? C'est ce qu'il est difficile de savoir, mais pourtant c'est probable.

Si nous comparons maintenant les récoltes de 1864 avec celles de 1863, nous voyons qu'en 1864, en opérant le triage le plus soigné de façon à retirer des grappes les plus mûres leurs grains les plus noirs, on n'a pu arriver à une acidité aussi faible qu'en 1863.

En 1864, le grain de ploussard, pris à la limite extrême de sa maturité, était beaucoup plus acide qu'en 1863, et cependant celui qui a fait l'objet des essais en 1864 avait quinze et vingt jours de plus d'âge, et à une époque où se fait de préférence la maturité du fruit. En revanche, le ploussard de 1864 avait un peu plus de sucre que celui de 1863.

\section{Sur la présence de la Gomme dans le viN.}

J'ai reconnu la présence dans tous les vins d'une proportion variable, mais toujours très sensible, d'une substance combinée à du phosphate de chaux et ayant toutes les propriétés générales des gommes, notanment celle de fournir par l'action de l'acide nitrique une assez grande quantité d'acide mucique, identique avec l'acide mucique dérivé de la gomme arabique et du sucre de lait.

Pour isoler la gomme du vin, réduisez ce vin au quinzième environ de son volume, laissez cristalliser le tartrate acide de potasse pendant 24 heures, et ajoutez à l'eau mère, plus ou moins visqueuse selon la proportion plus ou moins forte de la gomme, 3 à 4 fois son volume d'alcool à $90^{\circ}$. Le précipité s'offre sous deux états : Tantôt il se rassemble et s'agrège promptement en diminuant beaucoup de volume; on peut renverser le vase sans qu'il se détache des parois. Tantôt il reste sous forme de précipité floconneux. C'est que, dans ce dernier cas, la gomme est associée à des sels de chaux, principalement à du 
tartrate neutre. Le précipité lavé à l'alcool par décantation est purifié par dissolution dans l'eau, filtration et précipitation nouvelle par l'alcool. On a souvent beaucoup de peine à le débarrasser des sels de chaux auxquels il est associé.

L'oxydation de la gomme du vin par l'acide nitrique fournit du jour au lendemain une cristallisation assez abondante d'acide mucique recouvrant toutes les parois du vase qui a servi à l'opération. La plus petite quantité de gomme du vin permet de constater ce caractère.

Dans la liste des principes immédiats du moût de raisin que l'on trouve dans les auteurs classiques, l'existence d'une matière gommeuse est souvent indiquée. Cependant je n'ai pas trouvé de travail qui constate rigoureusement (par exemple, comme je le fais ici par le caractère de l'acide mucique) le fait de la présence de la gomme dans le vin, mais Fabroni, dans son traité De l'art de faire le vin( $\left(^{(}\right)$, dit que " dans les vésicules qui constituent la pulpe centrale du grain réside un suc plus gommeux que le suc des autres parties du grain."

Serait-ce là l'origine de l'indication de quelques auteurs au sujet de la présence de la gomme dans le moût ou dans le vin ? Je l'ignore. Quoi qu'il en soit, voilà un nouveau principe immédiat du vin, qu'il serait bien utile d'étudier avec plus d'attention qu'on ne l'a fait jusqu'à présent.

\section{OrigiNe de la gLycérine et de L'acide succinique daNs le viN.}

On sait aujourd'hui, par les résultats du Mémoire que j'ai publié en 1860 sur la fermentation alcoolique, que ce phénomène chimique ${ }^{2}{ }^{2}$ n'est pas tout à fait aussi simple que Lavoisier et Gay-Lussac l'avaient cru. Le sucre, en se décomposant sous l'influence du ferment, ne donne pas seulement naissance à de l'acide carbonique et à de l'alcool; il fournit en outre de la glycérine, de l'acide succinique, de la cellulose, des matières grasses, et probablement de petites quantités de beaucoup d'autres principes. C'est que l'acte de la fermentation alcoolique est aussi compliqué qu'un acte vital. Loin que le ferment se multiplie sans rien emprunter au sucre, et agisse par sa seule présence, I n'éprouve au contraire aucune modification importante qui soit indépendante de la matière fermentescible. On peut effectuer la fermen-

1. Fabrons. De l'art de faire le vin, traduit de litalien par F.-R. Baud. Paris, an X, in- $8^{\circ}$, ivec tableaux et 13 fig.

2. Voir p. 51-126 du tome II des CEurres de Pasteun : Mémoire sur la fermentation alcooique, et notamment : Première partie, 8 II à VIII. (Notes de l'Édition.) 
tation alcoolique dans de telles conditions que l'on soit assuré que pas une cellule de ferment ne se forme sans que le sucre lui ait fourni tout son carbone.

Il résulte de ces faits, qu'en calculant la proportion d'alcool que peut fournir un poids déterminé de sucre par l'équation théorique bien connue

$$
\mathrm{C}^{12} \mathrm{H}^{12} \mathrm{O}^{12}=4\left(\mathrm{CO}^{2}\right)+2\left(\mathrm{C}^{4} \mathrm{H}^{6} \mathrm{O}^{2}\right),
$$

on commet une erreur variable, mais toujours très sensible. Elle est variable, parce que les proportions de glycérine et d'acide succinique diffèrent beaucoup suivant les conditions dans lesquelles se fait la fermentation. S'il s'agit de la bière, la proportion de glycérine est d'autant plus élevée que la fermentation a été plus lente et que le développement du ferment a été plus pénible. Dans la fermentation du moût de raisin, les choses paraissent différer sensiblement. Rien de plus facile ni de plus rapide que cette fermentation. Le ferment semble se trouver dans les conditions les plus favorables à son développement, et néanmoins l'équation théorique de Gay-Lussac est fort en défaut.

J'ai trouvé en effet dans le vin des proportions notables de glycérine, 6,7 et 8 grammes par litre. Et je crois qu'il existe des vins, il est vrai de nature particulière, qui ont éprouvé une grande évaporation par un long séjour dans les tonneaux, tels que les vins de Château-Châlons, qui renferment jusqu'à 10 et 12 grammes de glycérine par litre.

En étudiant la différence entre l'équation théorique et l'équation réelle par la comparaison de la quantité de sucre du moût avec la quantité d'alcool du vin qu'il fournit, on reconnaît que l'équation théorique de la fermentation est encore plus en défaut qu'on n'aurait pu s'y attendre.

I. Le 14 octobre 1864, j’ai étudié une vendange de ploussard pur, récoltée la veille.

$$
\begin{aligned}
& \text { Moût \{ Acidité évaluée en acide tartrique . . 8,9 acide tartrique } \\
& \text { de la vendange. } \text { Sucre . . . . . . . . . . 221,4 par litre } \\
& \text { Grains } \quad \text { Acidité. . . . . . . . } 7,2 \text { acide tartrique } \\
& \text { de la vendange. }\{\text { Sucre . . . . . . . . 226,5 par litre }
\end{aligned}
$$

Le 13 novembre, j'ai étudié le vin provenant de cette vendange.

Acidité . . . . . . . 8,0 acide tartrique par litre

Alcool . . . . . . . 12,5 pour 100

En calculant théoriquement l'alcool d'après l'équation de Lavoisier et de Gay-Lussac, au taux de 221,4 de sucre par litre, on devrait trouver 
14,2 pour 100 d'alcool. La perte serait donc dans cette hypothèse de $14,2-12,5=1,70$, soit 11,3 pour 100 .

En calculant, au contraire, l'alcool théorique au taux de 226,5 grammes de sucre par litre, on devrait trouver 15,5 pour 100 de sucre. La perte, dans cette hypothèse, serait de $15,5-12,5=3,0$, soit 19,3 pour 100. La perte réelle est'donc comprise entre 11,3 et 19,3.

II. Le 15 octobre, étude d'une vendange de tous plants.

Acidité totale .......... 12,3 acide tartrique Sucre . . . . . . . . . 188,9

Le vin de cette vendange ne contenait que 10,3 d'alcool pour 100; on aurait dû trouver théoriquement 12,15 , perte 15,2 pour 100 .

Acidité du vin, évaluée en acide tartrique, 12,44.

III. Le 16 octobre, étude d'une vendange de ploussard pur.

Acidité du moût. ........ 9. 9,5 acide tartrique

Sucre .............. 196,4

Acidité totale évaluée en acide tartrique. $\quad 8,9$ acide tartrique

Sucre ............ 196,4

Le vin de cette vendange renfermait:

Acidité du moût des grains. . . . . 9,3

Alcool . . . . . . . . . 10,9 pour 100

Théoriquement on aurait dû trouver . . 12,6 pour 100 d'alcool

Perte........... 13,5 pour 100

IV. Étude d'une vendange de trousseau pur et du vin qui en est résulté $-13,1$ pour 100 de perte en alcool.

L'acidité du vin était un peu supérieure à celle de la vendange.

V. Étude d'une vendange de ploussard pur et du vin qui en est résulté $-11,7$ pour 100 de perte en alcool.

L'acidité du vin était un peu supérieure à celle de la vendange.

En résumé, il est évident, d'après l'ensemble de ces résultats, qu'une portion considérable du sucre contenu dans le moût n'est point du tout utilisée à faire de l'alcool. Pourtant je ne saurais affirmer que les pertes d'alcool que je viens de constater doivent être attribuées intégralement à une déviation de la fermentation prise du point de vue de l'équation théorique de Lavoisier et de Gay-Lussac. Il m'a paru que le marc condensait une forte proportion d'alcool. 
Les faits qui précèdent, tout en rendant compte de la grande quantité de glycérine que l'on trouve dans les vins, font vivement désirer une étude suivie et nouvelle de la fermentation du raisin. Des travaux, poursuivis sur divers points de la France, devraient être entrepris.

Dans les exemples que je viens de citer, l'acidité du vin a été trouvée supérieure à celle de la vendange. MM. Berthelot et de Fleurieu, dans une Note insérée aux Comptes rendus de l'Académie en avril $1864\left({ }^{(1)}\right.$, ont conclu à la disparition d'une portion notable des acides du moût autres que l'acide tartrique pendant la fermentation qui produit le vin. Il y a donc de nouvelles recherches à faire pour expliquer ces apparentes contradictions. Certainement le fait signalé par ces savants est très loin d'être général, et, dans la pluralité des cas, il y a augmentation de l'acidité par la fermentation, si j'en juge par les résultats que j'ai obtenus. Tout récemment $\left({ }^{2}\right), \mathrm{M}$. Boussingault a bien voulu me confier quelques-uns des résultats encore inédits d'un travail très soigné entrepris par son fils sur la fermentation des fruits à noyau $\left.{ }^{3}\right)$. Ce jeune chimiste a constaté également une augmentation de l'acidité du moût de raisin par la fermentation.

Sur la graisse des vins $(4)$.

Le ferment en chapelets de grains de la figure 15 est-il toujours le ferment de la viscosité des vins? Voici un fait relatif au moût de bière qui mériterait d'être suivi sur les vins blancs filants.

Il m'est arrivé à plusieurs reprises de chauffer du moût de bière non houblonné en bouteilles à $85^{\circ}$. Ce moût a toujours fermenté ultérieurement, mais sans donner autre chose qu'un ferment en chapelets, non de grains, mais de petits filaments semblables en tout pour l'apparence aux filaments de la bière et du vin tournés. En mème temps le moût devenait visqueux et filant.

1. Berthelot et Fleurieu (A. de). Sur les proportions comparées d'acide tartrique dans le raisin et dans le vin. Comptes rendus de l'Académie des sciences, LVIII, 1864, p. 720-723.

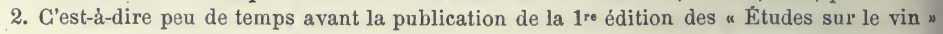
(1866).

3. Boussingault (Joseph). Sur la fermentation des fruits á noyau, p. 44-91 et p. 213-232 du tome IV, et p. 81-94 du tome V de : Boussingault (Jean-Baptiste). Agronomie, chimie agricole et physiologie. Paris (2。 édition), 1860-1884, 7 vol. in- $8^{\circ}$ (fig.).

4. Gette Note ne figurait pas dans la 1re édition des "Études sur le vin ". (Notes de l'Édition.) 


\title{
SUR LE PROcÉdÉ DE CONSERVATION DES VINS PAR LE CHAUfFage PRÉALABLE.
}

\begin{abstract}
A M. Le rédacteur en Chef du Moniteur sinicole (1).
\end{abstract}
Paris, 11 octobre 1865.

Monsieur le rédacteur,

Je lis dans votre estimable journal plusieurs lettres ou articles de quelques-uns de vos correspondants, qui tendent directement ou indirectement à diminuer, voire même à supprimer tout à fait la nouveauté du procédé de conservation des vins que j'ai publié récemment $\left(^{2}\right)$.

Permettez-moi d'y répondre, bien plus cependant avec l'intention d'instruire vos lecteurs qu'avec celle de faire de la polémique. J'ai une répugnance instinctive pour les discussions stériles.

La plus grande satisfaction du savant est celle que lui procure la découverte de faits nouveaux, de lois inconnues avant lui. Il n'est pas moins heureux lorsqu'il entrevoit dans les résultats de ses recherches quelques applications aux arts, au commerce, à l'industrie. Aussi ne doit-on pas s'étonner que ces sentiments fassent place chez lui à des regrets, lorsque, arrivé près du terme de recherches longues et consciencieuses, il se voit contraint de dire, avec Lavoisier, " qu'il y a toujours dans les sciences des personnes disposées à trouver que ce qui est nouveau n'est pas vrai, ou que ce qui est vrai n'est pas neuf ».

A peine avais-je appelé l'attention de l'Académie des sciences sur

1. Cette lettre a étẻ insérée au Moniteur vinicole, 10 année, 1865, p. 333-334, 341-342 et $345-346$, sous le titre : Le chauffage des vins (Communication de M. Pasteur, membre de l'Institut). Elle a été publiée sous forme de brochure intitulée : Sur la conservation des vins. Lettre adressée à M. le rédacteur en chef du Moniteur vinicole. Paris, 1865, H. Plon, $16 \mathrm{p}$. in $-8^{\circ}$.

La lettre était précédée dans le Moniteur vinicole de cette introduction signée Louis Tavernier : "Nous recevons de M. Pasteur la lettre suivante, dans laquelle l'éminent chimiste développe la véritable portée de ses expériences sur le chauffage des vins et le caractère de ses découvertes. Nos lecteurs accueilleront avec un sérieux intérêt cette précieuse communication, qui répond en même temps aux diverses correspondances que nous sommes ainsi heureux d'ąvoir provoquées. Soit qu'on le considère au point de vue curatif et conservateur de M. Pasteur, soit qu'on recherche seulement un moyen de modifier la constitution du vin, ce sujet présente une importance considérable. $\mathrm{ll}$ est permis de prévoir le temps oủ le chauffage, combiné avec certaines manipulations, pourra être le salut des vins et rendre ainsi d'immenses services à la production, au commerce et à la consommation." (Note de l'Édition.)

2. On trouvera tout ce que j'ai publié antérieurement sur les vins dans les Comptes rendus de l'Académie des sciences, séances des 7 décembre 1863, 18 janvier 1864, 1er mai, 29 mai et 14 août 1865 [p. 389-395, 396-406, 409-412, 413-417, 418-422 du présent volume]. 
l'utilité possible du chauffage préalable des vins comme moyen de conservation, que ce procédé fut déclaré, par les uns, déjà ancien et appliqué sur une grande échelle, et par les autres, mauvais et pouvant amener la ruine de ceux qui l'adopteraient.

Cette lettre, monsieur le rédacteur, a pour objet d'établir, non par des assertions sans preuves, mais par un examen scrupuleux des faits, que le procédé dont il s'agit, abstraction faite de tout jugement sur son efficacité, est entièrement nouveau, que personne ne l'a jamais appliqué dans le Midi ou ailleurs, et qu'il serait impossible à un membre quelconque d'une société de viticulture de produire authentiquement sur le bureau de cette société un litre de vin qui ait été conservé par mon procédé avant le jour de ma première Communication à l'Académie, le $1^{\text {er }}$ mai 1865 . Je demande seulement que l'on veuille bien lire attentivement ce que j'ai écrit sur le vin, et que l'on ne m'attribue pas des idées et des prétentions que je n'ai jamais eues.

Il est très vrai que quelques négociants, dans le Midi, ont chauffé et chauffent encore du vin, - je dirai tout à l'heure comment, mais c'est uniquement dans le but de faire changer en quelques jours la couleur rouge violacé du vin nouveau en couleur rouge pelure d'oignon; c'est-à-dire dans le but de faire paraître vieux un vin qui est très jeune. Jamais un négociant du Midi n'a fait chauffer du vin dans le but de le conserver. Tout à l'inverse de ceci, j'ai donné le moyen de conserver le vin sans toucher à sa couleur, bien que le vieillissement du vin, dans des conditions nouvelles, soit un effet ultérieur de l'application de mon procédé. Je n'ai point la prétention de vieillir le vin en quelques jours, mais d'avoir indiqué un moyen de rendre le vin inaltérable.

Entre un procédé pour changer la couleur du vin en quelques jours, de façon à faire croire qu'il a deux ou trois années d'âge au lieu de six mois, et un procédé pour le rendre inaltérable pendant une suite indéfinie d'années, il y a une différence qui n'aurait pas dû être méconnue, alors même que, dans les deux cas, la chaleur serait employée pour obtenir ces deux résultats distincts.

La famille de M. Privas (de Mèze) paraît être la première qui ait employé la chaleur pour donner au vin la couleur du vin vieux. Elle a appliqué ce procédé pendant plus de cinquante ans, et c'est d'Espagne qu'elle l'aurait tiré. Aujourd'hui elle l'a tout à fait abandonné, mais les cuves où se pratiquait l'opération existent encore. Je les visitai le 27 juin dernier, en compagnie de M. Marès, et conduit par M. Privas lui-même, qui y mit la plus grande obligeance. Nous allâmes ensuite visiter tous les trois les immenses chais de M. Thomas, où des essais 
de chauffage par le procédé Privas ont été tout récemment installés.

“Dans ces cuves en pierre de taille de Beaucaire, recouvertes d'une couche de peinture, nous dit M. Privas, et dont celle-ci jauge environ mille hectolitres, j'entreposais le vin tel qu'il m'arrivait de chez les propriétaires après la vendange et la fermentation. Dans un petit couloir placé sous nos pieds et que je vais vous faire voir tout à l'heure, il y avait une chaudière, de laquelle partaient des tubes de cuivre entrant dans la cuve. Le vin était chauffé par la vapeur circulant dans les tubes pendant vingt à vingt-cinq jours, à la température de 25 à $30^{\circ}$, afin d'achever la fermentation, parce que le vin nouveau contient toujours dans̀ le Midi un peu de sucre. Puis, à la fin, nous chauffions jusqu'à $75^{\circ}$, afin d'avoir la teinte du vin vieux. ”

J'ai écrit ces paroles le soir en rentrant à Montpellier, et, comme je viens de le dire, elles ont eu pour témoin auriculaire l'éminent agriculteur du Midi, M. Marès. L'exactitude scrupuleuse des faits est d'autant plus précieuse ici que la pratique dont je parle n'a jamais été publiée, à ma connaissance.

Le système est exactement le même chez M. Thomas, avec cette seule différence que la cuve est beaucoup moins vaste, et qu'elle est debout et de bois de chêne.

A quelle température chauffez-vous, demandai-je à $M$. Thomas, et combien de temps? " Je ne sais, nous répondit-il, à quelle température je chauffe. Cela dure cinq, six jours ou davantage, jusqu'à ce que je juge que la couleur est bonne, c'est-à-dire celle du vin vieux. Je n'emploie pas de thermomètre, c'est le changement de couleur qui me guide. Mais le vin prend un goût particulier que l'on n'aime pas, et qui oblige à le couper avec du vin nouveau. ”

Ce fait et cet usage sont immédiatement confirmés par M. Privas.

Tel est le procédé de chauffage pratiqué par de rares négociants dans le Midi, et abandonné même par le chef actuel de la famille qui l'aurait importé en France.

Reportez-vous un instant, monsieur le rédacteur, aux faits nouveaux que j'ai constatés dans l'étude du vin, de ses propriétés et des causes de ses altérations; ayez, d'autre part, sous les yeux, l'indication du procédé que j'ai fait connaitre, et vous comprendrez la différence absolue qui existe entre ce procédé de conservation et le procédé de vieillissement artificiel employé à Mèze.

$1^{\circ}$ Le vin est chauffé à Mèze pour lui donner la teinte de vin vieux!

a. Je le chauffe sans que la nuance de sa teinte soit le moins du monde changée. Ce n'est pas là le but que je me propose, et, bien plus, 
je serais en contradiction avec mes principes si j'y tendais par l'opération du chauffage.

$2^{\circ}$ Le vin est chauffé à Mèze pendant une ou plusieurs semaines!

$b$. Je le chauffe juste le temps nécessaire pour qu'il arrive à la température de 50 à $60^{\circ}$, et une minute suffirait si l'on pouvait atteindre cette température en une minute dans toute la masse, parce que je n'ai qu'un but en chauffant le vin, c'est de cuire en quelque sorte les germes des parasites qu'il renferme, germes qui l'altèrent s'ils viennent à se multiplier.

$3^{\circ}$ Le vin est chauffé à Mèze au contact de l'air!

$c$. Je le chauffe à l'abri de l'air.

$4^{\circ}$ Le vin chauffé à Mèze prend un goût sui generis, en même temps qu'il change de teinte!

$d$. Je le chauffe dans'des conditions telles qu'en le faisant déguster après refroidissement par un courtier expert, celui-ci a de la peine à lui reconnaître une différence de goût sensible relativement au même "vin non chauffé.

$5^{\circ}$ Le vin chauffé à Mèze est mêlé ensuite avec du vin nouveau!

$e$. Mes recherches démontrent que le vin nouveau apportera avec lui et introduira dans toute la masse les germes des maladies qui altéreront le mélạnge, tout comme si une portion n'avait pas été chauffée.

On ignore donc absolument à Mèze ce que l'on fait en chauffant le vin, sinon qu'on change sa teinte en teinte de vin vieux.

$6^{\circ}$ Le vin est chauffé à Mèze dans des cuves, puis placé dans des tonneaux et manipulé sans précaution à la manière de tous les vins!

$f$. Mes recherches prouvent qu'il pourra trouver dans l'air ou dans ces tonneaux, et même qu'il trouvera toujours dans ceux qui ont déjà servi, les germes des ferments parasites que j'ai reconnus être la cause exclusive des maladies des vins.

Ce qui précède montre jusqu'à l'évidence que les personnes qui ont prétendu que le procédé de conservation du vin que j'ai fait connaître était ancien et appliqué dans le Midi ont fait preuve à leur insu d'une grande ignorance, soit de ce qui se pratique et s'est pratiqué à Mèze, soit de mes travaux. Elles n'ont vu qu'une chose. - M. Pasteur chauffe le vin. On le chauffe aussi à Mèze. Donc le procédé de M. Pasteur est 
ancien. - L'histoire de la science et les progrès de ses applications exigent plus de circonspection et une connaissance plus exacte de ce dont on parle. Lorsqu'on se donne, comme publiciste à un titre quelconque, la mission élevée d'éclairer l'opinion publique, il serait convenable de ne point juger des choses sous leurs apparences, surtout lorsque l'expression va droit à diminuer le mérite d'autrui. La vérité devait être d'autant plus recherchée ici qu'aucun des ouvrages sur l'art de la vinification, même les plus récents, ceux de MM. Ladrey (1), Maumené $\left({ }^{2}\right)$ et Béchamp $\left({ }^{3}\right)$, ne disent un mot des pratiques de Mèze. Je parle, bien entendu, des éditions qui auront précédé ma première Note à l'Académie en mai $1865\left({ }^{4}\right)$.

Il y a ici un enseignement. On voit clairement qu'il faut se défier des on dit sur un procédé industriel non publié, principalement lorsque le progrès de la science vient éclairer la théorie, jusque-là inconnue, de ce procédé. Les on dit changent alor's de nature, et il devient facile, par la confusion des idées de la veille et de celles du lendemain, d'altérer la vérité.

La théorie du procédé de conservation des vins par chauffage préalable est des plus simples. Je la reproduis brièvement :

Les maladies des vins sont dues à des ferments organisés, ou végétations parasites, dont j'ai fait connaître les caractères, et tous les vins renferment les germes de ces ferments vivants. Cela étant, et personne, que je sache, ne conteste cette première base de mes études, j'ai recherché s'il ne serait pas possible de priver ces germes de leur vitalité par la chaleur, sans altérer le vin, de façon à s'opposer au développement de ses maladies. L'expérience a confirmé ces déductions logiques. Ainsi est né le procédé de conservation dont il s'agit, procédé très rationnel, comme on le voit.

Quant à la pratique de Mèze, pour changer la couleur du vin nouveau en couleur de vin plus vieux, elle est tout empirique. Mais les personnes qui ont lu avec attention ce que j'ai écrit sur le vin, et qui se sont familiarisées avec les résultats de mes expériences, comprendront facilement la théorie que je vais en donner. Le vin chauffé à Mèze change de couleur, uniquement parce que la cuve est exposée au contact de l'air. C'est l'oxygène de l'air qui produit le changement de

1. Ladrey (C.). Traité de viticulture et d'œnologie (2॰ édition). Paris, 1872-1873, 2 vol. in-16.

2. Maumené (E.-J.). Indications théoriques et pratiques sur le travail des vins et en particulier sur celui des vins mousseux. Paris, 1858 , vi -630 p. in- $8^{\circ}$.

3. Béciamp (A.). Leçons sur la fermentation vineuse et sur la fabrication du vin. Montpellier, 1863, xxvı-159 p. in-16.

4. Voir p. 409-412 du présent volume : Procédé pratique de conservation et d'amélioration des vins. (Notes de l'Édition.) 
couleur du vin. La chaleur ne fait qu'activer l'oxydation, comme elle active en général toutes les actions chimiques. Pourquoi chauffe-t-on le vin pendlant très longtemps? C'est précisément pour permettre à l'oxygène de l'air de pénétrer en quantité suffisante, d'autant plus que, ne connaissant pas du tout la théorie du procédé qu'ils pratiquent, et ne se doutant point que l'oxygène de l'air fût pour quelque chose dans le changement de couleur recherché, MM. Privas et Thomas ferment leur cuve (autant qu'elle peut l'être, toutefois, quand on chauffe un liquide qui se dilate) dans le but de conserver le plus possible les vapeurs alcooliques. Moins on facilitera l'accès de l'air dans la cuve, plus il faudra de jours pour produire la teinte désirée. De là, et suivant la nature du vin, les tâtonnements et le peu d'utilité d'un thermomètre. M. Thomas a bien raison de dire qu'il se guide sur la couleur seule, et je ne sais si M. Privas avait un souvenir bien exact du maximum de température, lorsqu'il nous dit qu'il allait à la fin de l'opération à $75^{\circ}$. C'était, en tous cas, pure perte de calorique. Il vaudrait mieux rester à basse température et employer quelques jours de plus. L'oxygène de l'air ne peut agir tout d'un coup. Il lui faut du temps, et, d'autre part, un degré de chaleur élevé ne peut rien sans une proportion suffisante d'oxygène. Toutefois je n'insiste pas, parce que je ne juge pas en ce moment la valeur de tels ou tels procédés. Je me borne à exposer leur but, leur mode d'application et leur théorie.

Considérons maintenant, monsieur le rédacteur, les procédés de vieillissement de Cette.

Les personnes qui ont prétendu que mon procédé de conservation du vin n'était pas nouveau ont mis en avant les pratiques de Cette, où l'on expose le vin en plein soleil. J'ai visité Cette, ayant toujours la bonne fortune de la compagnie de M. Marès, et j'ai vu ces magasins où gisent sur le sol les tonneaux de vin. C'était le 28 juin dernier. - A Cette, on expose le vin au soleil. M. Pasteur le chauffe directement; il a même, lui aussi, proposé l'emploi de la chaleur solaire. Son système n'a donc rien de nouveau. - Les personnes qui tiennent ce langage ne comprennent pas du tout les pratiques fort curieuses de Cette et moins encore celles que j'ai préconisées. Grâce aux recherches que j'ai faites sur le vin, je puis donner ici la théorie de l'exposition des vins au soleil, et j'espère qu'elle pourra servir de guide aux négociants de Cette, et peut-être transformer radicalement leur mode de fabrication ( ${ }^{1}$ ).

Les tonneaux que l'on expose au soleil y restent un an, dix-huit mois, deux ans et plus, soumis à toutes les intempéries des saisons.

1. Dans la lettre insérée au Moniteur vinicole, ne figurent pas les mots : " et peut-être transformer radicalement leur mode de fabrication ". (Note de l'Édition.) 
Notre visite, disais-je, a eu lieu le 28 juin. C'était par un soleil ardent, et qui durait depuis longtemps. Or, M. Marès, qui avait eu la précaution de se inunir d'un thermomètre centigrade, reconnut que la température du vin d'une des pièces était de $29^{\circ}$. Certes nous voilà bien loin du degré qu'il faut atteindre pour tuer les germes des ferments des maladies des vins, et, d'autre part, une exposition au soleil qui dure deux et trois ans ne ressemble guère à un chauffage de quelques heures, et que l'on pourrait réduire à la rigueur, comme je le disais tout à l'heure, à quelques minutes.

Que recherche le négociant de Cette, tout à fait à son insu? Quelle est, en d'autres termes, l'influence du soleil? Les résultats publiés de mes études sur les vins prouvent, d'une manière péremptoire, selon noi, que le soleil n'agit, dans les magasins de Cette, que comme moyen indirect d'oxydation lente du vin, parce que, au soleil, les parois des tonneaux donnent lieu à une évaporation bien plus rapide que dans la cave ou dans le cellier :

On ne chauffe pas le vin à Cette, on l'aère.

Vous me demanderez, sans doute, monsieur le rédacteur, pourquoi un vin blanc, exposé à l'air et au soleil pendant plusieurs années, ne s'altère pas, ne s'acétifie pas. N'allez pas croire, je le répète, que c'est parce que le soleil l'échauffe, comme fait la chaleur dans mes expériences. Non seulement on n'atteint pas le degré voulu pour tuer les germes du mycoderma aceti et autres, je viens de vous le prouver par l'observation thermométrique dans un des jours les plus chauds de cette année, mais j'affirme que l'exposition du vin au soleil, telle qu'elle est pratiquée à Cette, serait le moyen le plus efficace à employer pour perdre le vin et le transformer en vinaigre, si l'on n'y joignait un usage indispensable, à mon sens, et qui consiste dans le vinage du vin à diverses reprises pendant la durée de son exposition au soleil. J'ai la conviction que c'est par l'alcool principalement que le vin se conserve à Cette, et le fabricant dont le vin ne serait pas suffisamment alcoolisé s'exposerait à le faire tourner ou à l'aigrir, malgré la chaleur du soleil, ou mieux à cause de la chaleur du soleil. Ce n'est pas le tout que de chauffer du vin, il faut le faire à un degré convenable, sinon on se place tout juste dans les meilleures conditions pour le perdre.

Voici la preuve irréfutable de ce que j'avance : qu'un fabricant de Cette prenne le soin d'exposer du vin dans ses magasins, au soleil, non plus dans des tonneaux à parois de bois, mais dans des vases á parois de verre, remplis, bien bouchés! j'affirme que son vin blanc conservera 
sa couleur originelle, ne déposera pas, et ne prendra pas de bouquet sensible.

Vous trouverez, monsieur le rédacteur, ces résultats indiqués dans mes Notes à l'Académie des 29 mai et 14 août $1865(1)$.

Dans l'intervalle de quelques semaines, au contraire, s'il a la précaution de laisser de l'air dans les vases de verre, une moitié, par exemple, ou un tiers du vase, et surtout si le verre n'est pas coloré, le vin prendra une belle couleur un peu ambrée, un bouquet très prononcé, et il aura fait tous ses dépôts possibles, à tel point que jamais il ne déposera plus, quel que soit son âge. J'ai donc bien raison d'affirmer que c'est l'air qui est l'agent essentiel de la fabrication de Cette.

J'ai recommandé, depuis plusieurs mois, à M. Marès ainsi qu'à M.:Blouquier, habile négociant de Cette, de vouloir bien faire ces essais, afin de rechercher si le vin qu'on met présentement deux et trois ans à vieillir ne pourrait être vieilli en quelques semaines.

Pourquoi, me direz-vous, l'emploi de bonbonnes de verre? C'est afin d'utiliser non pas seulement la qualité calorifique des rayons du - soleil, mais leur qualité chimique, laquelle est perdue si les rayons solaires frappent des parois de bois. Le soleil, avec emploi des tonneaux de bois, est un agent d'évaporation, voilà tout; il deviendra un agent chimique propre à activer considérablement l'action de l'oxygène de l'air, dans le cas où l'on se servira de bonbonnes de verre à moitié pleines. En outre, la bonbonne de verre n'étant pas pleine, l'air intérieur s'y échauffera à plus de 50 et $60^{\circ}$, ce qui n'aura jamais lieu dans les tonneaux, et les germes du mycoderma aceti seront tués à la surface du liquide, et le vin, cette fois, même sans vinage ni chauffage direct, se conservera sans s'acétifier et sans tourner.

Je disais en commençant cette lettre que je n'avais jamais eu la prétention de vieillir le vin par le procédé du chauffage, mais j'avais, dans mes Communications à l'Académie, fait connaître les principaux résultats que je viens de rappeler sur l'emploi simultané de l'oxygène, de la chaleur solaire et des vases de verre pour vieillir le vin en quelques semaines, et ce sont tous ces faits et tous ces procédès que l'on a confondus et réunis dans un pêle-mêle informe avec les pratiques de Cette et de Mèze.

Toutefois, je me hâte de le dire, il faut craindre qu'en faisant du vin vieux en quelques semaines, par le moyen que je viens d'indiquer, le vin ne soit faible, sans corps, comme me le disait M. Marès, en se

1. Voir p. 413-417 du présent volume : Note sur les dépôts qui se forment dans les vins, et p. 418-422: Nouvelles observations au sujet de la conservation des vins. (Note de l'Édition.) 
servant d'un mot très vague, mais auquel on finit par donner un sens assez précis lorsqu'on étudie beaucoup le vin. Avec l'emploi des tonneaux dans le procédé d'exposition au soleil, l'oxygène de l'air agit avec d'autant plus de lenteur que le vin dégage pendant longtemps du gaz acide carbonique, parce que le vin arrive sucré et muté des celliers des propriétaires, et qu'il fermente encore longtemps.

Quoi qu'il en soit, si les essais que j'indique ne conduisent pas à modifier les procédés de Cette et à abréger considérablement leur durée, ce que l'expérience seule peut décider, ils convaincront du moins ceux qui les tenteront de l'exactitude de la théorie que je viens de donner de la plupart des changements de couleur, de goût et de bouquet des vins exposés au soleil dans les magasins de Cette, et de la différence radicale qui existe entre les procédés de cette ville et celui que j'ai proposé.

Ils diffèrent comme le jour de la nuit. Considérez, par exemple, monsieur le rédacteur, le passage de ma dernière Note à l'Académie qui se rapproche le plus des pratiques de Cette par les apparences: c'est celui où je demande l'essai de hangars vitrés à double enveloppe de verre exposés au soleil, dans le Midi (1). Quel était mon but? Celui de savoir si, en profitant de la propriété des rayons de chaleur obscurs de traverser difficilement le verre (vous savez que, dans des caisses noircies, on peut aller facilement à $90,100^{\circ}$ et plus), il ne serait pas possible d'élever le vin en quelques heures à 50 ou $60^{\circ}$, - en quelques heures, - notez-le bien, pour atteindre le degré voulu qui tue les germes des maladies. Et le lendemain, dans ce même hangar, qui peut être de très petite dimension, on recommencera sur une autre portion de vin, et le surlendemain, et ainsi de suite, tant que le soleil le permettra. Je le demande, y a-t-il là le moindre rapport avec l'exposition du vin au soleil telle que Cette la pratique?

Quels seront la nature des vases, leur capacité, le dispositif des hangars? Ce moyen même n'est-il pas plus défectueux que d'autres modes de chauffage plus coûteux en apparence? Je n'en sais absolument rien. Il ne faut pas demander au savant de tout faire et de tout essayer. C'est le devoir de l'industrie, lorsque des voies nouvelles lui sont indiquées, de se mettre en mesure, par des essais intelligents et peu coûteux, de rechercher si elles sont praticables avec profit.

J'arrive maintenant, monsieur le rédacteur, à une partie de ma tâche beaucoup plus agréable, parce qu'il me reste à nommer la personne qui a le plus approché du procédé de conservation que j'ai fait

1. Voir p. 418-422 du présent volume : Nouvelles observations au sujet de la conservation des vins. (Note de l'Édition.) 
connaître (1). Cette personne est M. de Vergnette-Lamotte. Je ne fais pas ici allusion à la Note de $\mathbf{M}$. de Vergnette du $1^{\text {er }}$ mai 1865 (2), qui a provoqué ma première Communication ce même jour à l'Académie des sciences $\left({ }^{3}\right)$. Relativement à cette Note et au point de vue de priorité de mon procédé, le doute n'est pas permis, puisque j'avais pris date trois semaines auparavant (11 avril 1865) par un brevet d'invention(4), dans le but de pouvoir suivre à mon aise toutes mes expériences et correspondre avec un grand nombre de personnes, sans craindre que l'on me devançât par quelque publication ou brevet (5).

Je dois seulement faire remarquer, en passant, que le procédé proposé par M. de Vergnette, le $1^{\text {er }}$ mai 1865 , n'a que des analogies avec le mien. Il consiste, en effet, à faire séjourner le vin dans un grenier chaud durant deux mois, les mois de juillet et d'août, par exemple, ou dans une étuve à la température d'un tel grenier chaud, toujours pendant deux mois.

Ici encore, je dois faire observer que le but de ma lettre n'est pas de juger l'efficacité des procédés dont je parle; car je serais obligé de déclarer que je ne crois guère à celle du séjour des vins fins de la Bourgogne pendant deux mois au grenier, et j'aurais même lieu de penser que souvent ce serait là le moyen de développer plutôt que de prévenir les maladies des vins. Si l'on songe que dans les grandes cuves du Midi, au moment de la fermentation de la vendange, la température s'élève à $40^{\circ}$ et peut-être davantage, on comprendra qu'il faille aller au delà de cette température pour priver les germes des maladies des vins de leur vitalité. J'ai dit que je croyais pouvoir indiquer un minimum de $45^{\circ}\left(^{6}\right)$, mais mes expériences se poursuivent, et présentement je n'oserais pas, pour une conservation définitive, descendre au-dessous de $50^{\circ}$ au moins. Je sais qu'à la Guadeloupe,

1. J'ai indiqué précédemment, page 207 et suivantes, les rectifications que comportent les détails historiques que je donne ici. Lorsque j'ai adressé cette lettre au Moniteur vinicole, j'ignorais complétement les expériences d'Appert que je rapporte textuellement page 362-363, et que j'ai tirées de l'oubli, où on les avait laissées depuis leur publication, par une Note sur l'emploi de la chaleur comme moyen de conservation du vin. Comptes rendus de l'Académie des sciences, séance du 4 décembre 1865, LXI, p. 979 [voir p. $425-426$ du présent volume]. (Note de Pasteur.)

2. Vergnette-Lamotte (A. de). Des effets de la chaleur pour la conservation et l'amélioration des vins. Comptes rendus de l'Académie des sciences, séance du 1er mai 1865, LX, p. 895-899.

3. Voir p, 409-412 du présent volume : Procédé pratique de conservation et d'amélioration des vins.

4. Voir le texte de ce brevet p. 410-411 du présent volume.

5. Dans la lettre insérée au Moniteur vinicole, Pasteur a fait suivre cet alinéa de la phrase suivante : " C'est, à mon avis, le meilleur mode de publicité que puisse adopter un savant qui veut suivre patiemment son œuvre, sans recourir à la solennité d'une publication académique $n$.

6. Voir p. 418-422 du présent volume : Nouvelles observations au sujet de la conservation des vins. (Notes de l'Édition.) 
ainsi que me l'a écrit dans une lettre très obligeante M. Vollmer, caissier central du trésor de la couronne, les caves sont inconnues, et que tout le vin est conservé dans des bouteilles empilées sous les toits des maisons. Mais il s'agit de vin de Bordeaux et du soleil des tropiques. Je ne crois pas qu'en Bourgogne, le vin dans des bouteilles empilées, dans les jours les plus chauds d'une année chaude, atteigne dans un grenier plus de $35^{\circ}$. C'est un hangar vitré, doublement vitré, qu'il faudrait. Enfin, il faut se placer dans les conditions dont je parlais tout à l'heure, et éviter un séjour prolongé à la chaleur.

Je ferai une remarque, précieuse pour les résultats de mes recherches, au sujet de la Note de M. de Vergnette du $1^{\text {er }}$ mai 1865 : c'est que les principes sur lesquels elle repose sont précisément ceux que j’ai fait. connaître à l'égard des maladies des vins. Ces principes, comme le dit fort bien M. de Vergnette, ont pu seuls expliquer les effets que la chaleur avait produits sur le vin dans certaines circonstances mal étudiées.

Mais, je le répète, ce n'est point de la Note de M. de Vergnette du $1^{\text {er }}$ mai 1865 que je veux parler. Ce qui intéresse particulièrement la question que je traite en ce mornent, c'est que M. de Vergnette avait autrefois appliqué la chaleur au vin et en avait remarqué certains effets comme conservation, ainsi que je l'ai appris pour la première fois par le numéro du Journal de Beaune du 13 mai 1865. M. de Vergnette a publié ses résultats dans un Mémoire intéressant qui se trouve inséré au recueil des travaux de la Société d'agriculture de Paris pour l'année 1850. Il est intitulé : De l'exportation des vins de Bourgogne dans les pays chauds (1). Ce travail, pour être compris, doit être lu en entier et non par phrases détachées.

Dans le cours de ce travail, et comme moyen de reconnaitre si un vin de qualité pourra supporter les longs voyages, M. de Vergnette conseille d'essayer, sur une petite portion, s'il ne s'altère pas par une élévation de température dans les limites de 60 à $70^{\circ}$. Si le vin s'altère étant chauffé, il s'altérera pendant le voyage; s'il se conserve sans altération immédiate par le chauffage, il pourra voyager. Je ne juge pas, je rapporte les principes qui guidaient M. de Vergnette.

M. de Vergnette a donc observé, avant moi, que du vin chauffé au bain-marie par le procédé d'Appert peut se conserver ensuite; mais M. de Vergnette, et c'est ici que reparaît toute la nouveauté de mon procédé, n'a rien déduit du fait qu'il avait observé, qu'un moyen de savoir si le vin à expédier pouvait supporter les longs voyages. En

1. Mémoires d'agriculture... publiés par la Société nationale et centrale d'agriculture, année 1850 , p. 513-524. (Note de l'Édition.) 
d'autres termes, voici du vin de Pomard ou de Volnay, que vous voulez envoyer au loin. S'altérera-t-il durant le trajet? M. de Vergnette vous dit: Prenez-en une bouteille, faites-la chauffer au bainmarie, et si le vin ne s'altère pas, séance tenante en quelque sorte, vous pourrez expédier la totalité de votre vin en toute sécurité tel qu'il est. Je n'ai pas besoin de dire, si l'on consulte ce que j'ai écrit sur le vin, combien cet essai serait illusoire et défectueux, car j'ai démontré qu'il n'y a pas un seul vin qui s'altère à la chaleur de 60 à $70^{\circ}$. A ce compte, tous pourraient donc voyager. Il n'en est pas moins vrai que M. de Vergnette est la personne qui a le plus approché du procédé de conservation que j'ai fait connaître, et c'est son travail, ainsi que la méthode d'Appert, et non les pratiques de Mèze et de Cette, que la vérité historique doit placer avant le mien.

M. de Vergnette avait si peu compris, parce que la science n'était pas alors assez avancée, la signification de ses essais de chauffage à 60 ou $70^{\circ}$ que son Mémoire, qui n'a d'autre but que de trouver le moyen de faire voyager les vins sans qu'ils se détériorent, a pour conclusion que la congélation préalable est ce moyen et le seul qu'il faille mettre en pratique.

Voici textuellement la fin du Mémoire de M. de Vergnette :

“En résumé, nous n'admettons pas que les vins doivent, pour ètre expédiés au dehors, subir aucun conditionnement qui entraîne avec lui l'addition de substances étrangères.

“ Pour nous, il n'est qu'une manière rationnelle d'améliorer les vins qui doivent faire de longs voyages, c'est de les concentrer par la congélation.

“ Ce procédé n'altère en rien leurs qualités.

“Soit au moyen de l'exposition des vins à l'air dans les hivers rigoureux, soit au moyen des mélanges frigorifiques, on sera toujours maître de congeler les vins au degré convenable.

“ Les vins qui ont voyagé dans les pays chauds présentent tous les caractères des vins que l'on soumet artificiellement dans les limites de 60 à $70^{\circ} \mathrm{C}$. à la chaleur d'un four ou à celle d'un bain-marie. Si, après avoir soumis à cette épreuve quelques échantillons des vins que l'on veut exporter, on reconnaît qu'ils y ont résisté, on pourra, en toute sécurité, les expédier; dans le cas contraire, on devra s'en abstenir. »

La nouveauté du procédé que j'ai proposé ne peut donc être l'objet d'un doute pour personne. Il serait bien à désirer que tous les brevets d'invention eussent, à ce point de vue, la même valeur.

Cette lettre, monsieur le rédacteur, laisse entière, je le répète de 
nouveau, la question d'efficacité et de valeur industrielle de mon procédé. Je crois avoir conduit assez loin les expériences et les travaux de longue haleine qui lui servent de base, pour oser le proposer avec confiance. Sans doute, j'aurais désiré l'étudier encore de plus près avant de le faire connaître. "Mais, comme dit Lavoisier, c'est le tort de tous ceux qui s'occupent de recherches chimiques d'apercevoir un nouveau pas à faire sitôt qu'ils en ont fait un premier, et ils ne donneraient jamais rien au public s'ils attendaient qu'ils eussent atteint le bout de la carrière qui se présente successivement à eux et qui paraît s'étendre à mesure qu'ils avancent pour la parcourir. »

C'est à la propriété et au commerce qu'il appartient de juger en dernier ressort la valeur industrielle du procédé dont il s'agit. Dans les questions d'application, les forces du savant sont souvent très limitées. Il est sensible, pour moi tout le premier, que l'étude du vin poursuivie à Paris est chose difficile. Combien de fois, dans le cours de mes recherches de ces dernières années sur les maladies des vins, n'ai-je pas regretté de ne pouvoir transporter mon laboratoire à Beaune ou à Bordeaux, au centre d'une grande production! Mais n'est pas maître qui veut des exigences matérielles de la vie.

Dans mon procédé il y a deux choses à considérer, celle de la conservation et celle du vieillissement ultérieur du vin. En ce qui concerne l'inaltérabilité absolue du vin, lorsqu'il a été porté, ne fût-ce qu'un instant, de 50 à $60^{\circ}$, et c'est là la question capitale, je ne puis croire que le temps vienne apporter quelque restriction à ma conviction. Mes essais ont eu pour objet plus de 1.200 bouteilles des vins les plus variés, et jusqu'à présent je n'ai pas encore vu une seule bouteille du vin qui avait été chauffé s'altérer, tandis que bon nombre de ces mêmes sortes de vins non chauffés et placés dans les mêmes conditions sont déjả profondément modifiés et montrent des dépôts flottants de cryptogames en abondance.

Au point de vue du vieillissement, j'ai la plus grande confiance dans un résultat favorable, parce que mes recherches m'ont conduit à cette opinion, que l'oxygène de l'air est l'agent essentiel du vieillissement du vin, soit en tonneaux, soit en bouteilles, et que je n'empêche en rien l'action lente de l'oxygène de l'air après le chauffage. Néanmoins, il n'est pas douteux que le jugement des années vaudra mieux que celui que je porte en ce moment. La composition du vin est si peu connue qu'il se pourrait qu'un principe mal déterminé encore, et que la chaleur modifierait, n'éprouvât plus par l'effet de l'oxygène de l'air des changements identiques avec ceux qu'il éprouverait dans les conditions ordinaires. C'est précisément par des craintes 
de cette nature que je cherche à connaître, comme on l'a vu par ma dernière Note à l'Académie, la température minima qu'il suffirait d'atteindre pour être sûr de la conservation ultérieure (1). Moins on élèvera la température sans nuire au résultat désiré, plus on sera voisin du vin naturel, et meilleur sans doute sera le procédé, sans compter la question de la plus grande économie.

La nature du vin n'est pas non plus à dédaigner. Toutes les sortes de vins peuvent recevoir l'application du procédé, parce que j'ai reconnu qu'il n'en est pas qui se troublent ou que la chaleur altère. J'estime cependant qu'une longue pratique et les besoins du commerce pourront indiquer que certains d'entre eux seront chauffés avec plus de profit que d'autres.

Je suis donc bien éloigné, en définitive, de donner le conseil d'élever des usines et des ateliers, et que l'on s'adonne d'emblée au commerce du vin préalablement chauffé. Ce serait être souverainement imprudent; mais, d'un autre côté, ce serait être à mon sens fort routinier que de ne pas tenter des essais, afin de juger la valeur du procédé, industriellement parlant, pour la localité où l'on se trouve.

- La question des débouchés des vins de France, du Midi en particulier, est liée encore de la façon la plus directe, suivant moi, à l'étude commerciale de ce procédé. On dit volontiers que les Anglais exigent des vins très alcooliques, et nous leur envoyons des vins vinés. Mais ils sont vinés, avant toute autre considération, parce que, s'ils ne l'étaient pas, ils s'altéreraient, et que bientôt le commerce n'en voudrait plus. Et cependant, il m'est avis que sous un certain poínt de vue le vinage peut devenir un obstacle au développement du commerce des vins. Je m'explique : le vin que nous envoyons en Angleterre ne paraît que sur la table du riche, et il y figure, par exemple, comme le madère sur la nôtre. Or, le vin a deux vertus qui sont fort distinctes : c'est un excitant et c'est un aliment. Si le madère et le vin de Cette, vinés à 18 et 22 pour 100 d'alcool, sont très bons pour nous aussi bien que pour les Anglais, c'est cependant à la condition que l'on en boira un ou deux petits verres par repas, parce que dans ces vins la qualité excitante prédomine. L'Anglais en supportera un peu plus que le Français, je le veux bien, par raison de race et de climat, mais il n'en fera pas sa boisson habituelle. Ce qu'il faut tenter, c'est de porter à bas prix sur la table de l'ouvrier, comme sur la table du lord d'Angleterre, le vin de France aliment, c'est-à-dire le vin naturel, celui dont Dieu a largement gratifié le beau pays de France. Alors les débouchés

1. Voir p. 418-422 du présent volume : Nouvelles observations au sujet de la conservation des vins. (Note de l'Édition.) 
seront immenses. Quelle est la condition expresse de cette extension du commerce des vins français? C'est qu'ils puissent voyager sans tourner, sans s'aigrir, sans devenir amers ou filants, alors même qu'ils ne seront pas vinés. Jusqu'à preuve du contraire, je crois avoir indiqué l'une des solutions de ce problème important.

Vous voudrez bien excuser, monsieur le rédacteur, la longueur de cette lettre. Je m'aperçois que j'aurais encore bien des questions de détail à traiter. J'en suis averti par les lettres qui me parviennent et les questions que l'on m'adresse. Ainsi je reçois, à l'instant où j'écris ces dernières lignes, une lettre où je trouve les trois questions suivantes :

$1^{\circ}$ Quel est le degré de chaleur (minima) auquel doit être soumis le vin en bouteilles?

$2^{\circ}$ Combien de temps faut-il chauffer le vin?

$3^{\circ}$ Cette opération peut-elle être exercée sur des vins en bouteilles depuis deux ou trois ans, et dans lesquelles les dépôts flottants et les parasites commencent à se montrer? Peut-on espérer arrêter la maladie et la guérir sans retour par le chauffage?

Voici mes réponses à chacune de ces questions :

I. Chauffez de 50 à $60^{\circ}$. Pour connaître la température du vin, placez parmi les bouteilles, bien bouchées et ficelées, une ou plusieurs bouteilles pleines d'eau avec un thermomètre dont la boule plonge dans l'eau de ces bouteilles. La température du thermomètre sera la température du vin. Retirez les bouteilles; frappez sur les bouchons pour les renfoncer, après que le refroidissement et la contraction du liquide seront suffisants; enlevez la ficelle; mastiquez ou ne mastiquez pas, comme bon vous semble. Les bouteilles peuvent être conservées debout.

Jamais les bouteilles ne se brisent, lors même qu'elles sont remplies de vin jusqu'au bouchon.

II. Il n'y a pas à se préoccuper du temps pendant lequel il faut chauffer le vin. Le temps n'entre pour rien dans le procédé. Il suffit que le vin atteigne le degré voulu de température, ne fût-ce qu'une minute.

Si l'on opère avec une étuve à air chaud, il faudra, pour atteindre ce degré, d'autant plus de temps qu'il y aura plus de bouteilles à chauffer.

Si l'on opère au bain-marie, dès que l'eau du bain qui entoure les bouteilles, et qui s'élève jusqu'à la cordeline, a atteint 80 ou $90^{\circ}$, il ne faut guère qu'une demi-heure ou une heure pour que toutes les bouteilles soient convenablement chauffées.

III. L'opération réussit sur tous les vins en bouteilles; mais il n'est pas très convenable de la pratiquer lorsqu'il y a déjà des dépôts. 
Il vaut mieux commencer par dépoter le vin et pratiquer le chauffage sur les nouvelles bouteilles.

Si le vin est malade, la maladie s'arrêtera au point où elle est, sans plus jamais reparaître; mais le vin ne sera pas guéri. Le procédé prévient les maladies, il ne les guérit pas. Néanmoins, lorsque je l'ai pratiqué sur des vins déjà malades, ils ont toujours été meilleurs après le chauffage. Les vins malades sont généralement saturés de gaz carbonique, dont la plus grande partie s'échappe par l'élévation de température.

Une autre lettre me demande si les vins communs peuvent subir avec profit le chauffage préalable. J'ai répondu indirectement tout à l'heure à cette question. Mais je dois ajouter que le commerce des vins en bouteilles dans les grandes villes, telles que Paris, pourrait très utilement pratiquer cette opération. Il ne faut pas plus de deux ou trois jours, en été, pour que les petits vins de coupage de Paris se couvrent de fleurs. Le chauffage les rend inaltérables, non seulement dans les bouteilles pleines, que l'on peut garder indéfiniment dans un appartement et debout, mais ils ne s'altèrent que très rarement en vidange.

Le commerce de détail chez les marchands de vins de Paris pourrait sans doute tirer un parti utile de ce même procédé. Pendant les chaleurs de l'été, le vin tiré par portions au tonneau s'aigrit souvent, pour peu que la totalité du vin du tonneau ne soit pas débitée en deux ou trois jours. Si le vin a été chauffé, il ne s'altérera pas. Il est facile de donner de l'air à un tonneau, sans craindre d'y introduire les germes du mycoderma aceti. Voici un moyen simple dont je me suis servi. On dirige un trait de flamme près de la bonde, on enfonce un poinçon dans la flamme à l'endroit chauffé, puis, dans le trou fait par le poinçon, on introduit un tampon d'amiante qui a passé dans le jet de flamme. De cette manière, c'est de l'air brûlé qui rentre dans le tonneau au moment où l'on fait un trou dans la douve, et ultérieurement l'amiante arrête les poussières qui sont en suspension dans l'air, du moins en presque totalité.

Veuillez agréer, monsieur le rédacteur, l'assurance de ma considération la plus distinguée.

L. Pasteur,

Membre de l'Académie des sciences.

Post-scriptum (1). - Le 26 octobre 1865, j’ai reçu la visite de deux

1. Ge post-scriptum a été ajouté par Pasteur à la brochure intitulée : Sur la conservation des vins. (Note de l'Édition.), 
personnes dont la compétence en matière de vins est très connue de tous les principaux négociants de Paris ( ${ }^{(1)}$.

Elles ont bien voulu, à ma demande, déguster les cinq sortes de vins suivants (2):

I. Vin d'Arbois, bon ordinaire de 1863 : bouteilles chauffées à $75^{\circ}$, le 5 avril 1865 ; bouteilles du même vin non chauffées.

II. Vin de coupage acheté à l'entrepôt de Paris : bouteilles chauffées, le 11 juin 1865 , à $65^{\circ}$; bouteilles du même vin non chauffées.

III. Vin du Cher, vieux, acheté à l'entrepôt de Paris : bouteilles chauffées, le 11 juin 1865 , à $65^{\circ}$; bouteilles du même vin non chauffées.

IV. Vin de Pomard de 1863, livré par M. Marey-Monge : bouteilles chauffées à $60^{\circ}$, fin juillet; bouteilles du même vin non chauffées.

V. Vin de Gevrey-Chambertin de 1859, acheté chez le propriétaire au prix de $5 \mathrm{fr}$. la bouteille : bouteilles chauffées, le 16 mai, à $65^{\circ}$; bouteilles du même vin non chauffées.

Voici l'appréciation des experts :

Vin d'Arbois. - Le chauffé est supérieur au non chauffé. Pas de différence sensible dans la couleur. Elle est plus vive dans le vin chauffé. Pas de dépôt sensible ni dans l'un ni dans l'autre.

Vin de coupage. - Le chauffé est supérieur au non chauffé. Même nuance de couleur, mais plus vive dans le chauffé. Déjà dépôt faible, mais sensible, dans le vin non chauffé. Pas du tout de dépôt dans le chauffé. La bouteille, retournée et agitée, offre le vin aussi limpide qu'auparavant.

Vin du Cher. - Le chauffé est supérieur au non chauffé. Mème nuance de couleur dans tous deux, mais elle est plus vive et plus agréable dans le chauffé. Pas du tout de dépỏt dans le chauffé. Il commence dans le non chauffé assez pour troubler légèrement le vin lorsqu'on retourne et qu'on agite la bouteille.

Vin de Pomard. - Le chauffé est supérieur au non chauffé. La couleur est la même, mais toujours plus vive dans le chauffé.

1. MM. Hemmet et Teissonnière.

2. Ce sont les vins dont il a été déjå question à la page 232 . 
La limpidité du vin chauffé est parfaite, pas encore de dépôt du tout. Le non chauffé offre un dépôt considérable et flottant, qui, examiné au microscope, montre des fils très longs, d'autres très petits, et enfin des granulations sphériques. Il a un goût d'amertume qui ne se retrouve que très faiblement dans le vin chauffé.

Vin de Chambertin. - Limpidité très grande et même couleur dans les deux cas. Autant de finesse et autant de bon goût dans le chauffé que dans le non chauffé, avec légère maigreur de plus dans le chauffé.

Ces mêmes vins seront dégustés dans les années suivantes, autant que cela sera possible par les mêmes personnes, et je m'empresserai de faire connaître les résultats $\left({ }^{1}\right)$.

Ces vins étaient tous en bouteilles. L'outillage pour le chauffage en fûts m'aurait entraîné à de grandes dépenses; aussi n'ai-je fait encore qu'un petit nombre d'expériences afin de me convaincre que l'on pouvait chauffer au bain-marie les tonneaux cerclés en fer, sans les détériorer. Quant à la manière dont le vin se comportera et à la rapidité plus ou moins grande de l'oxydation des principes du vin, d'où résulte, selon moi, son vieillissement, je n'ai que des inductions tirées de ce qui se passe pour le vin en bouteilles.

Or, nous venons de voir que des vins, ordinaires ou grands vins, qui ont déjà cinq ou six mois de séjour en bouteilles après l'opération du chauffage, ont été jugés meilleurs que les mêmes vins qui n'avaient pas été chauffés.

Le vin, du moins dans les six premiers mois après le chauffage, a donc vieilli sûrement en bouteilles. Bien qu'en fûts le vieillissement doive ètre beaucoup plus rapide qu'en bouteilles, d'après les principes que j'ai posés, il est vraisemblable que l'amélioration du vin y sera graduelle également.

J'ai fait déguster par les mêmes personnes les vins blancs vieillis en moins d'un mois par l'action directe de l'oxygène et du soleil, auxquels j'ai fait allusion dans ma lettre, et le résultat a dépassé mon attente. Car ces vins, qui étaient de la récolte de 1864, ont été jugés avoir plusieurs années d'âge, un goût et un bouquet de madère très sensibles, et, de mon côté, par des expériences particulières, j'ai reconnu l'impossibilité en quelque sorte de faire altérer ces vins. Dans certains cas, pour les vins rouges sucrés notamment, c'est le goût des 
vins de rancio qui se développe. J'ai préparé, par ces nouveaux procédés, des vins de liqueur qui m'ont paru avoir les meilleures qualités et qui sont tout à fait inaltérables. L'étude des produits d'oxydation qui se forment dans les circonstances dont je parle sera fort intéressante. Je l'ai commencée, et déjà je me suis assuré qu'outre la matière colorante, les acides et le sucre prennent part au phénomène dans une proportion très sensible.

Enfin, j'ai fait constater, par les mêmes experts, que tous les vins non chauffés dont j'avais maintenu les bouteilles debout étaient couverts de fleurs, et que pas une seule des bouteilles des mêmes vins qui avaient été chauffés, il y a plusieurs mois déjà, n'avait la moindre pellicule dans le goulot. Dans mes Communications à l'Académie, j'ai insisté sur la résistance remarquable des vins chauffés à l'altération, même par la vidange. Prenez dix bouteillẹs de vin chauffé, videz-les à moitié, replacez leurs bouchons et abandonnez-les à elles-mêmes; la plupart ne se couvriront pas de fleurs et ne s aigriront pas. Les germes du mycoderma vini et du mycoderma aceti (voir mes publications antérieures sur les effets de ces fleurs) ne sont pas assez répandus dans l'air pour que l'expérience dont je viens de parler n'ait pas le résultat que j'indique; mais le fait de non-altération n'est pas général, et il y aurait danger dans certains cas à exposer sans précautions au contact de l'air le vin qui a été chauffé. Les germes des autres maladies des vins doivent être plus rares encore dans l'atmosphère, et partant, il ne serait pas impossible qu'avec quelques soins convenables on pût utiliser des modes de chauffage dans des chaudières ou dans des cuves, et transporter le vin, après le chauffage, dans des tonneaux préparés pour le recevoir. L'industrie pourrait tenter, par exemple, de transformer l'outillage des pratiques du vieillissement de Mèze en outillage pour procédé de conservation.

J'ai la satisfaction d'ajouter, en terminant, qu'une Commission va s'occuper, à ma demande, d'étudier et de reproduire, avec un soin tout particulier, mes expériences et leurs résultats. La compétence et l'honorabilité de cette Commission seront reconnues et acceptées par tout le monde dès que les noms et la qualité de ses membres seront divulgués. Il est inutile de les faire connaître présentement ( ${ }^{(1)}$.

1. Je faisais ici allusion à la Commission du commerce des vins en gros de Paris, dont on a lu précédemment le rapport (p. 234-240). [Note ajoutée à la $2 \circ$ édition des « Etudes sur le vin.$]$ 
Extraits de LA $1^{\text {re }}$ et de LA $5^{\text {e }}$ Éditions DU Traité dès conserves D'APPERT.

Dans la première édition de son Traité des conserves alimentaires (1), Appert ne cite aucune expérience faite en vue de conserver les vins par l'application de sa méthode. Il ne parle que de la conservation du moût de raisin et de la possibilité de préparer avec ce moût, en toute saison, des vins mousseux. Cependant, lorsqu'il énumère, à la fin de sa brochure, tous les avantages de son procédé, sa confiance est si grande qu'il ajoute :

“ ..... $6^{\circ}$ Cette méthode facilitera l'exportation des vins de plusieurs vignobles. En effet, des vins qui peuvent à peine supporter un an, et encore sans déplacement, pourront être envoyés à l'étranger et se conserveront plusieurs années. ”

Dans une des éditions subséquentes de son Traité $\left(^{2}\right)$, il ne se borne plus à une assertion sans preuves, il rapporte en ces termes une expérience faite sur du vin de Beaune:

“ Une maison de Beaune, avec laquelle j'entretenais des relations, me pria de chercher les moyens de conserver les vins de ce cru pendant les longs cours, et elle eut soin d'accompagner sa prière d'un panier de bouteilles consacrées aux expériences. Animé du noble désir d'être utile à mon pays, et toujours plein de confiance dans les effets du calorique, je me mis au travail, et ne tardai pas à trouver la solution du problème. Voici comment je l'obtins :

“ Les bouteilles que l'on m'avait envoyées étaient mal bouchées et trop pleines, j'en retirai un peu de vin, de manière à laisser un vide de trois centimètres (un pouce) dans le goulot; je les rebouchai hermétiquement et les ficelai de deux fils de fer croisés. Après quoi je les mis dans le bain-marie, dont je n'élevai la chaleur que jusqu'à $70^{\circ}$, dans la crainte d'altérer la couleur.

“ Quinze jours après, j'envoyai à un de mes commettants du Havre douze bouteilles de ce vin, avec l'invitation d'en confier à plusieurs capitaines de navires pour qu'ils leur fissent essayer le long cours et me les rapportassent ensuite pour en faire la dégustation.

“ Afin de les comparer au retour, j'eus le soin de conserver par

1. Appert (Ch.). L'art de conserver, pendant plusieurs annėes, toutes les substances animales et végétales. Paris (1 $1^{\text {re }}$ édition), 1810, viri-226 p. in- $8^{\circ}$ (fig.).

2. Appert. Le livre de tous les ménages, ou l'art de conserver, pendant plusieurs années, toutes les substances animales et végétales, $5^{\circ}$ édition, revue par Prieur-Appert et Gannal. In Gollection A. Garême : Le Gonservateur. Paris, 1842 , in- $8^{\circ}$, p. 1-166. (Notes de l'Édition.) 
devers moi une certaine quantité de bouteilles auxquelles j'avais fait subir la même opération qu'à celles que je faisais embarquer, et, pour second terme de comparaison, j'en mis de côté quelques-unes, telles que je les avais reçues de Beaune.

" J'attendis plus de deux ans le retour de mes bouteilles; de six que mon commettant avait expédiées au long cours, deux seules revinrent de Saint-Domingue. Très curieux, comme on se l'imagine bien, de connaître le résultat d'une expérience aussi importante, je m'empressai de soumettre une de ces bouteilles à la dégustation d'un habile connaisseur. Il la compara avec deux autres, savoir, une qui était restée dans la cave de mon correspondant du Havre, et qu'il venait de me renvoyer récemment; et une autre, de celles que j'avais conservées intactes. Le résultat de cette triple comparaison fut extraordinaire : il démontra que ce vin, originairement le même, présentait trois qualités essentiellement différentes.

« La bouteille conservée chez moi, et qui n'avait pas subi la préparation, avait un goût de vert très marqué; le vin renvoyé du Havre s'était fait et conservait son arome; mais la supériorité de celui revenu de Saint-Domingue était infinie, rien n'égalait sa finesse et son bouquet; la délicatesse de son goût lui prêtait deux feuilles de plus qu'à celui du Havre, et au moins trois de plus qu'au mien. Un an après, j'eus la satisfaction 'de réitérer cette expérience avec le même succès [p. 105107]. "

J'ai déjà fait remarquer qu'Appert ne prouve pas ce qu'il avance. Les deux bouteilles demeurées en France ne s'étant pas altérées, aux termes mêmes de sa relation, et n'ayant fait que rester inférieures en qualité à celles qui avaient subi le voyage de Saint-Domingue, on a dû attribuer à l'influence du voyage les différences qu'il avait constatées. Ce doit être la cause de l'oubli dans lequel ont été laissés les essais d'Appert.

Sur la maladie de L'amertume des grands vins de Bourgogne. Lettre de M. De Verganette-Lamotte a M. Pasteur.

\section{Monsieur,}

Beaune, 27 avril 1864.

J'ai lu avec un vif intérêt les deux Études sur les vins que vous venez de publier( ${ }^{(1)}$, et vous voudrez bien me permettre de vous adresser à ce sujet

1. II. de Vergnette fait ici allusion à mes Communications à l'Académie des sciences du 
quelques observations. Dans votre travail sur les maladies des vins, vous décrivez celle qu'on désigne sous le nom d'amertume ou goút de vieux, et vous donnez les formes qu'affecte le ferment particulier que vous avez découvert dans les vins amers. Les vins que vous avez surtout observés sont les vins du Jura.

Dans la Cote-d'Or, nous récoltons deux sortes de vins : on obtient les uns avec le-pinot; ce sont eux qui ont valu à la Bourgogne la haute réputation de ses produits; les autres sont faits avec les raisins du gamay, et entrent comme vins ordinaires dans la consommation.

Si je donne ces détails, c'est que je trouve, monsieur, que vous avez parfaitement raison de commencer le compte rendu de vos travaux par la description des vins sur lesquels vous avez opéré, et ici il sera bien entendu que ce que je dirai s'appliquera seulement aux vins de pinot de la Cóte-d'Or.

Voyons quels sont les caractères que présentent les vins qui menacent de tourner à l'amer.

D'abord, nous distinguerons deux sortes d'amertume dans les vins : la première, celle qui les atteint de la deuxième à la troisième année de leur âge, et l'autre, que l'on rencontre dans les vins très vieux; cette dernière maladie, à laquelle on peut plus spécialement donner le nom de goût de vieux, est loin de présenter autant de gravité que la première, en ce sens que les vins qu'elle atteint ont été et sont restés bons pendant de longues années, tandis que l'amertume proprement dite altère et détruit même complétement le vin dans ses premières années. Au début du mal, le vin commence par présenter une odeur sui generis; sa couleur est moins vive; au goût on le trouve fade; nos tonneliers disent que le vin doucine; la saveur amère n'est pas encore prononcée, mais elle est imminente si l'on n'y prend garde; tous ces caractères ne tardent pas à augmenter rapidement; bientôt le vin devient amer, et on reconnaît à la dégustation un léger goût de fermentation dủ à la présence de quelques traces d'acide carbonique. Enfin, la maladie peut s'aggraver encore, la matière colorante s'altère complétement, le tartre est décomposé, et le vin n'est plus buvable.

Il n'est pas nécessaire que les symptômes du mal soient aussi avancés que nous venons de le dire pour que nos vins perdent une grande partie de leur valeur. Que le bouquet soit altéré, que la franchise ne soit pas entière, et voilà un vin qui valait 500 francs la pièce, et qui n'en vaut plus que 100 ; et une bouteille de romanée qui, payée 15 francs, vaudra à peine 1 franc.

L'amertume des vins est donc la maladie qui fait le plus de tort aux grands crus de la Bourgogne, ou mieux aux vins rouges de pinot de la Bourgogne et de la Champagne. L'amertume est pour nous la maladie organique des vins de pinot. C'est, du reste, la seule qu'ils aient à redouter. Nous ne connaissons ni la fermentation acéteuse des vins du Midi, ou de la côte du Rhône, ni la sécheresse acide des vins de Bordeaux, ni la graisse des vins mousseux de la Champagne.

Quelles peuvent être les causes de cette maladie? Qu'a-t-on fait jusqu'à

7 décembre 1863 et du 18 janvier 1864. [Voir p. 389-395 du présent volume : Études sur les vins. Première partie : De l'influence de l'oxygène de l'air dans la vinification; et p. 396-406 : Etudes sur les vins. Deuxième partie : Des altérations spontanées ou maladies des vins, particulièrement dans le Jura.] 
présent pour la prévenir? Quels moyens emploie-t-on pour guérir les vins malades?

Comme on l'a dernièrement constaté pour les vins de Beaujolais en 1859, la Bourgogne a eu des récoltes qui ont été, on peut dire, presque en entier perdues par cette maladie.

Si nous remontons jusqu'en 1822, nous trouvons que, dans les années 1822-1835-1838-1858-1861, quelques vins ont tourné à l'amer ; mais c'est surtout sur les 1840 et les 1842 que la maladie a le plus sévi. On remarque que les vins de 1825-1832-1844-1846-1847-1849-1854-1856-1862, vins durs et très chargés de tartre et de tanin, n'ont jamais souffert; que des vins au-dessous du médiocre, comme les 1860, se sont toujours conservés - mauvais il est vrai; - qu'il en a été de même des 1845, des 1853, etc., vins très acides au goût.

La richesse alcoolique du vin ne semble pas avoir une grande importance dans la question. Lorsqu'on essaye un vin, on recherche sa teneur en alcool, le poids de la matière extractive, le poids des cendres; nous dosons encore au moyen de liqueurs titrées la quantité d'acide libre que contient le vin; enfin on note si le vin est très coloré ou s'il l'est peu.

Je parlerai encore ici d'un autre genre d'observation qu'on ne saurait passer sous silence dans la question. J'attache une très grande importance aux faits que je vais signaler, parce que pour moi ils décident du moment de la vendange. Chaque année je note avec soin sur mes livres quel est l'état du raisin le jour où je le récolte; dans les jours qui précèdent, j'examine avec attention quelle est la maturation du fruit, s'il est sain, figué, desséché, pourri, si les baies sont ouvertes par la grêle ou les insectes, si le cep est ou non privé de ses feuilles, si ces feuilles ont eu ou n'ont pas eu le rougeot, etc. C'est surtout le matin, un peu avant le lever du soleil, que l'on peut reconnaître aisément les altérations que le grain peut présenter; enfin, chaque jour à midi, je prends dans la vigne la densité du moût.

Eh bien, si, nous servant de ces observations, nous recherchons si l'état du raisin au moment de la récolte a pu être pour quelque chose dans la durée du vin qu'il a produit, nous reconnaissons que l'amertume n'a pas attaqué les vins dont les raisins ont été récoltés très sains. Au contraire, la grêle en 1840, la pluie en 1842, avaient ouvert une grande partie des baies du fruit. En 1861, les ceps, à la vendange, étaient entièrement privés de leurs feuilles; enfin, généralement les vins les plus menacés sont ceux qui ont été récoltés après un été à la fois très chaud et très sec, suivi d'un automne pluvieux.

Nous avons encore trouvé que, dans certaines conditions, les vins très colorés ou très riches en matières extractives sont plus disposés que d'autres à tourner à l'amer. Ainsi, si le vin est à la fois coloré et dur (vins de 1844), il possède une santé à toute épreuve; s'il est coloré et fin (vins de 1842), c'est tout le contraire qui arrive. Enfin, des vins riches à la fois en matière extractive, en matière colorante et même en alcool (comme les 1858), ont pu quelquefois devenir malades, mais cela tient alors, comme nous l'expliquerons, à l'oubli des premiers principes de l'hygiène des vins.

Dans la première phase du mal, l'alcool, le tartre et la matière extrac- 
tive ne paraissent pas subir d'altération, la couleur seule est sensiblement changée.

Nous devons encore remarquer que les vins blancs ne tournent jamais à l'aner.

Peut-on, par la discussion de ces données, découvrir dans quelle proportion le vin doit, pour qu'il puisse se conserver, renfermer les divers éléments dont il se compose? Recherchons enfin quel est celui de ces éléments qui s'altère le premier dans la maladie de l'amertume.

Dans un des Mémoires que j'ai publiés sur l'œnologie (1), j'ai supposé qu'au point de vue de sa coloration, le vin se comportait comme les matières textiles. On y trouve en effet le mordant (qui est le tartre), la matière colorante, et le corps à colorer, qui est l'eau alcoolisée. J'ai reconnu depuis longtemps que, toutes les fois que la matière colorante n'était pas en proportion avec le mordant, pour les vins comme pour les matières textiles, la couleur ne tenait pas.

Je relaterai maintenant l'expérience que voici : lorsque, après avoir pressé un certain nombre de grains de raisin rouge, de manière à expulser au dehors toute la partie charnue de la baie ainsi que les pepins, et les avoir lavés à plusieurs reprises à l'eau froide, on fait digérer dans l'alcool les pellicules de ces grains, on obtient une solution d'un beau rouge rubis vineux; en laissant cette solution alcoolique exposée à la lumière diffuse, elle ne tarde pas à se décolorer. L'alcool conserve une légère nuance jaune, et au fond du flacon se trouve une substance d'un blanc grisâtre qui résulte de l'altération de la matière colorante.

C'est à la suite de ces données, et fort de toutes ces observations, que j'ai depuis 'longtemps considéré le premier degré de l'amertume des vins (le seul qui intéresse la Bourgogne) comme le résultat de l'oxydation de la matière colorante, et vous allez voir, monsieur, comment un raisonnement que je crois vrai m'a conduit à indiquer comme moyens préservatifs du mal, et comme remèdes, des procédés qui se trouvent aujourd'hui peu d'accord avec votre théorie de l'emploi de l'oxygène dans la vinification et le traitement des vins.

L'oxydation de la matière colorante du vin étant la cause première de l'amertume, j'ai demandé que le vin fût méché à chaque soutirage, que les caves fussent fermées aussi hermétiquement que possible; on doit y pénétrer peu souvent, et nos tonneliers y brûlent du soufre avant de les fermer; mais tous les éléments de la question n'étaient pas là, vous l'avez démontré. Il se trouve dans nos vins menacés un infiniment petit avec lequel je n'avais pas compté, c'est ce ferment (fig. $n^{\circ} 7$ de votre Mémoire) qui, lorsqu'il prend vie, donne naissance à des produits nouveaux, dont l'un, l'acide carbonique, se forme aux dépens du carbone de la matière colorante et de l'oxygène de... du tartre, peut-être $(2)$ ?

1. Vergnette-Lanotte (A. de). Note sur la vinification dans les grands crus de la Côted'Or, p. \%5-113, in : Mémoires sur la viticulture et l'œnologie de la Côte-d'Or. Dijon, 1846, 147 p. in $-8^{\circ}$. (Note de l'Édition.)

2. J'avais bien, depuis longtemps, reconnu ce fait de fermentations secondaires (Mémoires sur la viticulture et l'œnologie de la Côte-d'Or. Dijon, 1846, in-8 ${ }^{\circ}$, p. 100, 141, 142, 143), mais vous en avez donné une cause qui en explique mieux tous les phénomènes. (Note de $M$. de Vergnette.) 
J'étais plus dans le vrai lorsque je recommandais les remplissages et soutirages répétés; cependant comme, soit pour ce dernier motif, soit pour d'autres, j'ai depuis longtemps, mais grâce à une grande surveillance, il faut l'avouer, réussi à soustraire mes vins aux atteintes de la maladie qui nous occupe, je donnerai un rapide exposé des procédés de vinification que j'emploie et des soins que les vins reçoivent dans mes caves.

Lorsqu'à la vendange le raisin est sain, que la baie n'est pas ouverte, qu'il n'y a ni grains pourris, ni grains brûlés, lorsqu'on trouve dans les fruits de la vigne, comme le voulaient nos pères pour faire du grand vin, du figué, du mûr et du vert, le vin que l'on obtient de sa récolte est dans les meilleures conditions pour faire du vin de conserve; cependant, comme quelquefois, dans ce cas (années 1834, 1842, 1846, 1858, 1859), il renferme une grande proportion de matière extractive, on ne devra pas le tirer en bouteilles aussitót que des vins moins mùrs, et il faudra s'assurer, avant le tirage, qu'il ne fait plus dans le fủt qu'un dépôt insensible.

Lorsqu'il s'agit de vins très chargés de tartre, comme les 1854, ou très verts, comme les 1860 , on n'aura point de craintes à concevoir sur l'avenir de ces vins.

Mais si les raisins ont été mouillés à la vendange, s'ils ont souffert pendant l'été, si les baies ont été ouvertes par la grèle, etc., oh ! alors, nous savons par une longue expérience qu'un vrai danger peut menacer notre récolte. Alors on peut prolonger la durée du cuvage; quelques œnologues conseillent le vinage. L'addition par pièce de vin de 3 à 4 litres d'eau-de-vie blanche de Cognac à $65^{\circ}$ leur a toujours réussi.

Depuis longtemps, comme moyens préventifs, nous avons employé la congélation artificielle. Ce procédé nous a toujours donné d'excellents résultats, et jamais nous n'avons vu tourner à l'amer des vins qui avaient été gelés avec les soins convenables. C'est un fait aujourd'hui si généralement reconnu en Bourgogne que l'usage de mes appareils est très répandu, et cet hiver, une seule de nos maisons de commerce de la Cóte-d'Or a fait geler, en les employant, plus de 1.500 hectolitres des plus grands vins de notre côte. Le principe de conservation que les vins acquièrent par la gelée est tel qu'à Lyon, par exemple, où les vins de Bourgogne se conservaient mal dans les caves, on peut en boire d'excellents qui ont passé des étés et des hivers dans des meubles de salle à manger. II. Boussingault et M. Chevreul ont bien voulu, à la Société impériale d'agriculture, prendre la défense de mes procédés, qui, évidemment, sont les plus permis, puisqu'ils n'entraînent l'introduction dans le vin d'aucune substance étrangère. Sans entrer dans l'examen des changements organiques que la congélation détermine dans les vins, nous dirons que ce travail leur enlève de l'eau, et qu'en définitive ils présentent une grande limpidité et contiennent plus de tartre, d'alcool et de tanin.

Je vous ai dit, monsieur, que j'avais aussi employé le cuvage prolongé comme moyen préventif de l'amertume, et voyez combien il faut, dans cette question si complexe des vins, se rendre compte des moindres changements apportés dans la manière de les faire. M $^{110}$ Gervais avait recommandé le cuvage en vases clos, en indiquant qu'on arrivait ainsi à empêcher une grande déperdition dans le bouquet et l'alcool. On reconnut bien vite que 
l'appareil Gervais ne servait à rien à cet endroit, et on l'abandonna. Je fis comme tout le monde, et cependant, plus tard, je suis revenu au cuvage en vases clos, mais cette fois parce que je reconnus qu'avec ce procédé le chapeau n'était jamais altéré, et aussi que ce procédé me permettait de prolonger de beaucoup la durée du cuvage. M. Ladrey dit avec raison qu'on a trouvé de grands inconvénients dans le Jura et ailleurs aux longs cuvages; il n'en serait pas de même si l'on eût opéré en vases clos.

Il y a deux manières de faire cuver les vins en vases clos, ou en laissant une partie des fruits tels qu'ils sortent de la vigne, et alors il se produit là un fait de maturation reconnu depuis longtemps par M. Sampayo, ou bien encore en écrasant tous les raisins avant l'encuvage; dans le second cas, si le vin est moins riche en alcool, il l'est davantage en tanin : cela se concoit aisément.

On devra encore très fréquemment séparer les vins de leurs dépóts. En Bourgogne, les vins nouveaux sont soutirés trois fois dans la première année; la première fois au mois de mars, la seconde au mois de mai ou de juin, et la troisième à la fin d'août. Ce dernier soutirage n'avait lieu jadis qu'au mois de septembre ou d'octobre. J'ai contribué à en faire devancer l'époque, parce que j'ai reconnu que les vins étaient souvent en septembre atteints d'une fermentation secondaire qui pouvait altérer leur goût. J'ajouterai encore que les vins de pinot (année 1861) qui ont été mélangés avec un quart de vin de syrrat, ou un quart de vin de gamay 1858, ont parfaitement résisté à l'action du ferment de l'amer.

Plus tard, nos vins, jusqu'au moment où on les met en bouteilles, reçoivent encore deux soutirages par an, ceux de mai et d'aorit. J'ai déjà dit que je conseillais de ne mettre les vins en bouteilles que lorsqu'ils faisaient peu de dépôt dans le fût. Le mois que je préfère pour la mise en bouteilles est le mois de juillet. L'usage de boucher plein et à l'aiguille se généralise; c'est un grand progrès. Enfin, monsieur, nous avons, lorsque le vin est en bouteilles, à étudier la forme qu'affecte le dépôt qu'il y fait. Si au bout d'un an ce dépôt est à peine sensible, s'il est fixé, s'il a la forme d'une lentille, et si des deux extrémités de cette lentille partent des lignes se rendant, l'une au fond, l'autre au col de la bouteille, et si, en même temps, la bouteille se masque légèrement, on peut être assuré que le vin est dans de bonnes conditions, et l'on peut lui prédire une brillante longévité. Mais si le dépot prend d'autres formes, celle, par exemple, que nos tonneliers appellent cul de poule, si le dépót est abondant, gras et peu fixe, dans ce cas on doit faire la plus grande attention à ce vin; sa santé est très sérieusement menacée. Un dépotage fait avec soin et le bouchage à l'aiguille suffisent quelquefois pour rétablir le vin; d'autres fois il faut le remettre en füts.

Je ne puis, monsieur, dans cette lettre déjà trop longue, vous dire tous les soins que réclame la direction de nos caves, cependant vous saurez encore que chaque mois on remplit nos grands vins; le déchet annuel peut être de 9 à 10 litres par pièce de 228 litres. Il se fait un vide sous la bonde; les gaz qui s'y réunissent sont rarement en équilibre avec la pression atmosphérique. Dans les vins vieux, la pression intérieure est plus faible que la pression atmosphérique, c'est le contraire dans les vins nouveaux. 
Les gaz du tonneau contiennent de l'azote et de l'acide carbonique; la proportion de ces gaz varie avec l'âge et la santé du vin.

Je vous ai dit que je faisais brûler du soufre dans mes caves. A ce sujet, je citerai un fait d'endosmose très remarquable. Ayant fait une fois brûler des réchauds de charbon de bois dans une cave très bien close, l'acide carbonique, absorbé par le vin, lui donna un goût particulier (celui des vins qui ont séjourné dans une outre), et ce goût se retrouva même dans quelques bouteilles. Nous savons d'ailleurs que, si l'on conserve dans une méme cave des légumes, des choux, par exemple, et des vins, la franchise du vin est promptement altérée. Un autre fait très curieux et du même ordre est celui-ci : ayant un cellier qui se trouve placé sous de vastes magasins à fourrages, j'ai souvent remarqué qu'au moment de la récolte des foins il s'établissait un mouvement de fermentation très sensible dans les vins communs que $\cdot j$ 'y conservais.

Si, avec les soins que je viens d'indiquer rapidement, je suis arrivé à préserver mes vins de la maladie de l'amer, il faut encore dire quels sont les moyens que je conseille pour guérir les vins qui en sont atteints. Si le mal est profond, un coupage avec des vins plus,communs permet d'utiliser les vins amers, mais toutefois après les avoir déclassés. Si la maladie est récente et dans sa première période, on peut la guérir en mélangeant le vin malade avec un vin plus jeune et plus dur; ce coupage devra d'ailleurs être suivi de l'emploi de la congélation artificielle.

Vous voyez, monsieur, que tous les moyens que j'indique pour le traitement des vins menacés ou malades sont des moyens empiriques qui ne sont en rien basés sur les causes connues du mal. Il ne pouvait en être autrement. Ces causes, monsieur, vous les avez trouvées, et, permettez-moi de vous le dire, vous devez à la France viticole un travail sur le ferment de l'amer aussi complet que celui que vous avez publié sur la fermentation alcoolique.

Je viens de relire ce remarquable travail et vous ne sauriez croire, monsieur, combien pour la fermentation des cuves vous nous dévoilez de faits dont l'explication nous échappait. Ainsi, pour n'en citer qu'un, depuis vingt ans j'avais remarqué que jamais l'alcool du vin ne correspondait à la quantité de sucre, soit organique, soit additionné, que contenait le moùt. Vous avez trouvé dans le vin la glycérine et l'acide succinique; maintenant la glycérine ne nous donnera-t-elle pas plus tard de l'acide butyrique et ne trouverons-nous pas là l'explication de ce goùt rance que présentent certains vins vieux?

Je vous envoie avec cette lettre des photographies obtenues en 1858 par Bertch; ne trouvant pas que l'analyse des vins nous apprit souvent grand'chose sur eux, puisque des vins qui contiennent à peu près les mèmes sels ont une grande différence de valeur, je les étudie depuis longtemps au microscope, et, en 1858, j'eus l'idée de faire photographier les préparations microscopiques de mes vins. Vous verrez dans le $n^{\circ} 3$ des traces de vos ferments (1); mais je ne me préoccupais que des formes cristallines des

1. Il n'en est rien. J'ai fait voir depuis à M. de Vergnette au microscope les ferments des maladies des vins, et il a reconnu que ce qui lui paraissait ètre un indice de la présence des ferments était un amas de granulations de matière colorante. M. de Vergnette faisait ses essais 
sels. Ces traces de végétation microscopique que j'avais signalées depuis 1845 [Note sur la vinification, page $112\left({ }^{1}\right)$ ] ne me paraissaient pas mériter l'importance que vous leur avez reconnue. Vous avez trouvé là les causes premières de toutes les modifications qu'éprouvent ces liquides, qui, comme vous le dites si bien, sont toujours en mouvement; ce qu'il nous faut aujourd'hui, c'est d'être guidés par le raisonnement seul dans toutes les opérations que demande le traitement des vins dans les caves. Alors plus de vins malades, et vous aurez donné des millions à la France.

Si cette lettre peut avoir quelque intérêt pour vous, je vous demanderai la permission de vous entretenir une autre fois de l'action de l'air atmosphérique sur les vins, et de la disposition que nous devons adopter pour nos caves, et aussi, monsieur, s'il pouvait vous être agréable d'étudier les dépôts des vins gelés, je serais tout à votre disposition pour vous en adresser des échantillons. J'en dis autant pour les autres spécimens de nos vins que vous pourriez vouloir étudier (2).

en laissant évaporer une goutte de vin sur une lame de verre, et en examinant ensuite le dépôt formé. Celui-ci ne pouvait contenir que des cristaux de tartrates et de la matiére colorante. C'est en effet ce que montrent les photographies dont parle M. de Vergnette.

Pourtant dans une note de la 2e édition de son livre intitulé : le Vin [Paris, 1869], p. 328, M. de Vergnette affirme gratuitement que : " mon assertion est complétement erronée ". Je la maintiens dans toute sa rigueur. On peut lire, en effet, dans la 2e édition du livre de M. de Vergnette le passage suivant, page 157 :

" Nous faisions évaporer sur une lame de verre une goutte de vin provenant soit de vins " naturels, soit de vins factices de la même année, et la comparaison de la préparation micro" scopique montrait une grande différence entre les vins naturels et ceux qui ne l'étaient pas."

Il n'est pas nécessaire d'être très habile micrographe pour affirmer qu'à l'aide d'une pareille méthode, il est impossible d'apercevoir au microscope le mycoderma aceti que M. de Vergnette croit reconnaître dans la figure 3 . Qu'on examine, avec un peu d'attention, cette figure $3 \mathrm{du}$ livre de M. de Vergnette, page 148, et on verra sans peine que les petits points de cette figure sont amorphes dans le sens le plus absolu du mot, c'est-à-dire qu'ils manquent de cette netteté de contours, de cette identité de la forme indispensable pour qu'on puisse affirmer la présence d'un organisme; que sous ce rapport ils diffèrent complétement du mycoderma aceti, représenté dans la figure 1 de mon ouvrage. Ce sont là des faits que le lecteur peut constater de visu; mais ce qu'il ignore et ce que je dois lui apprendre, c'est que l'étiquette de la figure 3 du livre de M. de Vergnette (dont j'ai eu l'original entre les mains) est fausse; que les mots : mycoderma aceti, tartrate de chaux, ont été ajoutés postérieurement à la publication de mon livre; qu'enfin les petits grains de la figure de son livre ne rappellent que vaguement la photographie originale $\left({ }^{*}\right)$.

1. Vergnette-Lamotte (A. de). Loc. cit. (Note de l'Édition.)

2. A la lettre de M. de Vergnette-Lamotte, Pasteur répondit par cette lettre, restée en partie inédite :

« Paris, le 7 mai 1864.

“ Monsieur, je vous sais beaucoup de gré d'avoir eu la pensée de m'écrire au sujet de la maladie de l'amer et des soins que vous donnez à vos vins pour les préserver de leurs altérations spontanées. Si j'ai bonne mémoire, j'avais entendu parler de vous, Monsieur, par M. de Sénarmont dont la mort prématurée a été si regrettable. Je ne vous cacherai pas que j'ai pour ainsi dire commencé le voyage de Dijon à Meursault aux vacances derniêres dans l'intention d'aller vous demander divers renseignements et de profiter des conseils de votre longue expérience. Aujourd'hui vous voulez bien me les offrir. Je vous en suis doublement reconnaissant et je serais heureux d'unir mes efforts aux vòtres pour essayer d'empêcher cette vilaine maladie de faire tant de tort à vos riches récoltes.

"Vous considérez le premier degré de l'amertume des vins comme le résultat d'une oxydation de la matière colorante. La matière colorante change sensiblement dés le début. Mais n'est-ce pas tout simplement parce qu'une partie se fixe sur le ferment en voie de formation. Tous les ferments ont la propriété de se teindre facilement par les matières colorantes des liqueurs où ils prennent naissance. Celui de l'amer figure 7 de ma notice [Voir p. 401] est particulièrement dans ce cas. Il est parfois d'un beau rouge rubis. Il se pourrait, d'autre part,

(*) Les trois derniors alinéas ont été ajoutés à la 2e édition des "Études sur le vin \#. (Note de l'Edition.) 
Remarques au sujet de la lettre précédente (1).

On a peine à comprendre qu'une personne qui m'a écrit, en arril 1864, une lettre conçue dans de tels termes, où je suis pour ainsi dire supplié d'appliquer tous mes efforts à la recherche d'un moyen de prévenir les altérations des vins de la Bourgogne, où on fait connaître avec complaisance les moyens empiriques employés dans ce grand centre de production pour lutter contre les ravages de cette maladie, on a peine à comprendre, dis-je, que cette personne ait élevé une réclamation de priorité après que j'eus démontré le premier, en 1865, la parfaite efficacité d'un chauffage préalable pour prévenir toutes les maladies des vins $\left({ }^{2}\right)$.

Le bon sens public ne s'y est pas trompé. En 1867, le jury de l'Exposition univer'selle a décerné à mes Études sur le chauffage des vins un de ses grands prix; à l'étranger, le chauffage porte le nom de Pasteurisation (Pasteurisieren), et les appareils pour l'appliquer, appa-

que la matière colorante prit part en quelque chose aux transformations chimiques qui amènent l'altération et l'amertume.

"L'idée que la maladie est provoquée par une oxydation de la matière colorante vous a conduit á la pratique de mécher á chaque soutirage. Je crois cette pratique bonne mais par des motifs autres que ceux que vous supposez. J'ai reconnu que les levûres alcooliques prennent naissance avec une grande facilité dans des liquides aérés ou dans des liquides qui renferment des matières oxydables pouvant céder ensuite l'oxygène aux ferments. N'en est-i] pas ainsi du ferment de l'amer? On comprendrait dès lors comment l'acide sulfureux peut nuire á la production du ferment. Ce serait par la même raison qu'il empêche la production des levures alcooliques. C'est précisément l'ordre d'idées dans lequel je recherche en ce moment les moyens d'obvier à la maladie et à sa premiére apparition.

"Mais ce qu'il faut obtenir avant tout, et vous pourriez peut-être, Monsieur, m'aider beaucoup à sortir d'embarras, c'est le développement du ferment à la volonté de l'expérimentateur, afin de pouvoir le faire agir ensuite sur des liquides appropriés. Vous me rendriez un grand service, si vous pouviez m'envoyer des échantillons de vins tirant à l'amertume, d'autres non malades, mais très disposés par leur nature à le devenir. Je serais désireux également d'avoir des vins aussi gâtés qu'il est possible de les rencontrer. Ne pourriez-vous, dès à présent trouver dans vos caves, ou dans celles d'autres propriétaires, des vins dont partie se serait altérée et partie conservée. Ne trouveriez-vous pas également des échantillons qui présentecaient la maladie á son début, au moment où le vin commence à se troublér qu ferment loit être répandu dans toute la masse du liquide lorsque le mal se déclare. A ce moment, il sst jeune, en pleine vigueur et je pourrais le semer dans ceux des échantillons, le volnay par xxemple, que vous m'indiqueriez comme plus disposés à être atteints.

"Enfin, Monsieur, je recevrai avec reconnaissance la communication de vos idées et de vos ichantillons, et je serai heureux de vous faire connaitre mes résultats, et j'irai certainement rous faire visite un jour ou l'autre.

"Veuillez agréer, Monsieur, l'assurance de mes sentiments les plus distingués.

L. Pasteur.

« P.-S. - J'ai le plaisir de vous annoncer que je crois avoir trouvé aujourd'hui mème des chantillons de vins de Volnay en voie de première altération et où j'espére trouver le ferment ussi jeune que je puis le désirer. Je ne change cependant rien à la demande que j'ose vous aire d'échantillons de cette sorte. "(Note de l'Édition.)

1. Ces Remarques ont été ajoutées à la 2 édition des "Études sur le vin ".

2. Voir p. 409-412 du présent volume : Procédé pratique de conservation et d'amélioration es vins. (Notes de l'Édition.) 
reils à pasteuriser les vins (Wein-Pasteurisier-dpparat), ainsi que nous l'avons appris précédemment par une lettre datée de Hongrie, et due à la plume d'un habile œnologue, M. Terrel des Chênes. (Voir page 260; voir aussi page 286.)

\section{Comité central agricole de Sologne (1).}

\section{Séance du 10 mai au château impérial de Lamotte-Beupron.}

On sait que le Comité central de Sologne, dans sa séance d'automne de 1864, avait, sur la proposition de son président, M. le sénateur Boinvilliers, voté une médaille d'or de 1.000 francs « à l'inventeur d'un procédé qui serait rendu public, et qui permettrait aux vins de France les transports de terre et de mer, et le séjour prolongé, en tous pays, sans que leur goû ou leur parfum en fùt altéré. »

Une Commission, sur le rapport de laquelle le prix devait être décerné avait été désignée par le président; elle se composait de MM. le marécha Vaillant, président; Dumas, rapporteur; Brongniart et Moll.

Le Comité s'étant réuni le 10 mai, au château impérial de Lamotte Beuvron, la première partie de la séance a été consacrée à la lecture dı rapport de M. Dumas, que nous reproduisons en entier à cause de sor importance pour l'avenir de la viticulture en France.

\section{Rapport de M. Dumas.}

La question proposée n'intéresse pas seulement les vignobles de 1 : France, mais le pays tout entier; elle touche d'aussi près la population de départements consommateurs que celle des départements producteurs.

Le Comité nous a chargés, M. le maréchal Vaillant, MM. Brongniart Moll et moi, d'examiner si, parmi les expérimentateurs actuels, il en étai dont les recherches eussent conduit au but.

Votre Commission n'hésite pas à déclarer que les travaux de M. Pasteur membre de l'Académie des sciences, sont dans ce cas; qu'ils ont porté 1 plus vive lumière sur les causes qui déterminent les altérations des vins ainsi que sur les moyens qui permettent de les combattre, pratiquement avec certitude et avec succès; qu'en conséquence il y a lieu de lui décerne la médaille promise par le Comité.

En effet, M. Pasteur, à l'aide d'une série d'expériences dirigées avec 1 sentiment profond des lois de la nature et la connaissance exquise de moyens que la science possède pour les mettre en évidence, est parvenu rendre incontestables les cinq propositions suivantes : 
$1^{\circ}$ Les altérations dangereuses des vins tiennent à des causes qui se confondent avec celles auxquelles on attribue les fermentations.

$2^{\circ}$ Il suffit de chauffer les vins ordinaires à $50^{\circ}$ pour faire périr les végétaux microscopiques ou ferments qui les produisent. Les fermentations et toutes les altérations dangereuses des vins, dues à ces causes, sont ainsi arrêtées ou prévenues.

$3^{\circ}$ L'application de la chaleur, dans ces limites, ne modifie ni la couleur, ni le goùt des vins; elle en assure la limpidité.

$4^{\circ}$ Les vins qui ont été soumis à l'action de cette température paraissent capables de se conserver indéfiniment, sans altération, en vases clos.

$5^{\circ}$ Exposés à l'air, ces vins peuvent, il est vrai, y reprendre la propriété de s'altérer, après quelque temps, mais c'est parce que l'air leur apporte de nouveaux germes vivants de ces ferments qu'ils avaient perdus par l'action de la chaleur.

M. Pasteur a étudié les diverses maladies des vins; nous résumons les résultats de ses études.

$1^{0}$ Vins acides, piqués ou aigres. - Cette maladie est due à la présence du mycoderma aceti, qu'il ne faut pas confondre avec le mycoderma vini, lequel n'altère pas les vins, tandis que son congénère y développe du vinaigre, avec le concours de l'air, et les tourne plus ou moins vite à l'acescence.

$2^{\circ}$ Vins tournés, montés, poussés. - Ils doivent leur altération à des filaments d'une extrême ténuité, qui se rapprochent ou même parfois se confondent avec les filaments du ferment lactique. Aussi M. Pasteur, d'accord avec M. Balard, a-t-il trouvé des vins altérés par la présence de l'acide lactique; mais le fait n'est pas général. Quoique ces filaments ressemblent toujours à ceux qui constituent le ferment lactique et soient composés, comme lui, de chapelets d'articles analogues à la tige du blé ou à celle des bambous, on y reconnaît en réalité, au moyen du microscope, les signes de plusieurs maladies distinctes du vin, qu'on a confondues sous les mêmes noms, et qui n'ont de commun cependant que d'être produites par des végétaux microscopiques analogues.

$3^{\circ}$ Vins gras, huileux, flants. - Ils doivent encore leur altération à des filaments, mais ceux-ci sont formés de chapelets de grains et non de chapelets d'articles.

$4^{\circ}$ Vins amers, vins qui ont pris le goüt de vieux. - Ils présentent aussi un ferment. Il ressemble même sous beaucoup de rapports à celui qu'on observe dans les vins tournés, mais ses filaments sont plus gros et ses articulations plus sensibles. On sait que les vins sujets à tourner ne sont pas les mềmes que ceux qui passent à l'amer. 
Tous ces végétaux parasitaires et leurs analogues, qui n'auraient pas encore été reconnus ou distingués scientifiquement, périssent à la température de $65^{\circ}$ ou même de $50^{\circ}$. En élevant le vin qu'on veut conserver à une température comprise entre $50^{\circ}$ et $65^{\circ}$, on a donc la certitude que toute altération ultérieure de la liqueur, due à l'action et à la présence des végétaux vivants, devient impossible tant qu'on n'y a pas semé de nouveaux germes, soit par l'intervention des poussières de l'air, soit par le mélange du vin ainsi préparé avec des liquides qui n'auraient pas été convenablement chauffés eux-mêmes.

La température nécessaire pour faire périr les germes dans les liquides aqueux est de $100^{\circ}$ environ pour la plupart d'entre eux; elle a même quelquefois besoin d'être élevée un peu au-dessus de ce terme, quand il s'agit de liquides très altérables. Mais, à l'égard des vins, l'alcool qu'ils renferment favorisant par sa présence l'action purificatrice de la chaleur, une température très inférieure à $100^{\circ}$ suffit.

M. Pasteur, qui avait jugé d'abord nécessaire une température de $75^{\circ}$, a peu à peu abaissé le chiffre à $65^{\circ}$ et à $50^{\circ}$. Il pense qu'on pourra le descendre encore et s'arrêter vers $45^{\circ}$. Cette circonstance est d'un grand intérêt, car il est très facile, au moyen des rayons solaires seuls, tombant dans une chambre fermée, contenant les bouteilles, d'obtenir sans dépense une élévation semblable de température dans toutes les parties de la France, et surtout dans le Midi.

M. Pasteur s'est assuré que l'air ne joue aucun rôle dans les fermentations qui altèrent les vins, la fermentation acétique exceptée. Mais il résulte de ses expériences que l'air agit sur les vins privés de tout ferment et que, sous l'influence de la lumière, il les décolore et leur communique le goût des vins de Madère.

La lumière solaire directe n'agit pas sur les vins mis à l'abri de l'air.

Une Commission nommée par la chambre syndicale du commerce des vins de Paris a examiné avec la plus scrupuleuse attention les résultats obtenus par ce savant, et les a sanctionnés de son entière et concluante approbation.

M. Marès, correspondant de l'Académie des sciences, vient de mettre en usage, de son côté, le procédé de M. Pasteur pour ces vins de l'Hérault, altérables, qu'on ne peut garder qu'au moyen d'additions successives d'alcool; il a constaté qu'ils se conservent très bien, dès qu'ils ont été chauffés à $60^{\circ}$. Le vinage pourrait ainsi devenir une opération inutile.

Le procédé de M. Pasteur promet donc aux vignerons qui cultivent les 2 millions d'hectares de vignes que la France possède un meilleur placement des 50 millions d'hectolitres de vin qu'ils produisent.

Tous ces vins peuvent, à son aide, être convertis en vins de garde; ils deviennent propres à voyager sans altération; ils restent en vidange pendant plusieurs jours sans se troubler ou s'aigrir.

Le nord et le nord-ouest de la France recevront ainsi des vins à bas prix et cependant stables. La France pourra expédier au nord du continent des vins qu'elle a dû jusqu'ici consommer elle-même sur les lieux de production. L'Angleterre surtout, recevant des vins qui n'auront plus besoin d'être spécialement soignés, pour lesquels le séjour en cave sera moins nécessaire, 
et qui pourront demeurer en vidange dans l'appartement sans s'altérer, nous offrira un marché plus élastique.

Toutes les personnes qui ont visité l'Angleterre ont pu s'assurer, en effet, que l'installation des habitations et les pratiques de la vie domestique auraient besoin d'être modifiées, pour que l'usage des vins légers de France, qui réclament des soins particuliers, pût s'y généraliser. Le procédé de M. Pasteur, qui rend ces soins inutiles, est donc de nature à exercer l'influence la plus heureuse pour l'extension de ce débouché.

La science pure, ses méthodes les plus délicates, ses découvertes les plus stériles en apparence, inspirent aujourd'hui confiance et respect. Il n'est pas inutile pourtant de constater ici que ce problème, jugé presque inaccessible, M. Pasteur, pour le résoudre, n'a rien demandé au hasard. Il a tout obtenu du raisonnement, controlé par une suite d'expériences indiquées par la logique et renduas décisives par leur précision.

Les vues par lesquelles il éclaire si vivement l'une des plus belles questions économiques, il les avait solidement établies d'abord dans le domaine de la théorie.

Il a donc rendu, non seulement un service positif inappréciable à l'agriculture, mais, une fois de plus, il a montré quelle est la méthode qui permet à la science de résoudre ces problèmes importants et complexes que l'économie rurale pose si souvent, et devant lesquels, livrée à elle-même, la pratique est ordinairement impuissante.

Si le Comité central de la Sologne décerne la médaille d'or à M. Pasteur, ce savant éminent y verra une première preuve de la reconnaissance du pays. Quand le service rendu par son génie aura atteint, par une large exploitation, les proportions d'un bienfait national, la France saura lui trouver une récompense; mais la médaille que vous lui votez aujourd'hui rappellera que vous aviez signalé ce problème et que vous proclamez les premiers son heureuse solution.

A la suite du rapport, et après une discussion à laquelle ont pris part M. de Béhague, M. Guillaumin, député, M. Moll, M. le préfet du Cher et M. le président Boinvilliers, le conseil a, par un vote unanime, décerné la médaille d'or à M. Pasteur, membre de l'Institut (1).

\section{DE L'AMÉlioration des VINS PAR LE ChaUfFage (2).}

J'ai l'honneur de communiquer à l'Académie le procès-verbal de la dégustation de vingt-quatre sortes de vins naturels et des mêmes vins chauffés en bouteilles à des époques déjà éloignées.

1. Ce rapport a été reproduit dans le Bulletin de la Société d'encoujagement pour l'industrie nationale, 2 " sér., XIII, 1866, p. 410-413.

2. Comptes rendus de l'Académie des sciences, séance du 5 aoùt 1872 , LXXV, p. 303-308.

Cette Communication, postérieure à la publication de la $1^{\text {ro }}$ édition des " Etudes sur le vin $n$, ne figure que dans la 2 édition. (Notes de l'Édition.) 
Les résultats de cette dégustation intéresseront vivement les producteurs et les négociants en vins.

J'ai démontré, en 1864, que toutes les maladies habituelles des vins sont dues à des champignons microscopiques dont les germes trouvent dans ces liquides un milieu plus ou moins favorable à leur développement.

Guidé par mes expériences antérieures sur la résistance à l'influence de la chaleur des organismes microscopiques, résistance variable avec les espèces et la nature du milieu où elles vivent, je ne tardai pas à découvrir un moyen simple de tuer les germes dont il s'agit, et de prévenir par suite, pour toujours, les maladies habituelles des vins. Ce procédé, affirmé déjà empiriquement, mais non démontré par Appert (1), et que Scheele, au siècle dernier, avait appliqué avec succès à la conservation du vinaigre ${ }^{2}$, , consiste à porter le vin, ne fût-ce qu'un instant, à une température suffisamment élevée. Mais l'application de cette méthode de conservation laissait douteuse, à l'origine, une question capitale : quel serait le sort des vins, particulièrement des vins de qualité, pendant les années qui suivraient l'opération du chauf-

- fage? En assurant leur conservation indéfinie, ne compromettrait-on pas leur délicatesse et les qualités si recherchées que le temps leur donne, toutes les fois que les vins se conservent naturellement sans altération? L'expérience, et une expérience prolongée, pouvait seule répondre à ces doutes.

Dès 1865 et 1866, je disposai, à l'École Normale, une cave d'expériences comparatives, dans laquelle sont placés côte à côte des vins communs et des grands vins, dont partie de chaque sorte n'a pas été chauffée, et le restant chauffé à des températures variables, comprises entre $50^{\circ}$ et $75^{\circ}$. Déjà, en 1865 et $1869{ }^{(3)}$, plusieurs membres de la Commission syndicale des vins de Paris ont bien voulu se livrer à la dégustation comparée d'un grand nombre de ces échantillons et j'ai communiqué antérieurement à l'Académie les résultats de ces comparaisons.

Trois nouvelles années s'étant écoulées depuis la dernière dégustation et la plupart de ces vins se trouvant en expérience depuis six et sept ans, j'ai dû recourir de nouveau à l'obligeance des membres de la Chambre syndicale. Pour ajouter, s'il était possible, à l'autorité de son

1. APPERT. Loc. cit.

2. Voir p. 209 du présent volume l'extrait des Mémoires de chimie de Scheele.

3. Voir p. 234-240 du présent volume : Rapport de la Sous-Commission chargée de constater les rẻsultats des expériences de $M$. Pasteur sur la conșervation des vins (16 et 23 novembre 1865), et p. 253-256 : le Rapport de la Commission syndicale des vins de Paris (11 aout 1869). (Notes de l'Edition.) 
jugement, notre illustre confrère M. Chevreul, président de la Société centrale d'agriculture, a bien voulu, à ma demande, prier un certain nombre de membres de cette société de s'adjoindre à la Commission syndicale. Ce furent MM. Dumas, Barral, Bouchardat. M. Porlier, sousdirecteur au ministère de l'agriculture, a également assisté à cette constatation. Les appréciations ont été faites au scrutin secret, dans la forme rigoureuse déjà indiquée au compte-rendu d'une de nos séances, celle du 6 septembre $1869\left({ }^{(1)}\right.$.

Il résulte du procès-verbal de la dégustation qu'on peut considérer la pratique du chauffage comme un puissant moyen, non seulement de conservation, mais aussi d'amélioration des vins communs ou des vins fins.

Il est démontré par une épreuve de six à sept années que, après une exposition rapide à une température comprise entre $55^{\circ}$ et $65^{\circ}$, les vins, même les plus fins, non seulement n'éprouvent plus de maladies, mais en outre s'améliorent en prenant une qualité supérieure à celle que leur donne un vieillissement naturel, qui s'accomplit en dehors de toute maladie accidentelle.

Des personnes plus ou moins autorisées avaient déclaré que le chauffage enlèverait avec le temps de la couleur au vin. C'est le contraire qui est vrai, quand on opère à l'abri de l'air : la couleur s'avive par le chauffage. Elles avaient dit : le chauffage altérera, arec le temps, le bouquet des grands vins; cette opération les fera sécher, vieillarder. Tout au contraire, le bouquet parait s'exalter avec les années, et plus sûrement que si on ne les chauffe pas. Pour les chambertin, notamment, et les volnay, ce fait a été très remarqué par les dégustateurs. On avait dit encore qu'il était nécessaire de chauffer à des températures basses et pendant de longs mois. Ce sont autant d'erreurs, témoin certains vins de la dégustation dont il s'agit, qui ont été chauffés rapidement à $60^{\circ}, 65^{\circ}$ et même $75^{\circ}$, quoiqu'il soit superflu de chauffer à des températures trop élevées, ne fût-ce que par économie.

Une précaution qui paraît utile et que j'ai indiquée depuis longtemps consiste à chauffer les vins plutỏt jeunes que vieux, par exemple dans la première année pour les vins communs, et à l'époque de la mise en bouteilles pour les vins fins.

Dans la présente Note, il ne s'agit que des vins chauffés en bouteilles. Pour le chauffage sur de grandes quantités de vin, j'ai insisté et j'insiste de nouveau sur la nécessité d'éviter, le plus possible, le

1. Voir la note 1 de la p. 253 du présent volume. (Note de l'Édition.) 
contact de l'air. Il faut que, dans les appareils dont on fait usage, le vin soit, le plus possible, avant, pendant et après le chauffage, dans les conditions du vin chauffé en bouteilles. Le contact de l'air peut altérer la couleur et développer un goût de cuit généralement désagréable. Les insuccès que le chauffage en grand a pu présenter quelquefois tiennent à ce qu'on a négligé plus ou moins cette précaution.

Je termine en regrettant de n'avoir pas opéré sur les vins fins de la Gironde: Je savais qu'ils étaient en général de bonne conservation, et j'avais peu de relations avec ce grand centre de production; mais aujourd'hui qu'on peut être conduit à chauffer les vins dans le seul but de les améliorer, il y a un grand intérêt à ce que je renouvelle mes essais sur les vins, même les plus robustes.

Procès-verbal de la dégustation de vins chauffés et Non Chauffés,

faite le 10 juillet 1872, à l'École Normale, sur la demande de M. Pasteur, par MM. Teissonnière, membre de la Chambre de commerce; Célerier, président de la Chambre syndicale; Brazier jeune, ex-membre de la Chambre syndicale; en présence et assistés de MM. Barral, Bouchardat, Dumas, membres délégués par la Société centrale d'agriculture; et Porlier, sous-directeur au ministère de l'agriculture.

Vin blanc, chauffé en 1865 à $60^{\circ}$. - Le vin chauffé est meilleur à l'unanimité.

Vin rouge, coupage de Paris, à 45 centimes la bouteille, chauffé en mai 1865 à $75^{\circ}$. - Le vin chauffé est meilleur : différence très peu sensible, un peu plus de couleur dans le vin chauffé.

Vin rouge, coupage de Paris, à 45 centimes la bouteille, chauffé en mai 1865 à $60^{\circ}$. - Un des échantillons est devenu blanc, c'est le vin chauffé (1). Aucun des échantillons n'est altéré. Pour ces échantillons les bouteilles étaient debout.

Vin rouge, coupage de Paris, à 60 centimes la bouteille, chauffé en juin 1865 à $70^{\circ}$. - Le vin chauffé est en très bon état de conservation; le non chauffé est aigre et a perdu une partie de sa couleur.

1. M. Pasteur explique la perte de la couleur du vin chauffẻ par ce fait qu'aucune croûte par la fleur ne s'étant produite sur le vin chauffé, ce dernier s'est trouvé, en raison de la porosité du bouchon, constamment en contact avec l'oxygène de l'air, tandis que la croûte de fl eur formée sur le vin non chauffẻ l'a préservé de cette influence. 
Vin rouge du Midi non plâtré (petit montagne), chauffé à $65^{\circ}$ en décembre 1865. - Le vin chauffé est en très bon état deconservation malgré son âge; le vin non chauffé est dur et acide; il a perdu de sa couleur.

Vin rouge du Midi plâtré (petit montagne), chauffé à $65^{\circ}$ en décembre 1865. - Vins de qualité égale; un léger goût de fermentation dans le vin non chauffé. Le chauffé est un peu plus coloré.

Vin rouge d'Arbois 1865. (Il était malade en 1869, à l'époque à laquelle il a été chauffé.) Le vin chauffé est bon. Il a plus de couleur que le vin non chauffé, qui a un goût de fermentation assez prononcé. Il y a au fond de la bouteille un dépót flottant et abondant, tandis que, dans la bouteille de vin chauffé, ce dépôt est adhérent et peu abondant.

Vin de Bordeaux ordinaire chauffé en 1869 à $55^{\circ}$. - Différence insignifiante; voix partagées; couleur égale dans chaque échantillon.

Vin d'Arbois 1871, chauffé en avril 1872 à $60^{\circ}:-$ - Le vin chauffé est reconnu supérieur à l'unanimité, quoique la différence soit peu sensible. La couleur est la même dans les deux échantillons.

Vin de Chambertin 1865, chauffé en 1866 à $60^{\circ}$. - Le vin chauffé est reconnu supérieur; il est plus moelleux, son bouquet s'est bien développé. Il y a autour de la bouteille de vin chauffé un dépôt abondant et adhérent; le dépôt, au contraire, est léger dans l'autre bouteille, et il est flottant. Très bonne couleur égale dans les deux échantillons.

Vin de Volnay 1863, chauffé en décembre 1866 à 55 . - Les deux vins sont bien conservés. La majorité a préféré le vin chauffé. Couleur égale dans les deux échantillons.

Vin de Volnay 1865, chauffé en 1866 à $55^{\circ}$. - Les deux vins sont excellents. La majorité cependant est acquise au vin chauffé, comme plus moelleux. Couleur égale dans les deux échantillons.

Vin de Volnay 1864, chauffé en 1866 à $55^{\circ}$. - Le vin chauffé est reconnu bien supérieur à l'unanimité. La couleur est égale.

Vin de Volnay 1864, chauffẹ́ en décembre 1866 à $55^{\circ}$. - Le vin 
chauffé est reconnu supérieur à la majorité d'une voix ; vins excellents du reste. Couleur égale.

Vin de Volnay 1862, chauffé en décembre 1866 à $55^{\circ}$. - Le vin chauffé est bon. Le vin non chauffé est aigre et a perdu de sa couleur.

Vin de Pomard 1863 (Marey-Monge), chauffé en 1866 à $60^{\circ}$. - Le vin chauffé est reconnu supérieur à l'unanimité. Il a conservé sa couleur, tandis que le vin non chauffé a perdu la sienne; ce dernier est devenu presque blanc; il est amer.

Vin de Beaune 1857, chauffé en 1866 à 55\%. - Le vin chauffé a la majorité à une voix. Les deux vins sont bien conservés. Si l'on se reporte à la dégustation faite en 1869 , il en résulterait que le vin chauffé gagne (1).

Vin d'Echezeaux-Vougeot 1862, chauffé en 1866 à $55^{\circ}$. - Le vin chauffé a la majorité d'une voix; les deux sont excellents.

Vin d'Echezeaux-Vougeot 1861, chauffé en 1866 à $55^{\circ}$. - Le vin chauffé est reconnu supérieur par 4 contre 1.

Vin de Romanée 1862, chauffé en 1866 à $55^{\circ}$. - Le vin non chauffé est reconnu supérieur par 4 contre 1. Couleur égale.

Vin de Pomard 1861 (Marey-Monge), chauffé (²) en décembre 1866. Le vin chauffé est reconnu supérieur à l'unanimité. Il a conservé sa couleur, tandis que le vin non chauffé a perdu beaucoup de la sienne.

Vin de Pomard 1862 (Marey-Monge), chauffé en décembre 1866 à $55^{\circ}$. - Le vin chauffé est reconnu supérieur à l'unanimité. Il a conservé sa couleur, tandis que le vin non chauffé a perdu une partie de la sienne et il est amer.

Vin de Gevrey-Chambertin 1859, chauffé à $65^{\circ}$ en mai 1865. - Le vin chauffé est reconnu supérieur à l'unanimité. Il a conservé sa

1. A cette occasion, on peut remarquer que si le vin chauffé paraît avoir perdu quelquefois de sa finesse après le chauffage, il la reprend ultérieurement avec avantage.

2. La température n'est pas indiquée. (Note de l'Édition.)

(Remarque de M. Pasteur.) 
couleur, tandis que le vin non chauffé a perdu une partie de la sienne et est devenu dur.

Vin de Saint-Georges (Còte-d'Or 1858), chauffé en 1866 à $55^{\circ}$. - Le vin chauffé est supérieur à la majorité d'une voix. Le vin non chauffé a un peu moins de couleur que celui qui a été chauffé.

(Suivent les signatures.) 


\section{ADDENDUM}

Nous avons placé ici la présentation faite par Pasteur, à l'Académie des sciences, dè la brochure "Sur la conservation des vins; lettre adressée à M. le rédacteur en chef du Moniteur vinicole " (Voir la note 1 de la p. 343) et la présentation faite par lui à l'Académie des deux éditions des “Études sur le vin ». (Note de l'Edition.)

\section{[HOMMAGE A L'ACADÉMIE D'UNE BROGHURE INTITULÉE : SUR LA CONSERVATION DES VINS (1)]}

Le procédé de conservation des vins par le chauffage préalable ayant donné lieu à plusieurs réclamations de priorité, j'examine dans - cette brochure la valeur du procédé à ce point de vue particulier. Cette brochure peut se diviser en trois parties. Dans la première je montre la différence qui existe entre certaines pratiques suivies dans le Midi et le procédé que j'ai fait connaître. On a confondu à ce própos le vieillissement artificiel avec la conservation. Dans la deuxième partie j'expose mes idées et les résultats de mes expériences relativement aux procédés de fabrication des vins d'imitation usités à Cette. La troisième partie a pour objet les tentatives faites antérieurement par M. de Vergnette-Lamotte, l'un des correspondants de l'Académie. Je fais observer que M. de Vergnette est la personne qui a le plus approché du procédé de conservation par le chauffage préalable. M. de Vergnette a appliqué la méthode d'Appert à certains vins et en a remarqué de bons effets de conservation. Malheureusement, les principes qui lui servaient de guide l'ont empêché de saisir la véritable signification de ses essais et ce qu'il y avait de général et de pratique dans cette méthode. D'ailleurs la science n'était pas encore assez avancée pour que l'on pût bien comprendre les effets de la chaleur appliquée à un vin quelconque.

Je publierai prochainement l'ensemble de mes études sur les maladies des vins, avec de nouveaux développements sur toutes ces questions.

1. Comptes rendus de l'Académie des sciences, séance du 20 novembre 1865, LXI, p. $865-866$. 
[PRÉSENTATION A L'AGADÉMIE D'UN OUVRAGE INTITULÉ : “ ÉTUDES SUR LE VIN \#( ${ }^{(1)}$ ]

J'ai l'honneur de déposer sur le bureau de l'Académie un exemplaire [les bonnes feuilles] d'un ouvrage relatif aux maladies des vins et aux moyens de les prévenir.

Cet ouvrage sera livré prochainement à la publicité. Le retard ne provient que de la longueur du travail de reproduction des planches, qui sont nombreuses et assez difficiles à graver. En attendant, je désire fixer la date de l'achèvement du texte.

[PASTEUR FAIT HOMMAGE A L'ACADÉMIE D'UN OUVRAGE INTITULÉ : “ ÉTUDES SUR LE VIN. SES MALADIES;

GAUSES QUI LES PROVOQUENT. PROGÉDÉS NOUVEAUX POUR LE CONSERVER ET POUR LE VIEILLIR ( ${ }^{(2)}$ "]

J'ai l'honneur de faire hommage à l'Académie de l'ouvrage sur les maladies des vins dont j'ai déposé le texte sur son bureau, dans la séance du 13 août dernier. Cet ouvrage a été imprimé avec un grand soin à l'Imprimerie impériale, et est accompagné de 30 [32] planches gravées en taille-douce et coloriées. Il se compose de trois parties et d'un appendice.

Dans le court avertissement, j'expose que l'Empereur, préoccupé du préjudice que les altérations spontanées des vins portent au commerce de cette denrée, d'une importance si grande pour notre pays, avait daigné m'inviter, il y a trois ans, à diriger mes recherches vers la connaissance des maladies des vins et des moyens de les prévenir. Les traités de coinmerce n'ont pas donné les résultats qu'on

1. Comptes rendus de l'Académie des sciences, séance du 13 aout 1866, LXIII, p. 281.

2. Comptes rendus de l'Académie des sciences, séance du 24 septembre 1866, XLIII, p. $509-510$. 
en attendait au point de vue de l'extension de la production vinicole. La France et l'Algérie pourraient alimenter tous les marchés du globe si l'on savait éviter les maladies auxquelles les vins sont sujets pendant les transports par terre et par mer, et lorsqu'ils sont parvenus à leur destination. Danś certaines contrées de la France, le sol et le climat sont si bien appropriés à la culture de la vigne, qu'en 1864 le seul département de l'Hérault a produit plus de sept millions d'hectolitres de vin et, en 1865, plus de dix millions d'hectolitres.

La première partie de l'ouvrage renferme la description des maladies des vins et des ferments qui les occasionnent.

La deuxième traite de l'influence de l'oxygène dans les pratiques de la vinification.

La troisième, enfin, fait connaître un procédé industriel de conservation des vins, dont la propriété et le négoce sauront tirer, je l'espère, un immense profit. Déjà l'Académie a reçu à ce sujet une Communication importante de M. H. Marès, l'un de ses correspondants (1), et je sais que de divers còtés des essais sont tentés par beaucoup de personnes. Ce procédé est très pratique, puisqu'il n'est qu'une extension du procédé des conserves d'Appert.

J'appelle l'attention sur un rapport contenu dans la troisième partie de l'ouvrage, rapport émanant d'une Sous-Commission désignée par la Commission syndicale du commerce des vins dans Paris. La dégustation par des personnes exercées est toujours le criterium auquel il faut avoir recours en dernier ressort pour juger de la valeur comparée de divers échantillons de vins. Je devais donc solliciter l'appréciation, à ce point de vue, des personnes les plus autorisées. Les détails de la dégustation des vingt et une espèces de vin que j'ai soumis à MM. les membres de la Commission, et les conclusions de leur rapport, mettent en évidence les bons résultats que l'on peut attendre de la pratique du chauffage, pour les sortes les plus diverses de vins naturels, depuis les plus communs, tels que les vins de coupage du commerce de détail dans Paris, jusqu'aux vins des plus grands crus de la Bourgogne. Ainsi tombent devant l'autorité des faits et le jugement d'hommes compétents les contradictions qui se sont fait jour au sujet de la généralité d'application du procédé dont il s'agit, contradictions auxquelles j'avais jugé sans utilité de répondre, tant que mon ouvrage et le rapport de la Commission syndicale ne pouvaient être livrés à la publicité.

1. Mark̀s (H.). De l'influence de la chaleur sur les vins rouges liquoreux. Lettre adressée par M. H. Marès à M. Pasteur. Comptes rendus de l'Académie des sciences, LXII, 1866, p. 1168-1171. (Note de l'Édition.) 


\section{[PASTEUR FAIT HOMMAGE A L'ACADÉMIE \\ DE LA SECONDE ÉDITION DE SON OUVRAGE INTITULÉ : “ ÉTUDES SUR LE VIN "( $\left.{ }^{1}\right)$ ]}

La première édition, tirée à trois mille exemplaires cependant, ayant été promptement épuisée, l'auteur a dû s'occuper d'en publier une seconde.

Il y a fait entrer, à leur place, toutes les observations nouvelles dont le sujet s'est enrichi. L'ouvrage est divisé en quatre parties; la troisième, qui intéresse surtout la pratique, est presque complétement nouvelle.

Dans la première, l'auteur passe en revue les principales maladies du vin : l'acescence, la maladie des vins tournés, de la graisse, de l'amertume; après avoir montré combien les opinions vulgaires sur les causes de ces maladies sont vagues et peu fondées, il prouve que chacune d'elles est la conséquence de la vie et du développement d'un organisme spécial qui en est le signe distinctif.

Dans la deuxième, il prouve que le vieillissement du vin, sous ses aspects divers, est dù à l'action directe, lente et continue de l'oxygène de l'air sur les principes de ce liquide; il montre comment, en disposant de cet agent, on peut obtenir toutes les variétés de vin, avec le même moût de raisin, et dans quel sens il faut modifier les recettes de la pratique pour obtenir ces transformations plus sủrement et plus rapidement.

La troisième, rédigée par M. Raulin, contient ce qui a rapport à l'application du chauffage à la conservation et à l'amélioration des vins; un historique complet de la question; les résultats des expériences propres à former la conviction; enfin la description des appareils industriels de chauffage. ments.

Dans une quatrième partie, l'auteur a rassemblé les notes et les docu-

1. Comptes rendus de l'Académie des sciences, séance du 2 septembre 1872, LXXV. p. $575-576$. 

COMMUNICATIONS ET ARTICLES

\section{SUR LE VIN ET SES MALADIES}





\section{ÉTUDES SUR LES VINS.}

PREMIÈRE PARTIE : DE L'INFLUENGE DE L'OXYGENE DE L'AIR

DANS LA VINIFICATION (i)

Le vin est une des principales richesses agricoles de la France. Le sol, le climat, l'exposition dans un même sol, la nature des cépages, etc., sont autant de causes de modifications dans les qualités et même dans la nature propre du vin. C'est principalement à ces causes qu'il faut rapporter les nombreuses variétés de vins de notre pays. On ne changera point cela, et il y a intérêt à ne pas le tenter. Mais il est certain qu'un même moût de raisin, travaillé de diverses façons, peut produire bien des sortes et qualités de vins. En outre, les altérations des vins n'ont rien de nécessaire. On doit pouvoir les prévenir, puisqu'elles sont accidentelles. Il y a donc à faire une part assez large à l'expérimentation et à ses conséquences pratiques.

J'ai tenté d'appliquer à l'étude de la vinification et des altérations des vins quelques-unes de mes recherches de ces dernières années. Les faits nouveaux auxquels je suis arrivé me paraissent de nature à provoquer des essais utiles, et j'ose espérer qu'à ce titre l'Académie les accueillera avec indulgence, malgré les lacunes qu'elle apercevra dans mon travail, comme je les aperçois moi-même.

Ces lacunes sont peut-être inévitables, parce que dans un tel sujet le savant ne peut pas tout attendre de ses propres efforts. Lorsque ses expériences l'ont conduit à des vues particulières, il doit s'empresser de les communiquer au public, afin de les soumettre au contrôle d'essais industriels qu'il n'a guère les moyens d'effectuer lui-même.

Je m'occuperai dans cette première Communication de l'influence de l'oxygène de l'air dans la vinification.

1. Comptes rendus de l'Académie des sciences, séance du 7 décembre 1863 , LVII, p. $936-942$.

Le développement de cette Communication forme la presque totalité de la deuxième partie des "Etudes sur le vin " intitulée : "De l'oxygène de l'air dans la vinification " (p. 170-202 du présent volume). [Note de l'Édition.] 
Tout le monde connaît l'ingénieuse expérience de Gay-Lussac qui démontra ce que l'on avait depuis longtemps pressenti et énoncé sans preuves, que l'oxygène de l'air est nécessaire à la fermentation du moût de raisin. Le jus sucré du raisin renfermé dans les grains, encore réunis à la grappe qui les portait sur le cep, ne fermente pas. Il était dès lors facile de prévoir que l'air, et dans l'air l'oxygène, est nécessaire à là fermentation du moût de raisin.

Gay-Lussac fit passer cette idée de la spéculation dans le domaine des faits positifs. Il en donna la preuve expérimentale. Après avoir écrasé des grains de raisins sous une éprouvette renversée pleine de mercure, il vit qu'ils ne fermentaient pas, soit seuls, soit au contact de divers gaz. L'addition d'une petite quantité de gaz oxygène déterminait au contraire la fernentation.

En étudiant de plus près cette curieuse influence de l'oxygène dạs la fermentation alcoolique du moût de raisin, j'ai constaté les faits suivants :

10 Le moût de raisin ne renferme pas du tout de gaz oxygène en dissolution, et seulement de l'acide carbonique et de l'azote. J'ai opéré sur des raisins d'espèces différentes, blancs ou rouges. U'ne expérience faite sur du moût de raisins blancs, aussitôt après l'action du pressoir, a donné, par litre de moût, 58 centimètres cubes de gaz ayant pour composition en centièmes :

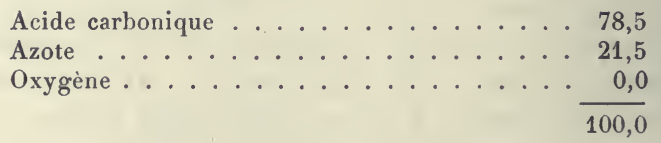

$2^{\circ}$ Si le moût est abandonné, même en grande surface, au contact de l'air, il ne s'oxygène pas. On n'y trouve, jusqu'à ce que la fermentation se déclare, que ces mêmes gaz acide carbonique et azote. Par conséquent, l'oxygène de l'air se combine au fur et à mesure de sa dissolution avec des principes oxydables que renferme naturellement le jus du raisin.

$3^{\circ}$ Cette combinaison de l'oxygène de l'air avec le moût n'est pas tellement rapide, que l'on ne puisse avoir du moût tenant en dissolution du gaz oxygène pendant quelques heures. On atteint ce résultat en agitant le moût avec l'air, et en analysant les gaz dissous aussitôt après l'agitation.

5 litres de moût ont été agités dans une grande bouteille de dix litres avec leur volume d'air pendant une demi-heure. 50 centimètres cubes de gaz extraits du moût un quart d'heure après l'agitation ont 
laissé 13 centimètres cubes de gaz non absorbables par la potasse, lesquels renfermaient 20 pour 100 de gaz oxygène.

La mème expérience répétée sur le même moût, en laissant reposer le liquide pendant une heure, après l'agitation avec l'air, n'a plus fourni que 6 pour 100 d'oxygène dans le gaz privé d'acide carbonique.

Enfin, en laissant du moût dans une bouteille bien bouchée en contact avec son volume d'air (à une température de $10^{\circ}$ afin de retarder la fermentation), l'air de la bouteille renfermait, au bout de quarante-huit heures, près de 3 pour 100 de gaz carbonique, et 14 pour 100 de gaz oxygène seulement. On avait agité à deux reprises le moût avec l'air pendant une demi-heure. Chaque litre de moût avait donc absorbé environ 70 centimètres cubes de gaz oxygène.

La combinaison de l'oxygène de l'air avec le moût modifie sa couleur. Le moût de raisins blancs, à peu près incolore dans le grain et au moment du pressurage, devient jaune brun en passant par les états intermédiaires. Le moût de raisins rouges renferme également des matières incolores qui brunissent par le contact de l'air. Enfin l'odeur $\mathrm{du}$ moût récent, qui est faible et a quelque chose de vert, prend peu à peu, s'il n'est pas filtré, une odeur agréable, éthérée, au moment où la fermentation commence, et cette odeur paraît être en rapport avec une aération lente du moût.

Mais ce qu'il importe peut-être davantage de remarquer, au point de vue des applications, c'est l'influence considérable de l'aération sur la fermentation du moût.

Laisse-t-on le moût exposé au contact de l'air en grande surface pendant plusieurs heures, ou l'agite-t-on avec de l'air, opération facile à pratiquer à l'aide d'un soufflet dont la douille est munie d'un tube qui plonge dans la cuve ou dans le tonneau (1), la fermentation du moût aéré est incomparablement plus active que celle du moût [non aéré, et la différence varie avec l'intensité de l'aération. Et il est digne d'attention que l'aération peut avoir lieu et produire des effets au moins aussi sensibles, alors même qu'on l'effectue pendant la fermentation, lorsque le liquide est déjà chargé d'acide carbonique et de levûre alcoolique.

L'aération du moût à des degrés divers se présente donc comme l'un des moyens les plus propres à influer sur la durée et l'achèvement complet de la fermentation.

Dans les localités où la vendange n'a lieu qu'en octobre, il arrive très fréquemment, et particulièrement dans les meilleures années,

1. Je ne prétends pas cependant qu'il soit indifférent d'employer l'un ou l'autre de ces deux modes d'aération. 
que le vin reste doux après la fermentation tumultueuse. Ce vin un peu sucré est sujet aux altérations et il n'est pas rare de le voir fermenter insensiblement pendant trois ou quatre ans.

On peut dire que dans tous les cas, ‘à moins qu'il ne s'agisse de vins liquoreux, il est utile que la fermentation se termine dès l'origine. Pour atteindre ce but, l'aération du moût, convenablement appliquée, sera peut-être un moyen aussi efficace que facile à mettre en pratique. N'aura-t-elle pas des inconvénients cachés? Nuira-t-elle à la couleur que l'on recherche dans les vins, à leur goût, à leur bouquet? Trouvera-t-on au contraire sur ce point de nouveaux avantages? C'est ici que doit intervenir cette alliance à laquelle je faisais allusion tout à l'heure des essais industriels tentés par les propriétaires intéressés, et des indications de la science. Remarquons d'ailleurs, qu'avantageuse ou nuisible, l'aération est une circonstance obligée de la vinification. Elle mérite donc à tous égards la plus sérieuse attention, alors même que l'on ne sortirait pas des usages habituels, parce qu'elle y intervient déjà présentement, à l'insu des praticiens, et dans une mesure abandonnée au hasard des circonstances et des coutumes locales.

Une autre conséquence facile à déduire des faits que j'ai exposés, c'est que le vin doit contenir des principes éminemment oxydables. M. Boussingault a reconnu depuis longtemps que le vin ne renfermait pas du tout de gaz oxygène en dissolution, et il avait même espéré se servir de la connaissance de ce fait pour déceler l'addition de l'eau ordinaire au vin. Malheureusement, dès le lendemain le vin ne contenait plus d'oxygène libre. Ces faits ont été confirmés récemment et étendus par M. Berthelot (1), qui ne connaissait pas les observations de M. Boussingault, publiées en 1859 dans une de ses leçons du Conservatoire des Arts et Métiers à laquelle j'assistais.

Ce que je tiens à faire observer à ce sujet, c'est que l'existence dans le moût du raisin de matières qui absorbent l'oxygène de l'air, qui l'absorbent encore après que la fermentation a commencé, entraîne inévitablement celle de principes semblables, plus ou moins modifiés par la fermentation, dans la composition du vin lui-même. C'est pour ce motif que l'on ne trouve pas d'oxygène dissous dans les vins conservés en vase clos. Si le vase qui renferme le vin n'est pas fermé, le vin se charge de gaz oxygène, et l'air du vin est même plus riche en oxygène que l'air atmosphérique, comme il arrive pour l'air dissous dans l'eau. Il y a cependant une circonstance où le vin exposé au con- 
tact de l'air ne contient pas d'oxygène libre : c'est lorsque sa surface est recouverte en tout ou en partie de mycoderma vini, ou fleurs du vin.

L'oxygène de l'air, qui se mêle au vin exposé au contact de l'air, ne s'absorbe donc pas aussi promptement qu'il se dissout. Sous ce rapport le moût de la vendange est plus oxydable ou dissout moins vite l'oxygène, puisque ce gaz disparaît au fur et à mesure de sa dissolution, quand le moût est en repos au contact de l'air.

Si l'on étudie les gaz du moût, pendant et après la fermentation, on reconnaît, comme on devait s'y attendre, que la liqueur est saturée de gaz acide carbonique sans mélange d'aucun gaz quelconque. Dans une expérience faite sur du vin nouveau, pris sur place, dans le tonneau même où la fermentation avait eu lieu, j'ai trouvé par litre 1 lit. 481 de gaz carbonique. Le vin était à la température de $7^{\circ}$.

Mais dès que le vin a fermenté dans la cuve et que le vin est mis en tonneau, les choses changent complétement. Les parois du tonneau donnent lieu à une évaporation active, variable avec l'épaisseur des douves, avec l'état du tonneau, avec la nature du vin, et enfin avec la cave, son exposition et la distribution de ses courants d'air.

Des effets d'endosmose de gaz et de vapeurs ont lieu constamment à travers le bois, et je crois pouvoir démontrer que c'est par l'action de l'oxygène de l'air pénétrant lentement dans le tonneau que le vin se fait, et que, sans l'influence de l'oxygène, le vin resterait à l'état de vin nouveau, vert, acerbe, et non potable.

Analysons, en effet, les gaz dissous dans un vin qui a été mis en tonneau depuis quelques mois ou depuis quelques années. Les analyses auxquelles je fais allusion ont été et doivent être effectuées sur place au moyen d'un procédé que je décrirai ailleurs (pour ne pas trop allonger cette Communication), et de façon à ne pas mettre le moins du monde le vin en contact avec l'air atmosphérique. Voici les résultats généraux de ces déterminations. Il y a absence constante de gaz oxygène. La raison en a été donnée tout à l'heure. On trouve de l'acide carbonique en proportions variables. Cela doit être, puisque, après la fermentation, le vin était sursaturé de ce gaz. Mais ce qu'il faut principalement remarquer, c'est que le vin renferme toujours de l'azote, dont la proportion est, dans tous les cas, sensiblement la même, de 16 centimètres cubes environ par litre. Or, ce gaz ne peut avoir été emprunté qu'à l'air atmosphérique, puisque nous avons reconnu que le vin, à l'origine, ne contenait en dissolution que du gaz acide carbonique pur. Si le vin s'est saturé de gaz azote, c'est qu'il s'est également saturé d'air, avec cette circonstance importante toutefois que l'oxygène correspondant à l'azote ne restant pas libre, et se 
combinant avec les principes du vin, un renouvellement incessant de l'oxydation doit avoir lieu.

On comprendra dès lors l'intérêt qu'il y aurait à déterniner cette proportion d'oxygène que le vin absorbe sans discontinuité pendant le long intervalle de son séjour en tonneau, et ultérieurement en bouteille; bien que, dans ce dernier cas, l'absorption soit à peine sensible. J'espère arriver directement à ce résultat. Mais je puis dès à présent donner de cette absorption un minimum qui accusera l'influence considérable de l'oxygène de l'air dans la vinification.

$\mathrm{Ce}$ minimum est fourni par la connaissance de la vidange qui s'établit naturellement dans tous les tonneaux, vidange que l'on peut mesurer exactement par l'ouillage. Or, il résulte des mesures que j'ai prises dans le Jura, confirmées par des renseignements qui m'ont été fournis par l'habile tonnelier-chef du Clos-Vougeot, qu'une pièce de bourgogne de 228 litres se vide par évaporation de plus de 10 litres par année, et le liquide évaporé est remplacé par de l'azote et de l'acide carbonique.

L'oxygène de plus de 10 litres d'air se fixe donc chaque année sur le vin de la pièce. Et, comme on conserve le vin en pièces le plus souvent trois ou quatre ans avant de le mettre en bouteilles, et quelquefois bien plus longtemps, il est facile de calculer que, dans cet intervalle, chaque litre de vin absorbe de 30 à 40 centimètres cubes de gaz oxygène pur.

Mais, je le répète, ce n'est là encore qu'un minimum éloigné de l'absorption de l'oxygène. Il y a, en effet, un échange continuel des gaz de l'intérieur du tonneau avec l'air atmosphérique, pendant que la vidange par évaporation s'effectue. Nous pouvons en avoir une preuve dans la diffusion de l'acide carbonique. J'ai dit tout à l'heure qu'un litre de vin nouveau pris à la température de $7^{\circ}$ avait donné près de $1 \frac{1}{2}$ litre de gaz carbonique dissous. Le même vin vieux de deux années n'ayant subi que deux soutirages en mars et en juillet, sans |collage, ne renfermait plus par litre que 200 centimètres cubes de gaz acide carbonique. Cette différence donne une idée de la diffusion continuelle des gaz dissous dans le vin, à travers les parois du tonneau. La proportion d'oxygène fixée pendant que le vin se fait, sur les principes oxydables empruntés au moût du raisin, est donc certainement bien supérieure à 30 ou 40 centimètres cubes par litre.

Il ne me paraît pas possible de douter que c'est cette oxydation qui fait vieillir le vin et qui lui enlève ses principes acerbes et provoque en grande partie les dépôts des tonneaux et des bouteilles. Des expériences directes m'ont prouvé, en effet, que l'oxygène vieillit le vin 
nouveau, l'adoucit, lui enlève de sa verdeur, et que, concurremment, il s'y forme des dépòts abondants. D'autres essais qui n'ont encore, il est vrai, que trop peu de durée, tendent à établir que le vin nouveau conservé dans des vases hermétiquement clos ne se fait pas et dépose très peu. Cependant l'action de l'oxygène, pour être efficace, doit être lente et ménagée. Si on l'exagère, on tombe dans les phénomènes signalés par M. Berthelot, qui a bien vu le côté nuisible de cette action de l'oxygène (1).

La comparaison de ce qui arrive à un même vin conservé en grands ou en petits tonneaux offre une preuve convaincante, quoique indirecte, des observations précédentes. Plus on exagère les dimensions des futailles, plus le vin met de temps à vieillir.

Si je ne me trompe, les faits dont je viens d'entretenir l'Académie suggéreront des idées nouvelles sur les méthodes à suivre pour conserver ou pour vieillir les vins, sur l'action des courants d'air dans les caves, sur l'influence des tonneaux neufs ou vieux, plus ou moins propres à l'évaporation. Je crois qu'ils donneront également l'explication de l'influence des voyages sur le vin. C'est là évidemment, à cause de l'agitation, un moyen de modifier beaucoup les conditions de l'aération du vin et de l'endosmose des gaz. Nul doute également que la mise en bouteilles a principalenient pour effet de diminuer, dans une grande mesure, l'aération du vin et d'allonger beaucoup, par là même, la durée de sa confection, ce qui, dans le langage ordinaire, s'appelle conservation du vin.

Pendant que le vin se fait en tonneau ou en bouteille, sous l'influence de l'oxygène de l'air, il arrive souvent que des altérations spontanées se manifestent sans causes apparentes bien déterminées. J'étudierai ces altérations ou maladies des vins dans une prochaine Communication.

1. Berthelot (M.). Action de l'oxygène sur le vin. Comptes rendus de l'Académie des sciences, LVII, 1863, p. 795 et 983 ; LVIII, 1864, p. 80 et 292. (Note de l'Édition.) 


\section{ETUDES SUR LES VINS.}

DEUXIÈME PARTIE : DES ALTÉRATIONS SPONTANÉES

OU MALADIES DES VINS, PARTICULIÈREMENT DANS LE JURA (')

Le vignoble du Jura produit des vins rouges de qualités très diverses et des vins blancs ordinaires ou de nature particulière, tels que les vins blancs mousseux, vins clairets, vins jaunes ou vins dits de garde de Château-Châlons et d'Arbois. Ces derniers, d'un prix assez élevé, sont des vins analogues au madère sec, et doués d'un bouquet très agréable.

Les altérations spontanées ou maladies des vins ne proviendraientelles pas de ferments organisés, de petits végétaux microscopiques, dont les germes se développeraient lorsque certaines circonstances de température, de variations atmosphériques, d'exposition à l'air, ..., permettraient leur évolution ou leur introduction dans les vins? Tel est le principal objet que j'ai eu en vue, dont l'idée m'avait été suggérée par mes recherches de ces dernières années.

Je suis arrivé, en effet, à ce résultat que les altérations des vins sont corrélatives de la présence et de la multiplication de végétations microscopiques. Il m'a paru utile de dessiner ces végétations dans une planche $\left(^{2}\right)$ jointe à cette Note, en y ajoutant les ferments organisés de quelques autres fermentations, afin que l'on puisse comparer entre elles les formes de ces diverses productions que je vais décrire succinctement.

\section{$\S 1$. - Des vins acides.}

Le mycoderma aceti est la cause de l'acidité que prennent en tonneau les vins rouges ou blancs du Jura. J'ai reconnu sa présence à la surface de tous les vins, en nombre considérable, qui m'ont été

1. Comptes rendus de l'Académie des sciences, séance du 18 janvier 1864, LVIII, p. 142-150 (1 $\mathrm{pl}$. avec 15 fig.).

La première partie du volume " Études sur le vin " intitulée " Causes des maladies des vins n (p. 115-169 du présent volume) est un développement de cette Communication.

2. Les figures de cette planche ont été placées ici dans le texte de la Communication. (Notes de l'Édition.) 
signalés comme vins acides, vins qu'il ne faut pas confondre avec les vins dits tournés ou montés.

La fig. 1 représente le mycoderma aceti. Ce végétal est formé d'articles courts, légèrement déprimés vers le milieu, et dont la longueur est un peu plus que double de la largeur. Ces articles sont réunis en chapelets qui, malgré la dislocation qu'amène la prise d'essai et l'observation microscopique, ont souvent de grandes longueurs pouvant atteindre $20,30,40, \ldots$, fois la longueur d'un article. Celle-ci est de $0^{\mathrm{mm}}, 0015$ environ. Elle varie un peu avec la composition de la liqueur et avec l'âge des articles.

Deux circonstances permettent d'expliquer le développement du mycoderma aceti à la surface des vins du Jura.

1 Les vins blancs appelés vins jaunes ne se confectionnent bien que dans des tonneaux qui sont en vidange; $2^{\circ}$ l'usage du pays est de ne pas ouiller les vins, soit communs, soit de qualité supérieure. Or, j'ai constaté qu'un vin ordinaire quelconque ne peut être conservé dans un tonneau en partie vide, alors même que le tonneau est bondonné fortement, sans que toute la surface du vin soit recouverte de mycoderma vini (fleurs du

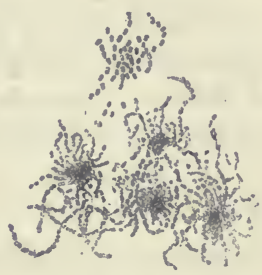

FIG. 1. vin), ou de mycoderma aceti (fleurs du vinaigre), ou d'un mélange de ces deux mycodermes.

Lorsqu'un vin tend à l'acidité, on ne peut bien étudier que sur place la cause de son altération, parce que le mycoderma aceti se forme toujours à la surface et non dans la masse du vin. On enlève la bonde, et, à l'aide d'une baguette de verre, on prélève une goutte de vin. La pellicule mycodermique laisse sa trace sur la baguette, et on l'observe au microscope. Je vais passer en revue les circonstances qui peuvent se présenter.

Premier cas. - Je suppose que le mycoderma aceti de la fig. 1, pur, sans mélange, se montre seul. Les vins jaunes en offrent de fréquents exemples. Il n'y a pas de doutes à garder. Le vin est malade et en voie de s'acétifier. J'ai trouvé dans ces nouvelles études une confirmation précieuse de celles que j'ai antérieurement présentées à l'Académie au sujet de la fermentation acétique proprement dite.

Si le mal est assez arancé pour que la saveur du vin accuse une acidité très prononcée, il est irréparable. Le mieux alors est d'enlever la bonde du tonneau en la laissant inclinée sur l'ouverture, afin que l'acétification continue plus facile, plus rapide, et que le vin se transforme complétement en vinaigre. 
L'acétification est-elle peu prononcée encore, on peut rétablir le vin en saturant l'acide acétique par une solution concentrée de potasse caustique pure. A cet effet, après avoir déterminé exactement le titre acide du vin malade, et celui d'un vin analogue de bonne qualité, on sature la différence des deux titres acides par la potasse. Cette opération réussit toutes les fois que l'acidité due à l'acide acétique ne dépasse pas 2 grammes environ d'acide acétique par litre. Je noterai en passant cette circonstance digne d'attention, que le bouquet des vins jaunes n'est nullement altéré par un commencement d'acétification. Il reparaît avec toute sa force première dès que la saturation par l'alcali a eu lieu.

Enfin, si l'acétification n'est pas sensible au goût, et indiquée seulement par la présence au microscope d'articles de mycoderma aceti en voie de développement, il faut soutirer le vin, en ayant le soin d'arrêter à temps le soutirage pour ne pas introduire dans le nouveau tonneau la pellicule de la surface du premier.

Deuxième cas. - Si l'étude microscopique de la pellicule du vin offre les végétations fig. 2 , fig. 5 et fig. 3 , ou d'autres variétés ana- logues, le mycoderma vini (fleurs du vin) est seul développé. Ces

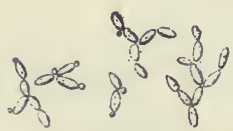

Frg. 2.

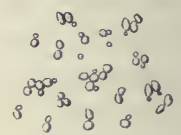

FIG. 3.

figures représentent diverses variétés de cette plante formée de cellules globuliformes ou d'articles plus ou moins allongés et rameux dont le diamètre varie de $0^{\mathrm{mm}}, 002$ à $0^{\mathrm{mm}}, 006$, et qui se reproduisent par bourgeonnement. Dans cette circonstance, et malgré la fonction physiologique de cette production, que j'ai fait connaître antérieurement à l'Académie (1), le vin n'a rien de fâcheux à redouter. Je réserre même la question de savoir si la fleur du vin, se développant dans des conditions aussi particulières, n'offre pas des avantages. Je me bornerai à faire remarquer aujourd'hui que la présence de ce mycoderme apporte un changement profond aux rapports qui existent entre le vin et l'oxygène de l'air, comparativement à ce qui se passe lorsque la pratique souvent répétée de l'ouillage empêche d'une manière absolue la formation du mycoderma vini. Telle est, en effet, dans ma manière de voir,

1. Voir p. 7-12 du présent volume : Études sur les mycodermes. Rôle de ces plantes dans la fermentation acétique. (Note de l'Édition.) 
l'influence principale de l'ouillage. Cette pratique s'oppose au développement de la fleur du vin, et il en résulte une mise en œuvre très modifiée de l'oxygène de l'air pénétrant par endosmose par les douves du tonneau. On comprendra mieux ces observations si l'on se reporte à la première partie de ma Communication.

Je puis être plus explicite en ce qui concerne les vins jaunes et affirmer sans hésitation que la variété de mycoderma vini, fig. 3, est indispensable à la bonne confection de ces vins; car en faisant déve-

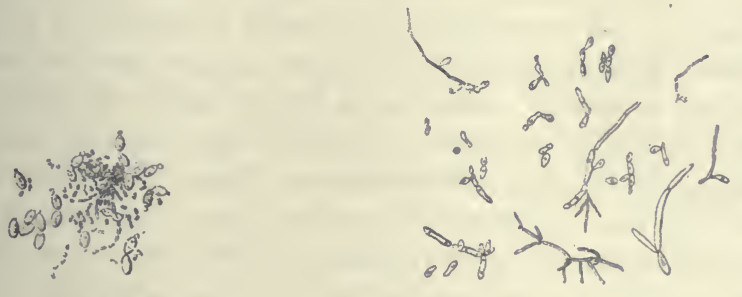

FIf. 4.

Fig. $\bar{~}$

lopper ce mycoderme sur des vins artificiels, j'ai fait naître d'une manière non douteuse une partie du bouquet propre au vin jaune. Aussi je crois pouvoir conseiller de semer, à la surface du vin, préparé pour vin jaune, le mycoderma vini emprunté à la pellicule d'un bon vin blanc ou jaune, dans laquelle le microscope n'aura pas accusé le mélange d'articles de mycoderma aceti. Le mycoderma vini joint d'ailleurs à sa vertu propre celle de mettre en quelque chose obstacle à la propagation du mycoderma aceti. Car il n'y a pas d'autre alternative que celle dont j'ai parlé. Le vin placé dans un tonneau que l'on n'ouille pas est forcément recouvert d'une pellicule mycodermique, constituée par l'un ou l'autre des deux mycodermes, ou par leur mélange. Si donc le mycoderma vini apparaît le premier, circonstance que l'on peut favoriser par l'ensemencement, il y aura beaucoup de chances pour qu'il utilise à son profit exclusif l'oxygène qui pénètre peu à peu dans le tonneau, et qu'il nuise d'autant à la formation de son congénère $\left({ }^{4}\right)$.

Troisième cas. - Je suppose enfin que le microscope offre un mélange analogue à celui de la fig. 4. C'est le mélange des deux mycodermes, fleurs du vin et fleurs du vinaigre. Je l'ai rencontré sur

1. Cela n'arrive toutefois que dans les cas de nourriture abondante. Si le mycoderma vini n'a pas d'aliments en quantité suffisante, il se mèle rapidement au mycoderma aceti, lequel vit á ses dépens. Je reviendrai bientôt sur ce fait que j'ai déjà traitẻ [loc. cit.], mais imparfaitement. 
les vins jaunes et sur les vins rouges très fins. Il est rare sur les vins rouges ou blancs ordinaires, à moins que l'on ne détermine dans le tonneau une vidange pour ainsi dire sans cesse renouvelée, comme il arrive toutes les fois que l'on tire à même à un tonneau pour les besoins journaliers.

Les vins rouges communs ne portent que le mycoderma vini parce que ce végétal se multiplie avec d'autant plus de facilité que les vins sont plus chargés de matières azotées et extractives. Mais lorsque le vin rouge est vieux, d'un très bon sol ou d'une très bonne année, circonstances qui contribuent à le rendre dépouillé de ces matières étrangères, le mycoderma vini ne se développe plus que péniblement à sa surface et se mêle volontiers au mycoderma aceti. Alors se déclare l'acétification. C'est ainsi que se perdent fréquemment les meilleurs vins rouges du Jura lorsqu'on les conserve longtemps en tonneau. S'ils restent couverts de mycoderma vini pur, sans mélange, ils prennent une qualité supérieure et acquièrent le goût des vins jaunes par des motifs analogues à ceux que j'ai tout à l'heure indiqués.

\section{$\S$ II. - Des vins qui restent doux après la fermentation.}

La fig. 6 représente une variété de levûre alcoolique fort intéressante. Il arrive assez souvent, principalement dans le Jura où les

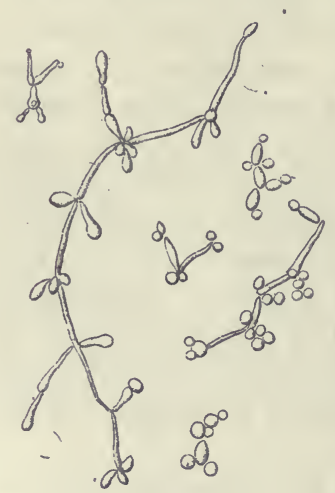

FIG. 6. vendanges se font vers le 15 octobre, saison déjà froide et peu favorable à la fermentation, que le vin est encore doux au moment de l'entonnaison. Cela se présente surtout dans les bonnes années où le sucre est abondant et la proportion d'alcool élevée, circonstance qui nuit à l'achèvement complet de la fermentation, lorsque celle-ci s'effectue à température basse. Le vin reste donc en tonneau, quelquefois pendant plusieurs années, en éprouvant une fermentation alcoolique insensible. J'ai toujours reconnu dans ces vins le ferment fig. 6. C'est une sorte de tige avec rameaux d'articles de distance en distance, lesquels sont terminés par des cellules sphériques ou ovoïdes qui se détachent facilement et forment comme les spores de la plante. On voit rarement le végétal aussi complet que le représente la fig. 6 , parce que ses diverses parties se disloquent, comme cela est indiqué dans la moitié droite de la figure. 


\section{$\S$ III. - Des vins amers.}

La fig. 7 représente le ferment qui détermine la maladie désignée sous le nom d'amertume des vins, goût de vieux... Ce sont des filaments noueux, branchus, très contournés, dont le diamètre atteint quelquefois $0^{\mathrm{mm}}, 004$ et qui varie depuis cette limite jusqu'à $0^{\mathrm{mm}}, 0015$ environ. Ces filaments sont ordinairement associés à une foule de petits grains bruns, sphériques, ayant à peu près $0^{\mathrm{mm}}, 0018$ de diamètre. J'ai étudié des vins amers de toutes les provenances, et j'y ai reconnu constamment la présence de ce curieux végétal, en quantité variable avec l'intensité de l'amertume du vin.

Cette maladie n'est pas rare dans les vins vieux du Jura; mais elle est plus fréquente

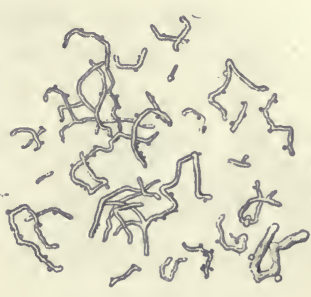

Fig. 7. dans les vins de Bourgogne. Cee sont les meilleurs vins qui en sont atteints de préférence. Je n'en ai pas vu encore d'exemple dans les vins blancs.

J'ignore quant à présent sur quels principes le ferment porte son action, et quelle est la substance qui développe le goût d'amer. Serait-ce le tanin ou les matières azotées? Je n'ai à ce sujet que des idées préconçues. Ce ferment ne produit pas de gaz en quantité appréciable.

Je ne suis pas davantage en mesure d'indiquer un remède à cette maladie. Je ne puis que conseiller une étude microscopique périodique des dépòts des tonneaux, ou d'une bouteille isolée si le vin est en bouteille. Un peu d'habitude dans l'examen des dépôts des bouteilles au travers du verre fait soupçonner facilement le mal lorsqu'il existe : le dépòt est noir et flottant. Le dessin de la fig. 7 sera un guide sùr pour l'observation microscopique. Aucune des autres végétations ne peut se confondre avec celle-ci.

Si le microscope accuse la présence naissante du ferment, le vin devra être immédiatement collé, puis remis en bouteille.

Il faut attribuer en partie les pratiques si répandues du soutirage et du collage à l'utilité de l'aération des vins pour les améliorer et les vieillir (voir la première partie de ma Communication), et à la nécessité de la précipitation des parasites, afin d'éviter leurs maladies. 


\section{§ IV. - Des vins tournés.}

La fig. 8 représente le ferment de la maladie des vins dits tournés, montés, qui ont la pousse, etc... Le terme par lequel on désigne cette maladie varie un peu avec les localités. Les vins rouges de toute nature, mème les vins blancs, sont sujets à cette maladie.

Ce sont des filaments très ténus, qui ont souvent moins de 1 millième de millimètre de diamètre. Je les ai mélangés dans la

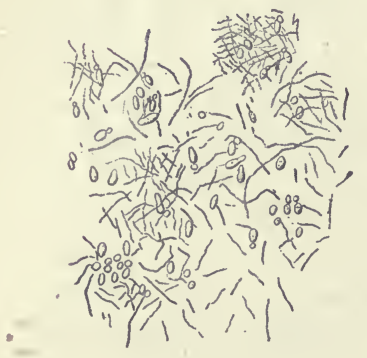

FIG. 8 . figure à quelques globules ou articles de la levûre alcoolique du vin. Ces filaments, étant extrêmement légers, flottent dans le vin et le troublent. Aussi est-on dans l'habitude de regarder le trouble du vin, dit tourné, comne étant produit par la lie qui a remonté dans le vin. Il n'en est rien. Le trouble est dû au ferment, fig. 8, qui s'est propagé peu à peu dans toute la masse du vin. On comprendrait cependant que, dans certains cas, très rares, car je n'en ai vu aucun exemple, la lie pût remonter et se mêler au vin par l'effet de la maladie, parce que le ferment dont il s'agit donne lieu à un faible dégagement de gaz.

Depuis l'année 1858, j'avais reconnu, dans des vins du Jura qui s'étaient altérés en bouteille, l'existence d'un ferment filiforme très différent de la levûre de bière et évidemment organisé. Mais c'est à M. Balard que l'on doit d'avoir mis en lumière, à propos d'une expertise de vins mal faite, la production fréquente et sur une grande échelle de ce même ferment dans les vins dits tournés du Midi (1).

Au premier examen, le ferment des vins tournés se confond avec celui de la fermentation lactique, surtout lorsqu'il a été agité, brisé et réduit en très petits filaments ou bâtonnets. Lorsqu'on l'étudie sur place, là où il a pris naissance, et sous ses divers aspects, on constate entre eux certaines différences qui consistent principalement en cè que le ferment des vins tournés est formé de filaments cylindriques très flexibles, sans étranglements apparents, de véritables fils, non rameux, et dont les articulations sont très difficiles à distinguer. Le ferment lactique, au contraire, est formé d'articles courts, légèrement déprimés à leur milieu, de telle sorte que pour. un certain jour on dirait 
une série de points lorsque plusieurs articles sont réunis bout à bout.

Il ne faut pas exagérer toutefois la distinction des deux ferments d'après ce caractère. On le retrouve à quelque degré dans la plupart de ces productions, à cause du mode de multiplication par fissiparité qui leur est habituel. Aussi je m'empresse de remarquer, à un point de vue plus général, que la nature d'un ferment ne peut être rigoureusement établie que par sa fonction physiologique(1).

Comment éviter cette maladie des vins tournés? Cela serait facile à quiconque prendrait le soin d'examiner ses vins de temps à autre au moyen du microscope. Dès que l'on reconnaîtrait dans une goutte de vin quelques-uns des filaments de la fig. 8, il faudrait aérer le vin par un soutirage qui, le plus souvent, suffit pour opérer la précipitation de tous ces filaments dans l'espace de quelques jours. Ce remède m'a paru assez efficace au début pour que l'on puisse croire que l'oxygene nuit à la vitalité propre du ferment.

Il arrive souvent que les vins de Champagne, ou les vins clairets et mousseux du Jura, prennent un goût de piqué très désagréable. J'ai reconnu que cette altération est constamment produite par le végétal microscopique dont je viens de parler.

\section{$\S \mathrm{V} .-$ Vins atteints des trois maladies précédentes.}

La fig. 9 représente les trois ferments mélangés des fig. 6, 7, 8 . C'est l'indice assuré que le vin a éprouvé successivement ou simulta-

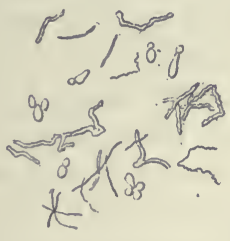

$$
\text { Fic. } 9 .
$$

nément trois altérations différentes, circonstance dont j'ai rencontré des exemples fréquents dans des vins qui avaient conservé du'sucre après les fermentations tumultueuse et insensible des premiers temps de la préparation du vin.

1. Pour mieux apprécier la différence de structure des ferments dont il s'agit, on pourra examiner simultanément les filaments du vin tourné et les petits articles de ferment lactique que renferme toujours le pain. L'étude de la fermentation panaire est à reprendre. Je la crois lactique et non alcoolique. 


\section{$\S$ VI. - Vins filants.}

La fig. 10 représente le ferment des vins blancs filants. Ce sont des chapelets de petits globules bien sphériques, ayant environ $0^{\mathrm{mm}}, 0012 \mathrm{de}$ diamètre; c'est un des ferments de la fermentation vis- queuse. J'ai constaté la présence de ces très petits : isra filants que j'ai pu me procurer, et je leur ai trouvé le

$\because, e^{4}$

FIc. 10. chimiques rigoureuses viennent confirmer ces données microscopiques.

\section{$\S$ VII.}

En résumant ces études (première et deuxième parties) dans ce qu'elles ont de plus général, on peut dire que le vin qui est produit par une végétation cellulaire, agissant comme ferment, ne s'altère que par l'influence d'autres végétations du même ordre; et, tant qu'il est soustrait aux effets de leur parasitisme, il se fait, il se mûrit, principalement par l'action de l'oxygène de l'air pénétrant lentement par les douves du tonneau. Sous le rapport pratique, le mieux est d'essayer de prévenir les altérations spontanées des vins. Or, d'après les observations qui précèdent, le microscope sera le guide le plus sûr pour reconnaître l'existence du mal et le spécifier dans sa nature, dès son apparition, c'est-à-dire à un moment où il est toujours possible de le combattre. D'ailleurs, en suivant quelques conseils et quelques précautions très simples, l'examen microscopique du vin, aidé des figures ci-jointes, conduira promptement et facilement à un résultat. Je dois ajouter que je ne crois pas que les vins soient sujets à d'autres maladies que celles que j'indique dans cette Communication.

\section{$\S$ VIII. - Ferments organisés de fermentations qui ne sont pas propres aux vins.}

J'ai représenté dans les fig. 11, 12, 13, 14, 15 des ferments de fermentations qui ne sont pas propres aux vins, mais qu'il n'est pas inutile de connaître, surtout ceux des fig. 11 et 12 , afin de ne pas les confondre avec les précédents.

Le ferment fig. 11, identique d'aspect et presque de volume avec 
celui de la fig. 10, est le ferment de l'urée dans l'urine (1). C'est encore un ferment pareil que l'on rencontre le plus souvent dans la fermentation du tartrate droit d'ammoniaque, et aussi dans la fermentation de la levâre de bière avec présence ou absence de carbonate de chaux.

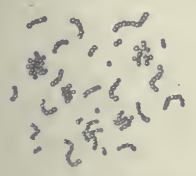

FiG. 11.

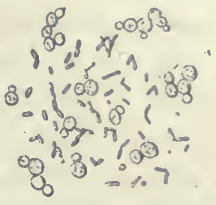

FIG. 12 .

Des expériences directes et précises pourront seules établir jusqu'à quel point ces chapelets de grains représentent un seul et même ferment pouvant vivre dans des milieux neutres, acides ou alcalins, capables de provoquer des fermentations diverses.

La fig. 12 offre le ferment de la fermentation lactique, mêlé à quelques globules de levûre de bière. Le ferment qui ressemble le plus à celui-ci est sans contredit le mycoderma aceti. Ce sont, dans les deux cas, des articles à peine étranglés vers leur milieu. Le diamètre est sensiblement le même. La ressemblance de ces deux

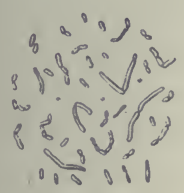

Fig. 13.

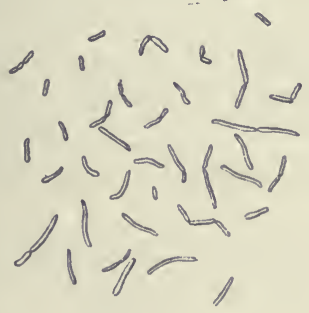

FIG. 14.

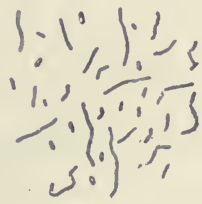

F'1G. 15.

petits végétaux cellulaires est quelquefois si grande, qu'il me paraît utile de rechercher si ce ne serait pas le même ferment avec deux modes de vie différents, auxquels correspondraient deux manières

1. Des expériences précises et longuement étudiées de M. Van Tieghem, agrégé préparateur à l'École Normale, démontreront que ces chapelets de grains sont bien décidément le ferment de la fermentation ammoniacale de l'urée [VAN Treanrm. Sur la fermentation ammoniacale. Comptes rendus de l'Académie des sciences, LVIII, 1864, p. 210-214]. Je n'avais fait que le pressentir, sans en donner des preuves rigoureuses, dans mon Mémoire sur la doctrine des générations dites spontanées. Annales de chimie et de physique, $3^{\bullet}$ sér., LXIV, 1862, p. 52 [et p. 248-249 du tome II des CEuvres De Pasteuk]. 
d'agir distinctes. C'est un point d'une grande importance que j'examinerai avec le soin qu'il mérite. Je dois faire observer cependant que les articles du ferment lactique sont ordinairement un peu plus longs et moins régulièrement étranglés que ceux du mycoderma aceti.

J'ai représenté dans les fig. 13,14, 15 diverses variétés d'infusoires de la fermentation butyrique. C'est avec regret que je me vois contraint de rendre, par des figures aussi imparfaites, ces curieux vibrions. Il faudrait ajouter à leur forme le sentiment de leurs mouvements, des flexions de leurs corps, des efforts qu'ils paraissent faire volontairement au moment de la reproduction pour se séparer les uns des autres lorsqu'ils sont réunis par chaînes d'articles.

Ces vibrions peuvent faire fermenter une foule de substances différentes, parmi lesquelles j'ai reconnu dernièrement la glycérine qui fermente sous leur influence avec une facilité remarquable. Et ici encore j'ai constaté que la vie de ces petits êtres pouvait s'accomplir en dehors du contact du gaz oxygène libre.

J'ai été secondé dans ces études préliminaires sur les vins, avec beaucoup de zèle et d'intelligence, par MM. Gernez, Lechartier, Raulin et Duclaux, agrégés préparateurs à l'École Normale. Qu'ils veuillent bien recevoir ici l'expression publique de mes remercîments et de mon affection. 
Ce procédé nouveau de dosage de l'acide tartrique est applicable à la recherche de la proportion de cet acide contenue dans les vins. Ma méthode repose essentiellement sur l'insolubilité du racémate de chaux dans les liqueurs neutres et sur le fait de la combinaison de l'acide tartrique gauche avec l'acide tartrique droit, combinaison qui donne lieu, sur-le-champ, à de l'acide racémique et à du racémate de chaux, s'il $y$ a des sels de chaux dans la liqueur. On obtient la proportion d'acide tartrique à moins de $1 / 100$ sans qu'il soit nécessaire de recourir à aucune pesée.

Si l'on applique ce procédé de dosage, que je décrirai prochainement avec tous les détails qu'il comporte (2), comparativement avec celui qui a été publié au mois d'août dernier par MM. Berthelot et de Fleurieu $\left.{ }^{3}\right)$, les résultats obtenus sont très différents dans les deux cas. L'erreur commise par l'emploi du procédé de MM. Berthelot et de Fleurieu s'élève ordinairement à 50 pour $100 \mathrm{du}$ poids de l'acide tartrique contenu dans le vin.

Les essais ont été pratiqués sur des vins rouges de Bourgogne, de Bordeaux et du Jura.

MM. Berthelot et de Fleurieu ont publié plus récemment un autre travail dans lequel ils sont arrivés à cette conclusion que, dans la fermentation du moût de raisin, une partie, quelquefois considérable, des acides libres disparaît (4).

Ne faut-il pas mettre en doute l'exactitude de ce résultat? Je n'ai pu m'en assurer définitivement depuis la publication du travail de ces savants, en opérant sur du moût de raisin en fermentation dans de

1. Bulletin de la Société chimique de Paris, nouv. sér., I, séance dn 2 i mai 1864, p. 449.

2. Voir p. 315-32/4 du présent volume.

3. Berthelot et Fleurieu (A. de). Sur le dosage de la crème de tartre, de l'acide tartrique et de la potasse contenus dans les vins. Comptes rendus de l'Academie des sciences, séance du 17 aout 1863, LVII, p. 394-398.

4. Berthelot et Fleurieu (A. de). Sur les proportions comparées d'acide tartrique dans le raisin et dans le vin. Ibid., séance du 18 avril 1864, LVIII, p. 720-723. (Notes de l'Édition.) 
grandes cuves, ainsi que je me propose de le faire à l'époque des vendanges prochaines; mais j'ai soumis à l'épreuve de petites quantités de moût de raisin conservé depuis la dernière récolte, et j'ai toujours reconnu qu'il y avait accroissement et non diminution de l'acidité.

\section{NOTE (1) SUR LES OBSERVATIONS PUBLIÉES PAR M. BERTHELOT}

Conformément à l'avis qui m'est suggéré par M. Berthelot dans ces Observations (2), j'attendrai que le Mémoire de 'MM. Berthelot et de Fleurieu (3) ait été publié en entier. On verra mieux alors de quel côté est la méprise. Mes expériences ne me permettent pas de modifier l'appréciation que j'ai donnée précédemment du procédé de dosage de la crème de tartre contenue dans les vins que ces savants ont fait connaître au mois d'août dernier.

1. Bulletin de la Société chimique de Paris, nouv. sér., II, 1864, p. 3.

2. Berthelot. Observations [sur la Gommunication précédente]. Ibid., nouv. sér., I, 1864, p. 449 .

3. Berthelot et Fleurieu (A. de). Sur le dosage de la crème de tartre, de l'acide tartrique et de la potasse contenus dans les vins. Comptes rendus de l'Académie des sciences, LVIII, 1863 , p. 394-398. C'est tout ce qui a paru de ce Mémoire, la $2^{\circ}$ partie n'en ayant pas été imprimée, d'après le Bulletin de la Société chimique, nouv. sér., I, 1864, p. 450. (Notes de l'Édition.) 
PROCÉDÉ PRATIQUE DE CONSERVATION ET D'AMÉLIORATION DES VINS (1)

J'ai entendu la Communication que M. Boussingault vient de faire au nom de M. de Vergnette-Lamotte avec d'autant plus d'intérêt que je m'occupe de la recherche de procédés pratiques de conservation des vins (2).

Dans une première série d'études que j'ai présentées à l'Académie il y a environ dix-huit mois $\left({ }^{3}\right)$, je suis arrivé à ce résultat que les maladies des vins, toutes celles du moins qui me sont connues présentenent, sont déterminées par le développement de végétaux microscopiques de la nature des ferments. Les recherches auxquelles je me suis livré depuis cette époque, non seulement m'ont confirmé dans cette opinion, mais elles me permettent d'annoncer aujourd'hui qu'il n'existe pour ainsi dire pas un seul vin qui ne soit malade à un certain degré, et qui, à un moment ou à un autre, n'ait subi l'action des ferments organisés dont je parle, notamment de celui que j'ai figuré dans ma deuxième Communication sous le $\mathrm{n}^{0} 8$ (4). Si la dégustation des vins n'a pas encore signalé ce fait, c'est que, pour le propriétaire comme pour le consommateur, le vin n'est réputé malade qu'alors que les produits nouveaux développés par les ferments parasites s'y trouvent en proportion relativement considérable; mais ils existaien $t$ depuis longtemps dans le vin, ainsi que les ferments qui les occasionnent. Aussi peut-on dire que lorsque du vin est mis en bouteille,

1. Comptes rendus de l'Académie des sciences, séance du $1^{\text {er }}$ mai $1865, \mathrm{LX}, \mathrm{p} .899-901$. La troisième partie du volume a Études sur le vin " intitulée a Conservation des vins " (p. 203-310) est un développement de cette Communication et de celles qui se trouvent p. 418-422 et p. 253-256 du présent volume. (Note de l'Édition.)

2. La présente Communication a été faite á l'Académie dans sa séance du 1er mai 1865, á la suite de la présentation par M. Boussingault d'une Note de M. de Vergnette-Lamotte [Des effets de la chaleur pour la conservation et l'amélioration des vins] dans laquelle ce savant cenologue proposait comme moyen de conservation des vins le séjour des vins dans un grenier pendant les mois de juillet et aout. Ibid., p. 895-899. (Note de Pasteur.)

8. Voir p. 389-395 du présent volume : Etudes sur les vins. Premiẻre partie : De l'influence de l'oxygène de l'air dans la vinification; et p. 396-406 : Études sur les vins. Deuxième partie : Des altérations spontanées ou maladies des vins, particuliérement dans le Jura.

4. Voir p. 402 du présent volume. (Notes de l'Édition.) 
le germe de sa maladie est enfermé avec lui. Pour conserver le vin, il fallait donc trouver le moyen de tuer ce germe. J'ai eu recours en prenier lieu à l'addition de substances chimiques dont j'ai obtenu quelques résultats intéressants, mais qui ne m'ont pas complétement satisfait pour divers motifs. Enfin j’ai essayé l'action de la chaleur, et je crois être arrivé à un procédé très pratique, qui consiste simplement à porter le vin à une température comprise entre 60 et $100^{\circ}$, en vases clos, pendant une heure ou deux.

L'Académie comprendra qu'il faille attendre plusieurs années pour juger un tel procédé dans son application industrielle, parce que le vin met souvent ún temps considérable à devenir malade. Aussi mon intention n'était pas de faire de longtemps une publication académique à ce sujet. Je nue suis borné, afin de prendre date, à une publicité dont j'ai déjà usé, et qui laisse au savant toute sa liberté d'esprit et d'action dans les recherches de cette nature, je veux parler de la demande d'un brevet d'invention (1).

1. Voici le texte de fee brevet (In : Description des machines et procédés pour lesquels des brevets d'invention ont été pris sous le régime de la loi du 5 juillet 1844. Année 1865, XGIII, (XIV. Arts chimiques. -7. Vin, etc., p. 2) :

a Brevet n 67006, en date du 11 avril 1865.

A M. Pasteur, pour un procédé relatif à la conservation des vins.

J'ai reconnu que les maladies ou altérations spontanées des vins sont produites par des ètres microscopiques dont les germes existent dans le vin avant qu'il devienne malade.

Le vin ne s'altère pas si ces germes sont tués.

Un moyen simple et pratique de faire périr ces germes consiste à porter le vin á une température comprise entre 60 et $100^{\circ}$.

L'application de ce procédé empêche toutes les fermentations irrégulières des vins, quelle que soit leur nature, sans altérer la qualité du vin.

$1^{\text {er }}$ Certificat, en date du 27 mai 1865.

Le procédé spécifié dans le brevet conduit à un moyen nouveau, sûr et rapide, d’élevage des vins.

Le vin est porté à la température de 60 à $70^{\circ}$, puis abandonné jusqu'au moment oủ il est fait; ensuite il est mis en bouteilles, s'il y a lieu. L'opération du chauffage est pratiquée soit en fûts (par l'air, l'eau ou la vapeur), soit en bouteilles, ou dans tels autres vases que l'on préférera.

L'application de ce procédé évite les fleurs, la pousse, la graisse, l'amer, l'acidité et toutes les fermentations accessoires, supprime l'ouillage et les sontirages, et permet de remplacer les caves par des celliers.

Pour vieillir le vin plus promptement encore et lui donner les qualités de ceux qui ont voyagé, il faudra laisser de l'air dans les vases, et opérer de préférence à la lumière.

Le commerce de détail exigerait un vin très robuste, pouvant être transvasé sans crainte et mis en vidange au besoin pendant un temps plus ou moins long. Ce sont, au contraire, les petits vins qui s'altèrent le plus facilement dans ces circonstances.

Le procédé que j'indique remédie à ces graves inconvénients. Le vin ne se détériore plus par la vidange; il présente d'ailleurs ces avantages, quelle que soit l'époque de l'élevage à laquelle le vin est porté à une température de 60 à $70^{\circ}$. Il faut préférer celle qui suit la fermentation normale. Enfin, ce procédé permet de supprimer le vinage et le plâtrage des vins.

2. Certificat, en date du 26 octobre 1865 .

La précédente addition contient l'indication d'un procédé de vieillissement très rapide du 
Bien que je ne veuille pas porter dès aujourd'hui un jugement définitif sur la valeur industrielle de mon procédé, je puis cependant faire connaître à l'Académie des circonstances qui lui feront bien augurer, je l'espère, de ce nouveau moyen de conservation des vins. J'ai fait déguster comparativement par nombre de personnes le même vin, chauffé et non chauffé, et, dans tous les cas, la supériorité a été donnée au premier. Le vin qui a été chauffé quelques heures, puis refroidi, à l'abri de l'air, a plus de bouquet, plus de franchise de goût, et même une plus belle couleur, sans avoir rien perdu de sa force. D'autre part, ce vin est devenu assez robuste pour que j'éprouve des difficultés à le faire altérer, alors mène que je le place dans les conditions les plus défavorables. Sa faculté de vieillir sous l'influence de l'oxygène de l'air n'est d'ailleurs pas compromise. J'ai annoncé, dans la Communication que je rappelais tout à l'heure à l'Académie, que c'était l'oxygène de l'air qui faisait le vin. Toutes mes recherches ultérieures ajoutent encore à l'exactitude de cette manière de voir.

L'intérêt qu'offrirait un procédé permettant de faire vieillir le vin, sans l'exposer à devenir malade, est considérable. Depuis que j'ai commencé ces études, j'ai été vraiment surpris de la prodigieuse quantité de vins qui s'altèrent chaque année en perdant la plus grande partie de leur valeur. J'ai quelque confiance dans le moyen que je viens d'indiquer pour porter remède à cet état de choses. Il sera facile également d'arrêter à volonté la fermentation normale de certains vins de façon à leur conserver le degré de douceur que l'on pourra désirer.

vin, et celle-ci a pour objet de déterminer l'application de ce procédé à la fabrication des vins de Cette.

Le vin sera placé dans des vases de verre non remplis renfermant une grande quantité d'air, plus ou moins, suivant la nature propre du vin, mais qui doit aller souvent jusqu'à plus de la moitié de la capacité des vases. Ceux-ci seront ensuite exposés au soleil, soit directement, soit sous hangar vitré.

En quelques semaines, le vin ainsi traité sera devenu vin vieux, aura fait ses dépôts, et aura pris les principales qualités recherchées dans les vins préparés par les procédés actuellement suivis à Cette, et qui consistent essentiellement dans l'exposition du vin au soleil, en tonneaux ordinaires, pendant deux et trois ans, plus ou moins.

La théorie et les avantages du procédé de vieillissement des vins indiqué dans la précédente addition, procédé que je précise ici pour la fabrication de Cette, sont donnés dans les Communications que j'ai adressées à l'Académie des sciences dans ses séances des 29 mai et 14 aoùt 1865 et dans une lettre qui sera insérée au numéro du Moniteur vinicole du 28 octobre 1865. "

M. Balard s'exprime ainsi dans la séance du 26 février 1872 à l'Académie des sciences, à propos de ce brevet : " Ce brevet fut pris par M. Pasteur, quand ses idées sur la conservation des vins furent bien arrètées, afin de se mettre en garde contre les frelons de l'industrie. Il l'a laissé volontairement tomber lans le domaine public, et ceux qui parlent avec un certain déılain de cette manière de s'assurer la propriété d'une découverte industrielle peuvent en faire (és lors usage gratuitement. " (Voir la note 2 , p. 223 du présent volume.) [Note de l'Édition.] 
Pour le chauffage du vin en bouteille, voici le procédé très simple et très pratique dont je me sers.

Après que le vin a été niis en bouteille, je ficelle le bouchon et je porte la bouteille dans une étuve à air chaud, en la plaçant debout. On peut la remplir entièrement, sans y laisser trace d'air. Voici ce qui se passe. Le vin se dilate et tend à soulever le bouchon; mais la ficelle le retient, de façon que la bouteille reste toujours parfaitement close, pas assez cependant pour que la portion de vin chassée par la dilatation ne suinte pas entre le bouchon et les parois du verre. La ficelle ne cède jamais, et je n'ai pas vu une seule bouteille se briser, quelque peu de soin que j'aie pris dans la conduite de la température de l'étuve. On retire la bouteille, on coupe la ficelle, on repousse le bouchon dans le goulot pendant que le vin se refroidit et se contracte; puis le bouchon est mastiqué, et l'opération est achevée.

Dans une pièce d'une dimension relativement petite et chauffée par un poêle ordinaire, on pourrait agir sur des milliers de bouteilles presque sans frais.

Quelques-unes de mes expériences, particulièrement les plus récentes, ont été faites sur des vins de Pomard de premier choix, que M. de Vergnette-Lamotte avait eu l'obligeance de mettre généreusement à ma disposition. Aujourd'hui même, je renvoie à M. de Vergnette une caisse de vin chauffé pendant une demi-heure à $64^{\circ}$, et il est convenu entre nous qu'il en fera la dégustation à de longs intervalles, par comparaison avec le même vin non chauffé, afin que nous soyons bien fixés l'un et l'autre sur la valeur de mon procédé. Mais je me hâte d'ajouter que nos études ont été entièrement indépendantes, et que, dans aucune de mes lettres, déjà nombreuses, je n'ai indiqué le moins du monde à $M$. de Vergnette ma manière d'opérer. C'est dans sa propre expérience qu'il a puisé les idées qui l'ont conduit à expérimenter l'influence de la température sur le vin. L'Académie sait que M. de Vergnette-Lamotte avait déjà, avec beaucoup de succès, employé le froid et la congélation à l'amélioration des vins (1), et je suis heureux de voir que sa Communication d'aujourd'hui assure, à certains égards, les espérances que je fonde sur le procédé de conservation que je viens d'avoir l'honneur de communiquer occasionnellement à l'Académie.

1. Vergnette-Lanotte (A. de). De l'exportation des vins de Bourgogne dans les pays chauds. Mémoires d'agriculture... publiés par la Société nationale et centrale d'agriculture, 1850, p. 513-524. (Note de l'Édition.) 
NOTE

SUR LES DÉPOTS QUI SE FORMENT DANS LES VINS (1)

Une des premières qualités que l'on recherche dans le vin est sa limpidité.

J'ai étudié attentivement les dépôts qui se forment dans les vins; je crois qu'il en existe de trois sortes seulement, que je vais passer en revue.

Une première sorte, bien connue, est due à des cristaux de bitartrate de potasse, de tartrate neutre de chaux ou d'un mélange de ces deux sels. Ces dépôts n'adhèrent pas aux parois des bouteilles, mais ils sont assez lourds pour se rassembler sous un petit volume, par un repos de quelques minutes. Ce n'est que dans des cas exceptionnels, très peu fréquents, que le bitartrate de potasse est en cristaux légers et soyeux, très ténus, dont le dépôt exige un temps un peu plus long. Considérés sous le point de vue physique, ces dépôts de tartre sont peı gênants. Au point de vue chimique, leur influence sur la composition et les qualités du vin n'a pour ainsi dire aucune importance, tant elle est peu sensible.

Une deuxième sorte de dépôts, souvent confondue avec la précédente, mais qui en est tout à fait distincte, est due à ces matières de couleur brune qui couvrent les parois des bouteilles, particulièrement dans la moitié qui regarde le sol, lorsque les bouteilles reposent couchées horizontalement. Ces dépòts sont constitués par de la matière colorante primitivement dissoute, et qui peu à peu est devenue insoluble par un effet d'oxydation, ainsi que je le dirai tout à l'heure. Cette matière colorante se montre au microscope, suivant les cas, sous trois états physiques bien distincts :

$1^{\circ}$ Elle est en feuillets translucides, colorés en jaune brun plus ou moins foncé, quelquefois avec nuance violette.

1. Comptes rendus de l'Académie des sciences, séance du 29 mai 1865, LX, p. 1109-1113. Pasteur traite du même sujet à la fin de la deuxième partie du volume a Êtudes sur le vin , intitulée "De l'oxygène de l'air dans la vinification "(p. 170-202 du présent volume). [Note de l'Édition.] 
$2^{\circ}$ D'autres fois, la matière colorante se dépose en granulations, en petits amas amorphes, pressés les uns contre les autres, et formant une couche adhésive d'un rouge brun ou violet.

$3^{\circ}$ Ces granulations prennent souvent une structure si régulière, que l'on croirait avoir sous les yeux des cellules organisées, tant leur sphéricité ést parfaite. Aussi diverses personnes, qui ont essayé de reconnaître au microscope les ferments des maladies des vins, ont été trompées par cette structure et ont pris ces globules pour des corps vivants.

Ces trois états physiques de la matière colorante devenue insoluble se trouvent fréquemment réunis. Les feuillets translucides sont ordinairement recouverts, au moins par places, de granulations amorphes ou de celles à apparence organisée. Ces deux derniers états de la matière colorante sont souvent aussi associés l'un à l'autre en proportions variables.

Les dépôts dont je parle, quel que soit leur état, sont le plus ordinairement adhérents aux parois des vases, circonstance importante, parce qu'elle permet de tirer le vin clair jusqu'aux dernières gouttes.

Sous le rapport physique, cette deuxième sorte de dépôts est également peu gênante. Quant au changement de composition qui en résulte pour le vin, on peut dire que sa présence correspond généralement à une phase d'amélioration graduelle, bien qu'elle soit accompagnée d'une diminution progressive de la couleur. Cela n'a pas d'inconvénient, si ce dépốt de couleur n'est pas trop prononcé. Quoi qu'il en soit, il y aurait intérêt à ce que cette sorte de dépôt se produisît dans les tonneaux. On y parviendra, je l'espère, par l'emploi du procédé de conservation des vins que j'ai indiqué récemment (1), et qui, d'après les essais que j'ai tentés, est applicable au vin en tonneau aussi facilement qu'au vin en bouteille.

Il importe beaucoup de connaître les causes occasionnelles des deux sortes de dépôts dont je viens de parler. En ce qui concerne les cristaux de tartre, on conçoit que de simples changements dans la température, joints aux modifications qui surviennent avec le temps dans la composition du vin, peuvent les provoquer. Je ne m'y arrête pas. Quant aux dépóts de la deuxième sorte, je crois pouvoir dire que leur principale et peut-être unique cause est due à une fixation du gaz oxygène, qui rend insoluble la matière colorante. Voici les expériences qui motivent cette opinion.

J'ai rempli entièrement ou partiellement des tubes de verre blanc 
de diver'ses espèces de vins. Ces tubes ont été abandonnés ensuite dans des conditions variables de température et de lumière, après avoir été fermés à la lampe. Chaque essai est reproduit un grand nombre de fois pour chaque sorte de vin. Il arrive, en effet, que les tubes partiellement remplis de liquide et où le vin se trouve au contact de volumes d'air variables peuvent donner naissance au mycoderma vini ou au mycoderma aceti si le vin n'a pas été chauffé. Ces tubes, pour le genre particulier d'études que j'avais en vue, étaient écartés. Il ne faut conserver que ceux dans lesquels le vin est soumis à l'action oxydante directe de l'oxygène de l'air.

Cela posé, voici les phénomènes que présentent les tubes conservés. Partout où il y a remplissage partiel des tubes et en dehors de toute production de ferments organisés, le vin donne lieu à des dépôts de matière colorante, qui reproduisent si fidèlement, au microscope et par les agents chimiques, toutes les propriétés et tous les aspects des dépôts de la deuxième sorte, qu'il n'est pas possible d'hésiter sur l'identité de nature de ces divers dépôts et vraisemblablement sur leurs causes respectives. L'analyse de l'air des tubes, faite, à diverses époques, pendant la formation des dépôts, démontre que ceux-ci sont toujours corrélatifs d'une notable absorption de gaz oxygène, d'autant plus marquée que les dépòts sont plus abondants. Si les tubes sont remplis de vin, c'est-à-dire si l'air ne peut intervenir comme agent d'oxydation directe, il ne se forme pas le moindre dépôt, alors même que les tubes sont exposés à la lumière vive du soleil pendant plusieurs mois. Or, la lumière, jointe à l'action de l'oxygène, a une influence considérable sur la rapidité de formation de ces dépôts. Dans l'obscurité, même dans une obscurité incomplète, ils sont lents à se produire.

Je suis donc porté à croire, d'après les résultats de ces expériences, que les dépòts que j'ai appelés de la deuxième sorte, et qui prennent naissance dans les tonneaux ou dans les bouteilles, sont dus à l'action de l'oxygène de l'air introduit dans le vin, soit par les pores du bois ou des bouchons, soit, au moment des soutirages, par dissolution d'air.

Au fur et à mesure que les dépôts se forment dans les tubes des expériences précédentes, la couleur du vin s'affaiblit de plus en plus, jusqu'à disparaître presque intégralement. Quelques jours suffisent si l'expérience se fait à la lumière. Le vin prend un bouquet sui generis, d'une vivacité particulière, et quelque chose de caramélique qui est certainement le goût de cuit des vins qui ont voyagé. Aussi interprète-t-on très mal, selon moi, l'influence des voyages sur le vin. Je 
suis persuadé que les changements que l'on constate doivent être attribués bien plus à l'action de l'oxygène de l'air qu'à l'élévation de la température. Deux circonstances favorisent l'introduction de l'oxygène durant le voyage aux Indes : une évaporation plus rapide à la surface des douves, et surtout les chocs du liquide contre les parois, agissant non comme agitation, mais comme cause de variations brusques et sans cesse répétées de la pression intérieure, d'où résulte une sortie des gaz azote et acide carbonique et une rentrée d'air à travers les pores du bois, bien plus active que dans le cas où le vin est abandonné en repos dans une cave froide. L'expérience est facile à faire: du vin renfermé dans des vases hermétiquement clos ne se modifierait pas sensiblement, ne prendrait pas le goût de cuit et ne déposerait pas; et dans des bouteilles l'effet sera beaucoup moins marqué que dans des tonneaux. J'ajoute que les vins portés à une température de 60 à 70 ou $80^{\circ}$ ne prennent jamais le goût de cuit et ne déposent pas. La limpidité du vin est au contraire accrue par cette opération, excepté pour quelques vins très jeunes.

J'arrive à la troisième sorte de dépòts des vins. Celle-ci est des plus gênantes et fort dangereuse; elle est constituée par ces végétations cryptogamiques sur lesquelles j'ai appelé l'attention de l'Académie ( $\left.{ }^{1}\right)$, et qui sont, à mon avis, la cause exclusive des maladies et de toutes les altérations des vins, que l'on désigne sous les noms de maladies de la pousse, de la graisse, de l'amer et de l'acide. Ces végétations n'adhèrent jamais aux parois de la bouteille ou du tonneau, à moins qu'elles n'aient été recouvertes, après leur formation, par les dépôts de la seconde sorte, et comme emprisonnées mécaniquement par eux, ce qui est fort rare. Ce sont de petits corps si légers, que la moindre agitation des vases les soulève, et il en résulte un trouble du liquide occupant un volume relativement considérable. Sous le rapport physique, leur présence est donc très préjudiciable, puisqu'ils occasionnent de grandes pertes au moment des soutirages ou des transvasements des bouteilles. Et, comme ces ferments d'autre part, tant par les principes qu'ils transforment que par les substances nouvelles qu'ils développent, détruisent les meilleures qualités des vins, ce n'est pas exagérer que d'affirmer que le mal qu'ils occasionnent est incalculable, surtout si l'on songe, comme je le disais récemment à l'Académie, que la plupart des vins sont sous l'influence de ces productions organisées. Je crois pouvoir ajouter que le prix élevé du vin, des grands vins principalement, a pour cause indirecte l'existence de

1. Voir p. 396-406 du présent volume : Études sur les vins. Deuxième partie : Des altérations spontanées ou maladies des vins, particuliẻrement dans le Jura. (Note de l'Édition.) 
ces ferments. Le prix de la main-d'œuvre dans les soins que le vin exige aujourd'hui leur est dû en grande partie. Si j'en crois mème les renseignements que in'a transmis un habile négociant anglais, les espérances sur l'extension du commerce des vins français depuis le traité avec l'Angleterre n'ont pas donné jusqu'à présent les résultats présumés, à cause des maladies auxquelles ils sont sujets au delà du détroit.

Si les principes que j'ai exposés sur la vinification sont exacts, principes qui se résument, d'une part dans l'influence bienfaisante et indispensable de l'oxygène de l'air, et d'autre part dans l'influence malfaisante de diverses végétations cryptogamiques, la perfection dans l'élevage des vins consisterait à abandonner le vin en tonneau jusqu'au moment où il serait regardé comme fait, puis en bouteille, sans que, à aucune période, on soit gêné par les maladies ou par les dépôts, et en éloignant toutes les pratiques de l'ouillage, des soutirages fréquents, du vinage et du plâtrage des vins. J'espère que l'on pourra parvenir facilement et très rapidement à ce résultat, à l'aide du procédé de conservation dont j'ai parlé récemment devant l'Académie (1).

1. Voir la Communication précédente : Procédẻ pratique de conservation et d'amélioration des vins. (Note de l'Édition.) 


\section{NOUVELLES OBSERVATIONS \\ AU SUJET DE LA CONSERVATION DES VINS ${ }_{\left({ }^{1}\right)}$}

J'ai eu l'honneur de communiquer antérieurement à l'Académie diverses Notes sur le vin ayant pour objet principal les changements qu'il éprouve avec l'âge, ses maladies, et les procédés pratiques que l'on peut mettre en usage pour le conserver sans altération (2).

Les résultats de mes études peuvent se résumer en peu de mots :

$1^{\circ}$ Le vin se fait, se mûrit, en d'autres termes, il passe de l'état de vin jeune à l'état de vin vieux, presque exclusivement par l'influence de l'oxygène de l'air.

$2^{\circ}$ Le vin ne s'altère point de lui-même, par un mouvement intérieur dú à des circonstances inconnues. Toutes les fois qu'il devient malade, c'est par l'action de végétations parasites qui s'y développent sous des influences diverses.

$3^{\circ}$ Les dépóts des vins ont exclusivement pour cause soit une oxydation produite par l'oxygène de l'air, soit la présence des parasites dont je parle, soit enfin, et le plus souvent, ces deux causes réunies.

$4^{\circ}$ Les dépòts dus à l'influence de l'oxygène sont des dépôts adhérents dans la plupart des cas. Ceux qui proviennent de la présence des parasites sont toujours flottants, et conséquemment nuisibles, au double point de vue physique et chimique.

$5^{\circ}$ Le problème si important à résoudre de la conservation des vins consiste donc uniquement, selon moi, à empêcher le développement des parasites du vin, en d'autres termes à détruire leurs germes, ou mieux à supprimer leur vitalité propre.

Le vin, disait-on, est un liquide dont les divers principes réagissent continuellement les uns sur les autres par des affinités mutuelles lentes, comme on voit un éther se former peu à peu dans le mélange d'un acide et d'un alcool.

1. Comptes rendus de l'Académie des sciences, séance du 14 aout 1865, LXI, p. 274-278.

2. Voir les Communications qui précédent. (Note de l'Édition.) 
Cette opinion sur la nature du vin et sur les changements progressifs de ses propriétés est tout à fait erronée (1).

Le vin nouveau, enfermé dans des vases clos à l'abri du contact de l'air :

$1^{\circ} \mathrm{Ne}$ dépose pas;

$2^{\circ} \mathrm{Ne}$ change pas de couleur;

$3^{\circ} \mathrm{Ne}$ prend pas de bouquet.

Le même vin, au contraire, soumis à l'influence de l'oxygène de l'air, à l'obscurité comme à la lumière, plus rapidement à la lumière :

10 Dépose considérablement jusqu'à devenir boueux, qu'il s'agisse du vin blanc ou du vin rouge;

$2^{\circ}$ Il perd entièrement le goût de vin nouveau;

$3^{\circ} \mathrm{Sa}$ couleur devient celle d'un vin de dix, vingt ans et plus;

$4^{\circ}$ Il prend au plus haut degré le goût et le bouquet des vins cuits de Madère et d'Espagne ou des vins qui ont voyagé.

Or, tous ces effets exagérés du vieillissement des vins par l'action de l'oxygène de l'air peuvent être réalisés dans l'intervalle de quelques semaines seulement.

Mais l'influence de l'oxygène est constamment jointe, quoique à des degrés divers, à l'action lente de végétations cryptogamiques auxquelles le vin donne asile et qui sont la source de toutes ses altérations.

Il est indispensable de détruire les germes de ces parasites, si l'on veut que le vin vieillisse promptement et sûrement sans jamais se détériorer.

J'ai annoncé à l'Académie (2) que ce résultat si désirable était facilement obtenu en portant le vin pendant quelques instants à une température suffisamment élevée. Toutefois, j’avais dû faire quelques réserves sur la valeur industrielle de ce procédé, parce que je ne jugeais pas suffisante la durée de mes essais.

La Communication que j'ai l'honneur de faire aujourd'hui à l'Académie a pour objet principal de compléter à ce dernier point de vue mes premières expériences dont je viens confirmer l'exactitude.

Il fallait résoudre une première question, celle de l'effet immédiat de l'élévation de la température. On ne pouvait songer à un procédé de conservation du vin qui aurait diminué en quelque chose les qualités propres du vin. Or, les épreuves les plus multipliées sur des vins de

1. Je ne prétends point révoquer en doute l'existence possible de produits éthérés formés à la longue dans le vin sans l'intervention de l'oxygène de l'air. J'affirme seulement que cet effet doit être regardé comme insensible en comparaison de ceux que je signale.

2. Voir p. 409-412 du présent volume : Procédé pratique de conservation et d'amélioration des vins. (Note de l'Édition.) 
France d'origines très diverses me permettent d'établir en toute assurance que le vin qui vient d'être chauffé et qui a refroidi :

$1^{\circ}$ N'a pas changé de couleur; sa couleur est plutôt avivée que diminuée;

$2^{\circ} \mathrm{Ne}$ perd rien de son bouquet;

$3^{\circ} \mathrm{Ne}$-dépose pas du tout.

Enfin, il est tellement semblable au même vin qui n'a pas été chauffé, qu'il faut soumettre les deux vins à une comparaison simultanée pour constater une légère différence dans leurs propriétés. Quoi qu'il en soit, si cette différence était à la défaveur du vin chauffé, il y aurait bien à craindre pour le succès du procédé de conservation dont il s'agit. Mais la dégustation faite par un courtier expert a donné 7 fois sur 9 la préférence au vin chauffé dans des essais que je dirigeais :moi-même, sans que l'expert eût la moindre idée de la nature des vins qu'il avait à juger; et, dans les deux cas où il a donné la préférence au vin non chauffé, son avis a été que les vins comparés étaient si peu différents l'un de l'autre, qu'il y avait, selon son expression, à s'y perdre. En outre, il n'a jamais accusé de goût de cuit, alors même que son attention était appelée spécialement sur l'existence possible de quelque saveur de cette nature (1).

Si le changement que l'élévation momentanée de la température apporte dans le vin est trop peu sensible pour déterminer une amélioration immédiate très appréciable, il en est tout autrement lorsqu'on envisage le vin sous le rapport de sa conservation. Il suffit que la masse du vin ait été portée quelques minutes seulement à la température de 60 à $70^{\circ}$ pour que le vin ait acquis une résistance extraordinaire à toutes "les maladies qui peuvent l'atteindre. Et cela est vrai d'un vin quelconque, blanc ou rouge, robuste ou délicat, très jeune ou plus ou moins vieux. J'ajouterai que mes dernières expériences me permettent d'espérer que le maximum de la température à atteindre pourra être abaissé à $45^{\circ}$, sans que l'on puisse toutefois descendre plus bas (2). Cette circonstance est très digne de fixer l'attention des proprié-

1. Il résulte de ce qui précède que, sous le rapport de l'amélioration du vin, le changement est trop peu sensible pour motiver l'opération du chauffage. Cependant, lorsqu'elle est pratiquée sur du vin nonveau qui renferme en dissolution un volume considérable de gaz acide carbonique, gaz que fait disparaitre en presque totalité l'élévation de la température, il se manifeste un changement de saveur plus appréciable et le vin parait tout de suite sensiblement amélioré.

2. Voir, an sujet de l'abaissement de la température, la Lettre au Moniteur vinicole, p. 343-361 du présent volume. Dans cette lettre du 11 octobre 1865 Pasteur écrit : " J'ai dit que je croyais pouvoir indiquer un minimum de $45^{\circ}$, mais mes expériences se poursuivent. et présentement je n'oserais pas, pour une conservation définitive, descendre au-dessous de $50^{\circ}$ au moins. " (Note de l'Édition.) 
taires, car je ne doute pas que l'on puisse construire des hangars vitrés à double enveloppe de verre dans lesquels on pourrait porter à cette température par la chaleur naturelle du soleil, surtout dans le Midi, des masses considérables de vin, sans dépense de combustible, en profitant de la propriété des rayons de chaleur obscurs de traverser difficilement le verre $\left({ }^{1}\right)$.

J'ai annoncé à l'Académie, dans sa séance du $1^{\text {er }}$ mai dernier $\left.{ }^{(2}\right)$, que j'avais mis en expérience de comparaison des vins de Pomard, chauffés et non chauffés, que je devais à l'obligeance de M. de VergnetteLamotte. D'autres échantillons du même cru, mais beaucoup plus vieux, m'avaient été donnés par M. Marey-Monge. Or, toutes les bouteilles de ces deux sortes de vins, qui n'ont pas été chauffés, sont aujourd'hui en grande voie d'altération. J'ai l'honneur de mettre sous les yeux de l'Académie la photographie du ferment parasite qui altère ces vins présentement. Au contraire, les mêmes vins, qui ont été portés à la température de $65^{\circ}$, sont absolument intacts, sans le moindre dépôt, tandis que la végétation parasite forme au fond des bouteilles altérées un dépôt flottant d'un travers de doigt d'épaisseur. Et tout ce dépòt n'a mis que trois mois seulement à se former. Enfin le vin qui a été chauffé a conservé toutes ses qualités, tandis que le vin non chauffé est amer et désagréable au goût.

La photographie que je place sous les yeux de l'Académie ntuntre très nettement, dans toutes les parties qui étaient bien au point, le mode de reproduction du végétal et son organisation par articles et sous-divisions d'articles ${ }^{(3)}$.

J'avais également annoncé à l'Académie, mais toujours un peu timidement, que le vin chauffé était devenu si peu altérable, qu'il se conservait même en vidange au libre contact de l'air. Je puis confirmer également l'exactitude de ce résultat. Cette expérience n'est après tout qu'un corollaire de celles que j'ai faites pour montrer l'inanité des observations que l'on invoque à l'appui de la doctrine des générations spontanées. Les germes des végétations propres à l'infusion organique acide qui constitue le vin étant détruits par la chaleur, le vin exposé à

1. Il n'y aurait qu'une chose à craindre, c'est que les douves des tonneaux se déjetassent. Ce mode de chauffage serait très convenable pour les bouteilles. Le chauffage des fats par l'eau à l'aide de la vapeur d'eau se fait également très bien.

2. Voir p. 409-412 du présent volume : Procédé pratique de conservation et d'amélioration des vins. (Note de l'Édition.)

3. Ce végétal est-il celui de la figure 7 ou de la figure 8 [des Etudes sur les vins. Deuxième partie : Des altérations spontanées on maladies des vins, particulièrement dans le Jura p. 401, 402 du présent volume]? J'ai présentement quelques doutes sur les différences spécifiques de ces deux productions, malgré leurs grandes différences apparentes. Je reviendrai sur ce sujet. 
un volume limité d'air, comme il arrive lorsqu'on met en vidange une bouteille de vin, ne peut plus s'altérer que par la propagation des germes tenus en suspension dans ce volume d'air, et, si ce volume d'air n'en contient pas de la nature de ceux qui peuvent se développer dans le vin, ce liquide restera absolument intact et soumis seulement à l'action chimique directe de l'oxygène de l'air C'est précisément ce qui arrive, et, neuf fois sur dix au moins, le vin qui a été chauffé, mis ensuite en vidange, n'éprouve pas la moindre acidification, alors même qu'on l'expose pendant des mois entiers dans une étuve à 30 ou $35^{\circ}$.

En résumé, je considère que le problème de la conservation indéfinie des vins, et de leur transport facile dans tous les pays du monde sans vinage préalable, est résolu de la manière la plus complète et la plus satisfaisante. Il appartient maintenant aux propriétaires de savoir 'profiter de ces résultats de la science. 


\section{LE GHAUFFAGE DES VINS (1)}

1. Lettre adressée le 11 octobre 1865 au Rẻdacteur en chef du Moniteur vinicole. Moniteur vinicole, $10^{\circ}$ année, 1865 , p. 333-334, 341-342 et 345-346. - Cette lettre se trouve reproduite p. 343-361 du présent volume. (Note de l'Édition.) 


\section{DE LA PRATIQUE DU CHAUFFAGE POUR LA CONSERVATION ET L'AMÉLIORATION DES VINS (1)}

DE L'AMÉLIORATION DES VINS PAR LE GHAUFFAGE (2)

1. Comptes rendus de l'Académie des sciences, séance du 6 septembre 1869, LXIX, p. 577-581. - Cette Communication se trouve reproduite p. 253-256 du présent volume.

2. Comptes rendus de l'Académie des sciences, séance du 5 août 1872, LXXV, p. 303-308.

- Cette Communication se trouve reproduite p. 375-381 du présent volume. (Notes de l'Édition.) 


\title{
DISCUSSION \\ AU SUJET DE LA PRIORITÉ \\ DE L'INVENTION DE LA MÉTHODE DU CHAUFFAGE \\ POUR CONSERVER LES VINS (1)
}

\author{
NOTE SUR L'EMPLOI DE LA GHALEUR \\ COMME MOYEN DE CONSERVATION DU VIN (2)
}

Dans la brochure intitulée : Sur la conservation des vins (3), dont j'ai eu l'honneur de faire hommage à l'Académie dans sa séance du

1. La discussion fut entamée 'par M. de Vergnette-Lamotte qui écrivit à Pasteur le 18 novembre 1865 cette lettre restée inédite :

"Monsieur, j'ai reçu et lu la notice que vous m'avez fait l'honneur de m'adresser (*). Je regrette que votre historique $d u$ chauffage du vin m'oblige à vous répondre. Mais je me le dois, ainsi qu'à l'Académie qui m'a nommé son correspondant. Si dans cette lutte que je suis forcé d'accepter, vous recevez quelque atteinte sérieuse, vous m'accorderez que six mois de silence prouvent que j'ai reculé aussi longtemps que possible devant cette dure nécessité.

« Veuillez agréer, Monsieur, l'expression de mes sentiments les plus distingués.

« Beaune, 18 novembre 1865.

Pasteur répondit par la lettre suivante restée aussi inédite:

De Vergnette-Lamottr. "

* Paris, ce 19 novembre 1865.

"Monsieur, je ne saurais vous exprimer l'étonnement et le chagrin que me cause votre lettre. Ces mots de lutte, d'atteinte sérieuse, de dure nécessité, de six mois de silence, m'affligent autant que je pourrais le dire, car je croyais sincèrement être la seule personne qui eût rendu justice à vos essais sur le chauffage dans la mesure de la vérité.

* Veuillez agréer, Monsieur, l'expression de ma vive peine et de mes sentiments les plus distingués.

Pasteur garda copie de sa réponse et écrivit å la suite:

L. Pasteur. "

“ Nota. - A cette date du 19 novembre 1865 j'étais encore sous l'impression de la publication de M. de Vergnette en 1850, oủ il a dépouillé Appert, lpar la phrase de son début. Je lui attribuais ce qu'avait fait Appert, à cause de cette phrase. Je n'ai connu ce qu'avait fait Appert que postérieurement, car c'est le 4 décembre 1865 que j'ai rétabli les droits d'Appert. Alors, de M. de Vergnette, il ne restait que des erreurs.

L. P. *

2. Comptes rendus de l'Académie des sciences, séance du 4 décembre 1865, LXI, p. 979.

3. Voir p. 343-361 du présent volume : Lettre adressée à M. le rédacteur en chef du Moniteur vinicole. (Notes de l'Édition.)

* Sur la conservation des vins. Lettre au Monileur vinicole du 11 octobre 1865, (voir p. 343-361.) 
20 novembre, j'ai dit que M. de Vergnette-Lamotte avait fait le premier des essais intéressants, dans lesquels il avait observé de bons effets de l'emploi de la chaleur, comme moyen de conservation, et que c'était seulement l'état trop peu avancé de la science au sujet de la constitution et des propriétés du vin qui l'avait empêché de comprendre ce qu'il y avait de général et de pratique dans l'emploi de la méthode d'Appert. J'ai reconnu depuis, en consultant les dernières éditions du Traité des conserves d'Appert (1), que cet habile industriel avait fait précisément les mêmes essais. Appert raconte $\left(^{2}\right)$ qu'ayant envoyé à SaintDomingue deux bouteilles de vin de Beaune chauffé à $70^{\circ}$ au bainmarie, et les ayant comparées à leur retour : $1^{\circ}$ avec une bouteille du même vin restée au Havre, $2^{\circ}$ avec une autre bouteille du même vin également, qui était restée dans sa cave, et toutes deux non chauffées, le vin de la bouteille conservée chez lui avait un goùt de vert; que celui de la bouteille du Havre était fait et conservait son arome, mais que la supériorité de celui revenu de Saint-Domingue était considérable; que rien n'égalait sa finesse, son bouquet; que la délicatesse de son goût lui prêtait deux feuilles de plus qu'à celui du Havre, et trois années au moins de plus qu'à celui de sa cave. Enfin il proclame qu'il y a là certainement un moyen fort simple de conserver le vin. Ce fait est resté complétement dans l'oubli. On a cru sans doute qu'Appert avait exagéré en inventeur enthousiaste de son système et de la généralité d'application qu'il lui attribuait, ou plutôt on a pensé que ces deux bouteilles de vin avaient pris plus de qualité à cause du voyage et non par l'influence de la chaleur préalable qu'elles avaient subie, d'autant plus qu'Appert ne dit pas du tout que les deux autres bouteilles restées en France se fussent altérées.

En résumé, ce n'est pas $\mathbf{M}$. de Vergnette-Lamotte, comme je l'ai dit, mais bien Appert lui-même qui a le premier remarqué, dans les temps modernes, de bons effets de la chaleur sur le vin comme conservation. Je dis dans jes tempśs modernes, parce que les anciens connaissaient des faits de cette nature. Ainsi les vins de Crète étaient portés à la température de l'ébullition pour empêcher leur altération, lorsqu'ils devaient passer la mer. Je reviendrai sur ces faits dans l'ouvrage que je rédige présentement et qui renfermera l'ensemble de mes études sur les maladies des vins.

1. Appert. Le livre de tous les ménages, ou l'art de conserver, pendant plusieurs années, les substances animales et végétales. $5^{\circ}$ édition, revue par Prieur-Appert et Gannal. In : Le Conservateur (coll. Carème). Paris, 1842, in-8, p. 1-166.

2. Loc. cit., p. 105-108. (Notes de l'Édition.) 
[CHAUFFAGE DES VINS]

LETTRE A M. QUESNEVILLE, DIREGTEUR DU MONITEUR SCIENTIFIQUE (1)

Paris, le 22 août 1866.

Monsieur,

Je vous prie de vouloir bien insérer, dans le plus prochain numéro de votre journal, les observations suivantes en réponse à un article que vous venez d'y publier sous la date du 15 août 1866.

Pourquoi donc, monsieur, vous échauffer ainsi et vous donner tant de mal à établir des choses que personne encore n'a contestées? Vous voulez que M. de Vergnette-Lamotte ait la priorité du procédé qu'il a fait connaître le $1^{\text {er }}$ mai 1865 à l'Académie (2), ainsi que cet auteur le réclame de votre journal par lettre en date du 10 juillet dernier; mais, si peu que cela vous soit agréable, et tant cela me touche peu, je serai de votre avis, à la condition toutefois qu'il s'agisse bien du procédé du $1^{\text {or }}$ mai 1865.

-Quel est donc ce procédé? S'inspirant de mes beaux travaux sur les mycodermes du vin, comme il veut bien les appeler obligeamment, M. de Vergnette a imaginé de remplacer la température élevée que les vins subissent pendant les voyages au long cours, par un séjour des vins, durant deux mois, dans une étuve ou dans un grenier, en juillet et aoùt. Ce procédé, monsieur, ne me regarde point, pas au delà du moins de ce que j'ai dit le $1^{\text {er }}$ mai $1865\left(^{(3)}\right.$ devant l'Académie et dans les termes que vous avez rappelés. Je porte le vin, ne fût-ce qu'ụn instant, à une température élevée, sans aucune prétention de vieillissement ni de changement de couleur. Le vin est devenu inaltérable. Voilà mon procédé. Quel rapport cela a-t-il avec un séjour de deux mois dans un grenier, avec changement de couleur, etc.? Allez

1. Moniteur scientifique, no du 1or septembre 1866, VIII, p. 753-757.

Cette lettre a paru aussi en brochure, sous le titre : "Conservation des vins. Lettre de M. Pasteur, membre de l'Institut, à M. Quesneville, directeur du Moniteur scientifique ", Paris, 1866, Gauthier-Villars, 10 p. in- $8^{\circ}$.

2. Vergnette-Lamotte (A. de). Des effets de la chaleur pour la conservation et l'amélioration des vins. Comptes rendus de l'Academie des sciences, 1 or mai 1865, LX, p. 895-899.

3. Voir p. 409-412 du présent volume : Procédé pratique de conservation et d'amélioration des vins. (Notes de l'Édition.) 
donc dire aux négociants de Bercy ou de l'Hérault de porter leurs vins dans des bouteilles empilées sous les toits pendant deux mois. Ils se moqueront de vous, tandis que vous avez pu lire dans les Comptes rendus de l'Académie que des viticulteurs du mérite de M. H. Marès, de Montpellier, songent à améliorer considérablement le commerce des vins en suivant mes indications ${ }^{(1)}$.

Je viens de dire que je passais condamnation sur le vif désir que vous aviez de voir M. de Vergnette en possession de la priorité de son procédé du $1^{\text {er }}$ mai 1865 . Pourtant, comme les questions de priorité vous touchent, avec raison, je vous apprendrai que, dans un voyage que j'ai fait dans le Midi, au mois de juin 1865, la première chose que j'aie vue, près d'Avignon, chez le propriétaire de l'hôtel où j'étais descendu, fut une rangée de bouteilles sur un toit. Elles étaient mises là pour améliorer, vieillir et conserver(2) le vin qu'elles renfermaient; on les y laisse quelques mois et on les descend à la cave. Notez que ceci se pratique de très longue date chez plusieurs propriétaires du Midi. Je vous enverrai des adresses, si vous le désirez.

Que pensez-vous maintenant, monsieur, de la priorité du procédé s de M. de Vergnette? Vous n'oseriez pas répondre que M. de Vergnette a perfectionné le procédé dont je parle en mettant les bouteilles sous la toiture et non par-dessus. Si tel était votre avis cependant, je vous dirais que ce perfectionnement a eu une conséquence curieuse que je désire que vous appreniez de la bouche de M. de Vergnette lui-même. Ayez la bonté de lire dans sa Note du $1^{\text {er }}$ mai $1865\left(^{3}\right)$ la phrase suivante :

“ La chaleur n'a donc pas sur le vin, lorsqu'il est en bouteilles, l'action maladive qu'on lui attribuait. "Cet on est charmant. Vous verrez dans le Mémoire de M. de Vergnette de 1850 quelle est la personne qui, entre autres que je ne connais pas pour ma part, attribuait à la chaleur une action maladive sur le vin. Cette personne est précisément M. de Vergnette. Mais poursuivons la citation de la phrase susdite: "Cependant la quantité d'air atmosphérique qui est en contact avec le vin doit être aussi faible que possible, autrement la fermentation acétique ne tarderait pas à se produire. " Voilà, monsieur, une révélation à laquelle vous ne vous attendiez peut-être pas. Ainsi, pour peu qu'il y ait de l'air dans les bouteilles, le vin s'aigrit dans le procédé de

1. Mark̀s (H.). De l'influence de la chaleur sur les vins rouges liquoreux. Lettre adressée par M. H. Marès à M. Pasteur. Comptes rendus de l'Académie des sciences, LXII, 1866, p. 1168-1171.

2. Pasteur a ajouté " et conserver " dans la brochure publiée chez Gauthier-Villars.

3. Vergnette-Lamotte (A. de). Loc. cit., p. 897. (Notes de l'Édition.) 
M. de Vergnette. Je le crois bien! C'est que les mycodermes doivent être fort à l'aise, sous les toits, pendant l'été, en Bourgogne surtout, non seulement le mycoderma aceti, mais aussi les autres mycodermes des figures 7 et 8 du Mémoire de M. Pasteur(1), dont parle M. de Vergnette, et que je lui ai appris à reconnaître au microscope dans mon laboratoire, au mois de février 1865, alors qu'il les confondait encore avec des granulations amorphes de matière colorante, ce dont je vous donnerai des preuves catégoriques, si cela peut vous intéresser.

Voilà ce qu'il en coûte, monsieur, de mettre les bouteilles sous les toits au lieu de les mettre dessus, comme dans le Midi. Le vin devient malade bien plus vite et plus facilement qu'à la cave.

Venons-en maintenant, monsieur, au Mémoire de M. de Vergnette de $\left.1850{ }^{(2}\right)$ auquel j'ai, le premier entre tous, rendu justice dans ma lettre au Moniteur vinicole $\left({ }^{3}\right)$ et dans la mesure de la vérité, avec le seul défaut peut-être d'y apporter trop de courtoisie. Mais, monsieur, pourquoi ne donnez-vous pas connaissance à vos lecteurs de l'avant-dernier alinéa de ce Mémoire? Il était pourtant si court et si instructif! En résumé, il n'est qu'une manière rationnelle, c'est M. de Vergnette qui parle, d'améliorer les vins qui doivent faire de longs voyages, c'est de les concentrer par la gelée. Est-ce clair? Appelez-vous cela un procédé de chauffage? Et la dernière phrase de ce Mémoire, pourquoi la taire? Elle est si explicite et dit si bien que M. de Vergnette n'a rien compris en 1850 à l'action de la chaleur sur les vins, comme je l'explique dans ma lettre au Moniteur vinicole.

Relisez donc, monsieur, cette lettre, et, si vous cherchez la vérité sans parti pris, c'est là que vous la trouverez, excepté sur un point, celui où il est dit que M. de Vergnette est la première personne qui ait autrefois appliqué la chaleur au vin et qui en ait remarqué certains effets comme conservation. Ceci était une erreur, monsieur. Au nom de M. de Vergnette il faut substituer celui d'Appert, sans autre changement; et dès que mes lectures pour le travail de la partie historique de l'ouvrage sur les vins que je viens de présenter à l'Académie m'eurent appris que c'était Appert qui avait fait de tels essais et non M. de Vergnette, je me suis empressé, parce qu'il est dans mes principes d'agir toujour's avec une grande loyauté, pour me servir du langage de votre correspondant, je me suis empressé,

1. Voir p. 396-406 du présent volume : Études sur les vins. Deuxième partie : Des altérations spontanées ou maladies des vins, particulièrement dans le Jura.

2. Vergatte-Lamotre (A. de). De l'exportation des vins de Bourgogne dans les pays chauds. Mémoires d'agriculture... publiés par la Société nationale et centrale d'agriculture, année 1850 , p. 513-524.

3. Voir p. 343-361 du présent volume. (Notes de l'Édition.) 
avant tout autre, de corriger cette erreur de noms, par ma Note du 4 décembre 1865 à l'Académie (1).

Et qui donc est le véritable auteur de cette erreur de noms? qui donc le premier a écrit de Vergnette au lieu d'Appert? C'est M. de Vergnette qui, dans son Mémoire de 1850, proclame sans aucune ambiguïté que c'est lui qui a appliqué, le premier, la chaleur aux vins. Voici sa phrase, la seule de tous ses écrits où le nom d'Appert soit cité :

" J'ai observé, il y a quelques mois, un fait assez important qui contribuera singulièrement à éclairer la question. Souvent obligé, au moment de la récolte, de conserver par la mẻthode d'Appert des moûts destinés à des expériences qui ne pouvaient être faites que plus tard, jai aussi appliqué ce procédé à des vins de différentes qualités (²). ”

Et M. de Vergnette, le 12 mars $1866(3)$, quatre mois après que j'eus revendiqué les droits d'Appert devant l'Académie, ose écrire à ce corps savant : “ J'ai toujours cité le nom d'Appert à propos du chauffage des vins. "Et vous, monsieur, vous vous laissez prendre à ce piège! Mais je vous croyais plus avisé.

Un mot encore et j'ai fini.

Vous parlez beaucoup de mes erreurs, monsieur, opposées aux fines distinctions de M. de Vergnette. Sachez bien, monsieur, que quand vous trouvez sous la plume de M. de Vergnette ces mots : "Erreurs de M. Pasteur ", vous trouvez sous la mienne et sur les mêmes objets ceux-ci : " Erreurs de M. de Vergnette », et qu'entre lui et moi je ne vous prendrai point pour juge.

$\mathrm{Au}$ reste, monsieur, je ne puis être surpris de rencontrer des erreurs, des omissions calculées, des personnalités injustes dans votre recueil, ni que mes adversaires s'adressent à vous pour réclamer vos bons offices contre moi. Je me console en pensant que vous avez le soin, à l'ordinaire, de me placer en bonne compagnie.

Laissez-moi, à ce sujet, vous confier quelque chose de ma philosophie : Un jour, étant candidat à l'une des places vacantes de l'Académie des sciences, dans les visites d'usage en telle occurrence, j'eus un entretien avec l'un de ses plus anciens et de ses plus dignes membres. " Mon ami, me dit-il, non sans quelque amertume, quand on ne dira plus de mal de vous dans certains journaux, dites-vous que vous faiblissez $\left({ }^{(4)}\right.$. "

1. Voir p. 425-426 du présent volume : Note sur l'emploi de la chaleur comme moyen de conservation du vin.

2. Vergnette-Lamotte (A. de). Loc. cit.

3. Vergnette-Lamotte (A. de). Conservation des vins par l'emploi de la chaleur. Comptes rendus de l'Académie des sciences, LXII, 1866, p. 596-602.

4. C'est Biot qui a dit ces paroles à Pasteur. (Notes de l'Édition.) 
Continuez donc, monsieur, selon vos habitudes, à dénigrer mes travaux et ma personne. Je puise dans vos attaques des encouragements à persévérer. Et pour finir selon votre manière :

\title{
$A$ bon entendeur salut.
}

Veuillez agréer, monsieur, l'assurance de mes sentiments les plus distingués.

\author{
L. Pasteur, \\ Membre de l'Académie des sciences.
}

P. S. - J'ai déclaré devant l'Académie, dans sa séance du $L^{\text {er }}$ nai 1865 , que je n'avais rien dit à M. de Vergnette qui lui indiquât la nature de mon procédé de conservation des vins, mais je tiens à faire savoir au public que depuis plus d'une année j'étais avec lui en correspondance très active au sujet de mes efforts constants et de tous les jours pour découvrir le moyen de prévenir les maladies des vins, notamment la maladie de l'amer, que M. de Vergnette m'avait signalée comme la plus redoutable pour la Bourgogne, m'écrivant que si j'atteignais ce but, " jaaurais donné des millions à la France (1) 》.

Voici textuellement deux de mes dernières lettres à M. de Vergnette :

( M. Pasteur à M. de Vergnette. Paris, le 4 avril 1865.

“ J'ai achevé la première étude que je voulais faire des vins que vous avez bien voulu m'envoyer. Voici le résultat auquel je suis arrivé : tous vos vins vieux sont malades.

“ L'ordre de l'altération est le suivant :

“Le $\mathrm{n}^{\circ} 12$ (vin de pinot, Beaune 1858) est le plus malade.

“ Le $\mathrm{n}^{\circ} 18$ (vin de pinot, Pomard 1858) l'est un peu moins.

“ Le $n^{\circ} 21$ (vin de pinot, Pomard 1863) l'est à peu près autant et mềme un peu plus que le $n^{\circ} 18$.

"Le $\mathrm{n}^{\circ} 19$ (vin de pinot, Pomard 1862) est le moins malade, mais il l'est sensiblement.

"Il ne vous sera pas possible de conserver ces vins, et j'ai tout lieu de croire que vos vins nouveaux, à peu près sains actuellement, s'altéreront eux-mêmes ultérieurement. Je vous serai très obligé de m'envoyer des dépóts de ces vins nouveaux à votre premier, à votre deuxième... soutirages.

"Mais voici une nouvelle importante et qui vous fera grand plaisir. » (En effet, depuis une année, personne ne me poussait avec plus

1. Voir p. $363-370$ du présent volume : Sur la maladie de l'amertume des grands vins de Bourgogne. (Note de l'Édition.) 
d'ardeur que M. de Vergnette à la recherche d'un moyen propre à empêcher l'amertume des grands vins de Bourgogne.)

" J'ai la ferme conviction que je suis en possession d'un moyen très pratique et sûr (ces mots sont soulignés dans la minute de ma lettre que j'ai sous les yeux), capable de prévenir toutes les maladies de vos grands vins. Vous pourrez les conserver aussi longtemps que vous le désirerez. Je voudrais avoir sur ce point l'appui de votre observation la plus scrupuleuse et la plus directe. Voici dès lors le service que je réclame de votre obligeance et de votre dévouement à la solution qui me préoccupe.

"Vous auriez la bonté de m'envoyer diverses sortes de vins choisis parmi les plus altérables de la Bourgogne, dix bouteilles environ de chaque sorte, quel que soit leur âge. Je traiterais moitié ou trois quarts du nombre de ces bouteilles par mon procédé, et je vous les renverrais, soigneusement étiquetées et paraphées, avec cette indication : $\mathrm{Ce}$ vin ne s'altérera plus.

"Vous les déposeriez tout auprès d'un nombre égal de ces mêmes bouteilles mises en réserve, et, dans six mois, dans un an, dans deux ans..., vous dégusteriez comparativement ces vins. De mon côté, je garderais quelques-unes de ces bouteilles, dans les mêmes conditions et dans le même but.

"Envoyez-moi autant de sortes de vins que vous le désirerez. Il vous sera facile d'intéresser quelques propriétaires à cette expérience, que je tiens à rendre aussi complète et aussi décisive qu'il est possible.

“ J'espère obtenir la remise des droits d'octroi. Ayez la bonté de me prévenir à l'avance du jour de l'envoi et de la date présumée de l'arrivée de la caisse ou des caisses.

" Si vous avez encore des vins à étudier sous le rapport de leur situation hygiénique actuelle, je me ferai un plaisir de les examiner, comme je viens de faire pour vos $n^{\text {os }} 12$ à 21 . J'espère qu'un jour viendra où chaque grand propriétaire fera faire ce genre d'étude, et que son commerce s'en trouvera fort bien. Mais j'ose espérer que l'application de mon procédé mettra fin à toutes les maladies. Si vous pensiez que ma présence à Beaune pût être utile à la réalisation de l'expérience dont je viens de vous entretenir, je m'y transporterais volontiers. Veuillez, etc. »

A la date du 8 avril 1865, M. de Vergnette me répond :

" Je suis tout disposé à donner mon concours à vos expériences, en vous adressant des vins de mes récoltes. Voici seulement un point sur lequel je désirerais être fixé. 
"Pouvez-vous opérer sur des vins de la qualité des $n^{0 s} 12,18,21,19$ ?

“Nos vins vieux ont tous votre ferment $\left.n^{\circ} 8{ }^{(}\right)$, à ce qu'il parait. (C'est moi qui souligne cette phrase.) Mais j'espère que vous vous trompez au sujet de nos vins nouveaux. "

Le 11 avril, je répondis à M. de Vergnette :

“Je m'empresse de vous remercier et de vous informer que je puis opérer sur des vins de la qualité des $\mathrm{n}^{0 s} 12,18,21,19$. Mon procédé n'a pas pour effet de guérir des vins malades, mais il arrête le mal lorsqu'il existe, et le prévient absolument lorsqu'il n'existe pas. Ce n'est pas un remède aux vins altérés, mais un préservatif, et, appliqué aux vins déjà altérés plus ou moins, il empêche la continuation de la maladie. Si vous m'envoyez les vins $n^{\circ s} 12,18,19,21$, je vous les renverrai dans un état tel qu'ils resteront ce qu'ils sont, plutòt meilleurs que moins bons, et qu'ils ne deviendront jamais amers. Veuillez, etc... »

Je tiens, monsieur, les minutes de ces lettres à votre disposition.

Il m'est impossible de ne pas faire remarquer qu'à la date du 8 avril 1865, M. de Vergnette constate que c'est de moi qu'il tient la connaissance que tous ses vins vieux sont malades par la présence du ferment $n^{\circ} 8$ de mon Mémoire. De là cette phrase de sa Note à l'Académie le $1^{\text {or }}$ mai 1865 [p. 896 des Comptes rendus] :

« En Bourgogne, quelques vins de 1858, et des meilleurs, ont aussi été atteints par cette maladie. En examinant le dépôt de ces vins au microscope avec un grossissement de 500 à 600 diamètres, on y trouve en abondance le mycoderme $n^{\circ} \delta$ des figures publiées dans le Mémoire de M. Pasteur. »

Il y avait trois semaines seulement que M. de Vergnette connaissait le fait, et il l'avait pris dans ma lettre du 4 avril ci-dessus. Je laisse au lecteur le soin de tirer d'autres inductions relatives à la Note de M. de Vergnette du $1^{\text {er }}$ mai 1865 , et dans laquelle il s'agit d'un procédé qui exige deux mois pour savoir ce qui se passe.

Chacun aura pu remarquer le silence que j'ai gardé à la suite de la Note si partiale et si erronée que M. de Vergnette a adressée le 12 mars 1866 à l'Académie des sciences $\left({ }^{2}\right)$. C'est que je déteste la polémique. Mais les attaques passionnées que M. de Vergnette a provoquées, il y a six mois, dans le Journal d'agriculture de M. Joigneaux et dans le Moniteur scientifique de M. Quesneville, m'obligent à sortir de ma réserve $(3)$.

L. Pasteur.

1. Voir fig. 8, p. 402.

2. Vergnette-Lamotte (A. de). Loc. cit. (Notes de l'Édition.)

3. Ce post-scriptum nous a été remis le 25 aoùt par M. Pasteur. (Note c'u Moniteu) scientifique.) 
LETTRE A M. QUESNEVILLE, DIRECTEUR DU MONITEUR SCIENTIFIQUE (1)

Monsieur,

Vous terminez l'avant-propos dont vous avez accompagné ma lettre du 22 août, en disant que ce qui vous gêne le plus, lorsque vous rencontrez mon nom, c'est l'approbation dont l'Académie encourage mes efforts. Si le bonheur, hélas! était entre nos mains, je serais le plus heureux des hommes, car il y a vingt années, monsieur, que j’ai le noble travers de ne vivre que pour mériter l'approbation de l'Académie et de m'attirer l'estime de savants tels que MM. Chevreul et Dumas, dont je ne vois pourtant jamais apparaître les noms sous votre plume qu'avec l'ironie pour compagne. Mais vous ajoutez que le jour où mes dignes maîtres changeront d'opinion et mettront une " sourdine " aux témoignages de leur bienveillance - excessive, je suis le premier à l'avouer et à en être couvert de confusion - vous changerez, vous, monsieur, vos critiques en éloges. Allons, je le vois bien, mon vieil académicien avait raison ( $\left.{ }^{2}\right)$ et j'ai sagement fait de lui prendre un peu de sa philosophie. Je vous suis mille fois obligé, monsieur, de votre proposition, mais, je vous en supplie, continuez vos critiques.

Ah! si j'avais plus d'âge et plus d'autorité et si j'osais, monsieur, vous donner un conseil amical! Votre journal serait, à mon avis, l'un des mieux informés et des plus utiles si vous aviez le bon goût d'y supprimer les personnalités et le persiflage qui l'embarrassent. Vous savez à merveille choisir vos articles et vos rédacteurs. Vous avez eu la bonne pensée de vous adresser à des hommes tels que MM. Gratiolet, Kopp, Radau, Naquet, etc. Vous avez traduit le savant et consciencieux rapport de M. Hofmann, publié les leçons de MM. Wurtz et Berthelot, etc... Mais ne compromettez-vous pas la dignité de la science par vos plaisanteries inutiles et blessantes? Le persiflage! mais c'est l'arme de l'ignorance. Que n'imitez-vous votre premier maître en comptes-rendus scientifiques, Fontenelle, avec sa douce indulgence pour les fautes et sa discrétion aimable dans l'éloge!

Et la gloire de votre pays, est-ce qu'elle ne vous touche pas? Estce que des hommes qui, comme MM. Chevreul et Dumas, sacrifient leur vie au bien public n'ont pas droit à votre bienveillance?

1. Moniteur scientifique, $\mathrm{n}^{\circ}$ du 15 septembre 1866 , VIII, p. 803.

2. Il s'agit des paroles de Biot citées par Pasteur p. 430. (Note de l'Édition.) 
Que doit-on dire et penser à l'étranger de toutes ces appréciations si frivoles de la plupart des organes de la presse française, soi-disant scientifique? A un jugement simple et vrai des découvertes qui naitrait d'une saine lecture, qui, en instruisant le public, éclairerait peut-être les auteurs eux-mêmes par la diversité des points de vue, ils substituent, presque sans discernement et le plus souvent avec la seule mesure des intérêts ou des passions individuels, ici l'éloge, là le blâme.

Pauvre France, me suis-je dit souvent, si la politique des premiersParis est traitée avec cette légèreté, qu'il doit être difficile de tenir les rênes de l'État!

Et pourtant combien est digne et utile la mission du journalisme scientifique quand elle est exercée avec modération dans les opinions sur les personnes et précision dans les informations sur les choses.

Mais veuillez me pardonner, monsieur, ces conseils d'occasion et ces vœux probablement superflus, en agréant l'assurance de mes, sentiments les plus distingués.

\section{Pasteur,}

Membre de l'Académie des sciences.

[Dans une lettre insérée au Moniteur scientifique, VIII, 1866, p. 801-803, M. de Vergnette-Lamotte critiqua vivement la « Lettre à M. Quesneville, directeur du Moniteur scientifique ». Pasteur lui fit la réponse suivante :]

\section{LETTRE AU MONITEUR SCIENTIFIQUE (1)}

Je ne suis pas d'humeur à laisser la vérité compromise, même par des divagations et des sophismes. Je répondrai donc à M. de Vergnette :

Il ne s'agit pas du tout de savoir si vous avez chauffé du vin avant moi en 1850. C'est un fait acquis et qui l'a toujours été puisque c'est moi qui, le premier, l'ai fait connaître aux lecteurs du Moniteur vinicole par ma lettre du 11 octobre 1865 (2); vous avez fait chauffer du vin avant moi, Appert en a chauffé avant vous, on en a chauffé avant Appert à Cette et à Mèze, et on en chauffait chez les Grecs et 'chez les Romains. Vous connaissez le proverbe menteur : Il n'y a rien de nouveau sous le soleil. Mais la vraie question, à laquelle vous ne 
voulez pas répondre, est celle-ci : Avez-vous compris l'effet de la chaleur sur le vin et en avez-vous déduit un procédé de conservation? N'avez-vous pas au contraire et uniquement placé sous le boisseau, par le fait de vos erreurs, la lumière qui aurait pu nous venir de l'indication d'Appert, indication que vous connaissiez pourtant, tout en la cachant à vos lecteurs? Dans votre essai sur le vin blanc copié textuellement d'Appert, vous ne pouviez pas comprendre sa signification, pour deux motifs : $1^{\circ}$ il aurait fallu établir que le même vin qui n'avait pas été chauffé était devenu malade; $2^{\circ}$ dans votre théorie il suffisait que ce vin fût robuste pour que ni la chaleur ni le voyage ne l'eussent altéré. Car, je ne saurais trop le répéter, puisque c'est le seul point qui importe, vous avez rapporté l'effet de la chaleur à la constitution du vin.

Vous avez prétendu que la chaleur avait une action " maladive » sur le vin.

Vous avez prétendu qu'il n'y avait que les vins robustes que la chaleur n'altérât pas quand on les chauffe, que ceux-là, en conséquence, on peut les faire voyager sans les chauffer préalablement.

- Vous avez prétendu que les vins d'une santé douteuse, impropres aux voyages, s'altèrent par l'application de la chaleur, et ceux-là, avez-vous dit, il ne faut ni les chauffer, ni les faire voyager. C'est l'inverse qui est la vérité, d'après mes démonstrations expérimentales.

Au point de vue d'un procédé de conservation, ces principes erronés avaient leur conséquence. Aussi, dans ce même Mémoire où vous aviez répété l'essai d'Appert, vous avez terminé avec une grande logique vis-à-vis de vous-même : " Il n'y a qu'un moyen rationnel d'améliorer les vins qui doivent faire de longs voyages, c'est de les concentrer par la congélation (4). 》

Quel est au contraire le mérite que j'ai le droit absolu de revendiquer dans ces études? C'est d'être arrivé par la voie la plus scientifique et la plus rationnelle à découvrir et la cause des maladies des vins et la cuisson par la chaleur des germes visibles et tangibles de ces maladies; enfin, d'avoir démontré l'excellence de l'indication d'Appert, bien avant même de la connaître, car cette indication était restée dans l'oubli le plus absolu, tant par votre faute que par ce grave motif, qu'Appert ne prouve absolument rien, vu que les deux bouteilles non chauffées restées dans ses caves, l'une à Paris, l'autre au Havre, n'étaient pas du tout devenues malades. Rien ne démontrait

1. Vergnette-Lamotte (A. de). De l'exportation des vins de Bourgogne dans les pays chauds. Mémoires d'agriculture... publiés par la Société nationale et centrale d'agriculture, 1850 , p. 513-524. (Note de l'Édition.) 
donc que la conservation de celles qui avaient fait le voyage de SaintDomingue était due à la chaleur qu'elles avaient subie avant leur départ. Le goût de leur contenu était meilleur, il est vrai; mais c'était le voyage qui en était la cause.

Rien ne saurait mieux prouver encore ce que j'avance que cette longue lettre que vous m'avez adressée en avril 1864, et dans laquelle rous décrivez tous les moyens que rous employez dans vos caves pour prévenir autant que possible les maladies de vos vins : vinage, acide sulfureux, congélation. Or, dans cette lettre vous ne faites pas la inoindre allusion au chauffage. Cette lettre est reproduite dans mon ouvrage sur les maladies des vins (1), et elle édifiera tout le monde.

Je suis contraint d'ajouter que tout le reste de votre réponse est un long paralogisme.

En effet :

$1^{\circ}$ Vous n'avez pas cité Appert à propos du chauffage des vins. C'est évident " pour ceux qui savent lire ". Vous l'avez cité pour les moûts, et sa méthode pour les moûts est connue de toutes les cuisinières.

$2^{\circ}$ Vous parlez d'essais que l'on fait présentement en Bourgogne. Cela n'a aucune signification dans une discussion relative à ce qui s'est passé en 1850 et en 1865, et ce qui durera dans les pratiques de la Bourgogne, c'est ce qui résultera de mes études propres, soyez-en assuré.

$3^{\circ}$ Vous n'avez pas vu ce qui se pratiquait dans le Midi, quand vous y avez été. Tant pis pour vous et pour la nouveauté de votre procédé du grenier.

$4^{\circ}$ Cagniard de Latour et Turpin « ont beaucoup à prendre » dans la théorie de la fermentation alcoolique. C'est vrai, et leur part a été faite par moi dans mon Mémoire sur cette fermentation dans la mesure exacte de la vérité scientifique, tout comme je vous l'ai faite dans ma lettre au Moniteur vinicole et dans mon ouvrage sur les maladies des vins, qui paraîtra dans quelques jours.

$5^{\circ}$ Vous voulez que je choisisse entre une assertion de ma lettre du 22 août et celle de son post-scriptum, au sujet des mycodermes décrits dans mon Mémoire ( $\left.{ }^{2}\right)$. C'est inutile. Elles sont toutes deux rigoureusement vraies et s'appliquent à des circonstances différentes. Vous le savez très bien, et nous avons des témoins.

1. Voir p. 363-3ro du présent volume.

2. M. de Vergnette avait objectẻ : M. Pasteur dans son post-scriptum (p. 431-433) donne à entendre qu'avant sa lettre du 4 avril 1865 (p. 431-432) je ne savais rien de ces mycodermes ; et dans sa lettre du 22 aout 1866 (p. 427-433) il prétend m'avoir appris á reconnaitre ces mycodermes dans son laboratoire au mois de février 1865. (Notes de l'Édition.) 
$6^{\circ}$ Vous ne m'avez pas écrit du tout, le 8 avril, à propos des " mycodermes » de vos vins vieux : Maisj"espère que vous vous trompez. Vous m'avez écrit: Mais j'espère que vous vous trompez poun vos vixs Nouveaux. En vous parlant de ces derniers vins nouveaux, je vous avais dit dans ma lettre du 4 avril : “ J'ai tout lieu de croire que vos vins nouveaux, ’̀̀ peu près sains actuellement, s'altéreront eux-mêmes ultérieurement (1). ” En me répondant que vous espériez que je me trompais à leur égard, vous exprimiez purement et simplement l'une des deux alternatives comprises dans cette phrase de ma lettre.

Vous dites qu'en polémique toutes les armes sont à mon usage. La seule arme dont j'aie eu besoin et la seule dont j'aie usé dans cette discussion contre vous a consisté dans mon respect le plus scrupuleux pour la vérité.

L. Pasteur,

Membre de l'Académie des sciences.

\section{NOTE AU SUJET D’UNE RÉClamation DE M. PAUl ThENARD, RELATIVEMENT AU CHAUFFAGE DES VINS (2).}

Notre confrère M. Paul Thenard a présenté au Conseil général de la Côte-d'Or, dans sa séance du 23 août dernier, une réclamation de priorité en faveur de M. de Vergnette-Lamotte, son compatriote, relativement au chauffage des vins. (Voir le numéro du 9 septembre courant du Journal d'agriculture pratique, de M. Lecouteux) [ $\left.{ }^{3}\right]$. Je proteste, de la manière la plus formelle, contre le récit erroné de M. Thenard. Les prétentions qu'il met en avant ne sont que la reproduction, en d'autres termes, d'une réclamation faite, il y a trois ans, par MM. de Vergnette

1. Voir p. 431 du présent volume.

2. Comptes rendus de l'Académie des sciences, séance du 13 septembre 1869, LXIX, p. 645 .

3. A l'occasion du rapport présenté par M. le baron Thenard au Conseil général de la Côted'Or, sur le chauffage des vins, rapport inséré dans le Journal d'agriculture pratique, 1869, II, p. 389-390, Pasteur adressa la lettre suivante au rédacteur en chef de ce journal :

Monsieur,

J'ai l'honneur de vous informer que je viens d'adresser à chacun des membres du Conseil général de la Côte-d'Or la lettre suivante. Je vous prie de vouloir bien l'insérer dans le plus 
et Quesneville, dans le Moniteur scientifique. J'ai répondu, sur-le-champ, dans ce même journal, par une Communication dont j'ai l'honneur de déposer un exemplaire sur le bureau de l'Académie (1).

J'adresse aujourd'hui même à chacun des membres du Conseil général de la Côte-d'Or un exemplaire de cette même brochure.

\author{
NOTE (2) \\ RELATIVE AUX COMMUNICATIONS
}

DE M. DE VERGNeTTE-LAMOTTE ( ${ }^{3}$ ) ET DE M. P. THENARD ( $\left.{ }^{4}\right)$

[SUR LE CHAUFFAGE DES VINS]

ADRESSÉES A L'ACADÉMIE

DANS LES SÉANCES DES 20 SEPTEMBRE ET 4 OCTOBRE

L'Académie sait comment les choses se sont passées. Dans la dernière session du Conseil général de la Côte-d'Or, M. le maréchal Vaillant, président, convaincu que le brevet d'invention pris par M. Pasteur, en 1865, renferme une riche mine d'or exploitable sans frais par ses compatriotes, fait part de cette bonne fortune à ses col-

prochain numéro de rotre journal, ainsi que la brochure qui y est jointe [Lettre à M. Quesneville, directeur du Moniteur scientifique, voir p. 427-433 du présent volume].

Veuillez agréer, etc..,

Paris, le 11 septembre 1869.

L. Pasteur.

Monsieur le Conseiller gẻnéral,

Paris, 12 septembre 1869.

Je trouve dans le Journal d'agriculture pratique, du 9 septembre courant, une réclamation de M. Thenard au Conseil général de la Côte-d'Or, en faveur de M. de VergnetteLamotle, relativement au chauffage des vins. Je proteste de la manière la plus formelle contre le récit erroné de $\mathbf{M}$. Thenard. Les prétentions qu'il met en avant ne sont qu'une autre édition d'une réclamation déjá produite, il y a trois ans, dans le Moniteur scientifique, dirigé par le docteur Quesneville.

J'ai l'honneur de vous adresser un exemplaire de la réponse que j'ai faite sur-le-champ, dans ce même journal, au mois d'août 1866.

Veuillez agréer, Monsieur le Conseiller général, etc...

\title{
L. Pasteur. \\ (Notes de l'Édition.)
}

1. Voir p. 427-483 du présent volume : Lettre à M. Quesneville, directeur du Moniteur scientifique. 911.

2. Comptes rendus de l'Académie des sciences, séance du 25 octobre 1869, LXIX, p. 905-

3. Vergnette-Lamotte (A. de). Remarques à loccasion de la Communication de M. Pasteur sur le chauffage du vin. Ibid., séance du 20 septembre 1869, LXIX, p. 693.

4. Thenard (P.). Réponse à la Note lue par M. Pasteur dans la séance du 13 septembre 1869, sur les droits à l'invention de la conservation des vins par le chauffage préalable. Ioid., séance du 4 octobre 1869, LXIX, p. 748. (Notes de l'Édition.) 
lègues du Conseil général. M. Paul Thenard, présent dans l'assemblée, ayant dans l'esprit des souvenirs confus, réclame la priorité en faveur de M. de Vergnette, rédige une Note qui est insérée au procès-verbal de la séance et qu'il fait paraître sans retard dans les journaux de la localité et dans les journaux d'agriculture de Paris. Cette Note étant pleine d'erreurs, je proteste aussitòt. Notre confrère a adressé une réponse à ma protestation; c'est cette réponse que je viens discuter devant l'Académie.

Première rectification. - M. Thenard s'était trop pressé d'écrire sa Note (1) au Conseil général, car on y lit, par exemple, que deux travaux qui ont été communiqués à l'Académie le même jour, par M. de Vergnette et par moi, ont été publiés à deux années d'intervalle, tant était grande la confusion des idées dans l'esprit de M. Thenard, quand il n'a pu résister au désir de prendre la parole ex abrupto devant le Conseil général.

Deuxième rectification. - La nouvelle réclamation de M. Thenard du 4 octobre a été précédée d'une autre de M. de Vergnette, le 20 septembre, dans laquelle il demande si c'est à dessein que j'ai supprimé les mots "lorsqu'on les traite par le procédé Appert », dans une citation d'un passage de sa Note du 12 mars $1866\left({ }^{2}\right)$; il ajoute que cette suppression " lui fait dire le contraire de sa pensée ». De quelle pensée? Écartons un sous-entendu qui peut tromper un lecteur inattentif, c'est que mon procédé d'aujourd'hui ne serait plus mon procédé du 11 avril $1865{ }^{(3)}$ et du ${ }^{\text {er }}$ mai suivant (4). Je proteste énergiquement contre cette assertion de la Note du 20 septembre et contre la réticence calculée de M. de Vergnette.

Troisième rectification. - Selon M. de Vergnette, le procédé d'Appert est détestable, soit pour les vins fins, soit pour les vins communs. Voici les termes de la condamnation prononcée par M. de Vergnette en 1866 :

"La plupart des vins de table, ceux que produit surtout la France, que leur provenance soit de la Bourgogne, du Bordelais ou de la còte du Rhòne, ne résistent pas à ce traitement (traitement Appert) au point de vue œnologique; ils deviennent secs, vieillardent et ne tardent pas à se décolorer..... Mais des vins, qui, sans exception, perdent leur valeur,

1. Voir cette Note, p. 217 du présent volume.

2. Vergnette-Lamotte (A. de). Conservation des vins par l'emploi de la chaleur. Comptes rendus de l'Académie des sciences, LXII, 1866, p, 596-602.

3. Il s'agit du brevet d'invention pris le 11 avril 1865 . Voir la note de la p. $410 \mathrm{du}$ présent volume.

4. Il s'agit de la Communication à l'Académie des sciences. Voir p. 409-412 du présent volume. (Notes de l'Édition.) 
si faible qu'elle soit, lorsqu'on les traite par le procédé Appert, sont les vins communs, tant ils se décolorent et deviennent secs et acides ( $\left.{ }^{1}\right)$. "

Telle est la condamnation si générale portée en 1866 sur le procédé Appert par M. de Vergnette-Lamotte. C'est déjà clair, mais cela le deviendra bien davantage tout à l'heure.

Quatrième rectification. - D'après N. Thenard, “ c'est vers 1850 que M. de Vergnette, examinant l'action du chauffage à 75 degrés sur les vins de Bourgogne, déclara qu'il leur enlevait la meilleure part de leur finesse et de leur bouquet, en les rendant secs et durs; que, tout au plus, il était utilement applicable aux vins blancs ».

Puisque c'est en $1850\left({ }^{2}\right)$, suivant M. Thenard, que M. de Vergnette a condamné pour la première fois le procédé Appert, citons textuellement cette condamnation, extrêmement différente, on va le voir, de celle de 1866 ; la voici, prise dans les conclusions complètes et textuelles du travail de M. de Vergnette, publié en $1850\left({ }^{3}\right)$. Cette fois, malheureusement pour M. de Vergnette, il y manque les mots : " par $l c$ procédé Appert ", car, dans le Mémoire dont je parle, M. de Vergnette s'est attribué tout ce qu'avait fait Appert, en le dénaturant. Je reviendrai tout à l'heure sur ce point.

"En résumé, nous n'admettons pas que les vins doivent, pour être expédiés au dehors, subir aucun conditionnement qui entraîne avec lui l'addition de substances étrangères.

" Poúr nous, il n'est qu'une manière rationnelle d'améliorer les vins qui doivent faire de longs voyages, c'est de les concentrer par la congélation.

" Ce procédé n'altère en rien leurs qualités.

"Soit au moyen de l'exposition des vins à l'air dans les hivers rigoureux, soit au moyen de mélanges frigorifiques, on sera toujours maître de congeler les vins au degré convenable.

"Les vins qui ont voyagé dans les pays chauds présentent tous les caractères des vins que l'on soumet artificiellement, dans les limites de 60 à $70^{\circ} \mathrm{C}$., à la chaleur d'un four ou à celle d'un bain-marie. Si, après avoir soumis à cette épreuve quelques échantillons des vins que l'on veut exporter, on reconnait qu'ils ont résisté, on pourra, en toute sécurité, les expédier; dans le cas contraire, on devra s'en abstenir » [p. 524].

1. Ibid., p. 599. (Note de l'Édition.)

2. Et non ver's 1850 , car il n'y a qu'un seul travail de M. de Vergnette, et il est bien de 1850. (. Note de Pasteur.)

3. Vergnette-Lamotte (A. de). De l'exportation des vins de Bourgogne dans les pays chauds, Mémoires d’agriculture... publiés par la Société nationale et centrale d'agriculture, année 1850 , p. 513-521. (Note de l'Édition.) 
Sont-elles assez claires, ces conclusions? Il n'y a qu'un procédé qui permette de faire voyager les vins de la Bourgogne, c'est la concentration par la gelée! Quant au chauffage, il a une action maladive sur les vins (expression de M. de Vergnette dans sa Communication du $1^{\text {er }}$ mai 1865).

Voulez-vous savoir si un vin est assez robuste pour voyager? Voulez-vous savoir s'il est nécessaire de lui appliquer la concentration par la gelée? chauffez-en un échantillon. Si la chaleur, séance tenante, ne l'altère pas, il est propre à l'exportation sans conditionnement quelconque. C'est le contraire si la chaleur l'altère; alors concentrez-le par la gelée, et faites-le voyager.

Voilà les principes de M. 'de Vergnette en 1850 : ce sont autant d'erreurs. M. Thenard aurait dû dire que M. de Vergnette n'ayait absolument rien compris au chauffage des vins en 1850 .

Cinquième rectification. - J'arrive plus directement aux affirmations de notre confrère $M$. Thenard, car $M$. Thenard n'a pas craint de procéder uniquement par affirmations, et sans preuves, dans une question aussi délicate. Commençons par la dernière phrase, qui est ainsi conçue : "Que M. Pasteur, au lieu de protester, daigne publier le brevet qu'il a pris sur la (matière avant le $1^{\text {er }}$ mai 1865 ; je serai le premier, s'il y a lieu, à reconnaitre mon erreur. »

Je m'empresse d'accéder à ce vœu. Voici, dans sa teneur exacte et complète, mon brevet du 11 avril 1865 (1), dont je dépose le texte original sur le bureau de l'Académie, en la priant de vouloir bien le conserver parmi les pièces de la correspondance de ce jour.

\section{Paris, 11 avril 1865.}

J'ai reconnu que les maladies ou altérations spontanées des vins sont produites par des êtres microscopiques dont les germes existent dans le vin avant qu'il devienne malade.

Le vin ne s'altère pas si ces germes sont tués. Un moyen simple et pratique de faire périr ces germes consiste à porter le vin à une température comprise entre 60 et $100^{\circ}$.

Je déclare prendre un brevet d'invention pour l'application de ce procédé. Il empèche toutes les fermentations irrégulières des vins, quelle que soit leur nature, sans altérer la qualité du vin.

Chose inouie, peut-être, dans les annales 'des brevets d'invention! voilà quatre années et demie et plus que, dans l'intérêt public, j'ai pris ce brevet, pour empêcher que d'autres personnes se fissent breveter à

1. Voir le texte in extenso de ce brevet, note de la p. 410 du présent volume. (Note de l'Édition.) 
l'occasion de mes recherches, et après toutes les expériences qui ont été faites dans cet intervalle, tant par moi que par d'autres, dans toutes les parties de l'Europe, de l'Afrique, de l'Amérique et de l'Australie, il n'y a pas une phrase à changer à ce document.

Les températures extrêmes de 60 et de $100^{\circ}$ que j'y indique embrassent toutes les conditions du problème, depuis les vins les plus fins et les plus délicats jusqu'aux vins les plus sucrés, dont on ne peut empêcher les fermentations alcooliques irrégulières ou maintenir l'état sucré à des degrés variables que par des températures de plus de 70 et $80^{\circ}$.

En d'autres termes, appliquez au vin le plus fin de la Bourgogne la température de 60 ou $65^{\circ}$, ne fût-ce que pendant une minute, ce vin acquerra toutes les propriétés de conservation et d'amélioration indiquées dans le rapport de la Commission syndicale des vins de Paris ( $\left.{ }^{1}\right)$. Ce n'est point du tout par raison de principe que, postérieurement à mon brevet, j'ai dit que l'on pouvait descendre à la température de $55^{\circ}$, mais simplement pour faire connaître un fait que j'avais constaté.

Par conséquent, les troisième et cinquième affirmations de $\mathbf{M}$. Thenard ne reposent sur rien et $\mathrm{M}$. de Vergnette n'a pas indiqué le premier la température minima qui évite l'altération que cause au vin, d'après lui, un chauffage de 60 à 70 ou $75^{\circ}$. La température minima de $60^{\circ}$, indiquée dans mon brevet, et même les températures immédiatement supérieures, produisent tous les effets désirables sur les vins les plus fins de la Bourgogne: La température de $55^{\circ}$ n'est nullement nécessaire a la pratique du chauffage, soit pour les vins fins, soit pour les vins communs.

La seule chose que j'aie changée dans l'application, depuis la prise de mon brevet, est de ne point laisser le vin séjourner même quelques instants à la température maxima à laquelle il est porté.

Qui oserait considérer d'ailleurs, comme un perfectionnement de mon brevet du 11 avril, le procédé postérieur de M. de Vergnette, dont voici textuellement les termes :

“En résumé, dit N. de Vergnette, il résulte de cette étude que la chaleur peut être employée avec succès dans l'élevage des vins. Son action sur les mycodermes (les mycodermes découverts par M. Pasteur) paraît très efficace lorsque les vins sont en bouteille.

" A défaut d'une étuve, on peut se servir d'un grenier chaud pour faire subir aux vins le traitement dont nous avons obtenu de si remarquables résultats.

1. Voir p. 253-256 du présent volume. (Note de l'Édition.) 
" Dans ce cas, voici comment on opère : on mettra les vins en bouteilles au mois de juillet, en ne choisissant jamais que des vins âgés de deux ans au moins, les fûts qui les contenaient étant, jusqu’à ce moment, restés dans la cave.

“ Les bouteilles ne seront point bouchées à l'aiguille, mais cependant à la mécanique.

“ Après le tirage, les bouteilles seront transportées et empilées au grenier. Elles y resteront deux mois, et les vins seront ensuite descendus en cave pour y être conservés comme de coutume jusqu'à ce qu'on les livre à la consommation. »

Est-il imaginable qu'on rapproche une opération consistant à porter tout d'un coup le vin, ne fût-ce qu'une minute, à une température de $60^{\circ}$, d'un procédé consistant à faire séjourner ce vin pendant deux mois dans une étuve ou dans un grenier pendant les mois de juillet et d'août?

M. de Vergnette dit qu'il faut avoir soin de coucher les bouteilles pendant le chauffage au grenier, car autrement l'air qui se trouve entre le vin et le bouchon permettrait le développement du mycoderma aceti et l'acescence du vin. Voilà donc la précision avec laquelle M. de Vergnette avait reconnu la température qui tue les mycodermes découverts par M. Pasteur. Il est des circonstances, au contraire, où il est très utile, quand on a appliqué mon procédé, de laisser les bouteilles debout, car alors le vin vieillit rapidement et dans les meilleures conditions, sans jamais offrir de mycodermes.

Quant à moi, je déclare que la meilleure manière d'altérer les vins fins de la Bourgogne consiste à porter ces vins dans un grenier pendant les mois de juillet et d'août.

Sixième rectification. - “C'est vers 1810 , ajoute M. Thenard, qu’Appert ( $\left.{ }^{1}\right)$, après des expériences décisives, a annoncé que des vins chauffés à la température de $75^{\circ}$ et en bouteilles bouchées pouvaient ensuite supporter les plus longs voyages sans crainte d'altération ultérieure. " Il est vrai qu'il ajoute tout aussitôt que M. de Vergnette a le premier condamné le procédé Appert!

Que signifient ces contradictions? Si la température indiquée par Appert fait sécher, vieillarder et décolorer les vins fins; d'autre part, si elle décolore, fait sécher et devenir acides les vins communs, comment pouvez-vous affirmer qu'en 1810 Appert a fait des expériences décisives sur leur conservation? Est-ce que c'est conserver un vin que de le perdre aussi absolument et de toutes les manières que je viens de

1. La première édition de « L'Art de conserver, pendant plusieurs années, les substances animales et végétales " d'Appert est de 1810. (Note de l'Édition.) 
rappeler? Le premier entre tous, j'ai revendiqué les droits d'Appert dans la question, mais avec justice et vérité, et non en le ravalant ou en l'exaltant, suivant les besoins d'une mauvaise cause. Cherchez, je rous prie, soit dans la presse quotidienne, soit dans la presse scientifique, depuis mes travaux de 1864 et de 1865, un seul nom, une seule phrase prouvant que quelqu'un avant moi a rappelé le mérite d'Appert au sujet de la question en litige.

Il est vrai, au début de mes recherches, le 11 octobre 1865 (voir ma Lettre au Moniteur vinicole) [1], trompé par le numéro d'un journal de Beaune du 13 mai 1865 et par le Mémoire de M. de Vergnette de 1850, j'ai attribué à ce dernier tout ce qu'avait fait Appert, tant ma bonne foi et mon impartialité étaient grandes! M. de Vergnette, avant ma Note du 4 décembre 1865 à l'Académie (2), Note qui, pour la première fois, a rappelé les mérites d'Appert, n'a cité qu'une fois Appert, et dans les termes suivants :

" J'ai observé, il y a quelques mois, un fait assez important qui contribuera singulièrement à éclairer la question. Souvent obligé, dans le moment de la récolte, de conserver, par la méthode Appert, des moûts destinés à des expériences qui ne pouvaient être faites que plus tard, j'ai aussi appliqué ce procédé à des vins de différentes qualités $\left({ }^{3}\right)$. »

Ce qui signifie clairement que M. de Vergnette aurait le premier appliqué la chaleur au vin; tandis que, dans le même travail, son expérience sur le vin blanc reproduisait celle d'Appert, moins la comparaison avec le vin non chauffé.

Je le répète, j'ai signalé le premier les expériences d'Appert; je l'ai fait avec la vérité et la justice qui lui étaient dues, et je prétends lui laisser ce qui lui appartient: personne n'a le droit d'en douter.

Conclusion. - Au moment de la prise de mon brevet, le 11 avril 1865, qui chauffait du vin, soit en France, soit ailleurs, pour le conserver sans altérer sa qualité? Personne. L'expérience d'Appert était tombée dans l'oubli, soit par défaut de preuves suffisantes, soit peutètre par les erreurs dont M. de Vergnette l'avait entourée, soit enfin parce qu'Appert ne connaissait pas les températures exactes qu'il fallait employer, et qu'il laissait la chaleur s'exercer trop longtemps. Aujourd'hui, dans tous les pays du monde, on chauffe du vin par le procédé indiqué dans mon brevet, c'est-à-dire à des températures variables de 60 à $100^{\circ}$, suivant la qualité et la nature des vins.

1. Voir p. 343-361 du présent volume.

2. Voir p. 425-426 du présent volume : Note sur l'emploi de la chaleur comme moyen de conservation du vin.

3. Vergnette-Layotte (A. de). Loc. cit. (Notes de l'Édition.) 
J'ai fait connaître la cause des maladies des vins, le moyen pratique de les prévenir, et établi les principes qui doivent guider l'opérateur dans cette application. Tous ces points sont inséparables.

Mes procédés, contestés d'abord et reconnus vrais ensuite, ont subi, depuis cinq ans, les deux phases par lesquelles passent, à leur début, les découvertes scientifiques ou les applications industrielles d'un grand intérêt, ces deux phases que Lavoisier, à propos de la triste histoire de Jean Rey, caractérisait ainsi : “Dans les sciences, il y a toujours des personnes disposées à trouver que ce qui est nouveau n'est pas vrai, ou que ce qui est vrai n'est pas neuf. "

[CHAUFFAGE DES VINS]

A M. LE RÉDACTEUR EN CHEF DU JOURNAL D'AGRICULTURE PRATIQUE (1) 3

Monsieur,

Paris, ce 26 octobre 1869.

Je lis dans votre numéro du 30 septembre dernier une lettre signée de Vergnette-Lamotte relative à une réclamation de priorité. Cette lettre se borne à des affirmations sans preuves.

Quand on a conscience de son bon droit, on s'abstient de toute injure pour le défendre; en cela je n'imiterai donc pas M. le vicomte de Vergnette-Lamotte, et je dirai seulement que toutes ses assertions sont erronées.

Vous trouverez dans les Comptes rendus de l'Académie des sciences pour la séance de lundi dernier(2) de quoi satisfaire amplement le ridicule défi de M. de Vergnette-Lamotte. Quant à ses injures dont vous pouvez voir le texte exact dans le numéro du Moniteur vinicole du 23 octobre courant, je les méprise.

Agréez, etc,

L. Pasteur, Membre de l'Institut.

1. Journal d'agriculture pratique, 1869, II, p. 671. Lettre en réponse à l'insertion d'une nouvelle réclamation de M. de Vergnette-Lamotte. Ibid., p. 490.

2. Il s'agit de la Communication qui précéde. (Note de l'Édition.) 
RÉPONSE (1)

A LA DERNIÈRE NOTE DE M. P. THENARD (2) SUR LE CHAUFFAGE DES VINS

Remarquons d'abord qu'il existe des différences profondes entre les assertions de cette nouvelle Note et celles des deux premières $\left(^{3}\right)$. M. Thenard n'a pas mis, il est vrai, à ces différences capitales des angles bien vifs, faits pour arrêter le regard et l'attention; mais on ne saurait attendre davantage d'un contradicteur mal engagé.

M. Thenard ne conteste plus la nouveauté et l'efficacité de mon procédé du 11 avril 1865, qui procurera des millions à la Bourgogne; mais il donne à penser que la reconnaissance envers l'inventeur gêne ses compatriotes. Soit : ce ne serait pas la première fois que les découvertes scientifiques n'auraient rencontré que l'ingratitude chez ceux qui en profitent. Les sentiments du Maréchal Vaillant, Président du Conseil général de la Côte-d'Or, sont tout autres.

La Note à laquelle je réponds paraît avoir principalement pour but d'expliquer la conduite tenue par M. Thenard. Mieux informé aujourdhui que Ie 23 août et le 4 octobre, M. Thenard doit reconnaître jusqu'à l'évidence que le Maréchal Vaillant, ne se proposant pas de faire au Conseil général une dissertation historique, mais bien l'annonce d'un procédé pratique propre à prévenir toutes les maladies des vins fins de la Bourgogne, sans altérer leurs qualités les plus délicates, ne pouvait raisonnablement parler que du procédé de mon brevet du 11 avril 1865, le seul qui réalise ces conditions, et nullement des procédés d'Appert et de M. de Vergnette.

En effet, si le Maréchal Vaillant eût entretenu ses compatriotes du procédé d'Appert, M. Thenard se fùt levé pour déclarer que ce procédé est très nuisible aux vins fins de la Bourgogne, et que c'est pour ce motif qu'on ne s'en est jamais servi. D'autre part, le Maréchal Vaillant n'aurait pu parler du procédé de M. de Vergnette qu'en blessant la justice et la vérité; car si mon procédé du 11 avril 1865

1. Comptes rendus de l'Académie des sciences, séance du 8 novembre 1869, LXIX, p. 973-974.

2. Thenard (P.). Note en réponse á la dernière Communication de M. Pasteur, sur le chauffage des vins. Ibid., p. 938-941. (Note de l'Édition.)

3. On trouve la première Note de M. Thenard dans le Journal dagriculture pratique, no du 9 septembre [1869, II, p. 389-390]. (Note de Pasteur.) 
est : $1^{\circ}$ antérieur à celui de M. de Vergnette; $2^{\circ}$ éprouvé et démontré efficace, celui de M. de Vergnette du $1^{\text {er }}$ mai suivant, consistant à porter le vin pendant deux mois dans un grenier ou dans une étuve de 45 à $52^{\circ}$, n’a jamais été appliqué par personne, et -il est si mauvais qu'on pourrait l'intituler dérisoirement, mais justement : "Procédé pour altérer la finesse et le bouquet des vins fins de la Bourgogne, ou pour les rendre malades plus vite et plus complétement qu'en les laissant dans la cave. ”

Ces quelques lignes suffiront pour réfuter toutes les erreurs qui subsistent encore dans la dernière Note de M. Thenard.

OBSERVATIONS ( 1 )

AU SUJET DE LA LECTURE DE M. DE VERGNETTE ( ( ) [SUR LE CHAUFFAGE DES VINS]

Il y a beaucoup de choses dans la Note que vient de lire M. de Vergnette. Les assertions au sujet de la priorité de l'invention du chauffage comme moyen de conservation des vins, qui sont seules en litige, se trouvent noyées et comme perdues au milieu de remarques qui me paraissent empruntées exclusivement à mes propres publications concernant cette pratique. Au lieu de répondre avec simplicité à des conclusions formulées avec précision par M. Balard (3), M. de Vergnette accumule des explications confuses, et m'oblige de rétablir quelque clarté dans ce débat.

M. de Vergnette prétend que déjà, en 1846 et en 1850, il a conservé des vins par le chauffage. J'affirme de nouveau et après M. Balard, qui l'a établi si clairement, qu'à ces époques, M. de Vergnette n'a introduit que des erreurs dans la question du chauffage, qu'il a rendue, en outre, profondément obscure. En 1850 , le chauffage, entre 50 et $75^{\circ}$, était pour M. de Vergnette une épreuve qu'il fallait faire subir à un échan-

1. Comptes rendus de l'Académie des sciences, séance du 18 mars 1872, LXXIV, p. 791-793.

2. Vergnette-Lamotre (A. de). Recherches sur la conservation des vins. Ibid., p. 787-791.

3. Balard. Sur l'invention de la méthode de conservation des vins par le chauffage. Comptes rendus de l'Académie des sciences, séance du 26 février 1872, LXXIV, p. 561-569. Voir p. 218-226 du présent volume. (Notes de l'Édition.) 
tillon de vin à exporter. Si l'échantillon résistait à cette épreuve de la chaleur, le vin était d'une santé robuste; il pouvait voyager. Dans le cas contraire, il fallait s'abstenir de l'expédier. Tout cela est erroné. Je le répète donc encore : M. de Vergnette n'a rien compris à l'action de la chaleur sur le vin en 1850 .

Il me vient à la pensée un argument : puisque M. Thenard trouve que M. de Vergnette a des droits à la priorité de l'invention du chauffage, pourquoi donc dans le rapport qu'il a lu, en 1864, à l'Académie, sur les titres de cet œnologue à la place de Correspondant, pourquoi, dis-je, M. Thenard n'a-t-il pas dit un seul mot du travail de 1850 de M. de Vergnette concernant le chauffage des vins? C'est qu'à cette date je n'avais rien publié encore sur la question du chauffage et son importance pratique.

Il y a un autre travail, un seul, de M. de Vergnette sur le chauffage des vins; il est de $1865\left(^{(1)}\right.$, postérieur de trois semaines à la prise de date que j'ai donnée à mes études, le 11 avril 1865. Sa Note fait connaître un procédé dont je laisse à M. de Vergnette toute la responsabilité : il consiste à placer les vins de Bourgogne sous un toit, dans un grenier, pendant deux mois, en juillet et août.

M. de Vergnette établit, dans la Note ci-dessus ( ${ }^{2}$ ), une distinction entre le chauffage en vase clos et le chauffage au contact de l'air. Cette distinction m'appartient, et j'ai, le premier, insisté pour que, dans le chauffage en grand, on se rapproche le plus possible des conditions du chauffage en bouteille.

M. de Vergnette dit encore (autant qu'on peut répondre d'avoir bien compris en écoutant une lecture, quelque attention qu'on y apporte) :

"Il faut chauffer les vins jeunes, pour les vieillir... Les vins vieux, soumis au chauffage, deviennent secs et vieillardent. »

N'ai-je pas publié que les vins chauffés après plusieurs années de bouteille conservent moins bien leurs qualités délicates que si on les avait chauffés plus jeunes?

M. de Vergnette dit encore qu'il a fait ressortir les avantages de l'emploi rapide d'une température peu élevée. Mais, avant qu'il connût exactement ma méthode, pourquoi donc M. de Vergnette conseillait-il d'exposer le vin à la chaleur lente d'un grenier pendant deux mois?

M. de Vergnette, pour établir qu'il a conservé du vin en 1850 par le chauffage, vient de lire la phrase suivante de son Mémoire portant cette date :

1. Veronette-Lamotte (A. de). Des effets de la chaleur pour la conservation et l'amélioration des vins. Comptes rendus de l'Académie des sciences, lor mai 1865, LX, p. 895-899.

2. La Note du 18 mars 1872. (Notes de l'Édition.) 
" ...... Nous avons toujours réussi, en faisant varier la température du bain de 50 à $75^{\circ} \mathrm{C}$., à préserver les vins de qualité, soumis à ces essais, de toute altération ultérieure. ”

Je le prie itérativement de lire la phrase suivante qui donne le vrai sens de celle qui précède.

M. de Vergnette s'y refusant, je la rétablis :

"Il n'en était pas de même pour ceux qui, d'une santé douteuse, ne présentaient point cette composition normale sans laquelle les vins ne se conservent pas. Dans ce cas, ils ne résistent pas à cette épreuve."

J'attends la réponse de $M$. de Vergnette, et je regrette son silence.

\section{RÉPONSE (1)}

\section{A UNE COMMUNICATION DE M. DE VERGNETTE-LAMOTTE (2) [SUR LE CHAUFFAGE DES VINS]}

La question n'est pas de savoir si le procédé de conservation des vins par le chauffage est une pratique pouvant rendre de grands services, ou si, parmi les vins vinés et plus ou moins aérés, chauffés par la marine, il en est qui ont pu devenir maigres, se dépouiller de leur couleur pendant un voyage au Gabon ou en Cochinchine. Nous traitons une question de priorité soulevée par M. Thenard, en faveur de M. de Vergnette, à l'instigation de M. Fremy.

Une seule chose importe, c'est de savoir si, en 1850, M. de Vergnette a conservé des vins par le chauffage. Je le nie de la manière la plus absolue et voici mes preuves $\left(^{3}\right)$.

Que dit M. de Vergnette pour appuyer ses prétentions ? Il cite la phrase suivante de son Mémoire de $1850\left(^{(4)}\right.$ :

1. Comptes rendus de l'Académie des sciences, séance du 25 mars 1872, LXXIV, p. $845-848$.

2. Vergnette-Lamotte (A. de). Observations relatives à la réponse faite par M. Pasteur, dans la séance précédente, à propos de la conservation des vins. 1bid., p. 843-845. (Note de l'Édition.)

3. Il existe deux Mémoires de M. de Vergnette sur le chauffage. Le premier est de 1850, le second du 1er mai 1865. - Ce dernier étant postérieur à la première prise de date de mes études, le 11 avril 1865, je n'ai à m'occuper que de ce que dit le Mémoire de 1850, puisque seul il peut faire autorité dans le débat. (Note de Pasteur.)

4. Vergnette-Lamotte (A. de). De l'exportation des vins de Bourgogne dans les pays chauds. Mémoires d'agriculture... publiés par la Société nationale et centrale d'agriculture, 1850, p. 513-524. (Note de l'Édition.) 
"Nous avons répété cette expérience sur d'autres vins, à l'époque de leur mise en bouteille; et toujours nous avons réussi, en faisant varier la température du bain-marie de 50 à $75^{\circ} \mathrm{C}$., à préserver de toute altération ultérieure les vins de qualité soumis à ces essais. "

L'Académie n'a pas oublié qu'invité par moi et par plusieurs de nos confrères à lire la phrase suivante qui donne à celle qui précède son véritable sens, M. de Vergnette s'y est refusé. Je rétablis cette phrase :

"Il n'en était pas de même pour ceux qui, d'une santé douteuse, ne présentaient point cette composition normale sans laquelle les vins ne se conservent pas. Dans ce cas ils ne résistent point à cette épreuve. 》

Que signifient donc ces mots de la première phrase : J'ai réussi à préserver des vins de qualité de toute altération. Ils signifient que les vins étaient d'une santé non douteuse, robustes, c'est-à-dire susceptibles de se conserver naturellement. Dans ce cas, dit M. de Vergnette, l'épreuve de la chaleur ne les altère pas; inais si les vins ont une santé douteuse, ne présentant point une composition sans laquelle ils ne se conservent pas, l'épreuve de la chaleur les altère. Tout ceci repose sur des erreurs; mais passons.

Nous verrons plus tard, poursuit M. de Vergnette, quel parti on peut tirer de ces observations. Lisons donc aux pages 523 et 524 du recueil où se trouve le Mémoire de M. de Vergnette quel est ce parti qu'il a tiré de ses observations sur le chauffage, observations erronées, je le répète.

"Nous savons que les voyages dans les pays chauds produisent sur les vins le mème effet que la chaleur d'un bain-marie ou celle d'un four, dans les limites de 60 à $70^{\circ} \mathrm{C}$. Si donc, après avoir soumis à la congélation les vins qui doivent être exportés, nous en exposons, dès qu'ils sont devenus assez limpides pour être tirés en bouteilles, un ÉcHaNTILlox à l'action de la chaleur, nous pouvons, dans le cas où ils résistent à cette épreuve, et si l'on se rappelle ce que nous avons dit plus haut, en conclure qu'ils résisteront aussi à toutes les fatigues des plus longs voyages."

La chaleur était donc pour M. de Vergnette une épreuve qu'il faisait subir aux vins, sur des échantillons, pour savoir si elle les altérait séance tenante. Par exemple : un propriétaire de vins qui doit faire une expédition a un grand intérêt à ne livrer que des vins qui se comporteront bien ultérieurement. Eh bien, dit M. de Vergnette, que ce propriétaire chauffe des échantillons de ces vins. S'il en est parmi ces échantillons qui résistent à l'épreuve du chauffage, les vins correspondants sont robustes, on peut les expédier. S'ils ne résistent 
pas à cette opération du chauffage, c'est qu'ils sont d'une santé douteuse, et il ne faut pas les livrer. Encore une fois, cela est erroné. Si l'on pouvait, en effet, connaître a priori quels sont les vins qui ont une santé douteuse, il faudrait précisément leur appliquer la pratique du chauffage préalable avant de les livrer. M. de Vergnette-Lamotte n'a donc pas conservé, en 1850, une seule goutte de vin par le chauffage. Cela a la clarté de l'évidence.

Dans le résumé qui termine son Mémoire, on retrouve mieux précisé encore ce caractère d'épreuve qu'il prétend faire subir à des échantillons de vins en les chauffant, épreuve complétement illusoire, puisqu'elle repose sur une erreur capitale, comme je viens de le dire.

Voici ce résumé. On lit p. 524 du Mémoire de 1850 :

" En résumé, nous n'admettons pas que les vins doivent, pour être expédiés au dehors, subir aucun conditionnement qui entraîne avec lui l'addition de substances étrangères.

“ Pour nous, il n'est qu'une manière rationnelle d'améliorer les vins qui doivent faire de longs voyages, c'est de les concentrer par la congélation...

“ Les vins qui ont voyagé dans les pays chauds présentent tous les caractères des vins que l'on soumet artificiellement, dans les limites de 60 à $70^{\circ} \mathrm{C}$., à la chaleur d'un four ou à celle d'un bain-marie. Si, après avoir soumis à cette épreuve quelques échantillons des vins que l'on veut exporter, on reconnait qu'ils y ont résisté, on pourra, en toute sécurité, les expédier; dans le cas contraire, on devra s'en abstenir. »

Parlons maintenant des droits d'Appert dans la question : je les ai revendiqués le premier, et je lui ai rendu la justice que M. de Vergnette lui a refusée en 1850. Le nom d'Appert n'est cité qu'une seule fois par M. de Vergnette-Lamotte; voici dans quels termes :

“ Ne peut-on pas, en outre, s'assurer $a$ priori si les vins résisteront aux fatigues qui résultent de leur envoi dans les pays chauds?

“ J'ai observé, il y a quelques années, un fait assez important qui contribuera singulièrement à éclaircir la question. Souvent obligé, dans le moment de la récolte, de conserver, par la méthode Appert, des moûts destinés à des expériences qui ne pouvaient être faites que plus tard, j’ai aussi appliqué ce procédé à des vins de différentes qualités. "

M. de Vergnette-Lamotte s'attribue donc dans cette dernière phrase le mérite d'avoir le premier appliqué la chaleur aux vins, tandis que ce mérite revient à Appert. Mais Appert, tout en affirmant la conservation, ne l'avait pas démontrée, et ce n'est pas devant cette Académie qu'il est besoin d'insister sur la différence qui sépare une affirmation d'une 
preuve. (Voir à ce sujet la Note de M. Balard [p. 218-226 du présent volume].)

On se prend aujourd'hui d'une belle passion pour les droits d'Appert; c'était en 1850 qu'il fallait les rappeler non pour les moûts, mais pour les vins, et surtout quand il s'est agi de l'expérience dont parle M. de Vergnette sur le vin blanc, expérience qui est la reproduction textuelle de celle d'Appert, sans la mention de son nom et sans la démonstration qui a manqué également à l'expérience de cet éminent praticien.

En résumé, Appert, ainsi que je l'ai publié le premier dans nos Comptes rendus (séance du 4 décembre 1865), a affirmé la possibilité de la conservation des vins par le chauffage, mais il ne l'a pas démontrée. M. de Vergnette, en 1850, s'est attribué le mérite qui revient à Appert d'avoir le premier appliqué la chaleur aux vins, et il a obscurci complétement la question par des erreurs palpables. J'ai, le premier, non seulement démontré la conservation possible de tous les vins naturels, les plus communs comme les plus fins, par une action préalable de la chaleur, à $60^{\circ}$, ne fût-ce que pendant une minute; j’ai donné, en outre, la théorie complète de cette pratique. En France comme à l'étranger, le temps et la raison ont déjà fait justice de toutes les assertions contraires. En Bourgogne notamment, je sais que l'on s'étonne des prétentions de M. de Vergnette et des affirmations gratuites de son ami M. Thenard, qui a cru pouvoir traiter ex abrupto, devant le Conseil général de la Côte-d'Or, en 1869, une question de priorité, n'ayant qu'une connaissance très insuffisante du sujet.

\section{[GHAUFFAGE DES VINS]}

LETTRE A M. LE DIRECTEUR DU JOURNAL D'AGRICULTURE PRATIQUE (1)

Monsieur le directeur,

Paris, le 14 juin 1872.

Dans un article de M. Gustave Heuzé, publié dans le dernier numéro

1. Journal d'agriculture pratique, 1872 , I, p. 896. 
du Journal d'agriculture pratique(1), je trouve ce passage : "Il est incontestable, ainsi que l'a démontré M. de Vergnette-Lamotte, que le chauffage en vases clos peut être utile aux grands vins. "Permettezmoi de faire observer aux lecteurs de votre journal que ce résultat est dû à mes recherches, et non à celles de M. de Vergnette. Pour s'en convaincre; il suffit de lire attentivement les discussions qui ont eu lieu récemment devant l'Académie des sciences et surtout la Note si précise de M. Balard du 26 février dernier ( ${ }^{2}$ ).

M. Heuzé ne traitait pas une question de priorité, et ce fait a pu lui échapper; mais il importe que, dans les questions scientifiques, le jugement de l'opinion publique ne s'égare pas sur les véritables auteurs du progrès.

Veuillez agréer, etc.

L. Pasteur,

Membre de l'Institut.

[M. de Vergnette-Lamotte répondit à Pasteur qui répliqua par la lettre suivante :]

LETTRE A M. LE DIRECTEUR DU JOURNAL D'AGRICULTURE PRATIQUE

Monsieur le directeur,

Paris, le 28 juin 1872.

Permettez-moi de répondre en quelques lignes à la lettre de $M$. de Vergnette-Lamotte, insérée dans votre dernier numéro (4).

Pour soutenir ses prétentions, M. de Vergnette cite une phrase de son Mémoire de $1850\left(^{(5)}\right.$; et il demande si je l'ai oubliée. Non, du tout, je ne l'ai pas oubliée; je la connais si bien que, sans même recourir au Mémoire original, je puis assurer que M. de Vergnette en a fait une citation tronquée. Il omet la moitié de la phrase qu'il cite, ce qui en dénature le sens, surtout si l'on rapproche cette phrase des deux suivantes dans le même travail, et où M. de Vergnette déclare,

1. Heuzé. Réponses à des questions posées (Dernière question) : Quels sont les résultats des nombreux essais tentés pour assurer par le chauffage la conservation des vins et en améliorer la qualité? Ibid., p. 835-837.

2. Balard. Sur l'invention de la méthode de conservation des vins par le chauffage. Comptes rendus de l'Académie des sciences, LXXIV, 1872, p. 561-569.

3. Journal d'agriculture pratique, 1872 , II, p. 31.

4. Vergnette-Lamotte (A. de). Ibid., 1872, I, p. 924.

5. Verganette-Lamotte (A. De) Loc. cit. (Notes de l'Édition.) 
chose inouïe, qu'il n'y a que les vins robustes capables de se conserrer naturellement, que le chauffage n'altère pas. Tous les autres, dit textuellement M. de Vergnette, ne résistent pas à celte épreuve. Contrairement à cette assertion si catégorique, M. de Vergnette prétend que, par la chaleur, il a conservé des vins altérables quinze années avant moi.

Mais, a-t-il donc oublié qu'en 1864, dans une lettre que j'ai rendue publique, il m'écrivait: Que je donnerais des millions à la France, si je parvenais à trouver un procédé capable de prévenir l'amertume des grands vins de Bourgogne (1)? A-t-il donc oublié également que le Mémoire dont il cite aujourd'hui une phrase tronquée se termine par cette déclaration : Pour nous, il n'es̀t qu'une manière rationnelle d'améliorer les vins qui doivent faire de longs voyages, c'est de les concentrer par la congélation?

Veuillez agréer, etc.

\section{Pasteer,} Membre de l'Institut.

[A une nouvelle réponse de $\mathrm{M}$. de Vergnette-Lamotte, Pasteur répliqua par la lettre suivante:]

LETTRE A M. LE DIRECTEUR DU JOURNAL D'AGRICULTURE PRATIQUE (2)

[Sans date.]

Monsieur le directeur,

Permettez-moi quelques nots de réponse à la dernière lettre que vous avez reçue de M. de Vergnette $\left.{ }^{3}\right)$, lettre fort singulière assurément.

De quoi s'agit-il?

Je rectifie un passage d'un article d'un de vos rédacteurs, M. Gustave Heuzé. M. de Vergnette vous envoie des observations critiques, dans lesquelles il traite la question de priorité d'invention de la méthode du chauffage, en s'appuyant sur une phrase qu'il a publiée en 1850. Je lui réplique aussitòt que cette phrase est tronquée et qu'il en a, par suite, dénaturé le sens; je lui rappelle qu'il est faux

1. Voir p. $363-370$ du présent volume.

2. Journal d'agriculture pratique, 1872, II, p. 91-93.

3. Vergnette-Lamotte (A. de). Ibid., p. 54-55. (Notes de l'Édition.) 
qu'il ait jamais conservé des vins altérables par le chauffage, puisqu'il a déclaré formellement, en 1850, que tous les vins d'une santé douteuse sont altérés par la chaleur. Je luı rappelle encore que, s'il avait trouvé, en 1850, le procédé de conserver les vins par le chauffage, il ne m'aurait pas écrit, en 1864, une longue lettre pour m'encourager à chercher un moyen de conservation, me disant que je donnerais des millions à la France, si je réussissais.

Au lieu de me répondre sur tous ces points, comme c'était son devoir, M. de Vergnette vous dit, en tournant bride tout à coup : " Je ne veux pas suivre M. Pasteur dans sa polémique; les revendications de priorité n'ont aucun intérêt pour vos lecteurs. "Je ne suis pas de cet avis. Les questions de priorité intéressent la moralité publique, parce qu'elles traitent de la propriété scientifique, plus respectable encore que toute autre propriété, et qu'il importe extrêmement que l'opinion publique ne s'égare pas sur les véritables auteurs des progrès scientifiques et industriels.

Si M. de Vergnette ne veut pas répondre à ma lettre, c'est tout simplement que je l'ai mis au pied du mur, et qu'il est couvert de cette confusion qu'il a déjà éprouvée devant l'Académie des sciences, lorsque, s'arrêtant dans une citation qui n'avait son véritable sens que dans la phrase suivante, il a refusé obstinément de lire cette phrase.

Le procédé de conservation des vins que M. de Vergnette réclamait de mes efforts en $\left.1864{ }^{(}\right)$, je l'ai découvert, et j'ai donné, en effet, à la Bourgogne notamment, des millions qu'elle n'a qu'à ramasser si elle le désire, et dont M. le vicomte de Vergnette, propriétaire et négociant en vins, a déjà largement profité. J'ai réussi dans cette recherche au delà de tout espoir, ainsi qu'on va le voir de nouveau très prochainement par le procès-verbal de la dégustation qui vient d'être faite dans mon laboratoire par les membres de la Commission syndicale des vins de Paris, en présence de plusieurs membres de la Société centrale d'agriculture (2).

M. de Vergnette, qui a chauffé du vin en 1850, mais sans comprendre ce qu'il faisait, voudrait aujourd'hui partager l'honneur de la découverte avec moi, mais je lui déclare qu'il n'y parviendra pas.

Quand il a dépouillé Appert en 1850 d'une manière si audacieuse, Appert était mort et n'a pu réclamer : c'est moi qui ai revendiqué ses droits. Quant à moi, j'ai le bonheur de vivre encore, et je saurai défendre la vérité.

1. Voir p. 363-370 du présent volume.

2. Voir p. 378-381 du présent volume. (Notes de l'édition.) 
Je bornerais là cette lettre, M. le directeur, si je n'avais à vous signaler encore, dans la Communication que vous avez reçue de M. de Vergnette, un procédé de discussion vraiment inqualifiable.

Voici le passage auquel je fais allusion :

“ D'ailleurs, M. Pasteur ne peut avoir oublié qu'il eut, en 1865, la pensée d'exploiter son brevet en s'associant avec moi, comme il me le donnait à entendre dans sa lettre du 13 [11] juillet. On comprend que je laissai cette lettre sans réponse. M. Pasteur reconnaissait donc alors que la découverte du chauffage ne lui appartenait pas, puisqu'il parlait d'en partager l'honneur. En définitive, je souhaite que M. Pasteur n'oblige jamais $\mathrm{M}$. Thenard et moi à sortir de la réserve que nous nous sommes imposée devant l'Académie dans ces regrettables débats. "

Je proteste énergiquement contre ces phrases ridiculement comminatoires, et je déclare que jamais, ni directement, ni indirectement, je n'ai eu la moindre idée d'associer M. de Vergnette à l'honneur de mes travaux, quoiqu'il m'en ait prié, par exemple, dans cette phrase de sa lettre du 10 juin 1864 :

" Ce que je sais, je le mettrai à votre disposition, et serai très heureux si vous voulez bien me faire une petite part dans la publication de vos travaux."

Ma lettre de juillet 1865, à laquelle M. de Vergnette fait allusion, ET DONT Fort heUREUSEMENT J'Ai GARdé LA Minute EXACTE, ne renferme quoi que ce soit qui signifie que je reconnaissais, en 1865, que M. de Vergnette eût la moindre part à l'honneur de la découverte du chauffage des vins. Elle dit le contraire.

Voici tout entière cette lettre :

Paris, le 11 juillet 1865.

Je n'ai reçu votre lettre qu'au retour d'un voyage dans le Midi qui a duré près d'un mois, et dont l'objet principal était l'étude de la maladie des vers à soie. C'est le ministre de l'agriculture qui, à mon grand regret, m'a chargé de cette mission. Aujourd'hui, elle me sourit davantage, parce que j'ai commencé des essais dont j'attends quelques indications utiles sur la nature de ce fléau. Mais tout cela sera bien long et bien difficile à suivre.

Je vous remercie de l'examen auquel vous vous livrez au sujet des vins chauffés que je vous ai renvoyés; j'en attendrai avec impatience le résultat. Cependant je suis déjà un peu fixé par ceux que me présentent les nombreux échantillons que j'ai éprouvés depuis quelques mois, et que je dois en partie à l'obligeance de vos compatriotes et amis. Ainsi II. Marey-Monge a bien voulu m'envoyer du pomard de 1848, en voie 
d'altération. M. Boillot, maire de Volnay, m'a envoyé du volnay qu'il croit prêt à s'altérer.

SUr tous ces vins, Mon procédé faIt MerveiLle.

Ainsi votre numéro 21 non chauffé est déjà en grande voie d'altération; le mẹme, numéro 21 , chauffé, est intact, et ainsi de beaucoup d'autres. Ces résultats, dont les premiers témoins sont les personnes de ina famille, ne laissent pas que d'amener pour moi à leur suite bien des ennuis. Vous aurez remarqué, dans le compte rendu du $1^{\text {er }}$ mai, que j'avais pris un brevet d'invention, dans le but principalement de suivre à mon aise l'application de ce moyen, et voilà que je suis tourmenté pour en profiter, ce qui me répugne pour toutes sortes de motifs. Ma femme, qui seule compte dans le ménage, et que l'avenir de ses enfants préoccupe, me donne les meilleures raisons en apparénce póur lever mes scrupules. Je ne sais pas même si elle ne devait pas vous en écrire et prendre conseil de votre expérience, voire même vous proposer une association (1)!

(Suivent quelques tristes paroles sur un malheur de famille.)

$$
\text { Signé : L. Pasteun. }
$$

Voilà la lettre, noble et digne, j'ose le dire, à laquelle M. de Vergnette-Lamotte n'a pas craint de faire allusion dans les termes mensongers que j'ai rappelés tout à l'heure.

C'est de mon PRocÉDÉ que je lui parle; je n'aurais pu faire allusion à son travail de 1850 ou du $1^{\text {er }}$ mai [1865], que pour en dénoncer les erreurs ; car M. de Vergnette n'a publié avant moi que des erreurs dans la question du chauffage des vins : ce qu'il a dit d'exact depuis lors, il l'a pris dans mes publications, sans me nommer jamais ou seulement dans les caś où il n'a pu agir autrement. J'en ai mille exemples. Je le mets aU défi de citer un SeUl fatt vrai sur Ge sujet

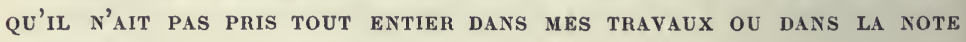
D'APPERT.

Je lui laisse toute la responsabilité de ses procédés de discussion, et je suis heureux qu'il déclare aujourd'hui mettre de côté la question de priorité de l'invention de la méthode du chauffage, la seule que j'aie jamais voulu traiter avec lui, parce que je suis bien décidé à ne pas me laisser dépouiller par lui comme il a dépouillé Appert en 1850.

\section{Pasteur,}

Membre de l'Académio des sciences et de la Société centrale d'agriculture.

1. Voir, à ce propos, la note 2 de la page 223 et la note 2 de la page 301 du présent volume. (Note de l'Édition.) 
RÉPONSE DE M. PASTEUR A M. DE VERGNETTE-LAMOTTE (1)

Ma visite à Poinard, le 15 septembre 1865, dont parle M. de Vergnette, avait eu pour unique objet la constatation de l'état des vins chauffés, que je lui avais renvoyés avec cette mention : Ces viss NE s'aLténeroNt JaMais; car il est la première personne que j'aie mise dans la confidence du succès de mes travaux. La réponse de M. de Vergnette à mon arrivée à Pomard a été celle-ci : Ces vins sont dans LA Cave de ma mére; Je X'ex ai pas la cLef. Je le regrette bikn.

L'histoire des propositions faites ou renouvelées dans le cours de cette visite est absolument apocryphe.

M. de Vergnette parle de rupture à propos de cette visite. Ses souvenirs le trompent. Son hospitalité a été très gracieuse; ma visite s'est terminée par une invitation très obligeante à dîner et à passer la nuit dans son château de Meursault, ce que je n'ai pu accepter.

La rupture date d'une lettre de $M$. de Vergnette du 18 novembre $1865{ }^{(2)}$, provoquée par la publication de ma lettre du 11 octobre, insérée au Moniteur vinicole un mois auparavant, dans laquelle j'exposais les observations de M. de Vergnette avec une extrême courtoisie, tout en les appréciant avec vérité. Le lecteur trouvera cette lettre reproduite dans mes "Études sur le vin » $\left({ }^{3}\right)$. Le ressentiment de II. de Vergnette me causa d'autant plus de surprise qu'à cette époque je lui attribuais encore tout ce qu'avait fait Appert, trompé que j'avais été par cette phrase de son travail de 1850 : "Souvent obligé, dans le moment de la récolte, de conserver des moûts par la méthode d'Appert, j'ai Aussi appliqué ce procédé à des vins de différentes qualités $\left({ }^{4}\right)$. 》

1. Journal d'agriculture pratique, 1872, II, p. 163-164.

Cette réponse a été motivée par une lettre de M. de Vergnette-Lamotte au Journal dagriculture pratique, 1872, II, p. 132-133 : ... « M. Pasteur, dit M. de Vergnette-Lamotte, est venu me trouver à Pomard et me renouveler ses propositions... Il m'avait d'ailleurs, dès le 7 mai 1864, écrit les lignes suivantes [Voir cette lettre in extenso, note 2 de la p. 370 du présent volume] : a Je ne vous cacherai pas que j'ai pour ainsi dire commencé le voyage de " Dijon à Meursault aux vacances dernières dans l'intention d'aller vous demander divers " renseignements et de profiter des conseils de votre longue expérience. Aujourd'hui, vous " voulez bien me les offrir. Je vous en suis doublement reconnaissant, et je serai heureux " d'unir mes efforts aux vôtres w... En résumé, je conteste \& M. Pasteur la découverte de la conservation des vins par le chauffage; l'invention appartient à Appert..."

2. Voir cette lettre note 1 de la page 425.

3. Vour p. 343-361 du présent volume. Lettre de M. Pasteur au Moniteur vinicole.

4. Voir p. 452 du présent volume. (Notes de l'Édition.) 
Ce n'est que le 4 décembre 1865 que je rectifiai cette erreur devant l'Académie.

Le respect seul de la vérité me fait faire cette déclaration au sujet de ma visite à Pomard; car je ne vois pas en quoi une proposition d'association aurait affirmé que M. de Vergnette avait une part dans la démonstration expérimentale de l'efficacité de la méthode du chauflage. Si je venais à proposer une association à l'un des grands industriels qui exploitent mon procédé de fabrication du vinaigre ou mon procédé de confection dé la graine de vers à soie, cela signifierait-il que je leur reconnais une part dans la découverte de ces procédés?

En présence du caractère donné à cette discussion par M. de Vergnette, je renonce à le suivre sur un terrain où il n'apporte plus que de la passion, réservant mon temps et mes forces à des soins plus profitábles à la science, et, s'il plaît à Dieu, à l'honneur de mon pays.

Les inventions heureuses sont d'ordinaire suivies de revendications plus ou moins vaines, dont le bon sens public finit toujours par faire justice.

Dans la question présente, c'est déjà fait.

* En France, le jury de l'Exposition universelle de 1867 a décerné un de ses grands prix à mes études sur le chauffage des vins; à l'étranger, le chauffage porte le nom de pasteurisation et les appareils pour l'appliquer appareils à pasteuriser les vins.

Je laisserai donc le temps achever son œuvre et mettre chacun à sa place; mais si cela devenait nécessaire, je demanderais aux sections réunies de chimie et d'agriculture de l'Académie de se faire juge du débat. J'attendrais leur sentence avec confiance, et je la recevrais avec respect.

L. Pasteur, Membre de l'Institut. 


\section{POURQUOI LE GOUT DE LA VENDANGE DIFFÈRE DE CELUI DU RAISIN (1)}

\section{Messieurs,}

Dans la conduite des affaires domestiques, on dit souvent qu'il n'y a pas de petites économies. Avec ron moins de vérité, on pourrait dire que dans l'exploration des lois de la nature, comme dans la recherche du progrès industriel, il n'y a pas de petites observations. Les plus simples parmi celles-ci, les circonstances les plus ordinaires, des précautions, en apparence, futiles peuvent acquérir une utilité considérable, décider quelquefois de la qualité des produits, devenir même la source d'applications nouvelles. Franklin, se trouvant un jour au milieu d'une foule nombreuse qui assistait à l'exhibition d'une grande nouveauté scientifique, entendit autour de lui ces paroles : "A quoi cela peut-il servir? " Franklin répondit aussitôt : " A quoi sert l'enfant qui vient de naître? " Parole charmante et profonde qui doit soutenir l'ardeur du savant dans la recherche des lois naturelles, et inspirer à l'homme du monde et au praticien la plus grande estime pour les nouveautés scientifiques, lors même qu'il ne saurait y entrevoir l'utilité d'une application immédiate.

Permettez-moi, messieurs, de placer sous les auspices de la philosophie de ce petit préambule l'exposition d'un fait nouveau qui intéressera peut-être un jour l'art de faire le vin, mais qui n'est encore qu'une simple observation scientifique.

Il n'est personne parmi vous qui n'ait fait la remarque plus ou moins consciente que la saveur si agréable d'un raisin mûr diffère beaucoup de celle de la vendange. Le moût de la vendange n'a pas du

1. Comptes rendus des travaux du Congrès viticole et séricicole de Lyon, 9-14 septembre 1872. (Séance dı 11 septembre 1872), p. 45-49.

Voir, p. 387-394 du tome 1 I des CEuvres DE PAsteun, la Communication intitulée : Faits nouveaux pour servir à la connaissance de la théorie des fermentations proprement dites. (Comptes rendus de l'Académie des sciences, LXXV, 1872, p. 784-790.) Pasteur traite le même sujet à la fin de cette Communication. (Note de l'Édition.) 
tout, en effet, le goût du jus des grains de raisin sur la grappe. L'odeur même de la vendange a quelque chose de particulier qu'on ne retrouve pas dans le raisin. Enfin, plus on s'éloigne du moment de l'égrappage, plus est grande la différence que je signale entre les grains du raisin et ceux qu'on retire de la cuve du vendangeur, indépendamment même de l'influence de la fermentation naturelle du moût, dont je fais abstraction pour le moinent.

D'où viennent ces différences? Vous l'ignorez tous, et moi-même je l'ignorais il y a deux mois à peine. Aujourd'hui, j'en connais l'explication, et c'est de celle-ci que je veux vous entretenir un instant.

Lorsqu'une grappe de raisin est détachée du cep de vigne, la vie n'est pas suspendue dans l'intérieur des grains de cette grappe. L'observation la plus vulgaire nous apprend que des phénomènes physiques et chimiques nombreux se passent dans les cellules de tous nos fruits domestiques après qu'on les a détachés de l'arbre qui les portait. Les acides, le tanin, des principes mal connus, qui leur communiquent leur verdeur, se transforment plus ou moins, en même temps que du sucre se développe en grande quantité. Plus tard, les phénomènes changent encore; de là, les expressions de maturation, de blessissement, etc. Pour être moins apparents que dans certains fruits, des actions analogues n'existent pas moins dans tous les organes des animaux et des végétaux pendant un temps variable, toutes les fois que la vie est suspendue dans les individus dont ces organes faisaient partie. Ces phénomènes, propres à l'intérieur des fruits et des organes dont nous parlons, sont toujours corrélatifs de changements profonds dans l'atmosphère extérieure. Des observations précises ont permis de constater qu'un fruit, une grappe de raisin, par exemple, suspendue dans l'air que nous respirons, le modifie sans cesse. Du gaz oxygène est absorbé par les grains du raisin, et un volume à peu près égal de gaz acide carbonique se dégage en même temps.

Modifions les conditions de cette expérience; entourons notre grappe de raisin d'un gaz inerte, par exemple de gaz acide carbonique. C'est une condition très facile à réaliser : Voici des cloches de cristal qui reposent sur des lames de verre. Ces cloches ont une tubulure munie d'un bouchon, percé de deux trous que traversent des tubes de verre, l'un pour l'entrée du gaz acide carbonique, l'autre pour sa sortie. Faisons communiquer le tube d'arrivée avec une source de gaz acide carbonique, qui, peu à peu, chassera l'air contenu dans la cloche. Si nous avons préalablement déposé dans cette cloche quelques grappes de raisin, tous les grains de celle-ci se trouveront bientòt enveloppés d'une atmosphère de ce gaz. Les jours suivants, aucun phénomène 
bien apparent ne se manifeste. Les grains conservent leur fermeté; leur couleur se modifie peu ou point. Si vous avez laissé auprès de la cloche, en plein air, des grappes pareilles, l'aspect des unes et des autres ne différera pas. En réalité, ces apparences sont trompeuses; des phénomènes chimiques très remarquables ont lieu dans tous les grains, aussi bien sous la cloche qu'à l'extérieur; mais ceux qui s'accomplissent sous la cloche diffèrent complétement de ceux qui se passent au dehors. Chose curieuse, les grains enveloppés d'acide carbonique dégagent de l'acide carbonique comme ceux du dehors, mais évidemment sans absorption correspondante d'oxygène, puisque ce gaz n'existe pas sous la cloche. Aussi tous les autres phénomènes diffèrent pour les deux sortes de grains. Les grains du dehors conservent, à peu de choses près, leur saveur sucrée, qui s'augmente plutôt qu'elle ne diminue. Les grains sous la cloche, au contraire, perdent du sucre, paraissent plus acides et surtout se chargent d'alcool, ce qui n'arrive pas pour ceux du dehors. Quand on soulève la cloche, on perçoit distinctement une odeur vineuse, mais ce qui est particulièrement digne de remarque (du moins, c'est le fait sur lequel je désire appeler votre attention), les grains qui ont été enveloppés de gaz acide carbonique ont absolument le goût de la vendange. Écrasez-les et goûtez leur jus, vous serez frappés de la similitude à peu près complète qui existe entre la saveur de ce jus et de celui de la cuve du vendangeur.

Les conséquences de ces faits ne peuvent laisser aucun doute sur l'explication de la différence entre le goût de la vendange et celui du raisin. En effet, l'expérience que nous venons de faire, vous la réalisez. vous-mêmes chaque fois que vous vendangez. Il existe, je l'ai prouvẻ ailleurs, dans le moût du raisin, des principes essentiellement oxydables. A peine le raisin est-il égrappé que le peu d'oxygène de l'air atmosphérique qui entoure les grappes, mouillées par un peu de ce moût, se trouve absorbé, et, par suite, les grains de raisin se trouvent, comme dans notre cloche, à l'abri de toute influence de ce graz oxygène.

Aussitòt les phénomènes dont nous venons de parler commencent à se manifester, et c'est ainsi que la vendange possède exactement la saveur, l'odeur et le goût de plus en plus vineux des grains de raisin enveloppés de gaz acide carbonique.

Telle est l'observation nouvelle que je tenais à vous faire connaître.

Pour rappeler la comparaison de Franklin, je dirai que voilà un enfant qui vient de naître. C'est à vous, messieurs, qu'il appartient de le suivre, de le faire grandir, et, s'il se peut, de le rendre un jour utile à la prospérité du pays. Si j'étais viticulteur, je voudrais tout de suite 
placer, sur des claies étagées, dans une chambre, des grappes de raisin, remplir l'espace de gaz acide carbonique, ne fût-ce qu'en faisant fermenter dans quelques baquets ou tonneaux, sur le sol de la chambre, une certaine quantité de vendange; puis, j'écraserais les grappes, au pressoir ou autrement, et je ferais fermenter le nouveau moût. Je varierais même cette expérience de diverses façons en laissant, par exemple, de petites quantités d'air, ou en supprimánt complétement l'oxygène; je laisserais aussi, pendant plus ou moins de jours, les grappes entourées de gaz inerte. J'opérerais enfin sur des raisins a des degrés variables de maturité. Quelles sortes de vins, quelles sortes d'eaux-de-vie pourrait-on retirer de ces moûts qui auraient fermenté, après avoir été placés dans ces conditions toutes particulières? Je l'ignore; mais puisqu'un fait scientifique nouveau vient de vous être soumis et qu'il intéresse évidemment les pratiques de la vinification, c'est à vous de rechercher s'il ne serait pas possible de lui trouver quelque application nouvelle pouvant être utile, commercialement parlant. Tout au moins, il importe de se préoccuper de l'influence qu'il peut avoir dans les pratiques de la cueillette du raisin et de la cuvaison à son début. Souvenez-vous qu'il n'existe pas de sciences appliquées, mais seulement des applications de la science. 


\section{SUR LA CONSERVATION DES VINS DE GRANDS CRUS DE LA BOURGOGNE (1)}

Samedi dernier, 17 janvier, j'ai reçu la visite de M. Boillot, maire de Volnay (Côte-d'Or).

Je prie la Société de me permettre de lui rendre compte de l'entrevue que j'ai eue avec cet honorable propriétaire dans la forme où elle s'est produite, celle du dialogue. Publiés de cette façon, les enseignements qui ressortent de cette conversation attireront peut-être l'attention des personnes intéressées à les bien connaître.

M. Boillot. - Je viens, monsieur, vous remercier de l'obligeance que rous avez eue de me faire adresser, par le secrétaire de l'Académie, les travaux déjà publiés sur le phylloxera, conformément à la demande que je vous en avais faite.

M. Pastevn. - Votre nom a été inscrit par ordre de M. le secrétaire perpétuel, et je pense que, en votre qualité de maire d'une commune clont le vignoble est très important, vous recevrez ce qui pourra être encore publié à l'avenir sur ce sujet.

Chauffez-vous votre vin, monsieur le maire?

M. Boillot. - Non, monsieur; je voudrais bien le chauffer, car nos vins de 1870 sont à la veille de se gâter. Mais comment les chauffer? Quel appareil employer? Et puis, il y a des personnes qui assurent que cela peut faire du mal à nos grands vins.

M. Pasteur. - En effet, on a même dit que « le chauffage équivalait pour ces vins à une amputation ». Voulez-vous bien, monsieur le maire, lescendre avec moi dans ma cave d'expériences... Voici des rangées de bouteilles de vins de vos grands crus, qui ont été chauffées; elles sont placées à côté d'autres des mêmes vins, non chauffées. L'expérience comparative date de l'année 1866 ; il y a plus de sept ans. Vous

1. Bulletin de la Société centrale dagriculture de France, séance du 21 janvier 18\%彳, 3. sér., IX, 1873-1874, p. 198-202. 
n'ignorez pas qu'en 1864 j'ai démontré que les altérations spontanées, ou maladies des vins, étaient produites par le développement, dans l'intérieur du vin ou à sa surface, de petits champignons microscopiques, dont les germes sont apportés dans le moût du raisin, à l'époque de la vendange, par les poussières en suspension dans l'air ou répandues à profusion à la surface des grains, du bois de la grappe, des feuilles, etc., etc., germes que les filtrations et les collages qu'on fait subir au vin n'enlèvent que très imparfaitement.

En 1865 (1), j’ai reconnu qu'il suffisait de porter le vin, ne fût-ce qu'une minute, à la température de $60^{\circ}$, pour tuer tous ces germes de maladie.

Ces découvertes, que le temps n'a fait que confirmer, étaient à peine publiées, que la contradiction, qui s'attache invariablement à toutes les nouveautés, même les mieux établies, déclara que ce moyen de conservation pouvait peut-être convenir à des vins communs, mais que bien certainement, par cette pratique, on enlèverait aux vins fins leur délicatesse et leur bouquet; qu'en un mot on les empêcherait de vieillir dans de bonnes conditions. Ceux qui parlaient ainsi affirmaient ce qu'ils ignoraient, ce que j'ignorais moi-même, puisque mes expériences sur le vieillissement des vins chauffés n'existaient pas encore. Le temps seul pouvait permettre de porter, sur la question particulière du vieillissement après chauffage, un jugement autorisé.

Dans ce but, je fis venir de la Bourgogne, en 1866, un certain nombre de bouteilles de chacun de vos grands crus: Chambertin, Nuits, Volnay, Pomard, Romanée, Vougeot, Échezaux, Saint-Georges, Beaune. Je chauffai une partie des bouteilles de chaque sorte, puis je les déposai à côté d'un égal nombre de bouteilles non chauffées.

Les voici tous, ces vins de vos grands crus. Choisissez vous-même, au hasard, deux bouteilles, l'une prise dans la rangée de celles qui ont été chauffées, l'autre dans la rangée des non chauffées. Vous allez les déguster, par comparaison...

M. Bolllot. - Vin de Pomard 1861. - Le vin chauffé vaut 4 francs la bouteille; le non chauffé ne vaut pas 1 franc la bouteille.

Vin de Pomard 1863. - Le vin chauffé vaut plus de 4 francs la bouteille; le non chauffé ne vaut pas 50 centimes la bouteille.

Vin de Volnay 1863. - Je reconnais mes étiquettes. C'est moi qui vous ai vendu ce vin en 1866. Le vin chauffé est excellent. Le vin non chauffé est bon aussi, bien conservé, mais ne vaut pas l'autre.

1. Voir p. 409-412 du présent volume: Procédé pratique de conservation et d'amélioration des vins. (Note de l'Édition.) 
Vin de Volnay 1864. - C'est encore de mon vin. Le non chauffé est bon, très beau, mais il est à son apogée. Il ne peut plus que perdre. Le vin chauffé est bien supérieur, très solide, il a encore une longue vie.

Ainsi donc, quand bien même on serait assuré que nos grands vins pourraient se conserver, ce qu'on ne sait jamais avec certitude, il faudrait encore les chauffer, parce que cela les améliore étonnamment à la longue.

Je me déclare satisfait et convaincu. Je ne veux pas déguster les autres vins. Je suis émerveillé. Ca me produit le même effet que si je vous voyais verser de l'or à pleines mains dans nos contrées. Ah! je ne savais pas cela!

M. Pasteur. - Vous voilà bien, mes chers compatriotes, occupés de politique, d'élections, de la lecture superficielle des journaux! Mais les livres sérieux qui traitent des affaires du pays, de vos propres intérêts, vous les laissez de còté! Cela vous demanderait quelque peine pour les comprendre et en suivre les sages avis, motivés par des travaux assidus qui, souvent, compromettent la santé de leurs auteurs.

I. Вогцот. - Détrompez-vous, monsieur; j'ai lu dans des Comptes rendus de l'Académie que M. Pasteur avait dit que le chauffage conserve et améliore nos vins; mais, en tournant la page, $j$ 'ai vu que des confrères de M. Pasteur le contredisaient et soutenaient que le chauffage tue les qualités de nos grands vins. Que voulez-vous que nous fassions, nous autres rignerons?

M. Pasteur. - Combien vous m'attristez, monsieur le maire! Vous mettez à nu un autre travers de notre caractère national, une sorte de penchant à la contradiction superficielle, qui ne supprime pas, sans doute, la vérité, mais qui en arrête le cours et peut retarder les applications les plus utiles. Nous n'aimons pas le succès chez le prochain. Notre premier mourement est d'en nier l'existence et la réalité. Pourtant, monsieur le maire, en lisant avec attention, vous auriez pu reconnaître que tout ce que j'arais annoncé était accompagné de faits précis, de rapports officiels, de dégustations par des hommes compétents, tandis qu'on ne m'avait opposé que des assertions sans preures.

M. Bolllot. - C'est vrai ; mais je vous assure, monsicur, que c'est bien difficile. Vos confrères qui vous ont contredit sont de grands propriétaires en Bourgogne; ils ont intérêt à connaître tout ce qui peut être utile à nos vins. Mais soyez tranquille, dorénavant je ne croirai plus vos contradicteurs, et tout de suite, en rentrant à Volnay, je vais m'occuper de cette affaire: inais quel appareil choisir? 
M. Pasteur. - Pour vos vins, qui sont des vins de grand prix, il faut prendre l'appareil le plus parfait; c'est la bouteille bouchée. Je vais faire chauffer, en votre présence, cinquante bouteilles. (L'opération dura une demi-heure au plus.)

M. Boillot. - Comment, c'est aussi simple que cela? Je n'en reviens pas; demain j'aurai commandé une grande marmite ou une bâche pareille à celle-ci pour chauffer mon vin. Est-ce possible, moi qui viens de perdre une pièce de vin de 1870 ! Je l'avais mise en bouteilles, il y a quelque temps, pour des conseillers généraux; je vais en prendre quelques-unes : je vois des choses flottantes, vos champignons de maladie évidemment. Je déguste; impossible de livrer ce vin, il commençait à se gâter.

M. Pasteur. - Pour prix de la leçon que je viens de vous donner, monsieur le maire, je vous demande de faire connaître tout ce que vous venez d'apprendre à vos administrés; ce sont des millions que vous donnerezà la Bourgogne.

M. Borllot. - C'est vrai. Et que pensez-vous, monsieur, des vins gelés?

M. Pasteur. - La congélation est une pratique beaucoup plus embarrassante et dispendieuse que celle du chauffage; elle produit un effet analogue au vinage ou à ce que vous appelez procéder les vins; mais elle n'empêche pas les maladies de se produire. Si vous voulez, je vais vous montrer des vins de vos grands crus qui ont été gelés et qui sont altérés.

M. Boillot. - C'est très vrai; je l'ai constaté souvent. Je ne saurais trop vous remercier, monsieur, de votre obligeance; je ne puis vous dire combien je retourne heureux et content à Volnay. Voulez-vous me permettre de vous envoyer 25 bouteilles de mon vin de 1870 ?

M. Pasteun. - Très volontiers, monsieur le maire, j'en chaufferai douze, cela arrêtera le mal au point où il se trouve, et je laisserai les autres bouteilles telles quelles. Chaque année, pendant douze ans, si Dieu me prête vie, je ferai déguster, par comparaison, une bouteille de chaque sorte, soit par vous, si vous venez à Paris, soit par un de vos compatriotes, soit même par ceux qui vous ont fait tant de tort en propageant légèrement des erreurs.

(A la suite de cette lecture, M. Pasteur fait déguster des vins de Pomard de la même année, 1863, les uns chauffés, les autres non chauffés. La supériorité des vins chauffés est reconnue incontestable.) 


\section{[SUR L'APPLICATION DU CHAUFFAGE A LA CONSERVATION DES VINS DE VOLNAY (1)]}

M. Pasteur fait suivre la présentation d'une Note de M. Paul Muller [ Sur la conservation des vins blancs d'Alsace au moyen du chauffage »] de quelques observations qui se réfèrent à une conversation qu'il a eue, le 17 janvier 1874, avec M. Boillot, maire de Volnay (Cote-d'Or), conversation qui a été publiée dans le Bulletin de la Société () et dans divers journaux d'agriculture.

A la suite de cette conversation, M. Boillot adressa à M. Pasteur vingtquatre bouteilles de vin de Volnay de 1870, qui paraissait en voie d'altération. Douze de ces bouteilles furent chauffées à $55^{\circ}$, le 13 juillet 1874 , et mises à côté des douze restantes non chauffées. Toutes les bouteilles chauffées sont très saines, sans dépôt flottant, très bonnes au goût. Toutes les bouteilles non chauffées commencent à être acides et amères et montrent un dépot flottant très abondant. Leur saveur laisse considérablement à désirer, et nul doute que, dans un an ou deux, elles ne seront pas buvables.

M. Pasteur s'est empressé d'écrire à M. Boillot pour lui demander ce qui élait arrivé au même vin chauffé, à Volnay, sur une plus grande échelle. Par une lettre en date du 16 décembre courant, M. Boillot a fait savoir à M. Pasteur que les vins chauffés et non chauffés s'étaient comportés chez lui absolument comme à Paris.

M. Pasteur fait ensuite déguster aux membres de la Société une bouteille de vin qui a été chauffé et une bouteille de vin non chauffé.

1. Bulletin de la Société centrale d'agriculture de France, séance du 22 décembre 1875 , XXXV, p. 742-745.

2. Voir la Communication précédente. (Note de l'Édition.) 


\section{SUR LES VINS FAITS AVEC DES CÉPAGES AMÉRICAINS (1)}

M. Pasteur donne lecture de la lettre suivante qu'il a écrite à M. Dumas, président de la Commission du phylloxera, à la date du 12 juin, sur la dégustation, dans son laboratoire, par M. Bouchardat, de quelques bouteilles de vins faits avec des cépages américains cultivés à Bordeaux par M. Laliman.

$\mathrm{Au}$ mois de novembre 1873, MM. Laliman et Max Cornu m'ont adressé quelques bouteilles de vins faits avec des cépages américains cultivés à Bordeaux, en me priant de les soumettre au chauffage afin de les conserver et d'en apprécier ensuite la valeur, comparativement avec des vins ordinaires de cépages bordelais.

Aussitôt après l'arrivée des échantillons, je les ai fait chauffer à $60^{\circ}$; mais ne me trouvant pas compétent pour juger de la qualité de ces vins, je les ai abandonnés dans une cave, jusqu'au moment où une occasion favorable se présenterait à moi pour les faire déguster. Tout récemment, à la suite d'une Communication de M. Bouchardat (2) à la Société centrale d'agriculture, la Société, sur.ma demande, a prié notre savant collègue, dont les connaissances en œnologie font autorité, de vouloir bien venir dans mon laboratoire pour apprécier les vins de M. Laliman. M. Bouchardat a accepté avec son obligeance accoutumée.

Voici le procès-verbal de la dégustation joint à la note descriptive des échantillons dressée par M. Cornu sur les indications de M. Laliman.

$N^{\circ} 1$. Vin de l'année 1872 fait avec des cépages divers (Jacques, Lenoir, Vitis æstivalis), (Clinton, $V$. riparia) et deux types rapportés au $V$. cordifolia, cépages résistants jusqu'ici. Les deux premiers cépages sont en grand excès.
Limpidité brillante; très belle couleur.

Odeur satisfaisante, agréable, de bon vin ordinaire.

Saveur franche d'un bon vin commun ordinaire.

Faible dépôt flottant dans la gouttière.

1. Bulletin de la Société centrale d'agriculture de France, séance du 17 juin $1874,3^{\circ}$ sér., IX, 1873-1874, p. 618-621.

2. Bouchardat. Rapport sur les travaux de M. Laliman relatifs au phylloxera. Ibid., p. 519-521. (Note de l'Édition.) 
$\mathrm{N}^{0}$ 2. Vin de l'année 1873. Mêmes cépages que les précédents.
Limpide; couleur vive et foncée. Odeur normale d'un vin commun très jeune.

Saveur agréable d'un vin commun droit, corsé.

Faible dépôt adhérent.
$\mathrm{N}^{\circ} 3$. Vin de l'année 1872 ; bordeaux ordinaire; vin de la propriété; c'est du vin de Palus qui se vend 550 à 600 francs la tonne (environ 9 hectolitres).
Très limpide; couleur plus faible que le $n^{\circ} 1$.

Odeur de vin ordinaire.

Saveur d'un vin commun acide, très inférieur au $\mathrm{n}^{\circ} 1$.

Dépôt presque nul.
$N^{\circ} 4$. Vin de l'année 1873. Mêmes cépages que les précédents.
Limpide; couleur plus faible que le $n^{0} 2$.

Odeur bonne.

Saveur agréable d'un vin nouveau commun.

Il y a, avec le $n^{\circ} 2$, la même différence qu'entre les $n^{\text {os }} 1$ et 3 .

Le $n^{0} 2$ est plus corsé que le $n^{0} 4$, mais sa saveur est moins franche, un peu plus âpre; il plairait peutêtre plus au commerce, à cause de sa couleur et de sa fermeté.
No 5. Vin de Long (ou Cunningham) Vitis æxtivalis, 1873; cépage résistant jusqu'ici.
$N^{\circ} 6$. Vin de Warren (ou Herbemont Vitis æxstivalis, 1871); cépage résistant jusqu'ici.
Limpide; couleur rosée.

Odeur un peu alcoolique, avec quelque chose de spécial.

Saveur alcoolique, sucrée, avec un bouquet spécial; un peu trop acide pour un vin de liqueur; en somme, agréable.

Faible dépôt flottant.

Moins commercial que tous les vins précédents.

Très limpide; couleur rosée très faible.

Odeur alcoolique et aromatique. Saveur étrange; ce vin ne paraît pas commercial.

Dépôt très faible, presque nul. 
$\mathrm{N}^{\circ}$ 7. Vin Delaware 1873 (Vitis restivalis, ou $V$. Labrusca, hybride?); cépage non résistant; le raisin est rosé, excellent; il mûrit vite; on en fait usage en Amérique pour la confection des vins spéciaux, faux champagne, faux lunel, etc. M. Laliman pense qu'il ferait très bien dans le Centre, dans le Loiret.

$\mathrm{N}^{\circ}$ 8. Vin d'Isabella (Vitis Labrusca), cépage non résistant; mélange des années 1868 et 1870.

L'intérêt de cette dégustation paraît se concentrer particulièrement sur les échantillons 1 et 2 , comparés aux échantillons 3 et 4 .
Très limpide; couleur rosée peu franche.

Odeur peu agréable, alcoolique. Saveur acide, avec arrière-goût étrange, qui rendrait ce vin impropre au commerce en France. Peu de dépôt. vin rouge ordinaire.

Odeur spéciale.

Saveur âpre, très étrange et désagréable, impropre au commerce. Dépôt adhérent.
Très limpide; bonne couleur de 


\section{[FERMENTATION DU MOUT DE RAISIN]}

Voir la Note "Quelques faits nouveaux au sujet des levûres alcooliques ", tome II des CEuvres de Pasteun, p. 150-158.

Voir la « Discussion avec MM. Fremy et Trécul sur l'origine et la nature des ferments ", tome II des CEvvies de Pastecr, p. 367-417, en particulier p. 385-386 "Nouvelles expériences pour démontrer que le germe de la levûre qui fait le vin provient de l'extérieur des grains de raisins ».

Voir les Communications "Sur l'expérience de Gay-Lussac relative an départ de la fermentation du moút de raisin par l'action de l'oxygène de l'air " et "Sur la fermentation du moût de raisin ", tome II des CEuvres p*: Pastevr, p. 427-429 et 429.

Voir la « Note sur la fermentation des fruits et sur la diffusion des germes des levûres alcooliques ", tome II des Euvres de Pasteur, p. 453-455.

Voir Examen critique d'un écrit posthume de Claude Bernard sur la fermentation, tome II des CEuvnes de Pasteur, p. 483-615.

Voir Études sur la bière, tome $\mathrm{V}$ des CEuvres de Pasteer.

(Note de l'Édition.) 


\section{[INTERVEATION(1) DANS LA DISCUSSION DE LA COMMUNICATION \\ DE M. BOUCHARDAT :] \\ " SUR LES EFFETS DE LA GELÉE DU 20 SEPTEMBRE SUR LES GÉPAGES DE BOURGOGNE »}

... M. Bouchardat dit que, cette année, la fermentation ne s'est pas établie régulièrement; que l'absence de pluie a empêché la production de mucédinées, de moisissures et de champignons. Il tient à constater le fait sans prétendre aller au delà.

M. Pasteur dit que le fait signalé par M. Bouchardat s'est produit dans beaucoup de localités, et il annonce, à ce sujet, avoir reçu une lettre de M. Jamin, qui lui faisait connaitre que, dans les Ardennes où il se trouvait, la vendange était faite, mais que le moút ne fermentait pas; les vignerons, ajoutait-il, étaient fort inquiets, et ils lui demandaient le moyen qu'il fallait employer pour faire fermenter le moût. M. Pasteur répondit qu'il n'y avait qu'à verser de l'eau chaude dans le moût; M. Jamin ayant suivi ce conseil, le moût entra en fermentation. Chez les vignerons qui n'ont pas suivi ce procédé, la fermentation a fini par se produire; mais ils ont perdu une certaine quantité de vin par les bondes. - A-t-il fait froid en Bourgogne? demande M. Pasteur à M. Bouchardat; c'est, en effet, le froid qui, dans les Ardennes, a empêché la fermentation; mais en ayant recours à l'eau chaude, on a pu la hâter, car il y a toujours bien assez de ferment extérieur.

M. Bouchardat. - ... L'observation de M. Pasteur est parfaitement juste; chez les vignerons, en général, la fermentation a été très longue à s'établir; ils avaient récolté pendant les journées les plus froides; elle a été plus active dans les caves que dans les celliers, parce qu'il fait plus chaud dans celles-là que dans ceux-ci.

M. Pasteur présente, à ce sujet, les observations suivantes :

Les pratiques de la vinification ont pour conséquence de modifier l'aération de la vendange et du vin. C'est ainsi que, lorsque le raisin est écrasé au moyen de cylindres, la fermentation vient après l'introduction de très peu d'air, tandis que lorsqu'il est piétiné par des hommes, il y a grande intervention de l'oxygène de l'air. L'aération des moûts ne modifie pas seulement les conditions de la fermentation,

1. Bulletin de la Société centrale d'agriculture de France, séance du 14 novembre 1877 , XXXVII, p. 501-502, 503 et 504. 
elle influe sur la qualité ultérieure du vin, et elle a pour résultat de le vieillir. M. Pasteur rappelle à ce sujet qu'il a étendu sur le bac à refroidir d'une brasserie un certain nombre d'hectolitres de vendange égrappée arrivant de la vigne, et qu'il l'y a laissé trois jours, en renouvelant, matin et soir, les surfaces à l'aide d'un râteau. Puis cette vendange a été mise en tonneau. Une autre portion de la même quantité de la mème vendange a été mise à fermenter dans une cuve, sans aération préalable.

Les deux vins que ces vendanges ont fournis différaient notablement : celui de la vendange aérée était du vin déjà fait comparé à l'autre. Il n'avait pas la verdeur de ce dernier. C'est beaucoup, en effet, par l'oxydation que le vin acquiert de la qualité, et c'est en suivant ce principe qu'en Bourgogne on hate le vieillissement du vin quand on le distribue en petits fûts. La surface d'évaporation et d'accès à l'intérieur est bien plus grande que s'il était logé dans de grands fûts. C'est ce que savaient bien les anciens propriétaires du clos V'ougeot. On recherche dans le vougeot la verdeur, et pour rendre celle-ci durable, ils enfermaient le vin dans des fûts tout recouverts de poix à l'extérieur.

Les pratiques de la vinification peuvent être modifiées et le sont, suivant les localités, de bien des manières. Les plus insignifiantes en apparence ont de l'importance. Que ne crée-t-on des stations vinicoles où toutes ces pratiques seraient étudiées dans leurs raisons d'être! Beaucoup déjà sont justifiées entièrement et en concordance avec la science. Mais combien de choses restent à faire !...

M. Pasteur reconnaitt [avec M. Duchartre] que l'écrasage avec le cylindre cannelé peut être bon pour le vin de l'Hérault, dont la délicatesse ni le bouquet n'ont jamais préoccupé, mais qu'il n'en est plus de mème s'il s'agit, par exemple, du vin de Pomard. La saveur et l'arome des grands vins sont sous la dépendance des moindres changements dans les pratiques usuelles...

M. Pasteur [confirmant une observation de M. Chatin] fait remarquer que, lorsque le raisin est gelé, il devient, en effet, jaune et prend alors une saveur particulière. Dans le Jura, le vin qui se fait avec le savagnin sur lequel on laisse passer la gelée a un arome qui rappelle celui du madère. 


\section{[INTERVENTION (1) DANS LA DISGUSSION SUR LES ESSAIS FAITS AU LABORATOIRE MUNICIPAL DE PARIS (A PROPOS DU SUCRAGE)]}

M. Pasteur s'étonne que l'on tire des résultats publiés par le Laboratoire municipal que le sucrage soit signalé comme une falsification.

Chaptal, dit M. Pasteur, le premier, a recommandé cette opération. Ce n'est donc pas une opération nouvelle. Il ajoute que la Commission de contróle des Laboratoires municipaux, instituée par M. le ministre du commerce, n'a pas encore beaucoup fonctionné. Il sera bon, toutefois, d'examiner de très près les faits reprochés au Laboratoire municipal par M. Gaston Bazille. Il est nécessaire d'avoir des éclaircissements à ce sujet.

En attendant, M. Pasteur ne peut admettre que le chimiste exercé qui est à la tête du Laboratoire municipal puisse taxer le sucrage comme une falsification.

Il rappelle que, vers 1860 , il a trouvé dans le vin deux principes immédiats qu'on n'y avait pas encore décelés : la glycérine et l'acide succinique.

Et, cependant, les vins contiennent, en moyenne, 5 à 7 grammes de glycérine et 1 gramme à 1 gramme et demi d'acide succinique par litre.

L'extrait sec des vins varie entre 16 et 24 grammes. Les vins contiennent donc, en moyenne, 20 grammes d'extrait sec, et l'acide succinique et la glycérine entrent ensemble pour un tiers et plus dans cette quantité. Que peut-on conclure d'analyses qui n'en tiennent aucun compte? Mais le Laboratoire n'a guère que des comparaisons à faire et non des analyses complètes.

1. Bulletin de la Société nationale d'agriculture de France, sẻance du 12 dẻcembre 1883 , XLIII, p. 660-661. 


\section{OBSERVATIONS (1) [A PROPOS DU VIN D'ORGE \\ DE M. G. JACQUEMIN]}

J'ai eu l'occasion de déguster le vin d'orge préparé par M. G. Jacquemin. Son Mémoire (2) est très intéressant et il est certain qu'il est parvenu à obtenir un véritable vin en se servant de la levâre du vin elle-même et du moût d'orge non houblonné. Ce vin a vraiment des qualités particulières; il est agréable; d'un goût un peu court; il a la saveur et les qualités d'un vin. Chaque levûre - et elles sont très nombreuses - a la propriété, en faisant fermenter un liquide sucré, de lui donner les qualités propres à cette levûre.

Le vin de M. Jacquemin, du moins celui que j'ai eu entre les mains, m'a paru rappeler un vin de Champagne un peu éventé, qui aurait perdu son acide carbonique.

1. Bulletin de l'Académie de médecine, séance du 29 mai 1888, 3e sér., XIX, p. 711-712.

2. JacQuemin (G.). - Du vin d'orge et de sa valeur au point de vue de l'alimentation. Ibid., p. 711. (Note de l'Édition.) 



\section{DOCUMENTS}





\section{I. - NOTE REMISE PAR PASTEUR \\ IU MiNistre DE L'INSTRUCTION PUBLIQUE ET DES CULTES (1)}

Lorsque le moùt du raisin et en général de tous les fruits sucrés ne fait plus partie de la plante qui l'a élaboré, au bout de quelques heures déjà il éprouve un mouvement de fermentation que l'on a appelée alcoolique, parce que le sucre du moùt disparaît et fait place ì de l'alcool. C'est ainsi que le vin prend naissance.

De tous les phénomènes de la chimie organique c'est peut-être le plus digne d'attention. Il a servi de type à une multitude d'autres analogues, et le mot de fermentation est devenu générique. A mesure que la science se perfectionne on sent de plus en plus que c'est par des réactions de cet ordre que l'organisme procède, et quand la lutte de la vie et de la mort a laissé celle-ci victorieuse, aussitôt l'être inanimé quel qu'il soit, animal ou plante, subit des métamorphoses de fermentation qui peu à peu ramènent toutes ses parties à des combinaisons simples, propres à faire rentrer ses éléments dans le cercle indéfini de la vie et de la mort.

Tout annonce également que c'est à des causes de cette nature que les maladies contagieuses doivent leur existence.

Séduit par la grandeur de ces études je m’y suis consacré tout entier depuis plusieurs années et j'ai été assez heureux pour leur laire faire quelques progrès.

Lavoisier, le premier, a soumis aux lumières de la chimie moderne le phénomène de la fermentation alcoolique. Il avait conclu de ses recherches que le sucre se dédouble, poids pour poids, en alcool et en gaz acide carbonique, et l'on a cru jusqu'à ce jour à l'exactitude parfaite des résultats de Lavoisier, qui paraissaient confirmés d'ailleurs par des travaux de Thenard et de Gay-Lussac.

En réalité la théorie admise était inexacte. J'ai établi par des expériences précises et multipliées que dans toute fermentation alcoolique une portion du sucre se transformait en glycérine et en acide succinique, deux produits que l'on est fort surpris de rencontrer dans la fermentation du sucre $\left({ }^{2}\right)$.

1. Cette Note inédite a été retrouvée dans les manuscrits de Pasteur, copiẻe de sa main. Elle est précédée de quelques lignes datées du 18 décembre 1859 et signées L. Pasteur. Dans ces lignes Pasteur relate qu'il a été reçu en audience par le ministre le 16 décembre, après lui avoir adressé une lettre dont le passage relatif à la composition du vin l'avait frappé. Le ministre dans cette entrevue demanda à Pasteur de lui remettre une Note pour la soumettre à l'Empereur. C'est cette Note que nous publions ici.

2. Voir p. 64-77 du tome II des Guvres ne Pasteur. (Wotes de l'Édition.) 
La conséquence imımédiate de ce résultat devait être la présence certaine de la glycérine et de l'acide succinique dans les liquides qui ont subi la fermentation alcoolique, notamment dans tous les vins. C'est en effet ce que j'ai constaté par des expériences directes.

Chose singulière et bien inattendue, un litre de vin renferme de 5 à 8 grammes de glycérine, et plus de 1 gramme d'acide succinique, substances douées chacune de propriétés remarquables. I a glycérine particulièrement est l'un des principes essentiels de toutes les matières grasses de l'économie, et il est difficile de ne pas croire à son influence prépondérante dans les qualités bienfaisantes du vin.

Quoi qu'il en soit, il est facile de comprendre jusqu'à quel point la question de la fabrication artificielle du vin par le mélange de tous ses principes était insoluble, puisque deux de ses éléments nécessaires qui y entrent pour plus d'un tiers, souvent plus de la moitié de ses matériaux solides, étaient restés inconnus.

A l'époque de la maladie de la vigne qui coïncida avec les grands approvisionnements de la guerre de Crimée, l'Empereur fut, dit-on, très préoccupé de cette question de la fabrication artificielle du vin, dont il confia l'étude à un chimiste illustre. Si je suis bien informé, M. Dumas, avec sa sagacité ordinaire, arriva à cette conclusion que le vin devait renfermer quelques substances encore indéterminées. Il eût été alors bien difficile de

$\because \quad$ les mettre en évidence et probablement la glycérine et l'acide succinique seraient encore à découvrir dans le vin si je ne les y avais recherchés avec la persuasion qu'ils devaient s'y trouver.

Est-ce à dire que des travaux ultérieurs conduiraient promptement à la solution de la question de la fabrication artificielle du vin. Je n'oserais répondre affirmativement. Ce qui est certain, e'est que la composition des vins, de cette précieuse boisson à laquelle la France doit une des principales richesses de son sol et peut-être quelque chose de son caractère national, réclame aujourd'hui des études nouvelles où l'on tiendrait compte de la présence de la glycérine et de l'acide succinique et des facilités que la connaissance de ce fait introduirait dans les analyses. Il faudrait examiner également quelle peut être l'influence de la glycérine et de l'acide succinique dans l'alimentation, associés ou non à des matériaux de la nature de ceux que l'on rencontre dans les vins.

Mais ce que la science réclame surtout, c'est l'examen persévérant des phénomènes de fermentation et de toutes les grandes questions qui s'y rattachent.

J'ai résolu de faire de ces belles études le but constant de mes efforts. Je n'aurais jamais osé appeler sur mes recherches désintéressées l'attention du chef auguste de l'État. Si par un acte spontané du ministre éminent qui préside aux destinées de l'instruction publique cette insigne faveur m'était réservée, je sens que je n'aurais qu'une préoccupation, celle d'ajouter à l'éclat du règne le plus illustre l'honneur de quelque découverte importante.

\section{Pasteur,}




\section{II. - COMMUNICATION DE M. BALARD : \\ SUR UNE ALTÉRATION SPONTANÉE DE CERTAINS VINS (1)}

Il est lacile de voir, en lisant les Traités d'œnologie les plus récents, combien nous savons peu de chose sur les maladies des vins. J'ai eu occasion d'étudier dans ces derniers temps une de ces altérations spontanées, à la suite de laquelle on dit que le vin est tourné. Cette altération, que rien ne fait soupçonner d'avance, se produit dans un temps très court.

Un grand propriétaire de vignobles de Montpellier, de mes amis, M. Serres-Solignac, avait vendu le 20 octobre du vin de bonne qualité agréé par l'acheteur. Le 14 novembre ce vin avait éprouvé une altération profonde. Il était trouble : la couleur avait été profondément altérée; de rouge vif elle était devenue rouge-jaunâtre. Le bouquet avait disparu; la saveur était un peu amère; il était tourné.

En constatant que quelques-uns de ces vins, évaporés au bain-marie et exposés à l'étuve à $110^{\circ}$, laissaient moins de matières solides que la quantité ordinaire que fournissent les vins du Midi dans des conditions semblables, on avait cru d'abord que ces vins avaient été additionnés d'eau, conclusion que repoussaient d'une manière absolue l'honorabilité du propriétaire et la fidélité de ses employés. Sans doute l'appréciation de la dose de matière solide contenue dans un vin donné peut, dans beaucoup de cas, fournir au chimiste des indications utiles; mais quand on songe aux différences de produits qui peuvent prendre naissance par suite des variations dans le cépage, le sol, la fumure, l'exposition, la maturité, les pluies, etc., on ne saurait admettre que cette observation seule puisse constituer une preuve d'altération, même dans les cas où on aurait affaire à des vins normaux, et à plus forte raison quand il est question de ces vins altérés dont la matière organique solide peut avoir subi des modifications qui nous sont inconnues. Dans-le cas actuel, des recherches plus complètes sont venues dissiper toute incertitude, car, outre que beaucoup de vins de cette année non incriminés n'ont pas fourni une quantité de matière fixe supérieure, la conservation dı titre alcoolique dans le vin altéré, la permanence dans les proportions de matière minérale, la constance de la dose de potasse, ne pouvaient laisser de doute chez les personnes les plus intéressées à en conserver, ni dans les esprits les plus prévenus, et indiquaient que le changement opéré dans le vin était le résultat d'une altération toute naturelle.

1. Comptes rendus de l'Acarémie des sciences, séance du 30 décembre 1861, LIII, p. $1226-1230$. 
Mais quelle était cette altération? On m'avait consulté à cet égard. Or, comme dans ces questions spéciales la science consiste surtout à connaitre à qui il faut s'adresser pour en acquérir, j'ai examiné le vin au microscope avec M. Pasteur. Il y a reconnu immédiatement et m'a appris à y distinguer dorénavant sans difficulté un ferment spécial organisé, analogue au ferment lactique, si ce n'est identique avec lui; et si j'ai eu de nouveau recours à son obligeance, ce n'a été que pour constater par des observations concordantes avec les siennes que je pouvais à mon tour transmettre fidèlement les notions que je venais d'acquérir.

Le ferment spécial que je n'ai pas seulement observé dans le vin de M. Serres-Solignac, mais dans beaucoup d'autres altérés comme les siens, se présente sous la forme de petits filaments droits d'une longueur égale environ au diamètre d'un grain de levûre; leur propre diamètre est environ dix fois plus petit. Quand ils sont en masse et suspendus dans un liquide exposé au soleil, ils se distinguent, par leur apparence nacrée, des globules de levûre ordinaire, qui, dans les mêmes circonstances, présentent un aspect terne.

Quelle est la nature spéciale de ce ferment? est-ce réellement celui qui, d'après M. Pasteur, coïncide avec toutes les fermentations lactiques? Pour essayer de le savoir, j'ai d'une part exécuté quelques expériences avec ce ferment lui-même, et j'ai de l'autre examiné analytiquement les vins altérés.

Une petite quantité de ces filaments, recueillis sur un filtre et mis avec de l'eau de levûre, du sucre et de la craie, a manifesté au bout de deux jours les phénomènes d'une fermentation lactique, qui est du reste passée rapidement à l'état de fermentation butyrique. J'ai pu dans cette circonstance vérifier l'exactitude des observations de M. Pasteur sur la coïncidence qui existe entre l'apparition des vibrions, qu'il a décrits, et l'acide butyrique. Dès qu'on a eu aperçu quelques individus de cette espèce de vibrions se mouvant dans le champ du microscope, la présence de l'acide butyrique est devenue manifeste. Ces êtres, par la rapidité avec laquelle ils meurent sur les bords de la goutte où l'oxygène est abondant et vivent au centre même où l'atmosphère réductrice se maintient quelque temps, montrent bien que les conditions de leur existence sont inverses de celles de beaucoup d'autres espèces d'infusoires.

Dans une autre expérience où le ferment a été mis avec du sucre et de la craie, mais sans eau de levûre, la fermentation est restée presque exclusivement lactique, et ce dernier acide a pu être sans difficulté manifesté dans le produit.

J'ai exécuté sur le vin altéré quelques expériences qui fort heureusement ont pu devenir comparatives et être faites aussi avec du vin de la même nature, mais non altéré. Une cuvée de ce vin avait été transvasée partie dans des futailles de 350 litres et partie dans un grand tonneau (foudre) de 15.000 litres de capacité. Or le premier vin s'était conservé sans altération, tandis que le second était tout à fait tourné, circonstance qui permet d'attribuer à la température, maintenue longtemps élevée dans le vin enfermé dans des tonneaux d'un grand volume, une influence sur l'altération. L'examen comparatif de ces deux vins pouvait donc éclairer sur 
les résultats de la fermentation anormale subie par celui qui avait été altéré.

Indépendamment de la différence des propriétés physiques sur lesquelles je ne reviens pas, l'analyse chimique m'a permis d'en constater d'autres non moins saillantes. Ainsi, tandis que le vin non altéré ne contenait pas d'acide acétique, semblable ainsi aux vins ordinaires qui n'en renferment jamais, celui des grandes futailles bien remplies d'où se dégageait encore de l'acide carbonique, et qui dès lors ne pouvait être suspecté avoir éprouvé les phénomènes de l'acétification ordinaire, en contenait des quantités sensibles, environ $1 \mathrm{gr} .5$ par litre.

Il restait dans les deux vins du glucose dont j'ai essayé de déterminer les proportions en dosant le cuivre du précipité formé par l'ébullition de ces vins avec la liqueur tartro-cuivrique. Dix centimètres cubes de vin non altéré ont fourni $0 \mathrm{gr} .007$ de cuivre; ce qui correspond, en attribuant au glucose la totalité de la réduction exercée par le vin, à 5 gr. 8 de ce corps par litre. Dix centimètres cubes de vin altéré n'ont réduit que 0,004 de cuivre; ce qui indique seulement 3,3 de glucose par litre.

La richesse en alcool de ces deux vins était sensiblement la même : ils contenaient, le premier 10,9 , et le second 10,7 d'alcool pour 100, ce qui, vu l'incertitude qui accompagne toujours ces sortes d'appréciations, équivaut à l'égalité de titre alcoolique.

J'ai recherché aussi dans le vin altéré la présence de l'acide lactique, et je suis parvenu à l'extraire et à le caractériser par la forme cristalline de son sel de zinc. Je m'attendais, je l'avoue, à voir le vin non altéré ne point en fournir pour sa part; mais l'emploi des mêmes procédés m'en ayant aussi montré l'existence dans ce vin, on ne pourrait savoir si la fermentation spéciale éprouvée par le vin altéré était une fermentation lactique que par des dosages comparatifs, dont l'étude plus délicate reste à faire. J'ai retiré aussi de l'acide lactique de plusieurs vins du Midi des années précédentes qui n'avaient jamais été réputés altérés. J'en ai retiré aussi, quoique en quantités beaucoup plus faibles, du vin de Mâcon.

Il semblerait, d'après ces premiers essais, que la présence de l'acide lactique dans les vins serait fréquente et peut-ètre normale, circonstance qui a lieu d'étonner quand on se rappelle comment les expériences de M. Pasteur ont parfaitement établi, contrairement à l'opinion reçue, qu'il ne s'en produit pas de traces dans la fermentation alcoolique opérée avec la levûre et le sucre. C'est ce que j'ai du reste vérifié par une recherche directe, et d'après le désir de $\mathbf{M}$. Pasteur lui-même, sur le résultat alcoolique d'une fermentation de ce genre qui lui restait de ses anciens essais; je n'en ai pas, comme lui, trouvé la plus petite proportion. Dans le cas où mes expériences ultérieures confirmeraient la présence constante de l'acide lactique dans les vins, il resterait à déterminer s'il est le résultat de la fermentation alcoolique du liquide spécial qui les fournit, ou bien s'il ne préexisterait pas dans le moût de raisin lui-même.

On sait que les fermentations lactiques éprouvent le plus souvent des déviations dans leurs allures, et qu'en devenant butyriques elles dégagent de l'hydrogène. J'ai essayé de constater ce caractère dans le vin examiné; mais le mouvement de fermentation que la chaleur de l'étuve a manifestée dans le vin altéré n'a dégagé que de l'acide carbonique; il n'était proba- 
blement qu'une recrudescence de la fermentation alcoolique ordinaire. Du vin non altéré qui l'a subie n'a produit aussi que des globules de levûre sans indice de ferment spécial. Du reste l'acide acétique extrait par la distillation du vin altéré ne contenait pas d'acide butyrique.

Il est permis de supposer que l'espèce d'altération que je viens de signaler n'est pas nouvelle, et c'est peut-être à elle qu'il faut attribuer l'acidité qui pendant l'été se manifeste spontanément dans certains vins sans que l'accès de l'air semble en avoir été la cause.

Il restera à étudier maintenant les conditions d'existence de ces êtres, et c'est ce que je ferai quand le soutirage des vins me permettra de m'en procurer suffisamment. C'est en connaissant leur manière de vivre qu'on pourra peut-être prévenir leur développement. A cet égard tout est encore à faire, et j'aurais attendu pour faire à l'Académie une Communication plus complète, s'il ne m'avait paru utile d'attirer l'attention des propriétaires de vignobles sur des faits qui les intéressent vivement.

Le Président de la Société d'agriculture du département de l'Hérault, M: Cazalis-Allut, à qui une expérience de cinquante ans en matière d'œnologie permet de fournir à la science les renseignements les plus précieux, a observé dans ces derniers temps, sur quelques vins, une recrudescence de fermentation alcoolique franche; le trouble qu'elle a produit dans les vins n'a été que momentané, et le vin, complété par elle plutôt que détérioré, avait repris au bout de peu de temps par le repos toutes ses qualités ordinaires.

L'observation microscopique n'est point en désaccord avec ces assertions, car sur douze échantillons de vins pris dans des points divers du département de l'Hérault, et qui m'avaient été envoyés par M. SerresSolignac, j'en ai trouvé un qui, trouble et modifié en apparence, ne contenait point de ferment spécial analogue au ferment lactique; mais dix autres en contenaient abondamment et témoignaient que la cause qui les avait altérés avait ainsi une certaine généralité.

On conçoit quelle importance il y a à connaître la vérité à cet égard. Si le vin est soumis simplement à une recrudescence de fermentation ordinaire, il n'y a qu'à attendre; mais s'il éprouve la fermentation spéciale que je signale, il est probable qu'il ira en se détériorant de plus en plus si elle est intense, à moins que par des collages abondants et des soutirages fréquents on ne parvienne à éliminer les êtres microscopiques dont le développement coïncide avec cette altération spéciale, et qui en sont probablement les agents. Il faudra, dans ce cas, se préoccuper du lavage des vases et de leur purification, avec autant de soin qu'on en emploie pour assainir les lieux où se sorit développées des chambrées de vers à soie malades de la muscardine. Or une simple observation microscopique suffit pour trancher la question et permet de constater l'existence de ce ferment spécial avec une entière évidence.

Qu'on me permette, en terminant, de faire remarquer par un autre exemple toute l'utilité des observations microscopiques dans les questions d'altération des vins. Parmi les échantillons qu'on m'avait adressés comme vins altérés, il y en avait un chez lequel je cherchais de bonne foi le ferment lactique, quand la vue de quelques globules de l'un des ferments acétiques 
que M. Pasteur étudie en ce moment, et qu'il m'a appris à discerner, me fit connaitre que le vin était aigri; déduction que son examen a confirmé d'ailleurs.

Ainsi, plus les faits se multiplient, plus nous voyons devenir intimes les rapports de la chimie avec cette plıysiologie des êtres microscopiques dont l'étude commence à peine, et qui jouent probablement dans les phénomènes de la nature un rôle des plus étendus. 


\section{III. - RAPPORT DE PASTEUR (1)}

\section{SUR LE MÉMOIRE DE M. JOSEPH BOUSSINGAULT \\ RELATIF A IAA FERMENTATION RAPIDE DES VINS}

On se souvient que la collection des vins admis à l'Exposition internationale de 1878 n'était pas une des moindres curiosités de cette grandiose exhibition des produits de l'industrie du monde entier. Le ministre de l'agriculture et du commerce, M. Teisserenc de Bort, eut la pensée hardie de faire analyser tous les vins exposés malgré le nombre des échantillons relativement immense, car il ne s'élevait pas à moins de quinze cents. Il faut louer le ministre d'une initiative qui devait avoir pour résultat de faire connaître, par un travail d'ensemble, les principes essentiels contenus dans cette multitude de vins venus de tous les coins de la terre habitée, avec des caractères d'authenticité et de pureté naturelle qu'un grand jury international était seul en état d'obtenir. Mais à qui confier ce colossal travail analytique? Il fallait une main très exercée, rompue aux analyses délicates, d'une autorité fondée sur des travaux antérieurs en concordance avec les difficultés du sujet et par suite acceptée de la science et de l'industrie. A ces garanties d'exactitude il fallait joindre une ardeur et un courage qui ne faibliraient pas devant l'immense labeur à accomplir. On trouva heureusement toutes ces qualités réunies dans un jeune membre adjoint du jury international, M. Joseph Boussingault, le fils de notre illustre confrère.

Dès le mois de novembre 1878, par les soins de M. Joseph Boussingault et de son aide dévoué, M. Aubin, préparateur au Conservatoire des Arts et Métiers, les vins étaient entreposés, rangés, étiquetés par ordre de provenances et de propriétaires dans un cellier de la ferme de la Faisanderie, à Joinville-le-Pont, ferme dépendante de l'Institut national agronomique. Le laboratoire spécial, muni d'instruments précis, vérifiés sous la dircetion de notre confrère, M. Boussingault, fut installé à Vincennes, et était prêt à fonctionner dès la fin de décembre 1878. Depuis lors, c'est-à-dire depuis deux ans, le travail n'a pas été interrompu. Il sera achevé dans le courant de l'année 1881. Plus de huit cents échantillons sont déjà analysés.

Le programme tracé par le ministre de l'agriculture demandait pour chaque échantillon de vin la détermination exacte de la densité; de la teneur en alcool; de la quantité de matières fixes; du degré d'acidité; de la quantité de sucre pouvant rester dans le vin. D'accord avec son père,

1. Bulletin de la Société nationale d'agriculture de France, séance du 29 décembre 1880 , XL, p. $815-819$. 
qui a été, à certains égards, l'âme de l'entreprise, M. Joseph Boussingault n'hésita pas à joindre, à la connaissance des principes que je viens d'énumérer, celle de deux éléments essentiels, la glycérine et l'acide succinique, malgré le surcroit de travail qu'allait exiger cette addition aux demandes que l'Administration réclamait et avait jugées suffisantes. Mais, outre l'intérêt que devait avoir la connaissance de ces principes propres à tous les liquides fermentés, la teneur d'un vin en glycérine ne permet-elle pas, par exemple, de reconnaître si le vin a été additionné d'alcool ou d'un mélange d'eau et d'alcool?

Le travail analytique était à peine commencé qu'une difficulté imprévue se présenta. Dans l'état actuel de la science, le dosage de la glycérine est très incertain lorsqu'il porte sur l'extrait d'un vin qui conserve des principes sucrés. La difficulté, dira-t-on, est facile à écarter : il suffirait de faire fermenter, au préalable, les sucres restés dans le vin avant de procéder à la détermination de la glycérine; mais quand on songe à la durée d'une telle fermentation complémentaire, qui doit aller forcément jusqu'à la disparition complète des sucres fermentescibles, durée qui n'est pas moins de huit à dix jours, on s'aperçoit bien vite que si cette opération peut être possible, facile mème, à la rigueur, quand il s'agit de quelques échantillons de vins seulement, elle serait mélée de complications insurmontables dans l'analyse d'un nombre considérable d'extraits de vins sucrés.

M. Joseph Boussingault ne se laissa pas arrêter par cette entrave, qui pouvait compromettre le succès d'une partie de sa tâche. Il eut le nouveau courage de se livrer à une étude originale qui, si elle réussissait, tournerait la difficulté de la manière la plus heureuse. Guidé par certaines observations de M. Dumas sur la fermentation alcoolique en présence de grandes quantités de levûre, se souvenant principalement d'une très ancienne et très judicieuse remarque de notre cher président, M. Chevreul, sur le ralentissement que la présence de l'alcool fait éprouver à la fermentation par un effet direct sur la vie des cellules de la levìre, M. Joseph Boussingault eut l'idée de provoquer une fermentation très rapide des extraits de vins, à principes sucrés, en forçant, d'une part, la quantité de la levîre et en portant, par l'effet du vide, jusqu'à l'ébullition, à une température de 30 à $40^{\circ}$, le liquide en fermentation. Dans ces conditions, la fermentation, au lieu de durer huit ou dix jours, s'achève en quelques heures.

Cette étude, très nouvelle et très bien conduite, de M. Boussingault, qui témoigne, chez son anteur, d'un esprit aussi inventif que pratique, a fait l'objet d'un Mémoire inséré dans les Annales de chimie et de physique $\left.{ }^{(}{ }^{1}\right)$. On y retrouve avec bonheur les qualités d'excellent analyste dont M. Boussingault nous a donné tant de fois le précepte et l'exemple.

Votre Section des cultures spéciales est heureuse de vous signaler le mérite tout à la fois scientifique et pratique du travail du jeune chimiste. En lui accordant vos encouragements, vous aurez la satisfaction de penser à la joie qu'éprouvera le vénéré doyen de l'agronomie française.

1. Boussingault (J.). Sur la fermentation alcoolique rapide. Annales de chimie et de physique, $5^{\bullet}$ série, XXII, 1881, p. 98-120.

Ce Mémoire parut en janvier 1881, quelques jours aprés le rapport de Pasteur. (Note de lÉdition.) 


\section{IV. - [A PROPOS DE LA FALSIFICATION DES VINS] RAPPORT DE MM. LES EXPERTS CHIMISTES BALARD, WURTZ ET L. PASTEUR}

[AFFAIRE N. GUERRE CONTRE H. MANHEIMER (1)]

On peut falsifier les vins rouges de plusieurs manières; mais, en se référant aux termes de l'ordonnance du président du Tribunal civil de Montpellier, les experts ont pensé qu'ils avaient principalement à résoudre les deux questions suivantes :

$1^{\circ}$ Les vins rouges, objet du litige, ont-ils été additionnés d'eau, d'alcool et de la matière colorante du vin?

$2^{\circ}$ Ces vins ont-ils été mêlés à des matières colorantes étrangères, * propres à modifier seulement la teinte des vins récoltés par le vendeur?

Le premier genre de fraude aurait altéré les proportions relatives des principes normaux du vin; par suite, l'alcool, l'acidité, la quantité totale des matières solides, etc..., ne seraient plus ce qu'elles sont à l'ordinaire dans les vins naturels.

Par le second genre de fraude, les rapports entre les porportions habituelles des principes du vin seraient sensiblement les mêmes que dans un vin naturel; mais la fraude pourrait être décelée par une étude approfondie de la nature des matières colorantes du vin suspect.

En conséquence, les experts ont dû se livrer à ces deux ordres de recherches : l'étude des proportions de quelques-uns des principes du vin et celle des matières que les falsificateurs emploient habituellement.

\section{Première partie,}

Les matières contenues dans le vin varient dans de certaines limites avec la nature des cépages, avec celle du sol, avec les années, etc... Il était donc nécessaire de comparer le vin suspect avec les vins naturels de l'année

1. In : Comptes rendus des travaux du Congrès international des directeurs des stations agronomiques. Session de Versailles, juin 1881. Paris, 1881, in-8 ${ }^{\circ}$ (Appendice aux procèsverbaux des séances), p. 412-430. La deuxième partie de ce rapport jusqu'au chapitre "Vins blancs ” (p. 504), avait déjà paru dans les Annales du Génie civil, 2॰ sér., 5e année, no du 11 novembre 1876.

Balard, Wurtz et Pasteur avaient été commis par le Tribunal civil de première instance de Montpellier à leffet de rechercher si des vins vendus par M. N. Guerre à M. H. Manheimer avaient étẻ falsifiés, comme le prétendait l'acheteur. Les analyses furent faites dans le laboratoire de Pasteur en février et nuars 1874 et les résultats consignés dans ce rapport. (Note de l'Édition.) 
1873. Par les soins de M. Gagne, séquestre, nous nous sommes procuré des vins naturels récoltés en 1873, dans la commune de Mèze ou aux environs.

Le tableau suivant fait connaître un certain nombre des résultats que nous ont offerts ces vins naturels, comparés au vin moyen de l'expertise, et au vin $n^{\circ} 2$ de Félines-le-Haut, lequel nous a paru le moins coloré de cette cave, et au vin $n^{\circ} 16$ de Félines-le-llaut, lequel nous a paru le plus coloré de la même cave.

\section{TABleaU $x^{0} 1$.}

\begin{tabular}{|c|c|c|c|c|}
\hline NATURE DES VINS & $\begin{array}{c}\text { ALCOOL } \\
\text { pour } 100\end{array}$ & $\begin{array}{c}\text { ACIDITE } \\
\text { gr. par litre }\end{array}$ & $\begin{array}{c}\text { ExTraIT } \\
\text { gr. par litre }\end{array}$ & $\begin{array}{l}\text { CENDRES } \\
\text { gr. par litre }\end{array}$ \\
\hline 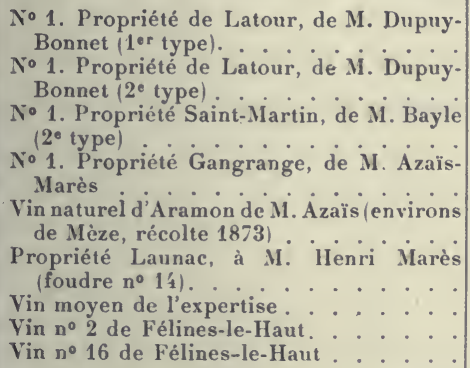 & $\begin{array}{c}9,45 \\
n \\
10,66 \\
10,3 \\
10,13 \\
9, ? \\
10,4 \\
11,0 \\
10,2\end{array}$ & $\begin{array}{l}4,3 \\
4,3 \\
5,6 \\
5,3 \\
4,2 \\
4,9 \\
5,1 \\
5,3 \\
4,9\end{array}$ & $\begin{array}{c}23,5 \\
" \\
26,6 \\
25,7 \\
24,0 \\
23,5 \\
25,0 \\
26,6 \\
21,0\end{array}$ & $\begin{array}{l}\text { " } \\
" \\
" \\
2,95 \\
4,6 \\
4,6 \\
3,2\end{array}$ \\
\hline
\end{tabular}

On y a joint un second tableau, faisant connaître séparément, pour les vins de chaque foudre qui ont servi à composer le vin moyen, les proportions d'alcool, d'extrait et de cendres.

L'alcool a été déterminé en distillant 200 centimètres cubes de vin et recueillant 100 centimètres cubes, auxquels on a ajouté 50 centimètres cubes d'eau de chaux et 50 centimètres cubes d'eau; puis on a redistillé et recueilli de nouveau 100 centimètres cubes, dont on a pris l'alcool à $15^{\circ}$, au moyen d'un alcoomètre très sensible et vèrifié dans ses indications par la mesure des densités de divers liquides alcooliques.

L'alcoomètre donnait le dixième de degré.

Les nombres inscrits au tableau sont la moitié de ceux fournis par l'alcoomètre.

L'acidité a été déterminée sur 10 centimètres cubes de vin, en employant de l'eau de chaux titrée; on ajoute l'eau de chaux en agitant constamment le liquide, jusqu'à ce qu'il se forme un précipité floconneux. Ce procédé de dosage est très sensible et très sûr.

Les nombres inscrits au tableau pour l'acidité représentent l'acidité totale du vin, évaluée en acide sulfurique monohydraté.

L'extrait a été obtenu en évaporant, un volume déterminé de vin, d'alcool au bain-marie, puis à l'étuve à $100^{\circ}$. On a souvent vérifié les résultats ainsi obtenus en évaporant 50 centimètres cubes de vin mêlés à 25 grammes de sulfate de potasse en petits cristaux bien desséchés. L'opération est plus 
rapide et donne des nombres un peu plus élevés, paree que l'on perd moins de substances volatiles du vin, notamment de glycérine. Le sulfate de potasse fait l'office de corps poreux, de sable, par exemple.

Les cendres ont été obtenues en incinérant au rouge naissant le résidu de 20 centimètres cubes de vin.

Les cendres des vins plâtrés au maximum ne contiennent plus de carbonates alcalins, tous les alcalis se trouvant à l'état de sulfates. Les cendres des vins de l'expertise étaient toutes faiblement alcalines, ce qui démontre que le plâtrage n'a pas été exagéré. On remarquera dans le tableau $n^{\circ} 1$ que le vin de M: Azaïs ne contient que $2 \mathrm{gr} .9$ de cendres par litre, tandis que les autres en ont fourni un poids sensiblement supérieur; ce qui s'explique vraisemblablement par cette circonstance que le vin de M. Azaïs n'avait pas été plâtré, ou ne l'avait été que fort peu.

Tableau $\mathbf{N}^{0}$ 2. - Vins de l'bXpertise.

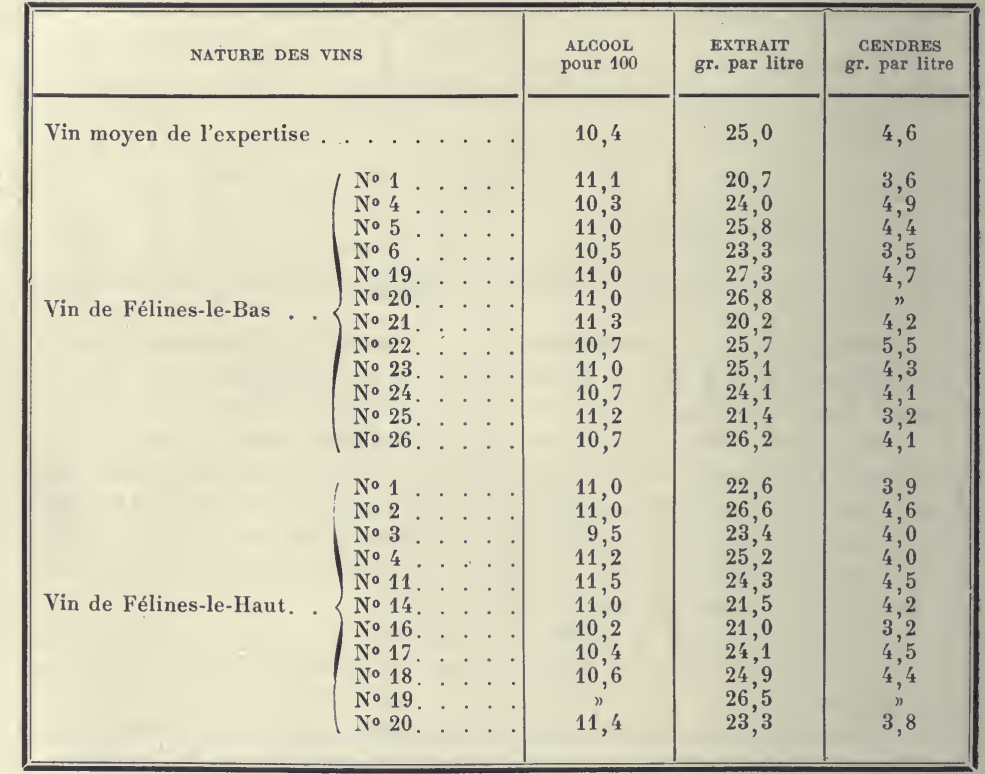

Il résulte clairement des comparaisons auxquelles donnent lieu les résultats inscrits dans les tableaux qui précèdent que, si les vins en litige ont été falsifiés, ils n'ont pu l'être par addition d'eau, d'alcool et des matières colorantes du vin, et que, en réservant la question des matières colorantes, dont il va être parlé dans la deuxième partie, ces vins ressemblent de tous points aux vins types auxquels nous les avons comparés. En conséquence, nous déclarons qu'ils sont parfaitement naturels. 


\section{Deuxième partie.}

On sait que la valeur vénale des vins s'accroit dans une certaine mesure avec leur richesse de coloration. Destinés souvent à faire des coupages avec des vins plus faibles d'autres localités, on trouve utile qu'ils apportent une certaine intensité de coloration et qu'ils fournissent à la fois au coupage l'alcoolicité et la couleur. Cette destination fait appeler ces vins vins teinturiers. Il eùt donc été possible que M. Guerre, voulant faire acquérir ce complément de qualité aux vins, très naturels d'ailleurs, qu'il avait récoltés, eùt renforcé leur nuance par l'addition de quelques matières colorantes étrangères, se livrant ainsi à une pratique à laquelle semblent provoquer en quelque sorte la vente publique de ces matières et l'indication de l'usage frauduleux auxquelles elles sont destinées.

On conçoit que, dans cette nouvelle recherche, nous ne pouvions plus trouver la même rigueur absolue qui avait caractérisé la première partie de notre travail. En réfléchissant que ces matières colorantes étrangères sont mélangées avec des quantités notables de celles du vin lui-même, on est même frappé a priori de la difficulté qu'il peut y avoir à les isoler et à les caractériser. Et puis, quand on a tiré des réactifs les indications les plus délicates qu'ils peuvent fournir, pourrait-on en déduire avec certitude complète l'absence absolue d'une proportion moindre encore que la limite à laquelle la sensibilité des réactifs avait forcé de s'arrêter?

Mais en considérant qu'après tout on ne fait pas la fraude pour la fraude même, qu'il faut qu'elle soit fructueuse pour qu'on la tente, nous avons pensé que, dans les cas où la recherche de la matière colorante étrangère était le plus difficile, nous étions autorisés à ne pas poursuivre cette recherche quand nous avions constaté que cette matière colorante $\mathrm{y}$ intervenait pour moins que $1 / 8$.

L'expérience nous avait d'ailleurs démontré que cette proportion de $1 / 8$ était inférieure à celle qui eût été nécessaire pour faire passer la teinte. du vin le plus clair des vins naturels examinés à la teinte du vin moyen de l'expertise, et a fortiori à celle du vin le plus coloré.

Nous avons done préparé des solutions de ces matières colorantes étrangères, de manière à les amener à avoir l'intensité de coloration du vin incriminé, et, mêlant ces solutions avec sept volumes d'un vin naturel analogue au vin incriminé, nous avons eu ainsi des vins renfermant des doses de matières colorantes connues de nous.

Ici se présente une objection. Ces mélanges, faits au moment même, offrent-ils les résultats qu'on eût obtenus si nous eussions opéré sur ces mélanges faits depuis quelques mois? Il est impossible d'admettre que l'altération, par le temps, des matières colorantes ajoutées puisse être telle qu'elle supprime de la part de ces matières toutes réactions propres à les déceler, en laissant aux vins falsifiés une identité absolue de propriétés avec des vins naturels du même âge. Or, l'expérience nous a démontré que, entre le vin moyen de l'expertise et les vins naturels récoltés dans la commune de Mèze, tous les réactifs n'ont pu manifester de différences 
appréciables autres que celles qui sont propres à des vins naturels de différentes colorations.

Pour procéder à la recherche des matières colorantes étrangères que pourrait contenir le vin, nous avons essayé de réaliser sur les mélanges soumis à notre étude des expériences dont les résultats caractéristiques et permanents, pour la plupart, fussent de nature à être appréciés de la même manière par tous les observateurs.

Frotter du vin sur la paume de la main, sentir l'odeur qu'il exhale, et de cette appréciation toute personnelle conclure, sans autre preuve, à l'existence de tel ou tel corps ajouté au vin, ne peut suffire à apporter la conviction dans les esprits. On a droit à réclamer des démonstrations plus sérieuses.

La nécessité de rechercher des matières colorantes diverses, en quantité petite, et plus ou moins masquées dans leurs propriétés par la matière colorante du vin elle-même, a exigé de nous un examen préalable et une discussion des diverses méthodes générales fondées sur les propriétés des matières colorantes, et propres à les manifester.

Si l'on peut isoler, du moins d'une manière relative, la matière colorante, il convient de la faire servir à teindre un tissu convenablement mordancé, ou une matière minérale blanche, sur laquelle elle se dépose en la colorant. Ce procédé est excellent quand on parvient à l'appliquer. On peut d'ailleurs, en traitant l'étoffe teinte par certains réactifs, acquérir la preuve de la nature spéciale de la matière déposée, et, en variant les mordants, obtenir, avec les mêmes matières colorantes, telle ou telle nuance plus ou moins caractéristique.

On peut constater comment se comportent les matières colorantes sous l'influence des agents de déshydrogénation; à cet égard, nul agent ne nous a paru plus utile pour ces recherches que l'hydrosulfite de soude récemment préparé.

Il y aurait aussi quelque chose à tirer de l'action des agents oxydants : chlore, brome, iode, acide hypochloreux, dont nous avions commencé l'étude. Elle n'a pas été poursuivie, notre conviction ayant été acquise par d'autres moyens; mais cette étude mériterait d'être reprise plus tard.

La seule expérience de cet ordre que nous ayons tentée est relative à l'action d'un mélange d'acide chlorhydrique et de chlorate de potasse sur le vin moyen de l'expertise et sur le vin naturel. Elle a eu pour but spécial de controler une assertion qui avait été émise concernant l'action de ces réactifs sur le vin suspect, assertion que nous avons reconnue dénuée de fondement.

On peut modifier par quelques réactifs la nuance de la matière colorante ajoutée, de manière à distinguer le vin qui la renfermerait du vin naturel pris pour terme de comparaison.

Enfin, outre les procédés qui permettent d'isoler, d'une manière relative au moins, la matière colorante cherchée, on peut teindre directement les étoffes imprégnées de mordants divers comparativement par le vin incriminé et par le vin type exempt de toute altération; de la différence ou de la similitude de couleur observée, on peut conclure à l'altération du vin ou à sa pureté. 
Les matières colorantes diverses que nous avons cherchées dans le vin de l'expertise sont :
L'indigo,
La fuchsine,
La cochenille,
Le campêche,

La rose trémière,

Le sureau,

L'hieble et la myrtille.

Les matières colorantes du dernier groupe sont très analogues à la matière colorante des vins eux-mêmes. Quant aux matières du premier groupe, elles sont tout à fait étrangères à leur nature; c'est dire, dès lors, que leur recherche est plus facile, et c'est par elles que nous allons commencer.

\section{Indigo.}

Nous mettrons en première ligne l'indigo, sous forme de carmin d'indigo, parce que, d'une part, cette matière colorante est employée fréquemment toute seule dans la falsification des vins, et que, de l'autre, elle aide à l'introduction. d'autres matières colorantes, dont elle ramène la teinte à celle du vin, et qui n'auraient pas pu étre employées seules, parce qu'elles n'ont pas la nuance que l'on veut imiter.

C'est par la teinture que l'on peut constater dans un vin la présence de cette couleur, quelque exiguë, en quelque sorte, qu'en soit la proportion. On introduit dans deux petites fioles semblables du vin contenant pour 50 centimetres cubes un dixième de milligramme d'indigo, soit 2 milligrammes par litre, quantité qui ne change la couleur du vin auquel on l'ajoute que d'une manière inappréciable; après avoir déposé dans ces deux liquides une bande de laine mordancée avee de l'acétate d'alumine, d'une surface de 5 centimètres carrés environ, l'on soumet les deux vases à une température voisine de l'ébullition pendant quinze ou vingt minutes. La petite bande attire la presque totalité de l'indigo contenu dans la liqueur, et les deux ćchantillons, dégorgés et séchés, présentent, celui qui a été teint dans le vin, la nuance pure du vin, l'autre, une nuance d'un bleu manifeste, quoique modifiée par le rouge du vin.

On peut aussi ajouter au vin additionné d'indigo un peu de sulfate de potasse, que l'on précipite par le chlorure de baryum; le sulfate de baryte, qui se dépose et qui se serait montré, après lavage, à peu près blanc s'il n'y avait pas eu d'indigo, se montre comme coloré en bleu d'une manière sensible. Dans ce dernier cas l'indigo, ainsi déposé sur une matière minérale très résistante, peut ètre soumis à toutes les expériences qui auraient pour résultat d'en faire connaître nettement la nature.

En exécutant les expériences que nous venons de décrire sur le vin moyen, nous n'avons obtenu aucun indice de l'existence de l'indigo; mais nous ne pouvions pas oublier qu'une note qui nous a été remise le 10 février 1874, par l'avoué de l'une des parties, mentionnait la présence de l'indigo par la formation du chloranile; nous avons, dès lors, répété l'expérience indiquée, et voici les résultats que nous avons obtenus :

Le vin moyen de l'expertise et le vin naturel du pays ont été traités 
comparativement par le chlorate de potasse et l'acide chlorhydrique, en vue de vérifier l'assertion dont il s'agit sur la formation du chloranile.

A 200 centimètres cubes de chacun des vins on a ajouté :

10 grammes de chlorate de potasse,

20 centimètres cubes d'acide chlorhydrique pur.

La liqueur a été chauffée doucement jusqu'à l'ébullition. La couleur a d'abord passé au rouge vif, puis il s'est formé un précipité floconneux rouge, avec teinte brunâtre. Dès que la liqueur a été en pleine ébullition, ces flocons se sont convertis en un précipité jaune, lequel est resté suspendu dans la liqueur et dans la mousse formée; on a alors arrêté l'opération, on a laissé déposer et on a filtré.

Le précipité jaune, lavé à l'eau, a été examiné au microscope, il s'est présenté sous forme de granulations amorphes, exactement semblables dans les deux cas.

Chauffé au fond d'un tube, le précipité formé avec l'un et l'autre vin s'est charbonné en émettant une vapeur blanche acide. Il s'est dissous dans l'alcool froid en formant une solution orangée, laquelle a passé au rouge brun par l'addition d'ammoniaque. Ici, identité complète de réactions entre les deux précipités. L'expérience ayant été répétée avec une dose moitié moindre de chlorate et d'acide chlorhydrique, les mêmes phénomènes se sont produits, mais plus lentement. Les précipités jaunes amorphes ont encore paru dans les deux liqueurs. Impossible de confondre le précipité jaune dont il s'agit avec le chloranile, composé défini jaune cristallisable et se sublimant par l'action de la chaleur.

\section{Fuchsine.}

Nous aurions pu nous dispenser de chercher directement la fuchsine dans le vin incriminé. En effet, cette matière colorante est loin d'avoir la couleur dı vin. Or, en ajoutant à du vin très clair de M. Marès de la fuchsine, même concentrée en toutes proportions, il nous a été impossible de l'amener jusqu'à la teinte foncée du vin de l'expertise. Cette matière colorante n'a donc pu être employée seule; si l'on fait intervenir l'indigo, celui-ci, ajoutant sa teinte bleue au rouge trop vif de la fuchsine, eût pu reproduire la nuance du vin suspect. Mais il aurait fallu pour cela une dose d'indigo bien supérieure à celle dont nous avions constaté l'absence dans les expériences antérieures; on peut conclure, dès lors, de ce fait, que la fuchsine ne pouvait être intervenue dans la falsification.

Nous n'avons pas moins essayé de caractériser la fuchsine d'une manière directe, soit par le procédé que l'on emploie à Montpellier, soit par des méthodes analogues.

Ces méthodes sont basées sur ce fait que, si l'on ajoute au vin incriminé son volume d'eau de baryte, la liqueur filtrée et jaunâtre, saturée par l'acide acétique, se colore en rose; et ce qui la colore est bien de la fuchsine, car cette matière est immédiatement décolorable par les hydrosulfites, et c'est ce qui arrive à la liqueur rose. 
Agitée avec une petite quantité d'alcool amylique, elle se décolore entièrement, et cet alcool vient surnager la liqueur, formant une zone de la couleur vive de la fuchsine. Enfin, si l'on traite cette liqueur rosée par un peu d'étoffe de soie non mordancée, celle-ci se colore d'une nuance qu'on reconnait bien pour celle de la fuchsine, à la manière dont une goutte d'acide chlorhydrique tache l'étoffe en jaune.

Ces phénomènes se sont produits avec du vin contenant 2 milligrammes de fuchsine par litre, avec une netteté et une intensité telles que la dose de cette substance, si elle en̂t été quatre ou cinq fois plus petite, eût encore donné des résultats très nets. On juge de là quelle est la sensibilité de ces réactions et l'efficacité de cette recherche, qui, appliquée au vin de l'expertise, n'a, il est presque inutile de le dire, rien donné qui pût faire soupçonner l'existence de cette couleur.

\section{Cochenille ammoniacale.}

Dans l'expertise actuelle, et en ne se préoccupant que du vin incriminé, on pouvait aussi, par des considérations semblables à celles que nous avons fait valoir pour la fuchsine, conclure que la cochenille ammoniacale n'avait pu contribuer à la falsification. En effet, on ne parviendrait pas, en ajoutant au vin clair Marès dont nous avons parlé plus haut, de la cochenille en grand excès, à atteindre la nuance du vin de l'expertise sans ajouter de l'indigo; or, la dose d'indigo qu'il faudrait ajouter est telle, qu'elle dépasserait beaucoup la quantité qui a été cherchée sans succès dans le vin examiné. De l'absence d'indigo on pourrait donc conclure à celle de la cochenille.

Nous n'en avons pas moins cherché cette matière colorante directement. Les caractères divers qu'elle présente, s'ajoutant et se corroborant l'un l'autre, permettent d'affirmer, avec beaucoup de certitude, la présence de la cochenille dans le vin, même quand elle n'y est qu'en très faibles proportions. Il suffit d'épuiser avec de l'eau 4 grammes de ces plaques, qu'on vend comme cochenille ammoniacale, pour obtenir un litre d'une liqueur d'une intensité de coloration sensiblement égale à celle du vin.

Dans nos premiers essais nous avons opéré avec un mélange de quinze volumes de vin et un volume de cette liqueur, constituant ainsi du vin cochenillé au seizième. En traitant le liquide, ainsi qu'on le fait à Montpellier, par une solution d'un sel à réaction alcaline faible, et notamment le borax, comparativement avec dı vin normal, on voit celui-ci prendre la nuance vert bleuâtre que lui communiquent les alcalis faibles, tandis que celui qui contient de la cochenille prend une couleur violacée qui est tout à fait caractéristique.

La coulcur de la cochenille résiste à froid à l'action désoxydante des hydrosulfites; mais, à l'ébullition, elle est promptement détruite par eux. On peut utiliser l'une et l'autre de ces propriétés pour la recherche de la cochenille dans les vins. En plaçant dans des tubes d'un diamètre égal quelques centimètres cubes, d'une part, du vin tenant de la cochenille, de l'autre, du vin pur de même nuance pour terme de comparaison, l'addition 
de quelques gouttes d'hydrosulfite diminue la teinte de celui-ci sans agir sur celle de la cochenille; il en résulte qu'après quelques instants, le vin contenant cette matière colorante parait plus coloré que le vin naturel. Mais, si l'on opère à chaud, la décoloration de la cochenille par l'hydrosulfite étant alors complète et instantanée, tandis que celle du vin est plus lente, c'est du cóté du vin altéré que se manifeste une décoloration comparative, qui constitue un nouvel indice. Ces caractères ne peuvent s'observer qu'avec des vins plus chargés de cochenille que celui sur lequel nous avons opéré. Il en est de même des bandes spéciales d'absorption produites par la cochenille, observées au spectroscope, et que nous avons essayé vainement de constater, vu la petite quantité de matière colorante étrangère que renfermait le mélange sur lequel nous opérions.

La méthode qui nous a servi à trouver la cochenille employée dans des proportions très faibles est la suivante : Comme, dans la recherche de la fuchsine, on précipite la matière colorante du vin par l'addition d'un volume égal d'eau de baryte, la liqueur filtrée se colore en rose par neutralisation de la liqueur, au moyen de l'acide acétique. On pourrait à l'aspect confondre cette couleur avec celle que communique la fuchsine, mais quelques gouttes d'hydrosulfite suffisent pour distinguer ces deux couleurs. La teinte de la cochenille résiste quelque temps à l'action du réactif désoxydant, tandis qu'elle disparaît instantanément quand la coloration est due à la fuchsine. On peut, d'ailleurs, en faisant bouillir la liqueur rosée sur un

* fragment de laine mordancée à l'acétate d'alumine, la teindre et reconnaitre sur l'étoffe les caractères de la teinture par la cochenille.

Le vin moyen de l'expertise, soumis aux divers moyens dont nous venons de parler, n'a pas présenté le plus léger indice qui pùt faire soupçonner qu'il contenait de la cochenille.

\section{Campéche.}

Le campêche, fort employé comme on sait dans la fabrication du vin de toutes pièces, ne paraît pas servir, dans le Midi, à la coloration artificielle des vins. Nous n'en avons pas moins cherché à reconnaître son existence dans le vin de l'expertise, par la méthode de la teinture et par l'emploi de l'aluminate de soude. Ce réactif, qui n'altère point sensiblement la couleur du vin, produit avec celle du campêche une nuance bleue assez pure et très foncée. Du vin, mêlé pour $7 / 8$ avec $1 / 8$ de solution d'extrait de campêche, de même nuance que lui, a été traité par ce réactif, comparativement avec le vin naturel. L'aluminate de soude a déterminé, dans le vin additionné de campêche, une coloration violette très sensible; mais la différence a été encore plus nettement accentuée en étendant les deux liqueurs d'une égale quantité d'eau.

Nous avons essayé l'action de cet utile réactif comparativement sur le vin de l'expertise et sur le vin naturel. Ces deux liquides se sont comportés de la même manière, et nous n'avons pas observé le plus léger indice de l'existence du campêche dans le vin incriminé.

Nous avons déjà vu que ce n'est que par une association convenable que 
les matières colorantes dont nous avons parlé jusqu'ici peuvent reproduire la teinte du vin. Il n'en est pas de même des matières colorantes qui nous restent à examiner. Celles-ci donnant, sans mélange et directement, la couleur du vin, on s'est depuis longtemps adressé à elles pour la coloration artificielle de ce liquide.

Ces couleurs ne sont pas seulement semblables à celles du vin par leur nuance; il est probable qu'elles lui ressemblent beaucoup aussi par leur nature, et que, sans être identiques, ce sont du moins des espèces chimiques très voisines. Elles présentent done beaucoup de propriétés communes, et que partage la matière colorante du vin.

Ainsi ces matières colorantes verdissent par les solutions alcalines; elles sont, comme celle du vin, précipitables par la baryte. Le précipité, vert bleuâtre avec le vin, est, avec la rose trémière et le sureau, d'un beau vert, un peu terne avec l'hièble et la myrtille. I.es liqueurs filtrées qui surnagent les précipités sont jaunes ou légèrement verdâtres. En saturant par l'acide acétique l'alcali qu'elles contiennent en excès, elles se colorent parfois d'une teinte rose, mais extrêmement faible et qui n'est peut-être due qu'à la dissolution d'une trace du dépot vert qui a passé au travers du filtre. Ces matières colorantes se décolorent toutes par l'hydrosulfite de soude, mais avec des différences dans la durée du temps nécessaire à la production du phénomène. Celle de la rose trémière est la plus altérable; la décoloration est à la fois instantanée et complète, tandis que celle du sureau et de l'hièble, et plus encore celle du vin, marchent graduellement et laissent souvent au liquide une teinte légèrement rougeâtre.

Les richesses tinctoriales des matières premières que l'on emploie pour la coloration sont différentes. En prenant pour unité la faculté tinctoriale de la mauve, celle du sureau n'est que 0,27 , celle de la myrtille 0,17 , et celle de l'hièble 0,15 , du moins pour les substances que nous avons employées et dans l'état où nous les avons trouvées dans le commerce.

Les prix de ces matières premières sont aussi inégaux; mais, en combinant ces prix avec les nombres qui représentent leur faculté tinctoriale, on trouve que, le prix de l'unité de pouvoir colorant de la mauve noire étant 1 , celui du sureau est 1,6 , celui de la myrtille 1,96 , et enfin celui de l'hièble 2,2. La couleur de la myrtille et de l'hièble coùtant ainsi deux fois plus que celle de la mauve, il est peu probable qu'on emploie, si ce n'est dans des cas tout particuliers, ces deux matières colorantes pour la falsification des vins; c'est le sureau, et plus généralement la mauve noire, que l'on utilise.

Malgré la similitude de propriétés de ces matières colorantes, nous sommes cependant parvenus à trouver quelques réactions spéciales qui permettent de les distinguer entre elles et de les reconnaitre quand elles existent dans les vins. Nous allons étudier successivement chacune d'elles.

\section{Rose trémière.}

Passe-ruse, rose trémière, mauve noire, tels sont les noms divers sous lesłuels est connue; dans le commerce, la fleur d'une malvacée (Althien 
rosea, parietas nigra) qui, d'après ce que nous avons dit, doit être la plus employée pour la coloration artificielle des vins.

L'altérabilité de cette matière colorante, plus rapide que celle du vin, semblerait, au premier aspect, offrir un bon caractère pour reconnaître la matière colorante de la rose trémière. En effet, si dans quelques centimètres cubes de vin pur et du même vin coloré par cette substance on verse la même quantité d'hydrosulfite, les nuances, égales à l'origine, cessent d'être identiques, et la décoloration, plus prononcée dans un cas que dans l'autre, indique l'existence du vin fraudé. Mais ce caractère, qui exige des comparaisons de teintes toujours difficiles, quoique ayant quelque valeur, quand le vin contient $1 / 4$ de matière colorante étrangère, devient trop incertain quand cette proportion est réduite à $1 / 8$ pour qu'on puisse se fier à ses indications.

Cette matière colorante de la mauve éprouve, de la part de l'alun, et surtout de l'alun ammoniacal, une altération qui la fait passer de la nuance du vin qu'elle possédait à une couleur violacée qui devient plus intense par l'élévation de la température.

Du vin coloré au $1 / 8$ peut ètre facilement distingué du même vin pur.

Il suffit pour cela d'opérer comparativement sur quelques centimètres cubes du vin normal et du vin devant à la mauve $1 / 8$ de sa couleur; on ajoute dans les deux tubes cinq ou six fois le volume de solution saturée d'alun ammoniacal. L'action commence à froid, mais elle devient plus manifeste quand on chauffe près de l'ébullition; on voit alors le tube contenant le vin pur conserver la couleur rouge brique du vin, tandis que celui qui contient le vin altéré par la matière colorante étrangère prend une couleur violette qui suffit pour le distinguer nettement du premier. On pourrait même pousser l'appréciation au delà de $1 / 8$.

En faisant cette expérience comparativement avec le vin moyen de l'expertise et du vin Latour, pris pour terme de comparaison, nous n'avons vu aucune modification dans la teinte de ces deux vins, tandis que celui qui contenait $1 / 8$ de matière colorante de la mauve se distinguait nettement, par sa coloration violacée, des deux précédents. Nous en avons, dès lors, conclu que le vin examiné, pas plus que le vin pur auquel nous le comparions, n'avait été falsifié par l'addition de la matière colorante de la mauve noire.

Nous pouvons même tirer de cette absence de coloration violacée une conclusion plus générale encore. En effet, la matière colorante du sureau, celle de l'hièble et de la myrtille se comportant de la même façon, en donnant aussi une teinte violacée dans le vin coloré par 1/8 de ces matières colorantes, l'absence de ces réactions par l'alun ammoniacal peut permettre de conclưre à l'absence de ces quatre matières colorantes étrangères.

L'alumine, sous la forme d'aluminate de soude, permet aussi de distinguer entre elles les matières colorantes de la mauve, du sureau et de l'hièble, et même de les retrouver quand elles n'interviennent que pour $1 / 8$ dans la couleur des vins.

Quand on verse dans 1 centimètre cube de ces infusions, également colorées en excès, huit à dix gouttes d'une dissolution très étendue d'aluminate de soude, assez pour que la liqueur se fonce en couleur et paraisse 
se troubler, on obtient des résultats différents : la mauve noire donne lieu à un précipité bleuâtre, et la liqueur surnageante est incolore; avec le sureau, il ne se forme pas de précipité, et la liqueur restée limpide est colorée en vert sali par un peu de rouge.

L'hièble et la myrtille se comportent de la mème manière; le liquide, resté limpide, teint seulement un peu moins de rouge et est dès lors d'un vert plus douteux.

Ces différences d'action, qui peuvent servir tout au moins à distinguer la matière colorante de la mauve de celle du sureau, ne se présentent pas avec assez de netteté pour qu'on puisse reconnaître par ce moyen du vin additionné de 1/8 de ces matières colorantes étrangères; mais l'aluminate de soude, agissant d'une manière différente sur le vin pur et sur le vin contenant une de ces trois matières colorantes, peut constituer un caractère générique analogue à celui de l'action de l'alun.

Il faut pour cela opérer comparativement avec 1 centimètre cube de chacun de ces liquides, auquel on ajoute quatre gouttes d'aluminate de soude seulement. En étendant ensuite de 12 centimètres cubes d'eau distillée environ chacune de ces liqueurs, on constate que le vin a conservé sa teinte, tandis que le vin qui renfermait une des trois matières colorantes étrangères prend une couleur violacée, qui n'a pas la même intensité avec les trois couleurs, mais qui est toujours facile à distinguer de celle du vin.

En faisant agir l'aluminate de soude sur le vin de l'expertise, il s'est comporté absolument comme le vin pur auquel nous le comparions, et a témoigné, par l'absence de nuance violette, qu'il ne renfermait aucune des trois matières colorantes que nous cherchions. La conclusion générale déduite de l'action de l'alun se trouve ainsi pleinement confirmée par celle de ce nouveau réactif.

Notre expertise, arrivée à ce terme, se trouvait terminée; nous croyons cependant utile d'ajouter quelques détails sur les procédés qui pourraient permettre de distinguer, dans une certaine mesure, ces matières colorantes dans les vins auxquels elles communiqueraient $1 / 8$ de leur couleur.

\section{Sureau.}

Nous avons trouvé dans le sulfate de fer un réactif propre à faire distinguer la matière colorante du sureau des autres matières colorantes végétales, par exemple, de la mauve, et à les reconnaître dans les vins. Quand on place dans 1 ou 2 centimètres cubes d'infusion de mauve un fragment gros comme un pois de protosulfate de fer, et qu'on opère d'une manière comparative avec l'infusion de sureau, on observe des phénomènes différents : les deux matières colorantes se foncent beaucoup dans leur couleur; mais, tandis que celle de la mauve devient d'un violet foncé, celle du sureau prend une teinte bleue très sensible.

Si, dans cet état, on produit une suroxydation par l'addition d'un égal nombre de gouttes de solution de brome, la teinte violette de la mauve s'exalte sans passer au bleu, tandis que celle du sureau passe au bleu foncé. I a matière colorante du vin n'éprouve pas d'altération sensible dans sa 
nuance, quand on traite quelques centimètres cubes de ce liquide de la même manière. Le vin cependant se trouble et se fonce par l'addition du brome; mais il n'y a pas de coloration bleue, et la masse délayée dans l'cau, ce qui rend les comparaisons plus faciles, présente des différences tranchées.

On peut utiliser ces propriétés pour la recherche du sureau dans le vin.

Si l'on opère par comparaison avec du vin naturel, la couleur bleuâtre qui se développe dans le vin additionné de sureau, surtout après l'addition de quelques gouttes de brome, contraste si nettement avec la couleur jaunâtre que prend le vin naturel, que l'on peut ainsi facilement constater la présence certaine de la matière colorante étrangère.

L'expérience faite dans ces conditions, avec le vin moyen de l'expertise et les vins naturels des environs de Mèze, nous a toujours donné une coloration identique dans tous ces vins; par conséquent, le vin incriminé n'a point été adultéré par addition de la matière colorante du sureau.

\section{Hièble et myrtille.}

Ces deux matières colorantes, qui présentent entre elles une grande ressemblance, peuvent ètre distinguées de celle du sureau par l'action des sels de fer.

Si l'on dissout à chaud, dans 2 ou 3 centimètres cubes de vin coloré - au 1/8, un petit cristal de protosulfate de fer, les deux liqueurs prennent une couleur violacée; si l'on ajoute alors quelques gouttes de solution de brome pour produire la suroxydation, la liqueur étendue d'eau présente une nuance vert jaune sale, et non la teinte bleue qui se manifeste avec le sureau.

En opérant avec du vin pur et du vin coloré par l'hièble, on observe aussi une différence, légère sans doute, mais sensible.

En étendant d'une égale quantité d'eaı les deux liqueurs après la suroxydation, on observe que celle qui contient de l'hièble est plus riche en couleur et présente une teinte sensiblement plus verte.

Le fer, à l'état d'alun de fer, nous permet aussi de distinguer ces matières colorantes entre elles, et mème de retrouver l'hièble dans les vins.

Si l'on dissout un petit cristal d'alun de fer dans les infusions de mauve, de sureau et d'hièble, on voit la mauve perdre la teinte violette, passer au jaune sans qu'il y ait formation de précipité. Avec le sureau, il se forme un précipité et une coloration verte; avec l'hièble et la myrtille, il y a aussi un dépot, mais la coloration est brune.

En opérant comparativement avec du vin pur et du vin contenant $1 / 8$ d'hièble, il se forme un précipité des deux côtés ; les deux liqueurs présentent une teinte brun jaunâtre, mais elle est sensiblement plus foncée quand on opère avec du vin tenant de l'hièble.

La myrtille se comporte de la même manière.

En essayant d'appliquer ces nouvelles réactions au vin de l'expertise et au vin pur pris pour terme de comparaison, nous n'avons rien observé qui n'ait confirmé les conséquences que nous avons déjà déduites de l'absence d'action de l'alun et de l'aluminate de soude. 


\section{Essais de teinture des étoffes par le vin.}

Nous avons indiqué les méthodes spéciales qui nous ont permis de reconnaître, dans les vins examinés, l'absence de telle ou telle matière colorante étrangère, mais il est un procédé général qui permet de constater si un vin a été altéré ou non, et cette constatation est si simple, qu'elle pourrait être utilisée par les personnes étrangères aux connaissances chimiques.

Il consiste à teindre comparativement, avec du vin pur d'une nuance analogue à celle du vin que l'on soupçonne, des fragments d'étoffe de laine, chargés de différents mordants.

Si l'on maintient pendant une heure environ, à une température voisine de l'ébullition, un fragment de cette étoffe mordancé par l'acétate d'alumine ou par un mélange d'alun et de crème de tartre, il se colore d'une nuance rouge plus ou moins intense, qui est celle du vin.

Cette couleur n'augmente pas sensiblement d'intensité quand on fait passer l'étoffe dans un autre bain de vin. Le premier traitement l'avait en quelque sorte saturée de cette couleur.

Mais, quand le vin est mèlé d'une petite quantité de matière colorante étrangère, l'étoffe, saturée de la couleur du vin, ne l'est pas pour cela de cette dernière matière colorante étrangère. Si dès lors on la fait passer dans un second ou dans un troisième bain semblable, elle se charge à chaque fois d'une nouvelle dose de la matière colorante ajoutée, et, tandis (fu'en opérant des réactions sur les vins purs et incriminés, les rapports dans les proportions de matière colorante du vin et de matière colorante étrangère restant constants donnent naissance à des phénomènes limités dans leur sensibilité, il arrive, au contraire, par ce procédé de teinture, que la matière colorante étrangère, s'accumulant sur le tissu, se trouve sur celui-ci en quantité proportionnellement plus grande que dans la liqueur méne. Cette accumulation, on le conçoit, peut dès lors donner lieu à des changements plus faciles à apprécier.

La matière colorante ainsi accumulée peut même, dans certains cas, être détachée du tissu de manière à ce qu'on puisse constater sa nature propre; ainsi, par exemple, en mettant dans de l'eau ammoniacale une étoffe sur laquelle a été fixé de l'indigo, on voit l'étoffe passer au vert, colorer la liqueur en bleu décolorable par les agents oxydants et désoxydants. L'étoffe imprégnée de la matière colorante du vin pur verdit aussi par l'ammoniaque, mais la liqueur ne se colore pas comme quand il y a de l'indigo.

Au licu de ces teintures successives, on peut d'ailleurs, ce qui revient à peu près au mème, opérer en une fois, mais en faisant intervenir alors du premier coup le volume de vin incriminé qu'on eût, dans la première méthode, employé d'une manière successive.

En variant les mordants, on peut, dans ces expériences, obtenir des résultats analogues, mais avec des colorations différentes.

Nous avons essayé les mordants d'alumine, de fer, de cuivre, d'étain peroxydé. Dans la recherche de l’indigo, de la fuchsine, de la cochenille, il 
convient d'employer le mordant d'alumine. Pour la mauve, le sureau, le mordant à l'oxymuriate d'étain est préférable.

La sensibilité de la réaction, quand on cherche l'indigo, la fuchsine et la cochenille, peut dépasser la limite à laquelle nous nous sommes arrêtés dans la recherche directe de chacune de ces couleurs en particulier. Dans la recherche des matières colorantes analogues à celles du vin, la sensibilité nous a paru au contraire moindre, et nous n'avons aperçu des différences bien sensibles que quand le vin renfermait 1/4 de matière colorante étrangère, tandis que, par les autres réactions que nous avons décrites, nous avons pu évaluer jusqu'au $1 / 8$.

Il n'est pas possible d'indiquer d'une manière absolue les couleurs obtenues dans ces différentes circonstances; elles varient en effet d'une expérience à l'autre, non seulement avec la couleur propre des vins purs et avec la nature du mordant, mais aussi avec les proportions de celui-ci. Il en est surtout ainsi pour le mordant d'étain, selon la forme sous laquelle l'acide stannique a été déposé sur le tissu, soit par ébullition avec oxymuriate d'étain additionné de crème de tartre, soit en passant l'étain dans un bain de stannate et en le traitant ensuite par l'eau acidulée d'acide sulfurique. Dans ce mode d'expérimentation, on ne peut dès lors rien conclure que par la comparaison des résultats obtenus en se plaçant dans les mèmes circonstances.

Cette comparaison faite dans ces conditions, avec le vin de l'expertise et des vins naturels analogues, aussi variés que nous avons pu nous en procurer, a toujours montré moins de différence entre le vin naturel et celui de l'expertise qu'entre ce dernier et les vins que nous avons falsifiés.

Ces expériences, comme on le voit, corroborent encore les résultats obtenus par la recherche individuelle des matières colorantes, et sont pour nous une nouvelle preuve que les vins examinés n'ont point été falsifiés par l'addition de matières colorantes étrangères.

A toutes ces preuves nous en ajouterons une dernière : l'examen microscopique des lies. Si le vin eût été altéré par la présence de matières colorantes étrangères ajoutées au moment de la vendange, les lies eussent probablement contenu des débris d'organes de ces matières étrangères : nous avons dès lors dû soumettre à l'examen par le microscope une bouteille de lies envoyée par M. Gagne et qui représentait la moyenne des lies de vin rouge prélevées dans les vaisseaux vinaires de Félines-le-Haut et Félines-le-Bas. Ces lies ne se composent que de globules de levûre, avec présence insignifiante d'autres organismes, mais sans débris qui accusent des additions frauduleuses. Leur nature témoigne qu'il n'est intervenu dans la fabrication des vins rien d'étranger au raisin.

Vins blancs.

Les vins blancs n'étaient pas en cause; toutefois, nous avons examiné le vin moyen au point de vue de sa teneur en alcool, de l'acidité, de l'extrait et de la quantité de crème de tartre, etc., etc.

Voici les nombres qui ont été obtenus par comparaison avec un vin blanc 
naturel de Launac, piquepoul de qualité supérieure, encore sucré au goût, ce qui explique le chiffre élevé de l'extrait :

\begin{tabular}{|c|c|c|c|c|}
\hline NATURE DES VINS & $\begin{array}{l}\text { ALCOOL } \\
\text { pour } 100\end{array}$ & $\begin{array}{c}\text { ACIDITÉ } \\
\text { gr. par litre }\end{array}$ & $\begin{array}{c}\text { EXTRATt } \\
\text { gr. par litre }\end{array}$ & $\begin{array}{c}\text { CRÈME } \\
\text { de tartre } \\
\text { gr. par litre }\end{array}$ \\
\hline Vin moyen de l'expertise. . . . . . & 11,65 & 4,5 & 18,2 & 3,5 \\
\hline $\begin{array}{l}\text { Vin piquepoul de la propriété de Launac, } \\
\text { à M. Henri Marès }\end{array}$ & 13,5 & 4,8 & 33,00 & $n$ \\
\hline
\end{tabular}

Conclusions générales.

Les experts déclarent que les vins soumis à leur examen et vendus par Guerre à Manheimer n'ont été ni fraudés, ni falsifiés; qu'ils ne contiennent pas de matière colorante étrangère; que leur titre alcoométrique est en rapport avec leur couleur et leurs qualités apparentes, en tenant compte des caractères généraux de la récolte en vins de l'année courante, spécialement de ceux de la commune de Mèze. 


\section{V. - DISGUSSION DES MÉTHOdes D'ANALYSE DES VINS (1)}

(A PROPOS D'UN ARRÉT DE LA COUR DE MONTPELLIER)

M. Pasteur, président. - Je suis heureux, messieurs, de m'associer à vos travaux, et de vous féliciter de la direction que vous avez résolu de leur imprimer. Vous voulez donner, autant que possible, aux analyses agricoles l'uniformité qui leur manque. Rien de plus sage. L'agriculture a besoin de résultats bien comparables et les méthodes analytiques ne peuvent $y$ conduire qu'à la condition que tous les observateurs s'attacheront à obtenir leurs déterminations par des manipulations de même nature. I a nécessité de cette manière de faire est commandée encore et surtout par le peu de rigueur que, dans l'état actuel de la science, on est en mesure d'apporter pour bon nombre d'analyses agricoles. En conséquence, les résultats de celles-ci sont essentiellement dépendants des pratiques suivies par l'analyste.

M. Grandeau. - ... Vous savez, messieurs, combien nous avons aujourd'hui de difficultés pour l'analyse des vins... Tout récemment, il y a eu un procès qui s'est engagé à Carcassonne sur la demande du vendeur; le tribunal a jugé, il y a eu appel à la cour de Montpellier et la cour a rendu un arrêt qui présente pour nous le plus grand intérêt, arrêt sur lequel je prierai M. Pasteur de nous donner son avis, non point au point de vue juridique, mais comme savant, afin que nous sachions bien si le mouillage est une falsification et s'il doit y avoir une jurisprudence qui permette régulièrement le mouillage. Un marchand de vins de Paris a acheté des vins; il a refusé en gare la livraison de la marchandise fournie, parce qu'elle n'était pas conforme à l'échantillon. Le tribunal de Carcassonne a jugé que l'acheteur devait prendre livraison. - M. Pasteur a été noinmé expert, il a déclaré, après expertise faite avec des échantillons prélevés par ses soins, que ce vin était additionné d'eau, de 25 pour 100 d'eau. Le tribunal a rendu un jugement par lequel - après avoir nommé M. Pasteur expert! - il a décidé qu'il n'y avait pas d'eau dans le vin. La cour de Montpellier a confirmé le jugement, et elle a déclaré que quand le vin était conforme à l'échantillon, - ce qui n'était pas d'ailleurs, - qu'il fût falsifié ou non, l'acheteur devait prendre livraison... (Suit l'exposé de cette affaire.)

M. Pasteur. - A propos de cette affaire de Carcassonne et de Mont-

1. In: Comptes rendus des travaux du Congrès international des directeurs des stations agronomiques. Session de Versailles, juin 1881. Paris, 1881, in-8. (Procès-verbal de la $4^{\circ}$ séance, 22 juin. Présidence de M. Pasteur, membre de l'Institut), p. 119-144. 
pellier, je dois dire que j'ai refusé trois fois de m'y livrer : je ne fais pour ainsi dire jamais d'expertises, d'abord à cause de mes occupations et aussi à cause de ce que vient de dire M. Grandeau, de l'extrême difficulté de bien faire l'analyse d'un vin, de déterminer s'il est falsifié ou non; c'est une des opérations les plus scabreuses de l'analyse immédiate en chimie organique. On m'avait présenté la chose de cette façon : le tribunal de Carcassonne a déjà été saisi d'expertises - il y avait eu deux experts avant moi, chargés de l'analyse de ce vin, - et on m'avait dit que le tribunal, très embarrassé, considérerait mon expertise comme tout à fait décisive, qu'il prendrait pour base de son jugement le résultat de mon travail. Etant donnée cette idée qui était plus ou moins fondée, j'ai négligé de donner très en détail l'examen que j'avais fait du vin, je me suis borné à indiquer d'une façon générale la méthode que j'avais suivie et à formuler le résultat définitif de mon examen. Si j’avais su que la conclusion de cet examen ne ferait pas loi pour le tribunal, je serais entré dans plus de détails. En réalité, les expertises qui avaient été faites avant moi ne m'ont point paru exactes; on avait trouvé des matières colorantes, de la mauve, la preuve aussi, croyait-on, de vins de raisins secs, etc., enfin des substances étrangères au vin naturel et qui auraient été ajoutées au liquide vendu. Le vendeur devait sans donte savoir à quoi s'en tenir sur ce point; il a donc résisté très énergiquement, d'autant plus que, suivant moi, il avait raison. Sur ces points d'accusations très graves, il n'ètait pas coupable. Mais, si le vin en litige n'avait pas reçu d'addition de matières étrangères au vin, telles que nous les connaissons, il fut évident pour moi qu'il avait reçu une addition d'eau considérable. Le vin devait contenir 8 pour 100 d'alcool et il les contenait. Sur ma demande, le vendeur eut l'obligeance et la parfaite loyauté, par l'organe de son représentant, de me dire d'où provenait le vin. Ce n'était pas du lieu convenu dans le marché, il provenait, non du Minervois, mais du village de Campagne, dans le département de l'Aude. Sur la foi de ce renseignement, je fis ce que j'avais déjà fait antérieurement, à l'occasion de l'expertise Guerre-Manheimer (1), et ce qu'il faut toujours faire, autant que cela est possible, quand il s'agit de l'analyse d'un vin, je me suis mis immédiatement en relations avec plusieurs personnes très honorables, soit du département, soit du village de Campagne, qui ont bien voulu m'envoyer des vins de divers propriétaires de ce village. J'ai eu, en tout, 12 échantillons de vins de ce village et de l'année même qui avait produit le vin en litige. C'est la comparaison très attentive de ces vins avec le vin en litige qui m'a permis d'asseoir mon jugement.

Je ne sais vraiment pas comment le tribunal de Carcassonne a pu juger comme il l'a fait, parce que rien n'était plus simple que de s'assurer que dans le village de Campagne il n'y avait pas de vin authentique ayant une teneur en alcool aussi faible que celle du vin en litige, c'est-à-dire de 8 degrès. Mon analyse a été faite dans les conditions suivantes : j’ai pris parmi les divers vins ceux que j'ai jugés les plus naturels, les plus authentiques, provenant des personnes du village de Campagne absolument au-dessus de tout soupçon et j'ai comparé le vin du litige avec ces divers vins, sans

1. Voir : Document IV, p. 490-505. (Note de l'Édition.) 
négliger toutefois l'étude des autres. Lorsqu'on se livre à une telle comparaison, il est facile de reconnaître s'il y a ou non des matières colorantes ajoutées au vin en litige, parce que, quel que soit le procédé que l'on emploie pour reconnaître ces matières, le procédé, fût-il défectueux à le juger d'une manière absolue, devient d'une sensibilité extrême quand il s'agit tout simplement de comparer les effets des réactifs. Le précipité qu'on détermine par un alcali ou par un sel, ou autrement, offre toujours quelque particularité qui fait qu'on reconnaît très bien si réellement le vin en litige est naturel ou non. Lorsqu'il s'est agi autrefois du grand procès que j'ai rappelé, qui a fait tant de bruit dans le Midi, le procès Manheimer, où il s'agissait d'une livraison de 300.000 francs de vin, le propriétaire, qui était un ami de mon très cher et vénéré maître, M. Balard, était à l'abri de tout soupcon. M. Manheimer refusait de prendre livraison, prétendant que le vin était falsifié. Malheureusement il trouva un pharmacien trop complaisant qui établit l'existence dans le vin des substances les plus diverses, - tout cela par fantaisie analytique; - M. Balard ne voulut accepter l'expertise que si je me joignais à lui. J'acceptai, mais à une condition, c'est, dis-je à M. Balard, que vous pourrez vous procurer du vin authentique récolté tout auprès de la propriété du vendeur, propriété qui était considérable. M. Balard, par les relations qu'il avait dans le Midi, puisqu'il était originaire de Montpellier, put obtenir des échantillons d'un tel vin, de plusieurs même; dès lors l'analyse devint facile, il nous fut bientôt démontré à $M$. Balard, à $M$. Wurtz, troisième expert, et à moi que le vin en litige était parfaitement naturel ( $\left.{ }^{(}\right)$.

J'ai procédé de même pour l'examen du vin dont je vous parle; j'ai pris les vins du village de Campagne, les meilleurs et les plus ordinaires, et j'ai comparé avec le vin en litige au point de vue des matières colorantes, des quantités d'extrait et des quantités de cendres et de la teneur en alcool avec un bon vin de ce village, en lui ajoutant de l'eau, de façon à le ramener de $12,13,14$ degrés d'alcool à 8 degrés; j'ai fait des échantillons qui ressemblaient à s'y méprendre au vin suspect pour la quotité d'extrait, la quantité de cendres et pour la teinte, et avec lesquels tous les réactifs donnaient exactement les mêmes caractères. Il m'a été impossible de me procurer des vins naturels authentiques, même des plus faibles de l'année, qui n'eussent pas plus de 9 et 10 degrés environ d'alcool et plus d'extrait que le vin en litige. Il fallut leur ajouter beaucoup d'eau à tous pour les ramener aux proportions du vin en litige. J'ai su depuis, en effet, que le vendeur avait acheté dans le village de Campagne toutes sortes de piquettes pour composer le vin qu'il avait à livrer au négociant parisien; mais, comme je l'ai dit à ce dernier: Prenez-y garde, faites faire une enquête dans le village de Campagne.

Sachez que, dans le Midi, l'addition de l'eau est considérée comme un péché véniel. M. Béchamp (2), lorsqu'il était professeur à la Faculté de médecine de Montpellier, dans des leçons qui ont été publiées, a été jusqu'à conseiller d'ajouter de l'eau au vin. On n'admet pas dans le Midi, je le répète, que l'addition d'eau au vin soit quelque chose de bien coupable, et

1. Voir p. 490-505 du présent volume : Document IV. (Note de l'Édition.)

2. Actuellement doyen de la Faculté de médecine catholique de Lille. 
comme le tribunal de commerce était composé de propriétaires qui ajoutent peut-être de l'eau à leur vin pour le vendre (Hilarité), il est probable qu'ils ont trouvé que, du moment qu'il était constaté qu'il n'y avait pas de matières étrangères, l'acheteur parisien était mal venu à vouloir résilier le marché. Pour en revenir à l'objet de vos travaux, je me résume en disant que, toutes les fois qu'on le peut, il ne faut accepter une expertise de vin, dans les eas difficiles, que si l'on est bien sùr de pouvoir comparer le vin en litige avec des vins naturels de même provenance, de mème année, parfaitement authentiques. Vous pourrez hardiment, dans ce cas, vous livrer à l'analyse; vous serez alors difficilement entraînés à des erreurs sérieuses.

Dans le cas contraire, l'analyse d'un vin devient une chose extrêmement délicatc, et si vous voulez que j'en donne une preuve topique, irréfutable, je vous dirai ceci : Il y a bien longtemps que les plus habiles chimistes, les pharmaciens, font des analyses de vins; vous savez, d'autre part, qu'en 1860 j'ai reconnu la présence dans le vin de deux produits qui n'y avaient pas encore été signalés : la glycérine et l'acide succinique (1); ces deux produits cntrent pour une proportion considérable dans l'extrait que l'on fait d'un vin quelconque. Vous savez que la quantité d'extrait d'un vin varie de 18 à 25 environ, plus ou moins; mettons une moyenne de 23 grammes d'extrait par litre. Eh bien, par litre vous avez dans presque tous les vins entre 1 et 2 d'acide succinique; vous avez de la glycérine qui peut aller jusqu'à 5,6 , 7 grammes. Il en résulte qu'il y avait sur ces 23 grammes d'extrait d'un vin 8 à 9 grammes quelquefois de matières qui étaient absolument inconnues des chimistes et des pharmaciens.

Prenez cependant les anciennes analyses de vins, vous verrez : tant d'alcool, tant de matières sucrées, tant de matières gommeuses, tant de bitartrate de potasse, et total : exactement la quantité d'extrait.

Il est évident que chacune de ces analyses était entachée d'une erreur colossale, puisqu'elle s'élevait à $5,6,7,8$ et 9 grammes sur 23 , c'est-à-dire plus du tiers, à 35,40 pour 100 du poids de l'extrait. Je ne rappelle cela que pour vous nontrer combien les analyses de vins sont difficiles, combien il faut être circonspect, surtout quand il s'agit de faire condamner quelqu'un pour fraude ou falsification.

M. Lechurtier. - ... Il faut que les stations agronomiques qui se trouvent dans des régions de vignobles puissent prendre les types déterıninés de vins dans des conditions déterminées et fournir aux chimistes des analyses exactes, complètes, d'après des méthodes déterminées d'avance, de manière qu'elles puissent servir de terme de comparaison.

M. Pasteun. - Il serait très utile, en effet, que les directeurs des stations agronomiques, et particulièrement ceux qui se trouvent dans les pays vinicoles, fissent pendant un certain nombre d'années des analyses des vins de leur circonscription. Je rappelle ici que le fils de notre grand agronome, M. Joseph Boussingault, chimiste distingué, qui a fait des travaux originaux sur la fermentation, a été chargé, par le ministre de l'agriculture, d'analyser tous les vins qui étaient à l'Exposition de 1878 (²);

1. Toir p. 64-77 du tome II des (Euvres de Pasteur.

2. Voir Document III, p. 488-489 du présent volume. (Notes de l'Édition.) 
c'est un travail colossal; il faut avoir beaucoup de courage pour l'entreprendre. Ces vins sont au nombre de 1.500 , je crois, et le travail est extrêmement avancé; l'acidité, la quantité d'alcool, la quantité de sucre, ce qui était une difficulté, tout cela est déterminé et sera publié. On y trouvera des types, car les vins de cette Exposition peuvent évidemment être considérés comme authentiques, naturels, au moins pour la majeure partie; mais ce travail s'applique à beaucoup de vins que nous n'avons pas, à des vins étrangers; il serait utile qu'il füt complété pour les vins de France, et même pour les vins les plus ordinaires qui n'ont pas figuré dans cette collection si remarquée de l'Exposition universelle de 1878.

M. Pichard. - Je crois que le Congrès désirera ne pas laisser échapper la bonne fortune qui lui échoit d'avoir M. Pasteur comme président, pour lui demander des renseignements sur une question très importante dans les vins, c'est le plâtrage des vins dans le Midi...

M. Pasteur. - J'ai très peu étudié les effets du plâtrage, j'ai constaté seulement, comme M. Pichard, que par cette opération, _ ce qui la rend extrêmement recherchée par les vignerons du Midi, - le vin prend tout de suite une superbe couleur, une grande limpidité, une plus grande solidité. Vous savez que la question du plàtrage a été résolue dans le sens de l'acceptation de cette pratique. Les tribunaux ne considèrent plus le plâtrage à certaine dose comme étant une falsification. Il est accepté pour les vins des hópitaux militaires et ceux de la marine jusqu'à la dose correspondant à 2 grammes de sulfate de potasse par litre.

M. Graxdeau. - ... Nous sommes assaillis d'analyses de vins dans la région de l'Est; je voudrais que nous eussions quelques points de départ précis et que M. Pasteur pût nous fixer, dès à présent, sur ce que nous pouvons considérer comme une falsification. Vous savez comment nous procédons dans les recherches que nous faisons; il y a un certain nombre de principes que nous savons doser : l'acide libre par l'eau de chaux, les cendres, l'alcool avec l'appareil Maligand.

... Je demande à M. Pasteur de nous donner son appréciation précise sur le point suivant : Quand dans un vin nous trouvons un dépôt de cendres, - quelle que soit l'année de la récolte, - de 2 grammes par litre, avec absence de carbonates, avec présence de sulfate de chaux, je demande si ces cendres peuvent être considérées comme cendres de vin naturel, surtout quand il y a 5-6 pour 1.000 d'acide libre. Quand on ne retrouve, après évaporation, que 1/2 ou 1 p. 1.000 d'acide libre, 2 'grammes de cendres, 16-17 grammes d'extrait, ne peut-on pas affirmer, sans fixer la quantité, qu'il y a addition considérable d'eau? Je demande à M. Pasteur si, avec 6 grammes d'acide par litre ( 1 gramme seulement d'acide volatil et 5 grammes d'acide tartrique qu'on peut isoler par liqueur éthérée ou alcool), nous sommes en droit, avec une quantité d'extrait de 14,15, 16 pour 1.000, d'affirmer qu'il y a addition d'eau et si nous avons raison d'encourager les tribunaux à poursuivre, quand nous sommes saisis par l'acheteur, le client, ou les négociants en vins?

M. Pasteur. - Je ne pourrai pas répondre péremptoirement aux questions qui viennent d'être posées par M. le commissaire général, parce que, je le répète, je n'ai pas fait assez d'analyses de vins; je n'ai jamais été expert que dans l'affaire de M. Manheimer et dans celle que je rappelais 
tout à l'heure. Je ferai seulement remarquer qu'il y a beaucoup de choses à considérer à côté des points que vient de signaler M. Grandeau; il ne faut pas omettre les modifications que peuvent amener dans la composition des vins les effets de leurs maladies; vous pouvez avoir un vin parfaitement naturel et qui a subi un commencement d'altération pouvant donner lieu, de ce chef, à des accusations de fraudes graves, à des procès, à des litiges; le vendeur cependant peut n'avoir rien à se reprocher; le vin peut s'ètre altéré à son insu; cette altération - par exemple, par le petit organisme-ferment du vin tourné - pourra modifier considérablement la quantité d'acide tartrique, de bitartrate de potasse, parce qu'il y aura eu décomposition de l'acide tartrique sous l'influence de ce ferment; je connais des expertises qui ont été faites avec l'ignorance de cette circonstance, qui ont conduit l'expert à affirmer que le vin avait été additionné d'eau, parce qu'on avait trouvé très peu d'extrait, mais ce n'était pas la faute du vendeur, c'était la faute de la maladie du vin. C'est une circonstance qu'il faut toujours avoir présente à l'esprit dans l'analyse d'un vin; il faut commencer par étudier au microscope le dépót du vin. Vous prenez une bouteille de vin, et vous l'abandonnez dans un endroit où la température ne varie pas pendant vingt-quatre heures; vous décantez le vin avec un syphon de diamètre très étroit qui met longtemps à vider une bouteille; il reste toujours quelque chose dans la gouttière; très souvent, on voit à l'œil nu la présence d'un dépôt; mais alors même que le vin vous paraît limpide, si vous l'abandonnez pendant vingt-quatre heures et que vous décantiez, que vous laissiez dans la gouttière de la bouteille seulement $1 / 2$ centimètre cube de liquide, si vous agitez avec force, en faisant tomber le vin dans un verre à pied, en regardant au microscope une goutte de ce liquide, vous trouverez toujours un dépot, même dans le vin qui paraît le plus limpide à l'œil. Il faut avoir grand soin d'étudier cette partie du dépôt au microscope. Si vous n'y voyez que des cellules de levure ou de mycoderma vini, vous pouvez juger que le vin n'a pas subi l'influence d'une maladie, le plus souvent du moins, parce que le vin aurait pu ètre filtré auparavant, mais c'est encore exceptionnel, et si vous ne voyez, je le répète, que du mycoderma vini, un petit organisme allongé ou des cellules plus ou moins arrondies, le vin n'a pas subi l'influence d'une maladie. Pourquoi le mycoderma vini n'indique-t-il pas une maladie? Parce qu'il est presque toujours à la surface du vin en ton neau, surtout pendant les premières années, et que ce voile de mycoderma vini tombe plus ou moins par l'agitation, au moment du soutirage, au fond du vin, et que, par conséquent, on le retrouve dans ce dépót. Mais si vous y voyez de petits filaments, ces filaments sont ordinairement ceux de la maladie qu'on appelle le vin tourné, le tour $d u$ vin, et dans ces cas-là la conclusion de l'examinateur du vin doit être extrêmement circonspecte, au point de vue des idées qu'il peut se faire sur le mouillage du vin, par exemple, parce qu'il peut y avoir une quantité d'extrait faible par suite de la fermentation de l'acide tartrique, ce qui lui ferait croire à un mouillage, alors qu'il n'y en a pas du tout et que le vin a seulement subi une altération qui a fait disparaitre de l'acide tartrique, qui a produit de l'acide carbonique et des acides volatils, n'intervenant pas ou dans une proportion diminuée pour former le poids total de l'extrait du vin. 
M. Grandeau parlait tout à l'heure du dosage de l'alcool. Je crois que ce dosage devrait toujours être fait par l'appareil de M. Maligand. Ce procédé est d'une sensibilité et d'une rigueur extrêmes, pourvu qu'on prenne quelques précautions; quand le vin est sucré, le procédé devient infidèle, mais il est si facile de recommencer l'opération en doublant le volume du vin avec de l'eau, en le triplant également, il est si aisé de se mettre à l'abri de cette cause d'erreur, relative à la présence du sucre, que ce procédé réunit toutes les conditions de rigueur, de rapidité d'exécution. Voici à cè sujet ce qui m'est arrivé : M. Paul Thenard avait été chargé de faire un rapport.sur cet appareil à l'Académie des sciences. J'ai fait beaucoup de dosages d'alcool de vin et de liquides fermentés, et je me servais du procédé de distillation de Gay-Lussac, en y apportant quelques soins particuliers. Ainsi, après avoir recueilli l'alcool, pour qu'il n'y ait pas de cause d'erreur provenant de la quantité d'acide acétique qui pouvait avoir passé en même temps que l'alcool, et qui passe surtout quand les vins ont eu un commencement d'altération par fermentation de maladie, j'avais soin de saturer par l'eau de chaux et de recommencer la distillation. Celle-ci seulement me servait à établir la quantité d'alcool dans le vin. Un jour, sans me rien dire, M. Paul Thenard m'envoya des échantillons de vins en me disant : Voulez-vous, mon cher confrère, déterminer la quantité d'alcool qui se trouve dans ces vins? - Je le fis avec tous les soins possibles, et lui en donnai par écrit les résultats. Immédiatement il me dit : Vos résultats sont en défaut de tel nombre de dixièmes de degré d'alcool, et il me démontra que c'était vrai. Il se servait lui, à ce moment, de l'appareil Maligand. Tout d'abord, j'avais peine à croire à l'erreur qu'il m'indiquait, mais j'ai reconnu que le procédé de Gay-Lussac est toujours un peu en défaut.

Quant à la quantité d'extrait, elle varie beaucoup. Faites déterminer par deux chimistes, même très habiles, la quantité d'extrait d'un même vin, il est probable que vous aurez deux résultats différents. D'abord, on n'indique pas toujours la méthode employée; on met : extrait - sans dire : l'extrait a été obtenu de telle façon; si vous obtenez l'extrait dans le vide, par exemple, ou si vous l'obtenez en chauffant à $100^{\circ}$, il est évident que les résultats seront différents. L'une des circonstances qui amènent ces différences consiste en ce que la glycérine distille facilement, même à la température de $100^{\circ}$, de sorte que si vous mettez plus ou moins de temps, vous pouvez avoir une perte sensible sur l'extrait. Si vous avez un vin qui a fermenté, qui a eu une maladie, qui a transformé, par exemple, l'acide tartrique en acide volatil, voilà une cause de perte, et l'extrait est alor's différent. Il faudrait convenir, pour déterminer les quantités d'extrait...

Un Mexbre. - A quelle température?

M. Pasteur. - A la température ordinaire, s’il s'agit du vide; mais avec un temps déterminé et puis, en outre, avec une certaine forme de vases. Il faudrait des vases tous uniformes, plats, des capsules plates qui auraient la même dimension, parce que la dimension variant amène des changements. 
Un Membre. - Et quelle quantité?

M. Pasteur. - Cent centimètres cubes si l'on veut se servir de l'extrait pour des déterminations ultéricures.

M. Graxdeav. $-\Lambda 100^{\circ}$ ?

M. Pasteur. - $\mathrm{A} 100^{\circ}$; si l'on prend $100^{\circ}$ pendant un temps déterminé, on aura toujours quelque chose de comparable..

M. Giraxdeau. - On pourrait prendre huit heures.

M. Pasteur. - Comme analyse, j'aime mieux le vide, l'évaporation dans le vide, parce que, alors, on perd beaucoup moins de glycérine et d'acide volatil. L'acide acétique distille assez difficilement dans le vide. Il faudrait déterminer le temps pour l'évaporation conplète, [le vin] placé dans le vide; laisser, je suppose, douze heures sous la cloche en renouvelant le vide si besoin est, en faisant l'extrait dans ces conditions, ce serait comparable; maintenant, si on préfère l'évaporation à $100^{\circ}$, laisser le temps, six heures, je suppose, sur le bain-maric; il m'est arrivé quelquefois d'employer du sulfate de potasse cristallisé pour faciliter l'évaporation toujours lente avec beaucoup de matières extractives; on pourrait convenir d'ajouter à 25 , à 50 centimètres cubes de vin un poids déterminé de sulfate de potasse en cristaux pulvérisés.

M. Grandenu. - Voudriez-vous nous indiquer exactement ce que vous proposez pour la dessiccation?

M. Pasteun. - Je prendrais 20 centimetres cubes et le vide pendant vingt-quatre heures.

M. LADrey. - ... Mais jamais, quand vous voulez avoir un résidu, il ne faut aller à une température supérieure à $60^{\circ}$, ou vous ave\% une altération dont vous ne pouvez pas déterniner exactement les conséquences.

M. Pasteun. - M. Ladrey a raison; il y a toujours une altération, surtout par oxydation, de la matière colorante, mais il s'agit ici d'épreuves tout à fait comparatives. Dans tous les cas, il vaudrait mieux le vide pour approcher d'une rigueur plus grande.

M. Ramox dF Ixxa. - A l'occasion de plaintes qu'il y a eu en Espagne pour l'altération des vins, j'ai été chargé de faire des analyses, surtout pour constater la présence de matières colorantes et spécialement de la fuchsine... Et alors j'ai eu l'idée d'opérer, non pas par la méthode ordinaire, mais en soumettant les vins de toutes sortes, de toutes régions, depuis le xérès jusqu'aux vins de l'ancienne Castille et de l'Andalousie, à une basse température : 20 degrés au-dessous de zéro, et alors, c'est une chose bien curieuse, toutes les falsifications se décèlent plus facilement qu'avec les anciens systèmes; cela se partage admirablement en partie alcoolique, en matières colorantes et en substances ajoutées qui sont dissoutes dans l'eau, et alors vous avez partagé l'échantillon en deux parties trés nettes. Je propose qu'on essaie cette méthode... 
M. Pasteur. - Messieurs, je suis persuadé, en effet, que ce doit être une excellente méthode qualitative, d'autant plus que l'opération peut se faire toujours par comparaison avec des vins que l'on saurait naturels, quand même ils ne seraient pas exactement de la même provenance. Un vin naturel exposé à une basse température ne doit pas souffrir de l'influence de l'oxygène de l'air, et certainement il peut se faire des cristallisations, par exemple, de bitartrate de potasse, qui pourraient servir à l'examen comparatif des vins; et je propose, pour ma part, que le Congres prenne en sérieuse considération ce moyen d'analyse qualitative.

M. Gayos. - J'avais demandé la parole à l'occasion de la proposition de M. Lechartier; mais elle est bien éloignée maintenant; je ne sais si je dois insister sur cette question.

M. Pasteur. - Vous voulez parler, je pense, de celle qui est relative à l'étude d'un certain nombre d'échantillons de vins de diverses régions de la France? Lc Congrès vous écoutera avec plaisir.

M. Gayox. - Je crains qu'il ne se soit produit un enchevêtrement dans la discussion. Je ne sais si je dois prendre la parole à présent.

M. Pasteun. - Peut-être le Congrès devrait-il être éclairé d'abord sur les méthodes, et, comme le disait tout à l'heure M. Grandeau, ces méthodes ne pourront ètre complétement portẻes à notre connaissance que par la publication des travaux qui nous seront envoyés et qui pourront être insérés dans les actes du Congrès.

Le Congrès serait certainement très heureux que quelques directeurs de stations établies dans des régions vinicoles voulussent bien se livrer à ces analyses de vins dans les pays qu'ils habitent. 


\title{
TABLE DES MATIÈRES
}

\author{
DU TOME III
}

Istroductiox dU TOME III .................... v

\section{ÉTUDES SUR I.E VINAIGRE}

Sur la fermentation acétique...................... 3

[Observations au sujet d'une Note de M. Terreil : "Production de cellulose dans une liqueur sucrée ayant fermenté $] \ldots . . \ldots . . . . . . .60$

Etude sur les mycodermes. Ròle de ces plantes dans la fermentation

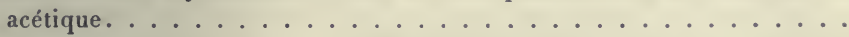

Suite à une précédente Comınunication sur les mycodermes. Nouveau procédé industriel de fabrication du vinaigre. . . . . . . . . .

[Quelques résultats nouveaux relatifs aux fermentations acétique et buty-

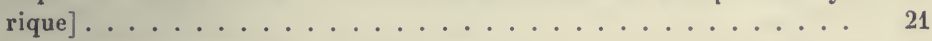

Mémoire sur la fermentation acétique (avec $5 \mathrm{fig}$. . . . . . . . . . 23

Première partie : Historique .............. . . 23

$\S$ I. - L'acide acétique provient de l'oxydation de l'alcool par

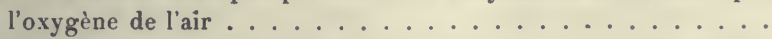

§ II. - Nécessité d'un ferment pour l'oxydation de l'alcool dans la fermentation acétique. Idées sur la nature de ce ferment .... .

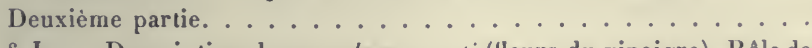

$\S$ I. - Description du mycodcrma aceti (fleurs du vinaigre). Rôle de cette plante dans la fermentation acétique ......... 36

§ II. - Pas de mycoderme, pas d'acétification . . . . . . . . 44

$\S$ III. - Manière d'agir du mycoderma aceti. . . . . . . . . . 46

§ IV. - Acétification sans matière albuminoïde. - Développement du mycoderına aceti à l'aide de sels ammoniacaux et de phosphates alcalins et terreux. - Preuves évidentes de la nature organisée du ferment. ............................... 51

$\S$ V. - Procédé des copeaux de hêtre. . . . . . . . . 53

§ VI. - Combustion de l'acide acétique par le mycoderma aceti . . 58 
$\S$ VII. - Altération spontanée dans la structure du mycoderma accti. - L'alccol peut disparaître sans qu'il soit transformé préa-

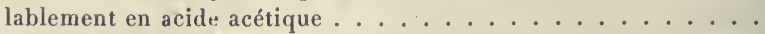

§ VIII. - Le mycoderma aceti submergé n'acétifie pas, alors même qu'il continue de vivre et de se multiplier. . . . . . . . . .

\$ IX. - Le mycoderma aceti envisagé comme parasite du mycoderma vini. . . . . . . . . . . . . . . . .

$\S \mathrm{X}$. - Des anguillules du vinaigre. Comment ellès nuisent à l'acé-

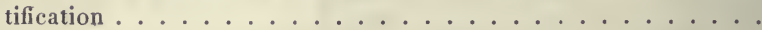

$\S$ XंI. - Application des résultats des paragraphes précédents . . .

Leçon sur le vinaigre de vin, professée à Orléans le 11 novembre 1867 (avec 4 fig.) . . . . . . . . . . . . . . .

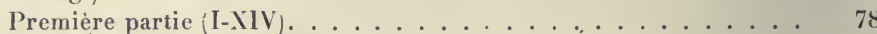

Deuxième partie $(\mathrm{XV}-\mathrm{XXIX}) \ldots \ldots . \ldots 90$

Note sur un Mémoire de N. Liebig, relatif aux fermentations. . . . . . . 107

\section{ÉTUDES SUR LE VIN}

ÉTUDES SUR LE VIN. SES MALADIES; CAUSES QUI LES PROVOQUENT. PROCÉDÉS NOUVEAUX POUR LE CONSERVER ET POUR LE VIEILLIR.

Avertissement de la première édition . . . . . . . . . . . . . 112

Préface de la deuxième édition . . . . . . . . . . . . . . . . 114

Première Partie : Causes des maladies des vins . . . . . . . . . 115

Introduction ............................ 115

Opinion ancienne sur les causes des maladies des vins . . . . . . . . 117

Opinion nouvelle sur les causes des maladies des vins et description de ces maladies ...................... . . 122

A. Maladie de l'acescence du vin. - Vins piqués, aigres, etc... . . . 123

B. Maladie des vins tournés, montés, qui ont la pousse, etc... . . . 137

C. Maladie de la graisse. - Vins filants, vins huileux. . . . . . . 155

D. Maladie de l'amertume. - De l'aner, du goût de vieux, etc. . . . 159

Deuxième partie : De l'oxygéne de l'ali dans la vinification . . . . . 170

De l'influence de l'oxygène de l'air dans la vinification . . . . . . 170

Étude sur la nature des gazcontenus dans le vin et dans le moùt de raisin. . . . . . . . . . . . . . 176

Tholsiène partie : Conservation des vins . . . . . . . . . 203

Procédés empiriques proposés pour la conservation des vins . . . . . . 203

Conservation du vin par le chauffage. Historique de la question. . . . . . . 207

Sur l'invention de la méthode de conservation des vins par le chauf-

fage. Note de M. Balard. . . . . . . . . . . . . 
Démonstration expérimentale des bons effets du chaufage . . . . . . .

Rapport de la Sous-Commission chargée de constater les résultats des expériences de M. Pasteur sur la conservation des vins ...

Observations au sujet du rapport précédent ..........

Rapport de la Commission syndicale des vins de Paris.......

Manière de conduire les expériences. . . . . . . . . . . . . . 261

Appareils industriels pour le chauffage du vin (par J. Raulin) . . . . . 266

APPendice. Notes et documents. . . . . . . . . . . . . 311

Dosage de l'acidité totale du moût de raisin. . . . . . . . . . 311

Dosage de l'acidité totale du vin . . . . . . . . . . . . . . 313

Dosage du sucre du moût de raisin . . . . . . . . . . . . . 314

Nouveau procédé de dosage de l'acide tartrique . . . . . . . . 315

De l'influence de l'aération sur la fermentation des moûts. . . . . . . 324

$\Lambda$ pplication de l'aération à la production de la mousse dans le vin de

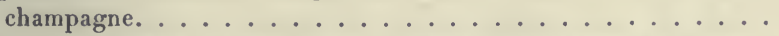

Note sur le cépage appelé enfariné. Singularité de sa maturation. . .

Indication d'une méthode pour étudier les principaux acides du vin .

Note sur le cépage appelé ploussard. . . . . . . . . . . .

Sur la présence de la gomme dans le vin . . . . . . . . . . 338

Origine de la glycérine et de l'acide succinique dans le vin. . . . . . 339

Sur la graisse des vins .................. . . . . 342

Sur le procédé de conservation des vins par le chauffage préalable.

A Monsieur le rédacteur en chef du Moniteur vinicole. . . . . . 343

Extraits de la $1^{\text {re }}$ et de la $5^{\text {e }}$ éditions du Traité des conserves d'Appert.

Sur la maladie de l'amertume des grands vins de Bourgogne. Lettre de M. de Vergnette-Lamotte à M. Pasteur ... . . . . . 363

Remarques au sujet de la lettre précédente . . . . . . . . . . 371

Comité central agricole de Sologne. Rapport de M. Dumas . . . . 372

De l'amélioration des vins par le chauffage . . . . . . . . . 375

Procès-verbal de la dégustation de vins chauffés et non chauffés . . . 378

AdDEXDUM

[Honmage à l'Académie d'une brochure intitulée : Sur la conservation des vins $]. \ldots \ldots \ldots \ldots \ldots$

[Présentation à l'Académie d'un ouvrage intitulé : « Études sur le vin $"] \ldots \ldots \ldots \ldots \ldots \ldots$

[Pasteur fait hommage à l'Académie d'un ouvrage intitulé : Études sur le vin. Ses maladies; eauses qu'ils provoquent. Procédés nouveaux pour le conserver et pour le vieillir ] . . . . . . .

[Pasteur fait hommage à l'Académie de la seconde édition de son ouvrage intitulé : "Études sur le vin $»$. . . . . . . . . .

Études sur les vins. Première partie : De l'influence de l'oxygène de

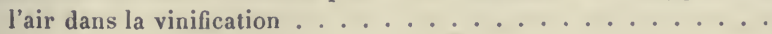


Etudes sur les vins. Deuxième partie : Des altérations spontanées ou maladies des vins, particulièrement dans le Jura (avec 15 fig.). .

Sur le dosage de l'acide tartrique dans les vins . . . . . . .

Note sur les observations publiées par M. Berthelot . . . . . . .

Procédé pratique de conservation et d'amélioration des vins. . . . .

Note sur les dépôts qui se forment dans les vins. . . . . . . . .

Nouvelles observations au sujet de la conservation des vins . . . . .

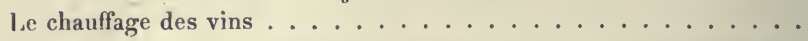

De la pratique du chauffage pour la conservation et l'amélioration des vins . . . . . . . . . . . . . . . 424

De l'amélioration des vins par le chauffage . . . . . . . . 424

Discussion au sujet de la priorité de L'invention de la Méthode du CHAUfFAgE POUR CONSERVER LES vinS . . . . . . . . .

Note sur l'emploi de la chaleur comme moyen de conservation du

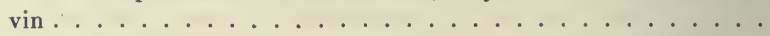

I.ettre à M. Quesneville, directeur du Moniteur scientifique . . . . . .

I.ettre à M. Quesneville, directeur du Moniteur scientifique. . . . .

Lettre au Moniteur scientifique. . . . . . . . . . . . . . .

Note au sujet d'une réclamation de M. Paul Thenard, relativement au

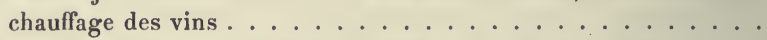

Note relative aux Communications de M. de Vergnette-Lamotte et de M. P. Thenard [sur le chauffage des vins] adressées à l'Académie dans les séances des 20 septembre et 4 octobre. . . . . . . .

A M. le rédacteur en chef du Journal d'ayriculture pratique . . . . . .

Réponse à la dernière Note de M. P. Thenard sur le chauffage des vins. . . . . . . . . . . . . . . . .

Observations au sujet de la lecture de M. de Vergnette [sur le chauf-

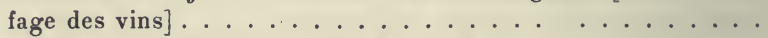

Réponse à une Communication de M. de Vergnette-Lamotte [sur le

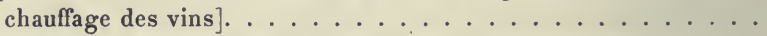

Lettre à M. le directeur du Journal d'agriculture pratique . . . . . . 453

Lettre à M. le directeur du Journal d'agriculture pratique. . . . . . . 454

Lettre à M. le directeur du Journal d'agriculture pratique . . . . . . 455

Réponse de M. Pasteur à M. de Vergnette-Lamotte . . . . . . . . . 459

Pourquoi le goût de la vendange diffère de celui du raisin. . . . . . . . . 461

Sur la conservation des vins de grands crus de la Bourgogne. . . . . . . . 465

[Sur l'application du chauffage à la conservation des vins de Volnay]. . . . 469

Sur les vins faits avec des cépages américains. . . . . . . . . . . . . 470

[Fermentation du moût de raisin] . . . . . . . . . . . . . 473

[Intervention dans la discussion de la Communication de M. Bouchardat:] Sur les effets de la gelée du 20 septembre sur les cépages de Bourgogne ... . . . . . . . . . . . . .

[Intervention dans la discussion sur les essais faits au laboratoire municipal de Paris (à propos du sucrage)] . . . . . . . . . . . . . . . . . .

Observations [à propos du vin d'orge de M. G. Jacquemin]. . . . . . . . . 
DOCUMENTS

I. - Note remise par Pasteur au ministre de l'Instruction publique et

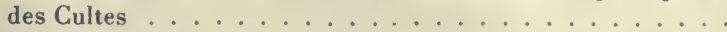

II. - Communication de M. Balard: Sur une altération spontanée de certains vins . . . . . . . . . . . . .

III. - Rapport de Pasteur sur le Mémoire de M. Joseph Boussingault relatif à la fermentation rapide des vins .........

IV. - $[\Lambda$ propos de la falsification des vins]. Rapport de MM. les experts chimistes Balard, Wurtz et L. Pasteur [Affaire N. Guerre contre H. Manheimer] . . . . . . . . . . . .

V. - Discussion des méthodes d'analyse des vins (A propos d'un arrèt de la Cour de Montpellier)............... 





\section{PLEASE DO NOT REMOVE}

CARDS OR SLIPS FROM THIS POCKET UNIVERSITY OF TORONTO LIBRARY UNIVERSITY OF TORONTO LIBRARY 
